Recruitment of Ostrea chilensis (Philippi, 1844) in Foveaux Strait, Southern New Zealand

BY

Keith P. Michael

\begin{abstract}
A thesis submitted to the
Victoria University of Wellington

in fulfilment of the requirements for the degree of

Doctor of Philosophy
\end{abstract}

Victoria University of Wellington

2019 


\section{Recruitment of Ostrea chilensis (Philippi, 1844) in Foveaux Strait, Southern New Zealand}

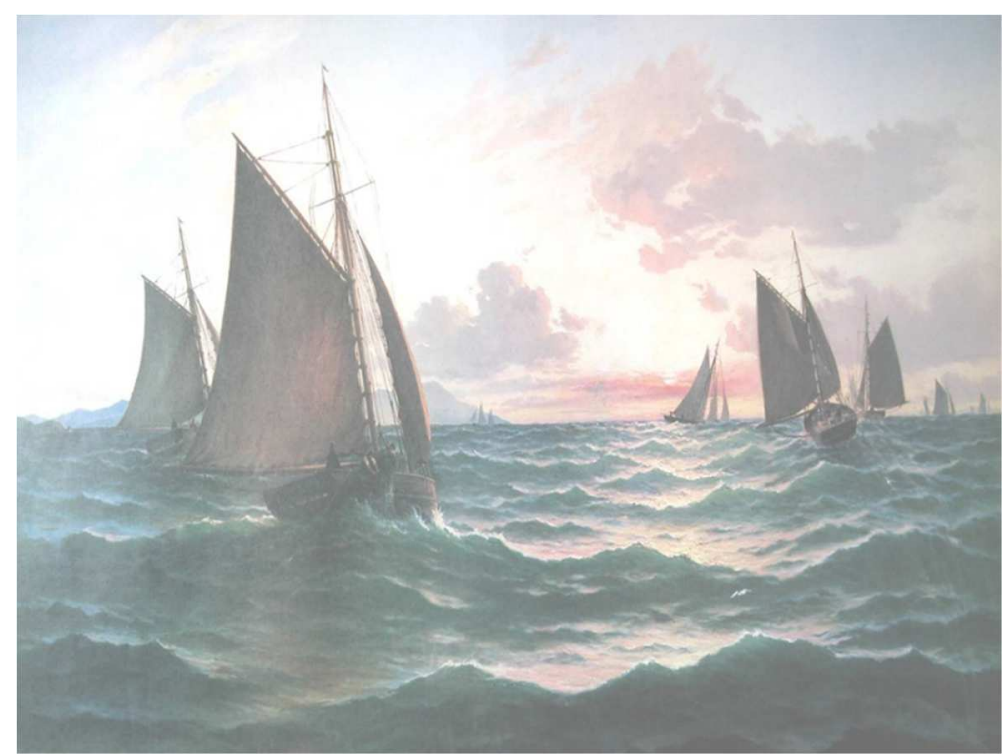

Sailing cutters dredging for oysters in Foveaux Strait c. 1880s. John Gibb (artist).

\section{BY}

Keith P. Michael

A thesis submitted to the

Victoria University of Wellington

in fulfilment of the requirements for the degree of

Doctor of Philosophy

Victoria University of Wellington

2019
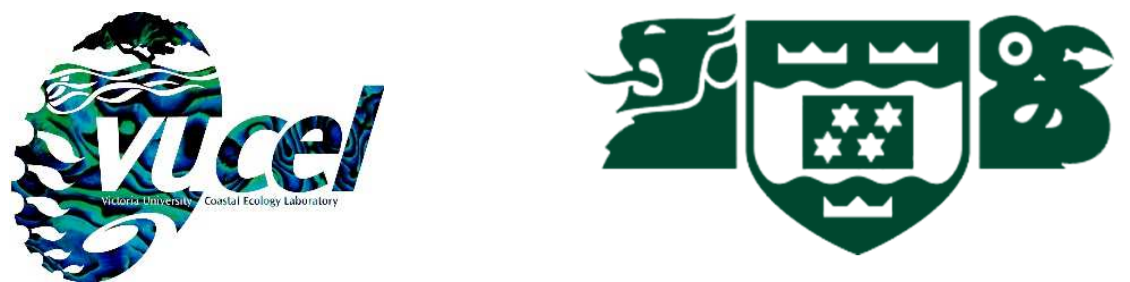
This thesis was conducted under the supervision of:

Prof. Jeffrey S. Shima (Primary Supervisor)

Victoria University of Wellington,

Wellington, New Zealand

And

Dr Stephen Hartley (Secondary Supervisor)

Victoria University of Wellington,

Wellington, New Zealand 


\begin{abstract}
This research evaluates fundamental ecological processes to facilitate an understanding of recruitment in Ostrea chilensis from Foveaux Strait, southern New Zealand. Foveaux Strait represents an extreme habitat for oysters that differs to the sheltered nearshore, muddy habitats of most other oyster populations. $O$. chilensis exhibits the extreme end of brooding strategies in Ostreinae, does not form extensive reefs, and comprises putative self-recruiting populations. The Foveaux Strait oyster fishery is nationally important. Recurrent disease mortality in these populations has put greater onus on understanding recruitment.
\end{abstract}

To evaluate the strength of a recruit-per-spawner relationship in oysters, seasonality in the settlement of larvae was determined. Most recruitment in any given year, over a 6-year period, occurred in the austral spring and summer (November to February). Fishery-wide, recruitment varied significantly between years, with most variation $(50.8 \%)$ explained by a year effect that represents the combined influences of climatic and biological conditions. Spawner densities and fishery areas explain further variation (13.8\% and $11.6 \%$, respectively), with further 2-way interactions between these factors. Recruits-per-spawner declined serially over time, despite similar or increasing densities of spawning-sized oysters. Average recruitment was lowest when spawner densities were highest; this suggests a more complex relationship between recruitment and density that has implications for management of this oyster fishery.

Recruitment to the $O$. chilensis fishery declined abruptly to low levels in 2010 and remained low until 2017. Relatively high spawning-stock sizes over this period had previously supported high recruitment. Density and oyster mortality from Bonamia exitiosa (a proxy for one or more infections) and their two-way interaction were the main determinants of recruitment. The highest recruitment occurred at times of low mortality and low density, suggesting 
reduced effects of disease on gametogenesis and reduced disease transmission. The contributions of climate factors were minor; however, a 3-way interaction between oyster density, mortality, and climate is likely to drive variation in recruitment. Pathobiomes (multiple infections in populations) may be important determinants of shellfish recruitment and population dynamics.

This research evaluates the hypothesis of self-recruitment from distributions of recruit densities around an isolated natal population, and from the relationship between recruitment and brooding-sized oyster densities. Distance from the natal population, direction along or across the tidal current, or brooders did not predict recruit densities. Recruit distributions imply greater dispersal and larval mixing than previously reported. The swift tidal currents and possibility of more variable pelagic larval durations may enhance mixing and connectivity between populations in Foveaux Strait.

Post-settlement mortality is the primary determinant of spatial structure in Foveaux Strait oysters. Productive fishery areas comprise mostly stable substrates of shells, sand, and gravel, with no or little other epifauna. Most $(66.8 \%)$ post-settlement survivors were on the heavy shells of both live and dead $O$. chilensis, which suggests an unusual recruit-adult relationship based on survival rather than settlement. Recruits and 1+ year spat grew larger and had lower mortality at eastern sites with the lowest exposure to oceanic swells and putative lowest sediment movement. Moreover, recruits on spat collectors also grew larger and had lower mortality at heights $\geq 12 \mathrm{~cm}$ than those $2 \mathrm{~cm}$ off the seabed.

This research suggests the effects of disease on brooding percentages and thereby larval supply may be the main determinant of the variation in recruitment in $O$. chilenesis, and the spatial structure of oyster populations in Foveaux Strait shaped by abiotic as well as biotic post-settlement mortality. 


\section{Acknowledgements}

First and foremost, I thank my primary supervisor Prof. Jeff Shima for his guidance, support and patience. Dr Stephen Hartley and staff at the School of Biological Sciences at Victoria University of Wellington provided encouragement and inspiration. I acknowledge the support of the Shima Lab at the Victoria Coastal Ecology Laboratory, especially Daniel McNaughtan and Becky Focht. I thank the dissertation reviewers Prof. Andrew Jeffs (UOA), Dr Alice Rogers (VUW), and Assoc. Prof. Paul Gribben (UNSW) for their contributions. Thank you to Patricia Stein, Mark Stephen and Mary Murray for their friendly assistance with admin.

Many friends and colleagues at NIWA supported me to complete this dissertation. Special thanks to Susan Jane Baird, Peter McMillan, Dr Sophie Mormede, and Dr Rosemary Hurst who always had time for a chat, critically reviewed manuscripts from this work, and their endless encouragement. I thank Dr Alison MacDiarmid for her encouragement to undertake this PhD.

I gratefully acknowledge the Bluff Oyster Management Company for their support with sampling and access to oyster industry data. The sampling programmes in Foveaux Strait would not have been possible without the assistance of Graeme Wright, David Skeggs, Victoria Pearsey, skipper Stephen Hawke and the crew of the oyster vessel F.V. Golden Quest to whom I am especially thankful.

For the many helpful discussions, assistance with accessing data, and advice on manuscripts from this thesis I thank, Dr Charles T.T. Edwards, Dr Murray Smith, Dr Ian Doonan, Dr Mark Hadfield, Dr Steve Chiswell, Dr Matt Pinkerton, Dr Brett Mullins, and Dr Jim Roberts from NIWA. My colleagues at the Ministry for Primary Industries Dr Henry Lane, Dr Anjali Pande, and Prof. Brian Jones with whom I shared many useful discussions on shellfish diseases. 
Assoc. Prof. Miles Lamare (Otago University) and three anonymous reviewers provided comments, which greatly broadened and strengthened two of the manuscripts from this thesis.

The Bluff Oyster Management Company Ltd directly funded research on recruitment and with some co-funding from Seafood Innovations Limited. The Ministry for Primary Industries levied research programmes funded surveys of oyster densities, and Bonamia exitiosa infection and mortality.

I especially thank my wife and "dissertation widow" Helen Costello, and family Madeleine, Emma, Lydia, Johanna for your encouragement and treats to keep me going, and brother George for filling in for my extended family duties. 


\section{Publications from this Thesis}

As of March 2019

Chapter 2. Michael, K. P., \& Shima, J. S. (2018). Four-year decline in Ostrea chilensis recruits per spawner in Foveaux Strait, New Zealand, suggests a diminishing stock-recruitment relationship. Marine Ecology Progress Series, 600, 85-98

Author contribution: K.P.M designed and performed the sampling, analysed the data and wrote the manuscript. J.S.S gave advice on the analysis and structure, and edited the manuscript.

Chapter 3. Michael KP (in prep). Pathogens disrupt gametogenesis and larval supply to Ostrea chilensis populations in Foveaux Strait, New Zealand

Author contribution: K.P.M designed and performed the sampling, analysed the data and wrote the manuscript. Climate data from Matt Pinkerton and Brett Mullins (NIWA). Jeff Shima and gave advice on the structure and editing. Prof. Brian Jones made comments on the manuscript

Chapter 4. Michael, K. P. (2019). Distributions of settlers suggest greater dispersal and mixing of Ostrea chilensis larvae in Foveaux Strait, New Zealand. New Zealand Journal of Marine and Freshwater Research, 53(2), 222-243

Author contribution: K.P.M designed and performed the sampling, analysed the data and wrote the manuscript. Jeff Shima suggested references to broaden scope and gave advice on the structure and editing. 


\section{Table of Contents}

\section{Contents}

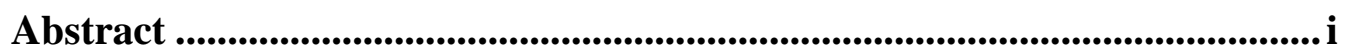

Acknowledgements ............................................................................................iii

Publications from this Thesis............................................................................... v

Table of Contents............................................................................................ vi

List of Illustrations .............................................................................................. ix

List of Tables.......................................................................................................... xvi

Chapter 1 : General Introduction ........................................................................ 1

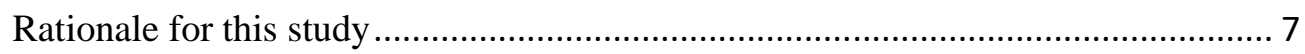

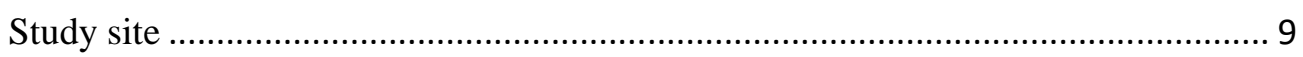

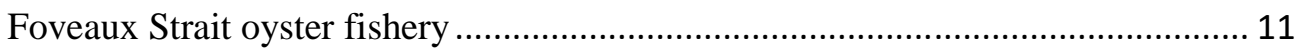

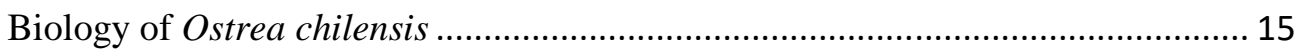

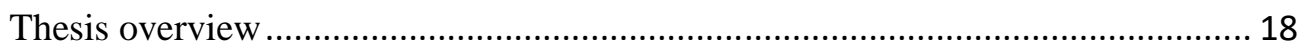

Key assumptions that underpin sampling designs and methods ......................... 20

\section{Chapter 2 : The relationship between $O$ strea chilensis spawner densities} and numbers of recruits ................................................................................... 25

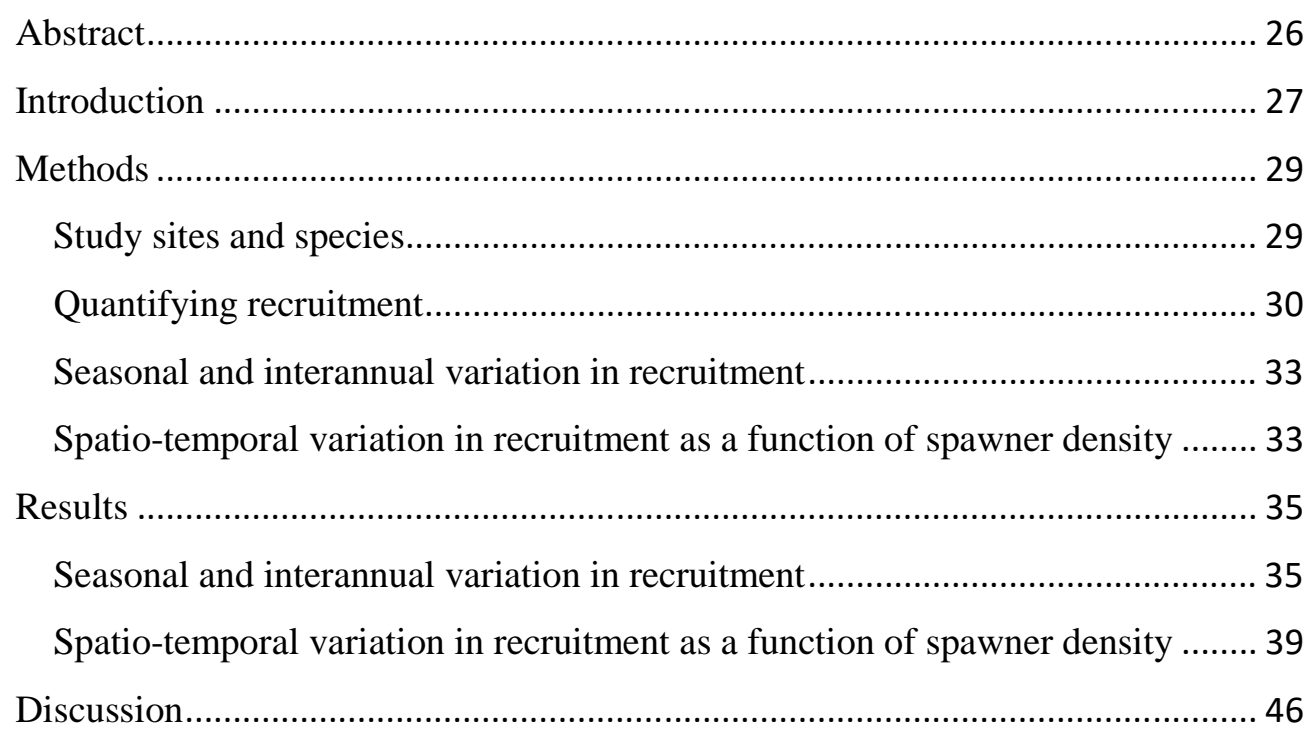


Chapter 3 : Evaluation of the effects of climatic and disease on Ostrea chilensis recruitment ................................................................................5 54

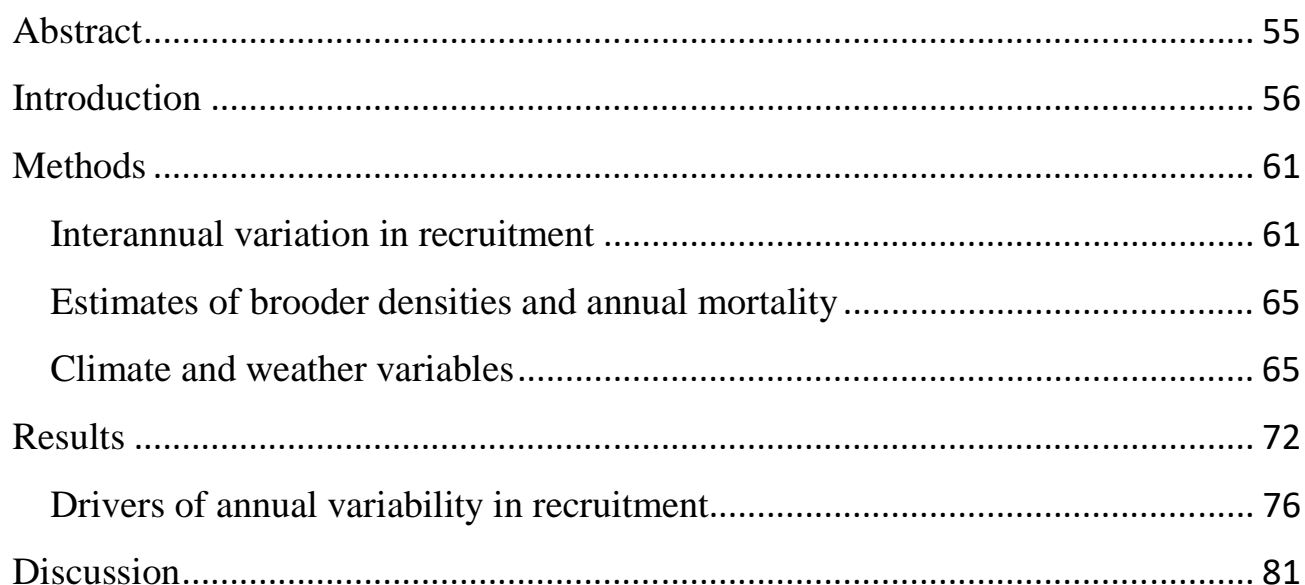

Chapter 4 : Dispersal and mixing of Ostrea chilensis larvae .....................90

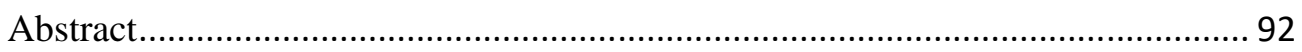

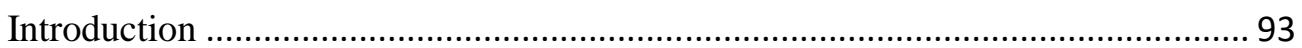

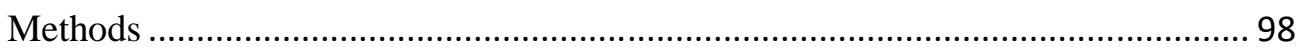

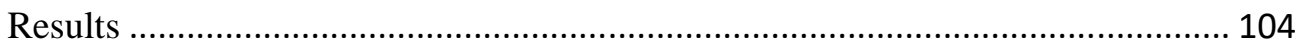

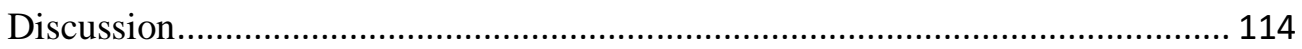

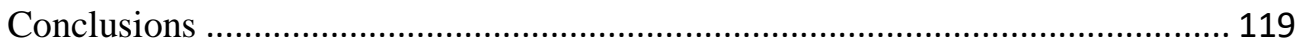

Chapter 5 : Settlement, growth, and survival of Ostrea chilensis ............ 121

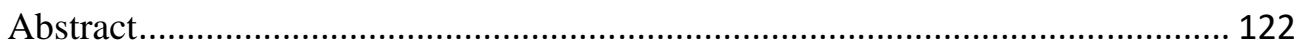

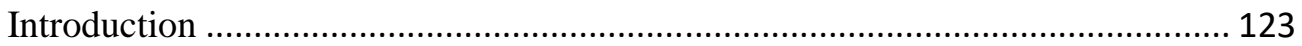

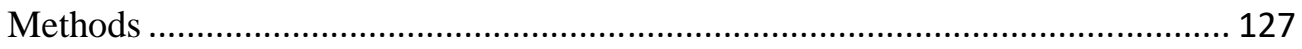

Benthic habitats and substrates targeted by commercial fishers...................... 128

Settlement substrata on which $O$. chilensis settle and survive........................... 129

Differences in growth and mortality ............................................................. 130

The survival and growth of recruits at different heights above the seabed........ 133

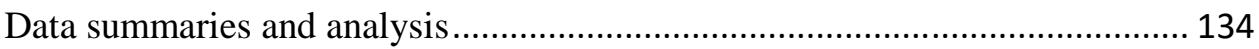


Chapter 5 : Settlement, growth, and survival of Ostrea chilensis

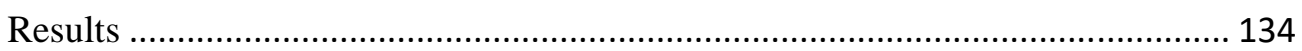

Benthic habitats targeted by commercial fishers ........................................... 134

Ostrea chilensis settlement substrata................................................................ 136

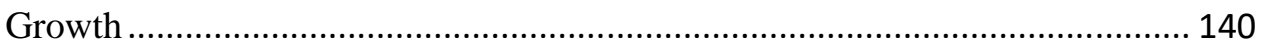

Differences in growth between western and eastern sites ................................ 141

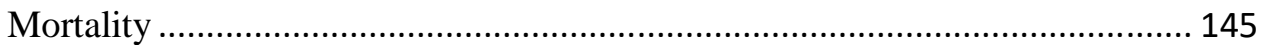

Differences in mortality between western and eastern sites ............................ 148

Differences in mortality with height above the seabed.................................... 149

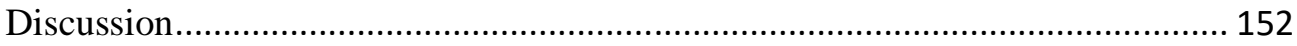

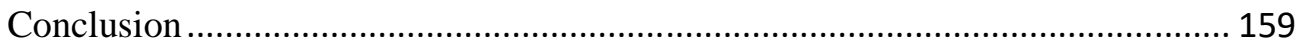

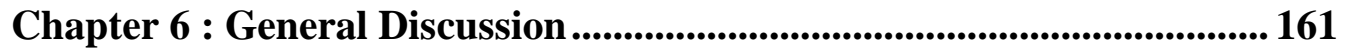

Larval supply and distribution ........................................................................ 163

Self-recruitment in $O$. chilensis ....................................................................... 166

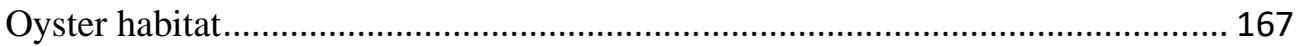

Essential habitat for Ostrea chilensis recruitment and abundance ....................... 168

Management considerations ……………………......................................... 172

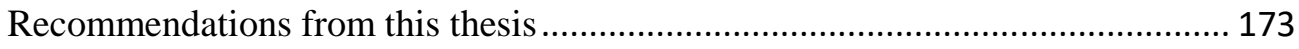

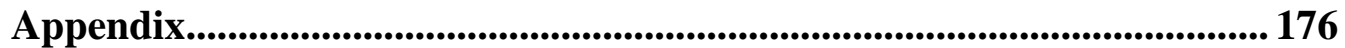

Estimates of spawner densities ........................................................................ 176

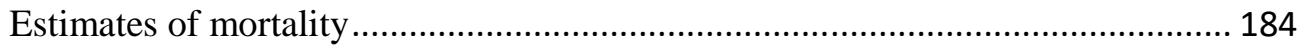

Climate variables …….................................................................................. 189

Growth and mortality $0+$ recruits and $1+$ spat .................................................. 170

Bibliography .......................................................................................................... 174 


\section{List of Illustrations}

\section{Chapter 1}

Figure 1-1. Posterior distributions of estimated recruit-sized biomass (as a percentage of $\mathrm{B}_{0}$ (the biomass before fishing began) from the OYU 5 stock assessment model (Fu et al. 2016). Horizontal dashed lines show 40\%, 20\%, and $10 \% \mathrm{~B}_{0}$. Image Kath Large, NIWA.

Figure 1-2. Foveaux Strait oyster stock (OYU 5) boundary and oyster fishery statistical reporting areas (delineated by grey lines and capitalised alpha numeric labels shown in black text), and the outer boundary of the 2007 stock assessment survey area (shaded blue) that encompasses the commercial fishery.

Figure 1-3: Three-dimensional surface plots of recruit-sized oyster densities from stock assessment surveys between 1993 and 2012.

\section{Chapter 2}

Figure 2-1. Foveaux Strait oyster stock (OYU 5) boundary (heavy black lines) and the outer boundary of the 2007 stock assessment survey area (grey lines) encompassing the commercial fishery. Seasonal and interannual variation in recruitment was sampled at a single site (light blue shading), and spatiotemporal variation in recruitment at 6 sites across the fishery (filled black circles). Inset shows the location of Foveaux Strait within New Zealand.

Figure 2-2. Passive artificial spat collectors used to estimate recruitment. Cement board plates $(220 \times 140 \mathrm{~mm}$ and $4 \mathrm{~mm}$ thick $)$ at heights of 10, 120, 240, and $360 \mathrm{~mm}$ above the seabed.

Figure 2-3. Spat plate recovered after c. 122 days showing O. chilensis recruits.

Figure 2-4. Oyster recruitment (mean \pm SE) by Season (labelled A, B, and C) from December 2005 to February 2011 at a single site (light blue shading, Fig. 1). Season A: 1 July to 31 October, Season B: 1 November to 28 or 29 February, Season C: 1 March to 30 June. Recruitment was estimated as the counts of living and dead oysters per collector (sample) settling over $122 \mathrm{~d}$. The $\mathrm{x}$-axis gives month and year of retrieval. 
Figure 2-5. Interannual and spatial variation in oyster recruitment (mean $\pm \mathrm{SE}$ ) assessed for the primary season of recruitment (November to February). Means and SE estimated from total counts of living and dead oysters from each collector (sample) which settled over $122 \mathrm{~d}$. Recruitment for sites with (A-C) putative high and (D-F) putative low spawner densities for areas East, South, and West, respectively.

Figure 2-6. Stock-recruitment relationships for oysters sampled at fixed locations across the fishery over successive years (2007-08 to 2010-11). Estimates of oyster recruitment (spat collector-1) are for the primary season (November to February). Each point represents counts from a single collector ( $n=3$ collectors deployed at each of 6 sites, each year). A few spat collectors were lost. Spawner densities estimated from dredge samples. Colours correspond to years as given in the key; fitted lines are from a negative binomial regression model, and shaded areas depict \pm SE.

\section{Chapter 3}

Figure 3-1. Foveaux Strait oyster stock (OYU 5) boundary (heavy black lines) and the outer boundary of the 2007 stock assessment survey area (grey lines) encompassing the commercial fishery. Sampling for seasonal and interannual variation in recruitment at a single site (light blue shading), spatio-temporal variation in recruitment at six sites across the fishery (filled black diamonds $\downarrow$ ), and the gradient sampling grid in blue with blue text. The lower right inset shows the location of Foveaux Strait within New Zealand.

Figure 3-2. The 2007 stock assessment area boundary shown as a heavy, black outer line, and the 26 stock assessment survey strata (light grey and blue lines). The Bonamia exitiosa survey area boundary (shown as a heavy blue line), the 14 core strata (shown as blue lines) and the single background stratum (BK) delimited by the stock assessment survey (black lines) and B. exitiosa survey (blue lines) boundaries. Strata are labelled with grey text. The site where spat collectors were deployed in 2015 (red filled circles), 2016 (blue circles), and 2017 (black circles). A polygon defining the area from which remote sensed data were extracted is shown in light blue shading.

Figure 3-3. Mean recruitment (spat per collector) $\pm 95 \%$ CI for 2006-2017 by year (A), percentage mortality of brooding-sized oyster population by year (B), mean density of brooders $\left(\mathrm{m}^{-2}\right)$ by year $(\mathrm{C})$. The light shaded region highlights the period of relatively high recruitment, while the dashed blue reference line shift to low recruitment in 2010. The darker shaded region highlights a period of low recruitment. 
Figure 3-4. The predicted mean recruitment (black line) of $O$. chilensis in the Foveaux Strait fishery area and 95\% CIs (grey lines) against mortality from time series data 2005-2017.

Figure 3-5. The predicted mean recruitment (black line) of $O$. chilensis in the Foveaux Strait fishery area and 95\% CIs (grey lines) against density from time series data 2005-2017.

\section{Chapter 4}

Figure 4-1. Foveaux Strait, southern New Zealand. Grey lines show the 2007 stock assessment survey area. The gradient design comprised four axes (North, East, South, and West), with the central cell encompassing the focal population; area boundaries shown in blue. Three, one nautical mile square cells extend along each axis (blue squares). Red filled circles scaled to brooder densities. Three randomly assigned spat collectors in each cell and nine collectors in the central cell encompassing the focal-population shown as black points.

Figure 4-2. Kernel densities of brooders ( $\geq 60 \mathrm{~mm}$ in length) within the research area (Foveaux Strait, southern New Zealand) from dredge sampling during February surveys 2009-2011 (Michael et al. 2009; Michael et al. 2011; Michael et al. 2012). Cell boundaries shown as black rectangles. Brooders scaled to density at sample locations shown as filled blue circles.

Figure 4-3. The percentage annual commercial catch of oysters (Ostrea chilensis) by reporting area, from skippers' 2011 season (1 March to 31 August, Michael 2012) logbooks. Percentage of the total annual catch shown as $5-10 \%$ (red), 3-4.9\% (orange), 1-2.9\% (yellow), and $<1 \%$ (light blue). The white background represents cells where no fishing took place. Reporting cell labels for the cells that comprise the sampling design shown in black text. The sampling grid shown as red lines.

Figure 4-4. The percentage length frequencies of live $O$. chilensis recruits. Spat collectors sampled during the summers (November to February) from 2011-12 to 2013-14.

Figure 4-5. Bar plots of mean recruit densities and 95\% confidence intervals for the three years of sampling during the summers (November to February)

from 2011-12 to 2013-14. 105 
Figure 4-6. Violin plots of $O$. chilensis recruit densities along four axes (Ax) extending west, north, east, and south from focal population for the summers (November to February) of 2011-12 to 2013-14. Violin plots show data points (dots) and probabilities for the range of recruit densities scaled to the highest recruit density. Mirrored probability distributions shown as shapes shaded by factor. Horizontal lines within distributions denote the median, 25th and 75th percentiles.

Figure 4-7. Changes in $O$. chilensis recruit densities (spat per collector) with increasing distance from the focal population over the four axes extending west, north, east, and south over the summers (November to February) of 2011-12 to 2013-14. Coloured lines and shading show fits from generalised linear model with a negative binomial distribution and a log link function (mean $\pm 1 \mathrm{SE})$.

\section{Chapter 5}

Figure 5-1. Foveaux Strait oyster logbook grid (1 nautical mile squares, grey lines) established by skippers to cover the commercial fishery area. The boundaries of the 2007 stock assessment survey area shown as a blue line. Heavy black lines in the west and east denote the OYU 5 stock boundaries. 128

Figure 5-2. The Foveaux Strait oyster fishery area delimited by the grey lines representing boundaries for stock assessment surveys and sites where settlement substrata and bycatch were sampled. Dive and dredge (2010 \&2011) sampling was within the area shaded light blue. The fishery-scale spat monitoring sites 2009-2012 are shown as black filled circles (e.g. West-low), and the 1999/2000 spat collector, growth and mortality investigation sites shown as black asterisks (W1 \&W2, E1-E4). Sites sampled for bycatch and oyster spat during the 2006 survey shown in blue diamonds and the 2007 survey in grey diamonds.

Figure 5-3. The percentage occurrences of each bycatch category from fishers' logbook data representing 100\% of the catch for years (oyster seasons, 1 March to 31 August) 2007 to 2016 combined. Kaeos (sea tulips, Pyura

pachydermatina) and mixed invertebrates mainly comprise mytilids, ascidians, and bryozoans. Boxplots show medians (solid lines) and the boxes the 25 and 75 percentiles. Whiskers shown at the 95 percentiles, with outliers shown as black circles outside of this range. 135

Figure 5-4. Percentage cover of collector plates by three categories of benthic taxa (algae, barnacles, other species) and by total cover by all taxa. Boxplots show medians (solid lines), boxes 25 and 75 percentiles, whiskers at 95 percentiles, and outliers shown as black circles above and below whiskers. . 139 
Figure 5-5. Total numbers of recruits versus percentage cover of all other benthic taxa combined by plate surface. Fitted line is a loess smoother and shaded area depicts \pm 1 SE.

Figure 5-6. Size (diameter $\mathrm{mm}$ ) of recruits (0+ oyster spat): natural-recruits (left panel) and recruits (right panel) at March 2000 (less than 140 days after settlement) by site and valve orientation. Jittered data points represent spat size coloured by valve orientation. Boxplots show medians (solid lines), mean (heavy dashed line), boxes at the 25 and 75 percentiles. Whiskers show at the 95 percentiles with outliers shown as black circles above and below whiskers. Bar widths scaled to the relevant sample sizes.

Figure 5-7. Heights ( $\mathrm{mm})$, as a proxy for diameter of recruits (0+ oyster spat) settled on passive spat collectors at six sites in Foveaux Strait between October 1999 and March 2000 (c. 140 days). There is stratification by plate height, and by plate surface. Plate heights (level) $1-4$ are at $36 \mathrm{~cm}, 24 \mathrm{~cm}, 12 \mathrm{~cm}$, and $~ 2$ $\mathrm{cm}$ (just off the seabed) respectively. There were two surfaces to each plate: the upper and lower (under side). Jittered data points represent spat size coloured by level. Boxplots show medians at each site (solid lines), mean height for all recruits at all sites (heavy dashed line), boxes 25 and 75 percentiles, whiskers at 95 percentiles, and outliers shown as black circles above and below whiskers. Bar widths scaled to sample sizes. 144

Figure 5-8. Mortality (percentage frequency of spat by valve) of recruits $(0+)$ by site, between October 1999 and March 2000.

Figure 5-9. Percentage length frequency of dead $O$. chilensis recruits (left valves) from spat collectors and oyster shells of growth experiments that died post settlement between October 1999 and March 2000.

Figure 5-10. The percentage mortality in $O$. chilensis, recruits $(0+)$ by total numbers of recruits. Fitted line is a loess smoother and shaded area depicts \pm 1 SE. Mortality of recruits from spat collectors (Collectors) by surface shown as pink dots and recruits attached to shells on cement board sticks as blue dots.

Figure 5-11. Mortality (percentage by surface) of naturally settled 0+ recruits on passive collectors by Site and Level between October 1999 and March 2000. Boxplots show medians (solid lines), mean (heavy dashed line), boxes 25 and 75 percentiles, whiskers at 95 percentiles, and outliers shown as black circles above and below whiskers. Bar widths scaled to sample sizes.

Figure 5-12. Mortality (percentage by surface) of naturally settled 0+ recruits on passive collectors by Surface and Site between October 1999 and March 2000. Boxplots show medians (solid lines), mean (heavy dashed line), boxes 25 and 75 percentiles, whiskers at 95 percentiles, and outliers shown as black circles above and below whiskers. Bar widths scaled to sample sizes. 
Figure 5-13. Ostrea chilensis recruits (shown with black arrow) on the inner surface of a right (flat) oyster valve (left) and the inner surface of an Oxyperas elongate (OEL) shell (right).

Figure 5-14. Boxplots of the weights of live oysters and oyster shell, the shells of other prominent bivalves in the bycatch, and gravel. R, Pr, and S denote recruit, pre-recruit and small size oysters respectively....

Figure 5-15. Image of the seabed (c. $4 \mathrm{~m} 2$ ) in the central Foveaux Strait fishery comprising sand and shell over gravels, with high oyster densities (2400 recruit-sized oysters per tow, $12 \mathrm{~m}^{-2}$ ).

Figure 5-16. The sediments of oyster habitat are occasionally mobile during storms and may bury oysters and recruits.

\section{Chapter 6}

Figure 6-1. Lenticular structures comprised sediment and shell, formed by hydrographic forces along the current axis south of Bluff Hill (see Cranfield et al. 2004). These structures provide the genesis for complex biogenic habitat ("reefs"). Cinctipora elegans and $O$. chilensis (black arrow) are among the early colonisers above the flat gravel seabed and beginning to be overgrown.

Figure 6-2. Cinctipora elegans overgrown and killed by a number of benthic taxa (left panel), Modiolus areolatus overgrown Dactylia varia (middle panel). Note gravel bound by byssus, and oyster spat settled on a spat collector overgrown by invertebrates, mainly bryozoans at the end of their second summer (right panel)

\section{Appendix}

Figure A-1. Spawner densities, oysters $\geq 50 \mathrm{~mm}$ in diameter) per $\mathrm{m}^{2}$ sampled from sites across the fishery in November 2007. Site codes prefixed with "Area" West (W), South (S), and East (E); and suffixed with Category of density, high density $(\mathrm{H})$, low density (L) respectively. Bars show mean densities with \pm 1 SE.

Figure A-2. Spawner densities by site from nearby, randomly allocated survey tows in strata where fishery-scale sites were located. Data from fishery independent surveys 2007-2011 (Michael et al. 2009a, 2009b, 2011, 2012, 2013). 
Figure A-3. Spawner densities sampled at each site before the spat collectors were deployed in November 2007 (Sample, red dots); and survey estimates sampled in February 2008 (Survey, blue dots). Growth in O. chilensis occurs only in the summer months (Dunn 2005) and the increase in spawner densities between November and February may more reflect recruitment of spawningsized oysters than sampling variation alone. Grey lines represent bootstrapped 95\% confidence intervals for "Sample" and "Survey" estimates and grey dots are the mean densities.

Figure A-4. The range of absolute oyster spawner densities $\left(\mathrm{m}^{-2}\right)$ sampled from random fishery surveys 2005-2011. Boxplots show medians, boxes the 25 th and 75th percentiles, and the whiskers 1.5 IQR. Outliers shown as black dots. Mean spawner densities shown as filled red circles and in black text.

Figure A-5. The percentage mortality of $O$. chilensis spat by settler densities, by Site. Fitted line is a loess smoother and shaded area depicts $\pm 1 \mathrm{SE}$.

Figure A-6. The cumulative percentage frequency of lengths of live and dead O. chilensis spat sampled 2008-2011 in season of recruitment (B: November to February).

Figure A-7. Regression of mean monthly SST $\left({ }^{\circ} \mathrm{C}\right)$ and air temperatures $\left({ }^{\circ} \mathrm{C}\right)$ recorded at the Tiwai Point weather station, Bluff $(-46.587,168.376)$, July 2002 to March 2017.

Figure A-8. Regression of mean monthly chlorophyll (Chl_a) Ocean case versus Blended case $\left(\mathrm{mg} \mathrm{m}^{-3}\right)$, July 2002 to March 2017.

Figure A-9. Wind rose for wind direction and speed at Tiwai Point, Bluff January 1980 to October 2017 (left panel) and by each of the period representing the three reproductive phases (right panel).

Figure A-10. Size (diameter mm) of oyster spat (1+) at March 2000, by site and by valve orientation. Jitter points represent spat size coloured by valve orientation. Boxplots show medians (solid lines), mean (heavy dashed line), boxes 25 and 75 percentiles, whiskers at 95 percentiles, and outliers shown as black circles above and below whiskers. Bar widths scaled to sample numbers.

Figure A-11. Percentage frequency of mortality of spat (1+) on each valve by site, between October 1999 and March 2000. 


\section{List of Tables}

\section{Chapter 2}

Table 2-1. Seasonal and interannual variation in recruitment of oysters between 2005 and 2011 at a single site in Foveaux Strait. Season B: 1 November to 28 or 29 February, Season C: 1 March to 30 June. Oyster recruitment is modelled as a function of Season and Year using zero-inflated negative binomial regression. Shown are the results of a negative binomial model for the count data (model statistics theta $=2.0943$, $\mathrm{df}=12$, and loglikelihood $=-492.4$ ) and the results of a zero-inflated model with logit coefficients for predicting excess zeros. The exponents of coefficients $\left(\mathrm{e}^{\text {coefficient }}\right)$ are shown with $95 \%$ confidence intervals (CI).

Table 2-2. Seasonal and interannual variation in recruitment of oysters at a single site in Foveaux Strait, between 2005 and 2011. Recruitment is modelled by factors Season, Year, and the interaction between Season and Year, using a negative binomial regression with a log link function. \% Dev: cumulative

percentage deviance explained, AIC: Akaike's Information Criterion. 38

Table 2-3. Spatio-temporal variation in oyster recruitment across the Foveaux Strait fishery between 2007 and 2011. Oyster recruitment is modelled as a function of Year, Spawner density, and Area, and their interactions, using data from Season B (settlement season) only. The best-fit negative binomial regression is shown. \% Dev: cumulative percentage deviance explained, AIC: Akaike's information criterion.

Table 2-4. Spatio-temporal variation in oyster recruitment across the Foveaux Strait fishery, 2007-08 to 2010-11. Oyster recruitment is modelled as a function of Year, Spawner density, and Area, and their interactions, using data from Season B (settlement period) only. Paired comparisons for the best-fit negative binomial model (model statistics theta $=10.3658$, $\mathrm{df}=43$, and loglikelihood $=-693.92$ ) are shown. Spawner densities (1)-(3) denote first- to third-order polynomials, respectively.

\section{Chapter 3}

Table 3-1. Multiple models of recruitment. Each time step and group of climate variables and their mean, 5th and 95th percentiles were run separately with density and mortality.... 
Table 3-2. Ranks of the relative variable importance for density, mortality and climate variables to predict recruitment using Cforest algorithm (Hothorn et al. 2005). Brooding-sized oyster density (Density), annual mortality from Bonamia exitiosa (Mortality), 3-monthly running means for Southern Oscillation Index (SOI3av), wind speed (WSpd), the difference in mean sealevel pressure between Hobart and the Chatham Islands (M1), mean chlorophyll a (Chl), Southern Oscillation Index (SOI), turbidity (Turb), the numbers of days of severe gales (DSGales), the difference in mean sea-level pressure between Christchurch and Campbell Island (Z2), and mean sea surface temperature (SSTav). Variable importance measure (VIM) and proxy for effect size (\%EF). Sensitivity analyses without Density (Var-1, VIM-1, and $\%$ EF-1), and without Density and Mortality (Var -2, VIM-2, and \%EF-2). Cforest run with options cforest_unbiased(ntree $=8000$, mtry $=2)$, and function varimpAUC to compute variable importance measures as the area under the curve as a proxy for effect size. VIMs represent the effects of variables in both main effects and interactions.

Table 3-3. The best-fit negative binomial regression of annual variation in oyster recruitment across the Foveaux Strait fishery between 2006 and 2017. Recruitment was estimated from recruit densities and modelled as a function of brooding-sized oyster density (Density), annual mortality from Bonamia exitiosa (Mortality), 3-monthly running means for Southern Oscillation Index (SOI3av), and the difference in mean sea-level pressure between Hobart and the Chatham Islands (M1), and their interactions. Percentage deviance (\%Dev) and cumulative percentage deviance (Cum\%Dev) explained.

Table 3-4. Annual variation in oyster recruitment across the Foveaux Strait fishery from 2006 to 2017. Oyster recruitment was modelled as a function of brooding-sized oyster density (Density), annual mortality from Bonamia exitiosa (Mortality), 3-monthly running means for Southern Oscillation Index (SOI3av), and the difference in mean sea-level pressure between Hobart and the Chatham Islands (M1), and their interactions. Density and mortality were modelled as first to third order polynomials, denoted (1)-(3) below. The best-fit negative binomial model statistics: Theta $=1.6254, \mathrm{SE}=0.0353, \mathrm{df}=3935$, $\log$-likelihood $=-43919.54$, and AIC $=43948$. NS denotes not significant..... 80 


\section{Chapter 4}

Table 4-1. Factors predicting the distributions $O$. chilensis recruits as a proxy for the dispersal of competent larval abundance from a focal population in the Foveaux Strait oyster fishery, 2011-12 to 2013-14. Recruit densities modelled as functions of year (Yr), distance (D), current axis (Cx), and their interactions (models 1-10) using negative binomial regression. Axis (Ax) was substituted for Cx for each model (models 11-13), because of the relatively small data size. Degrees of freedom (d.f.), Akaike Information Criterion (AIC), and percentage deviance explained (\% Dev) are given for each model. Selection of the best-fit model was based on AIC. Where AICs were similar between models, the percentage deviance explained (a measure of effect size, analogous to a variance component) and graphical evaluation of fits determined best-fit models (bold).

Table 4-2. Analysis of deviance for best-fit negative binomial Model 6 (glm.nb) and estimates for coefficients for factors year (Yr) and current axis (Cx). Degrees of freedom (d.f.), deviance (Dev), percentage deviance explained (\% Dev), residual degrees of freedom (Resid. d.f.), residual deviance (Resid. Dev), and $\mathrm{P}$ value ( $\operatorname{Pr}(>\mathrm{Chi}))$.

Table 4-3. Analysis of deviance for best-fit negative binomial Model 13 (glm.nb) and estimates for coefficients for factors year (Yr) and current axis $(\mathrm{Ax})$. Degrees of freedom (d.f.), deviance (Dev), percentage deviance explained (\% Dev), residual degrees of freedom (Resid. d.f.), residual deviance (Resid. Dev), and P value ( $\operatorname{Pr}(>\mathrm{Chi})$ ).

Table 4-4. Analysis of deviance for negative binomial models (glm.nb) of Recruits modelled against Ax, and Brooders. Sample sizes were too small to run interactions. Akaike Information Criterion (AIC), degrees of freedom (d.f.), deviance (Dev), percentage deviance explained (\% Dev), residual degrees of freedom (Resid. d.f.), residual deviance (Resid. Dev), and P value $(\operatorname{Pr}(>\mathrm{Chi})$ ) are given for each model. Best-fit model selected based on AIC, \% Dev, and graphical evaluation (shown in bold). 


\section{Chapter 5}

Table 5-1. Locations of the six sites used for growth and mortality investigations, where cement board sticks with $0+$ recruits and $1+$ spat on oyster shell (single valves), and spat collectors were deployed. Two sites selected in the western fishery area and four in eastern locations representing a range of habitats and exposures to oceanic swells (see Figure 5-2).

Table 5-2. Taxa and shells representing greater than $1 \%$ of the total bycatch composition by number that had $O$. chilensis recruits attached. Taxa: $O$. chilensis (OYS), the gastropod Astraea heliotropium (ASH), the Mytilid Modiolus areolatus (MOA), barnacles Balanus spp. (BAR), the mactrid Oxyperas elongate (OEL), and their shells denoted by suffix (_Shell). Numbers of each bycatch component (n), those with settlers attached (n.Recruits), the percentage of each bycatch component that had settlers attached (\%), the percentage of all bycatch components (\%TWS), and the percentage of all bycatch sampled with recruits attached (\%AWS).

Table 5-3. Estimates of the numbers of valves with and without recruits sampled from a single tow at the dive site in February 2008 (see light blue shaded area in Figure 5-2). Summary statistics of the number of each type of valve OYS, OEL, and ASH, and the numbers of live and dead oyster recruits. Percentage survival is the number of live recruits as a percentage of all recruits (live and dead).

Table 5-4. Growth in 0+ recruits and natural-recruits recovered in March 2000 (c. 140 days) at six sites in Foveaux Strait (see Figure 5-2). Median diameter mm (Median), mean diameter for comparison (Mean), $5^{\text {th }}$ and $95^{\text {th }}$ percentiles (P $0.05 \&$ P 0.95), and sample sizes (n).

Table 5-5. Growth increments in diameter $(\mathrm{mm})$ in 1+ oyster spat recovered in March 2000 after c. 140 days at 6 sites in Foveaux Strait (see Figure 5-2).

Median diameter mm (Median), mean diameter for comparison (Mean), $5^{\text {th }}$ and $95^{\text {th }}$ percentiles (P $0.05 \&$ P 0.95), and sample numbers (n).

Table 5-6. Mortality of $0+$ recruits settled on passive spat collectors between October 1999 and March 2000 (c. 140 days in Foveaux Strait) by Site, Level, and Surface. Mean (mean), standard deviation (SD), numbers of surfaces with settler (n), standard error of the mean (SE), and upper and lower 95\% confidence intervals $(95 \% \mathrm{CI})$ for lengths $(\mathrm{mm})$. 


\section{Appendix}

Table A-1: The locations of the six sites across the Foveaux Strait oyster fishery sampled for the spatio-temporal variation in recruitment.

Table A-2. Estimates of mean spawner densities (oysters $\left./ \mathrm{m}^{2}\right) \pm 1 \mathrm{SE}$ from predeployment sampling (November 2007) and annual February surveys (2007 to 2011) from strata containing the six sampling sites. Site codes prefixed with "area" west (W), south (S), and east (E) and suffixed with Category of density, high density $(\mathrm{H})$, low density $(\mathrm{L})$ respectively. For years when there was no sampling near sites, spawner density assigned as the mean value between the previous and following years estimates (year before 2007 and after 2011 not shown). Missing data shown in italics and underlined. Data from Michael et al. (2008a, 2009, 2009a, 2011, 2012). Mean distance (km) with SE, and minimum and maximum distances between dredge sample sites and collector sites also shown.

Table A-3. Oyster recruitment modelled as a function of Year, Site, and their interactions using a Negative Binomial Generalized Linear Model. Cumulative percentage deviance (\%Dev) for ranked variables and Akaike Information Criterion (AIC).

Table A-4. Estimates of pre-survey (Pre_M), post-survey (Post_M), and annual mortality (Mortality) from Bonamia exitiosa, mean population density of recruit-sized oysters (Density) with references by year for February surveys.

Table A-5. Heights of 0+ oyster spat settled on passive spat collectors between October 1999 and March 2000, c. 140 days at 6 sites in Foveaux Strait, by plate heights combined, and by plate surface. Median diameter mm (Median), mean diameter for comparison (Mean), 5th and 95th percentiles, and sample numbers (n). Plate heights 1-4: $36 \mathrm{~cm}, 24 \mathrm{~cm}, 12 \mathrm{~cm}$, and just off the seabed $(\sim 2 \mathrm{~cm})$ respectively. Surfaces represent the upper and lower (under side) of plates.. 172

Table A-6. Mortality of 1+ spat between October 1999 and March 2000 (c. 140 days in Foveaux Strait) by Site and valve-orientation. Mean (mean), standard deviation (SD), numbers of surfaces with settler (n), standard error of the mean (SE), and upper and lower $95 \%$ confidence intervals $(95 \% \mathrm{CI})$ for lengths (mm). 


\section{Chapter 1 : General Introduction}

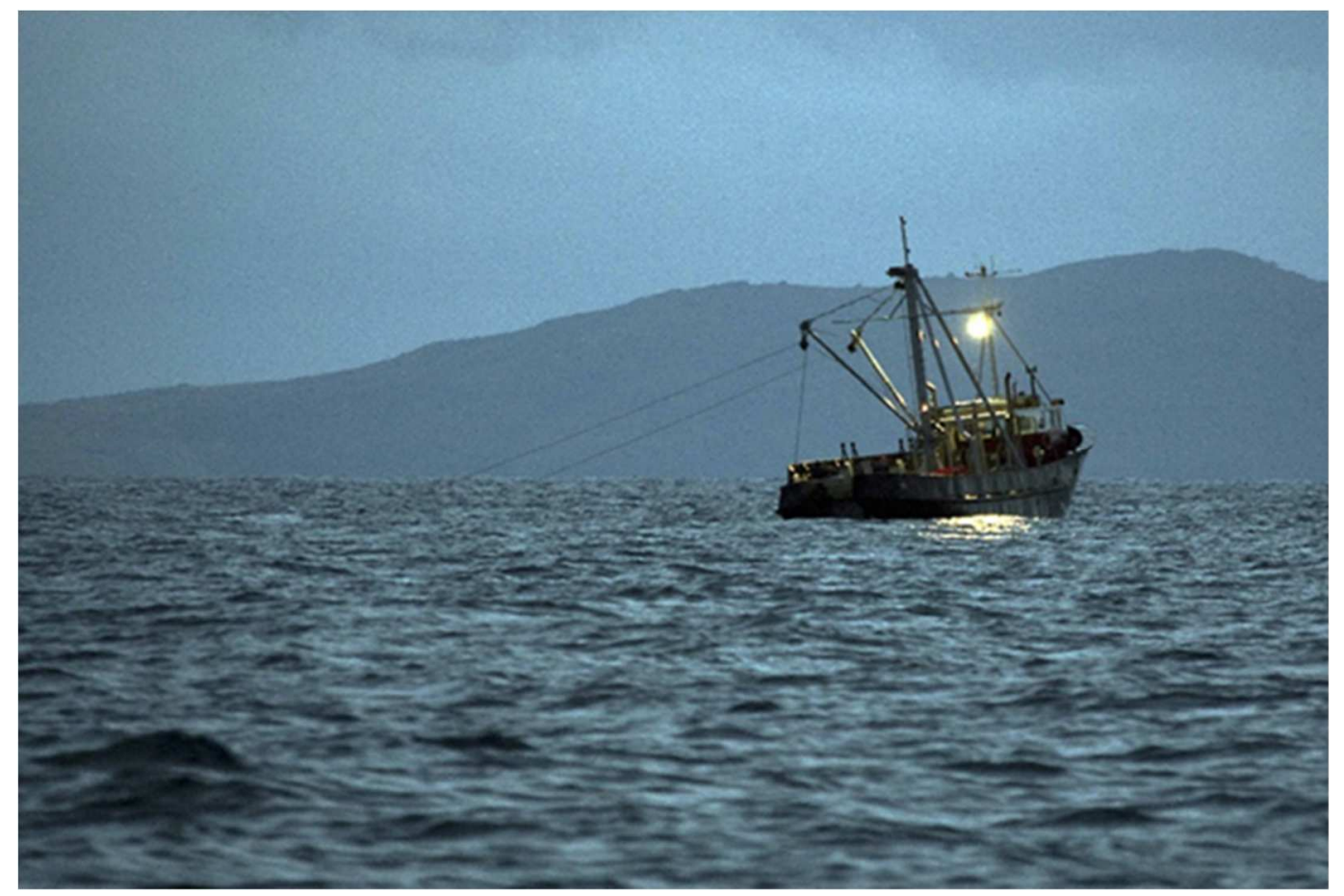

A commercial fishing vessel, the Southern Enterprise dredging for oysters (Ostrea chilensis) in Foveaux Strait, southern New Zealand (image courtesy of Tony Smith). 
Worldwide, oysters (Ostreidae Rafinesque, 1815) have been important to the ecology of benthic communities and to the wellbeing of many peoples. They inhabit a range of environments from sheltered intertidal mudflats (Powell 1979, Robjohns 1979, Wright 1990, Ruesink et al. 2005) to deep (greater than $80 \mathrm{~m}$ ) gravel substrates exposed to large oceanic swells (Buroker 1985, NABIS 2018). Historically, oysters were abundant in accessible intertidal and nearshore habitats, and were an important food source (Yonge 1966, MacKenzie et al. 1997a, MacKenzie et al. 1997b, MacKenzie et al. 1997c, Gercken \& Schmidt 2014). Many oyster stocks are now depleted (Beck et al. 2011, Schrobback et al. 2014) from over exploitation, the destruction of habitat through sedimentation (Diggles 2013), fishing practices (Rotschild et al. 1994, Jackson et al. 2001), and occasional uplift of nearshore areas by earthquakes (Aiken 1993).

These declines in wild fisheries have led to aquaculture initiatives to increase the global production of oysters. Oyster production is the highest amongst molluscs (FAO 2018) and almost all oyster production is for cupped oysters (Crassostreinae) (Wijsman et al. 2019), because of their faster growth rates and shorter production cycles. China reportedly produces by far the highest tonnages of cupped oysters globally (Wijsman et al. 2019). In contrast, Ostreinae account for a small percentage of global oyster production (FAO 2018, Wijsman et al. 2019). In many countries, mortality caused by disease has severely constrained production of endemic species as well as the non-native species introduced in an attempt to mitigate the effects of disease (Culloty \& Mulcahy 2007, Arzul \& Carnegie 2015, Pernet et al. 2016). Despite concerted efforts to reduce oyster mortality from disease, local levels of aquaculture production remain well below pre-disease production levels (Culloty \& Mulcahy 2007, Buestel et al. 2009, Arzul \& Carnegie 2015). The ecological and economic importance of oysters has prompted restoration strategies to rebuild wild populations (Schulte et al. 2009, Brown 2011) and the need to better manage them (Powell \& Klinck 2007, Powell et al. 2012, Ministry for Primary Industries 2017). 
Oysters are ecosystem engineers that structure benthic communities (Jones et al. 1994, Grabowski \& Peterson 2007), form complex habitats, and provide ecosystem services (Lenihan \& Peterson 1998, Coen et al. 1999, Coen et al. 2007, Beck et al. 2011, Grabowski et al. 2012). Habitats structured primarily by oysters and their shells are known as "oyster reefs" (Cowardin et al. 1979, Bahr \& Lanier 1981). The declines in oyster reefs and oyster fisheries have prompted efforts to conservative and restore of oyster populations (Peterson et al. 2003, Schulte et al. 2009, Beck et al. 2011, Brown 2011); however, the management of oyster fisheries has not changed greatly.

Historical management of oyster fisheries has generally been ineffective (Lenihan \& Peterson 1998, Beck et al. 2011, Ministry for Primary Industries 2017), as has the management of other sessile benthic invertebrate fisheries (MacKenzie et al. 1997a, MacKenzie et al. 1997b, MacKenzie et al. 1997c, Hobday et al. 2000, Karpov et al. 2000, Anderson et al. 2011a). Poor performance, in at least some management efforts, may be attributed to a disconnection between stock structure and management units that often leads to serial depletion (Hilborn et al. 2005). Moreover, most management efforts assume some level of a density-dependent relationship between stock size (the exploitable portion of a population) and recruitment in the form of a stock-recruit relationship (Ricker 1954, Beverton \& Holt 1957). This assumption has provided a level of convenience for managers of fisheries in that the control of spawning stock size (e.g. reference points (Mace 2012)) through harvest limits presumably ensures recruitment and thereby future yields. Management of sessile invertebrates based on stock-recruit relationships may have hastened the decline or collapse of some fisheries because the key processes that drive variability in recruitment and their interactions are not well described by stock-recruit functions used in stock assessment (King et al. 2015, Szuwalski et al. 2015).

Most sessile benthic invertebrates such as oysters have a two-stage life history: a planktonic stage where larvae or propagules are dispersed (primarily 
by currents), and a sessile post-settlement stage. In this thesis, recruits are defined as competent larvae that settle from the plankton and complete metamorphosis on substrata; consistent with the ecological definition of Stanwell-Smith \& Barnes (1997). Recruitment to the population is the number of recruits settled on substrata before post-settlement mortality occurs, and estimates of recruitment are therefore the numbers of live and dead recruits sampled on collectors or substrata on the seabed. Because Ostrea chilensis does not exhibit preferences for settlement substrata or specific settlement cues (pers. obs., and for O. edulis after Smyth et al. 2018), recruitment is assumed to reflect the numbers of competent larvae available for settlement at sampling locations. This definition of recruitment to a population differs to that of fisheryrecruitment, which is the addition of harvestable individuals from the survival and growth of recruits (Hilborn \& Walters 1992). In this thesis, I use the terms recruitment and fishery-recruitment to differentiate between recruitment to the population and to the fishery respectively.

Generally, recruitment in sessile benthic invertebrates including oysters, is a culmination of fundamental pre-and post-settlement processes that determine population demographics i.e., spatial structure and abundance (Rodriguez et al. 1993). The production of larvae, their dispersal and or retention, settlement success, and post-settlement survival and growth all play key roles. Recruitment is highly variable over space and time (Caley et al. 1996, Sale \& Kritzer 2003), and is driven by multiple processes that may differ among species, populations, locations, and with recruitment events (Thorson 1950, Shanks et al. 2003, Watson \& Barnes 2004, Broitman et al. 2008, Smale 2013). Both pre-and post-settlement processes are likely to shape recruitment (Sale \& Kritzer 2003, Shima et al. 2008, Cowen \& Sponaugle 2009, Hixon et al. 2012). Larval cohort strength, the numbers of larvae produced during a spawning event, is determined by: spawner density (Lundquist \& Botsford 2010), spawning and fertilization success (Levitan \& Sewell 1998); processes that determine larval 
growth and development (Rodriguez et al. 1993, Pineda et al. 2009), and larval survival (Rumrill 1990, Vaughn \& Allen 2010). Large larval cohorts are a prerequisite for high recruitment (Gaines \& Roughgarden 1985, Roughgarden 1988, Underwood \& Fairweather 1989, Gaines \& Bertness 1992, Caley et al. 1996, Siegel et al. 2008). However, recruitment strength is ultimately determined by physical and biological processes that determine dispersal and/or retention of larvae (Jones et al. 2009), including larval behaviour in the plankton, settlement (Coen et al. 2007, Siegel et al. 2008, Cowen \& Sponaugle 2009), and especially post-settlement survival of recruits (Hunt \& Scheibling 1997). In addition to natural variation in recruitment, human activities can severely reduce recruitment through harvests of sexually mature individuals (Levitan \& Sewell 1998), and/or negative impacts on the resources required for settlement, and post-settlement survival (Beck et al. 2001).

Recruitment processes and their interactions with one another are not well understood. The need to understand recruitment has become more urgent with increasing anthropogenic stressors (including increased exploitation of stocks) as well as climatic changes to marine systems. Improved understanding of recruitment processes can inform conservation, management and restoration efforts for sessile benthic invertebrate populations such as oysters.

Differences in reproductive strategies between subfamilies and between species within subfamilies of the family Ostreidae may in part drive variation in recruitment. Subfamily Ostreinae (Rafinesque, 1815) comprises true or flat oysters, which include Ostrea chilensis (Philippi, 1844), O. edulis (Linnaeus, 1758), O. lurida (Carpenter, 1864), O. puelchana (d'Orbigny, 1842), and $O$. stentina (Payraudeau, 1826). Members of this subfamily are larviparous (i.e. brood larvae). Brooding times vary between species, as do pelagic larval durations (PLDs). The subfamily Crassostreinae (Scarlato \& Starobogatov, 1979) comprise the cupped oysters, and includes Crassostrea virginica (Gmelin, 1791), Magallana gigas (Thunberg, 1793) formerly Crassostrea gigas (Salvi \& 
Mariottini 2017), Magallana ariakensis (Fujita, 1913), and Saccostrea glomerata (Gould, 1850). Members of this subfamily are oviparous, broadcast spawners, and typically have longer PLDs than members of subfamily Ostreinae. These differences in reproduction between Ostreinae and Crassostreinae and marked differences between the habitats and physical environments that these oyster species occupy highlights a need for species and location specific information on recruitment, i.e. the knowledge for the well-studied Crassostreinae may not be applicable to Ostreinae and vice versa.

Many of the processes that determine larval supply, settlement and survival may interact to shape patterns of recruitment (Pineda et al. 2007, Sale \& Kritzer 2003, Shima et al. 2008, Cowen \& Sponaugle 2009, Hixon et al. 2012). Successful recruitment is essential for the replenishment of local populations, and variation among subpopulations has important consequences for the larger metapopulation (Jones et al. 2009). Moreover, variation in recruitment influenced by habitat (Powell \& Klinck 2007, Soniat et al. 2012) and the effects of climate and or biological factors (Kimmel \& Newell 2007, Kimmel et al. 2014) affects the cumulative successes of these consecutive recruitment processes. These effects may greatly diminish the relationship between stock and recruits (after Szuwalski et al. 2015).

Ostrea chilensis (Ofoighil et al. 1999) was previously named O. lutaria (Hutton 1873), or Tiostrea chilensis (Chanley \& Dinamani 1980, Buroker et al. 1983). Also commonly known as the Bluff oyster, dredge oyster, or flat oyster. O. chilensis is endemic to New Zealand. O. chilensis has migrated to Chile through trans-Pacific rafting in eastward flow from northern New Zealand (Ofoighil et al. 1999), and has been introduced to Menai Strait, UK, (Walne 1974), and an unsubstantiated introduction to Tasmania, Australia in the 1920s (Dartnall 1970, Pollard \& Hutchings 1990). Jeffs \& Creese (1996), Stock (2000), Brown (2011), and Lane (2018) give overviews of the taxonomy, ecology, and biology of $O$. chilensis in New Zealand. $O$. chilensis is widely distributed at 
relatively low densities throughout New Zealand (Jeffs \& Creese 1996). Foveaux Strait is unique in that these oysters occur in high abundance and high densities (Jeffs \& Creese 1996, Ministry for Primary Industries 2017). There are four commercially exploited $O$. chilensis stocks in New Zealand (Ministry for Primary Industries 2017). Foveaux Strait (OYU 5) shows cyclic trends in abundance, driven by oyster mortality from Bonamia exitiosa (Berthe \& Hine 2003). Tasman Bay (OYS 7) has been in persistent decline and stock levels have been low since 2000. A small fishery in Cloudy and Clifford Bays (OYS 7C) was established by translocation of oysters from Foveaux Strait post 1917 (Otago Daily Times 1917). Stock levels and landings have been low, more so since 2012 (Ministry for Primary Industries 2017). Catch from the Chatham Islands (OYS 4) has been historically low. Most landings in OYS4 have been bycatch from the scallop fishery with oyster catches recorded since 2003 (Ministry for Primary Industries 2013).

\section{Rationale for this study}

A need to understand recruitment in $O$. chilensis in Foveaux Strait is the motivation for this study. Since 1985, oyster mortality resulting from disease is of particular importance: disease-related die-offs caused by Bonamia exitiosa are recurrent and substantial, with losses up to twenty times the commercial catch in some years (Doonan et al. 1994, Cranfield et al. 2005, Fu et al. 2016, Michael et al. 2018). Recruitment is critical to replenishing these losses. Harvests since 1985 have been relatively low and have had no detectable effect on future stock size, and at these levels unlikely to affect ongoing sustainability (Fu et al. 2016). During periods of low or no detectable disease mortality and long-term average recruitment, the fishery rebuilds quickly (Ministry for Primary Industries 2017). However, recruits-per-spawner declined markedly in 2010 and remained low over a long time despite spawner densities that have supported high recruitment 
in the past (Cranfield et al. 1999). A number of factors could have affected recruitment in these populations; recurrent disease mortality since 1985 may have caused a shift in fishery productivity. Credible estimates of recruit-sized biomass since 1960 (Figure 1-1) show a constantly increasing trend in abundance between 1965 and 1985 despite high levels of catch (c. 80 million oysters per year) and high fishing effort from 23 vessel operating in the fishery (Ministry for Primary Industries 2017). A B. exitiosa epizootic in 1985 (Doonan et al. 1994, Cranfield et al. 2005) caused a rapid decline in recruit-sized biomass (Figure 1-1). Recurrent B. exitiosa mortality has limited rebuilding of the fishery and caused cyclic patterns in the abundance of oysters and high density patches of oysters (Figure 1-1) that may affect recruitment. Increased climate variability and seawater temperatures may have also affected recruitment. The key focus of this research is an investigation of several potential explanations for this prolonged period of low recruitment.

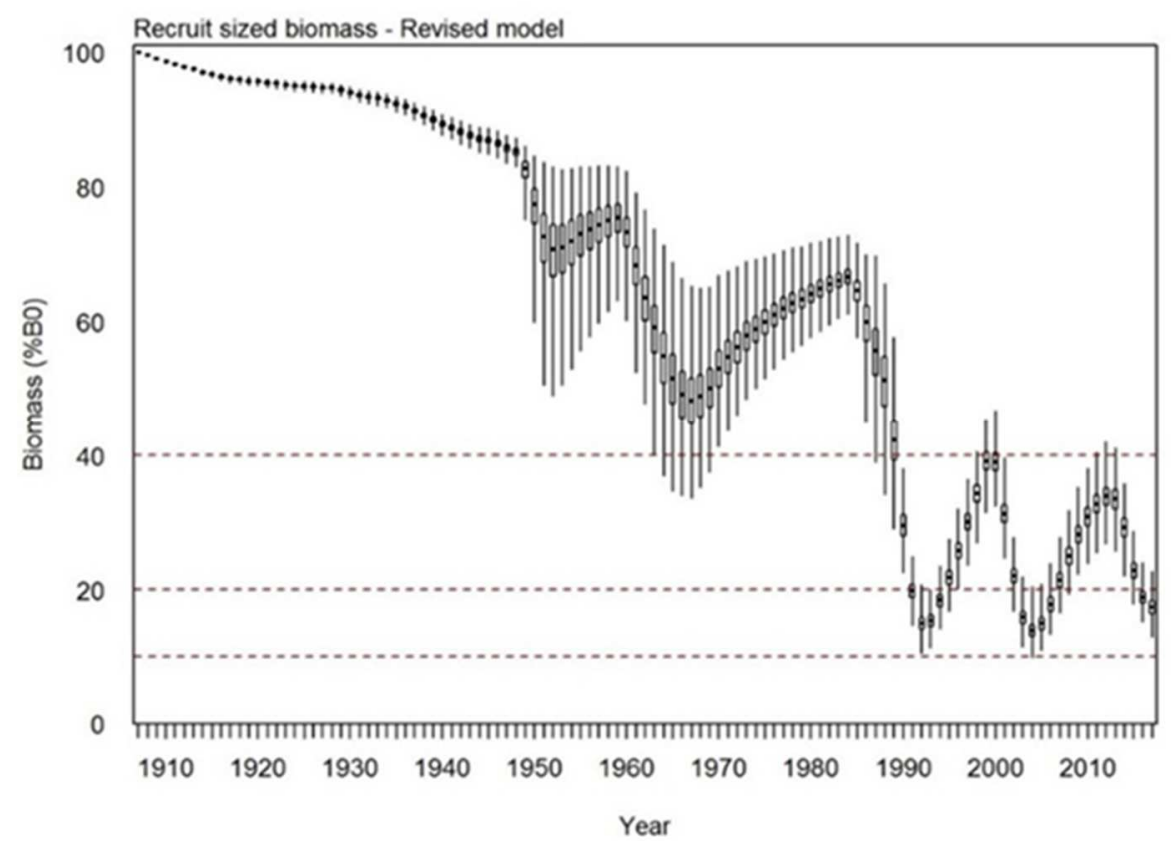

Figure 1-1. Posterior distributions of estimated recruit-sized biomass (as a percentage of $B_{0}$ (the biomass before fishing began) from the OYU 5 stock assessment model (Fu et al. 2016). Horizontal dashed lines show $40 \%, 20 \%$, and $10 \% B_{0}$. Image Kath Large, NIWA. 


\section{Study site}

Foveaux Strait is located between the South Island and Stewart Island in southern New Zealand. The western boundary of the Foveaux Strait oyster stock area (OYU 5) is defined by a line from Oraka Point (Southland) to Centre Island and on to Codfish Island and North Head (Stewart Island). The eastern boundary is a line between Slope Point (Southland) and East Cape (Stewart Island), see Figure 1-2. The commercial fishery area is well defined by the 2007 stock assessment survey area (shaded blue in Figure 1-2), as all commercial fishing occurs within this area. The seafloor rises from deep water on either side of the fishery area. On the western side of the fishery area, water depth is approximately $60 \mathrm{~m}$, and the bottom slopes gently upward to depth of $20 \mathrm{~m}$ in the east (around Ruapuke Island) before dropping in to deep water to the east. The western entrance to Foveaux Strait is the most exposed coastal area in New Zealand (Gorman et al. 2003), with large oceanic swells that produce a highenergy environment (Pickrill \& Mitchell 1979). Mean significant wave height is $2.7 \mathrm{~m}$, with waves exceeding $3 \mathrm{~m}$ more than $29 \%$ of the time and $10 \mathrm{~m}$ or more $1 \%$ of the time (Gorman et al. 2003). Tidal currents are swift and accelerate west to east (Stanton et al. 2001). This gradient in current speed is likely attributable to the increasingly shallow depth west to east, and to constrictions caused by the shoals, rocks, and islands that extend across much of the eastern entrance between Stewart Island and Slope Point. Net tidal current flow is mainly east to southeast (Houtman 1966, Gruning 1971), with this flow pattern feeding into the Southland Current along the Southland coast. On the south side of Ruapuke Island, the flow is generally to the northwest (Mark Hadfield, NIWA, personal communication). Tidal current speeds vary from 1.5 knots in the west to 4.0 knots in the east (Gruning 1971); however, wind driven currents can extend throughout the entire water column. The eastward transport increases when winds are from the west and reduces or reverses with easterly winds. Net displacement of water mass eastward is between $2.5 \mathrm{~km} \mathrm{~d}^{-1}$ (Steve Chiswell, 
NIWA, personal communication) and differs from earlier estimates of $7.0 \mathrm{~km} \mathrm{~d}^{-}$ ${ }^{1}$ in the western fishery area (Heath 1973), and $22 \mathrm{~km}$ in a NW direction each tidal cycle in south eastern areas (Cranfield 1968a). The residence time of water flowing through the fishery area is about 5 days (Cranfield \& Michael 1989), although based on net displacement this could be as long as 20 days in calm conditions with neap tides. Current flows and the topography of Foveaux Strait suggest that eddies capable of retaining larvae may form in the central strait under some conditions.

The seafloor of the fishery area is comprised of gravel substrates overlaid with sand in some areas (Cullen 1962, 1967). Current flows greatly increase during storms. Storm events can mobilise sediments that scour channels and/or form sand waves, banks, and dunes (Carter \& Lewis 1995, Hemer 2006). Benthic habitats vary with depth, substrate type, and wave exposure (Michael 2007). High primary production (Bradford et al. 1991) supports diverse and abundant benthic communities (Michael 2010), including high densities of Ostrea chilensis that comprise the Foveaux Strait oyster fishery. 


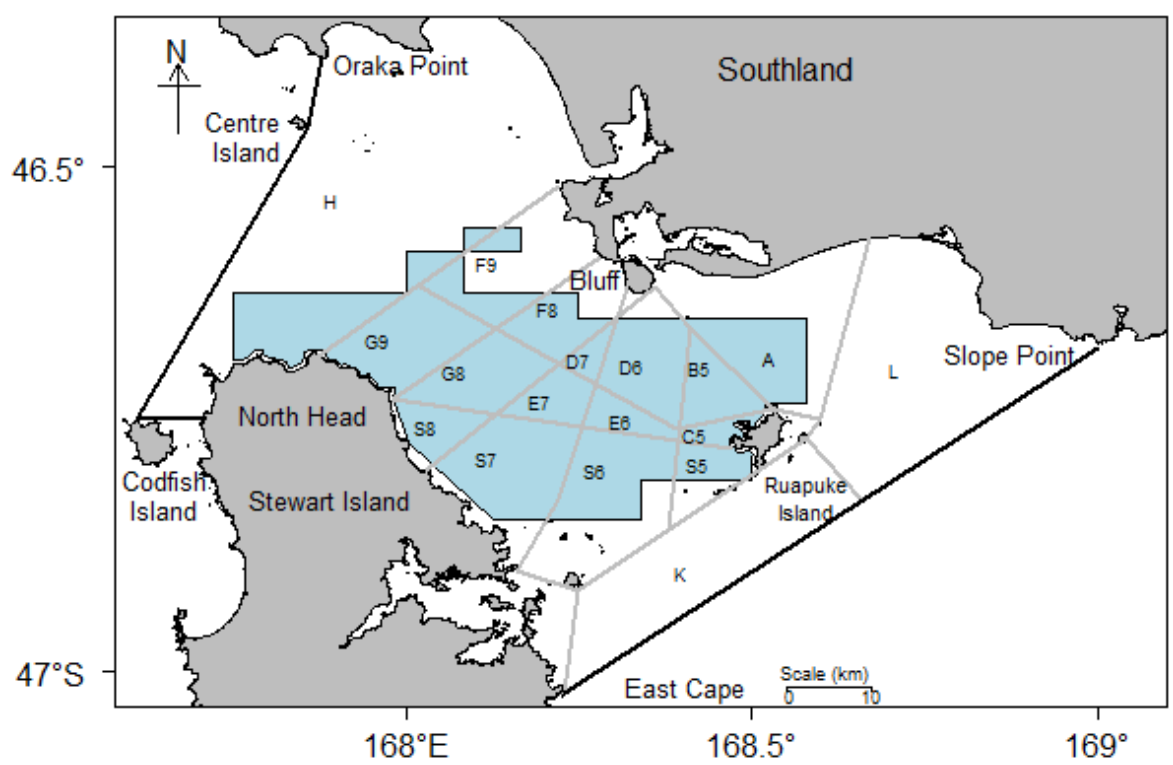

Figure 1-2. Foveaux Strait oyster stock (OYU 5) boundary and oyster fishery statistical reporting areas (delineated by grey lines and capitalised alpha numeric labels shown in black text), and the outer boundary of the 2007 stock assessment survey area (shaded blue) that encompasses the commercial fishery.

\section{Foveaux Strait oyster fishery}

The Foveaux Strait oyster (O. chilensis) fishery is commonly known as the Bluff oyster fishery, after the port town from which the fleet has been based since the 1880s. Oysters have been harvested from Foveaux Strait for over 150 years and the fishery is of high-value, and nationally significant for these reasons. Indigenous customary, recreational, and commercial fishers target oysters, which are important to the socio-economics of Southland, New Zealand (Michael et al. 2018). This is an entirely wild fishery, and is unlike many oyster fisheries elsewhere in that there has been no enhancement of stock, spat, or shell (settlement surfaces), e.g. Schulte et al. (2009). Shell enhancement trials in Foveaux Strait i.e., returning oyster shell after processing to oyster fishery areas, were largely unsuccessful (Street et al. 1973, Michael 2011).

Before the introduction of the Quota Management System in 1998, vessel numbers were limited (5-30), and at times the annual catch limited (Ministry for 
Primary Industries 2017). There is a six-month commercial fishing season for oysters extending from 1 March to 31 August. Management of the fishery assumes a single stock (OYU 5) (Ministry for Primary Industries 2017). Ostrea chilensis distribution is patchy within the $3300 \mathrm{~km}^{2}$ stock boundary, and the majority of oysters are concentrated in a smaller region of the managed area (the 2007 stock assessment survey area comprised $1072 \mathrm{~km}^{2}$, Figure. 1-2). Allen \& Cranfield (1979) and Stead (1971b) suggested the oyster fishery comprised a metapopulation of more than 50 discrete, dense localised populations generally separated by extensive areas with low $O$. chilensis densities. High densities of $O$. chilensis occur in a depth range of $20-50 \mathrm{~m}$ throughout the stock area.

Epizootics of the haplosporidian parasite Bonamia exitiosa appear to be a recurrent feature of the Foveaux Strait oyster population (Figure 1-3). B. exitiosa was first identified in samples taken during an epizootic in 1962-64 (Howell 1967, Hine \& Jones 1994) although reports of heightened mortality suggestive of disease mortality date back to 1906 (Hunter 1906). Substantial declines (c. 90\%) in recruit-sized $O$. chilensis (58 $\mathrm{mm}$ in length or larger) from B. exitiosa mortalities were recorded from 1985, 2000, 2013 (Doonan et al. 1994, Cranfield et al. 2005, Fu et al. 2016, Michael et al. 2018), reducing recruit-sized oyster population size and reducing high density patches of oysters (Figure 13). During periods of low B. exitiosa mortality and long-term average recruitment, the fishery rebuilds quickly and in the same fishery areas (Figure 1-3). 

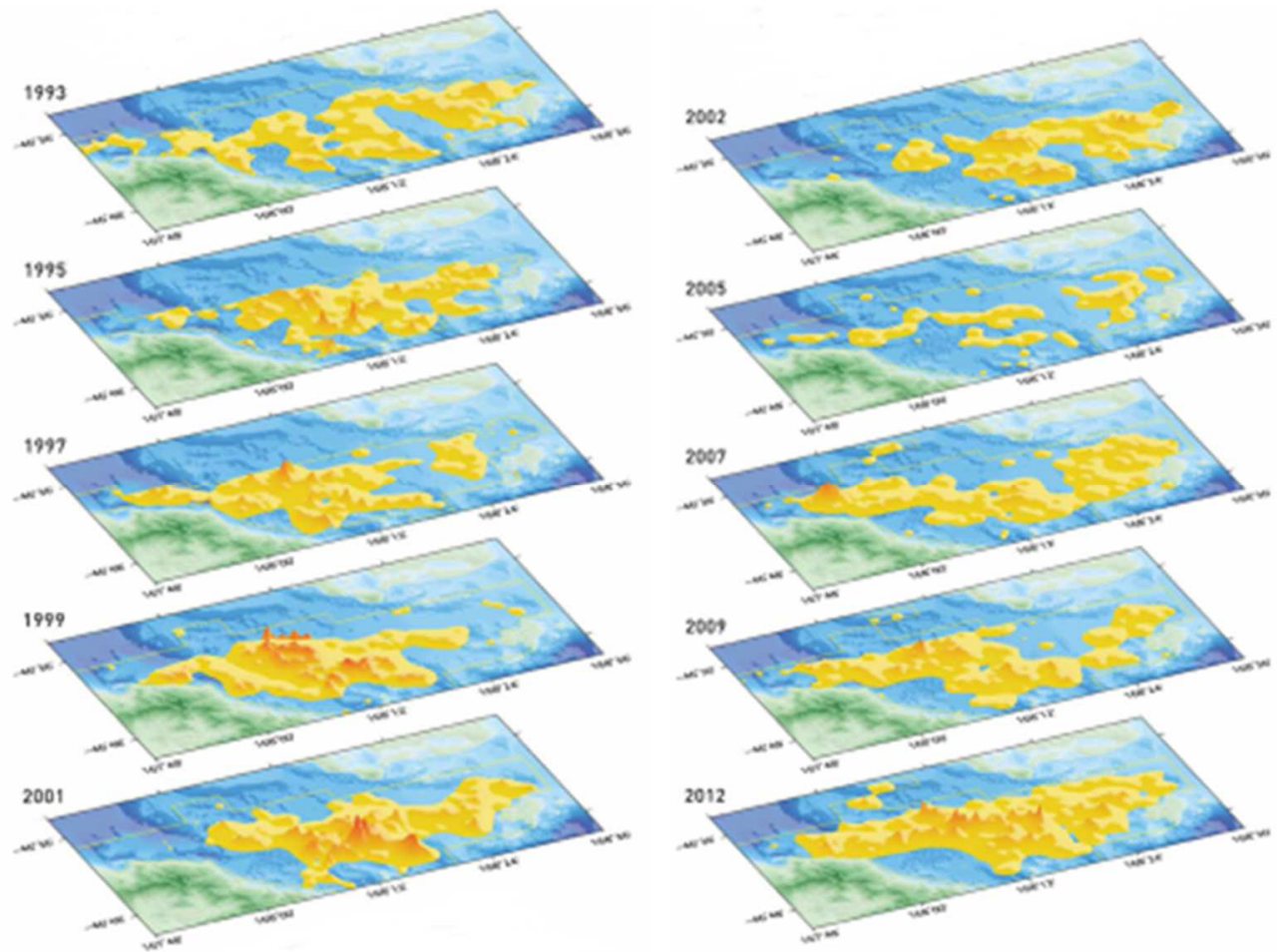

Figure 1-3: Three-dimensional surface plots of recruit-sized oyster densities from stock assessment surveys between 1993 and 2012.

Although B. exitiosa is responsible for oyster mortalities post 1985 , other pathogens such as an Apicomplexan parasite (APX) and Bucephalus longicornutus may play a significant role in oyster mortalities. B. longicornutus caused high oyster mortality ( $\geq$ 40\%) in Foveaux Strait between 1958 and 1964 (Howell 1967); however, the identification of $B$. exitiosa in oyster tissues sampled in 1964 (Hine \& Jones 1994) suggests co-infection is more likely the cause of mortality (J.B. Jones, MPI, pers. comm.). APX is not thought to cause high mortalities; however, its presence may increase the intensity of B. exitiosa infection in $O$. chilensis, increasing mortality (Hine 2002).

Recruit-sized $O$. chilensis oyster densities fell from 24 oysters $\mathrm{m}^{-2}$ in the 1960s (Allen \& Cranfield 1979) to 0.3 oysters $\mathrm{m}^{-2}$ in 1992 after the 1985 epizootic. In 1999, there was some recovery with an increase to 13 oysters $\mathrm{m}^{-2}$ (Michael et al. 2001); however, these numbers have not increased further 
because of recurrent mortality from disease. Oyster mortality appears to be density-dependent and disproportionately reduces the numbers of oysters in high-density patches. The reduction in the numbers of high-density patches has a significant effect on the fishery as these patches enable fishers to harvest economically. Before 1985, the annual commercial catch was about 80 million oysters (Dunn 2005). Since then, mortality from disease has reduced the stock size to low levels (Doonan et al. 1994, Cranfield et al. 2005). In response to the decline in oyster stock, the Ministry for Primary Industries (MPI) imposed a reduction in commercial catch from 80 to 15 million oysters annually in 1996 (Ministry for Primary Industries 2017). Disease mortality is the key determinant of oyster population decline. How it may affect recruitment is not known.

Cranfield et al. (1999) proposed a hypothesis that high densities of oysters only occur on complex biogenic habitat ("reefs") dominated by the bryozoans Cintipora elegans, and that fishing had severely reduced oyster habitat (Cranfield et al. 2004), causing a substantial decline in the oyster population. Between 1960 and 1985, the increased modification of benthic habitat by fishing and mechanical disturbance of oysters by the intense dredging may have been a major source of stress, increasing the susceptibility of oysters to this disease (Cranfield et al. 2005). Fishery data and anecdotal evidence pre and post-1985 show little support for these hypotheses. Oyster abundance increased during a period of high fishing effort and high catches (see Figure 11). The effects of fishing negatively affect benthic and cause changes to benthic habitats. However, the nature of these effects and their persistence are not known. The benthic taxa that have evolved in this high-energy environment could be well adapted to disturbance and their recolonization could be reasonably quick (Cranfield et al. 2001). The rapid decline of the oyster population was symptomatic "of newly introduced disease in an immunologically naïve population" (Cranfield et al. 2005). B. exitiosa was thought to be endemic to O. chilensis in Foveaux Strait (Cranfield et al. 2005); 
however, the extensive global distribution of B. exitiosa, that infects several oyster species (Hill et al. 2014) suggest a more generalist parasite (Arzul \& Carnegie 2015). The 1985 B. exitiosa epizootic could be a reintroduction of this species, or a co-infection of another pathogen such as an Apicomplexan parasite that substantially increased oyster mortality from B. exitiosa.

\section{Biology of Ostrea chilensis}

O. chilensis is a larviparous, protandrous hermaphrodite (Cranfield 1979). Oysters mature first as males from $19 \mathrm{~mm}$ in length, and then as simultaneous hermaphrodites with male and female gonads at $\geq 50 \mathrm{~mm}$ in length (Jeffs \& Hickman 2000). Seasonal patterns of gametogenesis are similar in populations throughout New Zealand; males tend to trickle-spawn throughout the year and females spawn predominantly in spring (September-October) (Jeffs \& Hickman 2000). Functional hermaphroditism is unlikely in the Ostreidae; however, ova and spermatozoa spawned simultaneously in a population of $O$. chilensis from northern New Zealand suggest that self-fertilisation is possible (Jeffs 1998a). The asynchronous gonadal development of males and females reduces fertilisation success within populations (Joyce et al. 2015). Broodingsized oysters are $\geq 60 \mathrm{~mm}$ in length (Jeffs \& Hickman 2000). Brooding occurs throughout the year, and peaks in November-December in southern areas including Foveaux Strait (Hollis 1962, 1963, Stead 1971a, Cranfield 1979, Westerskov 1980, Jeffs 1998a). Brooding starts earlier and finishes later (September to January) in warmer, northern areas (Jeffs et al. 1996, Brown 2011). The number of larvae released determines cohort size and predicted by the percentage of brooders in a localised population. In Foveaux Strait, only a small proportion of the spawning population brood, although 70-90\% develop male gonads (Cranfield 1979). Between $7 \%$ and $18 \%$ of individuals brooded in the 1960s, and 1970s (Hollis 1962, Stead 1971a, Cranfield 1979, Jeffs \& 
Hickman 2000) and 1-2\% in 1996-2000 (Bluff Oyster Enhancement Company, unpublished data). In New Zealand, the percentage of brooders increases with a decrease in latitude, which suggests temperature, is a primary determinant of successful spawning and fertilization, and therefore brooding. Brooding percentages increase from less than $20 \%$ in Foveaux Strait (46 S) to 55-78\% in Tasman Bay (41 S) (Brown et al. 2010), and to 78-90\% in northern New Zealand (36 S) (Jeffs 1996). Temperature along with other factors such as salinity and food availability contribute to differences in the duration of brooding in New Zealand, which typically ranges from 15 to 38 days (Westerskov 1980, Hollis 1963, Stead 1971a). Large (448 to $541 \mu \mathrm{m}$ ) larvae (Cranfield \& Michael 1989) brooded to pediveliger with eyespots (Hollis 1962, Stead 1971a) are fully competent and ready to settle immediately on release. As larval size increases with development, a small proportion of larvae may be forced out of the pallial cavity by space limitation caused by growing larvae and released early (Cranfield \& Michael 1989). In these cases, development can continue ex-parent (Hickman 2000). Larval release and almost all settlement in Foveaux Strait occur between November and February (Cranfield 1979, Michael 2011).

The larval biology of $O$. chilensis has given rise to the hypothesis that localised populations are self-recruiting (Cranfield 1968b; Cranfield 1979; Cranfield \& Michael 1989), as is hypothesised for Tasman Bay (Broekhuizen et al. 2011). Moreover, the large ova size and the absence of feeding (lecithotrophy) are associated with limited dispersal potential that should enhance selfrecruitment (Levin 2006). The mainly rapid settlement in O. chilensis underpins the expectation of a very short pelagic larval duration that suggests limited opportunity for larval transport and dispersal.

O. chilensis in Foveaux Strait grows to minimum legal size (MLS) in 4 to 5 years after settlement (Cranfield 1979), defined as oysters that are unable to pass through a $58 \mathrm{~mm}$ internal diameter ring. MLS equates to $58 \mathrm{~mm}$ in length - the maximum distance measured along the anterior-posterior axis. More than 
$60 \%$ of the oysters landed in the commercial catch are larger than $70 \mathrm{~mm}$ in length (Marsh et al. 2016), corresponding to an age $\geq 8$ years ( $\mathrm{Fu}$ et al. 2016).

The biology and ecology of $O$. chilensis differs to other species of oysters. For example, $O$. chilensis has only one main spawning event per year while multiple spawning events are common in Crassostrea virginica (Knights \& Walters 2010), O. edulis (Lapegue et al. 2006) and O. lurida (Pritchard et al. 2015). Pelagic larval durations are shorter in O. chilensis than for most other species. Durations range from 8-10 days in O. edulis (Lapegue et al. 2006), 1720 days in O. puelchana (Pascual \& Zampatti 1995), 15-25 days in C. virginica (Narváez et al. 2012, Puckett et al. 2014), 3-4 weeks in M. gigas (Robins et al. 2017), to one to eight weeks in O. lurida (Pritchard et al. 2015). Dispersal and connectivity are potentially greater in these other species.

Foveaux Strait differs markedly from the mainly low energy, shallow $(\leq 10 \mathrm{~m})$ estuarine and embayment, and intertidal habitats of other oysters: $O$. edulis (Lapegue et al. 2006), O. lurida (Pritchard et al. 2015), and C. virginica (Knights \& Walters 2010). Many oysters in these environments, especially the Crassostreinae, form reefs e.g. C. virginica (Kirby 2004) and M. gigas (Walles et al. 2015). O. chilensis may form small clusters of oysters from the successive over settlements of spat; however, they do not form "oyster reefs" (author's unpublished data). Currents aggregate $O$. chilensis shells, bound by epibenthic taxa to form lenticular structures, which are orientated along the tidal current axis. These structures are colonised by benthic taxa to become biogenic reefs (Cranfield et al. 1999, Cranfield et al. 2001). 


\section{Thesis overview}

Inferences of recruitment made from probabilistic models without descriptions of recruitment processes and empirical data may be misleading, and can bias an understanding of the processes influencing recruitment (Pineda et al. 2009). Empirical data on recruitment to O. chilensis populations is scant, and the understanding of recruitment process largely assumed from the oyster's reproductive biology. Brooding oysters release late stage, competent larvae with very short pelagic larval durations that mostly settle around the natal populations, i.e. these populations are demographically closed (self-recruit). Based on the assumption of mostly demographically closed populations, recruitment in Foveaux Strait oysters can be investigated using fishery spatialscale sampling without the need to consider spatio-temporal variations in the dispersal of larvae and connectivity among populations.

This research follows a reductionist approach where O. chilensis recruitment is partitioned into fundamental processes, and each one is investigated individually in the following chapters. The management of many fisheries including oysters a based on a stock-recruit relationship, where limiting catch to ensure the spawning stock is above reference points and thereby to ensure recruitment and future yield. Chapter 2 investigates the relationship between spawner densities and the numbers of recruits. In oysters and other invertebrates, factors other than spawner densities such as climate and/or disease may reduce spawning and brooding success, and thereby the supply of competent larvae for recruitment. These factors are investigated in Chapter 3. The assumption of self-recruitment to natal populations has implications for the spatial demographics of the oyster stock in Foveaux Strait, and the stock's resilience to fishing and disease mortality. The distributions of recruits (a proxy for competent larvae in the plankton) are described to investigate the potential for larval mixing and connectivity between populations in Chapter 4. Oyster do 
not exhibit preferences for the types of settlement substrata or require settlement cues (Ostrea appears to settle on any clean, hard substrata). Therefore, postsettlement mortality is investigated as a key determinant of the spatial structure of oyster populations in Chapter 5. A general discussion (Chapter 6) brings together the information from the proceeding chapters to provide new insights in to the recruitment of $O$. chilensis in Foveaux Strait, how recruitment may determine population dynamics, and shape their spatial structure. Chapters 2-5 are briefly summarised below and are in the format of stand-alone papers with a chapter-specific introduction and discussion to facilitate easier publication in journals. Consequently, some redundancies are inevitable.

Chapter 2 investigates the relationship between spawner densities and recruits. The numbers of recruits, i.e. numbers of competent larvae that settled on artificial substrata, were estimated from the densities of recruits on passive spat collectors. There are two concurrent sampling programmes: The first involved recruit densities sampled from a single area over 6 years to determine the seasonality of recruitment. The second sampling programme was a fisherywide study conducted over four years, whereby spat collectors were deployed at six sites; putatively high and low spawner density sites across each of three discrete fishery areas. Dredge samples were used to estimate densities of spawning-sized oysters. Recruit and spawner densities were modelled with a negative binomial regression to evaluate the stock-recruitment relationship.

Chapter 3 investigates whether other climatic and/or biological factors reduced spawning and brooding success, and thereby the supply of competent larvae for recruitment. Biological factors were limited to densities of broodingsized oysters and oyster mortality rates as indicators of fatal infections during spawning. These were estimated from surveys. Climatic factors include climate data (sea surface temperature, chlorophyll, and turbidity from remote sensing and conductivity, temperature, and depth (CTD) instrument) and climate indices (SOI, MI and Z2 indices). Climatic and biological variables were ranked in order 
of importance to the variation in recruitment using classification tree ensembles. Recruitment, oyster densities, mortality, and climate were modelled with negative binomial regression to determine key factors and their interactions.

Chapter 4 investigates the hypothesis of self-recruitment. Passive, artificial collectors were deployed in a gradient design around an isolated natal population in a 3-year study. The distributions of recruits that settled on these arrays of artificial substrata were used to infer larval mixing and connectivity between populations. Brooding-sized oyster densities were also estimated from dredge sampling, and the relationship between recruits and brooding-sized oyster densities was also investigated.

Chapter 5 investigates settlement and post-settlement survival as drivers of the spatial structure of oysters in Foveaux Strait. This chapter is mainly descriptive and establishes a foundation of empirical data for future research. Fishery and sampling data are used to: (1) identify benthic habitats on which high oyster densities occur, (2) identify surfaces on which $O$. chilensis larvae settle and survive, and (3) compare growth and mortality of recruits and juveniles between exposed and less exposed sites, and different heights above the seabed.

Chapter 6 synthesises recruitment processes from chapters 2-5 of this thesis in a general discussion of recruitment and highlights an improved understanding of oyster recruitment in Foveaux Strait. It also discusses the implications of the findings for the future management of the fishery, including roles for conservation and potential restoration efforts.

\section{Key assumptions that underpin sampling designs and methods}

Most of the literature on the biology of Ostrea chilensis dates before the 1985 Bonamia exitiosa epizootic. There is some uncertainty whether, and how, the change in fishery productivity as a result of this pathogen (Ministry for Primary Industries 2017) may have changed the reproductive success of oysters. Sampling designs and methods used in this research are based on this literature, 
and make two key assumptions: 1 . Brooder densities provide an indirect estimate of the numbers of competent oyster larvae in the plankton and thereby a proxy for larval supply, and 2. Passive, artificial spat collectors sample recruits to estimate the numbers of competent larvae in the plankton that settle and complete metamorphosis on artificial substrata, in this research on cement board plates.

This research assumes a close relationship between the numbers of brooders and the numbers of competent larvae available for settlement, and thereby larval supply at the sample locations. This assumption is based on similar percentages of brooders that release similar numbers of larvae, which settle quickly on available substrata close to their natal populations. A small proportion of the spawning population in Foveaux Strait $(<20 \%)$ brooded larvae pre-1985 (Hollis 1962, Stead 1971a, Cranfield 1979, Jeffs \& Hickman 2000). The proportion of brooders post-1985 has been consistently low (<2\% between 1996 and 2000, Bluff Oyster Enhancement Company, unpublished data). A number of factors including temperature and physiological condition affect reproductive success in O. chilensis (Westerskov 1980, Buroker et al. 1983, Joyce et al. 2015), and these factors are likely to drive interannual variation in recruitment. A little variation can also be expected at multiple spatial-scales in a given year. Data on the variation in fertility (numbers of larvae per brood) in $O$. chilensis from Foveaux Strait are scant. The estimates of mean fertility are similar: $6.5 \times 10^{4}$ (Walne 1983) and $5.7 \times 10^{4}$ (Cranfield \& Allen 1977). There are few estimates of the variability in fertility and these data are limited to ranges of fertility, $6.3 \mathrm{x}$ $10^{4}-6.7 \times 10^{4}$ (Walne 1973) and $0.7 \times 10^{4}-12.0 \times 10^{4}$ (Cranfield \& Allen 1977). Thus fertility may vary within subpopulations; however, fertility did not vary between different areas in Foveaux Strait (Cranfield \& Allen 1977).

O. chilensis broods larvae to late stage pediveliger that are fully competent and ready to settle, and have a putative, short pelagic larval duration (PLD) that suggests limited opportunity for larval transport and dispersal, 
reduced opportunities for larval mortality (Cranfield \& Allen 1977) and increased likelihood of self-recruitment. Additionally, attributes such as large, lecithotrophic larvae, such as those of $O$. chilensis in Foveaux Strait, are associated with short PLDs (Levin 2006). Moreover, the observations of Hollis (1962), Stead (1971a), Brown (2011), experiments of Cranfield (1968a), and predictive modelling of (Broekhuizen et al. (2011) all suggest short PLDs. These data suggest that large changes in larval supply (estimated indirectly as recruits per brooder) over any given year, are more likely to be driven by factors other than large variations in the percentages of brooders and their fertility.

Passive, artificial spat collectors are the main sampling method used for this research. It is assumed that $O$. chilensis larvae readily and consistently settle on these collectors to provide representative estimates of the densities of competent larvae in the plankton at sampling locations, i.e. spat collectors sample the densities of recruits as a proxy for larvae that have completed metamorphosis. Recruit densities on spat collectors do not estimate recruitment to the seabed per se, which is dependent on the availability of settlement substrata, usually shells (Smyth et al. 2018). O. chilensis appears to settle on any clean, hard substratum (mainly shell) and does not exhibit preferences for settlement substrata or requires specific settlement cues (pers. obs., and for $O$. edulis after Smyth et al. 2018). Moreover, O. chilensis readily settles on manmade substrata without conditioning and in the absence of conspecifics e.g. cement board (Cranfield 1968b, Brown et al. 2010). The settlement of larvae had previously been high on unconditioned plates deployed for similar periods of time in Foveaux Strait (1965-1967, 1999-2000; Cranfield 1968b, Cranfield et al. unpublished data). Spat collectors deployed with new cement board plates provide standard sampling units. There are a number of potential limitations of this sampling method, which are difficult to quantify.

Laboratory experiments, and observations of the release and settlement of $O$. chilensis larvae in the Hauraki Gulf (northern New Zealand, Andrew Jeffs 
per. comm.) suggest that some settlement occurs immediately after release and within meters of their maternal parent. Spat collectors are unlikely to sample this proportion of competent larvae and thereby underestimate recruitment. The proportion of larvae settling immediately and how this proportion varies spatially and temporally is not known; however, the small scale experiment of Cranfield (1968a), suggests that recruit densities on spat collectors represent recruitment within local natal populations.

O. chilensis larvae are poor swimmers (Stead 1971a), are thought to remain near the seabed (benthopelagic) in strong current conditions, and are phototaxic (Cranfield 1968b). If this is true, almost all settlement should occur on the seabed. However, it is likely that larvae are transported as passive particles by the swift currents in Foveaux Strait. Swift currents flowing over the seabed generate pulsing cyclic flows (internal seiches, see Gibbs 2001) that suspend sediments and particulates from the seabed and these particles are entrained in flows above the seabed. Larvae are likely to be transported in these flows and this vertical distribution could explain the previously high settlement and survival of recruits on cement board plates up to $360 \mathrm{~mm}$ above the seabed.

Water movement over the seabed is characterised by spatially and temporally variable flows depending on tidal currents, seabed topography, and wind direction and strength. Spat collectors could be deployed in areas that do not receive representative numbers of competent larvae in the plankton. This risk is mitigated in part by the randomly assign locations of spat collectors, and by replication. The mortality of competent larvae during settlement and metamorphosis, and early post-settlement predation could result in an underestimate of recruits on the cement board plates. The short PLD and maternal provisioning suggest greater likelihood of successful settlement (Cranfield 1979). The large prodissoconch (larval shell) and rapid growth markedly increases the detection of early settlers that have died from their left (lower) valves that remain attached to the substratum. A significant relationship between 
the planktonic larval abundance of Ruditapes decussatus (Linnaeus 1758) that has a much longer PLD (15-30 days) and recruit densities on spat collectors (Chícharo \& Chícharo 2001) suggest that on average, O. chilensis recruit densities estimated on spat collectors are likely to represent densities of competent larvae at sample locations. 


\section{Chapter 2 : The relationship between Ostrea chilensis spawner densities and numbers of recruits}

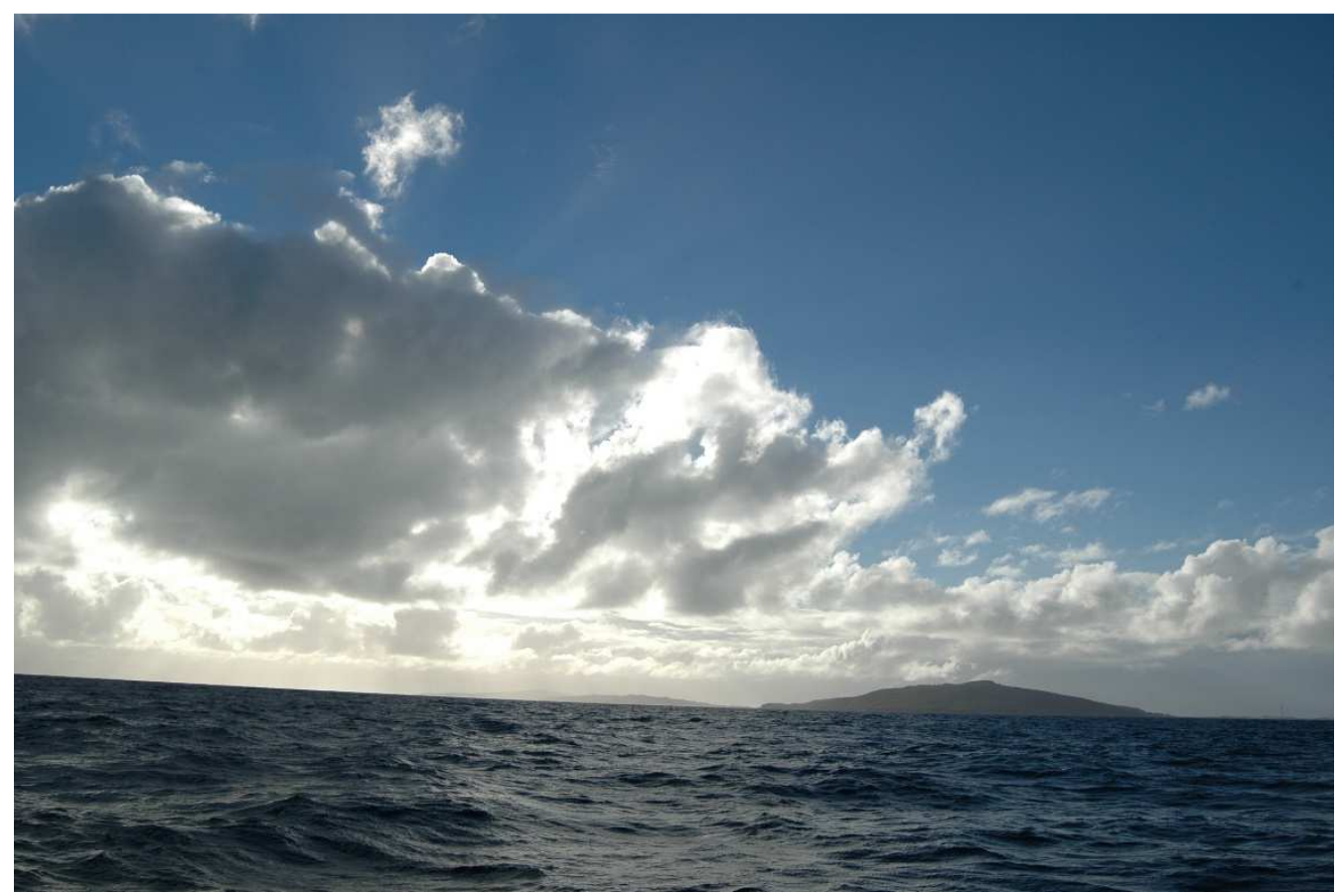

Motupohue / Bluff Hill stands as a beacon home. This landmark is visible throughout Foveaux Strait and before GPS, served as key reference for position fixing by many generations of oyster fishers. Image courtesy of Alan Blacklock. 


\begin{abstract}
Rebuilding and maintaining sufficient spawning stock to ensure recruitment is a key strategy for fisheries management and ecological restoration. This research evaluates variation in Ostrea chilensis recruitment across seasons and sites over 4-6 years in Foveaux Strait (New Zealand) to infer the relative importance of determinants of population recruitment. Recruitment varied significantly between seasons $(\mathrm{p}<0.001)$. Most recruitment in any given year $(97.8 \pm 0.9 \%$, mean $\pm \mathrm{SE})$ occurred in the austral spring and summer (November to February) with significant variation in recruitment between years ( $p<0.001)$. A separate fishery-wide study investigates the effect of spawner densities on recruitment. Spat collectors were deployed at six sites across three discrete fishery areas, and dredge samples were used to estimate densities of spawning-sized oysters. Counts of recruits and spawners were modelled with a negative binomial regression to evaluate the stock-recruitment relationship. Recruitment varied between years (50.8\% of the deviance explained), spawner densities (13.8\%), and areas (11.6\%), with further 2-way interactions between these factors. Importantly, analysis showed a continued decline in recruits per spawner, despite similar or increasing densities of spawning-sized oysters. Average recruitment for 2010-11 when spawner densities were highest was $4.6 \%$ of the level observed in 2007-08. The data suggest that factors other than densities of oysters play a major role in recruitment. Managing oyster fisheries as a single stock and maintaining oyster densities above management reference points alone may therefore not be sufficient to ensure recruitment to rebuild populations.
\end{abstract}




\section{Introduction}

Recruitment is notoriously variable (Caley et al. 1996, Sale \& Kritzer 2003) across a wide variety of taxa in marine systems: fish (Carr \& Syms 2006), algae (Vadas et al. 1992), and benthic invertebrates (Underwood \& Fairweather 1989, Rodriguez et al. 1993). The influence of climatic and biological factors on recruitment are well recognized. However, assumptions of static stockrecruitment relationships (Beverton \& Holt 1957) underpin fisheries management (Hilborn \& Walters 1992) and ecological restoration (Schulte et al. 2009). Rebuilding and maintaining sufficient spawning stock (Mace 2012) is a principal strategy to maximize larval production as a prerequisite to successful recruitment. However, stock-recruitment relationships remain poorly understood and the common assumptions of constancy in stock-recruitment relationships have important consequences for the many stocks where spawning stock size and recruitment are not positively correlated (Szuwalski et al. 2015). A mechanistic understanding of recruitment variability will better inform stock assessments and the identification of key drivers of recruitment dynamics. Here, variation in the recruitment of Ostrea chilensis in Foveaux Strait, southern New Zealand is described, and its relationship with stock size and other sources of variation evaluated.

Oysters (family Ostreidae) occur globally over a wide range of habitats. They can play key roles in benthic communities (Jones et al. 1994, Grabowski \& Peterson 2007) and provide important ecosystem services (Coen et al. 1999, Grabowski et al. 2012). Historically, oysters also provided highly valued fisheries, although many of these high-value stocks are now economically extinct (Beck et al. 2011). The $O$. chilensis fishery in Foveaux Strait is a highly valued and nationally important fishery for New Zealand (Ministry for Primary Industries 2017). O. chilensis biology and characteristics of the fishery differ markedly from other oyster species and fisheries (see Chapter 1). The short pelagic larval duration (PLD) of $O$. chilensis suggests limited opportunity for 
larval transport, and high self-recruitment to natal populations. The Foveaux Strait fishery is an entirely wild fishery with no enhancement of stock, spat, or shell. Management of this fishery assumes a single stock with a stockrecruitment relationship (Fu et al. 2016, Ministry for Primary Industries 2017). These assumptions affect projections of future stock size.

Oysters, like many marine taxa, have a pelagic larval stage and a sessile post-settlement stage. Both pre-and post-settlement processes are likely to shape their recruitment (Sale \& Kritzer 2003, Shima et al. 2008, Cowen \& Sponaugle 2009, Hixon et al. 2012). In addition, biophysical factors may affect recruitment patterns by altering larval quality and cohort size (Pineda et al. 2007), and dispersal and retention dynamics of pelagic larvae (Jones et al. 2009). A better understanding of the processes that shape recruitment will inform population models and management of the Foveaux Strait oyster fishery and have application to the management of other marine resources and communities. Evaluations of stock-recruitment relationships through time and among locations within a population are rare.

The nature and constancy of the stock-recruitment relationship that underlies management of the Foveaux Strait oyster fishery was investigated, and the significance of the combined roles of climatic and other biological factors on this relationship inferred. O. chilensis recruitment is operationally defined in Chapter 1 as the numbers of competent larvae that settle from the plankton after minutes to hours after release and complete metamorphosis on substrata; in this study on cement board plates on the spat collectors. Hence, the stockrecruitment relationship is evaluated with limited opportunity for larval dispersal and reduced opportunity for post-settlement mortality that can be highly variable in time and space (Hunt \& Scheibling 1997) and obscure stock-recruitment relationships. This study estimates oyster recruitment across a range of spatial and temporal (seasonal and interannual) scales. The relationship between 
recruits and spawner densities is evaluated and the relative importance of other determinants of population recruitment inferred.

\section{Methods}

\section{Study sites and species}

The Foveaux Strait oyster fishery (Figure $2-1$ is managed as a single stock OYU 5 (Ministry for Primary Industries 2017) and the fishery comprised a number of putative demographically closed populations (Stead 1971b, Allen \& Cranfield 1979). Fisheries-independent variation in oyster densities is mostly driven by periodic disease mortality (Doonan et al. 1994, Cranfield et al. 2005) caused by Bonamia exitiosa (previously B. exitiosus, Berthe \& Hine 2003), and variability in recruitment to the oyster population (Michael et al. 2015). This research evaluated oyster recruitment to Foveaux Strait populations, before postsettlement mortality, to understand drivers of fishery-recruitment.

Spawners (spawning-sized oysters) are defined as individuals $\geq 50 \mathrm{~mm}$ in diameter (after Dunn 2005). O. chilensis is a protandrous, larviparous hermaphrodite. Individuals mature first as males in the summer after settlement; they transition to females and initiate brooding in their fourth summer (Cranfield 1979, Jeffs \& Hickman 2000). Females typically brood larvae to late-stage pediveligers (Hollis 1962, Cranfield 1979, Chaparro et al. 2006). Cranfield \& Michael (1989) suggested that most O. chilensis larvae released into Foveaux Strait were competent and settle within minutes to hours after release (Cranfield 1979, Westerskov 1980, Chaparro et al. 2006). This putative short PLD motivates the hypothesis that most dispersal events will occur over short distances (Cranfield 1968a, Broekhuizen et al. 2011) and self-recruitment is likely to be high. Stock-recruitment relationships have therefore hypothesized to operate over relatively small spatial scales. 
The nature of stock-recruitment relationships may vary from year to year depending on biological and climatic conditions that may determine reproductive success of oysters. Here, an ecological definition of recruitment is used (i.e. the number of recently settled recruits) as per (Stanwell-Smith \& Barnes 1997) as opposed to a standard fisheries definition (i.e. the number of harvestable adults) that has been detailed in Hilborn \& Walters (1992).

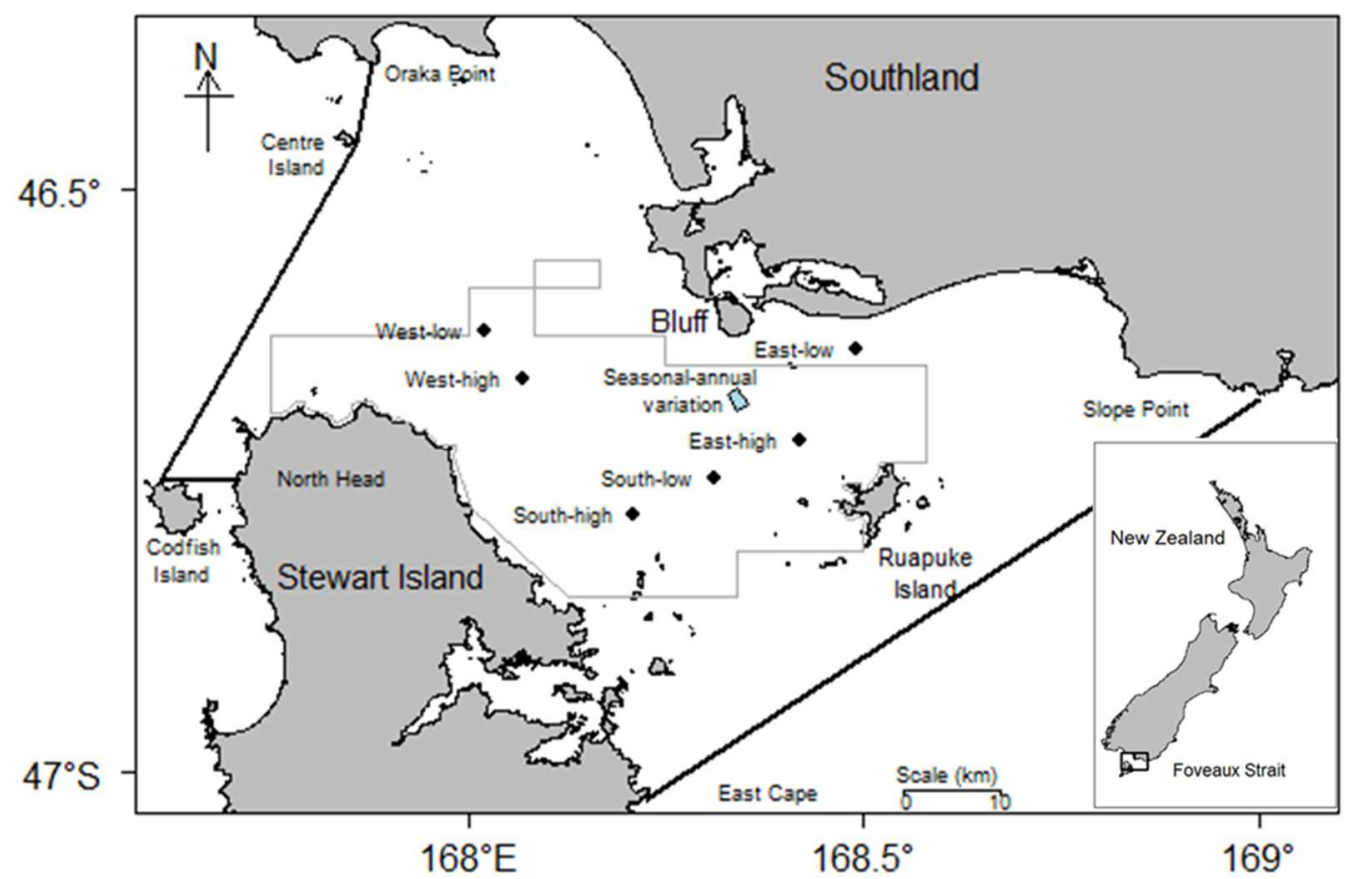

Figure 2-1. Foveaux Strait oyster stock (OYU 5) boundary (heavy black lines) and the outer boundary of the 2007 stock assessment survey area (grey lines) encompassing the commercial fishery. Seasonal and interannual variation in recruitment was sampled at a single site (light blue shading), and spatio-temporal variation in recruitment at 6 sites across the fishery (filled black circles). Inset shows the location of Foveaux Strait within New Zealand.

\section{Quantifying recruitment}

Recruitment was quantified from counts of recruits on artificial collectors (Cranfield 1968b, Brown et al. 2010). Spat collectors consisted of a reinforced concrete base with a steel frame holding 4 cement board settlement plates $(220 \times 140 \mathrm{~mm}$ and $4 \mathrm{~mm}$ thick) at heights of 10, 120, 240, and $360 \mathrm{~mm}$ above the seabed (Figure 2-2). Although conditioning of spat collectors and the 
establishment of biofilms have been shown to be important in some oyster species (e.g., C. virginia, Tamburri et al. 1992), Ostrea will settle on any clean hard substrate (Smyth et al. 2018). Because the settlement of $O$. chilensis larvae had previously been high on unconditioned plates deployed for similar periods of time in Foveaux Strait (1965-1967, 1999-2000; Cranfield 1968b, Cranfield et al. unpublished data), the settlement plates were not conditioned before deployment (Figure 2-3). Mooring lines with floats attached to each collector facilitated location and retrieval.

Oyster recruitment was sampled across years with deployment and recovery of spat collectors at approximately four-month intervals (i.e. targeting three 'seasons' per year). The sampling year (Year) began 1 July and ended the following 30 June, with year partitioned into 3 seasons. Season A (1 July to 31 October), when brooding begins, but before any significant settlement occurs. Season B (1 November to 28 or 29 February), when most settlement is thought to occur. Season C (1 March to 30 June), after the presumed period of peak settlement. Sampling began and ended in Season B as Season A was not sampled in the first year and Season C was not sampled in the last year. Each deployment of spat collectors used new cement board plates. Recruitment to each collector is the cumulative number of recruits on any plate surface (top or bottom) of any of the four plates of a given collector. Because this research focus was on recruitment before post-settlement mortality, recruitment was estimated as the total number of both living and dead recruits on plates $(>85 \%$ of oysters were alive at the time of recovery). Oyster spat that have died leave a record of their size at death, as either the whole shell (articulated valves) or only the attached left valve (once metamorphosis is complete after settlement, the shells of recruits grow quickly with the left valve continuing to attach to the substrata as it grows). Because actual deployment times varied around the target period by a small amount, estimates of recruitment were standardized to a $122 \mathrm{~d}$ sampling period for each season. 


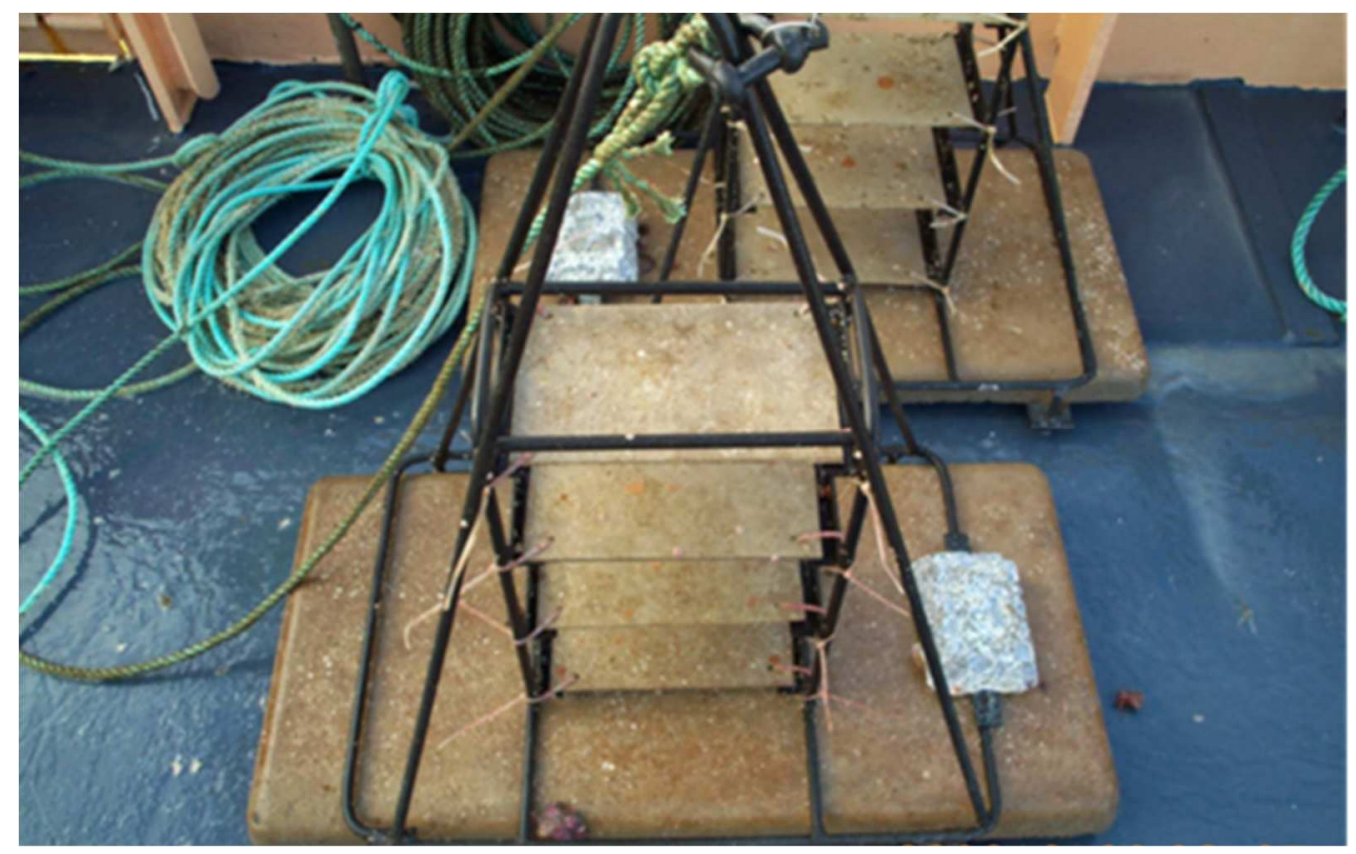

Figure 2-2. Passive artificial spat collectors used to estimate recruitment. Cement board plates $(220 \times 140 \mathrm{~mm}$ and $4 \mathrm{~mm}$ thick) at heights of 10, 120, 240, and 360 $\mathrm{mm}$ above the seabed.

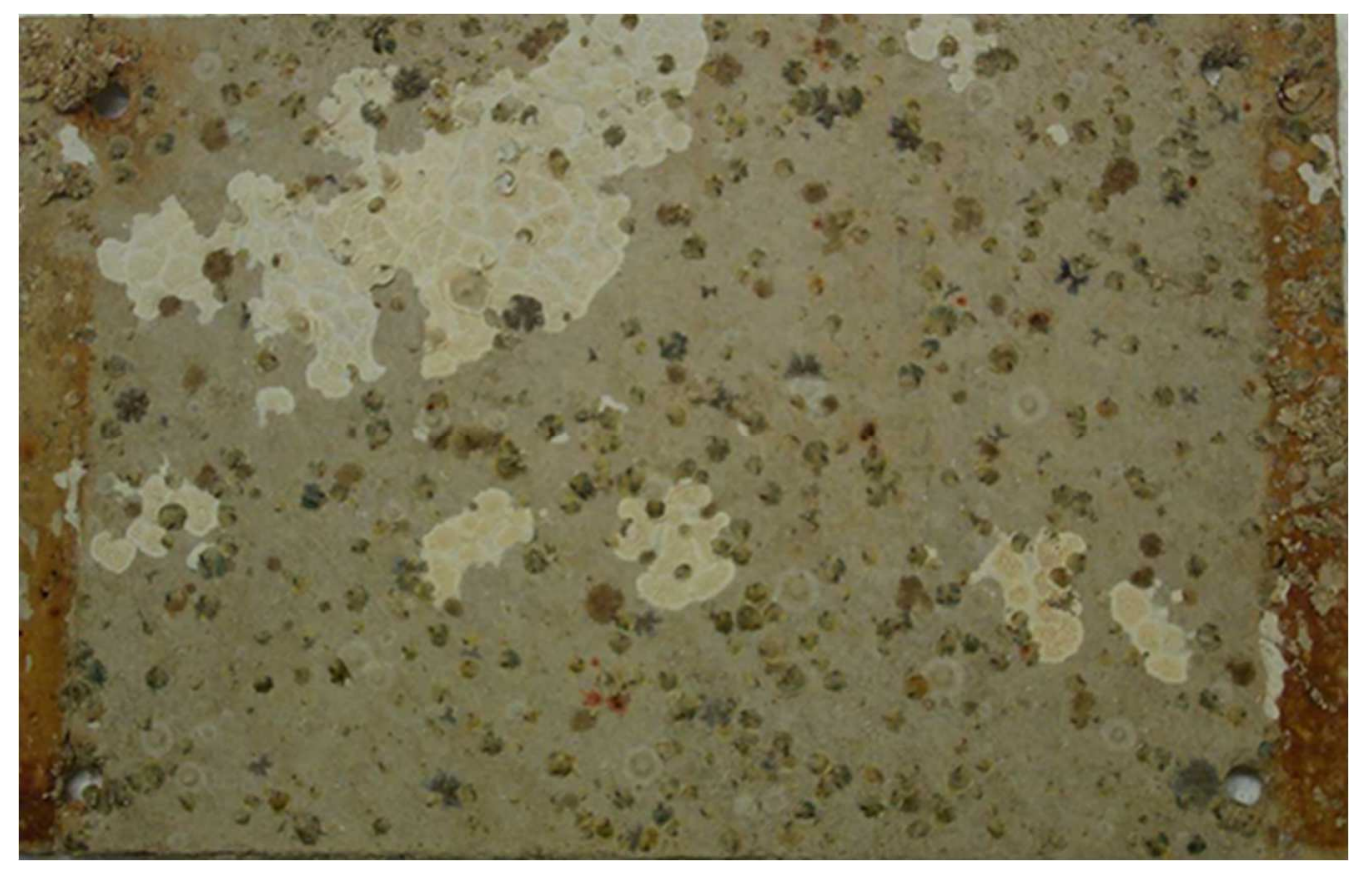

Figure 2-3. Spat plate recovered after c. 122 days showing $O$. chilensis recruits. 


\section{Seasonal and interannual variation in recruitment}

Seasonality and interannual variation in oyster recruitment were quantified with collectors deployed to a single site from December 2005 to February 2011. The site was closed to fishing. Specifically, a single collector was deployed to each of nine randomly selected locations within a $2.25 \mathrm{~km}^{2}$ area (see Figure 2-1). Collectors were sampled three times each year (Seasons A, B, and $\mathrm{C})$.

Oyster recruitment was modelled as a function of Season, Year, and the interaction between Season and Year. These count data had overdispersed distributions (chi-squared test statistic $=21323.4, \mathrm{p}<0.001$ for alpha $=0.05$ ), and contained many zeros (was zero-inflated: $W=0.24$ overall, and $W=0.85$, 0.03, and 0.12 for Seasons A, B, and C, respectively). Zeros originated from 2 sources: structural zeros because no or little settlement in Seasons A and C was expected, and sampling zeros where collectors recorded no settlement in Season B although some settlement was expected. These data were modelled with zeroinflated negative binomial mixed regression (ZINB) using the pscl package (Jackman 2008) in R (R Core Team 2016). A generalised linear model with negative binomial distribution (GLM.NB) using the pscl package was also evaluated and fits compared using the Vuong (1989) likelihood ratio tests function in the pscl package.

\section{Spatio-temporal variation in recruitment as a function of spawner density}

Spatial and interannual variation in recruitment of oysters was quantified in relation to estimates of spawner densities at different sites across the wider fishery (see Figure 2-1) to evaluate potential variation in stock-recruitment relationships operating over relatively small spatial scales. Six sampling sites were stratified across 3 discrete areas (Area) within the fishery with 2 sites in each of the West, South, and East areas (for site locations, see Figure 2-1 and also see Table A-1, estimates of spawner densities section in the Appendix). 
Minimum distances between sites ranged between 9.0 and $35.8 \mathrm{~km}$. The two sites within each area were selected non-randomly to establish contrasting densities of spawning-sized oysters ('Category': reflecting qualitatively high versus low density, see Figure A-1, estimates of spawner densities section in the Appendix). Distances between high and low paired sites ranged between 5.5 and $10.2 \mathrm{~km}$. Site selection was informed by previous surveys (Michael et al. 2005, Michael et al. 2006, Michael et al. 2008a, Michael et al. 2008b, Michael et al. 2009a), fishers' catch and effort data (Michael et al. 2012b), and interviews with oyster vessel skippers. Spawner densities were also estimated directly at each site before deployment of spat collectors (in November 2007) using standard dredge sampling procedures for Foveaux Strait oyster surveys (summarized in the estimates of spawner densities section in the Appendix, also see Michael et al. 2015). Mean spawner densities were estimated indirectly in subsequent years (2008-2011) using data from fishery-independent surveys conducted at nearby sites so as not to disturb these sites once spat collectors were deployed. These are summarized in the estimates of spawner densities section in the Appendix. Mean distances $(\mathrm{km})$ between dredge sample sites and collector sites ranged from 2.4 to $4.4 \mathrm{~km}$ (Table A2, estimates of spawner densities section in the Appendix) and are well within the potential transport of larvae in a six hour tidal cycle in normal flow (13 km, Steve Chiswell, NIWA, personal communication).

Three replicate spat collectors were deployed at each of the 6 sites (see Figure 2-1) in randomly selected locations that remained fixed during the study. Oyster recruitment was sampled between November 2007 and February 2011. Sampling was only in Season B of each year because almost all settlement occurred over this period; collectors were deployed in November and recovered in February. Foveaux Strait was closed to all oyster fishing 1 September to 28 or 29 February (Ministry for Primary Industries 2017) during the period the collectors were deployed. Between the 2007 and 2011 oyster seasons, there was no fishing within at least 1 nautical mile of 4 of the 6 sites (West-low, South- 
high, East-high, and East-low). A small amount of fishing occurred near Westhigh and South-low (between 0 and $3 \%$ of the total annual catch in any one year), and some disturbance of these collector sites may have occurred.

Interannual variation in recruitment, its coherence across the fishery, and its relationship to putative spawner density was modelled using a GLM with a negative binomial distribution and a log link function. Specifically, oyster recruitment was modelled as a function of Year, Spawner density, Area, and Category and the interactions between these factors. The effect of Spawner density was modelled as a third-order polynomial to increase the model's flexibility to better fit the data (Ver Hoef \& Boveng 2007). Model fits and compliance with statistical assumptions were evaluated graphically (after Zuur et al. 2010). The best-fit model was selected by removing non-significant factors or interactions based on Akaike's Information Criterion (AIC) (Akaike 1973).

\section{Results}

\section{Seasonal and interannual variation in recruitment}

On average in a given year, $97.8 \pm 0.9 \%$ (mean $\pm \mathrm{SE}$ ) of all recruits settled in Season B (Figure 2-4). Low levels of recruitment were observed in Season C $(2.2 \pm 0.9 \%)$ with almost none in Season A (Figure 2-4). Oyster recruitment varied significantly among Season and Year $(\mathrm{p}<0.001$, Table 2-1). Recruitment was consistently greatest in Season B, and drove among-year variation in oyster recruitment (Table 2-2, Figure 2-4). Recruitment was relatively high in 2006-07 and 2007-08 (Figure 2-4), on average 10-15\% higher than in 2005-06 (Table 2-1). Recruitment was significantly lower in 2009-10 and 2010-11 relative to 2005-06 ( $\mathrm{p}<0.001$, Table 2-1). In 2010-11, mean recruitment declined to $4 \%$ of the level in 2005-06 (Table 2-1). 
There was no significant difference between the zero-inflated negative binomial and negative binomial models (AIC-corrected Vuong $z$-statistic $=-$ $0.007, \mathrm{p}=0.497)$. Season explained $76.7 \%$ of the deviance in the best-fit model, with deviance explained to a lesser extent by interannual variation $(10.5 \%)$ and the interaction between Season and Year (3.9\%, Table 2-2). 
Table 2-1. Seasonal and interannual variation in recruitment of oysters between 2005 and 2011 at a single site in Foveaux Strait. Season B: 1 November to 28 or 29 February, Season C: 1 March to 30 June. Oyster recruitment is modelled as a function of Season and Year using zero-inflated negative binomial regression. Shown are the results of a negative binomial model for the count data (model statistics theta $=\mathbf{2 . 0 9 4 3}, \mathrm{df}=\mathbf{1 2}$, and log-likelihood $=\mathbf{4 9 2 . 4}$ ) and the results of a zero-inflated model with logit coefficients for predicting excess zeros. The exponents of coefficients ( $e^{\text {ceefficient })}$ are shown with $95 \%$ confidence intervals (CI).

\begin{tabular}{|c|c|c|c|c|c|}
\hline Source of variation & Coefficient & $\mathrm{SE}$ & $Z$ & $\mathrm{p}$ & $\mathbf{e}^{\text {coefficient }}(\mathrm{CI})$ \\
\hline \multicolumn{6}{|l|}{$\begin{array}{l}\text { Negative binomial } \\
\text { model }\end{array}$} \\
\hline Intercept & 0.758 & 0.450 & 1.684 & 0.092 & $2.135(0.883-5.161)$ \\
\hline $2006-2007$ & 0.142 & 0.246 & 0.576 & 0.565 & $1.152(0.712-1.864)$ \\
\hline 2007-2008 & 0.103 & 0.266 & 0.387 & 0.698 & $1.109(0.658-1.869)$ \\
\hline $2008-2009$ & -0.370 & 0.257 & -1.443 & 0.149 & $0.691(0.418-1.142)$ \\
\hline $2009-2010$ & -1.643 & 0.281 & -5.856 & $<0.001$ & $0.193(0.112-0.335)$ \\
\hline 2010-2011 & -3.252 & 0.321 & -10.139 & $<0.001$ & $0.039(0.021-0.073)$ \\
\hline Season B & 6.096 & 0.413 & 14.764 & $<0.001$ & $\begin{array}{r}444.081(197.697 \\
997.529)\end{array}$ \\
\hline Season C & 2.211 & 0.431 & 5.134 & $<0.001$ & $9.125(3.923-21.224)$ \\
\hline $\log ($ theta $)$ & 0.739 & 0.164 & 4.506 & $<0.001$ & \\
\hline \multicolumn{6}{|l|}{ Zero-inflated model } \\
\hline Intercept & 0.783 & 0.587 & 1.333 & 0.183 & $2.187(0.692-6.912)$ \\
\hline Season B & -21.271 & 4145.540 & -0.005 & 0.996 & 0 (0- Infinity) \\
\hline Season C & -2.976 & 0.805 & -3.696 & $<0.001$ & $0.051(0.011-0.247)$ \\
\hline
\end{tabular}


Table 2-2. Seasonal and interannual variation in recruitment of oysters at a single site in Foveaux Strait, between 2005 and 2011. Recruitment is modelled by factors Season, Year, and the interaction between Season and Year, using a negative binomial regression with a log link function. \% Dev: cumulative percentage deviance explained, AIC: Akaike's Information Criterion.

\begin{tabular}{lrrrrrrr}
\hline & df & Deviance & Residual df & Residual deviance & p & \%Dev & AIC \\
\hline & & & 126 & 1388.58 & & & \\
Season & 2 & 1108.39 & 124 & 280.18 & $<0.001$ & 0.767 & 1082.3 \\
Year & 5 & 114.37 & 119 & 165.82 & $<0.001$ & 0.872 & 1027.5 \\
Season $\times$ Year & 8 & 42.24 & 111 & 123.58 & $<0.001$ & 0.911 & 1004.7 \\
\hline
\end{tabular}




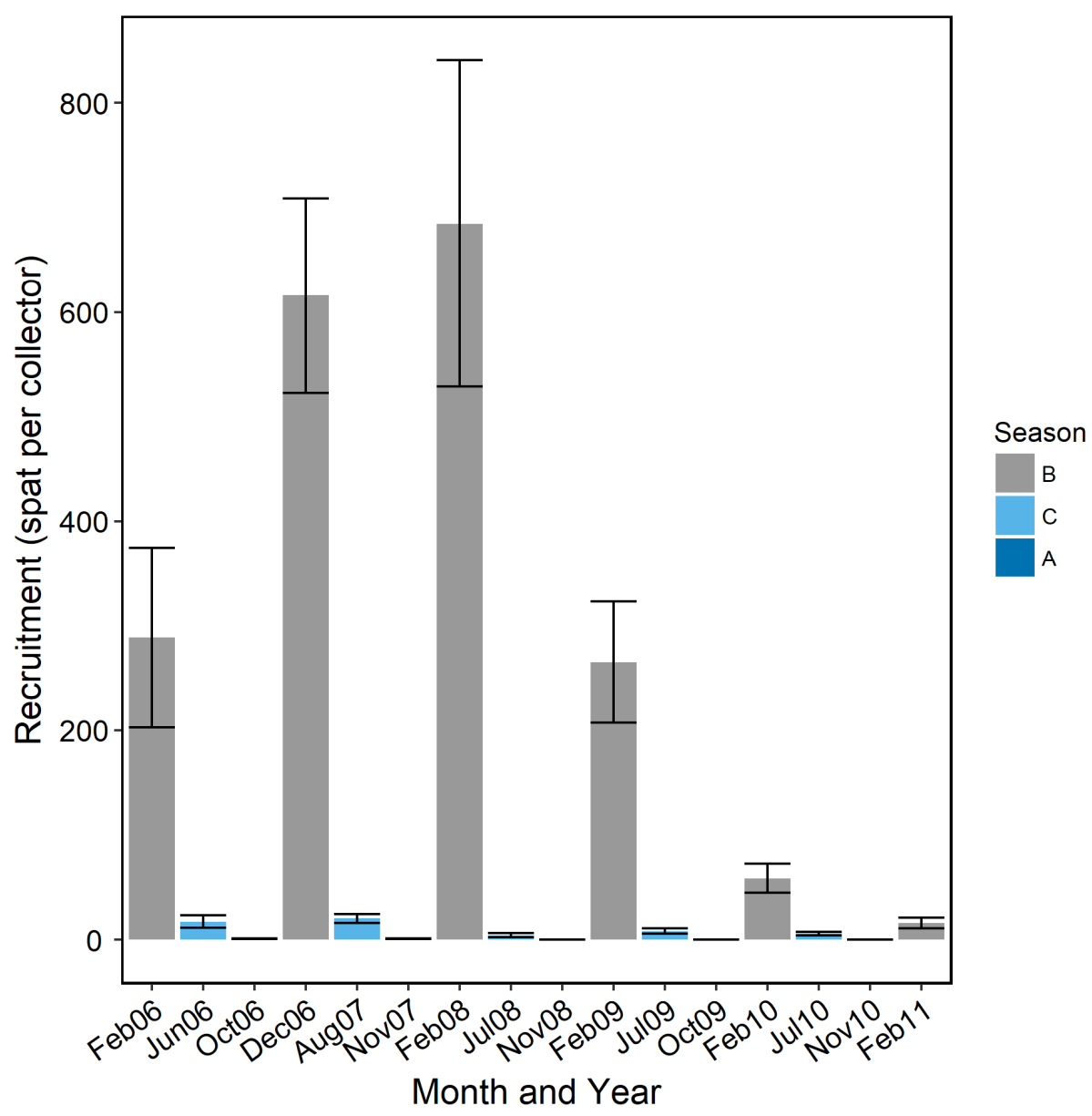

Figure 2-4. Oyster recruitment (mean $\pm \mathrm{SE}$ ) by Season (labelled $\mathrm{A}, \mathrm{B}$, and $\mathrm{C}$ ) from December 2005 to February 2011 at a single site (light blue shading, Fig. 1). Season A: 1 July to 31 October, Season B: 1 November to 28 or 29 February, Season C: 1 March to 30 June. Recruitment was estimated as the counts of living and dead oysters per collector (sample) settling over $122 \mathrm{~d}$. The $\mathrm{x}$-axis gives month and year of retrieval.

\section{Spatio-temporal variation in recruitment as a function of spawner density}

Spawner densities remained the same or increased over the study period. Spawner densities sampled directly from focal sites before deployment of the spat collectors were $0.1-1.8$ oysters $\mathrm{m}^{-2}$ (Figure A1, estimates of spawner densities section in the Appendix). For other times, spawner densities were 
estimated indirectly and were $0.3-4.6$ oysters $\mathrm{m}^{-2}$ (Figure A2 \& A3, Table A2, estimates of spawner densities section in the Appendix).

For the commercial fishery area, recruitment during Season B varied between years $(\mathrm{p}<0.001, \mathrm{df}=3$, deviance $=811.96)$, spawner density estimates $(\mathrm{p}<0.001, \mathrm{df}=2$, deviance $=189.76)$, and area $(\mathrm{p}<0.001, \mathrm{df}=2$, deviance $=$ 140.90) (Figure 2-5). There were also significant 2-way interactions between Spawner density and Area $(\mathrm{p}<0.001$, df $=6$, deviance $=114.04)$, and Spawner density and Year $(\mathrm{p}<0.001, \mathrm{df}=9$, deviance $=88.56)$. These interactions imply that recruitment patterns between years differed subtly by area and spawner densities (see Tables 2-3 \& 2-4 for the best-fit model). The factor Year explained $50.8 \%$ of the deviance, Spawner density $13.8 \%$, Area $11.6 \%$, and the 2-way interactions of Spawner density and Area and Spawner density and Year $9.9 \%$ and $8.0 \%$, respectively.

The stock-recruitment relationship for oysters in the fishery (Figure 26) varied significantly between years. Factor Area was dropped, forcing the model to use Spawner density and Year as predictors of recruitment variation. Spawner density remained significant $(\mathrm{p}<0.001, \mathrm{df}=3$, deviance $=39.778)$ when among-year variation in recruitment was taken into account $(\mathrm{p}<0.001$, df $=3$, deviance $=155.767)$. The interaction term (Year and Spawner density) also remained significant $(\mathrm{p}<0.001, \mathrm{df}=9$, deviance $=26.288)$, and accounted for a larger percentage of explained deviance (from $8.0 \%$ by the best-fit model with factor Area included, to 9.5\% without). Recruitment was greatest overall and highest with higher spawner densities in 2007-08. In all successive years, overall recruitment and the slope of the relationship between recruitment and Spawner density decreased despite fishery-wide increases in spawner densities (Figure 2$6)$. 
Table 2-3. Spatio-temporal variation in oyster recruitment across the Foveaux Strait fishery between 2007 and 2011. Oyster recruitment is modelled as a function of Year, Spawner density, and Area, and their interactions, using data from Season B (settlement season) only. The best-fit negative binomial regression is shown. \% Dev: cumulative percentage deviance explained, AIC: Akaike's information criterion.

\begin{tabular}{lrrrrrrr}
\hline & df & Deviance & Residual df & Residual deviance & p & \%Dev & AIC \\
\hline Year & & & 66 & 1429.23 & & & \\
Spawner density & 3 & 811.96 & 63 & 617.27 & $<0.001$ & 0.508 & 847.07 \\
Area & 3 & 189.76 & 60 & 427.51 & $<0.001$ & 0.646 & 828.57 \\
Spawner density $\times$ Area & 6 & 140.90 & 58 & 286.61 & $<0.001$ & 0.762 & 804.33 \\
Spawner density $\times$ Year & 9 & 114.04 & 52 & 172.57 & $<0.001$ & 0.861 & 780.00 \\
\hline
\end{tabular}


Table 2-4. Spatio-temporal variation in oyster recruitment across the Foveaux Strait fishery, 2007-08 to 2010-11. Oyster recruitment is modelled as a function of Year, Spawner density, and Area, and their interactions, using data from Season B (settlement period) only. Paired comparisons for the best-fit negative binomial model (model statistics theta $=10.3658, \mathrm{df}=43$, and log-likelihood $=-693.92$ ) are shown. Spawner densities (1)-(3) denote first- to third-order polynomials, respectively.

\begin{tabular}{|c|c|c|c|c|}
\hline Source of variation & Coefficient & SE & $\mathbf{Z}$ & $\mathbf{p}$ \\
\hline Intercept & -132.635 & 23.586 & -5.624 & $<0.001$ \\
\hline Year 2008-2009 & 152.523 & 28.681 & 5.318 & $<0.001$ \\
\hline Year 2009-2010 & 146.811 & 27.943 & 5.254 & $<0.001$ \\
\hline Year 2010-2011 & 144.964 & 27.707 & 5.232 & $<0.001$ \\
\hline Spawner density (1) & -2027.245 & 348.405 & -5.819 & $<0.001$ \\
\hline Spawner density (2) & -946.14 & 161.371 & -5.863 & $<0.001$ \\
\hline Spawner density (3) & -193.297 & 35.046 & -5.516 & $<0.001$ \\
\hline Area (South) & -8.474 & 15.205 & -0.557 & 0.577 \\
\hline Area (West) & -9.23 & 15.097 & -0.611 & 0.541 \\
\hline \multicolumn{5}{|l|}{ Spawner density $(1) \times$} \\
\hline Area (South) & -179.327 & 230.635 & -0.778 & 0.437 \\
\hline \multicolumn{5}{|l|}{ Spawner density $(2) \times$} \\
\hline Area (South) & -80.289 & 109.138 & -0.736 & 0.462 \\
\hline \multicolumn{5}{|l|}{ Spawner density $(3) \times$} \\
\hline Area (South) & -15.656 & 26.731 & -0.586 & 0.558 \\
\hline \multicolumn{5}{|l|}{ Spawner density $(1) \times$} \\
\hline Area (West) & -163.622 & 226.701 & -0.722 & 0.470 \\
\hline \multicolumn{5}{|l|}{ Spawner density $(2) \times$} \\
\hline Area (West) & -72.673 & 106.96 & -0.679 & 0.497 \\
\hline \multicolumn{5}{|l|}{ Spawner density $(3) \times$} \\
\hline Area (West) & -26.837 & 26.751 & -1.003 & 0.316 \\
\hline \multicolumn{5}{|l|}{ Year2008-2009x } \\
\hline Spawner-density (1) & 2256.905 & 422.251 & 5.345 & $<0.001$ \\
\hline
\end{tabular}


Table 2 4. Continued.

\begin{tabular}{lcrrr}
\hline Source of variation & Coefficient & SE & $\mathbf{Z}$ & p \\
Year2009-2010× & & & & \\
Spawner-density (1) & 2206.942 & 412.938 & 5.344 & $<0.001$ \\
Year2010-2011× & & & & \\
Spawner-density (1) & 2201.309 & 411.929 & 5.344 & $<0.001$ \\
Year2008-2009× & & & & \\
Spawner density (2) & 1048.731 & 197.343 & 5.314 & $<0.001$ \\
Year2009-2010× & & & & \\
Spawner density (2) & 1010.256 & 190.359 & 5.307 & $<0.001$ \\
Year2010-2011× & & & & \\
Spawner density (2) & 1012.736 & 192.724 & 5.255 & $<0.001$ \\
Year2008-2009× & & & & \\
Spawner density (3) & 232.837 & 45.889 & 5.074 & $<0.001$ \\
Year2009-2010× & & & & \\
Spawner-density (3) & 205.719 & 40.991 & 5.019 & $<0.001$ \\
Year2010-2011× & & & & \\
Spawner density (3) & 229.67 & 45.355 & 5.064 & $<0.001$ \\
\hline & & & & \\
\hline
\end{tabular}




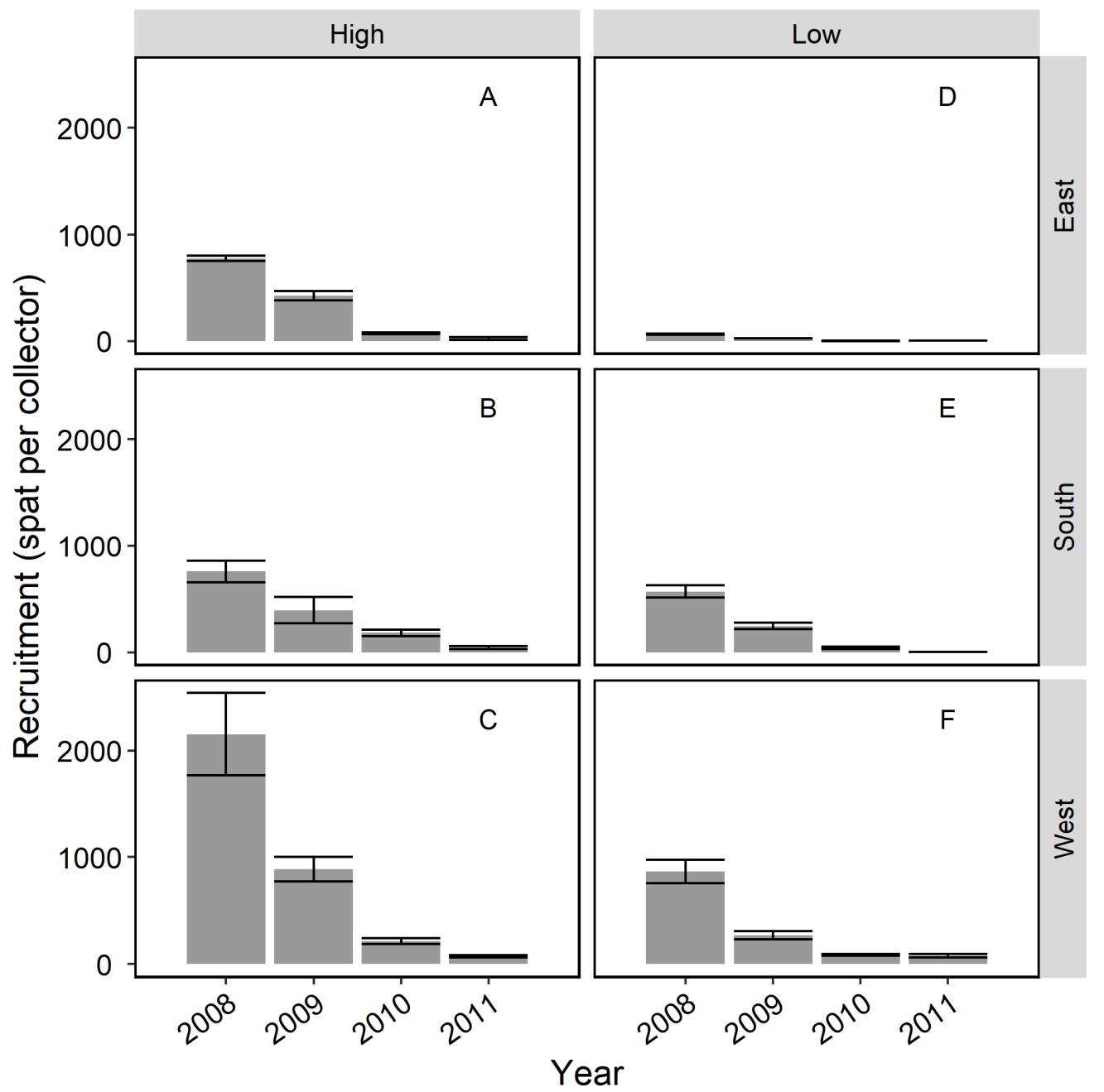

Figure 2-5. Interannual and spatial variation in oyster recruitment (mean $\pm \mathrm{SE}$ ) assessed for the primary season of recruitment (November to February). Means and SE estimated from total counts of living and dead oysters from each collector (sample) which settled over $122 \mathrm{~d}$. Recruitment for sites with (A-C) putative high and (D-F) putative low spawner densities for areas East, South, and West, respectively. 


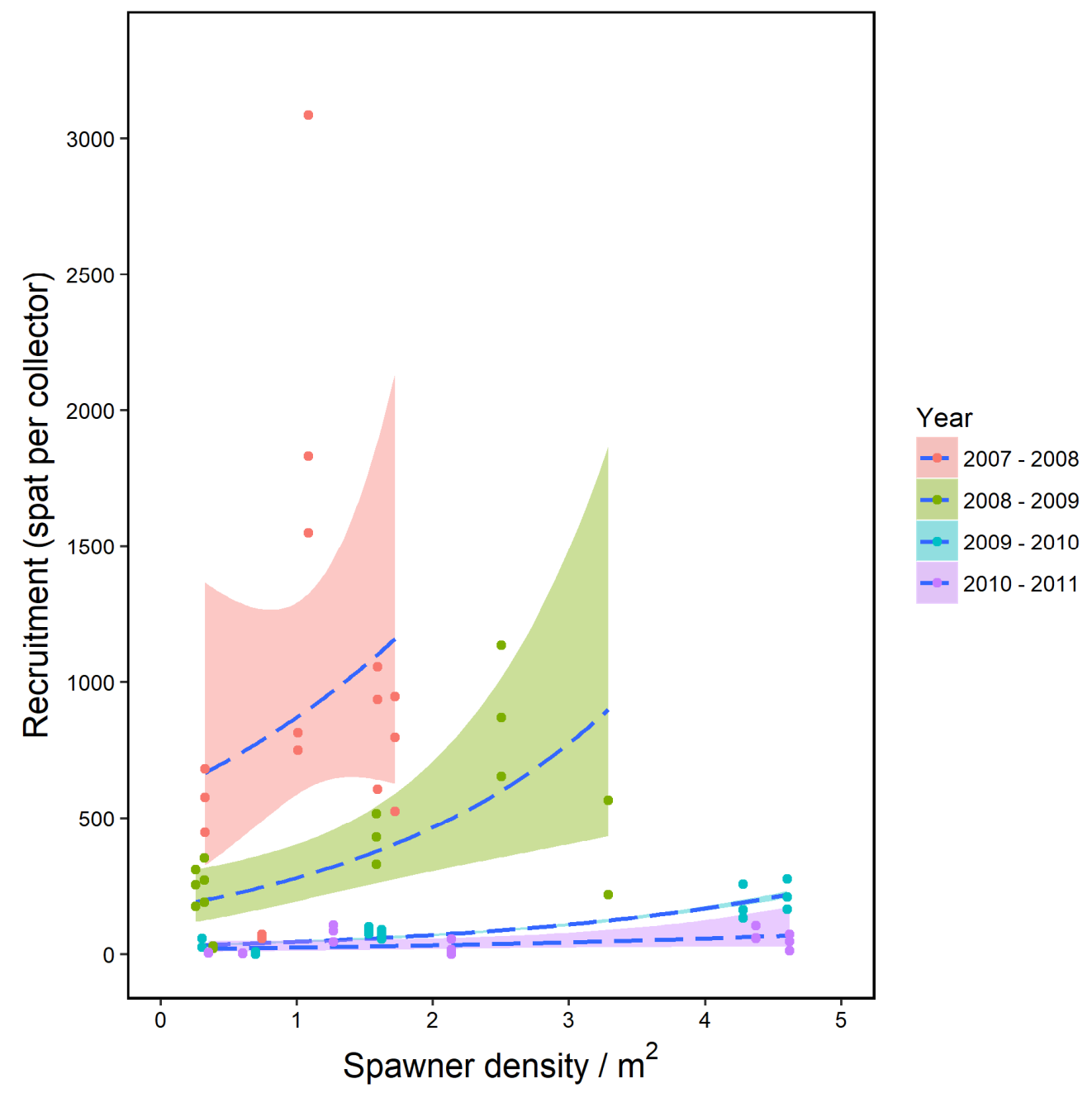

Figure 2-6. Stock-recruitment relationships for oysters sampled at fixed locations across the fishery over successive years (2007-08 to 2010-11). Estimates of oyster recruitment (spat collector-1) are for the primary season (November to February). Each point represents counts from a single collector $(n=3$ collectors deployed at each of 6 sites, each year). A few spat collectors were lost. Spawner densities estimated from dredge samples. Colours correspond to years as given in the key; fitted lines are from a negative binomial regression model, and shaded areas depict \pm SE. 


\section{Discussion}

Ostrea chilensis recruits per spawner declined over the successive 4 years of the fishery-wide study despite spawner densities that remained similar or increased over the same time. The high recruitment observed in 2007-08 and the subsequent decline in recruits per spawner was consistent with recruitment in the 6 year study at a single site (2005-06 to 2010-11, see Figures 2-4 \& 25). The oyster stock-recruitment relationships differed between years (see Figures 2-6), and by the significant interaction between Spawner density and Year in the model. The inference of a diminishing stock-recruitment relationship assumes that settler densities represent recruitment at the sites where larvae were brooded, and that our estimates of spawner densities from dredge sampling represent spawner densities at sites.

Recruitment inferred from counts of recruits on collectors assumes that O. chilensis in Foveaux Strait releases larvae that are competent and settled within minutes to hours after release (Hollis 1962, Stead 1971a, Westerskov 1980, Cranfield \& Michael 1989). This is the case in other fisheries (Chaparro et al. 2006, Broekhuizen et al. 2011). The putative short pelagic larval duration suggests that most dispersal events will occur over short distances (Cranfield 1968a, Broekhuizen et al. 2011). Moreover, O. chilensis readily settles on manmade substrates e.g. cement board (Cranfield 1968b, Brown et al. 2010), and in the absence of conspecifics. These data therefore infer that recruit densities mostly represent self-recruitment to sampling sites. During high settlement years, recruitment at sites was consistent with spawner densities (see Figure 2-5), and therefore with brooding and the release of competent larvae ready to settle. These assumptions underpin the hypothesis of a stock-recruit relationship.

Sampling in Season B represents annual recruitment. The timing of peak settlement relative to the time over which sampling occurs can affect estimates 
of recruit densities. O. chilensis broods throughout the year (Jeffs \& Hickman 2000). The levels of factors that determine peak brooding and subsequent settlement such as temperature and primary productivity are unknown. Before the Bonamia exitiosa epizootic in 1985 (Doonan et al. 1994, Cranfield et al. 2005), the highest numbers of brooders were recorded in November and December (Stead 1971a, Jeffs \& Hickman 2000) with $80-90 \%$ of settlement occurring from mid-December to mid-February (Cranfield 1979). As the timing of peak settlement may have changed, recruitment in all 3 seasons (A, B, C) was sampled in the separate 6 year study to ensure that sampling of the spatiotemporal variation in recruitment in Season B (November to February) gave reliable estimates of annual recruit densities. The seasonality of $O$. chilensis recruitment in Foveaux Strait was consistent with previous studies. In this study, $97.8 \%$ of settlement occurred in November to February (Season B), consistent with percentages of spat settling over that period during the 1960s and 1970s (Cranfield 1979).

An important assumption of this research is that recruit densities represent the densities of competent larvae ready to settle at the sampling sites, and therefore represent putative recruitment. Post-settlement mortality can affect estimates of recruit densities, especially over the four months that the spat collectors were deployed (after Knights \& Walters 2010). In Crassostrea virginica, both density-dependent and density-independent mortality determined the numbers of recruits surviving post-settlement (Knights \& Walters 2010). $C$. virginica population growth was negative after high recruitment events, when density-dependent mortality reduced oyster densities and cohort strengths. This research recorded low post-settlement mortality. Dead $O$. chilensis spat leave a record on the collector plates in the form of an attached left valve of their shells (see the estimates of mortality section in the Appendix). Overall, percent mortality was relatively low (14.6\%) and did not differ greatly between high settlement years 2007-2008 and 2008-2009 (15.1 and 13.7\%, respectively) and 
low settlement years 2009-2010 and 2010-2011 (16.6 and 7.6\%, respectively). Higher recruit densities did not incur increased mortality (Figure A-5), and there was no difference in the percentage mortality amongst sites (Figure A-5). Additionally, more than $95 \%$ of spat (live and dead) were less than $5 \mathrm{~mm}$ in length (Figure A-6). This suggests recent settlement and less opportunity for density-dependent mortality. The percentage mortality remained consistent by spat length (Figure A-6). It can be inferred from these data that the estimates of $O$. chilensis recruitment were not affected by density-dependent mortality. In contrast to the findings of Knights \& Walters (2010), O. chilensis recruit densities appeared to be determined mainly by larval supply.

Estimates of $O$. chilensis recruits per spawner from this study are sensitive to the estimates of spawner densities. The effect of spawner density averaged from dredge estimates sampled at larger spatial scales and not precisely at the locations where recruitment was evaluated. The depth, strong currents, and hard substrate limit the sampling methods available to estimate spawner densities effectively across the fishery area (see the estimates of spawner densities section in the Appendix) (Michael et al. 2008c). Stock assessments of the Foveaux Strait oyster fishery are informed by dredge sampling (Fu et al. 2016, Ministry for Primary Industries 2017). However, dredge sampling has limitations in Foveaux Strait and elsewhere. Dredge sampling gave poor estimates of market-sized $C$. virginica densities in Chesapeake Bay (United States of America (US.)). C. virginica densities in the New Jersey waters of Delaware Bay (US.) showed non-random spatial and temporal variability for market-sized oysters because of low and variable dredge efficiency (the scalar used to estimate absolute abundance) (Chai et al. 1992, Powell et al. 2007). Additionally, the patchy distribution of oysters suggests that low dredge sample numbers at each site may underestimate spawner density (Powell et al. 2017). The best available estimates of spawner densities were used and they are likely to represent differences in the spawner densities between sites. Repeat estimates 
of oyster density (Doonan et al. 1992, Michael et al. 2001) and of dredge efficiency (Fu et al. 2016) show good consistency in Foveaux Strait.

Manipulative studies to investigate the effects of spawner density on recruitment have been undertaken for O. chilensis in Tasman Bay, New Zealand (Brown 2011), and elsewhere for M. gigas and Saccostrea glomerata (Wilkie et al. 2013) and the bay scallop Argopecten irradians (Tettelbach \& Wenczel 1993, Peterson et al. 1996). The effects of increased spawner density on recruitment between these studies were mixed. Recruitment varied markedly between two sites with the same brooder densities (Brown 2011), with the complexity in the arrangement of settlement surfaces and oyster species (Wilkie et al. 2013), and recruitment increased markedly in enhanced areas receiving translocated bay scallops (Peterson et al. 1996). Manipulative studies were not considered for this study because of the depth (20-50 m), strong tides, exposure to large oceanic swells in the study area, and because handling of oysters is thought to exacerbate disease mortality from B. exitiosa (Diggles and Hine 2002). Instead, Site was modelled as a proxy for Spawner density that incorporated sites of putative high and low densities of spawners and an Area effect. Year, Site, and their interaction were significant $(\mathrm{p}<0.001$, Table A-3, estimates of spawner densities section in the Appendix). These sensitivity analyses undertaken here showed that the effect size of Year was robust to combinations of other factors representing spawner densities in alternative models. This suggests that factors other than spawner densities drove recruitment in Foveaux Strait in at least some years in the study period.

The significant interactions between Year, Area, and Spawner density suggest different patterns of recruitment through space and time with respect to putative spawner density. Recruitment scaled most strongly with spawner density in 2007-08. In this year, recruitment was relatively high at all sites even though spawner densities were less than 2 oysters $\mathrm{m}^{-2}$. By 2010-11, spawner densities were similar or had increased to over 5 oysters $\mathrm{m}^{-2}$, but average 
recruitment was only $4.6 \%$ of the levels observed in 2007-08. There were also marked spatial differences across the different sites. Recruitment to the Westhigh site was initially high (more than 2000 recruits collector $^{-1}$ ), but declined markedly in successive years (see Figure 2-5). In comparison, the East-low site was chronically low across all years of the study (see Figure 2-5). The East-low site may be an example of a localised population where spawner densities were too low to take advantage of favourable climatic and biological conditions for heightened recruitment and suggests a need to maintain local spawner densities to prevent serial depletion of stocks. Since the 1940s, spawner densities at Eastlow have been low, most likely the result of disease mortality (Cranfield et al. 2005, Dunn 2005), or possibly because of fishing effects (Cranfield et al. 1999). Both hypotheses implicate low spawner densities in low recruitment as many other commercial fishery areas in Foveaux Strait have sustained high effort and high catch and remained productive in spite of the same high $B$. exitiosa mortality (Michael 2007).

Biological reference points such as spawning stock biomass rely on a positive relationship between spawning stock sizes and recruitment (i.e. recruitment varies positively in relation to spawning stock size) and have been used to rebuild stocks towards maximum sustainable yield (see Mace 2012). Biological reference point based fisheries management has maintained or improved stocks in New Zealand (Ministry for Primary Industries 2017) and elsewhere, such as in the U.S.A (Soniat et al. 2014). However, stock-recruitment relationships are difficult to estimate for most species because there are few data for most stocks (Maunder 2012, Maunder \& Piner 2015). Moreover, estimates from models are often uncertain (Lee et al. 2012). The lack of relationship between stock size, spawner density, and recruitment is well known in oysters as many other factors determine recruitment success see Knights \& Walters (2010) and Soniat et al. (2014). The long PLD of $C$. virginica contributes to the high interannual variation in oyster numbers and biomass. C. virginica also 
forms oyster reefs, thereby creating their own habitat important to their recruitment and post-settlement survival. Shell abundance is therefore an important biological reference point, (Powell \& Klinck 2007, Soniat et al. 2012). The lack of a consistent stock-recruitment relationship in oysters and other sessile invertebrate stocks suggests that single biological reference point based management may not be appropriate for many of these stocks (after Powell et al. 2012). The diminishing stock-recruitment relationship in Foveaux Strait oysters has important implications for the management of Foveaux Strait oyster fishery and invertebrate stocks generally. This research is consistent with the findings of Szuwalski et al. (2015) in that it shows that other factors not measured in this study (most likely climatic and biological factors) more strongly influenced recruitment than spawning biomass in some years.

The Foveaux Strait oyster stock assessment model (Dunn 2005) uses a Beverton-Holt stock-recruitment relationship with steepness of 0.9 (i.e. high levels of recruitment are plausible during periods of low spawner density). High levels of recruitment were observed during a period of low spawner abundance and density between 2005-06 and 2007-08. At that time, spawning stock biomass in 2005 was $16 \%$ of $\mathrm{B}_{0}$ (the biomass before fishing began) (Fu et al. 2009). High recruitment was consistent with the stock-recruitment assumptions of Dunn (2005) based on survey data from 1992 to 2001. However, recruits per spawner decreased in times of relatively high spawner densities (2008-09 to 2010-11, see Figure 2-6). Spawning stock biomass in 2012 had increased to $34.5 \%$ of $\mathrm{B}_{0}(\mathrm{Fu} 2013)$. Our data did not show a stock-recruitment relationship consistent with the Beverton-Holt function used in the OYU 5 stock assessment model of Dunn (2005). While projections of future stock size were corroborated by subsequent surveys (the assessment model has performed well Fu 2013), our data suggest that factors other than spawner density strongly influence recruitment. Fishery indices of recruitment, catch sampling (Marsh et al. 2016) and population surveys (Michael et al. 2017b) show the low recruitment 
observed during this research continued through to 2016-2017. Collectively, these indicate a regime shift in recruitment. This regime shift suggest that the Beverton-Holt function may not predict recruitment well, and that estimates of future stock size may therefore be more uncertain for long-term projections. Maintaining spawning stock size at or above reference points alone may not ensure recruitment and rebuilding of the fishery.

Many invertebrate fisheries including $O$. chilensis in Foveaux Strait are managed by 'unit stocks' over large areas. A mismatch of the spatial scales of recruitment and fisheries management in other systems has led to overfishing, recruitment failure, serial depletion, and the eventual collapse of many invertebrate fisheries (Hilborn et al. 2005). Moreover, a persistent reduction in recruits per spawner may have flow-on effects on spawning success: consecutive years of low recruitment could reduce the density of $O$. chilensis spawning as males, potentially limiting sperm availability and fertilisation success. There is evidence of this phenomenon in both e.g. urchins (Levitan et al. 1992) and lobsters (MacDiarmid \& Butler 1999).

The diminishing stock-recruitment relationship in Foveaux Strait oysters may be due to non-mutually exclusive climatic and biological factors that can reduce cohort strength of competent larval and reduce recruitment to localised populations. Climate variability affects recruitment in fisheries (Hjort 1914), in oysters (Kimmel \& Newell 2007, Kimmel et al. 2014), and in other species (Anderson et al. 2011b, Miller et al. 2016). Models of population dynamics (Hilborn \& Walters 1992) and other models of varying complexity used in management approaches such as ecosystem-based fisheries management (EBFM), (Fulton 2010); Management Strategy Evaluation, (Fulton et al. 2014, Punt et al. 2014); and extended frameworks for fisheries assessments, (Hollowed et al. 2009) should ideally incorporate climate variability. However, these approaches are rarely implemented (Punt et al. 2014, Skern-Mauritzen et al. 2016) as discussed by Skern-Mauritzen et al. (2016, p 165): "Fisheries 
management is still predominantly single-species-oriented taking little account of ecosystem processes, implicitly ignoring that fish stock production depends on the physical and biological conditions of the ecosystem". The focus on EBFM across a range of fisheries will hasten the need to understand the effects of climate and to predict the long-term effects on recruitment (Collie et al. 2016).

Heightened recruitment can occur in oysters (Dunn 2005) as well as in other species such as scallops (Bethoney et al. 2016). In this study, prolonged (9-year) recruitment failure in oysters occurred over a time when spawner densities $\left(0.3 \mathrm{~m}^{-2}\right)$ had been previously sufficient to support high recruitment (Dunn 2005). Low recruitment continued after this study when mean spawner densities of $0.4-0.9 \mathrm{~m}^{-2}$ were above those reported by Dunn (2005). Climatic and biological factors with complex interactions may drive fishery-wide recruitment variability and may determine the persistence of their effects. However, careful consideration is required in the choice of climate data sets for analysis (Menge et al. 2011), and in the interpretation of correlations between climate and recruitment (e.g. Pacific sardine) (McClatchie et al. 2010, Lindegren et al. 2013). Long time series of recruitment data at appropriate spatial scales alongside biological and climatic data are required to explain the changes in stock-recruitment relationships observed during this study, and for the management of other marine populations and fisheries. An understanding of these effects will better inform stock assessment models to predict changes in populations, and to underpin EBFM (Hilborn \& Walters 1992, Fulton 2010, Punt et al. 2014, Collie et al. 2016, Koenigstein et al. 2016). The climatic and biological factors contributing to reduced recruits per spawner in Foveaux Strait oysters are the focus of Chapter 3. 
Chapter 3 : Evaluation of the effects of climatic and disease on Ostrea chilensis recruitment

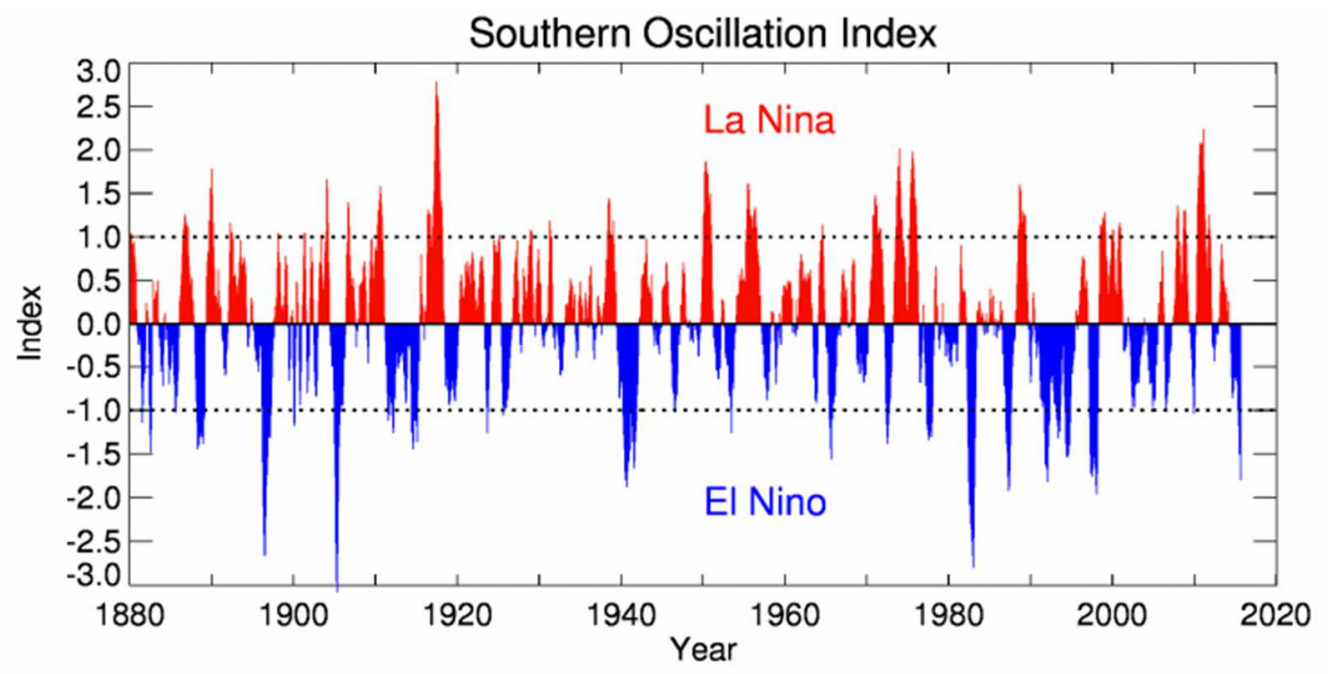

Image by NIWA 


\begin{abstract}
Recruitment to the Foveaux Strait Ostrea chilensis population declined abruptly to low levels in 2010 and remained low until 2017, in spite of a spawning-stock size over this period that had previously supported high recruitment. This research investigates the potential contributions of other factors: climate, food supply and availability, and pathogens to low recruitment.

Variable importance measures from classification tree ensembles were initially used to rank the contributions of these other factors to recruitment variation. Recruit densities were modelled as functions of oyster densities, oyster mortality, and climate variables with negative binomial regression to determine significant factors and their interactions. Oyster density and mortality, and their two-way interaction explained $68 \%$ of the deviance in the best-fit model. The highest recruitment occurred at times of low mortality indicative of low disease infection during gametogenesis and spawning and low oyster density, suggesting minimal effects of pathogens on the numbers of oysters brooding and reduced disease transmission. The contributions of climate factors were minor $(\sim 1 \%$ deviance). This research, together with fishery data and the pathology of concurrent infections in $O$. chilensis, suggests that a 3-way interaction between density, disease, and climate may drive variation in recruitment. Pathobiomes may be important determinants of shellfish recruitment and population dynamics, with important implications for stock assessment and enhancement.
\end{abstract}




\section{Introduction}

A period of historically low recruitment to the Ostrea chilensis population in Foveaux Strait between 2010 and 2017, and significant mortality from Bonamia exitiosa between 2013 and 2017, severely slowed rebuilding of the fishery between 2010 and 2013, and caused a significant decline in stock size thereafter (Ministry for Primary Industries 2017, Michael et al. 2018). B. exitiosa is an obligate parasite of oysters that can cause high mortality, primarily in the genus Ostrea (Carnegie 2017). Between 2012 and 2015, B. exitiosa reduced the recruit-sized (58 $\mathrm{mm}$ in length or larger) oyster population and brooding-sized oyster densities in Foveaux Strait to about 50\% of 2012 levels (Ministry for Primary Industries 2017). In 2015, the population size was still above levels that had previously supported high recruitment (Fu et al. 2016). Chapter 2 suggests that factors other than densities of brooding-sized oysters (hereafter referred to as brooders) operating at a fishery-wide scale more strongly influenced recruitment in some years. This chapter investigates the potential contributions of other factors: climate, food supply and availability, and pathogens to low recruitment.

Recruits are defined as competent larvae that settle from the plankton and complete metamorphosis on substrata; consistent with the ecological definition of Stanwell-Smith \& Barnes (1997). In this chapter, recruitment to the population is the number of recruits settled before post-settlement mortality occurs. Recruitment is assumed to reflect the numbers of competent larvae available for settlement and therefor settle on passive artificial collectors at sampling locations. Settlement to the seabed will be primarily dependent on the availability of clean hard substratum such as shells (Smyth et al. 2018). The magnitude of $O$. chilensis settlement and survival of juveniles (to a putative density dependent threshold Beverton \& Holt 1957, Ricker 1975) determines fishery-recruitment defined as the addition of harvestable individuals as per Hilborn \& Walters (1992), and therefore stock size and potential future harvests. 
The variation of recruitment over space and time may be explained by a series of successive recruitment processes (e.g. larval supply, dispersal, settlement and post-settlement mortality), and their flow-on effects on subsequent processes. Successful spawning and larval supply is a key prerequisite for successful recruitment. Abrupt medium to long-term shifts in recruitment are likely to reflect system changes, often driven by changes in climate (Holbrook et al. 1997, Peterson \& Schwing 2003, Perälä \& Kuparinen 2015). Knowledge of the factors driving variation in recruitment is fundamental to the management, conservation and enhancement of sessile benthic invertebrates including oysters (King et al. 2015, Levin \& Möllmann 2015, Szuwalski et al. 2015). An understanding of how biological (physical condition, physiological stress, and disease) and climatic (sea surface temperature, upwelling, and storm frequencies) factors interact is therefore essential.

Sufficient spawning stock and sufficiently high spawner densities are essential to ensure larval production in $O$. chilensis, and changes in spawner densities may drive variation in recruitment. A range of other factors and their interactions are also likely to affect recruitment. This study investigates climatic factors and the putative effects of disease. Climate is known to drive annual variation in recruitment in a number of marine species (Hjort 1914, Lehodey et al. 2006, Hollowed et al. 2011), with evidence of this in the Ostrediae family e.g. Crassostrea virginica (Kimmel \& Newell 2007, Kimmel et al. 2014).

Temperature and food rations have marked effects on gametogenesis (Westerskov 1980, Buroker et al. 1983, Joyce et al. 2015) and may play important roles in conditioning, initiating gametogenesis, and synchronising gonadal development (Joyce et al. 2015). At high temperatures $\left(\geq 20^{\circ} \mathrm{C}\right)$, the gonad cycle may advance rapidly and asynchronously to phagocytosis, thereby reduce fertilisation and brooding (Jeffs \& Hickman 2000). Temperature also affects brooding period (Chaparro 1990, Toro \& Morande 1998) and the stage of development when larvae are released (Joyce et al. 2015). Large larvae have 
greater settlement success (Cranfield \& Michael 1989, Chaparro 1990, Utting \& Millican 1997). As in other shellfish, fluctuations in food supply also play an important role in O. chilensis recruitment (Bradford et al. 1991, MacKenzie \& Rhodes 1997, MacKenzie \& Adamson 2004, Zeldis 2008, Rifi et al. 2011, Zeldis et al. 2011, Le Moullac et al. 2013). Studies conducted on O. chilensis in Chile suggest that an abundance of microalgae can increase gonad condition, enhance spawning success (Chaparro 1990), increase maternal provisioning (Wilson et al. 1996, Chaparro et al. 2006), and produce larger larvae (Chaparro 1990, Utting \& Millican 1997). Large larvae have increased rates of settlement and postsettlement survival in O. edulis (Robert et al. 2017). Foveaux Strait is a highly productive area (Bradford et al. 1991) and the strong tides there ensure the water mass (and therefore plankton) is well mixed both vertically and horizontally (Butler et al. 1992). Because of this homogeneous water mass, sea surface temperatures (SST) and primary productivity measured as Chlorophyll a (Chl) from remote sensing are used. These data are corroborated with in situ data from a conductivity, temperature, and depth (CTD) instrument incorporating a fluorometer. Climate indices can also describe broad scale trends in temperature, productivity and the sea conditions that drive then, including: the southern oscillation index (SOI), and sea level pressure indices (Z2 and M1, see methods for definition).

Reproductive processes may be further affected by storm surges that mobilise sediments (Carter \& Lewis 1995, Stanton et al. 2001, Walters et al. 2001, Hemer 2006) that bury oysters in coarse calcareous sand and gravel (Stead 1971b), and thereby reduce their ability to feed and cause physiological stress. These climatic factors and physiological stresses intensify disease (Diggles \& Hine 2002) as well as affecting recruitment. Storm surges are wind driven and the numbers of days of gales and severe gales extracted from weather station data. Suspended sediments increase turbidity, which is measured by remote sensing. 
Bonamia exitiosa is the primary cause of disease mortality in Ostrea chilensis in Foveaux Strait (Doonan et al. 1994, Cranfield et al. 2005); however, co-infections with other pathogens can intensify low intensity $B$. exitiosa infections to fatal levels. Oyster mortality from B. exitiosa (and most likely other co-infections) occurs after peak spawning and is used as a proxy for intense pathogenic infections during the reproductive period (gametogenesis and spawning). Climate factors such as high temperatures and low salinity, and low food supply or reduced access to food are known to increase disease susceptibility and intensify infections, as well as drive recruitment variability (Hine et al. 2002, Arzul et al. 2009, Engelsma et al. 2010, Rowley et al. 2014). Because all these factors determine energy budgets and physiological stress, 3way interactions between recruitment, climate and disease can be expected for this reason.

Pathogens disrupt reproduction and cause parasitic castration in many marine taxa (Sullivan et al. 1985, Oliva et al. 1999, da Silva et al. 2002, Hine \& Thorne 2002, Ngo et al. 2003, Valderrama et al. 2004, Moravec \& de Buron 2013). At high prevalence, these pathogens can affect population-scale recruitment. Several pathogens have been found in wild and farmed Ostrea chilensis populations throughout New Zealand (Dinamani et al. 1987, Hine 1997, Joyce et al. 2015). In Foveaux Strait, these pathogens include Bonamia exitiosa, Bucephalus longicornutus (Hine \& Jones 1994), and Apicomplexan spp. (APX) (Hine 2002, Lane et al. 2016, Suong et al. 2017). The effects of individual pathogens may be host specific, although concurrent infections of two or more pathogens can exacerbate the intensity of infections and mortality (Diggles 2004). For example, APX may increase the susceptibility of $O$. chilensis to B. exitiosa mortality (Hine 2002), and APX alone severely affects gametogenesis (Diggles \& Hine 2002). B. longicornutus can disrupt reproduction and cause parasitic castration, and has been responsible for high mortalities of O. chilensis in Foveaux Strait (Howell 1967). da Silva et al. (2009) 
found high to moderate intensities of $B$. ostreae infections in ripe, female $O$. edulis, as well as in partially spawned and reabsorbing females. This suggests the intensification of infection by $B$. ostreae associated with female maturation before spawning. Because B. ostreae and B. exitiosa are closely related pathogen of the genus Ostrea, bonamiosis in $O$. chilensis probably has a similar effect. Other infestations may also play critical roles in physiological stress, reduce the energy available to recruitment processes, and increase susceptibility to disease. Crassostrea virginica colonised by Cliona celata (a boring sponge, Grant, 1826) diverted significant energy from shell and somatic growth (and presumably reproductive processes) to shell maintenance and repair (Carroll et al. 2015). Cliona celata is common in the shells of $O$. chilensis in Foveaux Strait and may play a role in reducing larval supply and thereby recruitment.

This study investigates whether climate factors and disease, and any interaction between these factors reduces spawning and brooding success in $O$. chilensis and thereby recruitment to Foveaux Strait oyster populations. Because data on the prevalence and intensity of infections is not available for pathogens other than B. exitiosa, oyster mortality from annual surveys is used as a proxy for one or more high intensity infections present during gametogenesis and spawning. B. exitiosa infections intensify late in the gametogenic cycle and during spawning and O. chilensis mortality occurs after spawning (Hine 1991a). Brooder densities and oyster mortality are estimated from annual surveys. Climate data is sourced from remote-sensing satellites, CTD and weather stations. The responses of gonadal development, spawning, and brooding to variations in climate factors are likely to occur over relatively short timeframes (weeks). 


\section{Methods}

The Foveaux Strait oyster fishery (Figure $2-1$ is managed as a single stock OYU 5 (Ministry for Primary Industries 2017) and the fishery comprised a number of putative demographically closed populations (Stead 1971b, Allen \& Cranfield 1979). Fisheries-independent variation in oyster densities is mostly driven by periodic disease mortality (Doonan et al. 1994, Cranfield et al. 2005) caused by Bonamia exitiosa (previously B. exitiosus, Berthe \& Hine 2003), and variability in recruitment to the oyster population (Michael et al. 2015).

O. chilensis grows to recruit-size in four years or more after settlement (Cranfield 1979). More than 60\% of the recruited oyster population produces mature ova (Fu et al. 2016), and oysters $\geq 60 \mathrm{~mm}$ in length brood larvae (Jeffs $\&$ Hickman 2000). These larvae are fully competent and can settle on release.

\section{Interannual variation in recruitment}

Recruitment to the $O$. chilensis population is estimated from recruit densities on passive artificial collectors representing local densities of competent larvae. The collectors are similar to those used since the 1960s (Cranfield 1968b). Each spat collector held four, cement board settlement plates (220 x 140 x $4 \mathrm{~mm}$ ) at heights of 10, 120, 240, and $360 \mathrm{~mm}$ above the seabed. Although biofilms have been shown to be important in the settlement of some oyster species (e.g., C. virginia, Tamburri et al. 1992), Ostrea will settle on any clean hard substrate (Smyth et al. 2018). Because the settlement of O. chilensis larvae had previously been high on unconditioned plates deployed for similar periods in Foveaux Strait (1965-1967, 1999-2000; Cranfield 1968b, Cranfield et al. unpublished data), the settlement plates were not conditioned before deployment. Mooring lines with floats attached to each collector facilitated location and retrieval. 
Between the austral summers of 2005-06 and 2016-17, collectors were deployed in early November and recovered in late February. This period represents the time when $\sim 98 \%$ of settlement had occurred previously (see Chapter 2 and Cranfield 1968b). Each deployment of spat collectors used new cement board plates. Recruitment is defined as the numbers of recruits settled on collectors before post-settlement mortality occurs, and was calculated as the cumulative number of both living and dead recruits on any plate surface (top or bottom) of any of the four plates of a given collector. Deployment times varied by a small amount and estimates of recruitment were standardised to a 122-day sampling period each summer.

Data on recruitment comprises recruit densities from three separate sampling programmes:

1. Between 2005-06 and 2010-11, 36 collectors were deployed in each year to 6 fixed sampling sites, stratified across 3 discrete areas. See Chapter 2 for more details (see Figure 2-1).

2. Between 2011-12 and 2013-14, 45 collectors were deployed in each year to fixed sites according to a gradient design (Figure 3-1). See Chapter 4 for details.

3. Between 2014-15 and 2016-17, 45 collectors were deployed in each year to a stratified random sampling design (Figure 3-2). Passive spat collectors were deployed to the first three randomly allocated sites to be sampled for oyster densities and the status of B. exitiosa in each of the 15 strata (Figure 3-2). See Michael et al. (2018) for more details. 


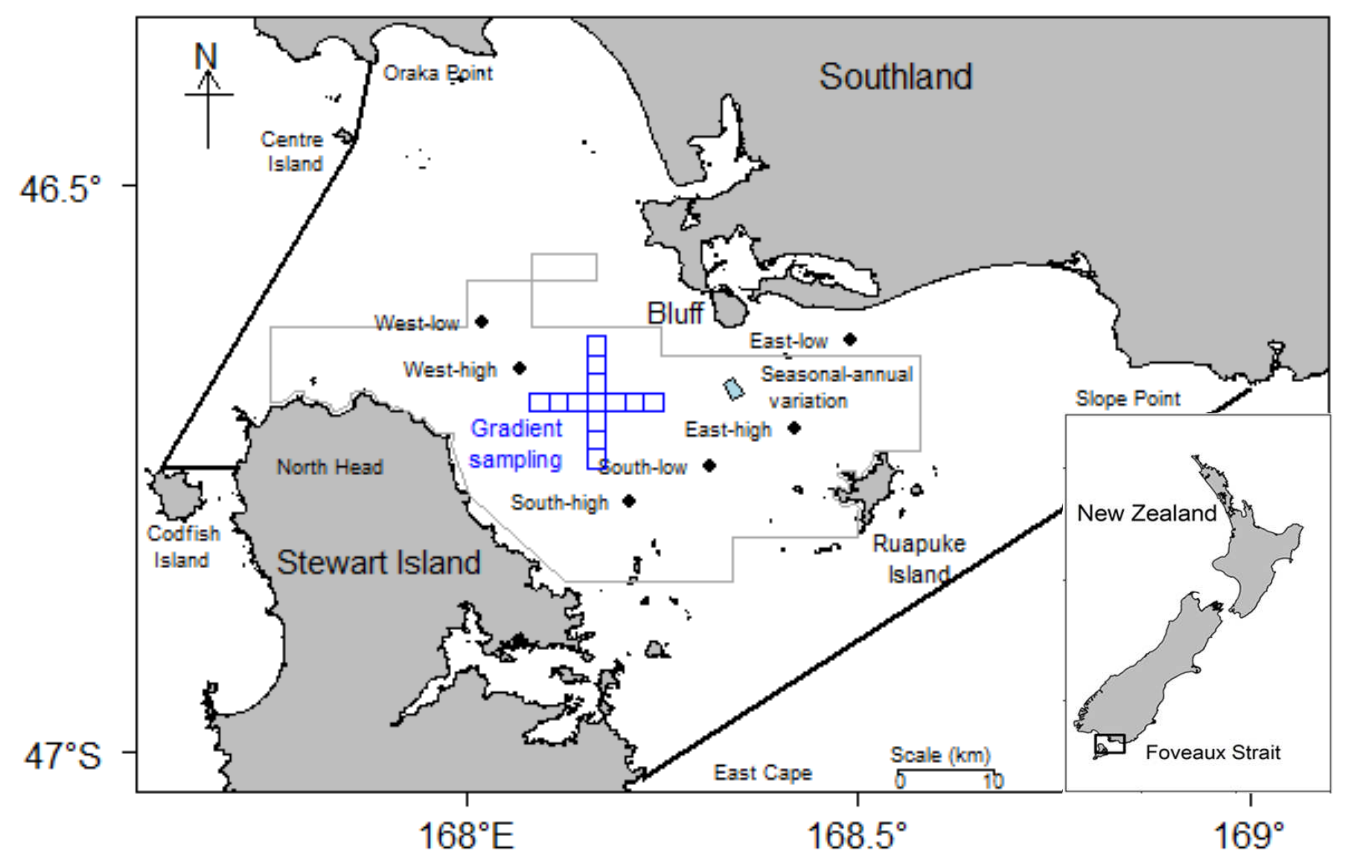

Figure 3-1. Foveaux Strait oyster stock (OYU 5) boundary (heavy black lines) and the outer boundary of the 2007 stock assessment survey area (grey lines) encompassing the commercial fishery. Sampling for seasonal and interannual variation in recruitment at a single site (light blue shading), spatio-temporal variation in recruitment at six sites across the fishery (filled black diamonds $\downarrow$ ), and the gradient sampling grid in blue with blue text. The lower right inset shows the location of Foveaux Strait within New Zealand. 


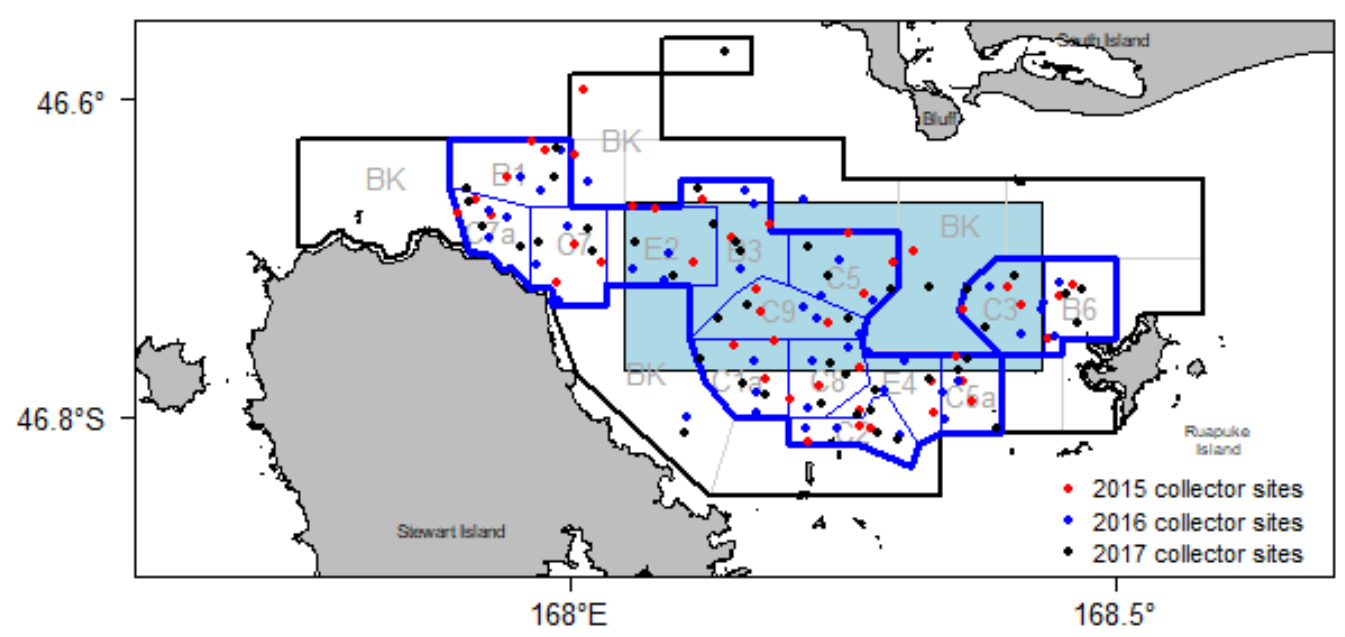

Figure 3-2. The 2007 stock assessment area boundary shown as a heavy, black outer line, and the 26 stock assessment survey strata (light grey and blue lines). The Bonamia exitiosa survey area boundary (shown as a heavy blue line), the 14 core strata (shown as blue lines) and the single background stratum (BK) delimited by the stock assessment survey (black lines) and $B$. exitiosa survey (blue lines) boundaries. Strata are labelled with grey text. The site where spat collectors were deployed in 2015 (red filled circles), 2016 (blue circles), and 2017 (black circles). A polygon defining the area from which remote sensed data were extracted is shown in light blue shading.

Annual recruitment data from collectors are corroborated using commercial catch sampling data. The numbers of $0+$ year oysters (spat from larvae produced during the previous year's spawning and settled the previous summer) attached on the shells of landed commercial-sized oysters was scaled to the size of the commercial catch over the same years (Large et al. 2018). Percentages of recruits each year between 2006 and 17, and percentages of the population size of $0+$ year oysters provide independent indices of recruitment. These are highly correlated (Pearson's correlation of $0.96, p<0.001)$. Estimates of recruitment from concurrent sampling at local scale as part of a seasonal study and from fishery-wide-scale sampling from 2007-08 to 2010-11 (see Chapter 2) provided two further estimates of recruitment. These were also highly correlated (Spearman's rank correlation rho 0.99, $\mathrm{p}<0.001$ ). The three time-series most likely reflect changes in fishery-wide scale recruitment. Because recruit densities 
represent spawning and brooding success in the previous calendar year, spat counts from catch sampling the following winter were assigned to the year gametogenesis began (i.e. commercial catch sampling year-1).

\section{Estimates of brooder densities and annual mortality}

Densities of recruit-sized oysters (58 $\mathrm{mm}$ in length or larger) from dredge samples were scaled for dredge efficiency, and scaled to population size (Michael et al. 2018, summarised in the estimates of spawner densities section in the Appendix). Variation in $O$. chilensis shell morphology and the size structure of oysters across the fishery area suggest that recruit-size is a good proxy for brooders as the difference in oysters brooding between $58 \mathrm{~mm}$ and 60 $\mathrm{mm}$ in length is likely to be negligible. Brooding-sized oyster density (hereafter density) is estimated at the beginning of the female gametogenic cycle.

Survey details and estimates of annual mortality in $O$. chilensis from $B$. exitiosa (hereafter mortality) are given in the estimates of annual mortality section and Table A-4 in the Appendix. Annual mortality estimates are scaled to population level, expressed as a percentage of the brooding population, and comprise the aggregate of two different estimates: pre-survey mortality and projections of post-survey mortality (days to weeks) from the proportion of oysters with fatal infections (see the estimates of mortality section in the Appendix). Because oyster mortality occurs in the calendar year following spawning events, mortality is assigned to the previous year (year-1) to link infection status to the year of gametogenesis.

\section{Climate and weather variables}

Climate variables and indices were divided into two groups to avoid collinearity and to facilitate the analysis of a relatively large number of variables for a relatively short time series of recruitment data. Values for group 1 variables were derived from satellite and weather stations to provide local scale conditions 
that change relatively rapidly. Data from NASA's MODIS Aqua satellite were sourced from the NOAA databases and extracted down to daily intervals from an area delimited by $46^{\circ} 39.900^{\prime}-46^{\circ} 46.200^{\prime} \mathrm{S}$ and $168^{\circ} 03.000^{\prime}-168^{\circ}$ $25.920^{\prime} \mathrm{E}$ (around 1600 pixels) at $1 \mathrm{~km}$ resolution encompassing the Foveaux Strait fishery area (shaded blue in Figure 3-2). These data were filtered to remove images with less than 100 pixels per record (Matt Pinkerton, NIWA, unpublished data). Group 2 climate indices represented regional conditions that persist for longer periods.

\section{Group 1 climate variables}

Level 3 sea surface temperature (SST, ${ }^{\circ} \mathrm{C}$ ) from MODIS Aqua are averaged temporally to daily intervals and spatially to $1 \mathrm{~km}^{2}$ (Reygondeauet al. 2011). These data were range-checked against published data from Bradford et al. (1991) and Butler et al. (1992) and unusually high and low values removed. Trends in daily air temperatures from Tiwai Point, Bluff, and two Invercargill aero stations collated from the National Institute for Water and Atmosphere's (NIWA) CliFlo database (http://cliflo.niwa. co.nz) were also compared. Mean monthly SST data showed good coherence with mean monthly air temperature data at Tiwai Point at the northern entrance to Bluff Harbour $\left(r^{2}=0.78\right.$, Figure A-7 in the climate variables section in the Appendix) and good coherence with in situ CTD data provided by Otago University. CTD casts at eight sites across the fishery area sampled on five occasions three-monthly between September 2017 and June 2018 showed temperature was vertically and horizontally consistent within a well-mixed water mass flowing through Foveaux Strait and consistent throughout the depth profile and across the commercial fishery area (Sam Hensman, Otago University, unpublished data). SST minima ranged from $7.4-9.5^{\circ} \mathrm{C}$ in July 2002 to 2017 were similar to Cranfield (1968a) and Butler et al. (1992). SST maxima in February ranged from $16.1-18.7^{\circ} \mathrm{C}$ in 2002 to 2017. 
Phytoplankton concentrations represented as chlorophyll a ( $\left.\mathrm{Chl} \mathrm{mg} \cdot \mathrm{m}^{-3}\right)$ provide a measure of food availability to oysters. MODIS-Aqua level 3 were data extracted from daily overpass data received by NIWA X-band satellite receiver using the standard blue-green band reflectance ratio algorithm that optimises estimates of chlorophyll. A resolution of $1 \mathrm{~km}$ was used as it is more appropriate for coastal regions (Pinkerton et al. 2015) Two data sets, a blended case of open ocean and coastal chlorophyll and an ocean case chlorophyll only showed good coherence $\left(r^{2}=0.78\right.$, Figure A-8 in the climate variables section in the Appendix). The ocean case was used for analysis for two reasons: the oyster fishery area in the middle of Foveaux Strait is more likely to be under the influence of oceanic water, and satellite products have higher uncertainty near the coast due to the presence of suspended sediment (Pinkerton et al. 2006). Chlorophyll levels were consistent throughout the water column, and had minima and mean values for Chl similar to published values. Some remote sensed values for Chl were abnormally high compared to published values. Maxima were truncated to below $20 \mathrm{mg} \cdot \mathrm{m}^{-3}$ for analysis.

Turbidity is an indicator of sediments suspended by storms (as well as neritic water) that may inhibit feeding in oysters. The concentration of turbidity (Turb) as Nephelometric Turbidity Units (NTU) from MODIS-Aqua data show high correlation between turbidity measured in-situ and satellite-derived turbidity (Pinkerton et al. 2014). Other measures of storms (a proxy for suspended sediments) include the numbers of days of severe gales (DSGales, > $\left.40 \mathrm{knots}, 20.8-24.4 \mathrm{~m} \cdot \mathrm{s}^{-1}\right)$ and high wind speed $\left(\mathrm{m} \cdot \mathrm{s}^{-1}\right.$, WSpd). These conditions are likely to produce large swells and strong currents that suspend and move sediments that may bury oysters. Daily DSGales and WSpd at Tiwai Point, Bluff were extracted from the NIWA CliFlo database (http://cliflo.niwa. co.nz). 


\section{Group 2 climate indices}

La Nina (the positive Southern Oscillation Index (SOI)) is characterised by more winds from the north and northeast. This leads to more settled and warmer anticyclonic weather in Foveaux Strait and less upwelling on the west coast of New Zealand's South Island. El Nino (negative index) is characterised by more winds from the west and southwest, cooler and less settled weather, and enhanced upwelling (Hurst et al. 2012). Monthly SOI were obtained from the National Center for Atmospheric Research Climate and Global Dynamics division (Trenberth 1984) and computed using the difference in the monthly mean sea level pressure anomalies between Tahiti and Darwin (Australia). The SOI is best represented as seasonal indices (3-monthly running means to annual May-April averages (SOI3av)). SOI and fisheries catch indices and seasonal upwelling have been linked to associated nutrient flux, enhanced phytoplankton, and SST (Hurst et al. 2012).

Sea conditions in the region of Foveaux Strait have been characterised using mean sea-level pressure indices (Z2 and M1) that describe monthly mean differences in average sea-level pressure between climate stations. These data were extracted by Brett Mullins (NIWA) from the NCAR database (Compo et al. 2010). $\mathrm{Z} 2$ is the monthly mean sea level pressure difference between Christchurch and Campbell Island. It approximately measures the strength of the westerly wind that may affect surface temperature (SST), primary production (Chl), and turbidity (Turb). M1 is the differences in pressure between Hobart and the Chatham Islands; a positive M1 results in more winds from the south and a negative value indicates more winds from the north. The strength of M1 may affect both SST and Chl (Hurst et al. 2012).

Climate and weather data are summarised as monthly and annual values, and in four monthly values to represent climatic conditions over the annual 
reproductive cycle of $O$. chilensis in Foveaux Strait (Jeffs \& Hickman 2000). The annual reproductive cycle is partitioned in to three phases below.

Phase 1: Post-spawning, brooding, and conditioning, January-April. Phagocytosis of unspent gametes occurs throughout the year with peaks in January-March (Jeffs \& Hickman 2000). Sea surface temperature and chlorophyll peak in this phase and are important to somatic and shell growth. Almost all growth occurs over this period (Dunn et al. 1998). Glycogen levels drop during spawning and begin to accumulate again during the gonadal resting phase (Abad et al. 1995). Any relationship between high chlorophyll, increased gonad condition, and increased recruitment may be obscured by the size of microalgae in blooms (after Dunphy et al. 2006), and the occurrence of summer storms that inhibit feeding.

Phase 2: Resting and early development, May-August. Temperatures drop to winter minima for a relatively short time in July-August. Temperatures below $12^{\circ} \mathrm{C}$ may play an important role in conditioning, stimulating gametogenesis, and synchronizing female spawning (Jeffs 1998b). However, these low temperatures may increase variability in reproductive state amongst individuals (Jeffs 1998a, b, Jeffs \& Hickman 2000, Joyce et al. 2015). Temperature minima initiate a switch in energy utilisation from somatic and shell growth to glycogen stores and maternal provisioning in O. edulis (Joyce et al. 2013).

Phase 3: Late development and spawning, September-December. A rapid increase temperature of about $2^{\circ} \mathrm{C}$ in September to October initiates spawning. Joyce (2015) suggested a spawning threshold $17-18^{\circ} \mathrm{C}$ for $O$. chilensis. Brooding occurs throughout the year and consistently peaks in November-December in Foveaux Strait (Hollis 1962, Stead 1971a, Cranfield 1979, Westerskov 1980, Jeffs \& Hickman 2000). Peak spawning should occur 
about a month or more before peak brooding, and consistent with the period of rapid rise in temperature.

Climate data were further summarised as means, 5th (minima) and 95th percentiles (maxima) within each month, phase, and year (Krebs \& Berteaux 2006) because thresholds are likely to initiate key reproductive processes. Seasonality (the timing of winter minima and summer maxima) is described using the decompose function in the tseries (V 0.10-45) package in R ( $\mathrm{R}$ Core Team 2016, Trapletti \& Hornik 2018).

\section{Analysis}

Cforest (Hothorn et al. 2005) in the Party package (version 1.3-0, Hothorn et al, http://party.R-forge.R-project.org) implemented in (R Core Team 2016) was used to rank the relative importance and contributions of climate, mortality and density variables to recruitment. Cforest provides robust variable importance measures from relatively small data sets and with large numbers of variables. Especially in cases where the predictor variables vary in their scale of measurement and there are nonlinear and complex high-order interaction effects (Strobl et al. 2007) The effects of each predictor variable are assessed individually as well as in multivariate interactions with other predictor variables with unbiased variable selection measures. The sensitivity of variable ranks and effect sizes to function selection (varimp and varimpAUC functions) was assessed using 2000, 5000, and 8000 trees for each function. The AUC-based importance of each variable is found using the area under the ROC curve (receiver operating characteristic curve). ROC is a graphical plot that illustrates the diagnostic ability of a binary classifier system as its discrimination threshold is varied). This AUC-based variable importance measure is better able to reliably rank variables in order of importance than those using varimp (Strobl et al. 2007). 
A generalised linear model with a negative binomial distribution and a log-link function was used to model recruits as a function of mortality and climate variables with two-way interactions between variables. Continuous variables (mortality, wind speed, chlorophyll, Turbidity, and sea surface temperature) were modelled as first to third order polynomials to increase model flexibility to better fit the data (Ver Hoef \& Boveng 2007). Models were constructed using the "add1" function in the R core stats package (version 3.4.1). This function computes a table of the changes in fit using all variables defined in the starting model with a single significant term added to the model at each iteration until the final model contains all significant variables. This approach allows significant variables to be added without being masked by others. Initial models were constructed using main effects only because of the relatively short time series and large numbers of variables in the available data. Significant terms were added based on the largest decrease in projected AIC.

Multiple models of annual recruitment were run as functions of annual density, annual mortality, and the two groups of climate variables by year, phase, and month. Means and percentiles were run separately (Table 3-1). Best fit models were compared, and an overall best-fit model was determined. Competing models that included two-way interactions were constructed and the overall best-fit model selected based on AIC. Model fits and compliance with statistical assumptions were evaluated graphically (after Zuur et al. 2010).

Table 3-1. Multiple models of recruitment. Each time step and group of climate variables and their mean, 5 th and 95 th percentiles were run separately with density and mortality.

\begin{tabular}{lrrrrrrrr}
\hline Time & & \multicolumn{4}{c}{ Group 1 Climate } & \multicolumn{3}{c}{ Group 2 Climate } \\
step & Density & Mortality & Mean & $\mathbf{5 \%}$ & $\mathbf{9 5 \%}$ & Mean & $\mathbf{5 \%}$ & $\mathbf{9 5 \%}$ \\
\hline Annual & $\checkmark$ & $\checkmark$ & $\checkmark$ & $\checkmark$ & $\checkmark$ & $\checkmark$ & $\checkmark$ & $\checkmark$ \\
Phase (1-3) & NA & NA & $\checkmark$ & $\checkmark$ & $\checkmark$ & $\checkmark$ & $\checkmark$ & $\checkmark$ \\
Monthly & NA & NA & $\checkmark$ & $\checkmark$ & $\checkmark$ & $\checkmark$ & $\checkmark$ & $\checkmark$ \\
\hline
\end{tabular}




\section{Results}

Recruitment declined to low levels between 2007 and 2010, and remained persistently low until 2017 (Figure 3-3, A). Mortality (Figure 3-3B) and density (Figure 3-3C) were the only two variables to show inverse trends. The climate variables did not show any such persistent trends over the sampling period.

Time series analysis of the climate data found significant departures from long-term seasonally adjusted trends (anomalies): unusually high sea surface temperatures in 2007 and low SST in 2010 corresponded to periods of high and low recruitment respectively. There is a mismatch between weather conditions attributed to climate indices and the weather recorded in Foveaux Strait, most of which was from the west or westerly quarter (Figure A-9 in the climate variables section in the Appendix). High recruitment occurred during negative M1 pressure index between 2006 and 2009 that should bring settled weather in northerly flows; however, the same conditions should occur during a positive anomaly for SOI3av in 2010 when recruitment was low. These conditions usually reduce upwelling off the west coast of the south Island; however, chlorophyll a between 2009 and 2011 was unexpectedly high.

Ranks and proxy effect sizes (defined as the individual variable percentages of all varimpAUC variable measures combined) from variable importance measures (VIMs) were robust to the numbers of trees generated and to negligible differences between the varimp and varimpAUC functions ( $\leq$ $0.01 \%)$. Density and mortality were the primary determinants of recruitment variability. These were followed (in order of rank) by: Southern Oscillation Index 3-monthly running means (SOI3av), wind speeds (WSpd), M1 sea-level pressure index, chlorophyll a (Chl), SOI, turbidity (Turb), numbers of days of severe gales (DSGales), Z2 sea-level pressure index, and sea surface temperature 
(SST) as the lowest rank (Table 3-2). Proxy effect sizes are shown in Table 32. Ranks without density, and without density and mortality did not change the importance of the top four climate variables: WSpd, M1, Chlav, and SOI3av (Table 3-2). 

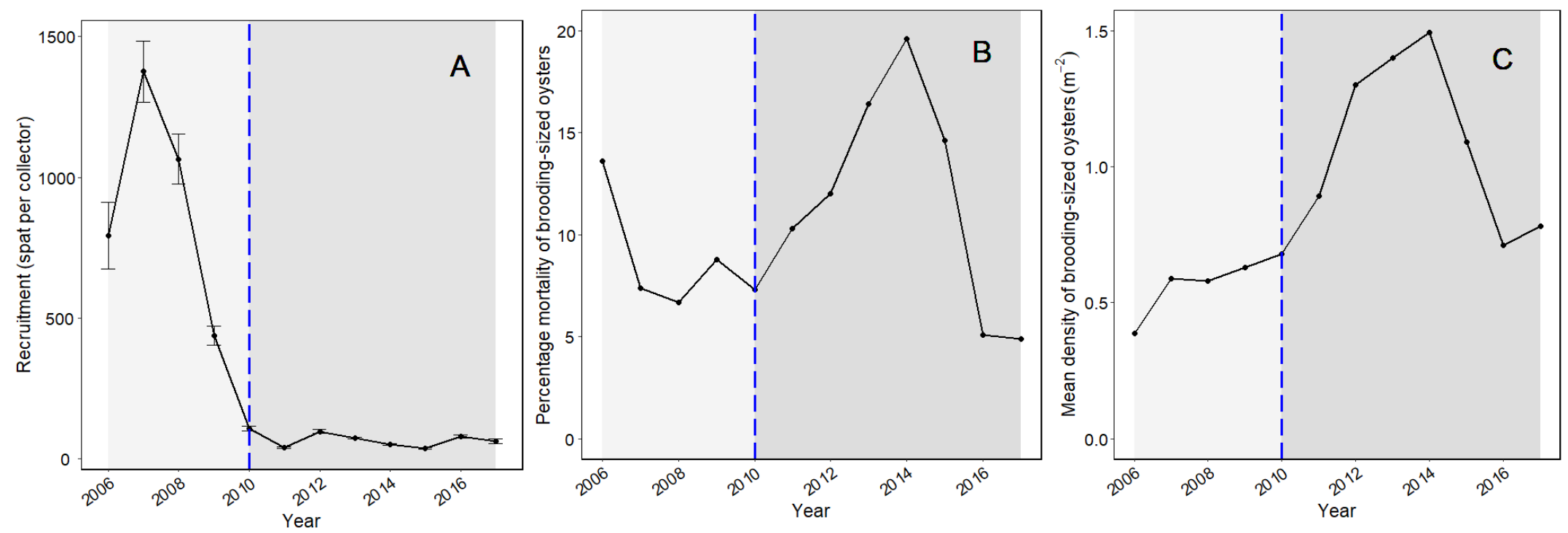

Figure 3-3. Mean recruitment (spat per collector) $\pm 95 \%$ CI for 2006-2017 by year (A), percentage mortality of brooding-sized oyster population by year $(B)$, mean density of brooders $\left(\mathrm{m}^{-2}\right)$ by year $(\mathrm{C})$. The light shaded region highlights the period of relatively high recruitment, while the dashed blue reference line shift to low recruitment in 2010 . The darker shaded region highlights a period of low recruitment. 
Table 3-2. Ranks of the relative variable importance for density, mortality and climate variables to predict recruitment using Cforest algorithm (Hothorn et al. 2005). Brooding-sized oyster density (Density), annual mortality from Bonamia exitiosa (Mortality), 3-monthly running means for Southern Oscillation Index (SOI3av), wind speed (WSpd), the difference in mean sea-level pressure between Hobart and the Chatham Islands (M1), mean chlorophyll a (Chl), Southern Oscillation Index (SOI), turbidity (Turb), the numbers of days of severe gales (DSGales), the difference in mean sea-level pressure between Christchurch and Campbell Island (Z2), and mean sea surface temperature (SSTav). Variable importance measure (VIM) and proxy for effect size (\% EF). Sensitivity analyses without Density (Var -1, VIM-1, and \%EF-1), and without Density and Mortality (Var -2, VIM-2, and \%EF-2). Cforest run with options cforest_unbiased(ntree $=\mathbf{8 0 0 0}, \mathbf{m t r y}=\mathbf{2}$ ), and function varimpAUC to compute variable importance measures as the area under the curve as a proxy for effect size. VIMs represent the effects of variables in both main effects and interactions.

\begin{tabular}{lrrrrrrrr}
\hline Variable & VIM & \%EF & Var-1 & VIM-1 & \%EF-1 & Var-2 & VIM-2 & \%EF-2 \\
\hline Density & 117299.3 & 38.1 & & & & & \\
Mortality & 65294.7 & 21.2 & Mortality & 144524.7 & 28.4 & & \\
SOI3av & 24023.4 & 7.8 & SOI3av & 65607.3 & 12.9 & WSpd & 95243.1 & 16.2 \\
WSpd & 17885.4 & 5.8 & WSpd & 53608.0 & 10.5 & M1 & 78086.9 & 13.3 \\
M1 & 15365.2 & 5.0 & M1 & 45363.3 & 8.9 & Chlav & 77478.8 & 13.2 \\
Chlav & 14630.4 & 4.8 & Chlav & 41481.1 & 8.2 & SOI3av & 72474.4 & 12.4 \\
SOI & 13298.6 & 4.3 & Turbav & 37686.0 & 7.4 & Turbav & 59210.4 & 10.1 \\
Turbav & 12295.8 & 4.0 & SOI & 37120.1 & 7.3 & DSGales & 56079.0 & 9.6 \\
DSGales & 10989.2 & 3.6 & DSGales & 30571.6 & 6.0 & SOI & 52069.8 & 8.9 \\
Z2 & 9347.5 & 3.0 & Z2 & 27936.0 & 5.5 & Z2 & 49890.5 & 8.5 \\
SSTav & 7487.8 & 2.4 & SSTav & 24858.0 & 4.9 & SSTav & 45923.0 & 7.8 \\
\hline
\end{tabular}




\section{Drivers of annual variability in recruitment}

Best-fit models of recruitment as functions of density, mortality, and climate variables showed mean, minima and maxima climate values generally differed little in their contribution to model deviance for any variable in any given phase. The best-fit model overall (Tables 3-3 \& 3-4) accounted for $68.6 \%$ of the deviance, which is analogous to an effect size in this context. The best-fit model suggests that brooder density and B. exitiosa mortality are likely to be the most significant factors contributing to variability in recruitment to the $O$. chilensis populations in Foveaux Strait. Two climatic variables were also significant in best-fit models (3-monthly running means for Southern Oscillation Index (SOI3av) and the difference in mean sea-level pressure between Hobart and the Chatham Islands (M1)); however, their effects did not contribute substantially to the variation in recruitment ( $<1 \%$ deviance). Variables were added in a stepwise iterative process in the order of their overall contribution to the model. This means that climatic variables and their interactions are unlikely to have been masked by the effects of density and mortality. On average, density $(\mathrm{p}<0.001, \mathrm{df}=3$, Deviance $=4184.7)$ and mortality $(\mathrm{p}<0.001, \mathrm{df}=3$, Deviance $=4123.1$ ) each accounted for $30 \%$ of the variation in recruitment in any given year. A significant two-way interaction between density and mortality ( $\mathrm{p}<$ 0.001, $\mathrm{df}=3$, Deviance $=1162.2$ ) accounted for a further $8 \%$ of the variation in recruitment. The climate variables SOI3av and M1 accounted for less than $1 \%$ of the best fit model deviance (Table 3-3).

The predicted response of recruitment to mortality (Figure 3-4) showed a rapid decline in recruitment above levels of $9 \%$ mortality. The increase in recruitment below this $9 \%$ threshold of mortality may reflect the 2-way interaction between mortality and density (Table 3-3) with the highest recruitment at times of low mortality and low density. Recruitment drops to low levels above a density of 0.5 oyster $\mathrm{m}^{-2}$ (Figure $3-5$ ). These results suggest 
substantial effects of density on the transmission and progression of disease and the effects of high intensity infections on reproductive success.

Recruitment modelled as functions of climate variables by reproductive phase (1-3), and with and without density and mortality showed chlorophyll a (Chl), sea surface temperature (SST), turbidity (Turb), and numbers of days of severe gales (DSGales) were significant climatic variables, although their contributions were minor, and their predictive plots showed poor fits to the data (plots not shown).

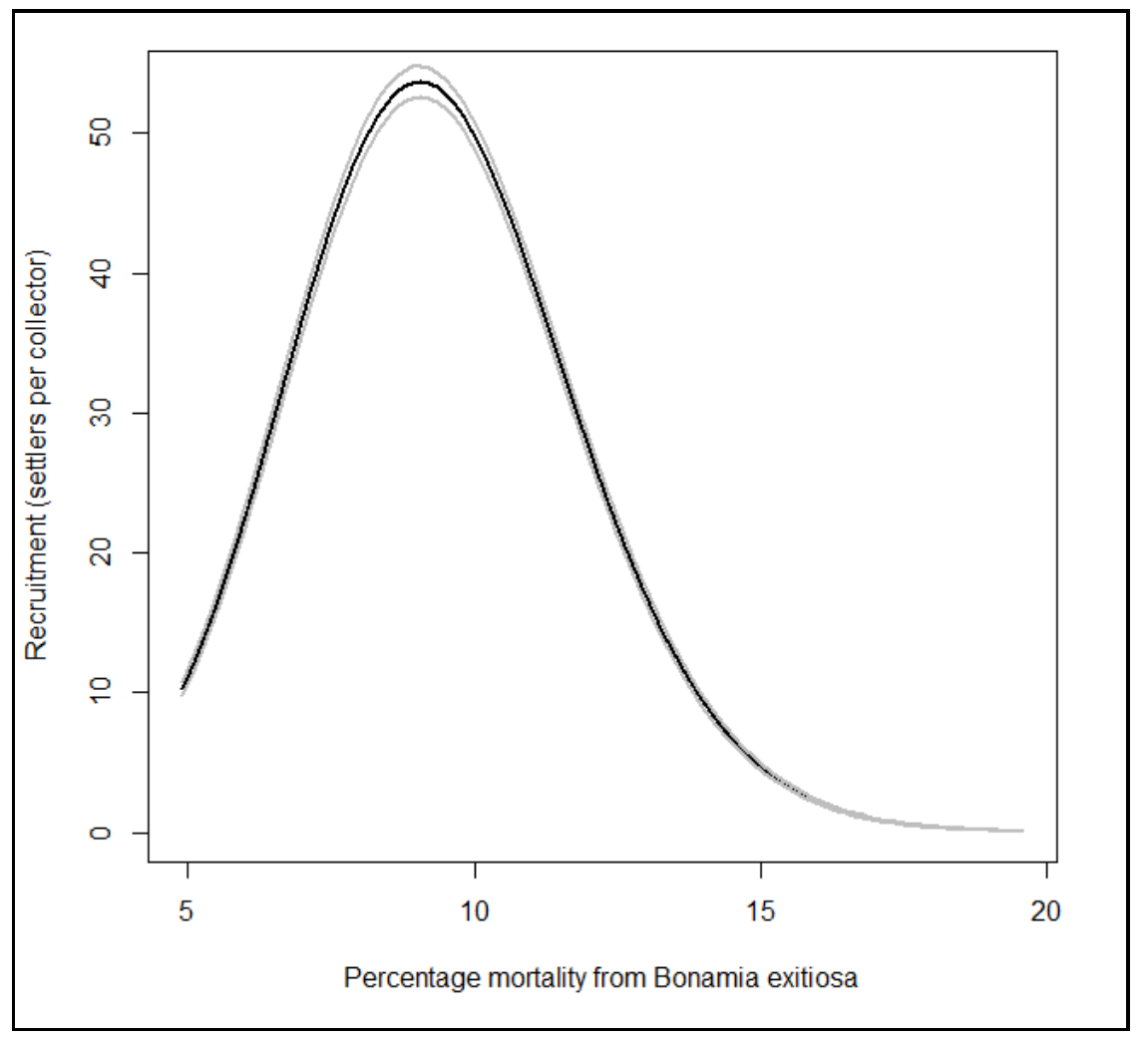

Figure 3-4. The predicted mean recruitment (black line) of $O$. chilensis in the Foveaux Strait fishery area and $95 \%$ CIs (grey lines) against mortality from time series data 2005-2017. 


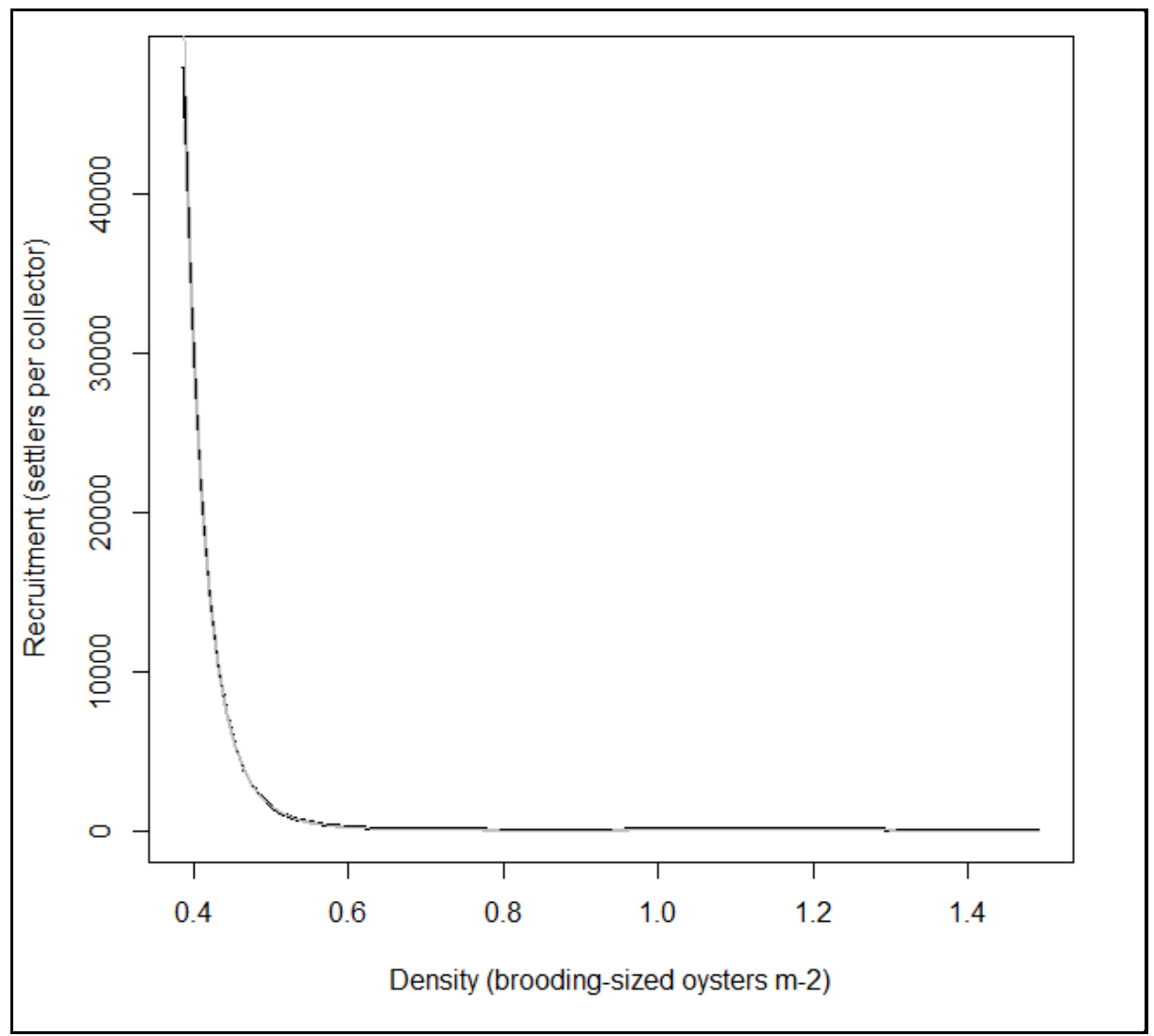

Figure 3-5. The predicted mean recruitment (black line) of $O$. chilensis in the Foveaux Strait fishery area and $95 \%$ CIs (grey lines) against density from time series data 2005-2017. 
Table 3-3. The best-fit negative binomial regression of annual variation in oyster recruitment across the Foveaux Strait fishery between 2006 and 2017. Recruitment was estimated from recruit densities and modelled as a function of brooding-sized oyster density (Density), annual mortality from Bonamia exitiosa (Mortality), 3-monthly running means for Southern Oscillation Index (SOI3av), and the difference in mean sea-level pressure between Hobart and the Chatham Islands (M1), and their interactions. Percentage deviance (\% Dev) and cumulative percentage deviance (Cum\% Dev) explained.

\begin{tabular}{|c|c|c|c|c|c|c|c|}
\hline & df & Deviance & Res. df & Res. deviance & $\mathbf{p}$ & \%Dev & Cum\%Dev \\
\hline & & & 3935 & 13932.2 & & & \\
\hline Density & 3 & 4184.7 & 3929 & 5624.4 & $<0.001$ & 30.0 & 30.0 \\
\hline Mortality & 3 & 4123.1 & 3932 & 9809.1 & $<0.001$ & 29.6 & 59.6 \\
\hline Mortality x Density & 4 & 1162.2 & 3923 & 4369.7 & $<0.001$ & 8.3 & 68.0 \\
\hline SOI3av & 1 & 71.5 & 3928 & 5552.9 & $<0.001$ & 0.5 & 68.5 \\
\hline M1 & 1 & 21 & 3927 & 5531.9 & $<0.001$ & 0.2 & 68.6 \\
\hline
\end{tabular}


Table 3-4. Annual variation in oyster recruitment across the Foveaux Strait fishery from 2006 to 2017. Oyster recruitment was modelled as a function of brooding-sized oyster density (Density), annual mortality from Bonamia exitiosa (Mortality), 3-monthly running means for Southern Oscillation Index (SOI3av), and the difference in mean sea-level pressure between Hobart and the Chatham Islands (M1), and their interactions. Density and mortality were modelled as first to third order polynomials, denoted (1)-(3) below. The best-fit negative binomial model statistics: Theta $=1.6254, \mathrm{SE}=0.0353, \mathrm{df}=3935$, log-likelihood $=$ 43919.54, and AIC = 43948. NS denotes not significant.

\begin{tabular}{lrrrr}
\hline Source of variation & Coefficient & SE & $\mathbf{Z}$ & $\mathbf{p}$ \\
\hline Intercept & 1.79 & 0.42 & 4.27 & $<0.001$ \\
Mortality (1) & -1004.00 & 117.00 & -8.58 & $<0.001$ \\
Mortality (2) & -149.60 & 24.83 & -6.03 & $<0.001$ \\
Mortality (3) & -187.70 & 17.81 & -10.54 & $<0.001$ \\
Density (1) & 616.20 & 80.33 & 7.67 & $<0.001$ \\
Density (2) & -18.87 & 17.40 & -1.09 & 0.278 \\
Density (3) & -247.20 & 38.31 & -6.45 & $<0.001$ \\
SOI3av & 0.00 & 0.03 & 0.02 & $\mathrm{NS}$ \\
M1 & 0.00 & 0.00 & 0.06 & $\mathrm{NS}$ \\
Mortality (1) x Density (1) & 13780.00 & 2064.00 & 6.67 & $<0.001$ \\
Mortality (2) x Density (1) & 41490.00 & 4982.00 & 8.33 & $<0.001$ \\
Mortality (3) x Density (1) & -2651.00 & 1051.00 & -2.52 & 0.012 \\
Mortality (1) x Density (2) & -9920.00 & 800.50 & -12.39 & $<0.001$ \\
\hline
\end{tabular}




\section{Discussion}

The highest recruitment occurred at times of low mortality and low oyster density. One explanation for this is reduced disease transmission at low density (Doonan et al. 1999), and potentially reduced effects of intense infections on recruitment processes at low oyster mortality. The best-fit negative binomial model was consistent with the variable importance measure ranks and the proxy effect sizes that included any interactions for key variables. These analyses were limited by the length and nature of time series data; they comprised a single cycle of recruitment from high to persistent low recruitment and these data met only the minimum requirement for analysis of climate time series data and drivers of recruitment variability. These limitations did not allow for key interactions between density, mortality and climate variables to be identified. Ranks and differences in proxy effect sizes (see Table 3-2) suggest interactions between climate variables and climate indices. The strength of inferences made from this research may be limited by the data; nonetheless, the analysis is highly informative and highlights particular areas that would benefit from the collection and analysis of more extensive climate, disease and recruitment data. These data show some support for the hypothesis that oyster density and mortality have an effect on oyster recruitment in Foveaux Strait.

The best-fit model suggests variation in annual recruitment to the Foveaux Strait oyster population is may be driven by oyster density and mortality (a proxy for intense infections during gametogenesis and spawning) and the interaction. Although data on the prevalence and intensity of pathogens present in co-infections and there physiological effects on the oyster host and specifically gametogenesis and spawning were not available, the interaction between oyster density and mortality suggests combined effects of Bonamia exitiosa and other pathogens on reproductive success. These findings are consistent with fishery data on changes in population size (Fu et al. 2016), oyster recruitment (Michael et al. 2001, 2018), with the pathology of B. exitiosa (Hine 
1991a, b), concurrent infections by one or more pathogens in O. chilensis (Diggles 2004) and their deleterious effects on reproductive success. High oyster densities in Foveaux Strait increase infection pressure and transmission of $B$. exitiosa (Doonan et al. 1994, Cranfield et al. 2005), which leads to higher prevalence and intensities of infection in the oyster fishery.

A mechanistic understanding of how density and mortality affect recruitment is beyond the scope of this research. However, the hypothesis informed by knowledge of diseases in O. chilensis in Foveaux Strait is proposed: namely, that recruitment to the Foveaux Strait oyster fishery since 1985 is driven by an interaction between oyster density and co-infection by one or more pathogens. This hypothesis is underpinned by fishery and disease data from Foveaux Strait. Firstly, the percentages of brooders and levels of recruitment differed markedly before and after the 1985 B. exitiosa epizootic (Doonan et al. 1994, Cranfield et al. 2005). Brooding percentages in oysters were 6\%-18\% in the 1960s and 1970s (Stead 1971a, Cranfield \& Allen 1977, Jeffs \& Hickman 2000) compared with 1-2\% in 1996-2000 (Bluff Oyster Enhancement Company data). Secondly, the effects of B. exitiosa infection or co-infections could be one explanation of these brooding differences. Thirdly, since 1985 rates of recruitment have been highest when oyster densities and mortality from $B$. exitios $a$ were lowest. There are three time periods in recently published research that support this: 1992/93 (Fu et al. 2016), 2005/06 (Michael et al. 2006), as well as in 2018 subsequent to this research (Michael et al. 2018). Furthermore, $B$. exitiosa was first detected in Foveaux Strait in 1964 (Hine \& Jones 1994) although there were no reports of disease mortality between 1964 and 1985 . Prolonged periods of low recruitment were unlikely over that time, and moderate to high levels of recruitment have been inferred by the consistently high catch rates and high and increasingly spawning-stock biomass at that time (see Figures $4 \& 7$, Fu et al. 2016). The hypothesis derived from this study assumes a link between recruitment and annual $B$. exitiosa mortality that occurs following 
gametogenesis and spawning being indicative of disruptive co-infections that disrupt gametogenesis and spawning, and reduce brooding and thereby larval supply.

One explanation for the differences in brooding pre and post the $1985 \mathrm{~B}$. exitiosa epizootic could be the disruption of gametogenesis by pathogenic coinfections. Jeffs \& Hickman (2000) found the same proportion of male and female oysters with phagocytosis of reproductive material by B. exitiosa in the 1970s, and Diggles \& Hine (2002) found higher levels in female gonads post 1985. Bonamia exitiosa mortality is used as a proxy for heightened prevalence of infection (the proportion of the population infected) and intensity of infection (parasite density in the host) by one or more pathogens during gametogenesis and spawning. An apicomplexan parasite (APX) and Bucephalus longicornutus individually or together can be co-infections with B. exitiosa. Although $B$. longicornutus generally occurs at low prevalence, and so even high intensity of infections results only in low mortalities (Hine \& Jones 1994), B. longicornutus can occur in high prevalence and cause high mortality $(\geq 40 \%)$, as it did in Foveaux Strait between 1958 and 1964 (Howell 1967). APX is widespread in this area. At high intensities of infection APX can affect reproduction in $O$. chilensis and may cause sterility (Steve Webb, Cawthron Institute, pers.com.). Oysters heavily infected with APX show disruption to reproduction; gonads have empty follicles that differ markedly from those in recently spawned oysters at a time that lacks coherence with spawning (Hine 2002). The pathology of APX infection is similar to that of Bonamiosis (disease caused by Bonamia spp.) (Hine 1997). B. exitiosa is present in the gonads of O. chilensis in Foveaux Strait all year round, albeit at low levels for most of the year (Hine 1991a). The oyster's response to infection places a high demand on its energy budget that may cause a reduction in, or complete cessation of gametogenesis (Diggles \& Hine 2002). The phagocytosis of ova by haemocytes containing B. exitiosa depletes lipid resources and so deprives the host of vital energy reserves as well as fuelling the 
rapid proliferation of B. exitiosa (Hine 1991b, a). Female and spent oysters are more likely to die from the intensifying infection than male and hermaphrodite oysters (Diggles \& Hine 2002), which suggests that the female gametogenic cycle is more likely to be disrupted. Although B. exitiosa does not directly parasitize viable gonads (Lane 2018), some studies have inferred a link between bonamiosis and disruption to the female gametogenic cycle in oysters. da Silva et al. (2009) found high to moderate intensities of B. ostreae infections in ripe, female $O$. edulis as well as in those with partially spawned and reabsorbing gonads, which suggests the intensification of infection by $B$. ostreae associated with female maturation before reabsorption of ova. Lacoste et al. (2001) described a potential mechanism for this that modulates the oyster haemocyte phagocytosis. Whether the increased energy demand to produce haemocytes to contain increasing infection also increases the levels of phagocytosis and reabsorption of ova (as a direct response to disease) is not known.

Co-infection by multiple pathogens is common in O. chilensis (Hine et al. 1986, Hine 1997, 2002, Joyce et al. 2015, Lane et al. 2016). There is, however, little information on how these pathogens interact with the host and with each other to intensify infections to fatal levels, or in the case of non-fatal infections, to reduce reproductive output. The interaction between oyster density and mortality shown by this research infer co-infections may be unidentified but significant driver of recruitment and population dynamics. Hine (2002) gives an example of co-infection by APX and B. exitiosa in O. chilensis. Although APX is not thought to cause high mortalities, its presence may increase the susceptibility of $O$. chilensis to $B$. exitiosa by denying the oyster energy to counter increasing B. exitiosa infections (Hine 2002). Additionally, $B$. longicornutus and B. exitiosa co-infection may have played a role in the 195864 mortalities of O. chilensis in Foveaux Strait (Howell 1967, Hine \& Jones 1994). B. longicornutus was initially identified as the cause of mortality although subsequent identification of $B$. exitiosa in preserved oyster tissues from that 
epizootic suggest that co-infection is more likely the cause of mortality (J.B. Jones, pers. comm.). It is not known whether APX was present in the fishery before 1985, and if it was not, whether co-infection with $B$. exitiosa could be an explanation for the recurrent oyster mortalities since 1985.

Little is known about the effects of non-fatal co-infections, how they may contribute to the intensification of disease, and their effects on reproduction. It is likely that concurrent, non-fatal infections disrupt reproduction. APX and $B$. longicornutus individually can cause gonadal castration. No confirmed mechanism of how B. exitiosa may disrupt gametogenesis has been identified. Non-fatal B. exitiosa infections that may disrupt gametogenesis and spawning increase in prevalence and intensity post-spawning, and are represented as heightened summer mortality in these data. Moreover, if the host is not killed by the intensification of infection, B. exitiosa may compete with the host and other pathogens (e.g. APX) for energy made available through the reabsorption of ova and compromise reproduction in the following cycle. In this study, the relatively high oyster mortality (> 9\%) from B. exitiosa resulted in reduced recruitment.

This research suggests that effective spread of infection and disruption to recruitment at a fishery spatial-scale may occur at 0.5 oysters $\mathrm{m}^{-2}$. Patchily distributed $O$. chilensis populations have waxed and waned in the same locations (Michael 2010). The 1985 B. exitiosa epizootic spread through the fishery in a wave of infection and mortality, as though through a naïve population (Cranfield et al. 2005). Doonan et al. (1999) estimated a threshold density of 1.26 recruitsized oysters $\mathrm{m}^{-2}$ triggered the 1985 epizootic and subsequent wave of mortality. Since then, patterns of infection and mortality have varied spatially and temporally through the fishery (Michael et al 2018). The transmission of $B$. exitiosa infection is oyster to oyster and density dependent. Oysters dying from B. exitiosa release $\sim 10^{6}$ infective particles that survive longer than 48 hours at normal summer temperatures in Foveaux Strait (Diggles \& Hine 2002). High mortality ( $20 \%$ of recruit-sized oysters $\mathrm{y}^{-1}$ ) produces high infection pressure 
caused by the release of substantial numbers of infective particles that are dispersed by rapid tidal flows. Diggles \& Hine (2002) experimentally determined the $50 \%$ lethal dose of $1.12 \times 10^{5}$. The spread of mortality in 1985 was slow $\left(\sim 5 \mathrm{~km} \cdot \mathrm{y}^{-1}\right)$ and $B$. exitiosa took $4-5$ years to spread through the relatively small Foveaux Strait fishery area (Cranfield et al. 2005). High prevalence of infection may persist in oyster patches for 2-3 years (Cranfield et al. 2005), suggesting that infections may take some time to intensify to fatal infections. Any effects of non-fatal infections on spawning and recruitment may persist at fishery spatial -scale for some years.

Climate variables affect host physiology (Engelsma et al. 2010), recruitment processes (Hjort 1914, Canning 2013, Joyce et al. 2013, Robert et al. 2017), and intensification of disease and host mortality (Hine et al. 2002, Arzul et al. 2009, Engelsma et al. 2010, Rowley et al. 2014). Because of the limitations of the data used in this study, the analysis may have underestimated the contributions of climate variables and their important interactions. Ranks of climate variables (see Table 3-2) suggests that food availability (shown be threemonthly average southern oscillation index and chlorophyll a) and the ability of $O$. chilensis to feed (inferred storms from wind speed indices) were more important to recruitment than sea surface temperature (the lowest ranked variable). Food availability (Chlorophyll a) is not likely to be limited. The climate variables: three-monthly average southern oscillation index (SOI3av), southern oscillation index (SOI), wind speed (WSpd), and numbers of days of severe gales (DSGales) from the westerly quarter and the Z2 sea surface pressure index all contribute to offshore upwelling west of Foveaux Strait. These conditions increase primary production, and the transport of plankton blooms into Foveaux Strait (Bradford et al. 1991, Butler et al. 1992, Hurst et al. 2012). Large oceanic swells and high wind-driven currents generated by storms also move sediments in Foveaux Strait (Carter \& Lewis 1995, Stanton et al. 2001, Walters et al. 2001, Hemer 2006). The burial of oysters in coarse calcareous sand 
may affect their ability to feed, thereby reduce energy available to recruitment processes, and increase physiological stress and susceptibility to disease. In this research, the complex high-level interactions between recruitment and climate, and climate effects on food supply, ability to feed, as well as estimating a threshold above which individuals cannot utilise high concentrations of food (Joyce et al. 2015) could not be resolved. Food supply (phytoplankton) can vary dramatically and can play an important role in the timing and success of spawning, larval survival and settlement in O. chilensis (Chaparro 1990), and the ability to tolerate infection.

No significant effects of sea surface temperature (SST) on recruitment were detected in this research, although other research has shown temperature to be important to spawning, brooding and settlement processes. The female gonadal cycle advances quicker in O. edulis in cooler water (Joyce 2013), and O. chilensis larvae from the cooler waters of Foveaux Strait are larger than those in Tasman Bay (central New Zealand) (Cranfield \& Michael 1989), and almost twice the size of hatchery produced larvae (Joyce et al. 2015). These studies suggests that SST may affect spawning, brooding, and settlement success and thereby recruitment; however, these effects were not detected in this study.

The same climatic and environmental factors that may stress oysters and affect recruitment may also intensify disease (Rowley et al. 2014, Adlard et al. 2015), and may thereby contribute to low recruitment. Inundation by sediments during storm events, and fishing effects (Vanbanning 1991, Cranfield et al. 1999, Cranfield et al. 2005) may play critical roles in physiological stress and disease. Increased water temperatures and mechanical disturbance in laboratory experiments increased the intensity of infection by $B$ exitiosa (Diggles \& Hine 2002). Recent outbreaks of B. exitiosa $(1985,1999$, and 2013) may be in part linked to strong El Nino events producing cooler temperatures and more gales. 
The putative effect of $B$. exitiosa and other pathogens on recruitment represent a shift in productivity of the Foveaux Strait oyster fishery. Recurrent epizootics from B. exitiosa since 1985 (Ministry for Primary Industries 2017) have caused significant losses to the recruited population and revenue to the fishery. This research suggests that these epizootics have reduced the ability of the $O$. chilensis population to rebuild. Commercial fishers rely on high-density patches of oysters to maintain economic catch rates (Hill et al. 2010). Any shift in productivity with high-density patches of oysters suffering recurrent high mortality and reduced recruitment will require new, collaborative fishing strategies to minimise the effects of disease, maintain sustainability, and maximise harvests and revenue.

Oysters play important roles in ecosystems and provide for important commercial, recreational and indigenous fisheries. This research suggests that shellfish pathogens may be an unrecognised determinant of variation in recruitment as well as mortality. Little is known about the communities of pathogens within host and host populations (pathobiomes) and whether and how they may affect population dynamics (Vayssier-Taussat et al. 2014, Stentiford et al. 2017, Sweet \& Bulling 2017). At a fishery scale, the marked reduction in recruits-per-spawner because of disease has important implications for stock assessment and management of fisheries. These fisheries mostly rely on stockrecruitment relationships. Reduced reproductive output and mortality also has important implications for the enhancement of wild invertebrate populations (such as $C$. virginica, Schulte et al. 2009) in habitats where pathogens may be present. For nearshore populations, anthropogenic effects of sedimentation and pollution together with increasing climate variability and climate change will increase the frequency and severity of disease events (Rowley et al. 2014). The integration of disease in population models in the way proposed by (Powell \& Hofmann 2015) that capture both mortality and recruitment effects of pathogens on population dynamics would greatly improve management of fisheries. 
This research suggest that disease not only causes declines in population size and spawner densities, but may also reduce recruitment through the disruption of gametogenesis and spawning, reduce brooding and thereby reduced recruitment. The high-level effects of climate on recruitment and disease are well known; however, little is known about the interactions between climate, pathobiomes and spawner density and how they may affect recruitment. Future research should include the prevalence and intensity of pathogens present in coinfections and their physiological effects on the oyster host and specifically gametogenesis and spawning. A mechanistic understanding of these interactions requires an extended time series data to inform the development of integrated recruitment models. 


\section{Chapter 4 : Dispersal and mixing of Ostrea chilensis larvae}

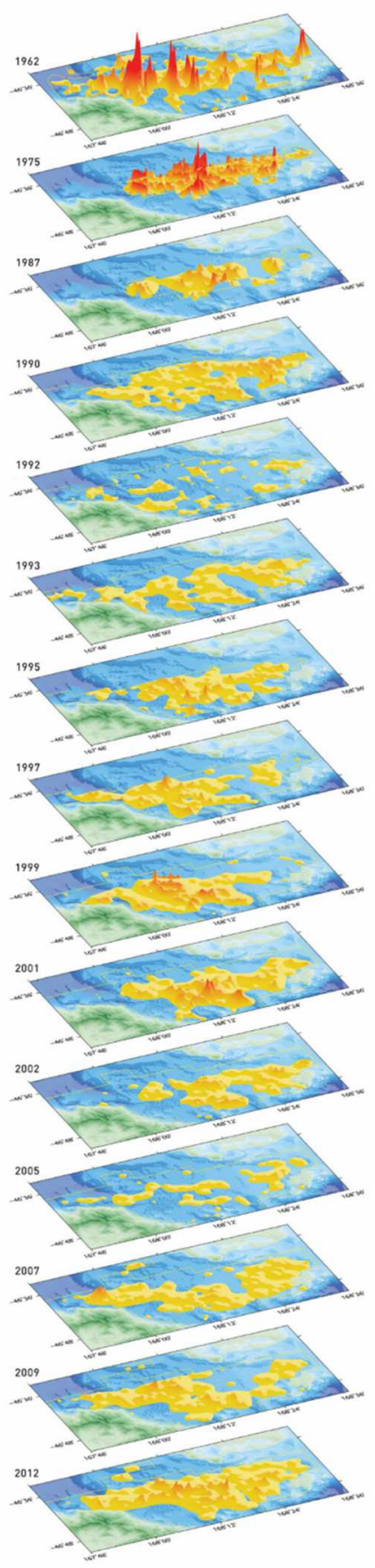

The distribution of $O$. chilensis in Foveaux Strait from dredge surveys 1962-2012. The demographics and biology of oysters suggests the fishery comprises localised, self-recruiting populations that have persisted in the same locations after high disease mortality from Bonamia exitiosa and periodic high levels of fishing. Image by Erika Mackay. 


\begin{abstract}
The Foveaux Strait oyster (Ostrea chilensis) fishery in southern New Zealand comprises many localised populations (oyster beds) that have survived 150 years of fishing and disease mortality. The reproductive biology of $O$. chilensis underlies the assumption that these populations are self-recruiting. Passive, artificial collectors deployed in a gradient design around an isolated natal population in a three-year study investigated the hypothesis of selfrecruitment. Patterns of recruits settling on collectors, a proxy for the distributions of competent larvae in the plankton, were used to describe putative dispersal. This research also investigated the relationship between recruits and brooder densities. Recruit densities were not predicted by distance from the natal-population both along and across the current, or by brooder densities. Settlement was widespread, and patterns of settlement imply greater dispersal and larval mixing than previously reported. The swift currents, and the possibility of a more variable pelagic larval duration may enhance mixing and connectivity between populations. Recruitment to mostly demographically open populations should provide some resilience to disease mortality and fishing.
\end{abstract}




\section{Introduction}

Oysters (Ostreidae, Rafinesque 1815) occur globally over a wide range of habitats. They structure benthic communities and provide ecosystem services (Coen et al. 1999, Gutierrez et al. 2003, Ruesink et al. 2005, Grabowski \& Peterson 2007, Grabowski et al. 2012). In New Zealand and internationally, oysters also comprise highly valued fisheries (Ministry for Primary Industries 2017). Worldwide, oyster reefs and fisheries are depleted (Beck et al. 2011, Alleway \& Connell 2015). Several restoration strategies have been implemented to rebuild oyster populations (Coen et al.2007, Schulte et al. 2009, Brown 2011, La Peyre et al. 2014, Zacherl et al. 2015). Knowledge of recruitment and the complex processes that regulate marine populations is fundamental the success of these restoration strategies, and to the conservation and management of oysters, and the benthic communities they are a part of. The spatial extent of dispersal and connectivity delineate population boundaries and therefore management units. This knowledge underpins models used to inform fisheries stock assessments (Hilborn et al. 2005), restoration strategies (Broekhuizen et al. 2011), and the design of marine reserve networks (Gaines et al. 2010, Puckett et al. 2014).

Recruitment - the addition of new individuals to localised populations is spatially and temporally variable. Three fundamental stages contribute to this variation: pre-settlement (spawning and brooding success, larval dispersal and survival), settlement (completion of metamorphosis on substrata), and postsettlement (recruit survival and growth). Discussion of these stages can be found in (Cowen \& Sponaugle 2009), (Shima et al. 2008), and (Hixon et al. 2012) respectively. The relative importance of these stages to recruitment success varies over space and time (Sale \& Kritzer 2003), and both between and within marine species (Jones \& Ricciardi 2014, Shima et al. 2015). There are a number of flow-on effects between these stages, which makes an understanding of presettlement, larval dispersal and connectivity fundamental to understanding 
recruitment. Sufficiently high spawning stock biomass (Beverton \& Holt 1957), spawner densities (Mendo et al. 2014), and favourable climatic and biological conditions are essential for larval production, large larval cohorts, and the potential for effective dispersal (Paris et al. 2007, Puckett et al. 2014). Biophysical factors determine larval transport, dispersal and retention of larvae. The time larvae spend in the plankton (pelagic larval duration), is often used as an indicator of the potential for dispersal. Larval traits such as large ova size and the absence of a feeding stage (lecithotrophy) suggest putative short pelagic larval durations (Levin 2006). A number of factors determine how many larvae disperse and how far they go. These include the pelagic larval duration, larval growth and survival, the initial size of larval cohorts and their fitness (Pineda et al. 2007). This fitness is likely to be dependent on maternal provisioning in lecithotropic larvae. Larval behaviour and their sensory abilities can play important roles in dispersal e.g. competent $C$. virginica larvae swam upward in highly turbulent flows (Wheeler et al. 2013), and Ostrea lurida using this vertical migration to access different flows in stratified water masses (Peteiro \& Shanks 2015), larvae altered bouyancy to facilitate settlement to suitable substrata (Hubbard \& Reidenbach 2015). These factors are especially relevant to the retention of larvae within natal populations (Sponaugle et al. 2002, Shanks et al. 2003, Levin 2006, Pineda et al. 2007, Broekhuizen et al. 2011). The direction and speed of current flows at the point where larvae are released, often influenced by wind speed and direction in coastal areas, determines larval transport (Puckett et al. 2014). How long larvae spend in the plankton may also determine how far they travel (Pineda et al. 2007).

High densities of Ostrea chilensis (Philippi, 1844) between the South Island and Stewart Island in southern New Zealand comprise the Foveaux Strait oyster fishery (Figure 4-1). O. chilensis (hereafter: oyster) in Foveaux Strait exhibits the extreme end of brooding strategies in Ostreinae; larvae develop in broods until fully competent and settle almost immediately (Cranfield 1979, 
Westerskov 1980). Moreover, Foveaux Strait represents an extreme in oyster habitat with a deep 20-50 m sand and gravel substrate, large oceanic swells and swift tidal currents. The demographics and biology of this population suggests the fishery comprises localised populations suspected to be self-recruiting (Allen 1979, Cranfield 1979). This research defines self-recruitment as the settlement of larvae to their natal population (Jones et al. 1999). That is, a demographically closed population based on the putative short pelagic larval duration and almost immediate settlement of $O$. chilensis (Cranfield 1979, Cranfield \& Michael 1989).

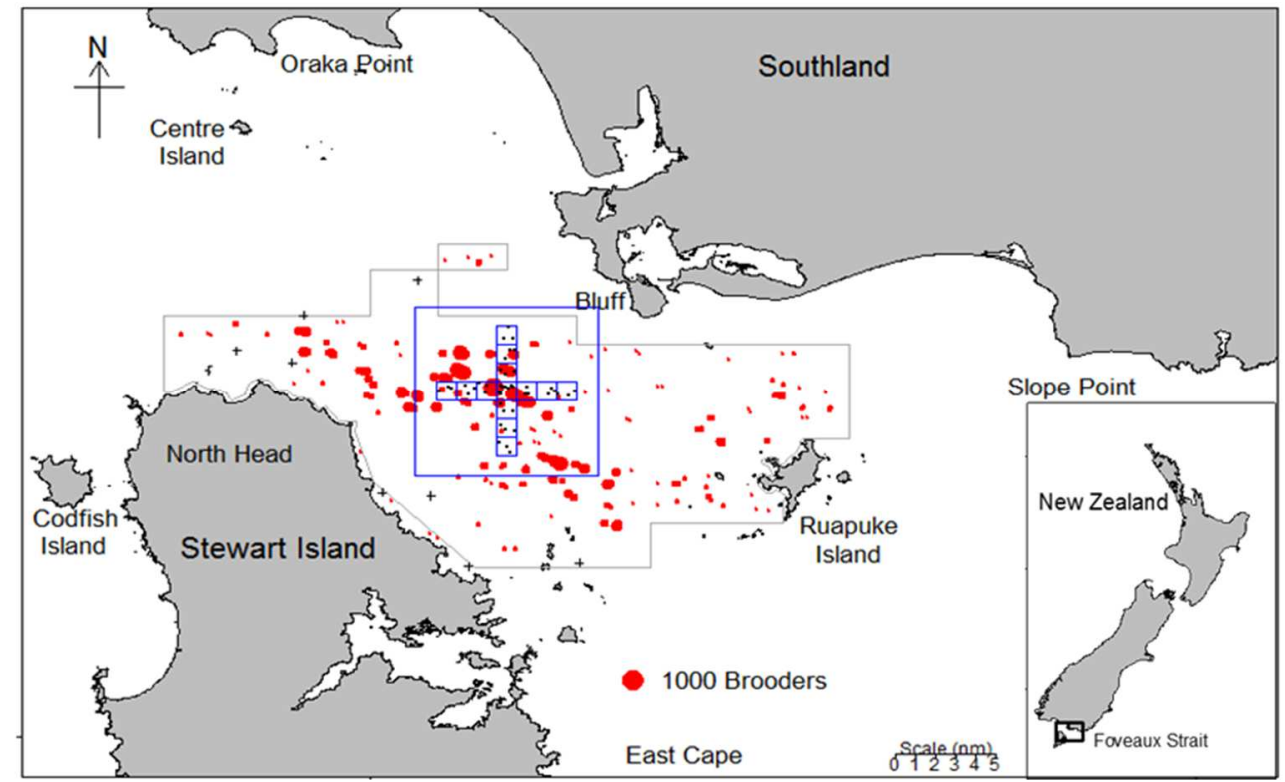

Figure 4-1. Foveaux Strait, southern New Zealand. Grey lines show the 2007 stock assessment survey area. The gradient design comprised four axes (North, East, South, and West), with the central cell encompassing the focal population; area boundaries shown in blue. Three, one nautical mile square cells extend along each axis (blue squares). Red filled circles scaled to brooder densities. Three randomly assigned spat collectors in each cell and nine collectors in the central cell encompassing the focal-population shown as black points.

Spatio-temporal variability in the availability of competent larvae contributes to local patchiness in recruitment in many marine populations. Localised populations of oysters have persisted in the same locations in Foveaux Strait after high disease mortality (Doonan et al. 1994, Cranfield et al. 2005) and 
periodic, high levels of fishing (Michael et al. 2008c). Whether the oyster populations are demographically closed (self-recruitment), demographically open (dispersal to distant populations, i.e., in Foveaux Strait, connectivity among spatially separated high density patches), or some proportion of open and closed (Jones et al. 2009) is the focus of this research. Temporal patterns in the distribution of competent larvae will help determine whether the stock comprises a metapopulation (Sale \& Kritzer 2003) or a number of self-recruiting localised populations. Self-recruitment tends to reduce resilience; given the high mortalities experienced by localised populations of oysters, an increased risk of serial depletion may therefore be expected.

Field studies of larval dispersal and connectivity are difficult. The small larvae from discrete and localised spawning events are difficult to identify and track to settlement. Moreover, the abundance of larvae from spawning events and larval mortality in the plankton are difficult to estimate. Probabilistic dispersal kernels (Siegel et al. 2003, Chiswell 2012) and deterministic models (Broekhuizen et al. 2011, Nicolle et al. 2013, Thomas et al. 2014, Smyth et al. 2016) estimate how far larvae of species with pelagic larval durations of days and weeks and with distributions over large geographical ranges disperse. Some models incorporate assumptions about larval behaviour and movement, larval mortality rates and information on physical processes. However, these models generally do not capture the complexity and variation in drivers of local transport and larval survival over relatively small spatial-scales. As a result, they may not predict dispersal and recruitment well (Wasson et al. 2016). These models are also unable to predict whether larvae survive settlement. Few models incorporate observed measures of dispersal to validate model predictions (Gawarkiewicz et al. 2007, Puckett et al. 2014). Arnold et al. (2017) showed some inconsistencies between modelled and sampled recruitment of Crassostrea virginica, model outcomes were not validated by field sampling. Reliable predictions of dispersal and connectivity in $O$. chilensis larvae would require information of the 
demographics of the localised-populations and data on the location, timing and duration of larval release relative to hydrographical features - these data were not available for $O$. chilensis in Foveaux Strait for this study. For further discussion on larval dispersal, see reviews by Levin (2006), Pineda et al. (2007), and Kool et al. (2013).

The relatively small area of the Foveaux Strait fishery and the uncertainty about the spatial-temporal variation in pelagic larval duration (Hollis 1962, 1963, Cranfield \& Michael 1989) have led to this study. Data on factors that influence dispersal in Foveaux Strait oysters are scant. This three-year field study evaluates the potential for larval dispersal and connectivity amongst localised populations of oysters in Foveaux Strait in order to test the hypothesis of self-recruitment. This research has two objectives. The first objective is to describe the distribution of oyster recruits on passive artificial collectors around a putative, localised natal population (focal-population). Recruit densities represent the availability of competent oyster larvae in the plankton that settle within minutes to hours after release (Cranfield 1979, Westerskov 1980). This knowledge underpins the hypothesis that most dispersal events will occur over short distances and self-recruitment is likely to be high i.e., recruit densities distributed tightly around the focal-population. Alternatively, widespread distribution of recruits implies larval mixing, and therefore some connectivity amongst distant populations, and be evidence against mostly self-recruiting populations.

Previous studies used the relationship between recruits and brooder density to infer Ostrea dispersal was limited and populations demographically closed (Cranfield 1968a, Brown 2011, Pritchard et al. 2015). The second objective evaluates this relationship between brooder densities and recruit densities as evidence for self-recruitment. The hypothesis of self-recruitment has an expectation of almost immediate settlement of competent larvae around the focal-population. A high correlation between brooders and recruit densities may 
imply self-recruitment, while no correlation could imply dispersal beyond the natal populations. This research also describes the consistency in the interannual distributions of recruit densities as many factors can influence larval dispersal. Evidence for mostly demographically open populations with larval mixing in Foveaux Strait has implications for resilience in localised oyster populations to the high disease mortality and fishing, and therefore their management.

\section{Methods}

Oyster distribution in Foveaux Strait is patchy with oysters concentrated in a smaller region of the managed area, the 2007 stock assessment area (see Figure 4-1). Management of the fishery assumes a single stock for convenience (OYU 5, Ministry for Primary Industries 2017) even though, Allen \& Cranfield (1979) suggest that this fishery is instead comprised of approximately 50 discrete, dense localised populations ( $>4$ nautical miles apart) that separated by extensive areas with low oyster densities. Stead (1971b) has suggested a higher number of populations within this area.

The larval biology of $O$. chilensis has given rise to the hypothesis that these localised populations self-recruit in Foveaux Strait (Cranfield 1968a, Cranfield 1979, Cranfield \& Michael 1989) and in Tasman Bay, New Zealand (Broekhuizen et al. 2011). O. chilensis is larviparous (Cranfield 1979) and in Foveaux Strait, up to $12 \%$ of the oyster population (c. $60 \mathrm{~mm}$ in length), brood larvae to pediveliger that are fully competent and can settle immediately on release (Hollis 1962, 1963, Stead 1971a, Jeffs \& Hickman 2000). These large, lecithotropic larvae have limited dispersal potential that should enhance selfrecruitment. A presumption of a very short pelagic larval duration underpins an expectation of mostly rapid settlement in O. chilensis, and thereby limited opportunity for larval transport and dispersal. Laboratory experiments suggest that most settlement occurs within hours (Stead 1971a, Brown 2011), while field 
experiments suggest that settlement occurs immediately around natal populations (Cranfield 1968a). O. chilensis larvae are poor swimmers (Stead 1971a), remain near the seabed (benthopelagic) in strong current conditions, and are phototaxic (Cranfield 1968b). Almost all settlement in Foveaux Strait oysters occurs between November and February (see Chapter 2 and Cranfield 1979).

The swift currents in Foveaux Strait could enable greater dispersal of $O$. chilensis larvae than predicted by Cranfield (1968a), Broekhuizen et al. (2011) and Brown (2011). Current speeds of 1.0-2.2 knots measured close to the sampling site in 1993 and 1998 flowed along an east-southeast west-northwest axis. Currents in Foveaux Strait may flow north for a time in strong southerly winds and vice versa (Mark Hadfield, NIWA, pers. comm.). The displacement of water mass in a single direction in normal flow is c. $13 \mathrm{~km}$. Net displacement of water mass is $2.5 \mathrm{~km} \mathrm{~d}^{-1}$ to the east (Steve Chiswell, NIWA, pers. comm.). The residence time of a water mass in the 2007 stock assessment area is 5 to 20 days (Cranfield \& Michael 1989).

A localised, focal-population was identified from research surveys 20092011 (Michael et al. 2009b, Michael et al. 2011, Michael et al. 2012a) (Figure 4-2), supplemented with annual catch data from fishers' logbooks (Figure 4-3) and oyster skipper interviews. The putative high brooder density in the focal population was spatially isolated from neighbouring populations by a surrounding area of low brooder density (Figures 4-2 \& 4-3), and by about 5 $\mathrm{km}$ between populations. 


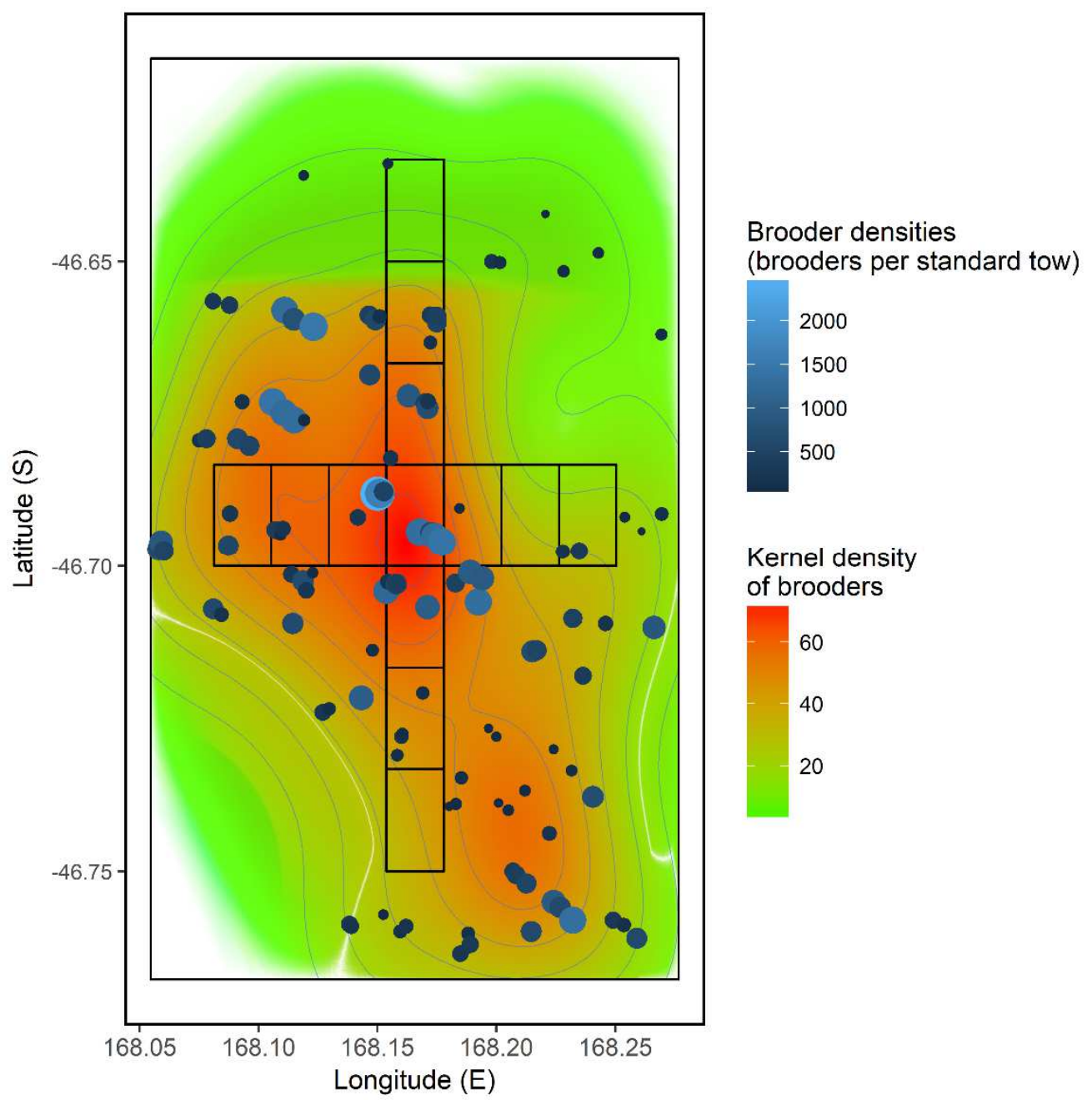

Figure 4-2. Kernel densities of brooders ( $\geq 60 \mathrm{~mm}$ in length) within the research area (Foveaux Strait, southern New Zealand) from dredge sampling during February surveys 2009-2011 (Michael et al. 2009; Michael et al. 2011; Michael et al. 2012). Cell boundaries shown as black rectangles. Brooders scaled to density at sample locations shown as filled blue circles. 


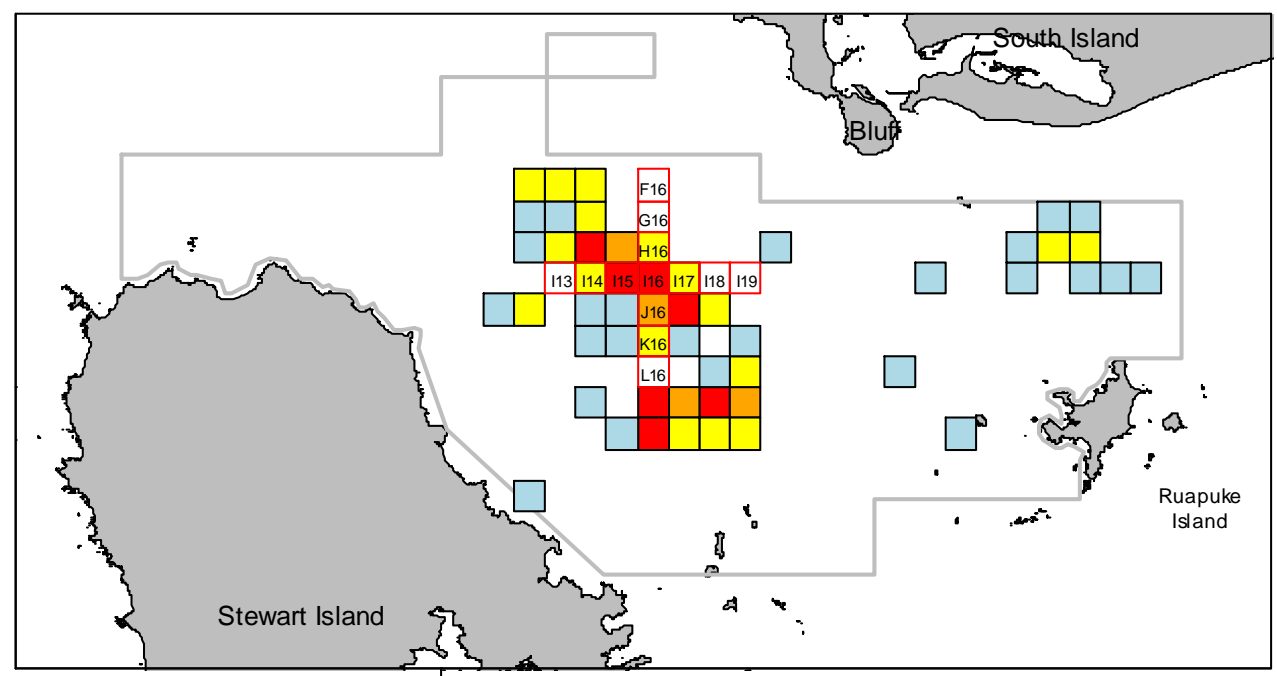

Figure 4-3. The percentage annual commercial catch of oysters (Ostrea chilensis) by reporting area, from skippers' 2011 season (1 March to 31 August, Michael 2012) logbooks. Percentage of the total annual catch shown as 5-10\% (red), 34.9\% (orange), 1-2.9\% (yellow), and $<1 \%$ (light blue). The white background represents cells where no fishing took place. Reporting cell labels for the cells that comprise the sampling design shown in black text. The sampling grid shown as red lines.

Sampling followed a gradient design because it was likely to be more sensitive in detecting dispersal from a point source (Ellis \& Schneider 1997). The gradient design is similar to the Helix design used by Sammarco \& Andrews (1989) to investigate differential localised dispersal and recruitment patterns in Great Barrier Reef corals. The Foveaux Strait oyster logbook reporting cells (one nautical mile squares) formed the basis for the sampling design (see Michael et al. 2012b). A central cell encompassed the focal-population (see Figure 4-2). Four axes orientated north, east, south, and west each extended three cells from the central cell (see Figure 4-2). Nine collector sites were randomly allocated to the central cell, and three sites to each of the three cells extending in each direction ( $\mathrm{n}=45$ per year). Collector locations remained fixed for the three years of sampling. Outside the sampling area, relatively high densities of brooders were present some distance across tide and to the north of the western axis (see Figure 4-3). 
O. chilensis competent larvae readily settle on manmade substrates without conditioning and in the absence of conspecifics (see Chapter 2). Sampling of recruits and estimates of recruitment used the same methods and passive spat collectors with cement board plates as detailed in Chapter 2. The collectors were deployed over three years (2011-12 to 2013-14) during the austral spring and summer (November to February). Recruitment to each collector is the cumulative number of recruits on any plate surface (top or bottom) of any of the four plates of a given collector. Because this research focus was on recruitment before post-settlement mortality, recruitment was estimated as the total number of both living and dead recruits on plates $(>92 \%$ of oysters were alive at the time of recovery; dead oysters leave a record of their size at death). At the end of the study (February 2014), brooder densities at each collector location were estimated using standard dredge sampling procedures for Foveaux Strait oyster surveys (see the estimates of spawner densities section in the Appendix for details, also Michael et al. 2017b). Estimates of recruitment were standardized to a $122 \mathrm{~d}$ sampling period for each season.

The timing of settlement peaks may vary from year to year. Comparison of recruit percentage length frequency distributions of live $O$. chilensis ensured sampling reliably captured peak settlement in each year. Oyster shell lengths (the greatest distance along the anterior-posterior axis), were measured to the lower whole millimetre.

Recruit densities are shown as points independent of distance along the four axes and within the focal-population, and with mirrored probabilities for the range of recruit densities observed (shaded areas) using violin plots in the ggplot2 package (Wickham 2009) in R Core Team (2016). Violin plots scale the probabilities for a given density by the highest recruit density observed along each respective axis. Interannual differences, reported as differences in the mean numbers of recruits, are used evaluate larval cohort sizes. 
The distribution of recruit densities around the focal-population may reflect the potential for mixing of larvae with neighbouring populations. Recruit densities (Recruits) modelled as a function of factors that represent distances and directions from the boundaries of the focal-population as indicators of the dispersal of competent larvae, both along and across current. Axis (Ax) represents the direction of settlement (West, East, North, and South) from the focal-population. Current Axis $(\mathrm{Cx})$ denotes either an along or across tidal current orientation, combining data from West and East (along current), and North and South axes (across current). Distance (D) is a measure from the boundary of the focal population (central cell) to the fixed spat collector locations. Year (Yr) is also a factor as interannual larval abundance can vary considerably at a fishery-wide scale independent to brooder density in some years (see Chapters 2 and 3). The 45 collectors deployed each year represent a balanced sampling design of nine collectors per $A x$ and nine in the central cell encompassing the focal-population. The sample size for analysis $(n=134$, as one collector was lost) is small. Negative binomial regression has preferable performance with relatively small sample sizes and for over-dispersed count data such as these recruit data (Gardner et al. 1995, Robinson \& Smyth 2008). The glm.nb function of the MASS package (Venables \& Ripley 2002) in R, with a log link function described the relationship between recruit densities and predictor variables. Multiple models used subsets of predictor variables and their interactions rather than a single model of all predictor variables because of the relatively small sample size. With non-significant factors and interactions removed, Akaike Information Criterion (AIC) (Akaike 1973) used to select the best-fit models (Table 4-1). Where AICs were similar between models, the percentage deviance explained (a measure of effect size, analogous to a variance component) decided the best-fit model. The graphical methods of Zuur et al. (2010) used to evaluate the best-fit models and their compliance with statistical assumptions. Recruits were also modelled as a function of brooders and Ax using 
glm.nb, modelling brooders as first to third order polynomials that provided increased flexibility to better fit to the data (Ver Hoef \& Boveng 2007).

\section{Results}

Sampling extended over peak settlement periods in each of the three years. The percentage length frequencies of recruits comprised unimodal, normal distributions with similar modes. Importantly, diminishing percentages of small recruits show that settlement declined by the end of each sampling period (Figure 4-4). Two of these years (2012-13 and 2013-14) show a small percentage of recruits were of large size (Figure 4-4). Allowing for some variability in growth, these larvae most likely settled early before the main settlement period.

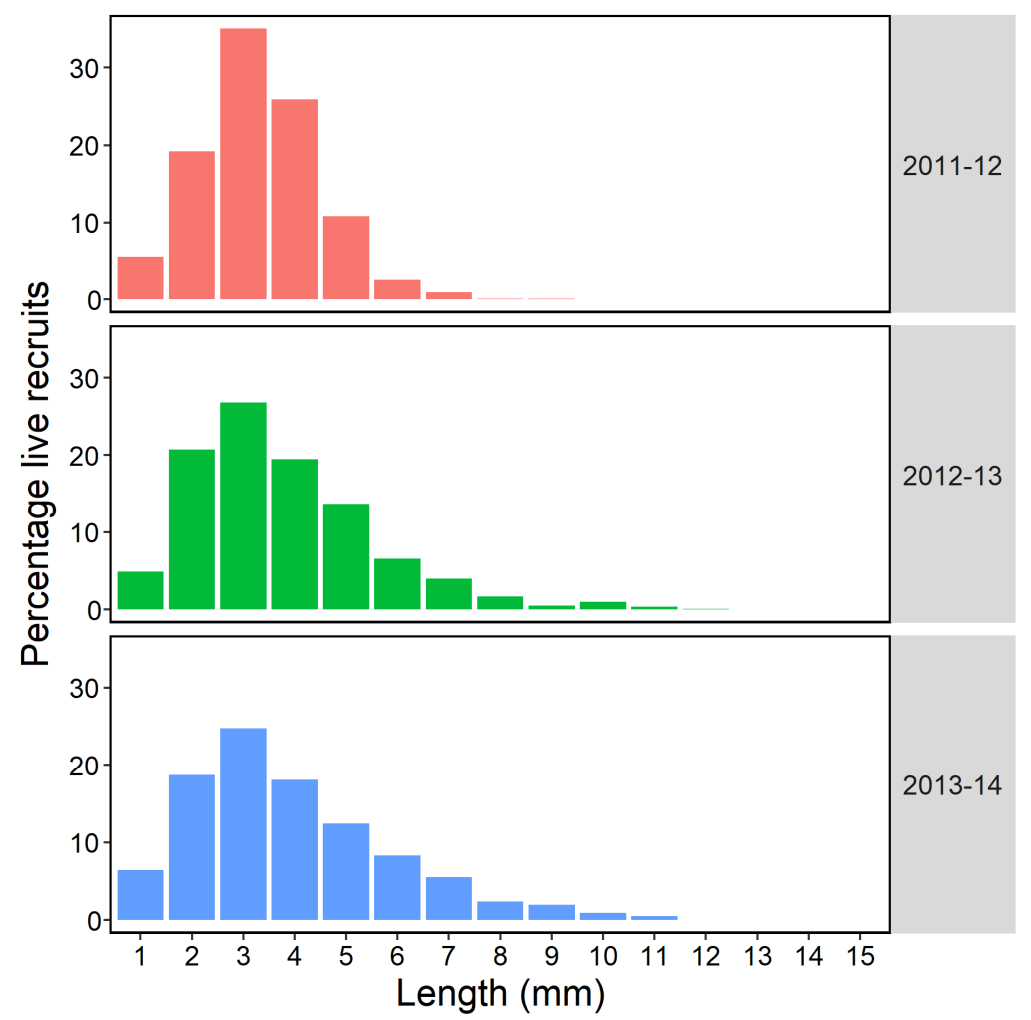

Figure 4-4. The percentage length frequencies of live $O$. chilensis recruits. Spat collectors sampled during the summers (November to February) from 2011-12 to 2013-14. 
Recruit densities declined significantly between 2011-12 and 2013-14 $(50.3 \%, \mathrm{P}=<0.003$, d.f. $=2$, Deviance $=11.358$ and see Table $4-2$ and Figure 4-5). There were increasingly fewer numbers of high recruit densities over the study period (Figure 4-6). Most sample sites received between 50 and 100 recruits per collector $\left(203-406 \mathrm{~m}^{-2}\right)$, irrespective of the distance or direction from the focal-population. For a given year, violin plots show similar probability distributions for the numbers of recruits (independent of distance), between the focal-population and the four axes (Figure 4-5). The range and median densities of recruits were also similar, regardless of current orientation or axis (Figure 4 6). Recruit densities were generally similar or lower within the focal-population relative to the four axes, which suggests widespread availability of competent larvae. High recruit densities decreased over subsequent years (Figures 4-5 \& 4-6).

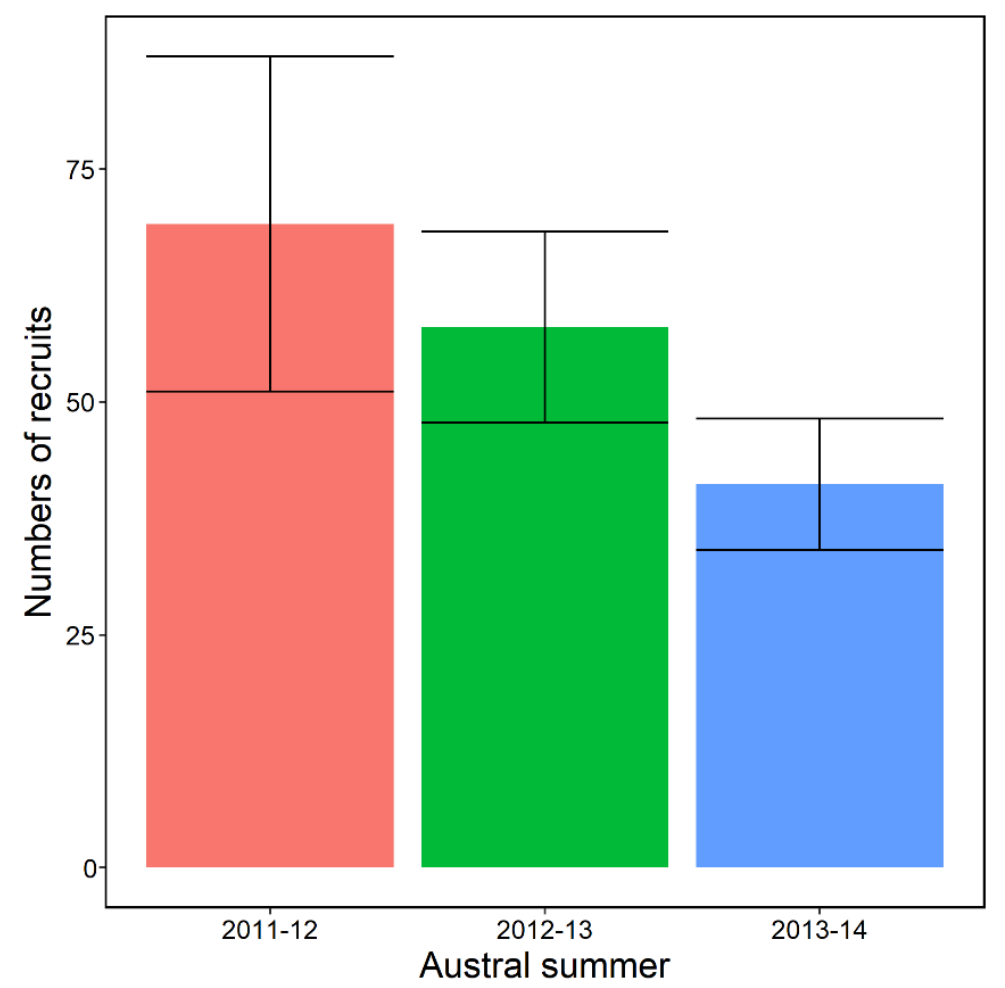

Figure 4-5. Bar plots of mean recruit densities and $95 \%$ confidence intervals for the three years of sampling during the summers (November to February) from 2011-12 to 2013-14. 
Models 1-10 were run with factors year (Yr), distance (D), current axis $(\mathrm{Cx})$, and their two-way and three-way interactions to determine a best-fit model (Table 4-1). AICs and the percentages of deviance explained did not vary greatly for the best-fit models (5-8), presumably because of the lack of pattern in the distribution of recruits (Figure 4-5). Model $6(\mathrm{Yr}+\mathrm{Cx})$ was chosen as the bestfit based on AICs, percentage of deviance explained, and slightly improved plots of residuals and QQ-plots. Models 11-13 (Table 4-1) substituted Cx for Ax, and all interactions that did not improve the model fits subsequently dropped. Model $13(\mathrm{Yr}+\mathrm{Ax})$ was the best-fit model of the three, and the best-fit overall based on the same criteria as above. Yr was the only significant variable with $\mathrm{D}, \mathrm{Cx}$, and $\mathrm{Ax}$ and their interactions accounting for distance and direction from the focal-population were not significant at alpha $=0.05$. The full model (Model 1, Table 4-1) accounted for $18.2 \%$ of the deviance while the best-fit Models 6 and 13 (Table $4-1$ ) accounted for $9.1 \%$ and $13.5 \%$ of the deviance respectively.

Recruitment is assumed to reflect the numbers of competent larvae available for settlement and therefor settle on passive artificial collectors at sampling locations. Settlement to the seabed will be primarily dependent on the availability of clean hard substratum (Smyth et al. 2018). Trends in recruit densities with increasing distance from the focal population boundary varied with axis direction (Figure 4-7, Table 4-3). Along current axes, settlement densities increased with increasing distance to the west and decreased to the east. Across current axes showed a similar pattern that increased to the north and decreased to the south. Increases in recruit densities were in directions towards neighbouring areas of relatively high brooder densities (Figures 4-1 \& 4-2). These trends were consistent among years. Trends in recruit densities by distance from the focal-population imply flat distributions of competent larvae, and therefore suggest putative flat dispersal kernels.

Putative brooder densities sampled in 2014 varied between axes, but had little effect on local recruit densities settled in 2013-2014. Recruits modelled as 
a function of brooders and Ax explained $47.0 \%$ of the deviance, however, brooders alone were not a good predictor of nearby settlement (Table 4-4). Moreover, trends in recruit densities varied with axis. Axis was the most significant factor $(\mathrm{P}<0.001$, d.f. $=4$, Deviance $=34.27)$ accounting for $45.5 \%$ of the deviance in model 3 (Table 4-4). 
Table 4-1. Factors predicting the distributions $O$. chilensis recruits as a proxy for the dispersal of competent larval abundance from a focal population in the Foveaux Strait oyster fishery, 2011-12 to 2013-14. Recruit densities modelled as functions of year (Yr), distance (D), current axis $(\mathrm{Cx})$, and their interactions (models 1-10) using negative binomial regression. Axis (Ax) was substituted for Cx for each model (models 11-13), because of the relatively small data size. Degrees of freedom (d.f.), Akaike Information Criterion (AIC), and percentage deviance explained (\% Dev) are given for each model. Selection of the best-fit model was based on AIC. Where AICs were similar between models, the percentage deviance explained (a measure of effect size, analogous to a variance component) and graphical evaluation of fits determined best-fit models (bold).

\begin{tabular}{|c|c|c|c|c|}
\hline Model & Factors and interactions & d.f. & AIC & $\%$ Dev \\
\hline 1 & $\mathrm{Yr}+\mathrm{D}+\mathrm{Cx}+\mathrm{Yr} * \mathrm{D}+\mathrm{Yr} \mathrm{r}^{*} \mathrm{Cx}+\mathrm{Yr} \mathrm{r}^{*} \mathrm{Cx}$ & 19 & 1338.731 & 18.2 \\
\hline 2 & $\mathrm{Yr}+\mathrm{D}+\mathrm{Cx}+\mathrm{Yr} * \mathrm{D}+\mathrm{Yr} * \mathrm{Cx}$ & 13 & 1337.134 & 12.4 \\
\hline 3 & $\mathrm{Yr}+\mathrm{D}+\mathrm{Cx}+\mathrm{Yr} \mathrm{r}^{*} \mathrm{D}$ & 9 & 1333.698 & 9.7 \\
\hline 4 & $\mathrm{Yr}+\mathrm{D}+\mathrm{Cx}+\mathrm{Yr} * \mathrm{Cx}$ & 11 & 1333.503 & 12.2 \\
\hline 5 & $\mathrm{Yr}+\mathrm{D}+\mathrm{Cx}$ & 7 & 1330.214 & 9.4 \\
\hline 6 & $\mathbf{Y r}+\mathbf{C x}$ & 6 & 1328.617 & 9.1 \\
\hline 7 & $\mathrm{Yr}+\mathrm{D}$ & 5 & 1329.377 & 7.5 \\
\hline 8 & $\mathrm{Yr}$ & 4 & 1328.686 & 6.7 \\
\hline 9 & $\mathrm{D}$ & 3 & 1336.171 & 0.7 \\
\hline 10 & $\mathrm{Cx}$ & 4 & 1334.912 & 2.8 \\
\hline 11 & $\mathrm{Ax}$ & 6 & 1333.548 & 6.1 \\
\hline 12 & $Y r+A x+D$ & 9 & 1326.787 & 6.7 \\
\hline 13 & $\mathbf{Y r}+\mathbf{A x}$ & $\underline{8}$ & $\underline{1325.189}$ & $\underline{\underline{13.5}}$ \\
\hline
\end{tabular}


Table 4-2. Analysis of deviance for best-fit negative binomial Model 6 (glm.nb) and estimates for coefficients for factors year (Yr) and current axis $(\mathrm{Cx})$. Degrees of freedom (d.f.), deviance (Dev), percentage deviance explained (\% Dev), residual degrees of freedom (Resid. d.f.), residual deviance (Resid. Dev), and P value (Pr (>Chi)).

\begin{tabular}{lrrrrrrr}
\hline & & & & & $\begin{array}{r}\text { Resid. } \\
\text { d.f. }\end{array}$ & $\begin{array}{r}\text { Resid. } \\
\text { Dev }\end{array}$ & $\begin{array}{r}\text { Pr } \\
(>\text { Chi) }\end{array}$ \\
\hline Factor & d.f. & Dev & \% Dev & & & \\
& & & & & 133 & 169.34 & \\
Yr & 2 & 11.358 & 6.7 & 131 & 157.98 & 0.003 \\
Cx & 2 & 4.131 & 2.4 & 129 & 153.85 & 0.127 \\
\hline
\end{tabular}

\begin{tabular}{lrrrr} 
Coefficients: & Estimate & $\begin{array}{r}\text { Std. } \\
\text { Error }\end{array}$ & z value & $\operatorname{Pr}(>\mid \mathbf{z})$ \\
\hline Intercept & 4.124 & 0.133 & 30.969 & $<0.001$ \\
Yr 2012-13 & -0.155 & 0.154 & -1.006 & 0.315 \\
Yr 2013-14 & -0.503 & 0.154 & -3.265 & 0.001 \\
Cx (Along) & 0.247 & 0.140 & 1.757 & 0.079 \\
Cx (Focal-popn) & -0.037 & 0.175 & -0.211 & 0.833 \\
\hline
\end{tabular}




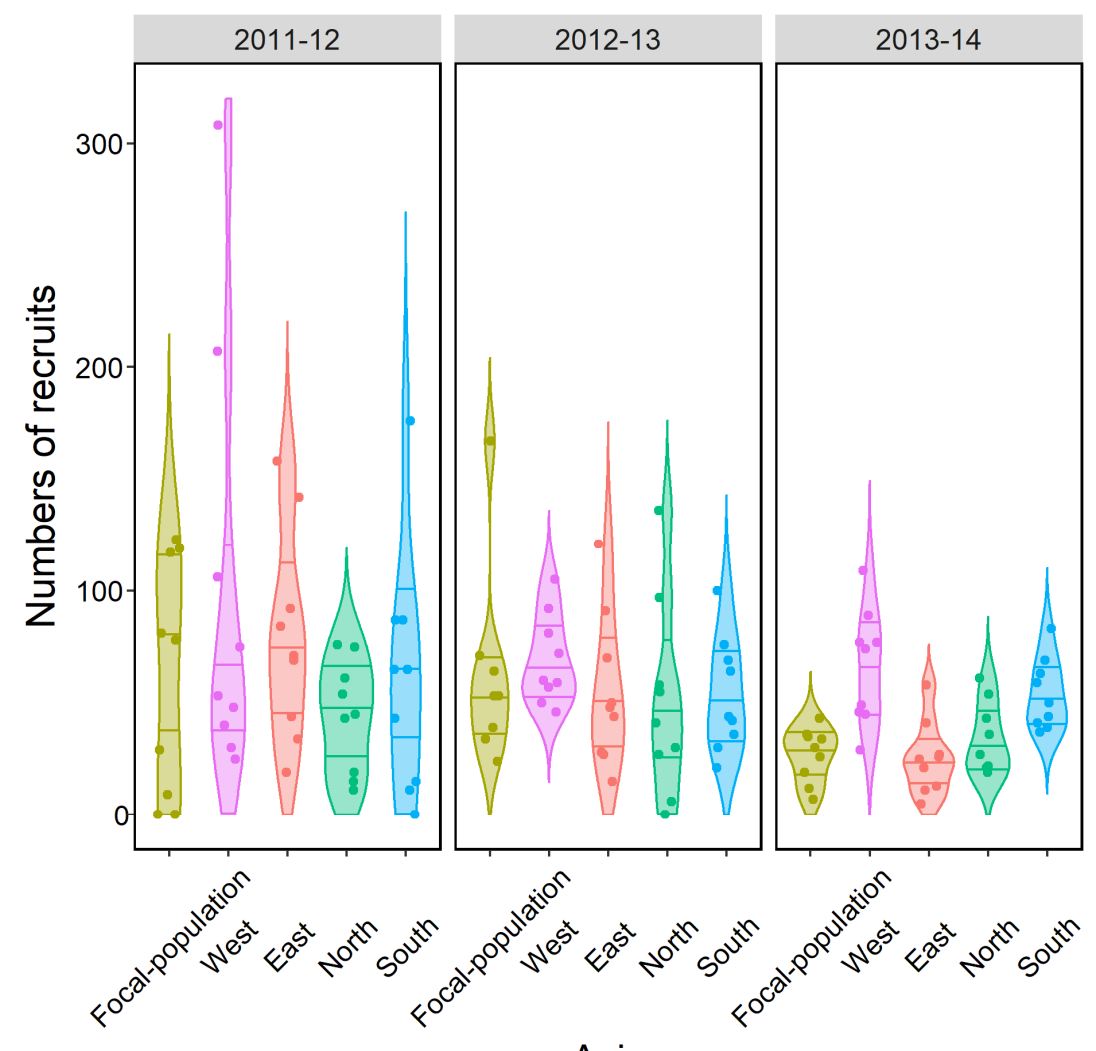

Axis

Figure 4-6. Violin plots of $O$. chilensis recruit densities along four axes (Ax) extending west, north, east, and south from focal population for the summers (November to February) of 2011-12 to 2013-14. Violin plots show data points (dots) and probabilities for the range of recruit densities scaled to the highest recruit density. Mirrored probability distributions shown as shapes shaded by factor. Horizontal lines within distributions denote the median, 25th and 75th percentiles. 


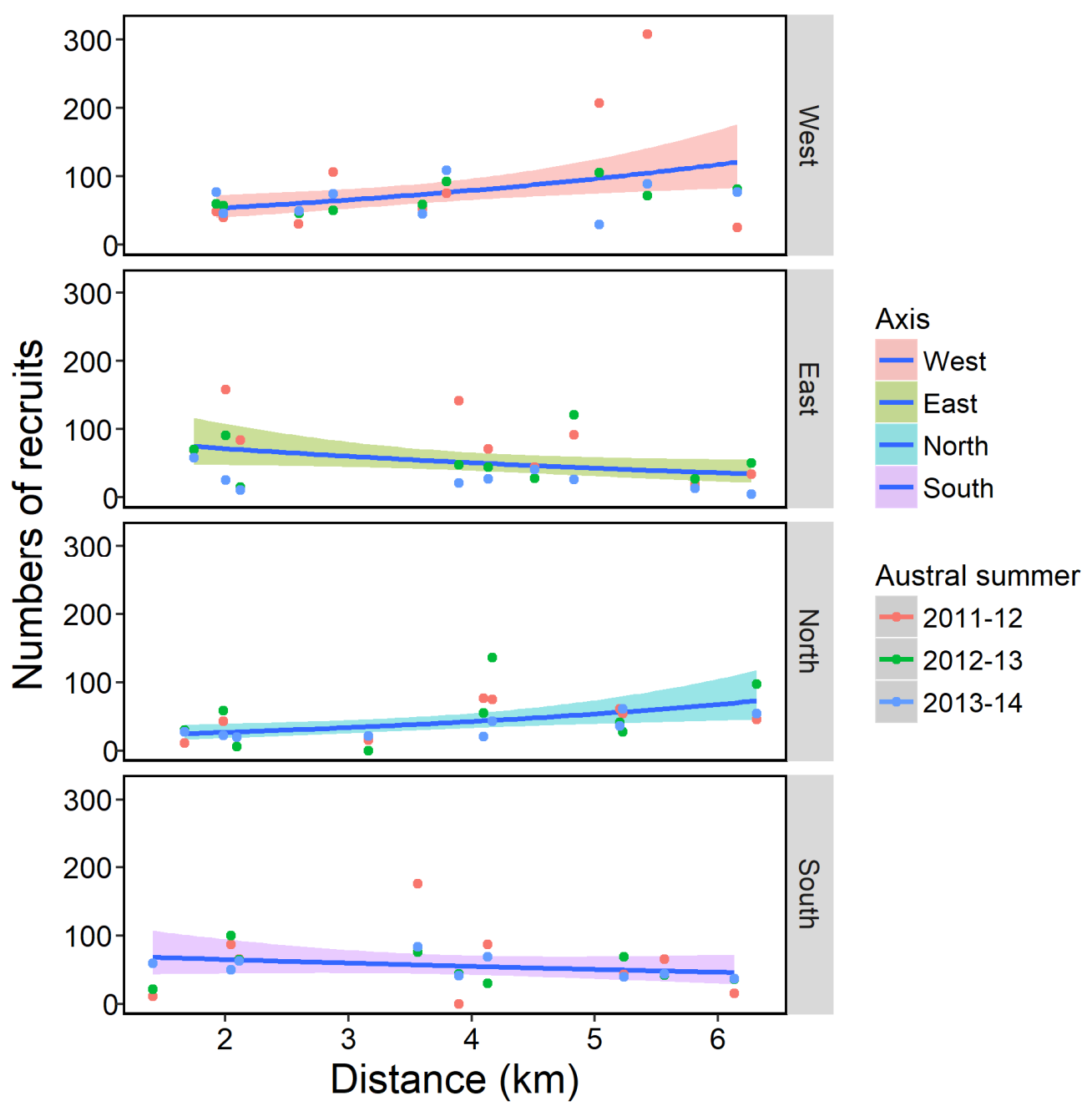

Figure 4-7. Changes in $O$. chilensis recruit densities (spat per collector) with increasing distance from the focal population over the four axes extending west, north, east, and south over the summers (November to February) of 2011-12 to 2013-14. Coloured lines and shading show fits from generalised linear model with a negative binomial distribution and a log link function (mean $\pm 1 \mathrm{SE}$ ). 
Table 4-3. Analysis of deviance for best-fit negative binomial Model 13 (glm.nb) and estimates for coefficients for factors year (Yr) and current axis (Ax). Degrees of freedom (d.f.), deviance (Dev), percentage deviance explained (\% Dev), residual degrees of freedom (Resid. d.f.), residual deviance (Resid. Dev), and P value (Pr (>Chi)).

\begin{tabular}{|c|c|c|c|c|c|c|}
\hline Factor & d.f. & Dev & \% Dev & Resid. d.f. & Resid. Dev & $\operatorname{Pr}(>$ Chi $)$ \\
\hline & & & & 133 & 177.93 & \\
\hline$Y r$ & 2 & 11.991 & 6.7 & 131 & 165.94 & 0.002 \\
\hline$A x$ & 4 & 11.994 & 6.7 & 127 & 153.94 & 0.017 \\
\hline Coefficients: & & & Estimate & Std. Error & $\mathrm{z}$ value & $\operatorname{Pr}(>|z|)$ \\
\hline Intercept & & & 4.131 & 0.162 & 25.553 & $<0.001$ \\
\hline $\operatorname{Yr} 2012-13$ & & & -0.151 & 0.150 & -1.002 & 0.317 \\
\hline Yr 2013-14 & & & -0.539 & 0.150 & -3.595 & 0.000 \\
\hline$A x$ (North) & & & -0.154 & 0.194 & -0.794 & 0.427 \\
\hline$A x$ (Focal-population) & & & -0.036 & 0.196 & -0.186 & 0.853 \\
\hline$A x$ (South) & & & 0.143 & 0.193 & 0.737 & 0.461 \\
\hline$A x$ (West) & & & 0.450 & 0.193 & 2.239 & 0.020 \\
\hline
\end{tabular}


Table 4-4. Analysis of deviance for negative binomial models (glm.nb) of Recruits modelled against Ax, and Brooders. Sample sizes were too small to run interactions. Akaike Information Criterion (AIC), degrees of freedom (d.f.), deviance (Dev), percentage deviance explained (\% Dev), residual degrees of freedom (Resid. d.f.), residual deviance (Resid. Dev), and $P$ value $(\operatorname{Pr}(>C$ Chi) ) are given for each model. Best-fit model selected based on AIC, \% Dev, and graphical evaluation (shown in bold).

\begin{tabular}{|c|c|c|c|c|c|c|c|c|}
\hline Model & AIC & Factor & d.f. & Dev & \% Dev & Resid. d.f. & Resid. Dev & $\operatorname{Pr}(>\mathrm{Chi})$ \\
\hline \multirow[t]{3}{*}{1} & 340.55 & & & & & 38 & 77.815 & \\
\hline & & Brooders & 1 & 8.195 & 10.5 & 37 & 69.620 & 0.004 \\
\hline & & $A x$ & 4 & 28.385 & 36.5 & 33 & 41.235 & $<0.001$ \\
\hline \multirow[t]{2}{*}{2} & 353.77 & & & & & 38 & 45.655 & \\
\hline & & Brooders & 1 & 4.689 & 10.3 & 37 & 40.967 & 0.030 \\
\hline \multirow[t]{2}{*}{3} & 339.66 & & & & & 38 & 75.298 & \\
\hline & & $A x$ & 4 & 34.27 & 45.5 & 34 & 41.029 & $<0.001$ \\
\hline
\end{tabular}




\section{Discussion}

There was no pattern detected in the distributions of recruit densities (thereby numbers of competent larvae) around the focal population over the three summers of sampling. None of the predictor variables investigated: directions either-way along or across the current, distance from the focal population, and density of putative brooders predicted recruit densities. The distributions of recruits suggest that competent $O$ strea chilensis larvae were widespread over the sample sites extending three nautical miles along the four axes from the focal population. Additionally, brooder densities sampled at spat collector locations did not predict recruit densities; this suggests that larvae either settled differentially at these sites, or more likely dispersed beyond the brooders. Pelagic larval duration, $O$. chilensis population demographics, and the small scale study of Cranfield (1968a) where high densities of recruits settled over the highest concentration of oysters have underpinned the hypothesis of demographically mostly closed populations (self-recruitment). Under the hypothesis of selfrecruitment, there was an expectation of Gaussian distributions (after Chiswell 2012) of recruit densities (indicative of dispersal kernels), with the highest numbers of recruits centred immediately on the focal population. The numbers of recruits should have decreased rapidly with an increase in distance down current. There was also an expectation of highly truncated Gaussian distributions of recruits along axes across current. The flat recruit distributions observed in this research, however, show similar numbers of competent larvae consistently along and across current in all directions from the focal population. These data suggest competent oyster larvae may be dispersed much greater distances by the swift currents in Foveaux Strait than predicted by Cranfield (1968b), and by Broekhuizen et al. (2011) in Tasman Bay $(<1 \mathrm{~km})$. Regardless whether these larvae have come from one or more localised populations, the distribution of recruits shows a potential for larval mixing that implies these populations are likely to be mostly demographically open rather than mostly demographically 
closed. Findings of this research do not support the hypothesis of mostly selfrecruitment. Moreover, previous studies in Foveaux Strait (Cranfield 1968a), in Tasman Bay central New Zealand (Brown 2011), and for a related oyster on the west coast of the US., Ostrea lurida (Pritchard et al. 2015) suggest that recruit densities were closely related to brooder density, and therefore dispersal was limited and those populations mostly demographically closed. This research found no relationship between $O$. chilensis brooder and recruit densities in Foveaux Strait. This lack of relationship is consistent with the findings of the fishery-wide study detailed in Chapters 2 and 3 during the low recruitment years between $2008-09$ and $2010-11$.

Recruit numbers and their peak densities decreased each year (see Figure 4-6). The declining trend is consistent with a continuing trend of declining recruitment in the Foveaux Strait oyster fishery since 2007-08 (Michael et al. 2017b). Mortality in O. chilensis caused by the oyster parasite Bonamia exitiosa (Doonan et al. 1994, Berthe \& Hine 2003, Cranfield et al. 2005) is a recurrent feature of the Foveaux Strait oyster population (Michael et al. 2017b). Fisherywide mortality from B. exitiosa over the summers of 2010-11 to 2012-13 reduced recruit-sized oyster densities and brooder densities by 10.3\%, 12.0\%, and $16.4 \%$, respectively (Michael et al. 2017b). Over the same period, recruit densities decreased to $50.3 \%$. Declining numbers of recruit-sized oysters and the potential effects of disease on reproduction (see Chapter 3, and Hine \& Jones 1994, Hine 2002) may have decreased the proportions of oysters brooding, with flow-on effects to the numbers of competent larvae and recruit densities. Overall, recruit densities were historically low (50-100 recruits per collector). These were much lower than recorded during 2007-08 (c. 2000 recruits per collector) at a nearby location West-high (see Chapter 2).

Larval cohort size can strongly influence the range of dispersal. Some oysters can vary reproductive output over space and time, e.g. Crassostrea 
virginica (Mroch et al. 2012). Any variation in the numbers of $O$. chilensis broods can strongly influence larval cohort size, with flow-on-effects on dispersal and connectivity, and therefore recruit densities. The percentages of brooders in Foveaux Strait may have decreased markedly since the 1960s and have been relatively low since the 1990s. Lower spawner densities and higher percentages of brooders in northern oyster populations (Jeffs \& Creese 1996, Brown et al. 2010) than in Foveaux Strait populations suggest that temperature may be a key factor in brooding percentages; however, Chapter 3 shows pathogens may have a larger effect the percentage of brooders within a population.

A key assumption of this research is that competent $O$. chilensis larvae in Foveaux Strait readily settle on manmade substrates without conditioning and in the absence of conspecifics. O. chilensis in Foveaux Strait readily settles on unconditioned cement board plates (Cranfield 1968b, Brown et al. 2010) and in areas with no or low oyster densities (see Chapter 2 for further discussion). This research found a strong positive correlation (Pearson's correlation, 0.96, $\mathrm{P}<$ 0.001) between the densities of recruits on spat collectors and the numbers of oyster spat (0+ year class) attached to commercial-sized oysters landed during the following winter fishing season over a twelve year period that included high and low settlement years (see Chapter 3). This research suggests that factors that induce settlement in other oysters and other marine invertebrates (reviewed by Rodriguez et al. (1993) do not appear to be important to the settlement of $O$. chilensis. In $C$. virginia these include conspecifics and biofilms (Tamburri et al. 1992), conspecific shell (Vasquez et al. 2014) and underwater sounds (Lillis et al. 2013). Manmade substrates and adult oysters of other species are also important factors in C. ariakensis settlement (Tamburri et al. 2008). This study is consistent with Smyth et al. (2018), Ostrea will settle on any clean, hard substratum. 
Longer pelagic larval durations may be one explanation for the flat settlement kernels observed in this study. The release of some early stage larvae in New Zealand (Cranfield \& Michael 1989) and in Chile (Chaparro 1990) suggests that pelagic larval duration may be more variable in $O$. chilensis than appreciated. In this study, the release of some $O$. chilensis larvae at an early stage of development, with longer pelagic larval durations and a greater opportunity to disperse further before settlement may have occurred (Jeffs \& Hickman 2000). Westerskov (1980) found smaller numbers of late-stage larvae compared to the numbers of early-stage larvae brooded by oysters of the same size, which suggests losses of larvae during development. In laboratory trials, larvae released early as veligers survived ex-parent and continued to develop to full competency (Hickman 2000). The reproductive biology of $O$. chilensis may not be a good predictor of pelagic larval duration, and its variability underestimated. If the proportion of larvae released early in Foveaux Strait (and elsewhere) is at times substantial, the swift currents in Foveaux Strait could increase dispersal and connectivity. Intraspecific variation is common in the development of larvae (Kamel et al. 2010), and may provide a bet hedge strategy (Crean \& Marshall 2009) in response to changing environments, usually temperature (Burgess \& Marshall 2011). Ostrea chilensis in Foveaux Strait may also employ this bet hedge strategy in response to changing conditions.

Simulations of larval dispersal in $C$. virginica and other marine taxa suggest that natal location, gamete or larval release date, and current flows (Edwards et al. 2007, Puckett et al. 2014), and variation in pelagic larval duration (Treml et al. 2012) account for the largest sources of variation in larval dispersal distance. In Foveaux Strait, site-specific differences may affect the numbers of brooders, brooding periods and synchrony in the release of broods. Wind can strongly influenced the speed and direction of tidal currents, and therefore determines larval transport. Moreover, Chiswell (2012) showed swift currents produce flat non-Gaussian dispersal kernels; therefore the swift currents in 
Foveaux Strait could result in flat recruit distributions along the current axis as observed in this study. A single flood or ebb tide may transport larvae up to 13 $\mathrm{km}$ in normal flows and considerably further in high flows. Wind generated cross-shelf flows are common at depths of 20-50 m (Lentz \& Fewings 2012), and are evident in Foveaux Strait and elsewhere (Puckett et al. 2014). These flows could in part explain the higher than expected levels of settlement across the current axes in this study. Regardless of normal flushing times (Gaines \& Bertness 1992), the bathymetry of Foveaux Strait may facilitate the development of gyres under some wind conditions that entrain and retain $O$. chilensis larvae over the fishery area. These conditions may be another explanation for the lack of pattern in the distribution of recruit densities.

The potential for larval transport in Foveaux Strait is higher than reported in Tasman Bay (c. $1 \mathrm{~km} \mathrm{~d}^{-1}$, Broekhuizen et al. 2011), and for other Ostreidae with longer pelagic larval durations (e.g. C. virginica with pelagic larval duration of 21 days and dispersal ranged $0.1-1.9 \mathrm{~km} \mathrm{~d}^{-1}$, Puckett et al. 2014). Despite the potential for long-range dispersal in larvae with long pelagic larval durations, some of these larvae exhibit substantial self-recruitment (Swearer et al. 2002, Swearer \& Shima 2010). Larval behaviour and their sensory abilities may play important roles in dispersal and especially in retention of larvae within natal populations. Deterministic models of dispersal show the effects of larval behaviour are mixed; these ranged from being of high importance in Corell et al. (2012) to having only a small effect elsewhere (Edwards et al. 2007, Puckett et al. 2014, Daigle et al. 2016). Swimming speeds for oysters are low (Hidu \& Haskin 1978, Dekshenieks et al. 1996) and high current speeds such as those in Foveaux Strait reduce swimming ability and vertical migration (see Peteiro \& Shanks 2015 for a discussion of this in Ostrea lurida). O. chilensis are poor and sporadic swimmers (Stead 1971a), remain near the seabed (are benthopelagic) and avoid light (are negatively phototaxic) (Cranfield 1968b). O. chilensis larvae could therefore be considered as passive particles carried by swift currents in 
Foveaux Strait and dispersal determined by pelagic larval duration and current flows. Additionally, the vertically mixed water mass in Foveaux Strait (Bradford et al. 1991, Butler et al. 1992) does not provide the advantages of different current flows, access to better food supplies, and of more favourable physical environments found in stratified water masses (Pineda et al. 2007, North et al. 2008).

\section{Conclusions}

The widespread and consistent distribution of recruits over the study area and the lack of relationship between brooders and recruits at paired sites imply greater dispersal and larval mixing of $O$. chilensis larvae than previously reported. The low recruit densities recorded in this research reflect relatively low larval cohort sizes that should result in more localised settlement than observed and by a truncated Gaussian distribution of recruits. The swift currents in Foveaux Strait, and the possibility that pelagic larval duration for some larvae may be longer than initially thought, suggest that dispersal may be further and connectivity may be higher than previously presumed for $O$. chilensis in Foveaux Strait. Although the O. chilensis fishery in Foveaux Strait is well studied, data on spatial and temporal variability in brooding, variation in the pelagic larval duration of oyster larvae, and the drivers of the variability in these stages have been scant. Moreover, the recurrent Bonamia exitiosa epizootics since 1985 discussed in Chapter 3 may have changed the reproductive output in oysters and reduced larval cohort size and possibly brooding periods. The lack of evidence for predominantly self-recruitment in $O$. chilensis from Foveaux Strait in this research and the uncertainty around pelagic larval duration emphasises the need for site-specific and species-specific information on recruitment for the management of oyster resources.

Many sessile benthic taxa including $O$. chilensis in Foveaux Strait have patchy distributions. Empirical studies of dispersal between subpopulations in 
the marine environment are rare (Gawarkiewicz et al. 2007, Pineda et al. 2007). Studies of the patterns in recruit densities at appropriate spatio-temporal scales provide estimates of the densities of competent larvae available for settlement, putative dispersal and the potential for larval mixing. These types of studies can inform the development of models and validate their predictions. Additionally, models of dispersal provide powerful tools to simulate the importance of factors driving dispersal (Puckett et al. 2014). A combination of modelling and empirical approaches will greatly increase our knowledge of dispersal, recruitment, and population structure.

This research found little evidence for mainly self-recruitment in $O$. chilensis from Foveaux Strait. Recruitment between mostly demographically open populations of $O$. chilensis should provide for greater resilience to oyster mortality from disease and fishing. The likelihood of a fishery-wide distribution of competent larvae and an abundance of settlement surfaces on the seabed (see Chapter 5) strongly suggests that post-settlement and density-dependent processes (Knights \& Walters 2010) probably drive the patchy spatial structure of oysters in Foveaux Strait. 


\section{Chapter 5 : Settlement, growth, and survival of Ostrea chilensis}

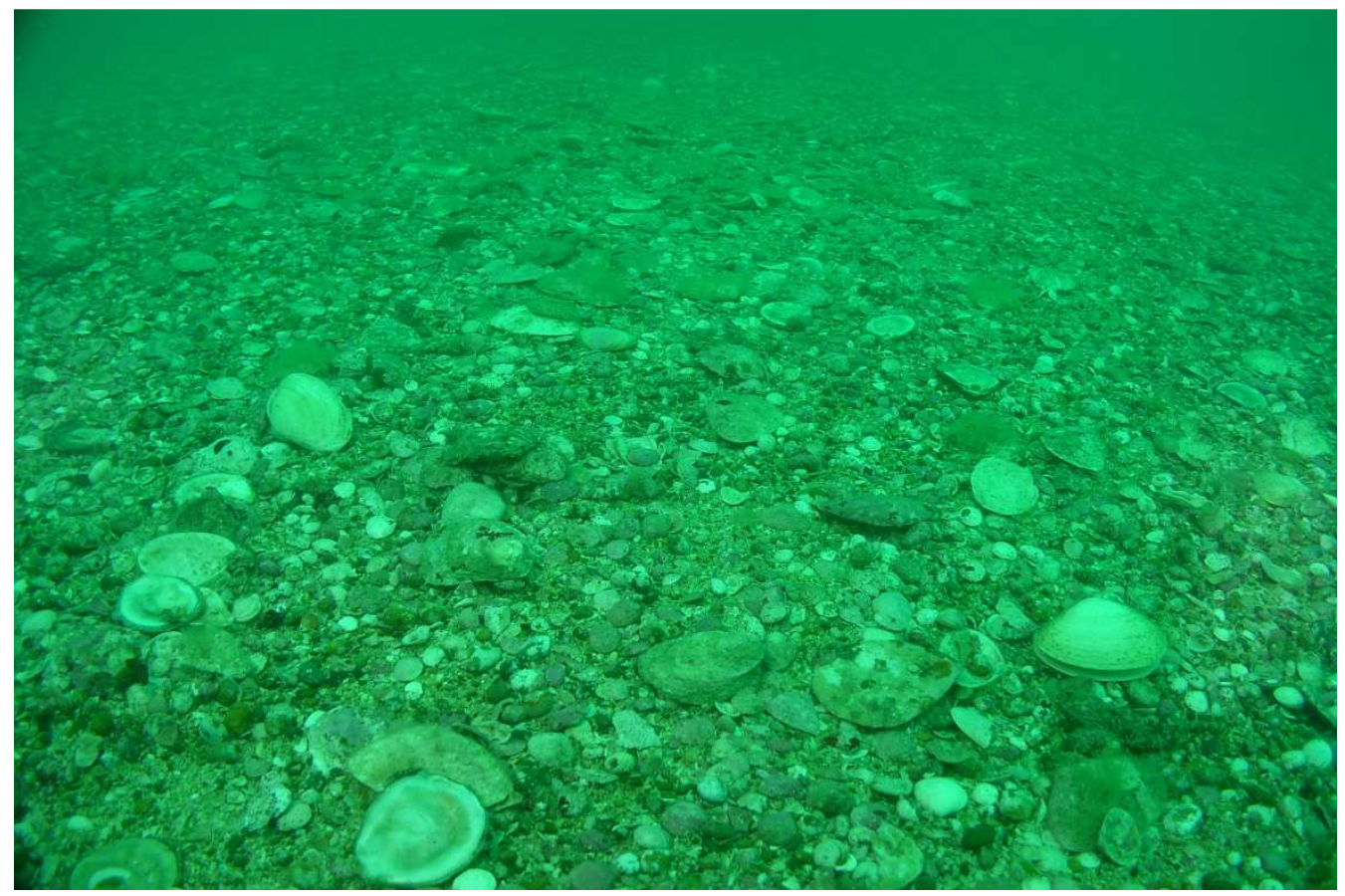

Shells for the settlement of $O$. chilensis larvae are abundant in Foveaux Strait. Image Mike Page, 


\begin{abstract}
Worldwide, many oyster populations have declined, and some are the focus of conservation and restoration efforts. Wild oyster fisheries without enhancement such as the Ostrea chilensis fishery in Foveaux Strait, southern New Zealand are rare. The spatial structure of this oyster population is typical of sessile benthic invertebrates and comprises of high-density populations separated by areas of low oyster density. Settlement and post-settlement mortality are investigated as key determinants of this spatial structure. In this research, fishery and bycatch sampling data, and growth and survival trials are used to: (1) identify benthic habitats on which high oyster densities occur, (2) identify substrata on which $O$. chilensis larvae settle and survive, and (3) compare growth and mortality of recruits $(0+)$ and spat $(1+)$ between exposed and less exposed sites, and at heights above the seabed. Shells for settlement of $O$. chilensis are abundant on the seabed. Most (66.8\%) post-settlement survivors were on the heavy shells of live and dead O. chilensis. Shells of Oxyperas elongate and Astraea heliotropium were also important. Productive fishery areas comprise mostly stable substrates of shells, sand, and gravels with little other epifauna. Sediment stability and height above the seabed are important to increased $O$. chilensis growth and reduce mortality. Findings from this research are not consistent with the need for complex biogenic habitat as essential habitat for the recruitment and abundance of $O$. chilensis in Foveaux Strait, and suggest an unusual stock-recruit relationship. Post-settlement mortality is the primary determinant of spatial structure.
\end{abstract}




\section{Introduction}

Distributions of sessile benthic invertebrates are typically patchy. Oysters (Ostreidae), like many sessile taxa, require suitable habitat as a critical prerequisite for settlement (Schulte et al. 2009), which is patchily distributed at multiple spatial-scales. Spatio-temporal variation in larval supply further adds to patchiness in settlement (see Cowen and Sponaugle 2009). Variable settlement and post-settlement mortality are also important determinants of the distributions of juveniles, and thereby patchiness in sessile adults (Hunt \& Scheibling 1997). The interaction of these stages of recruitment shape the demographics of sessile benthic invertebrate populations (David et al. 1997)

Intertidal and shallow estuarine habitats sheltered from oceanic swell typically have muddy substrates. Recruitment of oysters in these habitats is dependent on suitable substrata for settlement. Biogenic and shell reefs provide structural complexity that enhances larval settlement of oysters. Habitat complexity alters the turbulent boundary layer of the seabed (Eckman 1987, Jonsson et al. 1991, Hendriks et al. 2006, Wheeler et al. 2015). Water-borne biochemicals produced within these communities (Hidu 1969, Veitch \& Hidu 1971, Turner et al. 1994) and settlement substrata provided by conspecific and other shells (Tamburri et al. 2008, Vasquez et al. 2014) enhance settlement. There is a positive relationship between more settlement substrata and the increased probability of settlement (Powell \& Klinck 2007, Schulte et al. 2009, Smyth \& Roberts 2010, Soniat et al. 2012, Waldbusser et al. 2013). Complex habitats can stabilise sediments (Lenihan 1999), and reduce abiotic mortality of recruits (Thomsen \& McGlathery 2006, Brown 2011). The habitat complexity of oyster reefs provides refuge for juvenile oysters from predation (Grabowski 2004). However, mortality is dependent on predator oyster interactions (O'Connor et al. 2008), and high habitat complexity may increase predation of juveniles (Grabowski \& Powers 2004). Habitat complexity alters boundary flows that 
enhance feeding conditions for oysters and other filtering invertebrates (Lenihan et al., 1999).

The Ostrea chilensis fishery in Foveaux Strait, southern New Zealand is one of the last wild oyster fisheries without habitat or stock enhancement. $O$. chilensis distribution is patchy and comprises discrete, high-density subpopulations separated by areas of low oyster density (Allen \& Cranfield 1979, Michael 2010). Since 1998, levels of catch have been relatively low (7.510.0 million oysters per year with Total Allowable Catch of 15.0 million oysters, Ministry for Primary Industries 2017), less than $2 \%$ of the recruit-sized population. Between 2007 and 2012, oyster mortality from Bonamia exitiosa killed $8-12 \%$ of recruit-sized (legal-sized) oysters per year and up to $20 \%$ per year between 2013 and 2017. The trend in the abundance of oysters in the Foveaux Strait fishery is driven by disease mortality from B. exitiosa and the levels of recruitment (Ministry for Primary Industries 2017). The recurrent, high mortality of mainly recruit and pre-recruits (50-57 $\mathrm{mm}$ in length) oysters introduces high levels of oyster shell to the seabed that provides refugia and settlement substrata for a wide range of taxa, and is aggregated with sediments into physical structures by storms.

Competent $O$. chilensis larvae are likely to be ubiquitous in the fishery area and independent of the distributions of oysters (see Chapter 4). The $O$. chilensis habitat in Foveaux Strait differs markedly to those of other oysters, as does its reproductive biology (see Chapter 1). Settlement and post-settlement mortality in this species may therefore also differ markedly to that for other oysters. Cranfield et al. (1999) proposed a hypothesis: recruitment is dependent on complex biogenic habitat dominated by the bryozoans Cintipora elegans. High densities of oysters only occur on these biogenic reefs (Cranfield et al. 1999). This hypothesis is based an assumption that biogenic reefs may provide better conditions for settlement and post-settlement survival (Cranfield et al. 
$1999,2003,2004)$ as is the case in other complex habitats, such as the maerl grounds in Scotland (Hall-Spencer \& Moore 2000) and oyster reefs (Schulte et al. 2009). Cranfield et al. (2004) presented a theoretical model for succession in sessile benthic invertebrate species and benthic habitat regeneration believed to be important to oyster recruitment.

Anecdotal evidence suggests an alternative hypothesis: that oyster density in complex habitats is low and oyster condition poor (author's data; Stead 1971b) and oysters thrive on substrates with little epifauna (Fleming 1952, Cullen 1962, Stead 1971b, Robjohns 1979, Hill et al. 2010). Post settlement mortality is high in sessile invertebrates (Stoner 1990, Hunt \& Scheibling 1997, Pineda et al. 2006) and in Foveaux Strait oysters (Cranfield 1979). Mortality caused by both biotic processes (predation, over-colonisation, and disease) and abiotic disturbance that may include abrasion and or burial by sediments mobilised during storms, and incidental mortality from dredging (Cranfield et al. 1997). Of the relatively small numbers of $0+$ year class oysters (the previous summers spat) encountered by a dredge, up to $80 \%$ are killed; however, the mortality of recruit and pre-recruits oysters is substantially lower (Cranfield et al. 1997). Substrata suitable for settlement of $O$. chilensis in complex biogenic habitats are likely to be scarce as they are readily colonised by other epibenthic taxa. Moreover, oyster spat themselves provide settlement substrata and overcolonised by other taxa (author's unpublished data). Complex habitats may increase the abundance and variety of oyster predators: polychaete worms, gastropods, crabs, octopuses, and brittle stars (Cranfield 1975) and thereby increase predation pressure, only in part mediated by refuges provided by complex biogenic habitat (Talman et al. 2004). These contrasting hypotheses have prompted this research of settlement and survival of $O$. chilensis in Foveaux Strait.

Large swells and high tidal currents create a high-energy environment in Foveaux Strait that determines the distribution and stability of sediments and the 
composition and distribution of benthic communities, as in the UK (Bricheno et al. 2015, Joshi et al. 2017). Storms maintain a dynamic process of habitat destruction (through scouring and sediment inundation) and regeneration (Roff et al. 2015). The western entrance to Foveaux Strait is the most exposed coastal area in New Zealand (Gorman et al. 2003), and subjected to greater sediment mobility during storms than in the eastern area. Storms also increase tidal current flows, which are higher in the shallow, eastern strait. The effects of this changeable, high-energy environment on the spatio-temporal distribution of benthic communities are poorly known. Differences in benthic communities in Foveaux Strait, and the contributions of infauna and epifauna are most likely determined by the gradient of exposure to oceanic swells and the mobility of sediments (Michael 2007). The frequency and magnitude of disturbance determines resilience in these communities (DeAlteris et al. 1999). In Foveaux Strait, changes in benthic biogenic communities (Cranfield et al. 1999), release and transport of sediments (Cranfield et al. 2003), and spatio-temporal patterns of regeneration (Cranfield et al. 2001, 2004) are all attributed to dredging for oysters, with no consideration of the effects of the frequent storms. In this chapter, available data, some dating back to 1998, is used to explore the effects of exposure to oceanic swells and sediment movement on $O$. chilensis recruitment. Despite the limitations and age of these data, the aim is to summarise these in a way that will enable new hypotheses and future research to be undertaken.

The aims of this study are to: (1) identify benthic habitats on which commercial fishers target high densities of oysters, i.e. habitats important to fishers (2) identify the range of settlement substrata on which $O$. chilensis settle and survive, and (3) estimate differences in growth and mortality of 0+ recruits and $1+$ spat between western and eastern areas. As the normal flows in Foveaux Strait are swift and likely to transport sediment and shell, (4) this study also investigated how the survival and growth of recruits on artificial collectors may 
vary with height above the seabed. These data aim to provide insights into oyster recruitment and the important habitat attributes for successful settlement and post-settlement survival. Discussion of these research finding includes the roles of complex biogenic habitats to oyster production in Foveaux Strait specifically, which represents a different oyster habitat from those studied elsewhere.

\section{Methods}

The depth, strong currents, and hard substrate of Foveaux Strait limit the methods available to sample recruits and settlement substrata (Michael et al. 2008c). Photographic, video and grab sampling methods have severe limitations in Foveaux Strait. Most of the area is too deep for effective sampling by divers. Data to inform this study were collated from a number of programmes, these used three sampling methods: (1) dredge sampling, conducted over relatively broad geographic areas; (2) sampling by divers conducted in a localised, shallow eastern area; and (3) sampling by passive, artificial spat collectors at sites in western and eastern fishery areas. Dredge sampling can be an effective method for sampling recruits as they remain attached to large settlement substrata for $3+$ years and to a size greater than $30 \mathrm{~mm}$ in length. Moreover, the left cupped valves of dead recruits attached to the settlement substrata represent oyster mortality and their sizes at death (Cranfield 1968b). The portion of the area on cement board plates (comprising the spat collectors) settled by other organisms was also summarised; this competition for space may affect the space available to $O$. chilensis larvae and ultimately oyster recruitment. 


\section{Benthic habitats and substrates targeted by commercial fishers}

The Foveaux Strait oyster fishers' logbooks record fine spatial-scale catch and effort data from the fishery (Michael et al. 2012b). Daily data are recorded to a spatial resolution of one nautical mile squares based on a grid that covers the main oyster fishery area (Figure 5-1). Bycatch data provide qualitative and semi-quantitative information on the seabed composition (substrate) and the fauna encountered by the dredge to identify important habitats to oyster production. Eight categories are recorded in $10 \%$ increments: (A) empty dredge indicating fine sands only, (B) red algae, (C) kaeos (sea tulips, Pyura pachydermatina), (D) shell, (E) sand, (F) gravel, (G) sponges, and (H) mixed invertebrates (mainly comprising mytilids, ascidians, and bryozoans). Bycatch from fishers' logbook data are summarised graphically for years 2007 to 2016 combined.

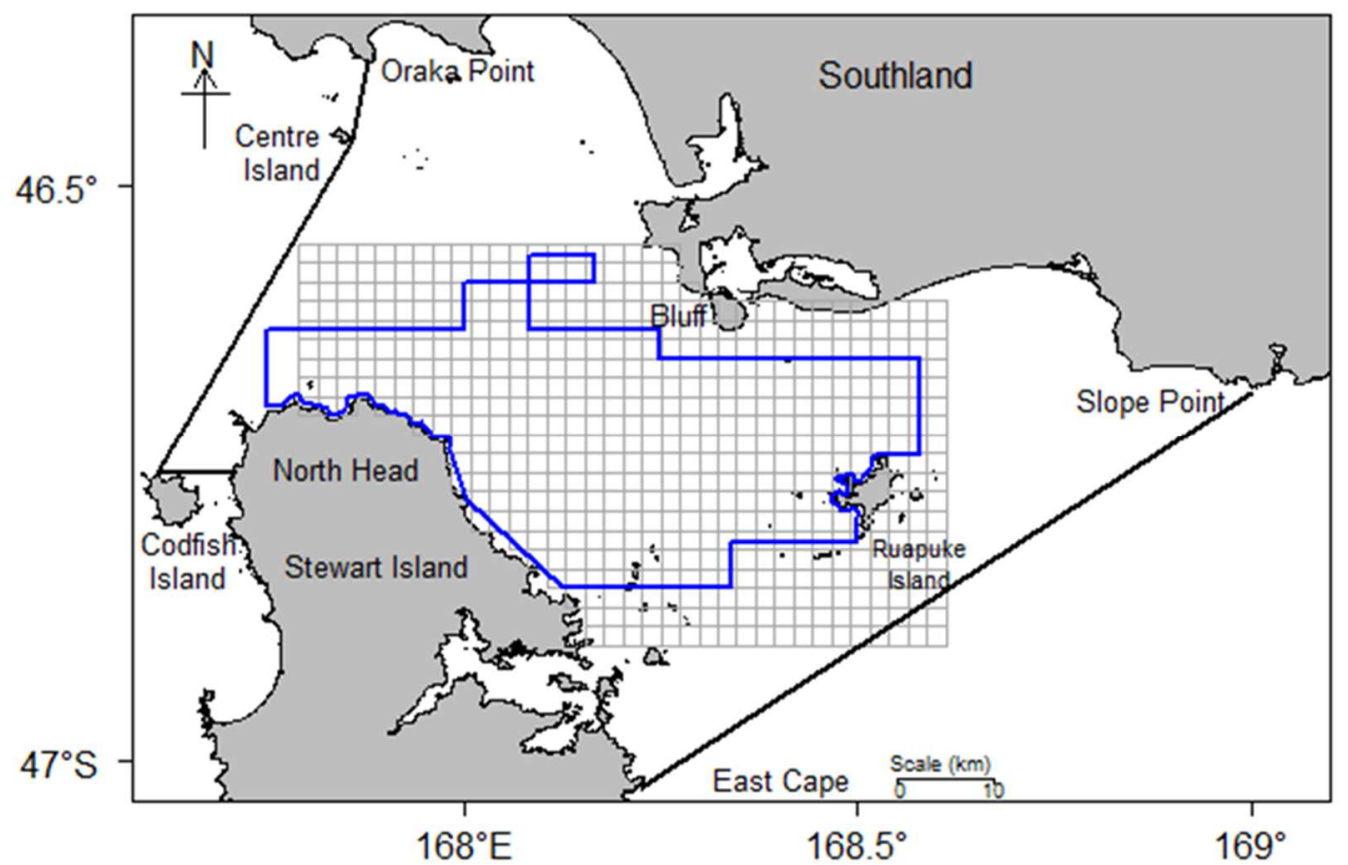

Figure 5-1. Foveaux Strait oyster logbook grid (1 nautical mile squares, grey lines) established by skippers to cover the commercial fishery area. The boundaries of the 2007 stock assessment survey area shown as a blue line. Heavy black lines in the west and east denote the OYU 5 stock boundaries. 


\section{Settlement substrata on which $O$. chilensis settle and survive}

Bycatch to investigate substrata for $O$. chilensis settlement was sampled during fishery surveys in February 2006, 2007, 2010, and 2011 (Figure 5-2), using standard Foveaux Strait oyster dredge sampling methods (see the estimates of spawner densities section in the Appendix). Dredges were landed unwashed to minimise the loss of small shells and other taxa. Dredge size selectivity and dredge efficiency (the scalar used to estimate absolute abundance from dredge samples) most likely vary between different sized and shaped taxa for the initial part of the dredge tow. However, filtration of dredge contents rapidly ceases, which allows sediments and small shells down to a size of c. $10 \mathrm{~mm}$ in diameter to be retained (author's unpublished data). No data on the dredge selectivity of different taxa are available, and the analysis of bycatch assumes similar dredge selectivity and efficiency among bycatch components. The numbers of taxa and their shells with and without recruits $(0+$ year class oysters that settled within months before February surveys) are summarised.

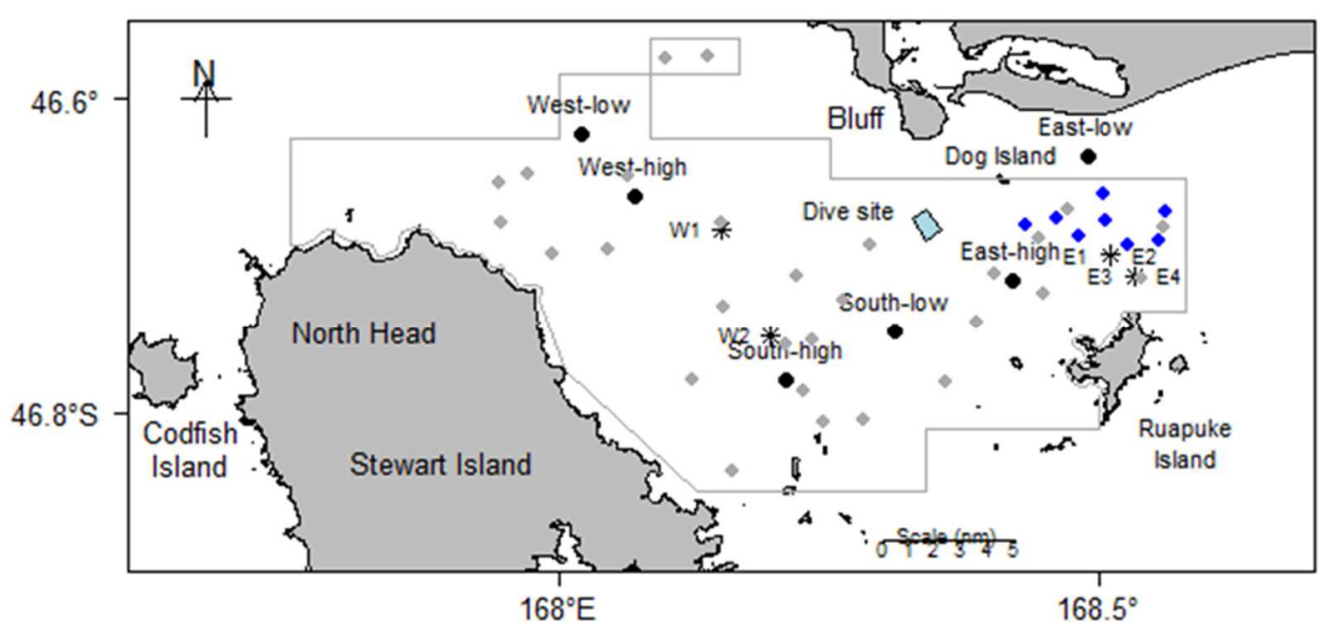

Figure 5-2. The Foveaux Strait oyster fishery area delimited by the grey lines representing boundaries for stock assessment surveys and sites where settlement substrata and bycatch were sampled. Dive and dredge ( 2010 \&2011) sampling was within the area shaded light blue. The fishery-scale spat monitoring sites 2009-2012 are shown as black filled circles (e.g. West-low), and the 1999/2000 spat collector, growth and mortality investigation sites shown as black asterisks (W1 \&W2, E1-E4). Sites sampled for bycatch and oyster spat during the 2006 survey shown in blue diamonds and the 2007 survey in grey diamonds. 
Divers sampled $27 \times 1 \mathrm{~m}^{2}$ quadrats from six shallow ( 20 m) sites in an eastern fishery area in December 2007 (indicated by "Dive site" in Figure 5-2). Data comprised counts of the numbers of shells (valves) of each species, with and without $O$. chilensis recruits. In February 2008, an opportunistic sample from the dive site was taken from a single dredge tow after a high recruitment event (see Chapter 2). Dredge contents were randomly subsampled and counts of valves and shells with and without recruits were scaled to the whole catch (x16 for O. chilensis (OYS), x8 for the mactrid Oxyperas elongata (OEL, Quoy \& Gaimard, 1835), and x1 for the gastropod Astraea heliotropium (ASH; Martyn, 1784). These counts are adjusted for dredge efficiency (0.17) and the area swept by the dredge $\left(1221 \mathrm{~m}^{2}\right)$. Summary statistics of the number of each valve of OYS, OEL, and ASH shells, and the numbers of live and dead oyster recruits are calculated.

\section{Differences in growth and mortality}

Sites selected for growth and mortality studies from historical sampling represent a range of habitats and exposures to oceanic swells (see Figure 5-2, Table 5-1). Of these, only two were available from the western fishery area and four in eastern locations. Sites are described in detail (Cranfield et al. 2004).Western sites (c. $40 \mathrm{~m}$ ) were predominantly sand and shell habitats and subjected to sediment movement during storms (Michael et al. 2008c). Eastern areas were in depths of 18-25 m. These sites habitats were predominantly gravel and shell with higher current flows, and variable sediment stability and benthic structure among sites. Eastern sites were mostly sheltered from oceanic swells although occasionally subjected to mobile sediments (Michael et al. 2008c).

Ostrea chilensis growth is strongly seasonal and only occurs over the summer (Dunn et al. 1998). A recruit and spat growth and mortality study was undertaken between October 1999 and March 2000, over the growing period. Spring storms are also frequent over this time, and some mortality was expected 
over this period. The Bluff Oyster Management Company Limited (BOMC) provided two year classes of settlers for this study, oyster recruits and spat. The 0+ year class recruits (hereafter recruits) comprised late stage larvae collected from oysters harvested from Foveaux Strait before the 1999 oyster season and settled on oyster valves held in mesh bags. The 1+ year old oyster spat (hereafter spat) were settled by the same method as the recruits in 1998, and in October 1998 transferred to wharfs in Bluff Harbour and held in suspended culture until October 1999 when mean diameter of recruits was c. $0.5 \mathrm{~mm}$ and mean diameter of spat was $8.6 \mathrm{~mm} \pm 0.1 \mathrm{~mm}($ mean $\pm \mathrm{SE})$.

Table 5-1. Locations of the six sites used for growth and mortality investigations, where cement board sticks with $0+$ recruits and 1+ spat on oyster shell (single valves), and spat collectors were deployed. Two sites selected in the western fishery area and four in eastern locations representing a range of habitats and exposures to oceanic swells (see Figure 5-2).

\begin{tabular}{lrrrr}
\hline Site & $\begin{array}{r}\text { Latitude } \\
\text { Deg }\end{array}$ & Min & $\begin{array}{r}\text { Longitude } \\
\text { Deg }\end{array}$ & Min \\
\hline W1 & 46 & 40.9640 & 168 & 9.0449 \\
W2 & 46 & 45.0164 & 168 & 11.7619 \\
E1 & 46 & 41.9453 & 168 & 30.6194 \\
E2 & 46 & 41.9453 & 168 & 30.6194 \\
E3 & 46 & 42.7541 & 168 & 31.9956 \\
E4 & 46 & 42.7541 & 168 & 31.9956 \\
\hline
\end{tabular}

Estimates of mean densities of recruits and spat were made from thirty randomly selected valves of each year class. Each oyster valve contained at least twenty recruits or spat. At the end of the study in March 2000, counts of live and dead recruits or spat per valve were recorded. Numbered cement board sticks (900 mm long, $120 \mathrm{~mm}$ wide and $9 \mathrm{~mm}$ thick) had ten oyster valves with either recruits or spat attached with cable ties. Hand drawn maps recorded the orientation of each oyster valve on the sticks and the location of each numbered recruit or spat on the valves. The orientation of each oyster valve recorded as cupped valve up (CU), cupped valve down (CD), flat valve up (FU), and flat 
valve down (FD). Only spat were measured for height (greatest distance dorsal ventral axis) and length (anterior posterior axis) to the nearest millimetre down in situ before deployment. Only oyster valve orientation was recorded from cement board sticks with recruits. The sticks were held in slotted boxes to protect valves from mechanical damage and held in flowing seawater until they were set out on the seabed in Foveaux Strait.

At each site (see Figure 5-2), five sticks with recruits, five sticks with spat, and five passive spat collectors were pegged to the seabed by divers in October 1999. Spat collectors consisted of a reinforced concrete base with a steel frame holding 4 cement board settlement plates. The settlement plates were not conditioned before deployment (see Chapter 2). Differential Global Positioning Systems (DGPS) with less than $1 \mathrm{~m}$ positioning accuracy was used to record the site locations where sticks and collectors were haphazardly distributed on the seabed.

Divers recovered the cement board sticks in March 2000 after deployments of between 130 and 138 days. Data on the height and length of recruits and spat, along with their status as alive or dead were recorded. Height and length data of spat at recovery were recorded against their initial measurements determined from their unique identifier comprising: stick, valve, and spat numbers and their location on the shell maps. The data for recruits were similarly recorded; however, because recruits were deployed to the seabed shortly after settlement, growth increments (length and height) were therefore the sizes of live recruits in March 2000. For live spat, growth increments were the differences in size between October 1999 and March 2000.

Once $O$. chilensis larvae settle, the juvenile shell grows quickly, extending away from initial larval shell (prodissoconch). During this time of rapid growth, the left valve remains attached to the settlement substratum for two to three years. Oyster spat that have died leave a record of their size at death, 
as either the whole shell (articulated valves) or only the attached left valve. The percentage size frequencies of dead spat provide information on when postsettlement mortality occurs. Estimates of mortality calculated as the proportion of dead to all spat (dead and alive) at March 2000. In addition to those recruits deployed on sticks, some larvae settled from the plankton and completed metamorphosis on the cement board sticks after they were deployed to the seabed. These $0+$ year recruits are distinguished in the data as "natural-recruits". Growth and mortality in recruits, natural-recruits and spat, are estimated separately. To avoid any confusion, no records were made of natural-recruits from shells on sticks with recruits. These data allow comparisons between sites, and the performance of recruits and natural-recruits.

The shapes of fast-growing juvenile oyster shells are determined by the available space around them, and their shapes may vary. Dunn et al. (1998) estimated growth as change in diameter ((length + height $) / 2)$. This research records growth as diameter, except for settler data from spat collectors recorded as heights only. Height and diameter are highly correlated $(\mathrm{R}=0.96)$, and for the small size range of recruits and spat, differences were negligible (less than 0.5 $\mathrm{mm})$.

\section{The survival and growth of recruits at different heights above the seabed}

Divers also recovered passive artificial spat collectors in March 2000, at the same time cement board sticks were recovered (after deployments of between 130 and 138 days). Data from recruits that settled on spat collectors were recorded by site, collector, height off the seabed (levels 1-4: $36 \mathrm{~cm}, 24 \mathrm{~cm}, 12$ $\mathrm{cm}$, and $\sim 2 \mathrm{~cm}$ respectively), and surface (upper and lower). Their heights only, and status as live or dead recorded as for recruits and spat from the cement board sticks. 


\section{Data summaries and analysis}

A Poisson distribution best represented the overdispersed settler count and size data. Samples contained different numbers and these data often contained missing values and were therefore analysed using non-parametric methods. Tests for overall significant differences among groups used the Wilcoxon rank sum (also known as Mann-Whitney test) and Kruskal-Wallis tests for pairwise comparison using the stats v3.5.1 package in $\mathrm{R}$ ( $\mathrm{R}$ Core Team 2016). Summary statistics are given as means with $95 \%$ CI or medians, $5^{\text {th }}$ and $95^{\text {th }}$ percentiles as appropriate.

\section{Results}

\section{Benthic habitats targeted by commercial fishers}

Benthic habitats and substrates targeted by commercial fishers are determined from fishers' logbook data. The oyster season in Foveaux Strait is 1 March to 31 August. Logbook data (2006-2017, 9241 records) represent 100\% of the catch from commercial fishing and prospecting (exploratory fishing) over that time. Almost all fishing occurred in areas of shell, sand and gravel dominated substrates (Figure 5-3), and these areas are likely to represent the most productive areas in the fishery. Mostly small volumes of epifaunal bycatch were present in the 8250 commercial dredge tows (Figure 5-3): sponges were present in $20.1 \%$ of tows and mixed invertebrates (comprised mytilids, ascidians, and bryozoans) in $24.9 \%$ of tows. Because of the greatly overdispersed percentages of these bycatch categories (Figure 5-3), median percentages and percentiles are given. Very few tows contained high percentages of biogenic bycatch. Of the tows that contained sponges or and mixed invertebrates, sponges accounted for a median of 5\% (5th \& 95th percentiles: $1 \% \& 30 \%$ ) and mixed invertebrates $5 \%$ (5th \& 95th percentiles: $1 \%$ \& 50\%) of 
the bycatch volume excluding oysters. This composition suggests some regeneration of epibenthic fauna as proposed by Cranfield et al. (2001).

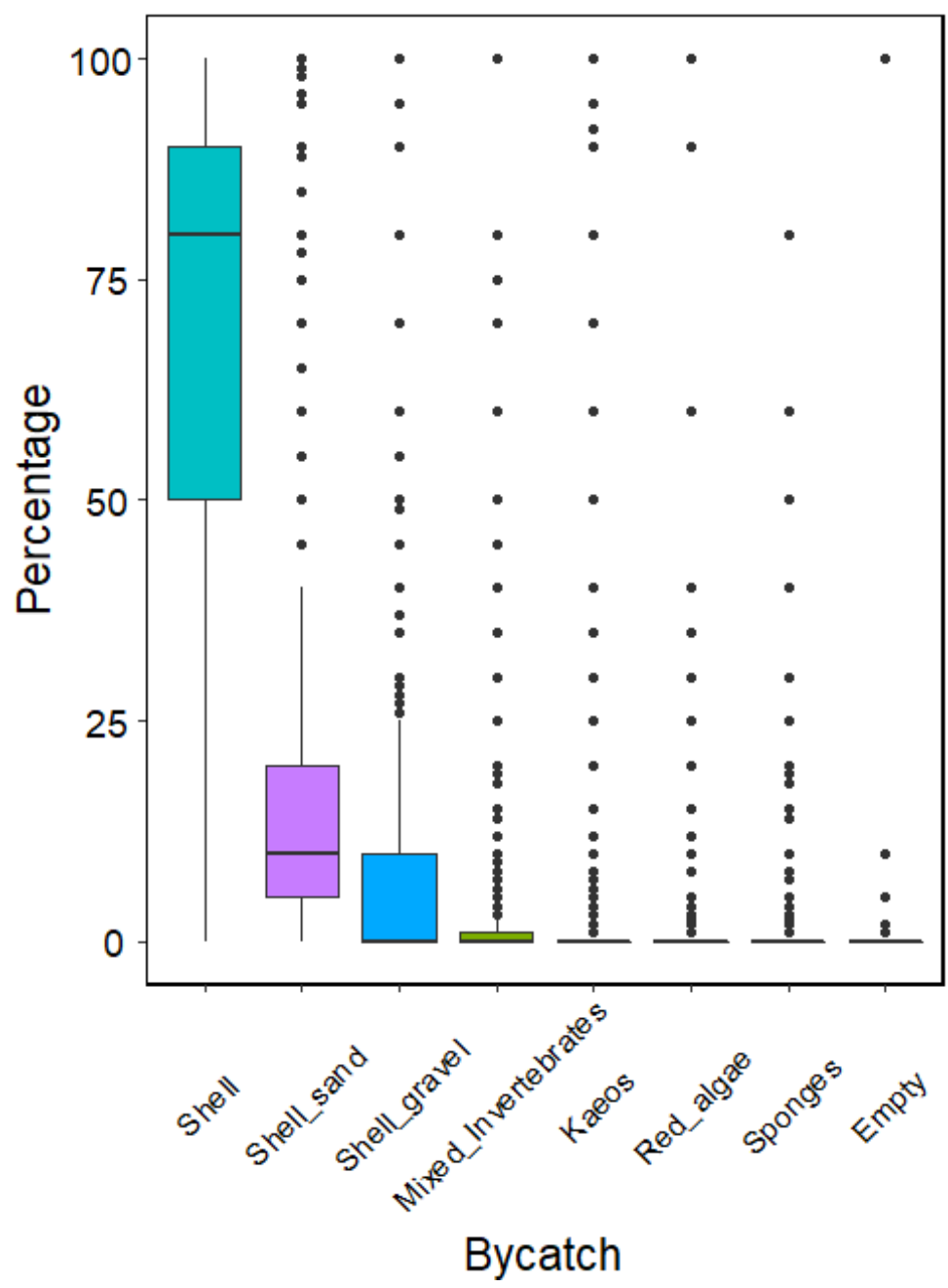

Figure 5-3. The percentage occurrences of each bycatch category from fishers' logbook data representing $100 \%$ of the catch for years (oyster seasons, 1 March to 31 August) 2007 to 2016 combined. Kaeos (sea tulips, Pyura pachydermatina) and mixed invertebrates mainly comprise mytilids, ascidians, and bryozoans. Boxplots show medians (solid lines) and the boxes the 25 and 75 percentiles. Whiskers shown at the 95 percentiles, with outliers shown as black circles outside of this range. 


\section{Ostrea chilensis settlement substrata}

Settlement substrata on which $O$. chilensis settle and survive were determined from the combined bycatch data from dredge sampling in 2006, 2007, 2010, and 2011. Although all benthic habitats were not sampled in the fishery area, fishers target high densities of oysters where ever they occur. Anecdotal evidence and Fleming (1952), Cullen (1962), Stead (1971b), Robjohns (1979), and Hill et al. (2010) suggest oyster densities are low in biogenic habitat; however, high densities of oysters can occur on the edges of "biogenic reefs" after Cranfield et al. (1999). Catches comprised the shells and live animals of 64 taxa $(n=13650)$. Recruits readily settled on the shells of live and dead $O$. chilensis (OYS) and the gastropod Astraea heliotropium (ASH). Together, the two substrata accounted for $90.8 \%$ of all post-settlement survivors (larvae that has settled and completed metamorphosis) (Table 5-2). Shells of the mytilid Modiolus areolatus (MOA, Gould, 1850), barnacles (Balanus spp.), and the mactrid Oxyperas elongate (OEL) accounted for a substantial portion of the remainder (Table 5-2). The percentages of live OYS, OYS_shell, and live ASH with settlers over all taxa was similar between 2006 and 2007: live OYS 42.6\% and $40.2 \%$, OYS shell $24.5 \%$ and $23.6 \%$, and ASH $18.9 \%$ and $20.7 \%$ respectively. Data from this research show live OYS and their shells are the most important substrata for settlement and survival. 
Table 5-2. Taxa and shells representing greater than $1 \%$ of the total bycatch composition by number that had $O$. chilensis recruits attached. Taxa: $O$. chilensis (OYS), the gastropod Astraea heliotropium (ASH), the Mytilid Modiolus areolatus (MOA), barnacles Balanus spp. (BAR), the mactrid Oxyperas elongate (OEL), and their shells denoted by suffix (_Shell). Numbers of each bycatch component (n), those with settlers attached (n.Recruits), the percentage of each bycatch component that had settlers attached (\%), the percentage of all bycatch components (\% TWS), and the percentage of all bycatch sampled with recruits attached (\% AWS).

\begin{tabular}{lrrrrr}
\hline Taxa & n & n.Recruits & \% & \% TWS & \%AWS \\
\hline OYS & 7817 & 390 & 5.0 & 48.6 & 3.1 \\
OYS_Shell & 2370 & 146 & 6.2 & 18.2 & 1.1 \\
ASH & 211 & 112 & 53.1 & 14.0 & 0.9 \\
ASH_shell & 675 & 80 & 11.9 & 10.0 & 0.6 \\
MOA_shell & 803 & 42 & 5.2 & 5.2 & 0.3 \\
BAR_shell & 219 & 16 & 7.3 & 2.0 & 0.1 \\
OEL_Shell & 489 & 8 & 1.6 & 1.0 & 0.1 \\
& & & & & \\
Totals & 12545 & 794 & & & \\
\hline
\end{tabular}

Samples collected by divers in December 2007 comprised mostly OYS $(\mathrm{n}=408)$ and OEL $(\mathrm{n}=145)$ shells. Samples did not contain any live recruitsized oysters. A mean of $87.5 \%$ (95\% CI 75.2 - 99.7\%) of all O. chilensis recruits were on OYS shell. The mean number of OYS valves with one or more recruits was $13.9 \%$ (95\% CI $6.3-21.4 \%$ ) and the mean of OEL valves with one or more recruits was $1.4 \%$ (95\% CI $0-3.1 \%)$. Dredge sampling 3 months later found most $O$. chilensis recruits were OYS shell (77.8\%), with some OEL (22.2\%) and only a few ASH shells (Table 5-3). The numbers of recruits per valve were similar between bycatch components (Table 5-3). 
Table 5-3. Estimates of the numbers of valves with and without recruits sampled from a single tow at the dive site in February 2008 (see light blue shaded area in Figure 5-2). Summary statistics of the number of each type of valve OYS, OEL, and ASH, and the numbers of live and dead oyster recruits. Percentage survival is the number of live recruits as a percentage of all recruits (live and dead).

\begin{tabular}{lrrrr}
\hline & OYS & OEL & ASH & All valves \\
\hline Total all valves & 7,248 & 2,064 & 4 & 9,316 \\
Number valves with spat & 4,960 & 1,336 & 4 & 6,300 \\
Percent of all valve types & 77.8 & 22.2 & 0 & 100 \\
Percent with spat & 68.4 & 64.7 & 100 & - \\
Percent of all valves, all & 53.2 & 14.3 & 0 & - \\
types with spat & & & & \\
& & & & 27,496 \\
Total number of spat (live & 21,056 & 6,424 & 16 & \\
and dead) & & & & \\
Spat per valve & 2.9 & 3.1 & 4 & \\
Number of live spat & 16,480 & 5,616 & 4 & \\
Percentage survival & 78.3 & 87.4 & 25 & \\
\hline
\end{tabular}

The effects of collector plate coverage by benthic taxa on Ostrea chilensis settler densities

Spat collector surfaces settled by benthic taxa combined covered a median surface area of $30 \%$, ranging from $0 \%$ to $100 \%$ (Figure 5-4). Primarily filamentous algae accounted for a median of 3\% (range: $0 \%$ to $90 \%$ ), barnacles (mostly Balanus decorus, Darwin, 1854) a median of 5\% (range: 0\% to 95\%), and other species combined a median of 3\% (range: $0 \%$ to $41 \%$ ). No inhibition of $O$. chilensis settlement or competition for settlement space was detected (Figure 5-5). An upward trend in settler densities with increasing cover may reflect local-scale current flows and the numbers of all larvae encountering the spat collectors. 


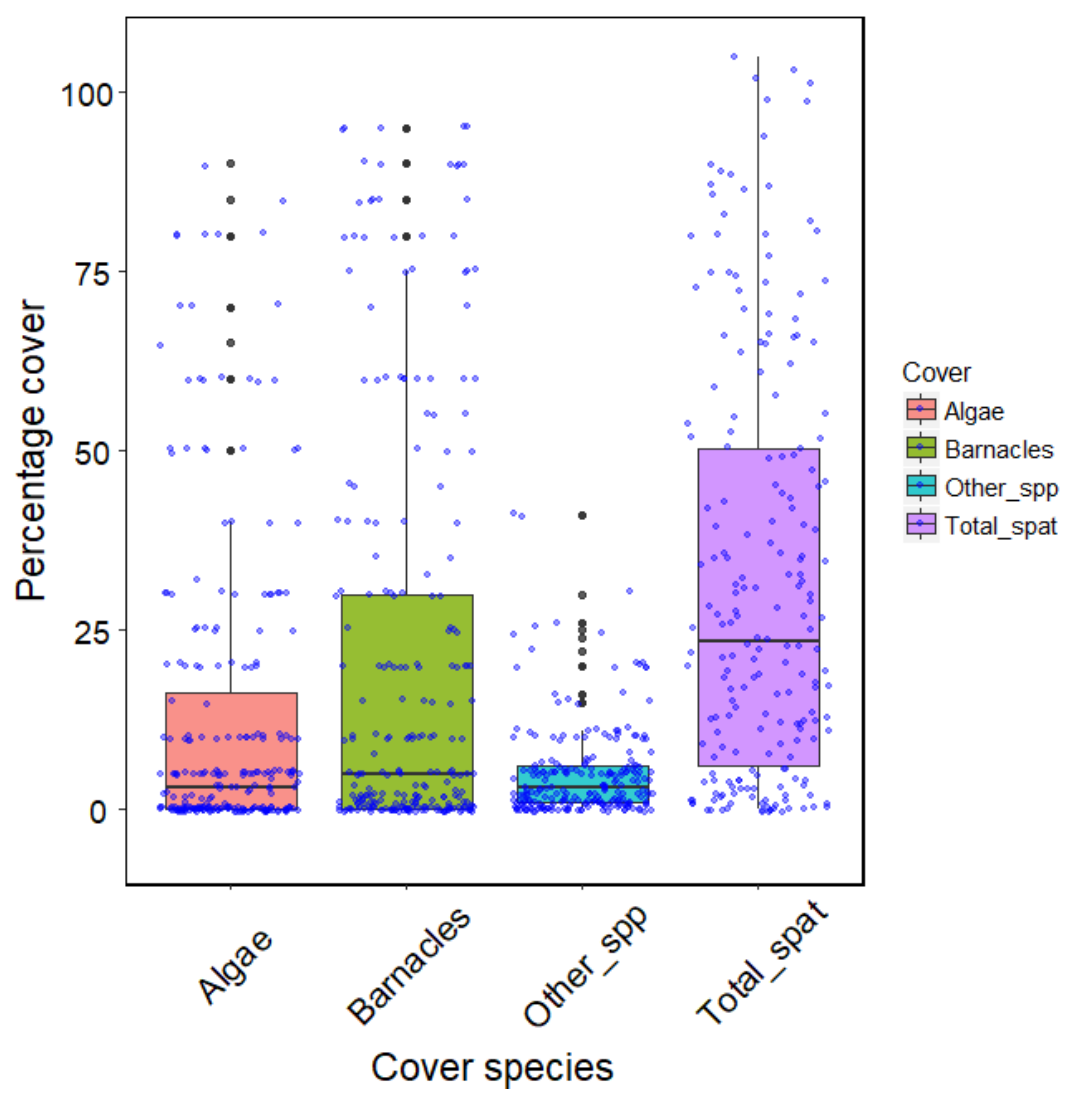

Figure 5-4. Percentage cover of collector plates by three categories of benthic taxa (algae, barnacles, other species) and by total cover by all taxa. Boxplots show medians (solid lines), boxes 25 and 75 percentiles, whiskers at 95 percentiles, and outliers shown as black circles above and below whiskers. 


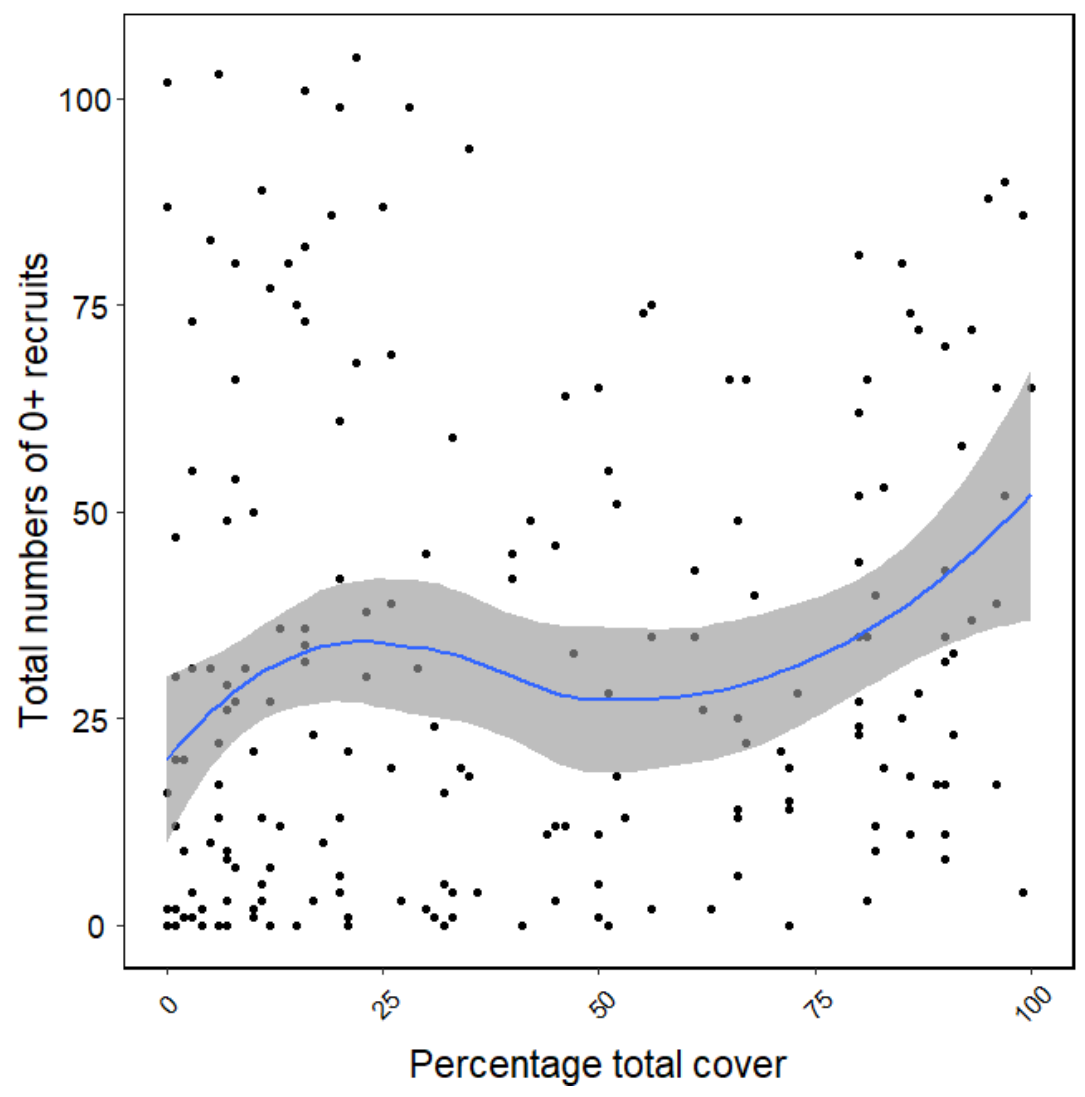

Figure 5-5. Total numbers of recruits versus percentage cover of all other benthic taxa combined by plate surface. Fitted line is a loess smoother and shaded area depicts \pm 1SE.

\section{Growth}

Recruits across all sites $(\mathrm{n}=1232)$ grew to a mean diameter of $4.5 \mathrm{~mm}$ $\left(5^{\text {th }} \& 95^{\text {th }}\right.$ percentiles: $\left.2.0 \& 8.5 \mathrm{~mm}\right)$, and natural-recruits $(\mathrm{N}=138)$ grew to a median diameter of $4.5 \mathrm{~mm}$ ( 5 th $\neg 95$ th percentiles $2.0-9.5 \mathrm{~mm})$. Natural-recruit sizes may represent several settlement events (larval cohorts). Growth in recruits and natural-recruits was not significantly different across all sites $(\mathrm{p}=0.659)$. Recruits on passive collectors $(n=10918)$ across all sites and all levels (heights above the seabed) grew to a median height of $5.0 \mathrm{~mm}$ (5th \& 95th percentiles 2 \& $10 \mathrm{~mm})$. Spat recovered in March $2000(\mathrm{n}=714)$ had a median diameter of 
$17.0 \mathrm{~mm}(5$ th $\&$ 95th percentiles $8.5 \& 27.0 \mathrm{~mm})$. Mean increment in diameter after c. 140 days grow out was $8.0 \mathrm{~mm}$ (95\% CI: 1.5-15.5).

\section{Differences in growth between western and eastern sites}

Growth in $0+$ recruits on cement board sticks differed significantly between western and eastern areas $(\mathrm{p} \leq 0.001)$, which had median diameters of $2.5 \mathrm{~mm}$ and $4.5 \mathrm{~mm}$ respectively. Growth also differed significantly between sites, recruits grew significantly less at western sites (W1 \& W2) $(\mathrm{p} \leq 0.001)$ (see Figure 5-6 and Table 5-4).

The numbers of live natural-recruits on shells that settled from the plankton and survived after metamorphosis were low. Recruit growth differed significantly $(\mathrm{p} \leq 0.001)$ between western and eastern areas, with median diameters of $2.7 \mathrm{~mm}$ in the west and $4.5 \mathrm{~mm}$ in the east. Growth also differed significantly between sites $(\mathrm{p} \leq 0.001)$, and recruits grew less at W2 $(\mathrm{p}<0.023)$ than the other five sites including W1, (see Figure 5-6 and Table 5-4).

Growth of all recruits on artificial spat collectors was not significantly different between western and eastern areas $(\mathrm{p}=0.29)$. A key difference between recruits on collectors and recruits attached to shells on cement board sticks is that recruits on collectors are mostly growing above the seabed and recruits attached to shells are on the seabed. Growth of recruits on all plates and levels was significantly different between sites ( $\mathrm{p} \leq 0.001$, Figure 5-7 and Table A-5 in the growth and mortality $0+$ recruits and $1+$ spat section in the Appendix), pairwise Wilcox test showed growth at only three sites were not significantly different (E1 \& E2, E1 \& W1, and E4 \& W2). Recruit sizes were significantly different both between heights (levels), and between upper and lower plate surfaces ( $\mathrm{p} \leq 0.001$, respectively). All combinations of levels, top to bottom (360 $\mathrm{mm}, 240 \mathrm{~mm}, 120 \mathrm{~mm}$, and $20 \mathrm{~mm}$ off the seabed) except for the middle two plates (Level $2 \&$ Level 3) were significantly different $(p \leq 0.001)$ to each other. 
The largest recruits were on the highest plates (Level 1) above the seabed and recruits closest to the seabed (Level 4) were smaller than for levels 1-3. Recruit size at level 4 was not significantly different between sites ( $\mathrm{p}=0.857)$, Figure 57 and Table A-5 in the growth and mortality $0+$ recruits and 1+ spat section in the Appendix. Recruits on the upper surfaces of plates were significantly larger than those on the under/lower surfaces $(\mathrm{p} \leq 0.001)$.

Spat (1+) growth increments (diameter) were not significantly different $(\mathrm{p}=0.086)$ between eastern and western areas; however, these increments were significantly different $(\mathrm{p} \leq 0.001)$ between sites (Figure A-10 in the growth and mortality 0+ recruits and 1+ spat section in the Appendix and Table 5-5). Spat grew less than the mean for all sites at W2 and more than all sites at E4 (Figure A-10 in the growth and mortality $0+$ recruits and $1+$ spat section in the Appendix). 


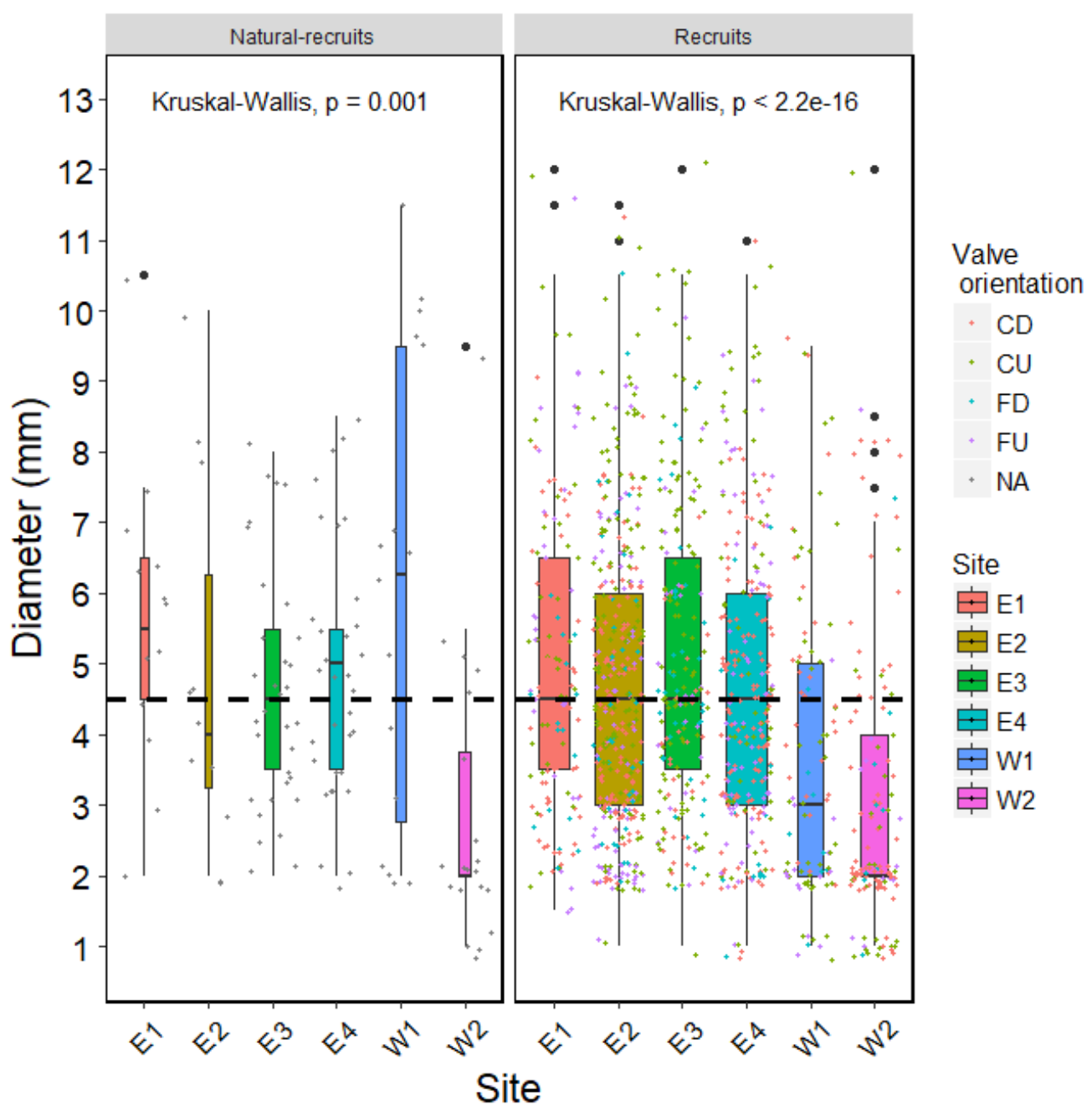

Figure 5-6. Size (diameter $\mathrm{mm})$ of recruits $(0+$ oyster spat): natural-recruits (left panel) and recruits (right panel) at March 2000 (less than 140 days after settlement) by site and valve orientation. Jittered data points represent spat size coloured by valve orientation. Boxplots show medians (solid lines), mean (heavy dashed line), boxes at the 25 and 75 percentiles. Whiskers show at the 95 percentiles with outliers shown as black circles above and below whiskers. Bar widths scaled to the relevant sample sizes. 


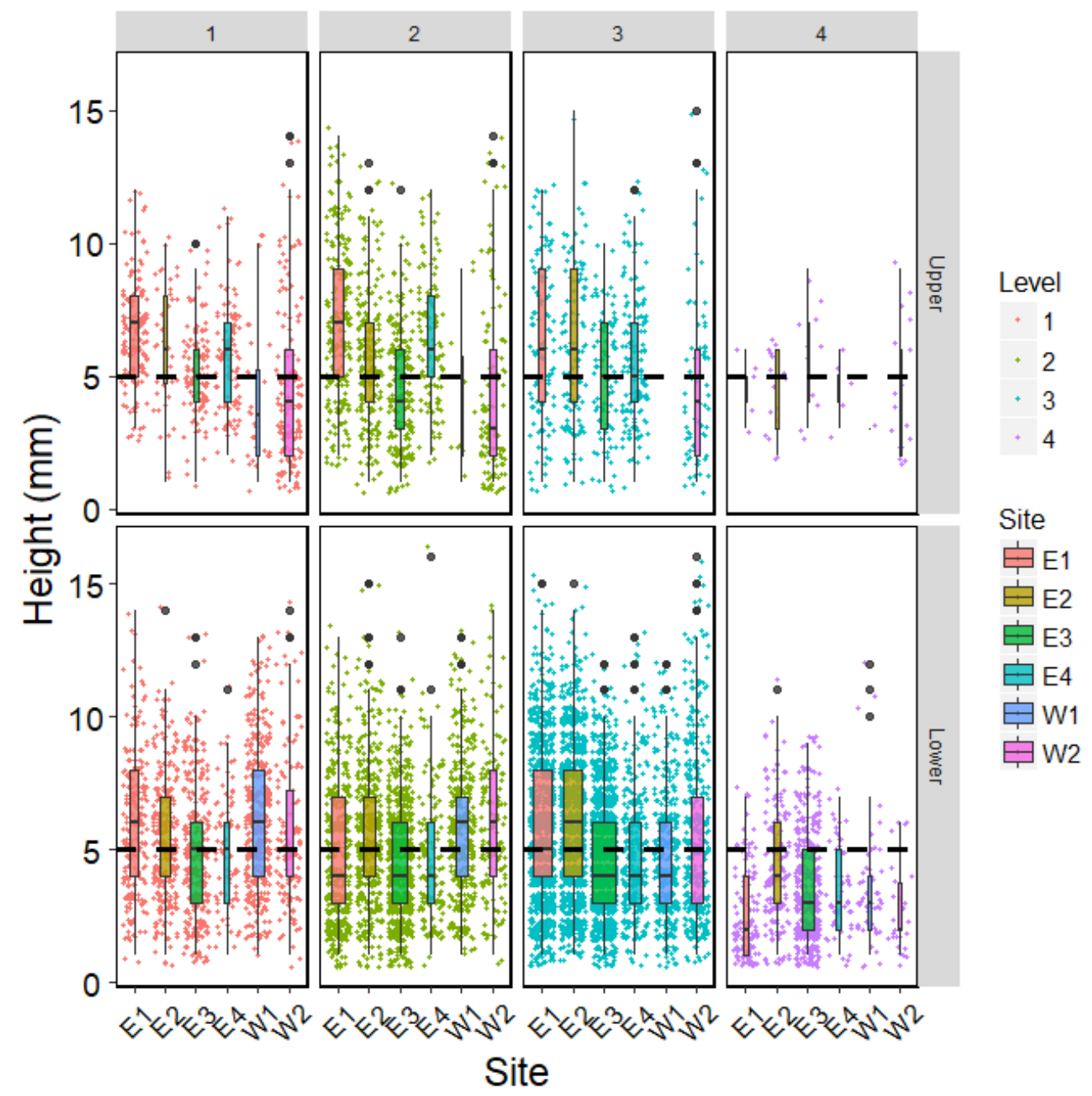

Figure 5-7. Heights ( $\mathrm{mm})$, as a proxy for diameter of recruits (0+ oyster spat) settled on passive spat collectors at six sites in Foveaux Strait between October 1999 and March 2000 (c. 140 days). There is stratification by plate height, and by plate surface. Plate heights (level) $1-4$ are at $36 \mathrm{~cm}, 24 \mathrm{~cm}, 12 \mathrm{~cm}$, and $\sim 2 \mathrm{~cm}$ (just off the seabed) respectively. There were two surfaces to each plate: the upper and lower (under side). Jittered data points represent spat size coloured by level.

Boxplots show medians at each site (solid lines), mean height for all recruits at all sites (heavy dashed line), boxes 25 and 75 percentiles, whiskers at 95 percentiles, and outliers shown as black circles above and below whiskers. Bar widths scaled to sample sizes. 
Table 5-4. Growth in 0+ recruits and natural-recruits recovered in March 2000 (c. 140 days) at six sites in Foveaux Strait (see Figure 5-2). Median diameter $\mathrm{mm}$ (Median), mean diameter for comparison (Mean), $5^{\text {th }}$ and $95^{\text {th }}$ percentiles (P 0.05 \& P 0.95), and sample sizes (n).

\begin{tabular}{lrrrrr}
\hline Site & Median & Mean & P 0.05 & P 0.95 & n \\
\hline Recruits & & & & & \\
E1 & 4.5 & 5.0 & 2.0 & 8.6 & 157 \\
E2 & 4.5 & 4.7 & 2.0 & 8.5 & 373 \\
E3 & 4.5 & 5.1 & 2.0 & 9.0 & 198 \\
E4 & 4.5 & 4.7 & 2.0 & 8.5 & 283 \\
W1 & 3.0 & 3.7 & 1.0 & 8.1 & 98 \\
W2 & 2.0 & 3.1 & 1.0 & 8.0 & 123 \\
& & & & & \\
Natural-recruits & & & & & \\
E1 & 5.5 & 5.6 & 2.7 & 8.6 & 14 \\
E2 & 4.0 & 4.8 & 2.0 & 9.0 & 11 \\
E3 & 4.5 & 4.6 & 2.3 & 7.5 & 33 \\
E4 & 5.0 & 4.8 & 2.0 & 8.0 & 33 \\
W1 & 6.3 & 6.0 & 2.0 & 10.4 & 16 \\
W2 & 2.0 & 2.9 & 1.0 & 5.7 & 20 \\
\hline
\end{tabular}

Table 5-5. Growth increments in diameter $(\mathrm{mm})$ in 1+ oyster spat recovered in March 2000 after c. 140 days at 6 sites in Foveaux Strait (see Figure 5-2). Median diameter $\mathbf{m m}$ (Median), mean diameter for comparison (Mean), $5^{\text {th }}$ and $95^{\text {th }}$ percentiles $(P 0.05 \& P(0.95)$, and sample numbers $(n)$.

\begin{tabular}{lrrrrr}
\hline Site & Median & Mean & P 0.05 & P 0.95 & n \\
\hline E1 & 8.0 & 7.9 & 2.5 & 13.5 & 152 \\
E2 & 7.8 & 7.9 & 2.5 & 13.5 & 124 \\
E3 & 9.0 & 9.4 & 2.6 & 17.9 & 85 \\
E4 & 9.5 & 9.9 & 3.5 & 15.4 & 63 \\
W1 & 9.0 & 8.8 & 2.6 & 15.5 & 124 \\
W2 & 6.5 & 7.3 & 1.0 & 16.5 & 166 \\
\hline
\end{tabular}

Mortality

The loss of $0+$ recruits from oyster shell (valves) on cement board sticks pegged to the seabed was high and only a small percentage (up to 25\%) of the estimated 200 recruits per valve initially attached to shells were found at the time of recovery. Of the recruits that remained, the distributions of their mortalities 
by valve ( $\mathrm{n}=289$ valves) was bimodal (Figure 5-8); generally, there was either no mortality (on between $52.5 \%$ and $72.5 \%$ of individual valves), or all spat died (100\% mortality on between $2.5 \%$ and $40.0 \%$ of valves).

Mortality of recruits on passive spat collectors from all sites, collectors, levels and surfaces combined $(\mathrm{n}=224)$ was $17.1 \%(95 \%$ CI $14.0 \%-20.3 \%)$. Mortality was similar to that estimated for $0+$ recruits that had naturally settled on Ostrea chilensis (OYS) and Oxyperas elongata (OEL) shells (21.7-22.6\%) sampled by divers in December 2007 (see Table 5-2). Most O. chilensis recruits (65.7\%) died between $2 \mathrm{~mm}$ and $5 \mathrm{~mm}$ in diameter (Figure 5-9). Mean size of all dead recruits from all collectors and growth studies $(n=570)$ in 1999/2000 was $5.7 \mathrm{~mm}(95 \%$ CI $5.3-6.0 \mathrm{~mm})$. Settler mortality does not appear to be density dependent (Figure 5-10).

Mortality of spat (1+) by valve varied within sites. Mean percent mortality per valve $(n=257$ valves) was $59.3 \%$ (95\% CI $55.5-63.1 \%)$. 


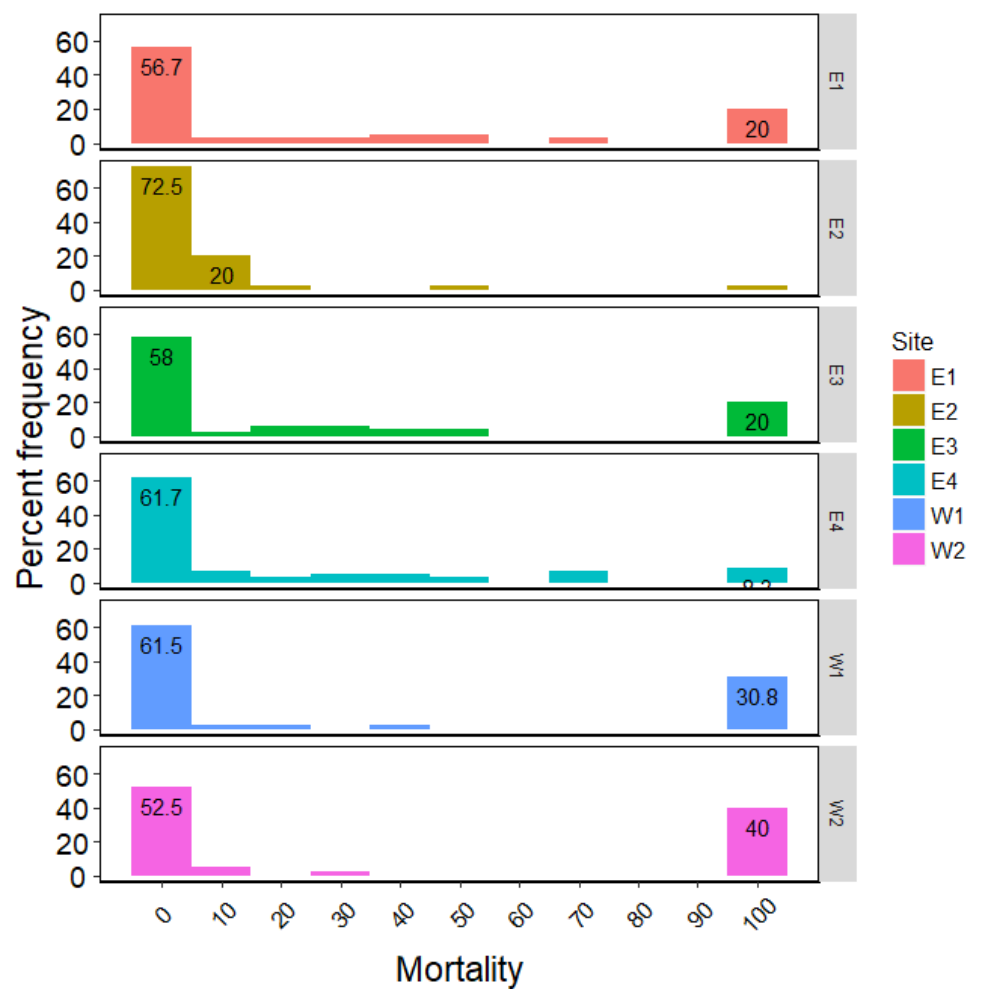

Figure 5-8. Mortality (percentage frequency of spat by valve) of recruits $(0+)$ by site, between October 1999 and March 2000.

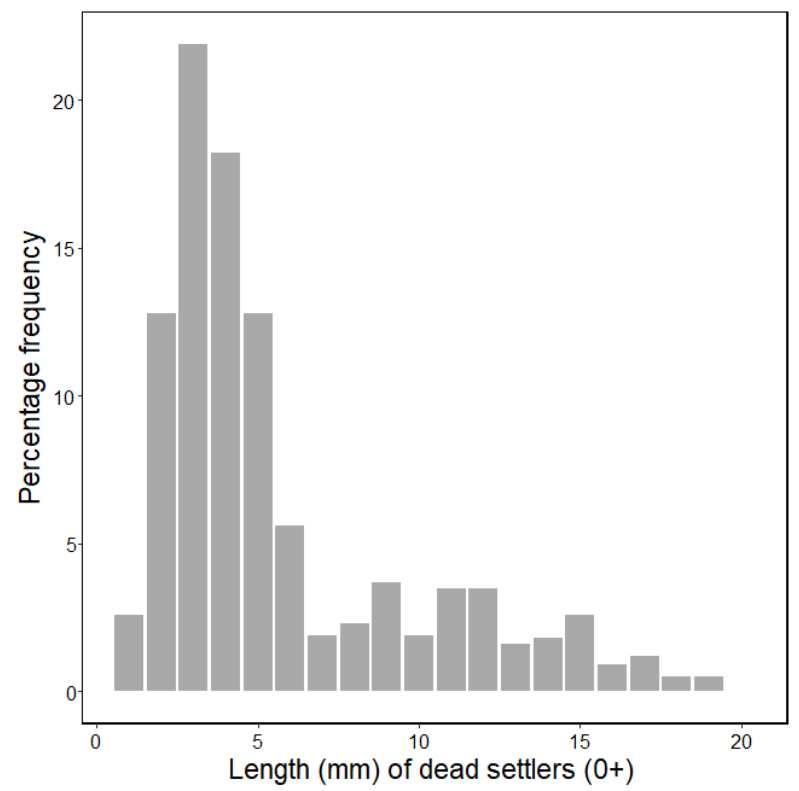

Figure 5-9. Percentage length frequency of dead $O$. chilensis recruits (left valves) from spat collectors and oyster shells of growth experiments that died post settlement between October 1999 and March 2000. 


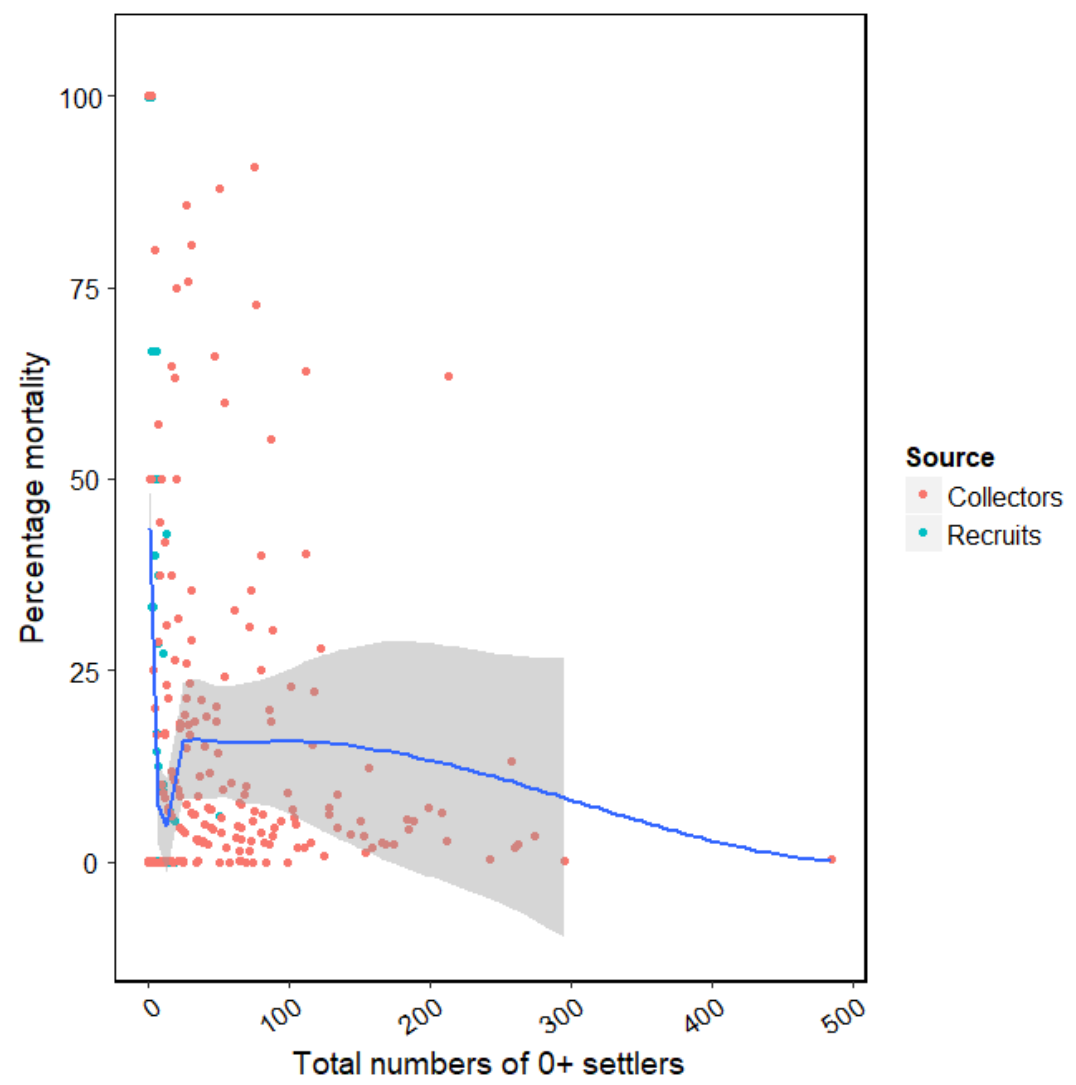

Figure 5-10. The percentage mortality in $O$. chilensis, recruits $(0+)$ by total numbers of recruits. Fitted line is a loess smoother and shaded area depicts \pm 1 SE. Mortality of recruits from spat collectors (Collectors) by surface shown as pink dots and recruits attached to shells on cement board sticks as blue dots.

\section{Differences in mortality between western and eastern sites}

Mortality of $0+$ recruits attached to shells on cement board sticks was not significantly different between western and eastern areas $(\mathrm{p}=0.079)$ and between sites $(\mathrm{p}=0.078)$. Mortality was significantly different between valve orientation $(\mathrm{p}=0.006)$; it was lower on cupped valve up (CU) than on flat valve down (FD) $(\mathrm{p}<0.001)$, and on cupped valve down $(\mathrm{CD})$ than on flat valve down (FD) $(\mathrm{p}=0.022)$. The loss of recruits from oyster shell (valves) held on the seabed at the different sites was greater than $18.9 \%$ at E1, 38.5\% at E2, $22.1 \%$ at E3, 32.6\% at $\mathrm{E} 4,11.3 \%$ at $\mathrm{W} 1$; and $14.3 \%$ at $\mathrm{W} 2$. The instantaneous mortality of all recruits 
could not be estimated because losses from individual valves could not be quantified; however, if the estimate of 200 recently settled spat per valve in October 1999 is correct, mortality may be $>90 \%$ if the recruits assumed to be missing between October 1999 and March 2000 are included as dead.

Mortality of spat $(1+)$ per valve was significantly different $(\mathrm{p} \leq 0.001)$ between sites, in pairwise comparisons (Figure A-11, in the growth and mortality $0+$ recruits and $1+$ spat section in the Appendix). However, was not significantly different between western and eastern area $(\mathrm{p}=0.253)$, and was not significantly different between valve orientations $(\mathrm{p}=0.13)$ (Table A-6 in the growth and mortality $0+$ recruits and $1+$ spat section in the Appendix).

\section{Differences in mortality with height above the seabed}

Mortality of $0+$ recruits on spat collectors was significantly different between sites ( $\mathrm{p} \leq 0.001)$ (Figure 5-11), between levels $(\mathrm{p} \leq 0.007)$, and between surfaces $(\mathrm{p}=0.049)$ (Figure 5-12 and Table 5-6). On average, mortality on lower plates was significantly different to plates higher on collectors, and the mortality on the upper surfaces of plates significantly higher than on the lower surfaces (Table 5-6). 
Table 5-6. Mortality of $0+$ recruits settled on passive spat collectors between October 1999 and March 2000 (c. 140 days in Foveaux Strait) by Site, Level, and Surface. Mean (mean), standard deviation (SD), numbers of surfaces with settler (n), standard error of the mean (SE), and upper and lower $95 \%$ confidence intervals $(95 \% \mathrm{CI})$ for lengths $(\mathrm{mm})$.

\begin{tabular}{lrrrrrr}
\hline & Mean & SD & n & SE & $\begin{array}{r}\text { Lower } \\
\text { CI }\end{array}$ & $\begin{array}{r}\text { Upper } \\
\text { CI }\end{array}$ \\
\hline Site & & & & & & \\
E1 & 22.0 & 29.1 & 39 & 4.7 & 12.6 & 31.4 \\
E2 & 20.3 & 26.2 & 39 & 4.2 & 11.8 & 28.8 \\
E3 & 8.4 & 10.7 & 39 & 1.7 & 5.0 & 11.9 \\
E4 & 5.0 & 7.3 & 37 & 1.2 & 2.5 & 7.4 \\
W1 & 28.5 & 31.6 & 33 & 5.5 & 17.3 & 39.7 \\
W2 & 20.0 & 22.3 & 37 & 3.7 & 12.5 & 27.4 \\
& & & & & & \\
Level & & & & & & \\
$1(36 \mathrm{~cm})$ & 13.4 & 17.3 & 59 & 2.3 & 8.9 & 17.9 \\
$2(24 \mathrm{~cm})$ & 11.7 & 20.0 & 60 & 2.6 & 6.5 & 16.9 \\
$3(12 \mathrm{~cm})$ & 11.8 & 17.2 & 57 & 2.3 & 7.3 & 16.4 \\
$4 \quad(2 \mathrm{~cm})$ & 34.9 & 33.1 & 48 & 4.8 & 25.3 & 44.5 \\
& & & & & & \\
Surface & & & & & & \\
Lower & 14.1 & 21.1 & 118 & 1.9 & 10.3 & 18.0 \\
Upper & 20.5 & 26.6 & 106 & 2.6 & 15.4 & 25.6 \\
\hline
\end{tabular}




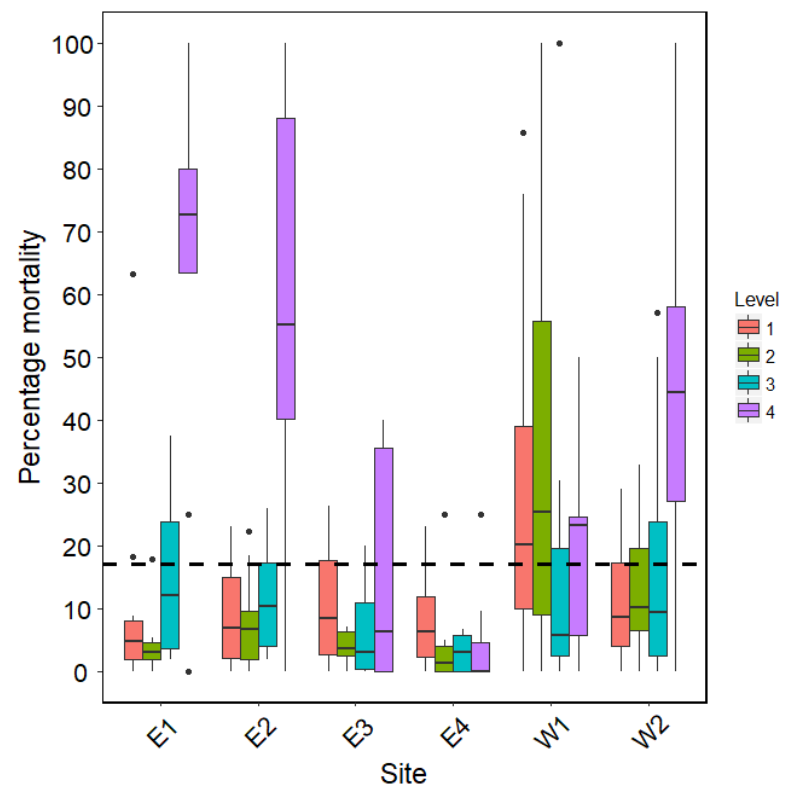

Figure 5-11. Mortality (percentage by surface) of naturally settled $0+$ recruits on passive collectors by Site and Level between October 1999 and March 2000.

Boxplots show medians (solid lines), mean (heavy dashed line), boxes 25 and 75 percentiles, whiskers at 95 percentiles, and outliers shown as black circles above and below whiskers. Bar widths scaled to sample sizes.

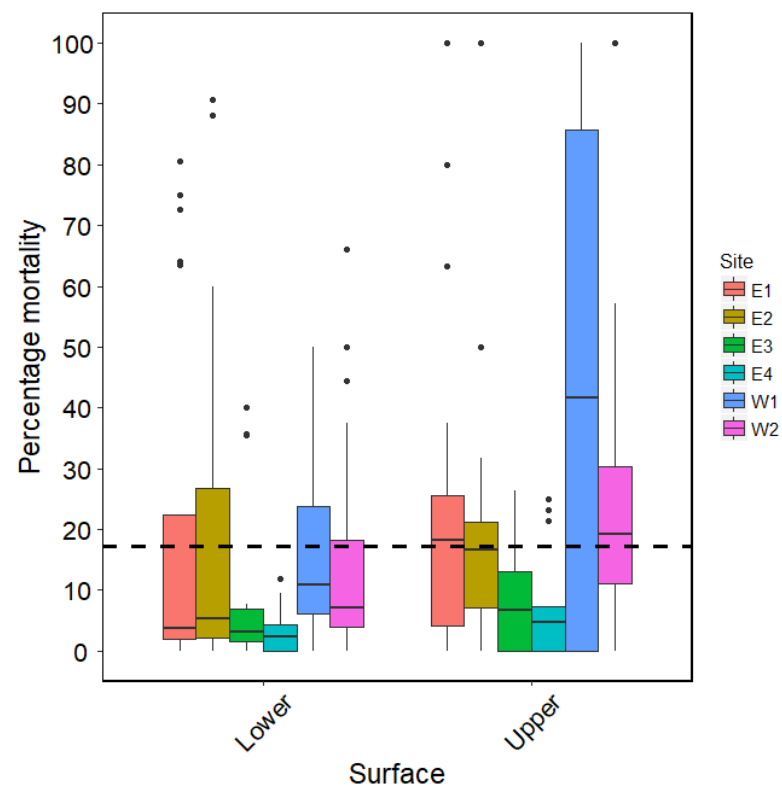

Figure 5-12. Mortality (percentage by surface) of naturally settled $0+$ recruits on passive collectors by Surface and Site between October 1999 and March 2000. Boxplots show medians (solid lines), mean (heavy dashed line), boxes 25 and 75 percentiles, whiskers at 95 percentiles, and outliers shown as black circles above and below whiskers. Bar widths scaled to sample sizes. 


\section{Discussion}

Data from fishery and bycatch sampling, and growth and survival trials suggest settlement of Ostrea chilensis 0+ recruits is greatest on clean shell, survival greatest on heavy or cupped shells such as those of $O$. chilensis, Oxyperas elongate and Astraea heliotropiumon and habitats with little other epifauna. Fishery bycatch data showed commercial fishers repeatedly target high densities of oysters on low complexity habitats, and benthic communities quickly recolonise fished areas. The sediments in these habitats are occasionally mobilised by storms. Live $O$. chilensis and their shells represented the most important substrata for settlement and post-settlement survival, possibly offering greater protection from the effects of mobile sediments. Growth and survival are higher $2 \mathrm{~cm}$ off the seabed and greater, away from moving sediments that may cause mortality through abrasion or burial of recently settled $O$. chilensis recruits. These findings suggest high levels of biotic and abiotic mortality in $O$. chilensis $0+$ recruits that influence oyster population dynamics. Spat (1+ year) have lower mortality. Findings from this research suggest an alternative hypothesis for essential habitat for settlement and post-settlement survival of $O$. chilensis in Foveaux Strait, and suggest an unusual stock-recruit relationship in Foveaux Strait oysters.

Fishers target high-density patches of oysters to maintain high catch rates (Hill et al. 2010). These patches rebuild in the same locations (Michael 2010), and are repeatedly fished (Hill et al. 2010). Bycatch data show these high-density patches occur on shell, sand and gravel dominated substrates (see Figure 5-3). These data suggest that habitat on which high densities of oysters occur may not have changed greatly from the 1960s (Fleming 1952, Cullen 1962, 1967, Stead 1971b). The essential oyster habitat described by this research differs to that suggested by Cranfield et al. (1999), commercial densities of oysters only occur on epifaunal reefs dominated by the bryozoans Cintipora elegans and that regeneration of biogenic habitat is important to oyster recruitment (Cranfield et 
al. 2004). In an extensive survey of the oyster population in Foveaux Strait 196064, Stead (1971) found oyster density was low and oyster condition poor on complex biogenic habitat. Hill et al. (2010) interviewed skippers, some with 50 years of experience about oysters, fishing and oyster habitat. Most skippers reported oysters being more abundant and of better quality on shell, sand and gravel dominated substrates with little other bycatch, as well as on the edge of underwater topographical features including biogenic areas. This research shows that competent $O$. chilensis larvae in Foveaux Strait are likely to settle on the shells of a range of benthic taxa although post-settlement survival is greatest on live oysters and oyster shell rather than in complex biogenic habitat as hypothesised by Cranfield et al. (1999). Given the abundance of suitable settlement substrata and ubiquitous distributions of larvae in Foveaux Strait, recruit survival is a key determinant of the spatial patterns of recruitment in $O$. chilensis.

The larvae of sessile benthic organisms including oysters generally settle on any "clean" stable surface (Wahl 1989), including shells of oysters and gastropod species (Heasman et al. 2004, Lok \& Acarli 2006, Trimble et al. 2009, Smyth \& Roberts 2010, Romero et al. 2013, Waldbusser et al. 2013, Smyth et al. 2018). Moreover, the importance of persistent, heavy shells to the settlement of oyster larvae in Ostreinae is well recognised: O. chilensis (Brown 2011), O. edulis (Smyth \& Roberts 2010, Smyth et al. 2018), O. lurida (Trimble et al. 2009), O. puelchana (Pascual \& Zampatti 1995), and O. angasi (Heasman et al. 2004), and the Crassostreinae, e.g. C. virginica (Waldbusser et al. 2013). Settlement substrata for $O$. chilensis were abundant in bycatch throughout Foveaux Strait and mostly comprised live oysters, oyster shell and the shells of bivalves and gastropods, and recruits found on the shells of a wide range of bivalves (Figure 5-13). O. chilensis recruits were most abundant on large shells in this study. Although large shells provide a larger substratum and therefore greater chance of settlement, greater post-settlement survival than greater 
settlement is more likely. Small bivalve shells such as Glycymeris modesta and Tawera spissa are abundant in Foveaux Strait (author's unpublished data), and were represented in samples the selectivity of dredge sampling most likely underestimated their numbers. Small shells did not have settlers attached. This research shows that recruitment in $O$. chilensis is not limited by available settlement substrata as it is in other oyster populations (Schulte et al. 2009, Trimble et al. 2009, Knights \& Walters 2010, Brown 2011).

Live $O$. chilensis and A. heliotropium and their shells were the heaviest components of the catch (Figure 5-14) and are less likely to be moved by the swift currents than lighter components under normal sea conditions and tidal flow. Cullen (1967) found the tidal currents in Foveaux Strait could move gravel and shell, and eventually erode large flat heavy shells to calcareous grit. Lighter shells can be tumbled over the seabed by normal current speeds (Cullen 1967), and small spat on these shells are likely to be abraded off or buried (Figures 515 \& 16). Stead (1971) found live oysters with live and dead spat attached buried under $125 \mathrm{~mm}$ of pea gravel in eastern fishery areas. Sediment volume, sediment size and transport increases markedly during storms, as illustrated by the large waves of heavy cobbles in depths of $60 \mathrm{~m}$ at the western entrance to Foveaux Strait (see Station 51 on page 8 of Michael et al. 2008c). The disappearance of recruits $(0.5 \mathrm{~mm}$ diameter) from shells held on the seabed was high $(67.4 \%-$ $88.7 \%$ ), which suggests that abrasion by mobile sediments as well as the likelihood of predation.

Growth in $O$. chilensis is strongly seasonal and all growth occurs over the summer months (Dunn et al. 1998). Mean growth was similar across all sites for all recruits and natural-recruits $(4.5 \mathrm{~mm}-5.0 \mathrm{~mm}$ diameter), and slightly more than for data recorded in subsequent studies between 2006 and 2017 (n = $34107)$ median of $4.3 \mathrm{~mm}\left(5^{\text {th }} \& 95^{\text {th }}\right.$ percentiles $1.2 \& 7.2 \mathrm{~mm}$ (authors unpublished data). During this period, median settler diameters differed significantly between years ( $\mathrm{p}<0.001)$, smallest median diameters in 2009 (2.4 
mm diameter) and largest in 2014, 2016, and 2017 (4.8 mm). These larger sizes are consistent with sizes from this study. The median annual size is probably more likely determined by the timing of peak settlement (a single but protracted settlement is assumed) than growth rates.

In this research, the growth of recruits attached to shells on cement board sticks at western sites was significantly less than at eastern sites, which suggests that western sites were more vulnerable to the effects of mobile sediments. Sticks holding the shells with recruits $(0+)$ and spat $(1+)$ at the W2 site were buried under 20-30 mm of coarse shelly sand. Recruits (0+) that settled higher on the passive spat collectors $(12-36 \mathrm{~cm}$ off the seabed) and clear of the seafloor grew significantly larger than those settle on the lowest plate $\sim 2 \mathrm{~cm}$ off the seabed (Table A-5). This suggests longer and better feeding conditions, which is consistent with growth in C. virginica on oyster reefs (Lenihan 1999). Spat (1+) had a mean diameter of $8.6 \mathrm{~mm}$ in October 1999, compared with the $4.5 \mathrm{~mm}-$ $5.0 \mathrm{~mm}$ diameter of recruits (0+) in March 2000. The differences in size between recruits at the end of the growing season and spat at the beginning of their grow out period may more reflect differences between feeding condition in suspended culture in Bluff Harbour than interannual difference in growth. Increased growth in suspended culture is similar to the effects of height and flow on $C$. virginica reefs (Lenihan 1999). 


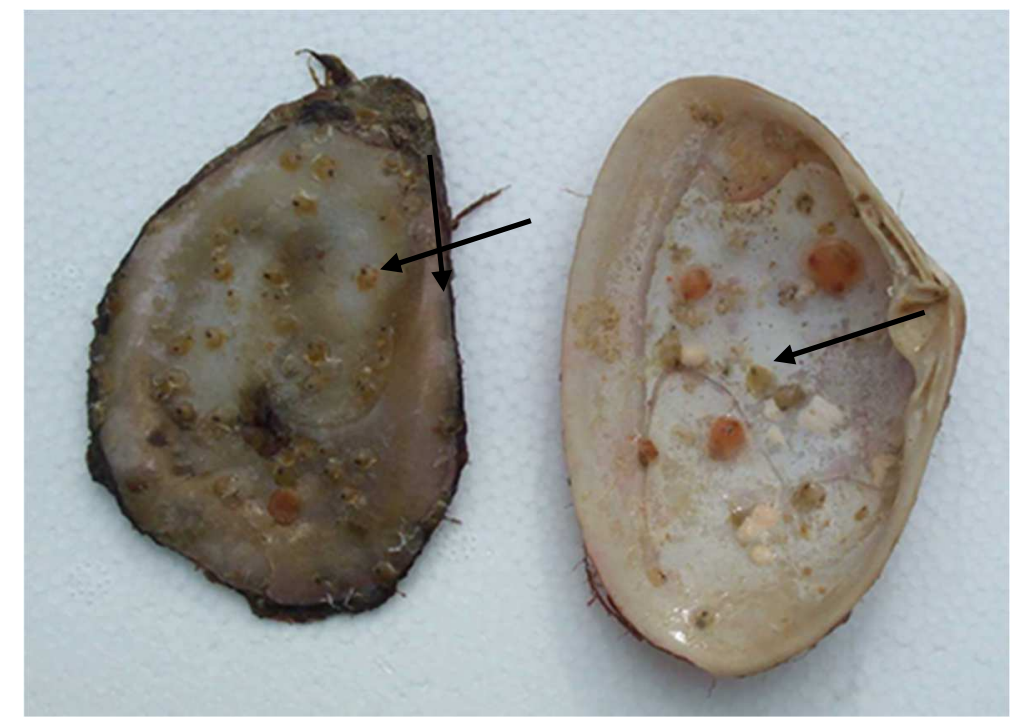

Figure 5-13. Ostrea chilensis recruits (shown with black arrow) on the inner surface of a right (flat) oyster valve (left) and the inner surface of an Oxyperas elongate (OEL) shell (right).

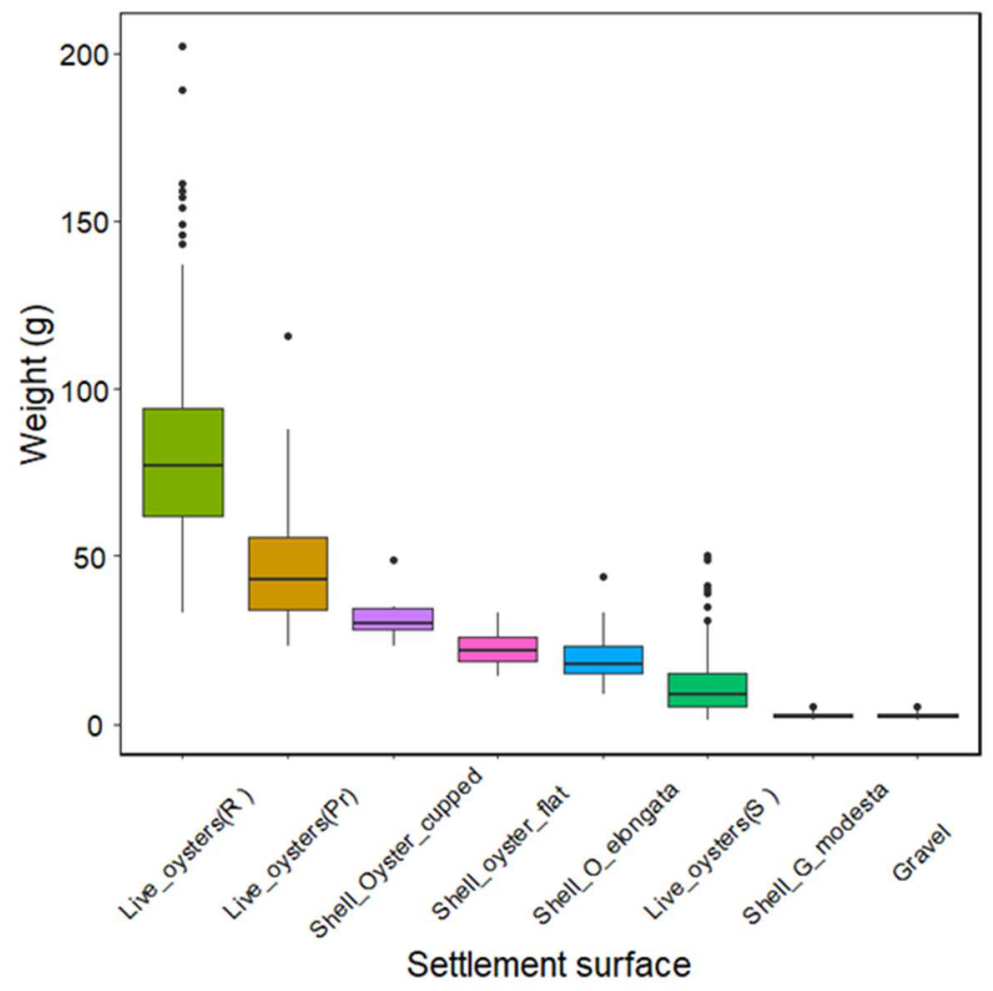

Figure 5-14. Boxplots of the weights of live oysters and oyster shell, the shells of other prominent bivalves in the bycatch, and gravel. $\mathrm{R}, \mathrm{Pr}$, and $\mathrm{S}$ denote recruit, pre-recruit and small size oysters respectively. 


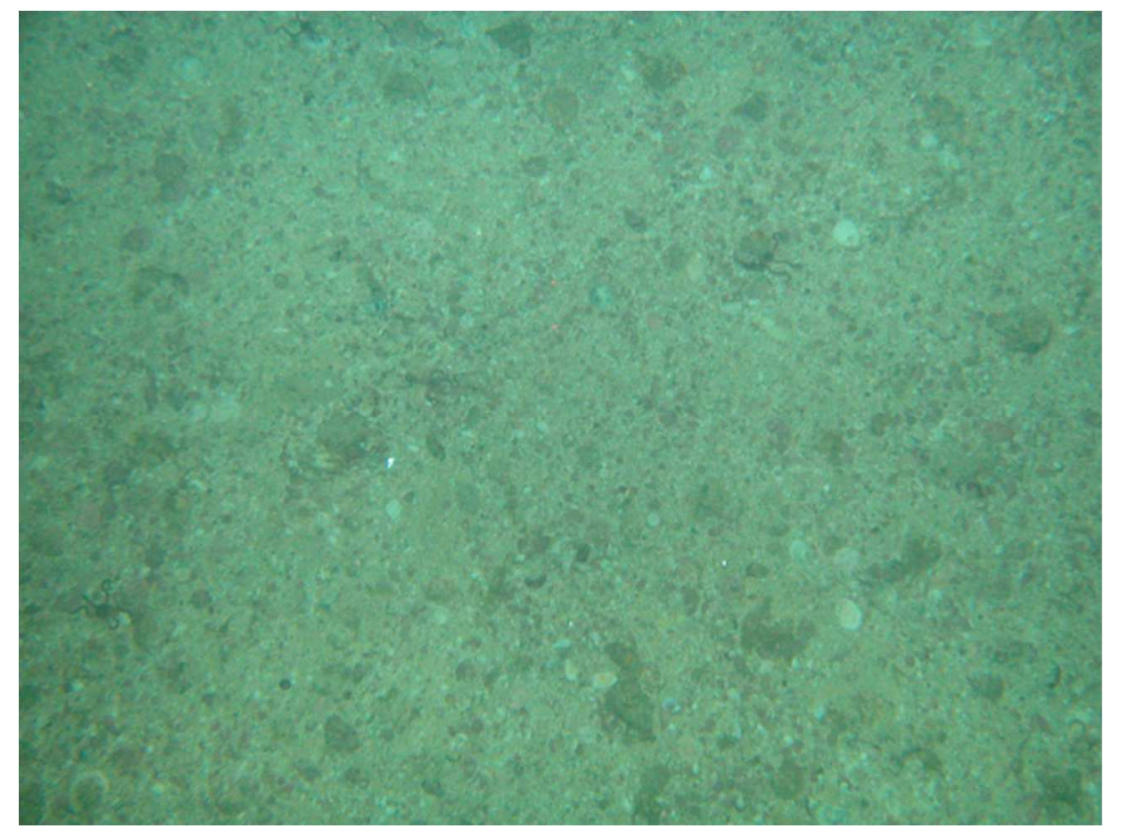

Figure 5-15. Image of the seabed (c. $4 \mathrm{~m} 2)$ in the central Foveaux Strait fishery comprising sand and shell over gravels, with high oyster densities (2400 recruitsized oysters per tow, $12 \mathrm{~m}^{-2}$ ).

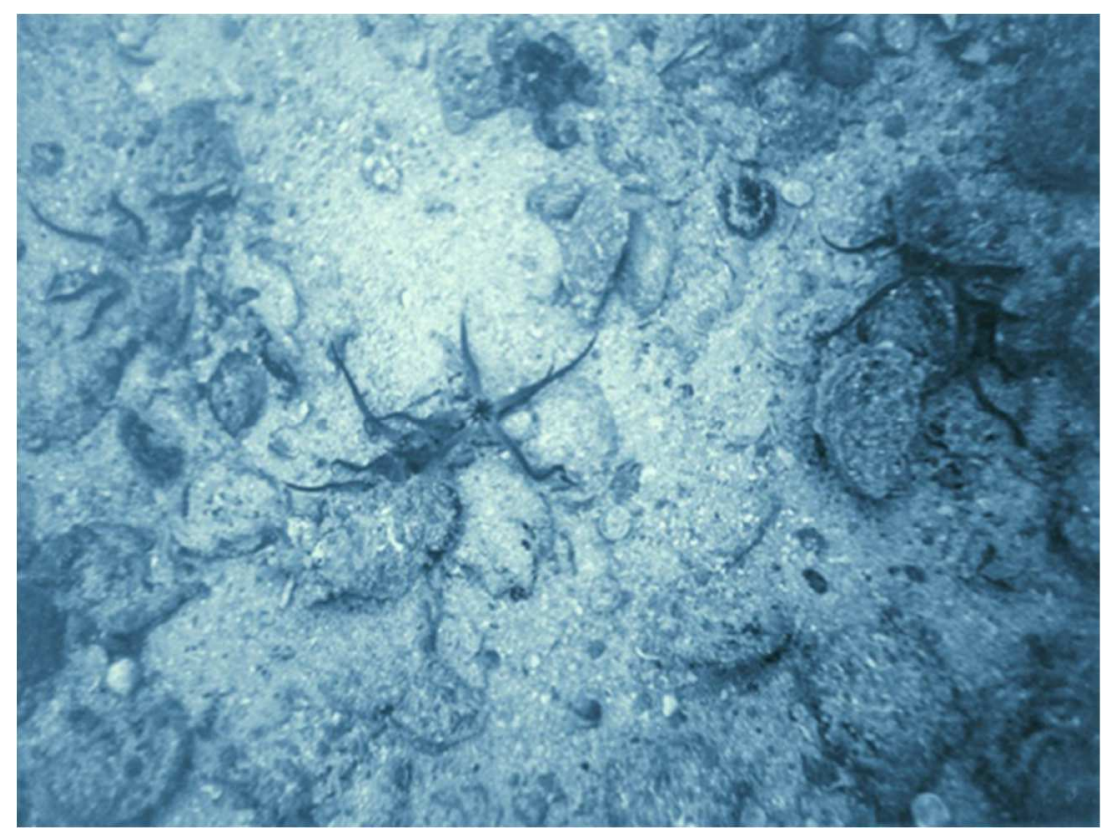

Figure 5-16. The sediments of oyster habitat are occasionally mobile during storms and may bury oysters and recruits. 
Settler densities of sessile invertebrates can influence levels of mortality, primarily through predation (Talman et al. 2004). Knights \& Walters (2010) found both density-dependent and density-independent mortality in C. virginica. In this research, no density dependent mortality was apparent (see Figure 5-8) over the c. 140 days recruits on shells and on collectors were held on the seabed. Reported mortality of recruits varies greatly from $3 \%$ of spat on collectors (Cranfield 1968b) to high predation (>90\%) of recruits (Cranfield 1979). Predation is assumed as the cause of death, from the drill holes in the upper (right) valves from boring gastropods, probably Calliostoma spp. that are abundant in Foveaux Strait. Mortality of recruits on shells was bimodal (see Figure 5-6), which is likely indicative of differential effects of mobile sediments on valves and substrata. A larger percentage of valves suffered $100 \%$ mortality of recruits at the more exposed western sites than at eastern sites. The shell of $O$. chilensis is inequivalve; the right valve is flat and relatively smooth with scaly laminations whereas the left valve is convex with short irregular corrugations (Powell 1979). Mortality of recruits was higher on flat valves than the curved valves that may offer some protection from mobile sediments and abrasion when shells are tumbled by the swift tidal flows. Overall, median mortality of recruits on collectors $(6.7 \%)$ was lower than the median mortality $(8.4 \%)$ between 2006 and 2017 ( $n=1369$ ) (author's unpublished data). However, mortality on the bottom plates more exposed to mobile sediments was significantly higher (34.9\%). Cranfield (1968b) found most spat mortality occurred immediately after settlement whereas in this study $65.7 \%$ died at a size range of $2 \mathrm{~mm}-5 \mathrm{~mm}$ in diameter, sometime after settlement suggesting a wide spread abiotic mortality. Area of settlement, shell weight (see Figure 5-14) and shell shape are shown to be important factors that influence post-settlement survival. 
Recruits (0+) and spat (1+) at W2 survived burial under sand, which is reportedly a regular occurrence in the observations of Stead (1971) and Cullen (1962), who suggested that oysters may be regularly covered in sand and gravel throughout the fishery area. Further evidence for the burial of oysters by moving sediments comes from fishers' observations, oysters in high-density patches disappear after storms and reappear some time later. The regular deposition of coarse calcareous sediments overlaying gravel substrates (Cullen 1967) during rough weather and the clearance of these sediments by tidal currents could explain these observations. Moreover, moving sediments could possibly offer oysters a level of protection from predation and over colonisation by benthic taxa (live oysters generally do not have epifauna attached). Storms may also move oysters as sedimentary particles. Moving sediments appear to play a key role in the demographics of oysters in Foveaux Strait.

\section{Conclusion}

Recruitment to the Foveaux Strait Ostrea chilensis population is not settlement surface limited and shells suitable for settlement are abundant. This includes a substantial quantity of oyster shells from the recurrent mortality of oysters from Bonamia exitiosa (Doonan et al. 1994, Cranfield et al. 2005, Fu et al. 2016). Competent $O$. chilensis larvae readily settle on the shells of a range of species. Post-settlement mortality can be high depending on sediment stability and settlement height above the seabed, and most likely independent of settler densities. Abiotic mortality caused by moving sediments, together with over-colonisation and predation may be the primary determinant in the spatial patterns of recruitment in Foveaux Strait. Post-settlement survival is highest on heavy, live $O$. chilensis and their shells. The importance of heavy, live oysters in the high-energy environment of Foveaux Strait suggests an unusual recruit-adult relationship. The most productive fishery areas are those with mostly stable substrates of shell sand and gravel. This research provides evidence in support of an alternative hypothesis for recruitment of $O$. chilensis 
in Foveaux Strait that shows oyster recruitment is highest on low complexity habitats, where sediments are less mobile, and that recruitment increases with height above the seabed. Finding from this research are not consistent with the need for complex biogenic habitat as essential habitat for the recruitment and abundance of Ostrea chilensis in Foveaux Strait. 


\section{Chapter 6 : General Discussion}
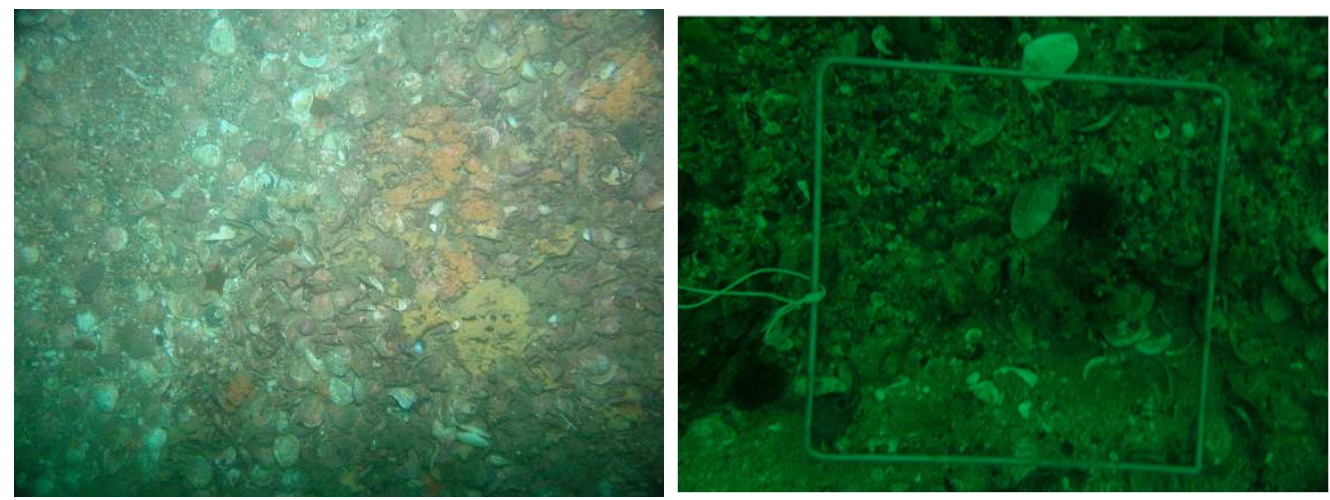

Storms can mobilise sediments and cause recruit mortality and inundate epibenthic communities. Regenerating habitat before (left) and after a December storm (right). 
This $\mathrm{PhD}$ thesis provides new information on fundamental stages of recruitment in Ostrea chilensis from Foveaux Strait. This research differs to that published for this oyster in New Zealand. Findings of this research provides new insights into the effects of disease on recruitment as well as mortality. The findings of this study emphasise the importance of species-specific, locationspecific information to understand population dynamics and inform the management of sessile benthic invertebrates. This research investigated prerequisites for successful recruitment: larval supply (Chapters 2, 3 and 4), and critical habitat, settlement and post-settlement survival (Chapter 5 with discussion in Chapter 6), . This is also the first study into recruitment since 1985, when recurrent epizootics of Bonamia exitiosa began and may have started to affect recruitment. A fishery wide, empirical study such as this one is rare. The extreme differences of oyster habitat in Foveaux Strait compared to other populations made a location specific study essential. This study used dredge sampling and vessel deployed equipment due to the difficulty in undertaking manipulative experiments in Foveaux Strait. The sampling scope and spatiotemporal scale provided a new fishery-wide perspective on recruitment. This scope comprised the nature of a stock-recruit relationship, larval supply and the distribution of competent larvae inferred from the distributions of settler densities, and requirements for settlement and post settlement survival of recruits.

Prior to this thesis, our understanding of recruitment in $O$ chilensis from Foveaux Strait was largely derived from both laboratory and field studies conducted during the 1960s and 1970s (Hollis 1963, Cranfield 1968b, Cranfield 1968a, Stead 1971a, Allen \& Cranfield 1979, Cranfield 1979, Westerskov 1980), or from samples collected around that time (Jeffs \& Hickman 2000). This thesis documents an unusually long period of low recruitment between 2010 and 2017 in a post 1985 period where disease has changed fishery productivity (Ministry for Primary Industries 2017). Spawner biomass based upon inferences derived 
from earlier studies ought to have been sufficient to replenish the population, but this had not occurred. This discrepancy highlighted the need to evaluate recruitment dynamics in the context of more recent disease regimes and/or changing environmental conditions.

This research found that the stock-recruit relationship in O. chilensis is weak in some years, and that disease may play a significant role in recruitment and population dynamics. Infections by one or more pathogens may reduce brooding levels in the populations and based on the reproductive biology of $O$. chilensis, severely reduce larval cohort strength and settler densities, and thereby recruitment. However, the distributions of recruits suggest that competent larvae were ubiquitous in Foveaux Strait. This suggests some larval mixing and exchange, and at least low levels of demographically open populations. This mixing provides some resilience against serial depletion from reduced numbers of high-density patches. Shells for settlement are also abundant. Post-settlement mortality is generally high but spatially variable, most likely determined by environmental conditions. Post-settlement mortality may determine the demographics of oyster populations. This thesis provides new information on essential oyster habitat and drivers of fisheries production.

\section{Larval supply and distribution}

Recurrent epizootics and warming seas have not changed the timing of peak settlement in $O$. chilensis from the 1960s and 1970s despite the potential of these factors to change the timing of spawning, brooding and settlement. Long data time series that capture multiple cycles of high and low recruitment are critical to understand variation in recruitment, key drivers of this variation, and to provide data for modelling. Sampling settler densities between November and February provides an effective index of annual recruitment. The high correlation with $0+$ year recruits sampled from the commercial catch corroborates trends in 
recruitment. The close relationship between $0+$ year recruits sampled on passive spat collectors at the end of summer and these same recruits sampled again from the commercial catch during the autumn and winter oyster season can also highlight high post-settlement mortality events that can inform stock assessments.

Spawner densities are important to larval supply, which is the first of a number of critical stages of recruitment. Localised populations with high spawner densities had high recruitment in high recruitment years although populations with comparably low densities showed little recruitment in any given year, which suggests a threshold density below which larval production fails (Chapter 2). Conditions other than spawner densities were key determinants of larval production (in this oyster, are assumed to be closely linked to densities of $0+$ recruits) that persisted for several years with prolonged low recruitment (Chapters 1 and 2). Even with relatively high spawning stock biomass. A disconnect between recruits and spawners could be at least partly explained by the reproductive biology of true oysters (subfamily Ostreinae). The stock-recruit relationship assumes most brooding-size individuals will contribute to larval supply in any given year. Within a given population, there may be high spatial, temporal, and annual variation in brooding. Asynchronous gonadal development in oysters (Joyce et al. 2015) and low proportions of oysters successfully brooding larvae reduce larval supply. Moreover, spatio-temporal variations in larval release (Puckett et al. 2014) affect the size of larval cohorts and patterns of larval dispersal.

In Chapter 3, high recruitment only occurred at a time when both spawner density and disease mortality were low. These data together with our understanding of the effects of shellfish pathogens and historical fishery data suggest that climate, oyster density, the effects of pathogens and their three-way interactions probably determine brooding success and therefore $O$. chilensis 
larval supply in Foveaux Strait. Chapter 3 suggest that disease and disease mortality from $B$. exitiosa affect brooding success and together with oyster density were key contributors to variation in recruitment. B. exitiosa mortality implies pathogenic infections during gametogenesis. At least three pathogens occur in the Foveaux Strait $O$. chilensis populations: Bonamia exitiosa, Bucephalus longicornutus, and an Apicomplexan (APX). Each of these pathogens can occur singularly or as co-infections; and affect gametogenesis and cause gonadal castration, although a mechanism by which this this occurs for Bonamiosis is yet to be determined. Both the effects and mechanisms by which pathogens affect brooding success in $O$. chilensis need to be tested.

This research is the first to show a counter intuitive process whereby in some years, low spawner densities resulted in high recruitment while high spawner densities resulted in low recruitment. Based on fishery data and information on pathogens of $O$. chilensis in Foveaux Strait, one explanation for this is fishery wide-scale disruption of recruitment by pathogens and that disease mortality that reduces spawner densities actually increases rather than decreases recruitment. Co-infections were likely to have been a significant contributor to the 1985 epizootic in Foveaux Strait (Hine 2002). However, there is little information on the prevalence and intensity of pathogens and co-infections in $O$. chilensis before 1985. Both B. exitiosa and B. longicornutus were present in 1958 to 1964 during a period of heightened mortality. Although B. exitiosa was identified in oyster tissues sampled in 1964, no further mortality was recorded until 1985, and therefore it is unlikely that B. exitiosa alone was responsible for the 1985 epizootic. Hine (2002) identified APX as a co-infection post 1985 . The spread of infection, as through a naïve population, suggest that APX may have been a newly introduced pathogen some time before 1985. Another explanation for the 1985 epizootic proposes the effects of fishing; however, this is unlikely as levels of disturbance were high for twenty years prior to the epizootic. Other potential explanations include genetic changes in the host susceptibility and/or 
disease pathogenicity (Henry Lane, MPI pers. comm.), and the extraordinary El Nino event in 1983 that may have increased the susceptibility of $O$. chilensis to B. exitiosa (Brian Jones, Murdoch University, Perth, pers. comm.). While it is likely that these factors may have contributed to the 1985 epizootic, the putative effects of co-infection are most likely. B. exitiosa together with other pathogens compete with the host for available energy, especially during the reabsorption phase of the female reproductive cycle. This competition may have legacy effects on energy available future reproduction and maternal provisioning. This research found the highest recruitment occurred at a time of low disease mortality. The possibility of $B$. exitiosa affecting gametogenesis is worthy of further investigation.

\section{Self-recruitment in $O$. chilensis}

The evidence for self-recruitment to natal populations in $O$. chilensis is based on laboratory observations (Hollis 1962, Stead 1971a, Brown 2011), relatively small spatial-scale experiments (Cranfield 1968a), predictive modelling (Broekhuizen et al. 2011), and the patchy spatial structure of the Foveaux Strait populations (Allen \& Cranfield 1979). The spatial scale of sampling in this study was large enough to identify predominantly selfrecruitment to the focal-population over the three years of sampling if it had occurred, i.e. localised settlement around the focal population should have been greater than some distance away from it. Moreover, historically low settler densities in 2012-14, suggest small larval cohorts that are likely to have reduced larval mixing and dispersal between localised populations. However, settler densities were widespread that suggests greater larval mixing than previously reported. In years of average to high larval cohorts, greater mixing and dispersal than indicated by this research is likely.

Finding of this research suggest that pelagic larval duration in $O$. chilensis may be more variable than thought and at times larvae may be carried 
further by the strong tidal currents in Foveaux Strait. This variation may arise from larvae released at earlier stages of development because of space limitations in the pallial cavity (see biology of $O$. chilensis in Chapter 1 ) or in response to environmental disturbance (Joyce et al. 2015). Moreover, the strong tidal currents may reduce the opportunity for settlement and limit the effectiveness of larval behaviour, conspecific settlement and settlement cues. These findings differ to previous studies and the predictions of $O$. chilensis dispersal (Broekhuizen et al. 2011). Pineda et al. (2009) warned that inferences made from probabilistic models may be misleading without an understanding of recruitment processes and data. This research provides a better understanding of recruitment and settler data that could be useful for validating future models.

\section{Oyster habitat}

This research provides information on settlement and post-settlement survival of $O$. chilensis in Foveaux Strait that provides a different perspective on oyster habitat. Findings from this research suggest that usually stable sediments, an abundance of shell, and sparse to low benthic epifauna are the key elements for oyster habitat in Foveaux Strait. Small encrusting bryozoans are abundant throughout Foveaux Strait (Cranfield et al. 2004) and play key roles in structuring benthic communities. They bind and stabilise mollusc shells and sedimentary particles (Dennis Gordon, NIWA, pers. comm.); as well as facilitating the settlement and survival of benthic taxa. These opportunistic species are likely to play a significant role as primary colonisers and were occasionally abundant on spat collectors deployed in this study. At a fishery spatial-scale, red algae and Pyura pachydermatina also provide a stabilising role on gravels. This is particularly true in the shallower eastern areas where tidal current flows are strongest and water depth is shallowest, which allows for good light penetration for algal growth. The mytilids, mainly Modiolus areolatus and Modiolarca impacta, also bind and stabilise sedimentary particles and shells (Cranfield et al. 2001). This study showed low settlement of $O$. chilensis on 
mytilids. In high densities, mytilids are more likely to be colonised by sponges and ascidians.

Bycatch data from this research showed abundant and diverse bivalve communities comprised of $O$. chilensis, Oxyperas elongate, Tucetona laticostata, Panopea smithae, Glycymeris modesta, and Tawera spissa in Foveaux Strait. The shells of dead bivalves are exposed by orbital velocities of swell and tidal currents, and provide an abundance of settlement substrata for oysters and other benthic taxa. Of these six species, oysters were the most abundant and most important. The recurrent $B$. exitiosa epizootics maintain high levels of oyster shell and their large, heavy shells persist longer in this environment. $O$. chilensis readily settle on any clean substratum; however, abiotic mortality of recruits on small or light shells (probably from abrasion and burial) is higher than for heavy shells. Oysters and oyster shell are key determinants of settlement and post-settlement survival in $O$. chilensis.

\section{Essential habitat for Ostrea chilensis recruitment and abundance}

This thesis adds new information to the discussion on complex biogenic reefs as essential habitats for Ostrea chilensis recruitment and abundance (Cranfield et al. 1999, Cranfield et al. 2001, Cranfield et al. 2003, Cranfield et al. 2004, Cranfield et al. 2005). The differences in habitat and the reproductive biology between Ostreinae and Crassostreinae highlighted by this and other studies suggest caution is needed when information from other settings and from other species are used to describe essential habitats.

Chapter 5 shows recruitment and abundance of $O$. chilensis is higher on stable habitats with low complexity. This provides evidence for an alternative hypothesis to that proposed by Cranfield et al. (1999): that climax biogenic habitats dominated by the bryozoans Cinctipora elegans (Stage 5, Figure 4 in Cranfield et al. 2004) are thought to be critical to oyster recruitment (Cranfield 
et al. 1999, Cranfield et al. 2003, Cranfield et al. 2004). Cinctipora elegans is regarded as a structuring species (Batson \& Probert 2000, Cranfield et al. 2003); however, it is less resistant to abrasion than the more calcified encrusting species found in Foveaux Strait. C. elegans is one of the first colonisers on elevated structures, which grows quickly (Michael 2011), and readily over-settled by many other taxa (Figure 6-2, author's unpublished data). The growth of colonisers can be rapid, such as the colonial ascidian Botryloides leachi that can quickly over-colonise epibenthic fauna.

Climax benthic communities in Foveaux Strait are much more likely to be dominated by erect sponge complexes (Figure 2 (e) in Cranfield et al. 2003 and see Roberts et al. 2006). Sponges readily overgrow C. elegans colonies, as is the case in the tropical systems (Lopez-Victoria et al. 2006). Allelo-chemicals released on the surfaces of sponges for defence prevent other larvae from settling, e.g. ascidian larvae do not settle on Crella incrustans (Carter, 1885) (Davis et al. 1991), and some sponge species deter grazing by urchins (Wright et al. 1997). C. incrustans, Chondropsis spp. (Cranfield et al. 2004) are abundant in Foveaux Strait and together with Dactylia varia (Gray, 1843) dominate some climax communities (author's unpublished data).Although complex habitats may provide substrate stability and structural height above the seabed, both found to be important in this study, settlement substrata are likely to be scarce. Moreover, mortality from predation and over settlement is also likely to be high on these structures (author's unpublished data).

Oyster shells contribute substantially to good oyster habitat. Lenticular structures comprising shells, sand and gravel accumulated by hydrological forces provide stability and height (see Cranfield et al. 2004 for further detail on this hypothesis). These structures are often the foundations for settlement and succession of sessile benthic invertebrates and are the genesis of biogenic "reefs" (Figure 6-1) (Smyth \& Roberts 2010, Romero et al. 2013, Waldbusser et al. 2013). The colonisation of the structures depends on sources of reproductive 
propagules and delivery mechanisms (Caddy \& Defeo 2003). Colonising propagules could be transported considerable distances in the swift currents of Foveaux Strait and spatial and temporal patterns of colonisation are likely to vary depending on the species of larvae or propagules available for settlement. Benthic taxa other than oysters that settled on spat collectors during the study suggest the composition of the communities will differ between areas.

Chapter 5 suggests that if oysters settle early during the settlement period, and above the seabed (Figure 6-1), they are likely to benefit from higher growth and lower mortality through better conditions for feeding and survival. However, findings from this research suggest that succession toward a climax benthic community is likely to decrease oyster settlement and increase feeding inhibition and mortality. These inferences are consistent with studies of oyster reefs in the US. (Grabowski \& Powers 2004, O'Connor et al. 2008). Complex biogenic habitat may provide refuges to mitigate predation (Talman et al. 2004); however, increased habitat complexity and biodiversity may increase numbers of predators and therefore reduce the ability of habitat to mediate predation (Grabowski \& Powers 2004). Moreover, mortality will vary dependent on whether increased species complexity actually provides effective refuges from predator prey interactions (Grabowski 2004), i.e. mortality will be dependent on predator identity (O'Connor et al. 2008). 


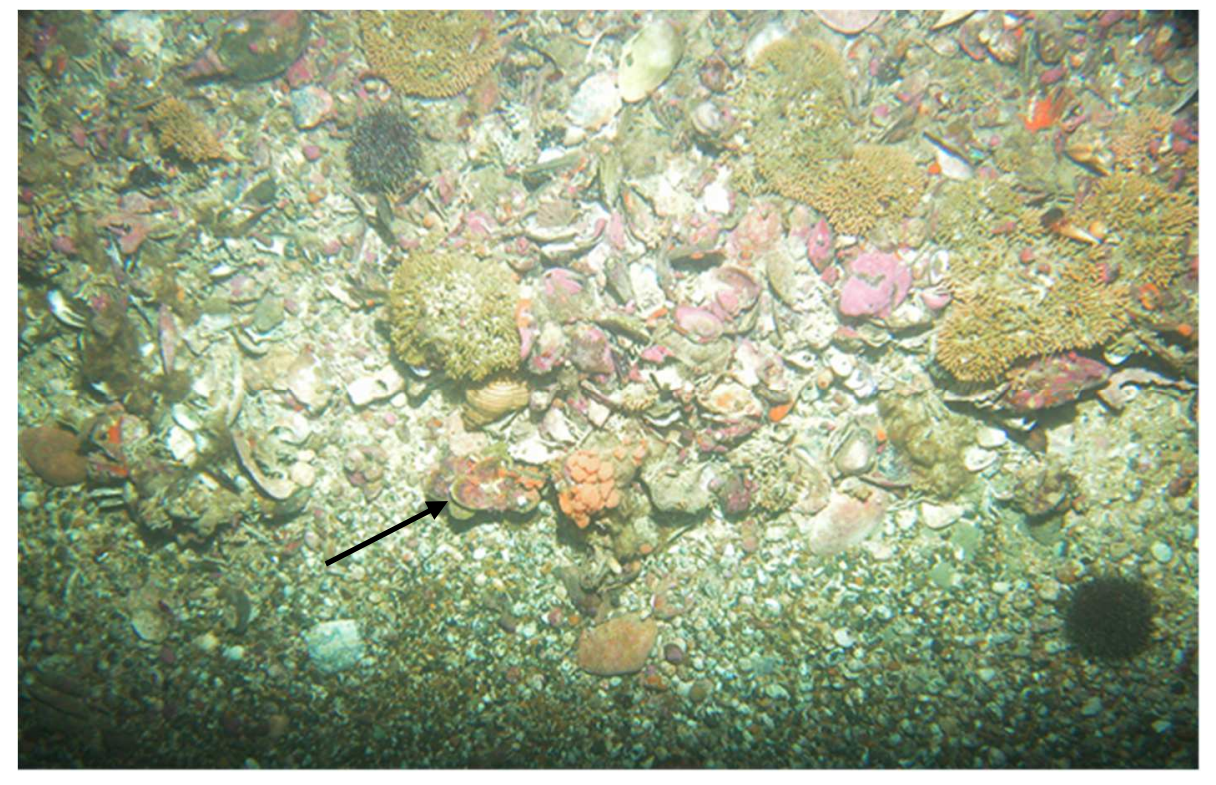

Figure 6-1. Lenticular structures comprised sediment and shell, formed by hydrographic forces along the current axis south of Bluff Hill (see Cranfield et al. 2004). These structures provide the genesis for complex biogenic habitat ("reefs"). Cinctipora elegans and $\boldsymbol{O}$. chilensis (black arrow) are among the early colonisers above the flat gravel seabed and beginning to be overgrown.
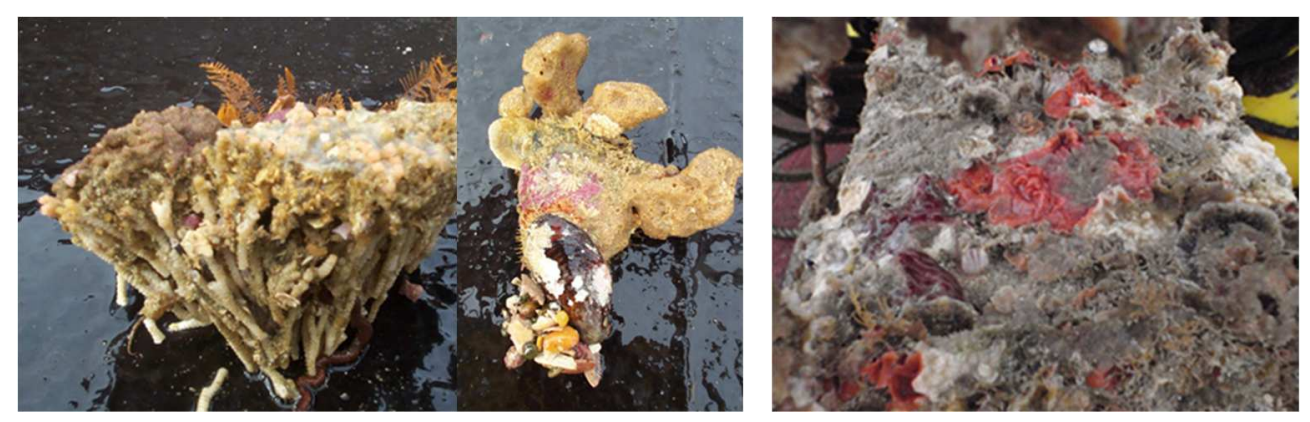

Figure 6-2. Cinctipora elegans overgrown and killed by a number of benthic taxa (left panel), Modiolus areolatus overgrown Dactylia varia (middle panel). Note gravel bound by byssus, and oyster spat settled on a spat collector overgrown by invertebrates, mainly bryozoans at the end of their second summer (right panel). 


\section{Management considerations}

Oysters are typically managed using tools and approaches developed for finfish stocks although their inability to readily move from unfavourable environmental conditions and biotic challenges makes them more vulnerable to recruitment failure and serial depletion than mobile species. The fisheries management systems failure to incorporate such significant differences in stock structure and recruitment has potentially contributed to population declines (King et al. 2015, Szuwalski et al. 2015).

The management of most fisheries and benthic invertebrate populations assumes a fundamental relationship between spawning stock biomass (SSB) and recruitment. By simply managing SSB through harvest controls, recruitment is expected to progress toward maximum yield. Adequate SSB and spawner densities are critical for reproduction; however, stock-recruit relationships (Ricker 1954, Beverton \& Holt 1957) in sessile benthic invertebrates are often weak because factors other than stock size and spawner densities substantially contribute to variation in recruitment. Fisheries management, especially for sessile benthic invertebrates, has been slow to formally recognise the poor relationship between SSB and recruitment alone and to integrate key drivers of the variation in recruitment. Therefore, management of these fisheries has generally been ineffective and fisheries have declined or collapsed as a result (MacKenzie et al. 1997a, MacKenzie et al. 1997b, MacKenzie et al. 1997c, Lenihan \& Peterson 1998, Hobday et al. 2000, Karpov et al. 2000, Anderson et al. 2011a, Beck et al. 2011, King et al. 2015, Szuwalski et al. 2015, Ministry for Primary Industries 2017). The lack of a consistent stock-recruitment relationship suggests that single biological reference point based management may not be appropriate for many of these stocks (after Powell et al. 2012). Models of population dynamics (Hollowed et al. 2009, Fulton 2010, Fulton et al. 2014, Punt et al. 2014) can incorporate key drivers of variation in recruitment although these complexities have rarely been incorporated in any capacity until recently (Punt 
et al. 2014, Skern-Mauritzen et al. 2016). This is presumably due to a lack of knowledge and data on recruitment. This research highlights the need for information on the recruitment in sessile benthic invertebrate populations.

Sessile benthic invertebrates, especially those nearshore, face increasing challenges from climate variability and change, environmental and habitat degradation, and disease. A better mechanistic understanding of recruitment processes and long-time series of recruitment, biological (including disease) and climatic data at appropriate spatial scales are needed to inform stock assessment models. This information will also be critical for Ecosystem-Based Approaches to Fisheries Management (Hilborn \& Walters 1992, Fulton 2010, Punt et al. 2014, Collie et al. 2016, Koenigstein et al. 2016), which are currently being advocated in New Zealand's Sustainable Seas National Science Challenge.

This thesis suggests that disease could limit population-scale recruitment, and that the effects of multiple pathogens may be an unappreciated and hidden driver of wild shellfish population dynamics. Many important wild shellfish stocks are in decline in New Zealand (Ministry for Primary Industries 2017), and elsewhere (Caddy \& Defeo 2003, Beck et al. 2011). The effects of disease mortality on wild shellfish populations are well known (Arzul \& Carnegie 2015). Diseases also affect meat condition, growth and recruitment. Recruitment failure is a feature of declining populations and Chapter 3 suggests that co-infections may play substantial roles in these failures.

\section{Recommendations from this thesis}

1. The low contribution of spawner densities to $O$. chilensis recruitment in some years and the inferred effects of disease and oyster density on larval supply have implications for stock assessment. A better understanding of the processes driving larval abundance, and time series of settler data will better inform further development of stock assessment models and improve the fiveyear projections of future stock size required for this fishery (Ministry for 
Primary Industries 2017). Since 1985, recurrent cycles of 'boom and bust' within oyster density thresholds suggest a shift in production. Fishers rely on highdensity patches for economic catch rates. New spatial fishing strategies may be required to minimise losses and disruption, and to maximise recruitment and the numbers of high-density patches available to fishers.

2. There is a need for a better understanding of the extent of larval dispersal amongst subpopulations to understand recruitment at fishery scale. Thomas (2015) sampled five sites in Foveaux Strait as part of a larger study of the genetic structure of $O$. chilensis populations around New Zealand. He found oysters from two sites in Foveaux Strait and a site in the Awarua Estuary (Bluff Harbour) were from the same genetic stock. These findings may provide some evidence for longer dispersal and connectivity between populations. However, the two other nearby sites in southern Foveaux Strait aligned more closely with distant populations raising some uncertainty about these results. High-resolution studies of $O$. edulis population genetics successfully used single-nucleotide polymorphisms (SNPs) (Gutierrez et al. 2017, Hollenbeck \& Johnston 2018). Genetic studies may help to resolve patterns of recruitment at finer scales and undertaken in conjunction with sampling of settler densities should provide a more detailed description of mixing and dispersal.

This thesis has provided a better understanding of recruitment in Ostrea chilensis from Foveaux Strait and in doing so highlighted several crucial knowledge gaps in understanding recruitment in $O$. chilensis generally. The effects of co-infections on gametogenesis, synchrony in spawning, brooding percentages in populations, larval development at release, and variation in pelagic larval durations are poorly understood. Knowledge of diseases in shellfish populations that are important to fisheries and to ecosystems is scant. Increasing climate variability, environmental stresses, and new pathogens introduced to naïve populations are likely to increase the frequency and severity 
of disease. As shellfish provide the high socio-economic and ecological benefits, information to better understand and assess the effects of disease on recruitment and population dynamics is critical. Baseline studies of pathobiomes, the prevalence and intensity of pathogen infections are an important first step. These data are critical to determine whether future epizootics are new introductions to naïve populations or the result of changes in climatic and environmental factors, and or co-infections. Time series data for key stocks are critical to explore how multiple pathogens and their interactions affect recruitment and population dynamics. These data should include climatic, environmental, hosts' physiological status and the interactions between pathogens in host populations. This thesis has shown that these processes are especially applicable to $O$. chilensis in Foveaux Strait. 


\section{Appendix}

Table A-1: The locations of the six sites across the Foveaux Strait oyster fishery sampled for the spatio-temporal variation in recruitment.

\begin{tabular}{lllllll}
\hline Site & \multicolumn{2}{l}{ Latitude } & \multicolumn{3}{l}{ Longitude } \\
\hline East-high & 46 & 42.9000 & $\mathrm{~S}$ & 168 & 25.1760 & $\mathrm{E}$ \\
West-high & 46 & 39.7020 & $\mathrm{~S}$ & 168 & 4.1520 & $\mathrm{E}$ \\
South-high & 46 & 44.8560 & $\mathrm{~S}$ & 168 & 18.6300 & $\mathrm{E}$ \\
West-low & 46 & 37.3020 & $\mathrm{~S}$ & 168 & 1.2480 & $\mathrm{E}$ \\
East-low & 46 & 38.1720 & $\mathrm{~S}$ & 168 & 29.3940 & $\mathrm{E}$ \\
South-low & 46 & 46.7340 & $\mathrm{~S}$ & 168 & 12.6240 & $\mathrm{E}$ \\
\hline
\end{tabular}

\section{Estimates of spawner densities}

Because of the depth, strong currents, and hard substrate of Foveaux Strait, dredge sampling is the only method available to estimate oyster densities. Photographic, video and grab sampling methods have severe limitations in Foveaux Strait. Repeat estimates of oyster density (Doonan \& Cranfield 1992, Michael et al. 2001) show good consistency. Dredge efficiency, the proportion of recruit-sized oysters encountered by the dredge actually retained (0.17), is the scalar used to adjust oyster densities from dredge sampling to absolute abundance (Fu et al. 2016).

Many of the six sites sampled across the fishery were deeper than $40 \mathrm{~m}$ meaning they were too deep for divers to sample. Before spat collectors were deployed in November 2007, standard dredge sampling methods (Michael et al. 2015) were used to estimate Ostrea chilensis spawner densities (Table A-2). After 2007, mean estimates of recruits to the fishery ( $\geq 58 \mathrm{~mm}$ in length) and prerecruit-(50-57 $\mathrm{mm}$ in length) sized oysters were used as putative estimates of local spawner densities ( $\geq 50 \mathrm{~mm}$ in length) from nearby survey sites (Michael et al. 2013), to avoid disturbing the spat collector sites (Table A-2). These surveys sampled different combinations of subareas (survey strata) each year (Table A-3). For years when there was no sampling near the sites, interpolated 
means of spawner density were estimated from the previous and following year's estimates (Table A-3). Spawner densities were estimated after spawning and settlement occurred, but before significant disease mortality and any fishing.

Sampling used a $3.3 \mathrm{~m}$ wide commercial oyster dredge towed in a straight-line, down tide. The standard tow length was 0.2 nautical miles $(371 \mathrm{~m})$, and target speed of $2.5-3.0$ knots. Estimated sampling efficiency of the dredge was 0.17 (95\% confidence intervals 0.13 - 0.22, Dunn 2005). Estimates of absolute $O$. chilensis density were calculated using this scalar.

Spawner densities (oysters $/ \mathrm{m}^{2}$ ) were calculated by adjusting catches to a standard tow distance $(371 \mathrm{~m})$, scaling for dredge efficiency $(0.17)$, and dividing by the area swept $\left(1224.3 \mathrm{~m}^{2}\right)$. Because of the low sample numbers $(3-4$ tows at each site), 95\% CIs were estimated using nonparametric bootstrapping $(B=1000)$. Figure $A-1$ shows spawner densities for the six sites (Table $A-1)$ in November 2007. 
Table A-2. Estimates of mean spawner densities (oysters $\left./ \mathbf{m}^{2}\right) \pm 1 \mathrm{SE}$ from pre-deployment sampling (November 2007) and annual February surveys (2007 to 2011) from strata containing the six sampling sites. Site codes prefixed with "area" west (W), south (S), and east $(E)$ and suffixed with Category of density, high density $(H)$, low density $(L)$ respectively. For years when there was no sampling near sites, spawner density assigned as the mean value between the previous and following years estimates (year before 2007 and after 2011 not shown). Missing data shown in italics and underlined. Data from Michael et al. (2008a, 2009, 2009a, 2011, 2012). Mean distance $(\mathbf{k m})$ with $\mathrm{SE}$, and minimum and maximum distances between dredge sample sites and collector sites also shown.

\begin{tabular}{|c|c|c|c|c|c|c|c|c|c|c|c|c|}
\hline \multicolumn{13}{|c|}{ Pre-deployment } \\
\hline \multirow[t]{3}{*}{ Site } & \multicolumn{2}{|l|}{$\mathbf{E H}$} & \multicolumn{2}{|l|}{$\mathbf{E L}$} & \multicolumn{2}{|l|}{ SH } & \multicolumn{2}{|l|}{ SL } & \multicolumn{2}{|l|}{ WH } & \multicolumn{2}{|l|}{ WL } \\
\hline & Mean & SE & Mean & SE & Mean & SE & Mean & SE & Mean & SE & Mean & SE \\
\hline & 1.26 & 0.11 & 0.16 & 0.10 & 1.53 & 0.47 & 0.11 & 0.06 & 1.83 & 0.59 & 0.11 & 0.08 \\
\hline \multicolumn{13}{|c|}{ Survey estimates } \\
\hline Stratum & $\mathbf{C 3}$ & & C6a & & C8 & & B7 & & E2 & & B2 & \\
\hline Year & Mean & SE & Mean & SE & Mean & SE & Mean & SE & Mean & SE & Mean & SE \\
\hline 2007 & 1.05 & 0.05 & 0.77 & 0.34 & 1.69 & 0.54 & 0.32 & - & 0.99 & 0.25 & 1.18 & 0.25 \\
\hline 2008 & 1.01 & 0.40 & 0.74 & 0.22 & 1.72 & 0.18 & $\overline{0.32}$ & 0.08 & 1.08 & 0.25 & 1.59 & 0.60 \\
\hline 2009 & 1.58 & 0.64 & 0.32 & 0.15 & 3.27 & 0.82 & 0.25 & 0.06 & 2.65 & 0.73 & 0.32 & 0.22 \\
\hline 2010 & 1.62 & 0.36 & 0.70 & 0.67 & 4.28 & 1.62 & $\underline{0.32}$ & - & 4.61 & 0.85 & 1.53 & - \\
\hline 2011 & 2.13 & 0.79 & 0.60 & - & 4.62 & 1.63 & $\overline{0.35}$ & 0.10 & 4.37 & 0.76 & 1.30 & - \\
\hline
\end{tabular}


Table A-2. Continued.

\begin{tabular}{lllllll}
\hline Site & EH & EL & SH & SL & WH & WL \\
Stratum & C3 & C6a & C8 & B7 & E2 & B2 \\
\hline Survey tow distances & $(\mathbf{k m})$ from collector sites & & & & \\
Mean & 2.6 & 4.4 & 2.4 & 3.4 & 4.0 & 4.0 \\
SE & 1.4 & 1.3 & 0.9 & 0.6 & 1.0 & 1.5 \\
Minimum & 0.4 & 2.6 & 1.3 & 3.0 & 1.7 & 1.5 \\
Maximum & 5.3 & 5.9 & 3.5 & 4.3 & 5.5 & 5.8 \\
\hline
\end{tabular}




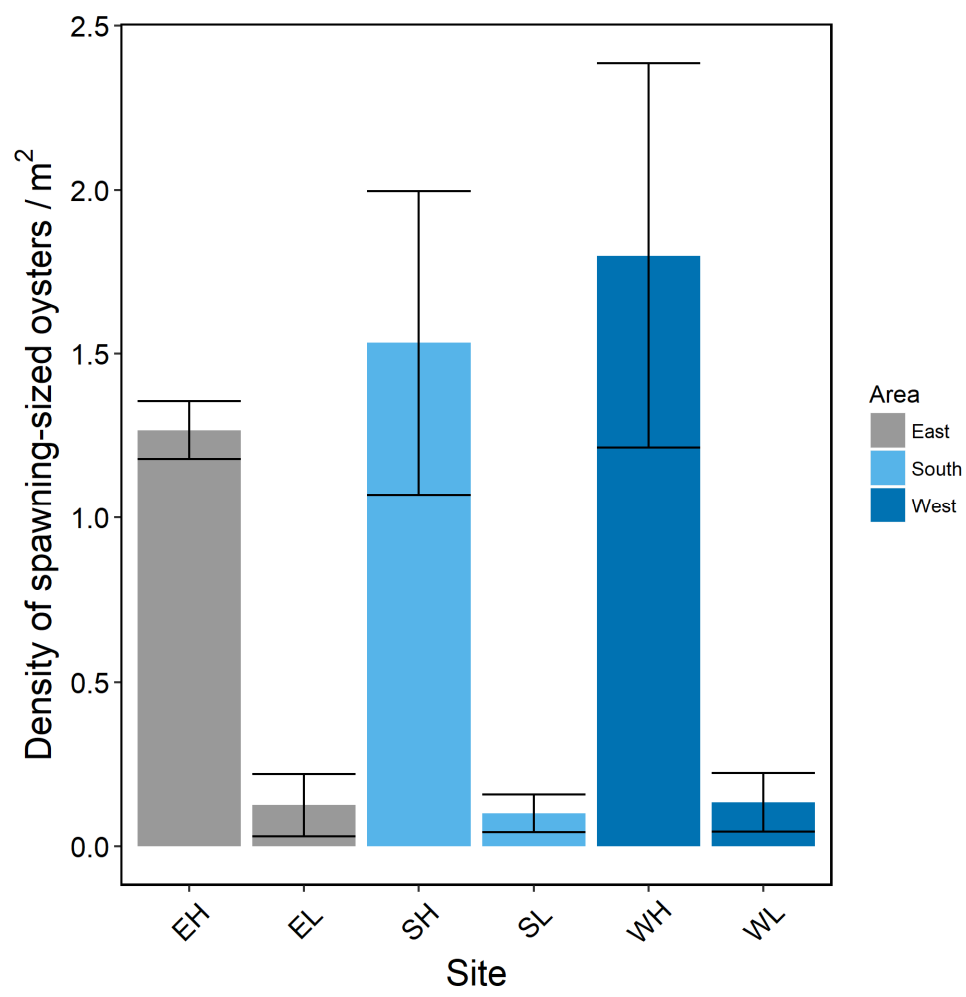

Figure A-1. Spawner densities, oysters $\geq 50 \mathrm{~mm}$ in diameter) per $\mathrm{m}^{2}$ sampled from sites across the fishery in November 2007. Site codes prefixed with "Area" West (W), South (S), and East (E); and suffixed with Category of density, high density $(\mathrm{H})$, low density $(\mathrm{L})$ respectively. Bars show mean densities with $\pm 1 \mathrm{SE}$.

Putative annual estimates of spawner densities are derived from stratum level estimates from fishery independent surveys 2008-2011 (Michael et al. 2009a, Michael et al. 2009b, Michael et al. 2011, Michael et al. 2012a), and only from those samples that were randomly allocated (Figure A-2). Spawner densities at collector sites assumed: dredge tows before sampling began were representative of localised densities, and these local densities remained the same or increased over the sampling period consistent with the estimates from fishery independent surveys. 


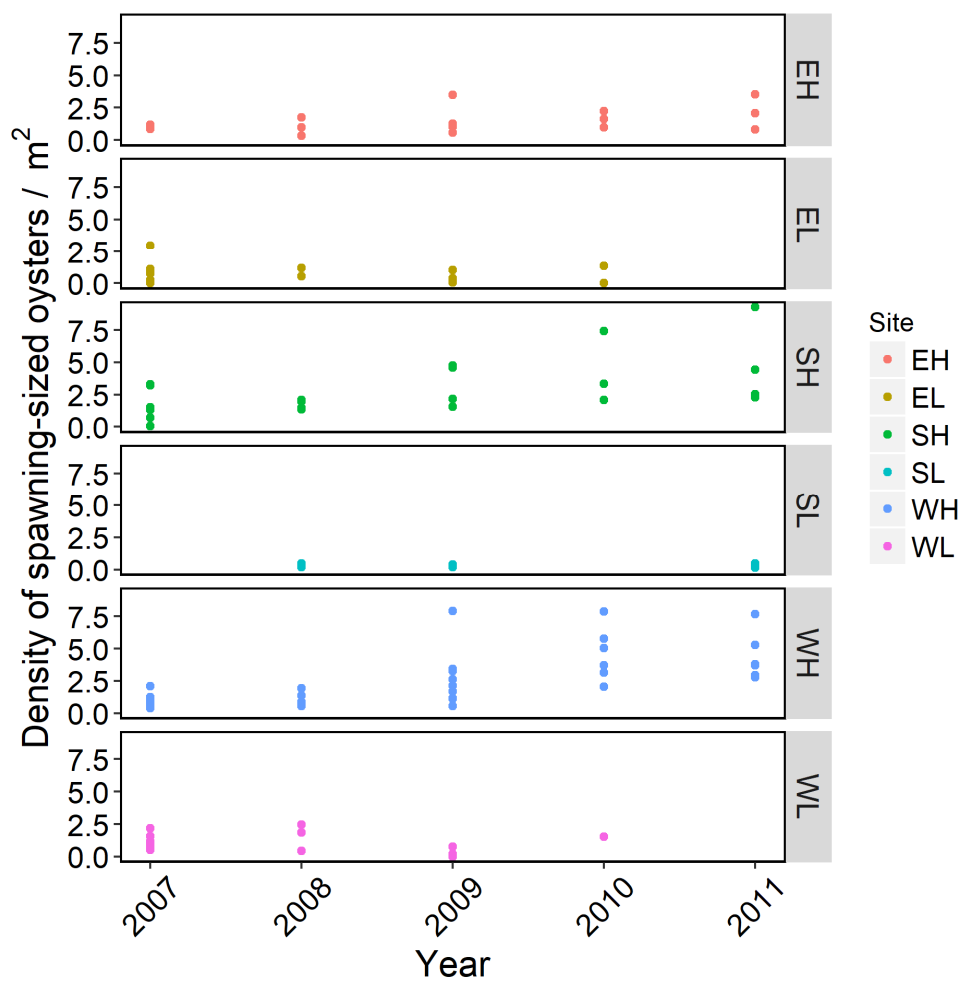

Figure A-2. Spawner densities by site from nearby, randomly allocated survey tows in strata where fishery-scale sites were located. Data from fishery independent surveys 2007-2011 (Michael et al. 2009a, 2009b, 2011, 2012, 2013).

Spawner densities sampled (Sample) in November 2007 and putative estimates from surveys in February 2008-11 (Survey) were similar at four of the six sites except the West-Low and East-Low sites (Figure A-3). Growth in $O$. chilensis occurs only in the summer months (Dunn et al. 1998), and the increase in spawner densities between November 2007 and February 2008 may be more indicative of recruitment of spawning-sized oysters than sampling variation alone. Moreover, survey strata define fishery areas of relatively high spawner density and the random locations of the survey samples likely to be closer to our spat collector sites. Spawner densities at West-Low and East-Low sites were similar over the study period, February 2008 to February 2011 (see Figure A2). 


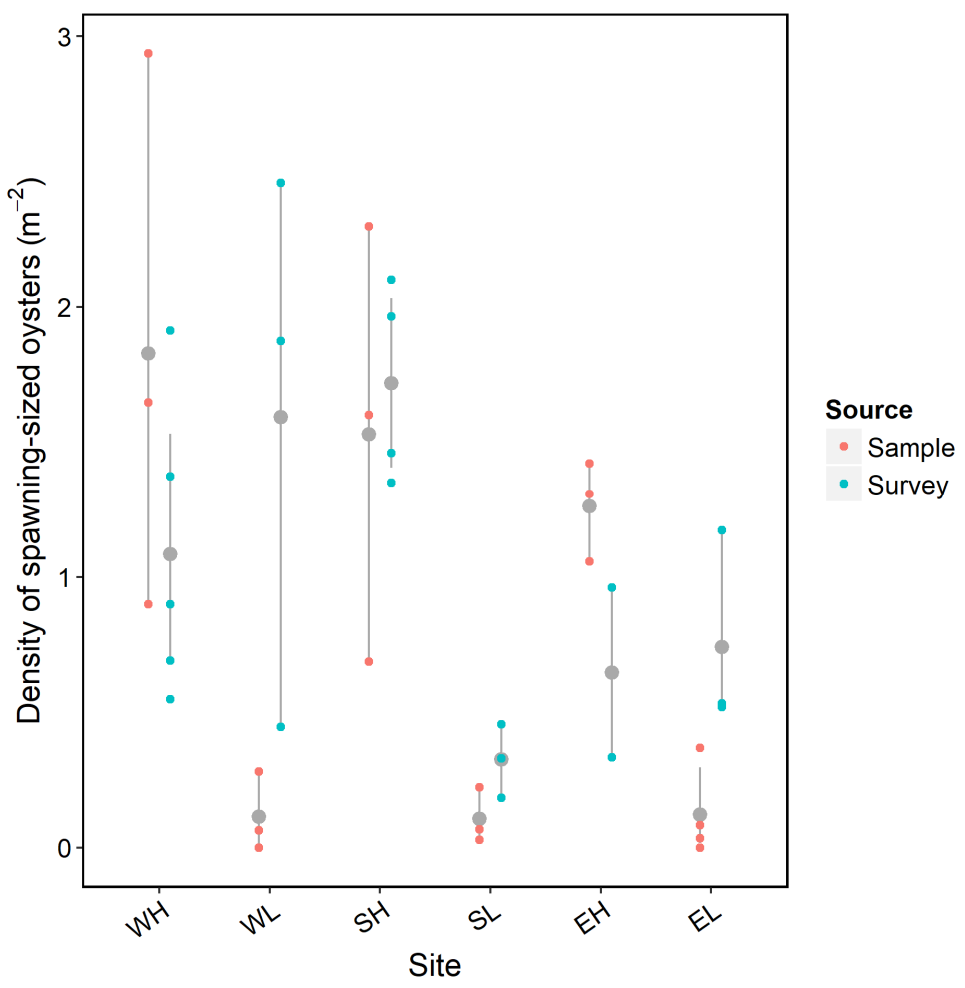

Figure A-3. Spawner densities sampled at each site before the spat collectors were deployed in November 2007 (Sample, red dots); and survey estimates sampled in February 2008 (Survey, blue dots). Growth in $O$. chilensis occurs only in the summer months (Dunn 2005) and the increase in spawner densities between November and February may more reflect recruitment of spawningsized oysters than sampling variation alone. Grey lines represent bootstrapped 95\% confidence intervals for "Sample" and "Survey" estimates and grey dots are the mean densities.

Assessments of the Foveaux Strait O. chilensis stock (Fu 2013) shows the population size of oysters recruiting to the fishery increased $47 \%$ between 2007 and 2012, and catch per unit effort (CPUE), indicative of oyster densities in commercial fishery areas, increased $70 \%$ over the same period. Small annual surveys between stock assessments (Michael et al. 2015) show similar or increasing spawner densities 2006-2008 when recruitment was high, but higher densities in 2009-2011 when recruitment was low. A slight decline in density occurred in 2011, due to summer mortality from B. exitiosa, but after the time of spawning and brooding. Estimates of spawner densities used in the study 0.1- 
1.8 in 2007 and $0.3-4.6$ in 2011 (see Table A-2) are similar to the 75 percentiles of spawner densities in the fishery (Figure A-4).

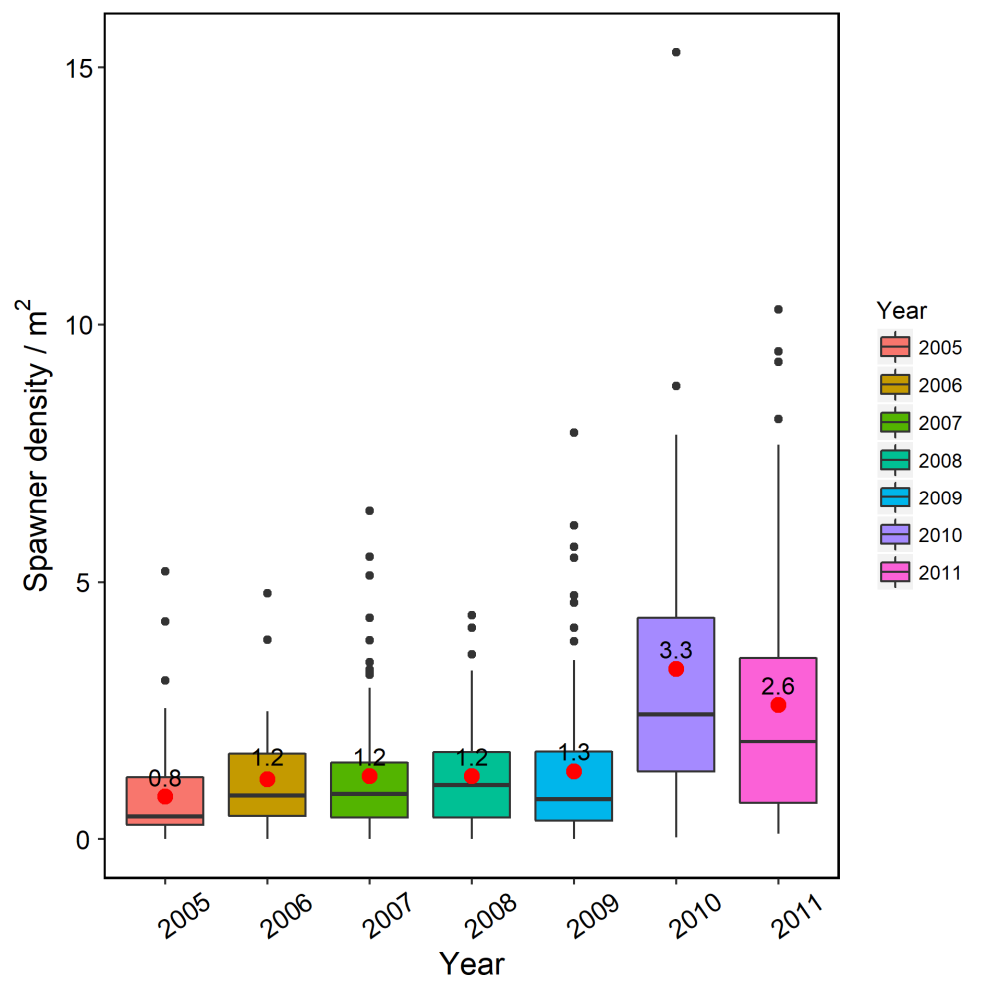

Figure A-4. The range of absolute oyster spawner densities $\left(\mathrm{m}^{-2}\right)$ sampled from random fishery surveys 2005-2011. Boxplots show medians, boxes the 25th and 75th percentiles, and the whiskers 1.5 IQR. Outliers shown as black dots. Mean spawner densities shown as filled red circles and in black text.

Site is a location specific factor comprising area and category and is a proxy for local spawner density. To test the sensitivity of the effect of factor year in the generalized linear model to spawner density, factor spawner density was substituted for area. Year and site were significant, as was their interaction. The year effect remained the same at $50.8 \%$ of deviance. 
Table A-3. Oyster recruitment modelled as a function of Year, Site, and their interactions using a Negative Binomial Generalized Linear Model. Cumulative percentage deviance (\% Dev) for ranked variables and Akaike Information Criterion (AIC).

\begin{tabular}{|c|c|c|c|c|c|c|c|}
\hline & $\mathrm{df}$ & Deviance & $\begin{array}{r}\text { Residual } \\
\text { df }\end{array}$ & $\begin{array}{l}\text { Residual } \\
\text { deviance }\end{array}$ & $\mathrm{p}$ & $\%$ Dev & AIC \\
\hline & & & 66 & 1429.23 & & & 897.57 \\
\hline Year & 3 & 811.96 & 63 & 617.27 & $<0.001$ & 0.508 & 847.07 \\
\hline Site & 5 & 472.56 & 58 & 144.71 & $<0.001$ & 0.883 & 756.76 \\
\hline Year*Site & 15 & 60.7 & 43 & 84.01 & $<0.001$ & 0.941 & 743.92 \\
\hline
\end{tabular}

\section{Estimates of mortality}

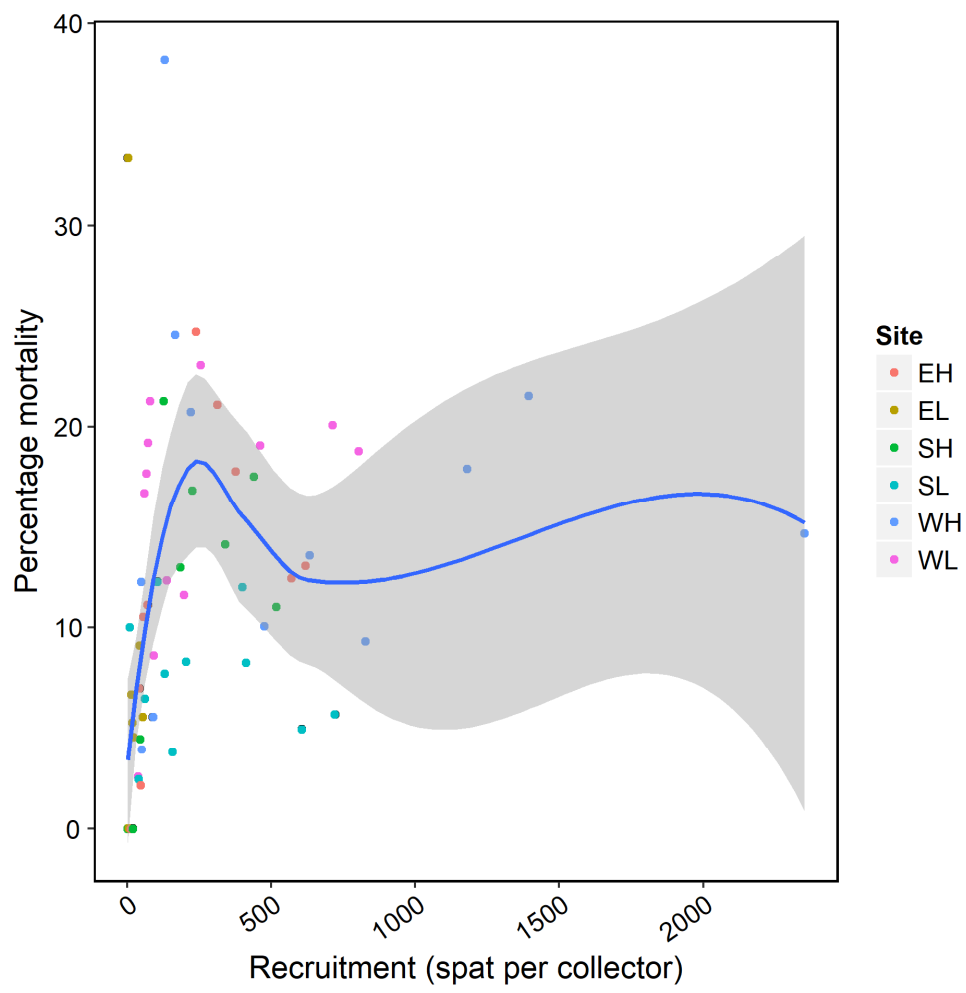

Figure A-5. The percentage mortality of $O$. chilensis spat by settler densities, by Site. Fitted line is a loess smoother and shaded area depicts $\pm 1 \mathrm{SE}$. 


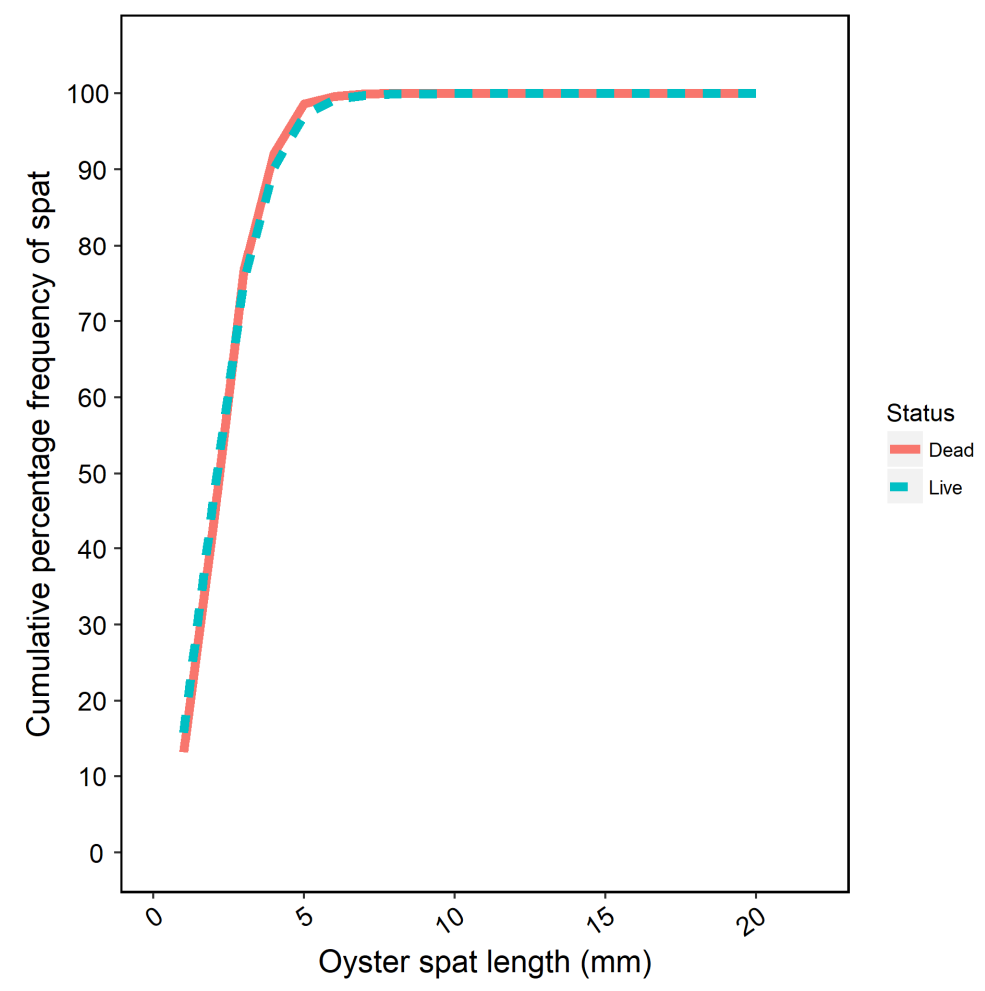

Figure A-6. The cumulative percentage frequency of lengths of live and dead $O$. chilensis spat sampled 2008-2011 in season of recruitment (B: November to February).

\section{Estimates of annual mortality}

Almost all mortality of Ostrea chilensis from Bonamia exitiosa since 2000 occurs between January and March. February (austral summer) surveys estimate annual mortality when it is at its peak. Estimates of recruit-sized (i.e., brooding-size) oyster mortality between 2006 and 2017 are given in Table A-4 (see Michael et al. 2018 for details). Annual mortality comprises the aggregate of two different estimates, both scaled to population level and expressed as a percentage of the recruited population:

1. Pre-survey mortality estimated from the absolute population size of articulated shells of oysters that had died over the summer, just before and 
during the survey and moribund oysters (i.e. recruit-sized new clocks and gapers - see Michael et al. (2018) for definitions and details), and

2. Projections of post-survey mortality that occur in days to weeks, from the proportion of oysters with fatal infections (categories 3+ infections based on the classification of Diggles et al. (2003). Bonamia exitiosa infections were scaled-up to the size of the recruited oyster population.

Estimates of recruit-sized ${ }^{1}$ oysters, gapers ${ }^{2}$ and new clocks ${ }^{3}$ are from standard dredge sampling (see above). All 15 strata were sampled by spat collectors and by dredging (see Figure 3-2). Estimates of abundance for each stratum were calculated using 0.17 as a scalar for dredge efficiency to calculate absolute density (oysters $\mathrm{m}^{-2}$ ) see Fu et al. 2016, and density scaled by the size of the stratum area $\left(\mathrm{km}^{2}\right)$ (see Michael et al. 2018 for details). Aggregated stratum estimates give absolute population estimates. Pre-survey mortality is percentage of dead recruit-sized gapers and new clocks over recruit-sized live oysters, gapers and new clocks.

Up to 25 recruit-sized, oysters were sampled from each site for DNA testing and heart imprints (heart ventricles that are dissected from oysters and dabbed on to a glass slides, to extract samples of haemolymph and haemocytes containing Bonamia exitiosa cells) and to estimate B. exitiosa infection (see Michael et al. 2018 for details) and post-survey mortality (fatal infections). The numbers of infected oysters (prevalence ${ }^{4}$ ) were estimated using quantitative polymerase chain reaction (qPCR) and droplet digital polymerase chain reaction (ddPCR). Estimates of ntensity ${ }^{5}$ of infection made from a subsample of heart imprints for oysters that tested positive by qPCR or ddPCR at each site. Scores of intensity of infection used the categorical scale of Diggles et al (2003), and the numbers of non-fatal (categories $1 \& 2$ ) and fatal (categories 3 - 5) scaled-up to the size of the recruit-sized oyster population by strata, and for the survey area.

${ }^{1}$ Recruit-sized, unable to pass through a $58 \mathrm{~mm}$ internal diameter ring. 
${ }^{2}$ Gapers, live, but moribund oysters containing the whole oyster and valves (the two shells of a bivalve shellfish) remaining apart after the adductor muscle has lost its ability to contract.

${ }^{3}$ New clocks. Clocks are the articulated shells of recently dead oysters with the ligament attaching the two valves intact. New clocks defined as those that had clean inner valves that had retained their lustre but may have had some minor speckling of fouling organisms.

${ }^{4}$ Prevalence is as the proportion of oysters in the sample or population with $B$. exitiosa infection, usually estimated using qPCR or ddPCR.

${ }^{5}$ Mean intensity is defined from histology samples (heart imprints) only as the mean frequency of stages 1-5 oysters (i.e. the mean stage of all oysters examined that had at least one B. exitiosa cell observed). 
Table A-4. Estimates of pre-survey (Pre_M), post-survey (Post_M), and annual mortality (Mortality) from Bonamia exitiosa, mean population density of recruit-sized oysters (Density) with references by year for February surveys.

\begin{tabular}{lrrrrr}
\hline Year & Pre_M & Post_M & Mortality & Density & Reference \\
\hline 2006 & 0.062 & 0.074 & 0.136 & 0.39 & (Michael et al. 2008a) \\
2007 & 0.016 & 0.058 & 0.074 & 0.59 & (Michael et al. 2008b) \\
2008 & 0.019 & 0.048 & 0.067 & 0.58 & (Michael et al. 2009a) \\
2009 & 0.023 & 0.065 & 0.088 & 0.63 & (Michael et al. 2009b) \\
2010 & 0.008 & 0.066 & 0.073 & 0.68 & (Michael et al. 2011) \\
2011 & 0.036 & 0.066 & 0.103 & 0.89 & (Michael et al. 2012a) \\
2012 & 0.032 & 0.088 & 0.120 & 1.30 & (Michael et al. 2013) \\
2013 & 0.043 & 0.121 & 0.164 & 1.40 & (Michael et al. 2014b) \\
2014 & 0.076 & 0.120 & 0.196 & 1.49 & (Michael et al. 2014a) \\
2015 & 0.045 & 0.101 & 0.146 & 1.09 & (Michael et al. 2015) \\
2016 & 0.006 & 0.044 & 0.051 & 0.71 & (Michael et al. 2017b) \\
2017 & 0.015 & 0.035 & 0.049 & 0.78 & (Michael et al. 2017a) \\
\hline
\end{tabular}




\section{Climate variables}

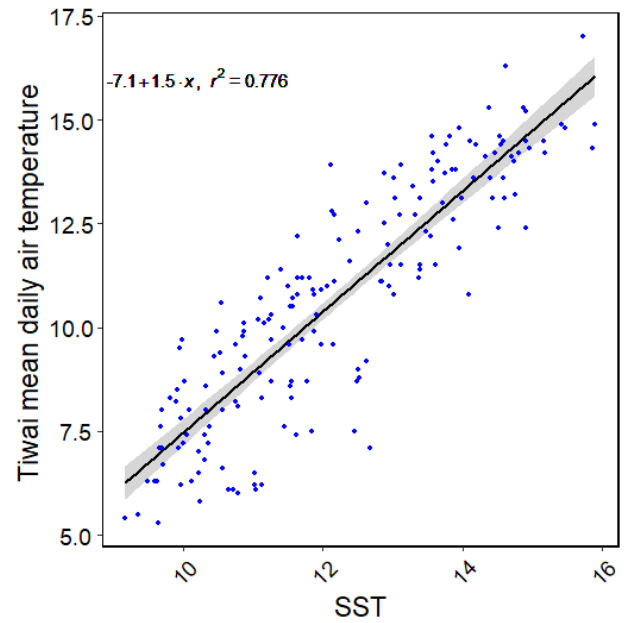

Figure A-7. Regression of mean monthly SST $\left({ }^{\circ} \mathrm{C}\right)$ and air temperatures $\left({ }^{\circ} \mathrm{C}\right)$ recorded at the Tiwai Point weather station, Bluff (-46.587, 168.376), July 2002 to March 2017.

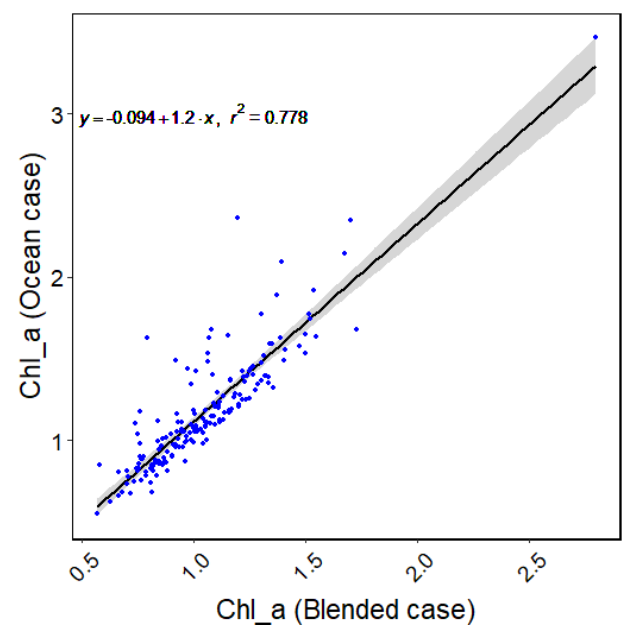

Figure A-8. Regression of mean monthly chlorophyll (Chl_a) Ocean case versus Blended case $\left(\mathrm{mg} \mathrm{m}^{-3}\right)$, July 2002 to March 2017. 


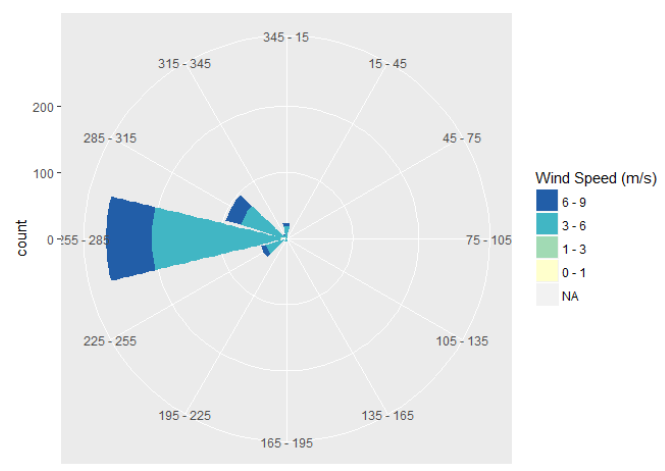

Figure A-9. Wind rose for wind direction and speed at Tiwai Point, Bluff January 1980 to October 2017 (left panel) and by each of the period representing the three reproductive phases (right panel).
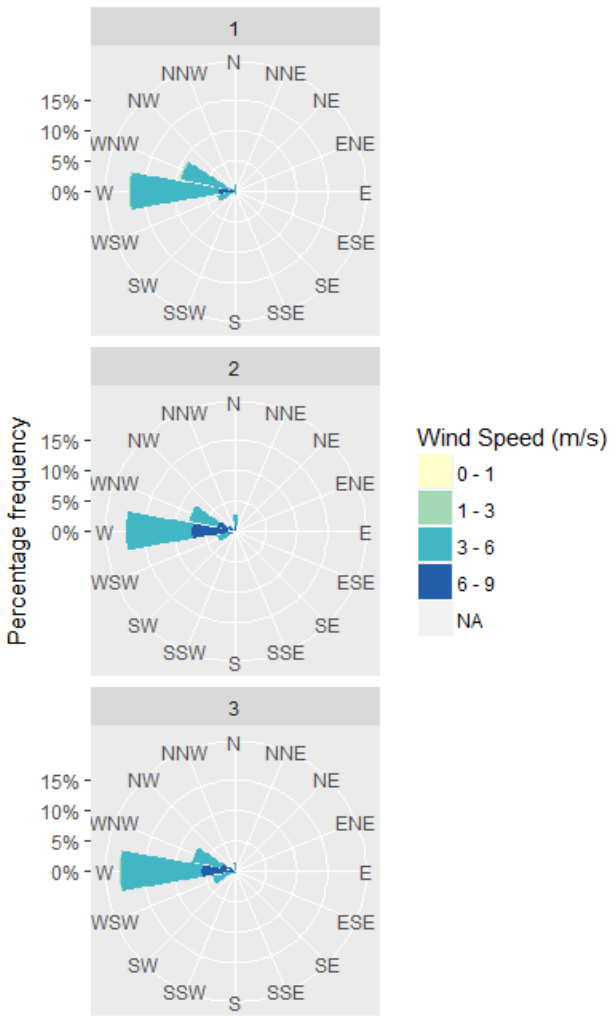


\section{Growth and mortality $0+$ recruits and $1+$ spat}

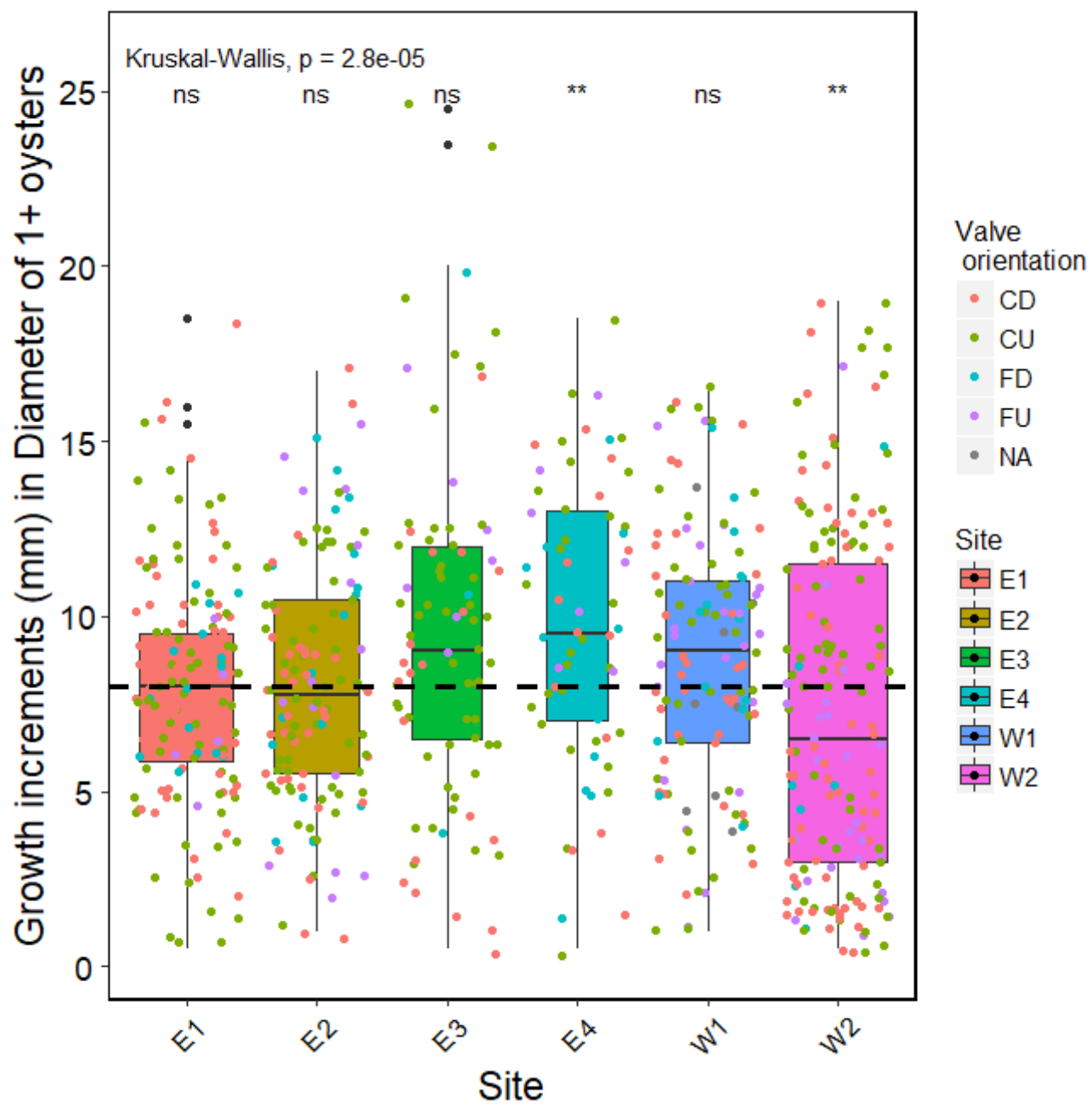

Figure A-10. Size (diameter mm) of oyster spat (1+) at March 2000, by site and by valve orientation. Jitter points represent spat size coloured by valve orientation. Boxplots show medians (solid lines), mean (heavy dashed line), boxes 25 and 75 percentiles, whiskers at 95 percentiles, and outliers shown as black circles above and below whiskers. Bar widths scaled to sample numbers. 


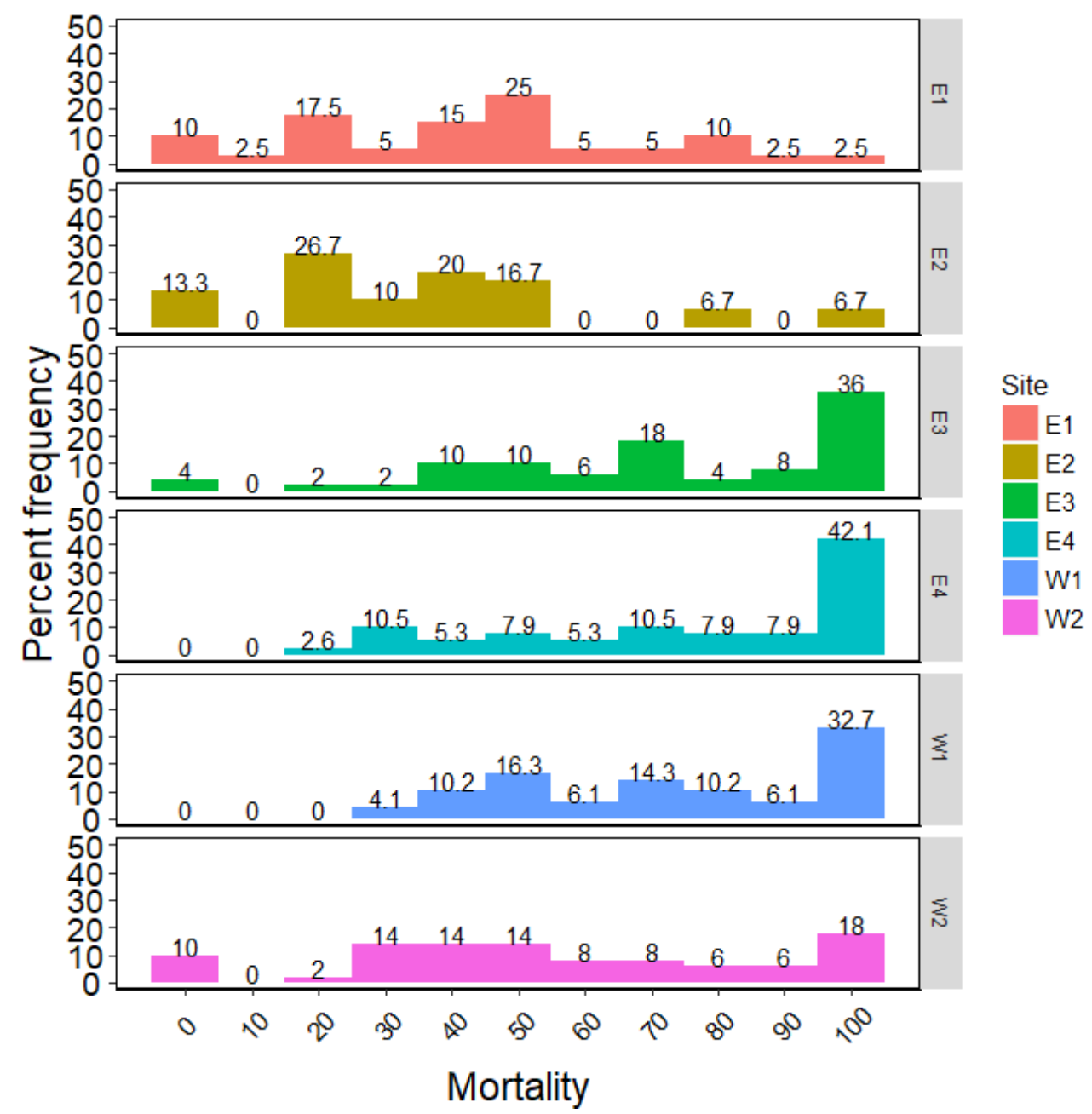

Figure A-11. Percentage frequency of mortality of spat (1+) on each valve by site, between October 1999 and March 2000. 
Table A-5. Heights of $0+$ oyster spat settled on passive spat collectors between October 1999 and March 2000, c. 140 days at 6 sites in Foveaux Strait, by plate heights combined, and by plate surface. Median diameter mm (Median), mean diameter for comparison (Mean), 5th and 95th percentiles, and sample numbers (n). Plate heights 1-4: $36 \mathrm{~cm}, 24 \mathrm{~cm}, 12$ $\mathrm{cm}$, and just off the seabed $(\sim 2 \mathrm{~cm})$ respectively. Surfaces represent the upper and lower (under side) of plates.

\begin{tabular}{lrrrrr}
\hline & Median & Mean & P 0.05 & P 0.95 & n \\
\hline Site & & & & & \\
E1 & 5.0 & 5.2 & 1.0 & 10.0 & 2641 \\
E2 & 5.0 & 5.2 & 1.0 & 10.0 & 2570 \\
E3 & 4.0 & 4.6 & 1.0 & 8.0 & 3467 \\
E4 & 5.0 & 5.1 & 2.0 & 10.0 & 988 \\
W1 & 5.0 & 5.4 & 2.0 & 10.0 & 1467 \\
W2 & 4.0 & 5.0 & 1.0 & 11.0 & 1274 \\
& & & & & \\
Height & & & & & \\
1 & 5.0 & 5.5 & 2.0 & 10.0 & 2217 \\
2 & 5.0 & 5.2 & 2.0 & 10.0 & 3348 \\
3 & 5.0 & 5.3 & 2.0 & 10.0 & 5323 \\
4 & 2.0 & 2.9 & 1.0 & 7.0 & 1519 \\
Surface & & & & & \\
Lower & 5.0 & 4.9 & 1.0 & 10.0 & 9920 \\
Upper & 5.0 & 5.5 & 2.0 & 10.0 & 2487 \\
\hline
\end{tabular}


Table A-6. Mortality of 1+ spat between October 1999 and March 2000 (c. 140 days in Foveaux Strait) by Site and valve-orientation. Mean (mean), standard deviation (SD), numbers of surfaces with settler (n), standard error of the mean (SE), and upper and lower $95 \%$ confidence intervals (95\% CI) for lengths ( $\mathrm{mm})$.

\begin{tabular}{lrrrrrr}
\hline & Mean & SD & n & SE & Lower CI & Upper CI \\
\hline Site & & & & & & \\
E1 & 40.2 & 25.1 & 40 & 3.96 & 32.2 & 48.2 \\
E2 & 35.5 & 26.8 & 30 & 4.90 & 25.5 & 45.5 \\
E3 & 71.0 & 28.7 & 50 & 4.06 & 62.9 & 79.2 \\
E4 & 74.7 & 28.3 & 40 & 4.47 & 65.6 & 83.7 \\
W1 & 70.7 & 25.0 & 49 & 3.57 & 63.5 & 77.9 \\
W2 & 53.7 & 31.0 & 50 & 4.39 & 44.9 & 62.5
\end{tabular}

Valve-

orientation

\begin{tabular}{lllrlll} 
CD & 57.2 & 30.8 & 83 & 3.38 & 50.5 & 63.9 \\
CU & 58.1 & 31.2 & 107 & 3.01 & 52.2 & 64.1 \\
FD & 53.8 & 30.5 & 23 & 6.36 & 40.6 & 66.9 \\
FU & 68.7 & 31.0 & 46 & 4.57 & 59.5 & 77.9 \\
\hline
\end{tabular}




\section{Bibliography}

Abad M, Ruiz C, Martinez D, Mosquera G, Sánchez J (1995) Seasonal variations of lipid classes and fatty acids in flat oyster, Ostrea edulis, from San Cibran (Galicia, Spain). Comparative Biochemistry and Physiology Part C: Pharmacology, Toxicology and Endocrinology 110:109-118

Adlard RD, Miller TL, Smit NJ (2015) The butterfly effect: parasite diversity, environment, and emerging disease in aquatic wildlife. Trends in Parasitology 31:160-166

Aiken D (1993) Bivalve culture in Chile: Seaweed and salmon still dominate the Chilean aquaculture production statistics, but bivalve culture is attracting a lot of attention. Journal of the World Aquaculture Society 24:6

Akaike H (1973) Maximum likelihood identification of Gaussian autoregressive moving average models. Biometrika 60:255-265

Allen RL (1979) A yield model for the Foveaux Strait oyster (Ostrea lutaria) fishery. Rapports et Procès-verbaux des réunions Conseil Permanent International pour l'Exploration de la Mer 175:70-79

Allen RL, Cranfield HJ (1979) A dredge survey of the oyster population in Foveaux Strait. Rapports et Procès-verbaux des réunions Conseil Permanent International pour l'Exploration de la Mer 175:50-62

Alleway HK, Connell SD (2015) Loss of an ecological baseline through the eradication of oyster reefs from coastal ecosystems and human memory. Conservation Biology 29:795-804

Anderson SC, Flemming JM, Watson R, Lotze HK (2011a) Serial exploitation of global sea cucumber fisheries. Fish and Fisheries 12:317-339

Anderson SC, Mills Flemming J, Watson R, Lotze HK (2011b) Rapid Global Expansion of invertebrate fisheries: trends, drivers, and ecosystem effects. PLoS One 6:e14735

Arnold WS, Meyers SD, Geiger SP, Luther ME, Narváez D, Frischer ME, Hofmann E (2017) Applying a coupled biophysical model to predict larval dispersal and source/sink relationships in a depleted metapopulation of the eastern oyster Crassostrea virginica. Journal of Shellfish Research 36:101-118 
Arzul I, Carnegie RB (2015) New perspective on the haplosporidian parasites of molluscs. Journal of Invertebrate Pathology 131:32-42

Arzul I, Gagnaire B, Bond C, Chollet B, Morga B, Ferrand S, Robert M, Renault T (2009) Effects of temperature and salinity on the survival of Bonamia ostreae, a parasite infecting flat oysters Ostrea edulis. Diseases of Aquatic Organisms 85:67-75

Bahr LM, Lanier WP (1981) The ecology of intertidal oyster reefs of the South Atlantic Coast: A community profile. (No. 81/15). US Fish and Wildlife Service. FWS/OBS

Batson PB, Probert PK (2000) Bryozoan thickets off Otago Peninsula. New Zealand Fisheries Assessment Report. 2000/46. 31 p

Beck MW, Brumbaugh RD, Airoldi L, Carranza A, Coen LD, Crawford C, Defeo O, Edgar GJ, Hancock B, Kay MC, Lenihan HS, Luckenbach MW, Toropova CL, Zhang G, Guo X (2011) Oyster reefs at risk and recommendations for conservation, restoration, and management. BioScience 61:107-116

Berthe FCJ, Hine PM (2003) Bonamia exitiosa Hine et al. 2001 is proposed instead of Bonamia exitiosus as the valid name of Bonamia sp. infecting flat oysters Ostrea chilensis in New Zealand. Diseases of Aquatic Organisms 57:181

Bethoney ND, Asci S, Stokesbury KDE (2016) Implications of extremely high recruitment events into the US sea scallop fishery. Marine Ecology Progress Series 547:137-147

Beverton RJH, Holt SJ (1957) On the Dynamics of Exploited Fish Populations. Her Majesty's Stationery Office, London. 553 p.

Bradford JM, Cranfield HJ, Michael KP (1991) Phytoplankton biomass in relation to the surface hydrography of southern New Zealand and possible effects on the food chain. New Zealand Journal of Marine and Freshwater Research 25:133-144

Bricheno LM, Wolf J, Aldridge J (2015) Distribution of natural disturbance due to wave and tidal bed currents around the UK. Continental Shelf Research 109:67-77 
Broekhuizen N, Lundquist CJ, Hadfield MG, Brown SN (2011) Dispersal of oyster (Ostrea chilensis) larvae in Tasman Bay inferred using a verified particle tracking model that incorporates larval behavior. Journal of Shellfish Research 30:643-658

Brown SN (2011) Ecology and Enhancement of the flat oyster Ostrea chilensis (Philippi, 1845) in central New Zealand. Doctor of Philosophy in Zoology, University of Canterbury, Canterbury, New Zealand.

Brown SN, Handley S, Michael K, Schiel D (2010) Annual pattern of brooding and settlement in a population of the flat oyster Ostrea chilensis from central New Zealand. New Zealand Journal of Marine and Freshwater Research 44:217-227

Buestel D, Ropert M, Prou J, Goulletquer P (2009) History, status, and future of oyster culture in France. Journal of Shellfish Research 28:813-820

Burgess SC, Marshall DJ (2011) Temperature-induced maternal effects and environmental predictability. The Journal of Experimental Biology 214:2329-2336

Buroker N, Chanley P, Cranfield H, Dinamani P (1983) Systematic status of two oyster populations of the genus Tiostrea from New Zealand and Chile. Marine Biology 77:191-200

Buroker NE (1985) Evolutionary patterns in the family Ostreidae: Larviparity vs. oviparity. Journal of Experimental Marine Biology and Ecology 90:233-247

Butler E, Butt J, Lindstrom E, Teldesley P, Pickmere S, Vincent W (1992) Oceanography of the subtropical convergence zone around southern New Zealand. New Zealand Journal of Marine and Freshwater Research 26:131-154

Caddy JF, Defeo O (2003) Enhancing or restoring the productivity of natural populations of shellfish and other marine invertebrate resources FAO Fisheries Technical Paper Rome.159p.

Caley MJ, Carr MH, Hixon MA, Hughes TP, Jones GP, Menge BA (1996) Recruitment and the local dynamics of open marine populations. Annual Review of Ecology and Systematics 27:477-500 
Canning A (2013) The Settlement and Survival of the Chilean Oyster (Ostrea chilensis) in Relation to Climate Warming during the Summer of 2013, within the Menai Strait, North Wales. MSc, University of Wales, Bangor, Menai Bridge, Anglesey

Carnegie RB (2017) Bonamiosis of oysters caused by Bonamia exitiosa. ICES Identification Leaflets for Diseases and Parasites of Fish and Shellfish. 6 $\mathrm{p}$

Carr M, Syms C (2006) Recruitment. In: The Ecology of Marine Fishes: California and Adjacent Waters. L.G. Allen, D.J. Pondella, and M. H. Horn (eds.), p 411-427. University of California Press, Berkeley 670 p.

Carroll JM, Shaughnessy KA, Diedrich GA, Finelli CM (2015) Are oysters being bored to death? Influence of Cliona celata on Crassostrea virginica condition, growth and survival. Diseases of Aquatic Organisms117:31-44

Carter L, Lewis K (1995) Variability of the modern sand cover on a tide and storm driven inner shelf, south Wellington, New Zealand. New Zealand Journal of Geology and Geophysics 38:451-470

Chai A-L, Homer M, Tsai C-F, Goulletquer P (1992) Evaluation of oyster sampling efficiency of patent tongs and an oyster dredge. North American Journal of Fisheries Management 12:825-832

Chanley P, Dinamani P (1980) Comparative descriptions of some oyster larvae from New Zealand and Chile, and a description of a new genus of oyster, Tiostrea. New Zealand Journal of Marine and Freshwater Research 14:103-120

Chaparro OR (1990) Effect of temperature and feeding on conditioning of Ostrea chilensis Philippi, 1845 reproductors. Aquaculture Research 21:399-405

Chaparro OR, Navarrete LR, Thompson RJ (2006) The physiology of the larva of the Chilean oyster Ostrea chilensis and the utilisation of biochemical energy reserves during development: An extreme case of the brooding habit. Journal of Sea Research 55:292-300

Chícharo L, Chícharo MA. 2001. Effects of environmental conditions on planktonic abundances, benthic recruitment and growth rates of the bivalve mollusc Ruditapes decussatus in a Portuguese coastal lagoon. Fisheries Research. 53(3):235-250 
Chiswell SM (2012) Non-Gaussian larval dispersal kernels in Gaussian ocean flows. Aquatic Biology 16:203-208

Coen LD, Brumbaugh RD, Bushek D, Grizzle R, Luckenbach MW, Posey MH, Powers SP, Tolley SG (2007) Ecosystem services related to oyster restoration. Marine Ecology Progress Series 341:303-307

Coen LD, Luckenbach MW, Breitburg DL (1999) The role of oyster reefs as essential fish habitat: a review of current knowledge and some new perspectives. American Fisheries Society Symposium 22:438-454

Collie JS, Botsford LW, Hastings A, Kaplan IC, Largier JL, Livingston PA, Plagányi É, Rose KA, Wells BK, Werner FE (2016) Ecosystem models for fisheries management: finding the sweet spot. Fish and Fisheries $17: 101-125$

Compo GP, Whitaker JS, Sardeshmukh PD, Matsui N, Allan, R. J., , Yin X, Gleason BE, Vose RS, Rutledge G, Bessemoulin P, Bronnimann S, Brunet M, Crouthamel RI, Grant AN, Groisman PY, Jones PD, Kruk, M. C., , Kruger AC, Marshall GJ, Maugeri M, Mok HY, Nordli O, Ross TF, Trigo RM, Wang XL, Woodruff SD, Worley SJ (2010) International Surface Pressure Databank (ISPDv2). In: Research Data Archive at the National Center for Atmospheric Research CaISL (ed) Dataset

Corell H, Moksnes P-O, Engqvist A, Döös K, Jonsson PR (2012) Depth distribution of larvae critically affects their dispersal and the efficiency of marine protected areas. Marine Ecology Progress Series 467:29-46

Cowardin LM, Carter V, Golet FC, LaRoe ET (1979) Classification of wetlands and deepwater habitats of the United States. US Department of the Interior, US Fish and Wildlife Service

Cowen RK, Sponaugle S (2009) Larval dispersal and marine population connectivity. Annual Review of Marine Science 1:443-466

Cranfield HJ (1968a) An unexploited population of oysters Ostrea lutaria Hutton, from Foveaux Strait. Part 1. Adult stocks and spatfall distribution. New Zealand Journal of Marine and Freshwater Research $2: 3-22$ 
Cranfield HJ (1968b) An unexploited population of oysters Ostrea lutaria Hutton, from Foveaux Strait. Part II. Larval settlement patterns and spat mortality. New Zealand Journal of Marine and Freshwater Research 2:183-203

Cranfield HJ. 1975. Molluscs: Bluff oysters. 1. New Zealand's nature heritage. 5(71)):1965-1970.

Cranfield HJ (1979) The biology of the oyster, Ostrea lutaria, and the oyster fishery of Foveaux Strait. Rapports et Procès-verbaux des réunions Conseil Permanent International pour l'Exploration de la Mer 175:44-49

Cranfield HJ, Allen RL (1977) Fertility and larval production in an unexploited population of oysters, Ostrea lutaria Hutton, from Foveaux Strait. New Zealand Journal of Marine and Freshwater Research 11:239-253

Cranfield HJ, Carbine G, Michael KP, Dunn A, Stotter DR, Smith DJ (2001) Promising signs of regeneration of blue cod and oyster habitat changed by dredging in Foveaux Strait, southern New Zealand. New Zealand Journal of Marine and Freshwater Research 35:897-908

Cranfield HJ, Doonan IJ, Michael KP. 1997. Incidental mortality of Foveaux Strait Dredge oysters during dredging. Final Research Report Project SOOY002 (Unpublished report held by NIWA, Wellington.). Wellington: NIWA. Final Research Report Project SOOY002.

Cranfield HJ, Dunn A, Doonan IJ, Michael KP (2005) Bonamia exitiosa epizootic in Ostrea chilensis from Foveaux Strait, southern New Zealand between 1986 and 1992. ICES Journal of Marine Science 62:3-13

Cranfield HJ, Manigetti B, Michael KP, Hill A (2003) Effects of oyster dredging on the distribution of bryozoan biogenic reefs and associated sediments in Foveaux Strait, southern New Zealand. Continental Shelf Research 23:1337-1357

Cranfield HJ, Michael KP (1989) Larvae of the incubatory oyster Tiostrea chilensis (Bivalvia: Ostreidae) in the plankton of central and southern New Zealand. New Zealand Journal of Marine and Freshwater Research 23:51-60 
Cranfield HJ, Michael KP, Doonan IJ (1999) Changes in the distribution of epifaunal reefs and oysters during 130 years of dredging for oysters in Foveaux Strait, southern New Zealand. Aquatic Conservation: Marine and Freshwater Ecosystems [Aquat Conserv: Mar Freshwat Ecosyst] 9:461-483

Cranfield HJ, Rowden AA, Smith DA, Gordon DP, Michael KP (2004) Macrofaunal assemblages of benthic habitat of different complexity: the relative importance of fishing disturbance and source of propagules to habitat regeneration in Foveaux Strait, New Zealand. Journal of Sea Research 52:109-125

Crean AJ, Marshall DJ (2009) Coping with environmental uncertainty: dynamic bet hedging as a maternal effect. Philosophical Transactions of the Royal Society B: Biological Sciences 364:1087-1096

Cullen DJ (1962) The influence of bottom sediments upon the distribution of oysters in Foveaux Strait, New Zealand. New Zealand Journal of Geology \& Geophysics 5:271-275

Cullen DJ (1967) The Submarine geology of Foveaux Strait. New Zealand Oceanographic Institute Memoir, New Zealand Department of Scientific and Industrial Research Memoir 3367 p

Culloty SC, Mulcahy MF (2007) Bonamia ostreae in the native oyster Ostrea edulis: a review. Marine Environment and Health Series (Dublin) 29:136

da Silva PcM, Magalhães AR, Barracco MA (2002) Effects of Bucephalus sp.(Trematoda: Bucephalidae) on Perna perna mussels from a culture station in Ratones Grande Island, Brazil. Journal of Invertebrate Pathology 79:154-162

Daigle RM, Chassé J, Metaxas A (2016) The relative effect of behaviour in larval dispersal in a low energy embayment. Progress in Oceanography 144:93117

Dartnall A (1970) The asterinid sea stars of Tasmania. Papers and Proceedings of the Royal Society of Tasmania 104:73-80

David P, Berthou P, Noel P, Jarne P (1997) Patchy recruitment patterns in marine invertebrates: a spatial test of the density-dependent hypothesis in the bivalve Spisula ovalis. Oecologia 111:331-340 
Davis AR, Butler AJ, van Altena I (1991) Settlement behaviour in ascidian larvae: preliminary evidence for inhibition by sponge allelochemicals. Marine Ecology Progress Series 72:117-123

DeAlteris J, Skrobe L, Lipsky C. 1999. Thesignificance of seabed disturbance by mobile fishing gear relative to natural processes: A case study in Narraganset Bay, RI. American Fisheries Society Symposium,. (Fish Habitat: Essential Fish Habitat and Rehabilitation

Dekshenieks M, Hofmann EE, Klinck JM, Powell EN (1996) Modeling the vertical distribution of oyster larvae in response to environmental conditions. Marine Ecology Progress Series 136:97-110

Diggles BK (2004) Survey of dredge oysters (Ostrea chilensis) from Foveaux Strait for Bonamiosis, oyster condition, and other concurrent infections. DigsFish Pathology Services Report.15 p

Diggles BK (2013) Historical epidemiology indicates water quality decline drives loss of oyster (Saccostrea glomerata) reefs in Moreton Bay, Australia. New Zealand Journal of Marine and Freshwater Research 47:561-581

Diggles BK, Cochennec-Laureau N, Hine PM (2003) Comparison of diagnostic techniques for Bonamia exitiosus from flat oysters Ostrea chilensis in New Zealand. Aquaculture 220:145-156

Diggles BK, Hine PM (2002) Bonamia exitiosus epidemiology in Foveaux Strait oysters. NIWA Final Research Report to the Ministry of Fisheries. Project No. OYS1999/01A/other services. (Unpublished report held by the Ministry of Fisheries, Wellington). $52 \mathrm{p}$

Dinamani P, Hickman RW, Hine PM, Jones JB, Cranfield HJ, MAF Fisheries Fisheries Research Centre. Wellington (1987) Report on investigations into the disease outbreak in Foveaux Strait oysters, Tiostrea lutaria, 1986-87. $30 \mathrm{p}$

Doonan IJ, Cranfield HJ (1992) Foveaux Strait oyster (Tiostrea chilensis) assessment, 1992. New Zealand Fisheries Assessment Research Document 92/11 (Unpublished report held in NIWA library, Wellington). MAF Fisheries, Wellington 
Doonan IJ, Cranfield HJ, Michael KP (1994) Catastrophic reduction of the oyster, Tiostrea chilensis (Bivalvia: Ostreidae), in Foveaux Strait, New Zealand, due to infestation by the protistan Bonamia sp. New Zealand Journal of Marine and Freshwater Research 28:335-344

Doonan IJ, Cranfield HJ, Michael KP (1999) Analysis and modelling of Bonamia sp. epizootic data 1986-1992 and estimation of critical density of infection. Unpublished Final Research Report to the Ministry of Fisheries held by the NIWA library, Wellington

Dunn A (2005) Stock assessment of Foveaux Strait dredge oysters (Ostrea chilensis) for the 2003-04 fishing year. New Zealand Fisheries Assessment Report 2005/25:63 p

Dunn A, Doonan IJ, Cranfield HJ, Michael KP, Stotter DR (1998) Modelling growth of the Foveaux Strait Oyster (Tiostrea chilensis). Final Research Report to the Ministry of Fisheries (Project OYS9801). Unpublished report held in the NIWA Library, Wellington.16 p

Dunphy BJ, Hall JA, Jeffs AG, Wells RMG (2006) Selective particle feeding by the Chilean oyster, Ostrea chilensis; implications for nursery culture and broodstock conditioning. Aquaculture 261:594-602

Eckman JE (1987) The role of hydrodynamics in recruitment, growth, and survival of Argopecten irradians (L) and Anomia simplex (Dorbigny) within eelgrass meadows. Journal of Experimental Marine Biology and Ecology 106:165-191

Edwards K, Hare J, Werner F, Seim H (2007) Using 2-dimensional dispersal kernels to identify the dominant influences on larval dispersal on continental shelves. Marine Ecology Progress Series 352:77-87

Ellis JI, Schneider DC (1997) Evaluation of a gradient sampling design for environmental impact assessment. Environmental Monitoring and Assessment 48:157-172

Engelsma MY, Kerkhoff S, Roozenburg I, Haenen OLM, van Gool A, Sistermans W, Wijnhoven S, Hummel H (2010) Epidemiology of Bonamia ostreae infecting European flat oysters Ostrea edulis from Lake Grevelingen, The Netherlands. Marine Ecology Progress Series 409:131142 
FAO (2018) The state of world fisheries and aquaculture 2018. Meeting the sustainable development goals. Aquaculture Department, Food and Agriculture Organization of the United Nations, Rome

Fleming CA (1952) A Foveaux Strait oyster bed. New Zealand Journal of Science and Technology 34:73-85

Fu D (2013) An updated stock assessment for Foveaux Strait dredge oysters (Ostrea chilensis) for the 2012 fishing year. Unpublished report held by the Ministry for Primary Industries, Wellington. Final Research Report for OYS2009-01C, Objective 1.56 p

Fu D, Dunn A, Michael KP (2009) Estimates of the length frequency from commercial catch sampling of Foveaux Strait dredge oysters (Ostrea chilensis) in 2008. Final Research Report for Ministry of Fisheries research project OYS2007-01, objective 3 (Unpublished report held by the Ministry of Fisheries Wellington):16 p.

Fu D, Dunn A, Michael KP, Hills J (2016) The development and performance of a length-based stock assessment of Foveaux Strait oysters (Ostrea chilensis, OYU 5) in southern New Zealand, and application to management. Fisheries Research 183:506-517

Fulton EA (2010) Approaches to end-to-end ecosystem models. Journal of Marine Systems 81:171-183

Fulton EA, Smith AD, Smith DC, Johnson P (2014) An integrated approach is needed for ecosystem based fisheries management: insights from ecosystem-level management strategy evaluation. PLoS One 9:e84242

Gaines SD, Bertness MD (1992) Dispersal of juveniles and variable recruitment in sessile marine species. Nature 360:579-580

Gaines SD, Roughgarden J (1985) Larval settlement rate: A leading determinant of structure in an ecological community of the marine intertidal zone. Proceedings of the National Academy of Sciences 82:3707-3711

Gaines SD, White C, Carr MH, Palumbi SR (2010) Designing marine reserve networks for both conservation and fisheries management. Proceedings of the National Academy of Sciences 107:18286-18293 
Gardner W, Mulvey EP, Shaw EC (1995) Regression analyses of counts and rates: Poisson, overdispersed Poisson, and negative binomial models. Psychological Bulletin 118:392

Gawarkiewicz GG, Monismith SG, Largier J (2007) Observing larval transport processes affecting population connectivity: progress and challenges. Oceanography 20:40-53

Gercken J, Schmidt A (2014) Current status of the European Oyster (Ostrea edulis) and possibilities for restoration in the German North Sea. Neu Broderstorf. 2014. BFN report

Gibbs MM (2001) Sedimentation, suspension, and resuspension in Tasman Bay and Beatrix Bay, New Zealand, two contrasting coastal environments which thermally stratify in summer. New Zealand Journal of Marine and Freshwater Research. 35(5): 951-970

Grabowski JH (2004) Habitat complexity disrupts predator-prey interactions but not the trophic cascade on oyster reefs. Ecology 85:995-1004

Grabowski JH, Brumbaugh RD, Conrad RF, Keeler AG, Opaluch JJ, Peterson $\mathrm{CH}$, Piehler MF, Powers SP, Smyth AR (2012) Economic valuation of ecosystem services provided by oyster reefs. American Institute of Biological Sciences 62:900-909

Grabowski JH, Peterson CH (2007) Restoring oyster reefs to recover ecosystem services. In: Kim Cuddington JEBWGW, Alan H (eds) Theoretical Ecology Series, Book Volume 4. Academic Press

Grabowski JH, Powers SP (2004) Habitat complexity mitigates trophic transfer on oyster reefs. Marine Ecology Progress Series 277:291-295

Gruning JF (1971) New Zealand Pilot: The coasts of North and South Islands of New Zealand, Stewart Island and adjacent islands, Kermadec, Chatham, Bounty, Antipodes, Auckland and Campbell Islands. Hydrographic Department, Great Britain. 504 p

Gutierrez AP, Turner F, Gharbi K, Talbot R, Lowe NR, Peñaloza C, McCullough M, Prodöhl PA, Bean TP, Houston RD (2017) Development of a medium density combined-species SNP array for Pacific and European oysters (Crassostrea gigas and Ostrea edulis). G3: Genes, Genomes, Genetics:g3-117 
Gutierrez JI, Jones CG, Strayer DL, Iribarne OO (2003) Mollusks as ecostsem engineers: the role of shell production in aquatic habitats. Oikos 101:7990

Hall-Spencer JM, Moore PG (2000) Scallop dredging has profound, long-term impacts on maerl habitats. ICES Journal of Marine Science 57:14071415

Heasman M, Diggles BK, Hurwood D, Mather P, Pirozzi I, Dworjanyn S (2004) Paving the way for continued rapid development of the flat (angasi) oyster (Ostrea angasi) farming industry in New South Wales. Final Report to the Department of Transport \& Regional Services. Project No. NT002/0195. June 2004. New South Wales Fisheries Final Report Series No. 66

Heath R (1973) Direct measurements of coastal currents around southern New Zealand. New Zealand Journal of Marine and Freshwater Research $7: 331-367$

Hemer MA (2006) The magnitude and frequency of combined flow bed shear stress as a measure of exposure on the Australian continental shelf. Continental Shelf Research 26:1258-1280

Hendriks IE, van Duren LA, Herman PM (2006) Turbulence levels in a flume compared to the field: implications for larval settlement studies. Journal of Sea Research 55:15-29

Hickman RW (2000) Use of premature New Zealand dredge oyster Tiostrea lutaria Hutton larvae for spat production. Aquaculture Research 31:529536

Hidu H (1969) Gregarious setting in the American oyster Crassostrea virginica Gmelin. Chesapeake Science 10:85-92

Hidu H, Haskin HH (1978) Swimming speeds of oyster larvae Crassostrea virginica in different salinities and temperatures. Estuaries 1:252-255

Hilborn R, Orensanz JM, Parma AM (2005) Institutions, incentives and the future of fisheries. Philosophical Transactions of the Royal Society B: Biological Sciences 360:47-57

Hilborn R, Walters CJ (1992) Quantitative fisheries stock assessment. Choice, dynamics and uncertainty. Chapman and Hall, New York 
Hill NAO, Michael KP, Frazer A, Leslie S (2010) The utility and risk of local ecological knowledge in developing stakeholder driven fisheries management: The Foveaux Strait dredge oyster fishery, New Zealand. Ocean \& Coastal Management 53:659-668

Hill KM, Stokes NA, Webb SC, Hine PM, Kroeck MA, Moore JD, Morley MS, Reece KS, Burreson EM, Carnegie RB. 2014. Phylogenetics of Bonamia parasites based on small subunit and internal transcribed spacer region ribosomal DNA sequence data. Dis Aquat Org. 110(1-2):33-54.

Hine P, Diggles B, Parsons M, Pringle A, Bull B (2002) The effects of stressors on the dynamics of Bonamia exitiosus Hine, Cochennec-Laureau \& Berthe, infections in flat oysters Ostrea chilensis (Philippi). Journal of Fish Diseases 25:545-554

Hine P, Thorne T (2002) Haplosporidium sp. (Alveolata: Haplosporidia) associated with mortalities among rock oysters Saccostrea cuccullata in north Western Australia. Diseases of Aquatic Organisms51:123-133

Hine PM (1991a) The annual pattern of infection by Bonamia sp in New Zealand flat oysters, Tiostrea-chilensis. Aquaculture 93:241-251

Hine PM (1991b) Ultrastructural observations on the annual infection pattern of Bonamia sp. in flat oysters Tiostrea chilensis. Diseases of Aquatic Organisms 11:163-171

Hine PM (1997) Health status of commercially important molluscs in New Zealand. Surveillance: MAF Biosecurity, MAF Authority reporting New Zealand's Animal Health Status 24:25-30

Hine PM (2002) Severe apicomplexan infection in the oyster Ostrea chilensis: a possible predisposing factor in bonamiosis. Diseases of Aquatic Organisms 51:49-60

Hine PM, Dinamani P, Jones JB (1986) Results of a survey of parasites and diseases of oysters (Tiostrea lutaria) around New Zealand, JulyNovember 1986. Unpublished report held by the NIWA library, Wellington. $11 \mathrm{p}$

Hine PM, Jones JB (1994) Bonamia and other aquatic parasites of importance to New Zealand. New Zealand Journal of Zoology 21:49-56 
Hixon MA, Anderson TW, Buch KL, Johnson DW, McLeod JB, Stallings CD (2012) Density dependence and population regulation in marine fish: a large-scale, long-term field manipulation. Ecological Monographs 82:467-489

Hjort $\mathbf{J}$ (1914) Fluctuations in the great fisheries of northern Europe viewed in the light of biological research. ICES Journal of Marine Science

Hobday AJ, Tegner MJ, Haaker PL (2000) Over-exploitation of a broadcast spawning marine invertebrate: Decline of the white abalone. Reviews in Fish Biology and Fisheries 10:493-514

Holbrook SJ, Schmitt RJ, Stephens JS (1997) Changes in an assemblage of temperate reef fishes associated with a climate shift. Ecological Applications 7:1299-1310

Hollenbeck CM, Johnston IA (2018) Genomic Tools and Selective Breeding in Molluscs. Frontiers in Genetics 9:253

Hollis PJ (1962) Studies on the New Zealand mud-oyster, Ostrea lutaria, Hutton, 1873. MSc, Victoria University, Wellington, New Zealand

Hollis PJ (1963) Some studies on the New Zealand oysters. Zoological Publications Victoria University, Wellington:1-28

Hollowed AB, Aydin KY, Essington TE, Ianelli JN, Megrey BA, Punt AE, Smith ADM (2011) Experience with quantitative ecosystem assessment tools in the northeast Pacific. Fish and Fisheries 12:189-208

Hollowed AB, Bond NA, Wilderbuer TK, Stockhausen WT, A'mar ZT, Beamish RJ, Overland JE, Schirripa MJ (2009) A framework for modelling fish and shellfish responses to future climate change. ICES Journal of Marine Science: Journal du Conseil 66:1584-1594

Hothorn T, Bühlmann P, Dudoit S, Molinaro A, Van Der Laan MJ (2005) Survival ensembles. Biostatistics 7:355-373

Houtman TJ (1966) A note on the hydrological regime in Foveaux Strait. New Zealand Journal of Science 9:472-483

Howell M (1967) The trematode, Bucephalus longicornutus (Manter, 1954) in the New Zealand mud-oyster, Ostrea lutaria. Transactions of the Royal Society of New Zealand (Zoology) 8:221-237 
Hubbard AB, Reidenbach MA (2015) Effects of larval swimming behavior on the dispersal and settlement of the eastern oyster Crassostrea virginica. Marine Ecology Progress Series 535:161-176

Hunt HL, Scheibling RE (1997) Role of early post-settlement mortality in recruitment of benthic marine invertebrates. Marine Ecology Progress Series 155:269-301

Hunter RC (1906) Report on oyster beds in Foveaux Strait. Report on New Zealand Fisheries 1905.16-17

Hurst R, Renwick J, Sutton P, Uddstrom M, Kennan S, Law C, Rickard G (2012) Climate and ocean trends of potential relevance to fisheries in the New Zealand region. New Zealand Aquatic Environment and Biodiversity Report No 90. Ministry of Fisheries, Wellington

Jackman S (2008) The pscl Package. In: Simon Jackman with contributions from Alex Tahk AZ, Christina Maimone and Jim Fearon (ed) Political Science Computational Laboratory, Stanford University

Jackson JB, Kirby MX, Berger WH, Bjorndal KA, Botsford LW, Bourque BJ, Bradbury RH, Cooke R, Erlandson J, Estes JA (2001) Historical overfishing and the recent collapse of coastal ecosystems. Science 293:629-637

Jeffs AG (1998a) Gametogenic cycle of the Chilean oyster, Tiostrea chilensis (Philippi, 1845), in north-eastern New Zealand. Invertebrate Reproduction \& Development 34:109-116

Jeffs AG (1998b) Reproductive biology and early life history of the Chilean oyster, with special reference to populations in northern New Zealand. PhD, University of Auckland, Auckland

Jeffs AG, Creese RG (1996) Overview and bibliography of research on the Chilean oyster Tiostrea chilensis (Philippi, 1845) from New Zealand waters. Journal of Shellfish Research 15:305-311

Jeffs AG, Creese RG, Hooker SH (1996) Annual pattern of brooding in populations of Chilean oysters, Tiostrea chilensis, (Philippi, 1845) from northern New Zealand. Journal of Shellfish Research 15:617-622 
Jeffs AG, Hickman RW (2000) Reproductive activity in a pre-epizootic wild population of the Chilean oyster, Ostrea chilensis, from southern New Zealand. Aquaculture 183:241-253

Jones CG, Lawton JH, Shachak M (1994) Organisms as ecosystem engineers. Oikos 69:373-386

Jones G, Milicich M, Emslie M, Lunow C (1999) Self-recruitment in a coral reef fish population. Nature 402:802

Jones GP, Almany GR, Russ GR, Sale PF, Steneck RS, van Oppen MJH, Willis BL (2009) Larval retention and connectivity among populations of corals and reef fishes: history, advances and challenges. Coral Reefs 28:307325

Jones LA, Ricciardi A (2014) The influence of pre-settlement and early postsettlement processes on the adult distribution and relative dominance of two invasive mussel species. Freshwater Biology 59:1086-1100

Jonsson PR, Andre C, Lindegarth M (1991) Swimming behavior of marine bivalve larvae in a flume boundary-layer flow - evidence for near-bottom confinement. Marine Ecology Progress Series 79:67-76

Joshi S, Duffy GP, Brown C (2017) Mobility of maerl-siliciclastic mixtures: Impact of waves, currents and storm events. Estuarine Coastal and Shelf Science 189:173-188

Joyce A, Holthuis TD, Charrier G, Lindegarth S (2013) Experimental effects of temperature and photoperiod on synchrony of gametogenesis and sex ratio in the European oyster Ostrea edulis (Linnaeus). Journal of Shellfish Research 32:447-458

Joyce A, Webb S, Mussely H, Heasman K, Elliot A, King N (2015) Toward selective breeding of a hermaphroditic oyster Ostrea chilensis : Roles of nutrition and temperature in improving fecundity and synchrony of gamete release. Journal of Shellfish Research 34:831-840

Kamel SJ, Oyarzun FX, Grosberg RK (2010) Reproductive biology, family conflict, and size of offspring in marine invertebrates. Integrative and Comparative Biology 50:619-629 
Karpov K, Haaker P, Taniguchi I, Rogers-Bennett L (2000) Serial depletion and the collapse of the California abalone (Haliotis spp.) fishery. Canadian Special Publication of Fisheries and Aquatic Sciences:11-24

Kimmel DG, Newell RIE (2007) The influence of climate variation on eastern oyster (Crassostrea virginica) juvenile abundance in Chesapeake Bay. Limnology and Oceanography 52:959-965

Kimmel DG, Tarnowski M, Newell RIE (2014) The relationship between interannual climate variability and juvenile eastern oyster abundance at a regional scale in Chesapeake Bay. North American Journal of Fisheries Management 34:1-15

King JR, McFarlane GA, Punt AE (2015) Shifts in fisheries management: adapting to regime shifts. Philosophical Transactions of the Royal Society of London B: Biological Sciences 370:20130277

Kirby MX (2004) Fishing down the coast: Historical expansion and collapse of oyster fisheries along continental margins. Proceedings of the National Academy of Sciences of the United States of America 101:13096-13099

Knights AM, Walters K (2010) Recruit-recruit interactions, density-dependent processes and population persistence in the eastern oyster Crassostrea virginica. Marine Ecology Progress Series 404:79-90

Koenigstein S, Mark FC, Gößling-Reisemann S, Reuter H, Poertner H-O (2016) Modelling climate change impacts on marine fish populations: processbased integration of ocean warming, acidification and other environmental drivers. Fish and Fisheries 17 (4): 972-1004

Kool JT, Moilanen A, Treml EA (2013) Population connectivity: recent advances and new perspectives. Landscape Ecology 28:165-185

Krebs CJ, Berteaux D (2006) Problems and pitfalls in relating climate variability to population dynamics. Climate Research 32:143-149

La Peyre M, Furlong J, Brown LA, Piazza BP, Brown K (2014) Oyster reef restoration in the northern Gulf of Mexico: Extent, methods and outcomes. Ocean \& Coastal Management 89:20-28

Lacoste A, Malham SK, Cueff A, Poulet SA (2001) Noradrenaline modulates oyster hemocyte phagocytosis via a $\beta$-adrenergic receptor-cAMP signaling pathway. General and Comparative Endocrinology 122:252259 
Lane HS (2018) Studies on Bonamia parasites (Haplosporidia) in the New Zealand flat oyster Ostrea chilensis. PhD, University of Otago, Otago

Lane HS, Webb SC, Duncan J (2016) Bonamia ostreae in the New Zealand oyster Ostrea chilensis: a new host and geographic record for this haplosporidian parasite. Diseases of Aquatic Organisms118:55-63

Lapegue S, Beaumont A, Boudry P, Goulletquer P European flat oyster-Ostrea edulis. Proc GENINPACT-Evaluation of genetic impact of aquaculture activies on native population A European network, WP1 workshop Genetics of domestication, breeding and enhancement of performance of fish and shellfish. GENINPACT Final Scientific Report 70-75

Large K, Doonan IJ, Michael KP. (2018). Foveaux Strait oyster (OYU 5) stock assessment. An updated stock assessment for Foveaux Strait dredge oysters (Ostrea chilensis) for the 2017 fishing year. Prepared for Bluff Oyster Management Company Ltd. NIWA Client Report: 201819WN (Project BOM17302). 117 p

Le Moullac G, Soyez C, Sham-Koua M, Levy P, Moriceau J, Vonau V, Maihota M, Cochard JC (2013) Feeding the pearl oyster Pinctada margaritifera during reproductive conditioning. Aquaculture Research 44:404-411

Lee H-H, Maunder MN, Piner KR, Methot RD (2012) Can steepness of the stock-recruitment relationship be estimated in fishery stock assessment models? Fisheries Research 125:254-261

Lehodey P, Alheit J, Barange M, Baumgartner T, Beaugrand G, Drinkwater K, Fromentin J-M, Hare S, Ottersen G, Perry R (2006) Climate variability, fish, and fisheries. Journal of Climate 19:5009-5030

Lenihan HS (1999) Physical-biological coupling on oyster reefs: How habitat structure influences individual performance. Ecological Monographs 69:251-275

Lenihan HS, Peterson CH (1998) How habitat degradation through fishery disturbance enhances impacts of hypoxia on oyster reefs. Ecological Applications 8:128-140

Lentz SJ, Fewings MR (2012) The wind and wave-driven inner-shelf circulation. Annual Review of Marine Science 4:317-343 
Levin LA (2006) Recent progress in understanding larval dispersal: new directions and digressions. Integrative and Comparative Biology 46:282297

Levin PS, Möllmann C (2015) Marine ecosystem regime shifts: challenges and opportunities for ecosystem-based management. Philosophical Transactions of the Royal Society B: Biological Sciences 370

Levitan DR, Sewell MA, Chia F-S (1992) How distribution and abundance influence fertilization success in the sea urchin Strongylocentotus franciscanus. Ecology 73:248-254

Lillis A, Eggleston DB, Bohnenstiehl DR (2013) Oyster larvae settle in response to habitat-associated underwater sounds. PLoS One 8:e79337

Lindegren M, Checkley Jr DM, Quinn T (2013) Temperature dependence of Pacific sardine (Sardinops sagax) recruitment in the California Current Ecosystem revisited and revised. Canadian Journal of Fisheries and Aquatic Sciences 70:245-252

Lok A, Acarli S (2006) Preliminary study of settlement of flat oyster spat (Ostrea edulis L.) on oyster and mussel shell collectors. The Israeli Journal of Aquaculture-Bamidgeh:105-115

Lundquist CJ, Botsford LW. 2010. Estimating larval production of a broadcast spawner: the influence of density, aggregation, and the fertilization Allee effect. Canadian Journal of Fisheries and Aquatic Sciences. 68(1):30-42

Lopez-Victoria M, Zea S, Wei E (2006) Competition for space between encrusting excavating Caribbean sponges and other coral reef organisms. Marine Ecology Progress Series 312:113-121

MacDiarmid AB, Butler MJ (1999) Sperm economy and limitation in spiny lobsters. Behavioral Ecology and Sociobiology 46:14-24

Mace PM (2012) Evolution of New Zealand's fisheries management frameworks to prevent overfishing. ICES Document CM 50:09

MacKenzie JR, Clyde L, Burrell JR, Rosenfield A, Hobart WL (1997a) The history, present condition, and future of the molluscan fisheries of north and central America and Europe: Volume 2, Pacific Coast and Supplemental Topics. NOAA/National Marine Fisheries Service, (NOAA Technical Report NMFS, 128) 
MacKenzie JR, Clyde L, Burrell VG, HOBART WL (1997b) The History, Present Condition, and Future of the Molluscan Fisheries of North and Central American and Europe: Volume 1, Atlantic and Gulf Coasts. NOAA/National Marine Fisheries Service, (NOAA Technical Report NMFS, 127)

MacKenzie JR, Clyde L, Burrell VG, Rosenfield A, Hobart WL (1997c) The History, Present Condition, and Future of the Molluscan Fisheries of North and Central America and Europe: Volume 3, Europe. NOAA/National Marine Fisheries Service, (NOAA Technical Report NMFS, 129)

MacKenzie L, Adamson J (2004) Water column stratification and the spatial and temporal distribution of phytoplankton biomass in Tasman Bay, New Zealand: implications for aquaculture. New Zealand Journal of Marine and Freshwater Research 38:705-728

MacKenzie L, Rhodes L (1997) Tasman Bay Scallops; Feast or Famine? Seafood New Zealand 5:38-39

Marsh C, Michael KP, Wright G, Fu D (2016) Estimates of the length frequency from commercial catch sampling of Foveaux Strait dredge oysters (Ostrea chilensis) in 2015. Final Research Report for Ministry of Fisheries research project OYS2013-01, objective 9 (Unpublished report held by the Ministry for Primary Industries, Wellington):25 p.

Maunder MN (2012) Evaluating the stock-recruitment relationship and management reference points: application to summer flounder (Paralichthys dentatus) in the US mid-Atlantic. Fisheries Research 125:20-26

Maunder MN, Piner KR (2015) Contemporary fisheries stock assessment: many issues still remain. ICES Journal of Marine Science: Journal du Conseil 72:7-18

McClatchie S, Goericke R, Auad G, Hill K (2010) Re-assessment of the stockrecruit and temperature-recruit relationships for Pacific sardine (Sardinops sagax). Canadian Journal of Fisheries and Aquatic Sciences 67:1782-1790 
Mendo T, Moltschaniwskyj N, Lyle J, Tracey S, Semmens J (2014) Role of density in aggregation patterns and synchronization of spawning in the hermaphroditic scallop Pecten fumatus. Marine Biology 161:2857-2868

Menge BA, Gouhier TC, Freidenburg T, Lubchenco J (2011) Linking long-term, large-scale climatic and environmental variability to patterns of marine invertebrate recruitment: Toward explaining "unexplained" variation. Journal of Experimental Marine Biology and Ecology 400:236-249

Michael KP (2007) Summary of information in support of the Foveaux Strait Oyster Fishery Plan: The Foveaux Strait ecosystem and effects of oyster dredging. Final Research Report for the Ministry of Fisheries for project ZBD200504 (Unpublished manuscript held by the Ministry of Fisheries, Wellington): $120 \mathrm{p}$.

Michael KP (2010) A summary of information from Foveaux Strait oyster (Ostrea chilensis, OYU 5) strategic research 2000-2009: A context for the 2010 strategic research plan. New Zealand Fisheries Assessment Report 2010/20:37 p

Michael KP (2011) Increasing production and revenue of Foveaux Strait oysters through the development of management strategies, technology, and industry capability. To develop and evaluate strategies to increase oyster production and minimise the effects of disease. 1 April 2006 to 31 March 2011. NIWA Client Report: WLG2011-46 (Project SIL07301) Available from the Bluff Oyster Management Company Limited, Invercargill:56 p.

Michael KP, Bilewitch J, Forman J, Hulston D, Sutherland J, Moss G, Large K (2018) A survey of the Foveaux Strait oyster (Ostrea chilensis) population (OYU 5) in commercial fishery areas and the status of Bonamia (Bonamia exitiosa) in February 2018. New Zealand Fisheries Assessment Report 2018/XX.64 p

Michael KP, Dunn A, Andrew. N. L., Breen PA (2001) Foveaux Strait dredge oyster (Tiostrea chilensis) stock assessment, 1999. New Zealand Fisheries Assessment Report 2001/38:42 p.

Michael KP, Dunn A, Forman J (2005) A survey of Bonamia exitiosa infection in Foveaux Strait dredge oysters (Ostrea chilensis), oyster density and recruitment, January 2004. Unpublished report held by the Ministry of Fisheries, Wellington. $31 \mathrm{p}$ 
Michael KP, Dunn A, Forman J (2006) A survey of Bonamia exitiosa infection, and oyster density and recruitment in Foveaux Strait dredge oyster (Ostrea chilensis), January 2005. New Zealand Fisheries Assessment Report 2006/40:31 p

Michael KP, Dunn A, Forman J (2008a) A survey of Bonamia exitiosa infection, and oyster density and recruitment in Foveaux Strait dredge oysters (Ostrea chilensis), February 2006. New Zealand Fisheries Assessment Report 200/47:35 p

Michael KP, Dunn A, Forman J (2009a) The status of infection by Bonamia exitiosa in Foveaux Strait oysters (Ostrea chilensis), changes in the distributions and densities of recruit, pre-recruit, and small oysters, and projections of disease mortality in February 2008. New Zealand Fisheries Assessment Report 2009/32 (Unpublished Report held by the Ministruy of Fisheries, Wellington):50 p

Michael KP, Dunn A, Forman J, Arlidge A (2008b) A survey of the distribution and absolute abundance of pre-recruit and recruited dredge oysters (Ostrea chilensis) in both non-commercial and designated commercial areas of Foveaux Strait, and estimates of the prevalence and intensity of infection by Bonamia exitiosa, February 2007. New Zealand Fisheries Assessment Report 2008/61:50 p

Michael KP, Forman J, Fu D, Hulston D (2012a) The status of infection by Bonamia (Bonamia exitiosa) in Foveaux Strait oysters (Ostrea chilensis) in February 2011, estimates of pre-survey and projections of post-survey disease mortality, and implications for the projections of future stock status made in the 2009 stock assessment for OYU 5. New Zealand Fisheries Assessment Report 2012/37:55 p

Michael KP, Forman J, Hulston D (2015) A survey of the Foveaux Strait oyster (Ostrea chilensis) population (OYU5) in commercial fishery areas and the status of bonamia (Bonamia exitiosa) in February 2015. New Zealand Fisheries Assessment Report 2015/73:86 p

Michael KP, Forman J, Hulston D, Bilewitch J, Moss G (2017a) The Foveaux Strait oyster and Bonamia surveys, February 2017. NIWA Client Report (2017374WN) prepared for the Bluff Oyster Management Company Ltd for project BOM17302. 
Michael KP, Forman J, Hulston D, Fu D (2011) The status of infection by Bonamia (Bonamia exitiosa) in Foveaux Strait oysters (Ostrea chilensis), changes in the distributions and densities of recruit, pre-recruit, and small oysters in February 2010, and projections of disease mortality . New Zealand Fisheries Assessment Report 2011/5:51 p

Michael KP, Forman J, Hulston D, Maas E, Fu D (2014a) A survey of the Foveaux Strait oyster (Ostrea chilensis) population (OYU5) in commercial fishery areas and the status of bonamia (Bonamia exitiosa) in February 2014. Unpublished report held by the Ministry for Primary Industries, Wellington. $98 \mathrm{p}$

Michael KP, Forman J, Hulston D, Sutherland J (2017b) A survey of the Foveaux Strait oyster (Ostrea chilensis) population (OYU 5) in commercial fishery areas and the status of bonamia (Bonamia exitiosa) in February 2016. New Zealand Fisheries Assessment Report 2017/42.

Michael KP, Forman J, Maas E, Hulston D, Fu D (2014b) The status of infection by bonamia (Bonamia exitiosa) in Foveaux Strait oysters (Ostrea chilensis) in February 2013, estimates of summer disease mortality, and implications for the projections of future stock status made in the 2012 stock assessment for OYU 5. New Zealand Fisheries Assessment Report 2014/49:63 p

Michael KP, Fu D, Forman J (2009b) Foveaux Strait oyster (Ostrea chilensis) 2009 stock assessment: estimates of oyster population size, the distribution of oyster densities, the status of bonamia infection in oysters, and status of the fishery. New Zealand Fisheries Assessment Report 2009/45:56 p

Michael KP, Fu D, Forman J, Hulston D (2013) The Foveaux Strait oyster (Ostrea chilensis, OYU5) stock assessment survey and status of Bonamia infection and mortality, February 2012. New Zealand Fisheries Assessment Report 2013/09:64 p

Michael KP, Fu D, Wright G (2012b) Increasing production and revenue of Foveaux Strait oysters through the development of management strategies, technology, and industry capability. To develop the capability of the Bluff oyster industry to develop, evaluate, and manage harvest and fishery management strategies. 1 April 2009-30 June 2011. NIWA Client Report: WLG2012-44 (Project SIL07301, Objective 4), held by the Bluff Oyster Masngement Company Limited, Invercargill, NZ:119 p. 
Michael KP, Gorman R, Hadfield M, Richardson K (2008c) Summary of information in support of the Foveaux Strait Oyster Fisheries Plan: The Foveaux Strait ecosystem and effects of oyster dredging. NIWA Information Series No 68:18 p

Miller MJ, Feunteun E, Tsukamoto K (2016) Did a "perfect storm" of oceanic changes and continental anthropogenic impacts cause northern hemisphere anguillid recruitment reductions? ICES Journal of Marine Science: Journal du Conseil 73:43-56

Ministry for Primary Industries (2013) Review of sustainability and other management controls for Chatham Island dredge oyster (OYS 4). MPI Discussion Paper No: 2013/19.

Ministry for Primary Industries (2017) Fisheries Assessment Plenary, November 2017: stock assessments and stock status. Compiled by the Fisheries Science Group, Ministry for Primary Industries, Wellington, New Zealand.

Moravec F, de Buron I (2013) A synthesis of our current knowledge of philometrid nematodes, a group of increasingly important fish parasites. Folia Parasitologica 60 (2): 81-101

Mroch RM, Eggleston DB, Puckett BJ (2012) Spatiotemporal variation in oyster fecundity and reproductive output in a network of no-take reserves. Journal of Shellfish Research 31:1091-1101

NABIS (2018) The National Aquatic and Biodiversity Information System. Ministry for Primary Industries. Wellington, New Zealand. (https://catalogue.data.govt.nz/dataset/national-aquatic-biodiversityinformation-system-nabis-fish-layers)

Narváez DA, Klinck JM, Powell EN, Hofmann EE, Wilkin J, Haidvogel DB (2012) Modeling the dispersal of eastern oyster (Crassostrea virginica) larvae in Delaware Bay. Journal of Marine Research 70:381-409

Ngo T, Berthe FC, Choi K-S (2003) Prevalence and infection intensity of the ovarian parasite Marteilioides chungmuensis during an annual reproductive cycle of the oyster Crassostrea gigas. Diseases of Aquatic Organisms 56:259 
Nicolle A, Dumas F, Foveau A, Foucher E, Thiebaut E (2013) Modelling larval dispersal of the king scallop (Pecten maximus) in the English Channel: examples from the Bay of Saint-Brieuc and the bay of Seine. Ocean Dynamics 63:661-678

North EW, Schlag Z, Hood R, Li M, Zhong L, Gross T, Kennedy VS (2008) Vertical swimming behavior influences the dispersal of simulated oyster larvae in a coupled particle-tracking and hydrodynamic model of Chesapeake Bay. Marine Ecology Progress Series 359:99-115

O'Connor NE, Grabowski JH, Ladwig LM, Bruno JF (2008) Simulated predator extinctions: Predator identity affects survival and recruitment of oysters. Ecology 89:428-438

Ofoighil D, Marshall BA, Hilbish TJ, Pino MA (1999) Trans-Pacific range extension by rafting is inferred for the flat oyster Ostrea chilensis. Biological Bulletin 196:122-126

Oliva ME, Olivares AN, Diaz CD, Pasten MV (1999) Parasitic castration in Concholepas concholepas (Gastropoda: Muricidae) due to a larval digenean in northern Chile. Diseases of Aquatic Organisms 36:61-65

Otago Daily Times (1917) Oysters in Cook Strait. Otago Daily Times, Dunedin 19 July 1917, Dunedin

Paris CB, Chérubin LM, Cowen RK (2007) Surfing, spinning, or diving from reef to reef: effects on population connectivity. Marine Ecology Progress Series 347:285-300

Pascual MS, Zampatti EA (1995) Evidence of a chemically mediated adultlarval interaction triggering settlement in Ostrea puelchana: applications in hatchery production. Aquaculture 133:33-44

Perälä T, Kuparinen A (2015) Detecting regime shifts in fish stock dynamics. Canadian Journal of Fisheries and Aquatic Sciences 72:1619-1628

Pernet F, Lupo C, Bacher C, Whittington RJ (2016) Infectious diseases in oyster aquaculture require a new integrated approach. Philosophical Transactions of the Royal Society B: Biological Sciences 371:20150213

Peterson CH, Grabowski JH, Powers SP (2003) Estimated enhancement of fish production resulting from restoring oyster reef habitat: quantitative valuation. Marine Ecology Progress Series 264:249-264 
Peterson CH, Summerson HC, Luettich RA (1996) Response of bay scallops to spawner transplants: A test of recruitment limitation. Marine Ecology Progress Series 132:93-107

Peterson WT, Schwing FB (2003) A new climate regime in northeast Pacific ecosystems. Geophysical Research Letters 30 (17)

Pickrill RA, Mitchell JS (1979) Ocean wave characteristics around New Zealand. New Zealand Journal of Marine and Freshwater Research 13:501-520

Pineda J, Hare JA, Sponaugle S (2007) Larval transport and dispersal in the coastal ocean and consequences for population connectivity. Oceanography 20:22-39

Pineda J, Reyns NB, Starczak VR (2009) Complexity and simplification in understanding recruitment in benthic populations. Population Ecology $51: 17-32$

Pineda J, Starczak V, Stueckle TA (2006) Timing of successful settlement: demonstration of a recruitment window in the barnacle Semibalanus balanoides. Marine Ecology Progress Series 320:233-237

Pinkerton M, Gall M, Wood S (2014) Remote sensing of suspended solids in Lyttelton Harbour/Whakaraupō water using satellite images. Environment Canterbury Technical Report R14/55. Christchurch.

Pinkerton MH, Bell R, Chiswell SM, Currie K, Mullan AB, Rickard G, Stevens C, Sutton P (2015) Reporting on the state of the New Zealand marine environment: recommendations for ocean indicators as part of the Atmospheric and Ocean Climate Change Tier 1 Statistic. New Zealand Aquatic Environment and Biodiversity Report: 151. Ministry for Primary Industries, Wellington

Pinkerton MH, Moore GF, Lavender SJ, Gall MP, Oubelkheir K, Richardson KM, Boyd PW, Aiken J (2006) A method for estimating inherent optical properties of New Zealand continental shelf waters from satellite ocean colour measurements. New Zealand Journal of Marine and Freshwater Research 40:227-247 
Pollard D, Hutchings P (1990) A review of exotic marine organisms introduced to the Australian region. 2. Invertebrates and algae. Asian Fisheries Science 3:223-250

Powell A, W, B. (1979) New Zealand Mollusca: Marine Land and Freshwater Shells. Willian Collins Publishers Ltd, Auckland

Powell EN, Ashton-Alcox KA, Kraeuter JN (2007) Reevaluation of eastern oyster dredge efficiency in survey mode: Application in stock assessment. North American Journal of Fisheries Management 27:492511

Powell EN, Hofmann EE (2015) Models of marine molluscan diseases: trends and challenges. Journal of Invertebrate Pathology 131:212-225

Powell EN, Klinck JM (2007) Is oyster shell a sustainable estuarine resource? Journal of Shellfish Research 26:181-194

Powell EN, Klinck JM, Ashton-Alcox K, Hofmann EE, Morson J (2012) The rise and fall of Crassostrea virginica oyster reefs: The role of disease and fishing in their demise and a vignette on their management. Journal of Marine Research 70:505-558

Powell EN, Mann R, Ashton-Alcox KA, Kuykendall KM, Long MC (2017) Can we estimate molluscan abundance and biomass on the continental shelf? Estuarine, Coastal and Shelf Science 198:213-224

Pritchard C, Shanks A, Rimler R, Oates M, Rumrill S (2015) The Olympia oyster Ostrea lurida: Recent advances in natural history, ecology, and restoration. Journal of Shellfish Research 34:259-271

Puckett BJ, Eggleston DB, Kerr PC, Luettich RA (2014) Larval dispersal and population connectivity among a network of marine reserves. Fisheries Oceanography 23:342-361

Punt AE, A'mar T, Bond NA, Butterworth DS, de Moor CL, De Oliveira JA, Haltuch MA, Hollowed AB, Szuwalski C (2014) Fisheries management under climate and environmental uncertainty: control rules and performance simulation. ICES Journal of Marine Science: 71:2208-2220

R Core Team (2016) R: A Language and Environment for Statistical Computing. R Foundation for Statistical Computing, Vienna. 
Reygondeau G, Demarcq H, Bonhommeau S, Chassot E, Nieto K, Polovina JJ, Huret M, Dulvy NK. 2011. Satellite remote sensing for an ecosystem approach to fisheries management. ICES J Mar Sci. 68(4):651-666.

Ricker WE (1954) Stock and recruitment. Journal of the Fisheries Board of Canada 11:559-623

Ricker WE (1975) Computation and interpretation of biological statistics of fish populations. Bulletin of the Fisheries Research Board of Canada 191:2973

Rifi M, Le Pennec G, Salem MB, Souissi JB (2011) Reproductive strategy of the invasive cockle Fulvia fragilis in the Bay of Tunis (Tunisia). Journal of the Marine Biological Association UK 91:1465-1475

Robert R, Vignier J, Petton B (2017) Influence of feeding regime and temperature on development and settlement of oyster Ostrea edulis (Linnaeus, 1758) larvae. Aquaculture Research 48:4756-4773

Roberts DE, Cummins SP, Davis AR, Chapman MG (2006) Structure and dynamics of sponge-dominated assemblages on exposed and sheltered temperate reefs. Marine Ecology Progress Series 321:19-30

Robins PE, Tita A, King JW, Jenkins SR (2017) Predicting the dispersal of wild Pacific oysters Crassostrea gigas (Thunberg, 1793) from an existing frontier population - a numerical study. Aquatic Invasions 12:117-131

Robinson MD, Smyth GK (2008) Small-sample estimation of negative binomial dispersion, with applications to SAGE data. Biostatistics 9:321-332

Robjohns HC (1979) Bluff oyster industry. Bluff Oyster Boat Owners [Association], Invercargill

Rodriguez SR, Ojeda FP, Inestrosa NC (1993) Settlement of benthic marineinvertebrates. Marine Ecology Progress Series 97:193-207

Roff G, Chollett I, Doropoulos C, Golbuu Y, Steneck RS, Isechal AL, van Woesik R, Mumby PJ (2015) Exposure-driven macroalgal phase shift following catastrophic disturbance on coral reefs. Coral Reefs 34:715725 
Romero MV, Brezina SS, Hernandez D, Casadio S, Bremec C (2013) Differential settlement of associated species on Ostrea puelchana d'Orbigny, 1842 (Ostreidae) in Patagonia (Argentina). American Malacological Bulletin 31:311-321

Rotschild B, Ault J, Goulletquer P, Heral M (1994) Decline of the Chesapeake Bay oyster population: a century of habitat destruction and overfishing. Marine Ecology Progress Series 111:29-39

Roughgarden J, Gaines S, Possingham H (1988) Recruitment dynamics in complex life cycles. Science 241:1460

Rowley AF, Cross ME, Culloty SC, Lynch SA, Mackenzie CL, Morgan E, O'Riordan RM, Robins PE, Smith AL, Thrupp TJ, Vogan CL, Wootton EC, Malham SK (2014) The potential impact of climate change on the infectious diseases of commercially important shellfish populations in the Irish Sea-a review. ICES Journal of Marine Science 71:741-759

Ruesink JL, Lenihan HS, Trimble AC, Heiman KW, Micheli F, Byers JE, Kay MC (2005) Introduction of non-native oysters: Ecosystem effects and restoration implications. Annual Review of Ecology Evolution and Systematics 36:643-689

Sale PF, Kritzer JP (2003) Determining the extent and spatial scale of population connectivity: decapods and coral reef fishes compared. Fisheries Research 65:153-172

Salvi D, Mariottini P (2017) Molecular taxonomy in 2D: a novel ITS2 rRNA sequence-structure approach guides the description of the oysters' subfamily Saccostreinae and the genus Magallana (Bivalvia: Ostreidae). Zoological Journal of the Linnean Society 179:263-276

Sammarco PW, Andrews JC (1989) The Helix experiment: Differential localized dispersal and recruitment patterns in Great Barrier Reef corals. Limnology and Oceanography 34:896-912

Schrobback P, Pascoe S, Coglan L (2014) History, status and future of Australia's native Sydney rock oyster industry. Aquatic Living Resources 27:153-165

Schulte DM, Burke RP, Lipcius RN (2009) Unprecedented restoration of a native oyster metapopulation. Science 325:1124-1127 
Shanks AL, Grantham BA, Carr MH (2003) Propagule dispersal distance and the size and spacing of marine reserves. Ecological Applications 13:159169

Shima JS, Noonburg EG, Swearer SE (2015) Consequences of variable larval dispersal pathways and resulting phenotypic mixtures to the dynamics of marine metapopulations. Biology Letters 11:20140778

Shima JS, Osenberg CW, St Mary CM (2008) Quantifying site quality in a heterogeneous landscape: recruitment of a reef fish. Ecology 89:86-94

Siegel DA, Kinlan BP, Gaylord B, Gaines SD (2003) Lagrangian descriptions of marine larval dispersion. Marine Ecology Progress Series 260:83-96

Skern-Mauritzen M, Ottersen G, Handegard NO, Huse G, Dingsør GE, Stenseth NC, Kjesbu OS (2016) Ecosystem processes are rarely included in tactical fisheries management. Fish and Fisheries 17:165-175

Smyth D, Kregting L, Elsasser B, Kennedy R, Roberts D (2016) Using particle dispersal models to assist in the conservation and recovery of the overexploited native oyster (Ostrea edulis) in an enclosed sea lough. Journal of Sea Research 108:50-59

Smyth D, Mahon AM, Roberts D, Kregting L. 2018. Settlement of Ostrea edulis is determined by the availability of hard substrata rather than by its nature: Implications for stock recovery and restoration of the European oyster. Aquatic Conservation-Marine and Freshwater Ecosystems. 28(3):662-671

Smyth D, Roberts D (2010) The European oyster (Ostrea edulis) and its epibiotic succession. Hydrobiologia 655:25-36

Soniat TM, Cooper N, Powell EN, Klinck JM, Abdelguerfi M, Tu S, Mann R, Banks PD (2014) Estimating sustainable harvests of eastern oysters, Crassostrea virginica. Journal of Shellfish Research 33:381-394

Soniat TM, Klinck JM, Powell EN, Cooper N, Abdelguerfi M, Hofmann EE, Dahal J, Tu S, Finigan J, Eberline BS (2012) A shell-neutral modeling approach yields sustainable oyster harvest estimates: a retrospective analysis of the Louisiana state primary seed grounds. Journal of Shellfish Research 31:1103-1112 
Sponaugle S, Cowen RK, Shanks A, Morgan SG, Leis JM, Pineda J, Boehlert GW, Kingsford MJ, Lindeman KC, Grimes C (2002) Predicting selfrecruitment in marine populations: Biophysical correlates and mechanisms. Bulletin of Marine Science 70:341-375

Stanton BR, Goring DG, Bell RG (2001) Observed and modelled tidal currents in the New Zealand region. New Zealand Journal of Marine and Freshwater Research 35:397-415

Stanwell-Smith D, Barnes DKA (1997) Benthic community development in Antarctica: recruitment and growth on settlement panels at Signy Island. Journal of Experimental Marine Biology and Ecology 212:61-79

Stead DH (1971a) Observations on the biology and ecology of the Foveaux Strait dredge oyster (Ostrea lutaria, Hutton). N.Z. Fisheries Technical Report No.68. New Zealand Marine Department, Wellington. 49 p.

Stead DH (1971b) Survey of Foveaux Strait oyster beds 1960-64. New Zealand Fisheries Technical Report No. 16. Published by the New Zealand Marine Department. 29 p

Stentiford GD, Sritunyalucksana K, Flegel TW, Williams BAP, Withyachumnarnkul B, Itsathitphaisarn O, Bass D (2017) New paradigms to help solve the global aquaculture disease crisis. PLOS Pathogens 13:e1006160

Stock R (2000) Brooding and larval biology of the flat oyster, Tiostrea chilensis. MSc, University of Otago, Dunedin, New Zealand.

Stoner DS (1990) Recruitment of a Tropical colonial ascidian: Relative importance of pre-settlement vs. post-settlement processes. Ecology $71: 1682-1690$

Street RJ, Crowther GS, Kirkman JS. 1973. Oyster shell return experiment: Foveaux Strait 1970-1971. Wellington: Fisheries Division, Ministry of Agriculture and Fisheries. N.Z. Fisheries Technical Report No.10. 15 p.

Strobl C, Boulesteix A-L, Zeileis A, Hothorn T (2007) Bias in random forest variable importance measures: Illustrations, sources and a solution. BMC Bioinformatics 8:25 
Sullivan JT, Cheng TC, Howland KH (1985) Studies on parasitic castration: castration of Ilyanassa obsoleta (Mollusca: Gastropoda) by several marine trematodes. Transactions of the American Microscopical Society:154-171

Suong NT, Webb S, Banks J, Wakeman KC, Lane H, Jeffs A, Brosnahan C, Jones B, Fidler A (2017) Partial 18S rRNA sequences of apicomplexan parasite ' $\mathrm{X}$ '(APX), associated with flat oysters Ostrea chilensis in New Zealand. Diseases of Aquatic Organisms127:1-9

Swearer SE, Shima JS (2010) Regional variation in larval retention and dispersal drives recruitment patterns in a temperate reef fish. Marine Ecology Progress Series 417:229-236

Swearer SE, Shima JS, Hellberg ME, Thorrold SR, Jones GP, Robertson DR, Morgan SG, Selkoe KA, Ruiz GM, Warner RR (2002) Evidence of selfrecruitment in demersal marine populations. Bulletin of Marine Science $70: 251-271$

Sweet MJ, Bulling MT (2017) On the Importance of the Microbiome and Pathobiome in Coral Health and Disease. Frontiers in Marine Science 4: 9

Szuwalski CS, Vert-Pre KA, Punt AE, Branch TA, Hilborn R (2015) Examining common assumptions about recruitment: a meta-analysis of recruitment dynamics for worldwide marine fisheries. Fish and Fisheries 16:633-648

Talman SG, Norkko A, Thrush SF, Hewitt JE (2004) Habitat structure and the survival of juvenile scallops Pecten novaezelandiae: comparing predation in habitats with varying complexity. Marine Ecology Progress Series 269:197-207

Tamburri MN, Luckenbach MW, Breitburg DL, Bonniwell SM (2008) Settlement of Crassostrea ariakensis larvae: effects of substrate, biofilms, sediment and adult chemical cues. Journal of Shellfish Research 27:601-608

Tamburri MN, Zimmer-Faust RK, Tamplin ML (1992) Natural sources and properties of chemical inducers mediating settlement of oyster larvae: A re-examination. The Biological Bulletin 183:327-338 
Tettelbach S, Wenczel P (1993) Reseeding efforts and the status of bay scallop Argopecten irradians (Lamarck, 1819) populations in New York following the occurrence of" brown tide" algal blooms. Journal of Shellfish Research 12:423-431

Thomas LJ (2015) A molecular and population genetics study of the Bluff Oyster (Ostrea chilensis). PhD, Victoria University of Wellington,

Thomas Y, Dumas F, Andrefouet S (2014) Larval dispersal modeling of pearl oyster Pinctada margaritifera following realistic environmental and biological forcing in Ahe Atoll Lagoon. PLoS one 9(4), e95050

Thomsen MS, McGlathery K (2006) Effects of accumulations of sediments and drift algae on recruitment of sessile organisms associated with oyster reefs. Journal of Experimental Marine Biology and Ecology 328:22-34

Toro JE, Morande PR (1998) Effect of food ration and temperature on length of brooding period, larval development and size of pediveligers released in the Chilean oyster Ostrea chilensis. Journal of the World Aquaculture Society 29:267-270

Trapletti A, Hornik K (2018) tseries: Time Series Analysis and Computational Finance.

Treml EA, Roberts JJ, Chao Y, Halpin PN, Possingham HP, Riginos C (2012) Reproductive output and duration of the pelagic larval stage determine seascape-wide connectivity of marine populations. Integrative and Comparative Biology 52:525-537

Trenberth KE (1984) Signal versus noise in the Southern Oscillation. Monthly Weather Review 112:326-332

Trimble AC, Ruesink JL, Dumbauld BR (2009) Factors preventing the recovery of a historically overexploited shellfish species, Ostrea lurida Carpenter 1864. Journal of Shellfish Research 28:97-106

Turner E, Zimmer-Faust R, Palmer M, Luckenbach M, Pentchef N (1994) Settlement of oyster (Crassostrea virginica) larvae: Effects of water flow and a water-soluble chemical cue. Limnology and Oceanography 39:1579-1593

Underwood AJ, Fairweather PG (1989) Supply-side ecology and benthic marine assemblages. Trends in Ecology \& Evolution 4:16-20 
Wijsman JWM, Troost K, Fang J, Roncarati A (2019) Global production of marine bivalves. Trends and challenges. In: Smaal AC, Ferreira JG, Grant J, Petersen JK, Strand $\varnothing$ (eds) Goods and Services of Marine Bivalves. Springer International Publishing, Cham

Utting SD, Millican PF (1997) Techniques for the hatchery conditioning of bivalve broodstocks and the subsequent effect on egg quality and larval viability. Aquaculture 155:45-54

Vadas RL, Johnson S, Norton TA (1992) Recruitment and mortality of early post-settlement stages of benthic algae. British Phycological Journal 27:331-351

Valderrama K, Oliva M, Campos B, Brown D (2004) Parasitic castration of Eurhomalea lenticularis (Bivalvia: Veneridae) by a digenetic trematode: quantitative histological analysis. Diseases of Aquatic Organisms 59:151-158

Vanbanning P (1991) Observations on Bonamiasis in the stock of the European flat oyster, Ostrea edulis, in the Netherlands, with special reference to the recent developments in Lake Grevelingen. Aquaculture 93:205-211

Vasquez HE, Hashimoto K, Kitamura H, Satuito CG (2014) Wheat germ agglutinin-binding glycoprotein extract from shells of conspecifics induces settlement of larvae of the Pacific oyster Crassostrea gigas (Thunberg). Journal of Shellfish Research 33:415-423

Vayssier-Taussat M, Albina E, Citti C, Cosson JF, Jacques M-A, LEBRUN MH, Le Loir Y, Ogliastro M, Petit M-A, Roumagnac P, Candresse T (2014) Shifting the paradigm from pathogens to pathobiome: new concepts in the light of meta-omics. Frontiers in Cellular and Infection Microbiology 4,29

Veitch F, Hidu H (1971) Gregarious setting in the American oyster Crassostrea virginica Gmelin: I. Properties of a partially purified "Setting factor". Chesapeake Science 12:173-178

Venables WN, Ripley BD (2002) Modern Applied Statistics with S. Fourth Edition. Springer, New York. ISBN 0-387-95457-0 
Ver Hoef JM, Boveng PL (2007) Quasi-Poisson vs. negative binomial regression: how should we model overdispersed count data? Ecology $88: 2766-2772$

Vuong QH (1989) Likelihood ratio tests for model selection and non-nested hypotheses. Econometrica: Journal of the Econometric Society: 307-333

Wahl M (1989) Marine epibiosis. I. Fouling and antifouling: some basic aspects. Marine Ecology Progress Series 58:175-189

Waldbusser GG, Powell EN, Mann R (2013) Ecosystem effects of shell aggregations and cycling in coastal waters: an example of Chesapeake Bay oyster reefs. Ecology 94:895-903

Walles B, Mann R, Ysebaert T, Troost K, Herman PMJ, Smaal AC (2015) Demography of the ecosystem engineer Crassostrea gigas, related to vertical reef accretion and reef persistence. Estuarine, Coastal and Shelf Science 154:224-233

Walne PR (1963) Breeding of the Chilean oyster (Ostrea chilensis Philippi) in the laboratory. Nature. 197: 676.

Walne PR (1974) Culture of Bivalve Molluscs: Fifty Years Experience at Conwy. Fishing News Book Ltd. Famham, Surrey, England.189

Walters RA, Goring DK, Bell RG (2001) Ocean tides around New Zealand. New Zealand Journal of Marine and Freshwater Research 35(3):567-579

Wasson K, Hughes BB, Berriman JS, Chang AL, Deck AK, Dinnel PA, Endris C, Espinoza M, Dudas S, Ferner MC (2016) Coast-wide recruitment dynamics of Olympia oysters reveal limited synchrony and multiple predictors of failure. Ecology 97:3503-3516

Westerskov K (1980) Aspects of the biology of the dredge oyster Ostrea lutaria Hutton, 1873. PhD Thesis, University of Otago, Dunedin

Wheeler JD, Helfrich KR, Anderson EJ, McGann B, Staats P, Wargula AE, Wilt K, Mullineaux LS (2013) Upward swimming of competent oyster larvae Crassostrea virginica persists in highly turbulent flow as detected by PIV flow subtraction. Marine Ecology Progress Series 488:171-185 
Wheeler JD, Helfrich KR, Anderson EJ, Mullineaux LS (2015) Isolating the hydrodynamic triggers of the dive response in eastern oyster larvae. Limnology and Oceanography 60:1332-1343

Wilkie EM, Bishop MJ, O'Connor WA (2013) The density and spatial arrangement of the invasive oyster Crassostrea gigas determines its impact on settlement of native oyster larvae. Ecology and Evolution $3: 4851-4860$

Wilson JA, Chaparro OR, Thompson RJ (1996) The importance of broodstock nutrition on the viability of larvae and spat in the Chilean oyster Ostrea chilensis. Aquaculture 139:63-75

Wright JT, Benkendorff K, Davis A (1997) Habitat associated differences in temperate sponge assemblages: the importance of chemical defence. Journal of Experimental Marine Biology and Ecology 213:199-213

Wright K (1990) Nelson and Marlborough Oyster History. Book 2. Nelson Historical Society (Inc.), Nelson

Yonge CM (1966) Oysters. Collins Clear-Type Press, London and Glasgow

Zacherl DC, Moreno A, Crossen S (2015) Exploring restoration methods for the Olympia oyster Ostrea lurida Carpenter, 1864: Effects of shell bed thickness and shell deployment methods on shell cover, oyster recruitment, and oyster density. Journal of Shellfish Research 34:819830

Zeldis J (2008) Origin and processing of nutrients in Golden and Tasman Bays. NIWA client report, NIWA Project ELF08205 TSDC35, May 2008, Book CHC2008-052

Zeldis J, Hadfield M, Morrisey D, Broekhuizen N, Stenton-Dozsey J (2011) Tasman Aquaculture: guidance on farming additive species - Stage 1. NIWA client report, NIWA Project PRM201022, February 2011 CHC2011-005

Zuur AF, Ieno EN, Elphick CS (2010) A protocol for data exploration to avoid common statistical problems. Methods in Ecology and Evolution 1:3-14 
Recruitment of Ostrea chilensis (Philippi, 1844) in Foveaux Strait, Southern New Zealand

BY

Keith P. Michael

\begin{abstract}
A thesis submitted to the
Victoria University of Wellington

in fulfilment of the requirements for the degree of

Doctor of Philosophy
\end{abstract}

Victoria University of Wellington

2019 


\section{Recruitment of Ostrea chilensis (Philippi, 1844) in Foveaux Strait, Southern New Zealand}

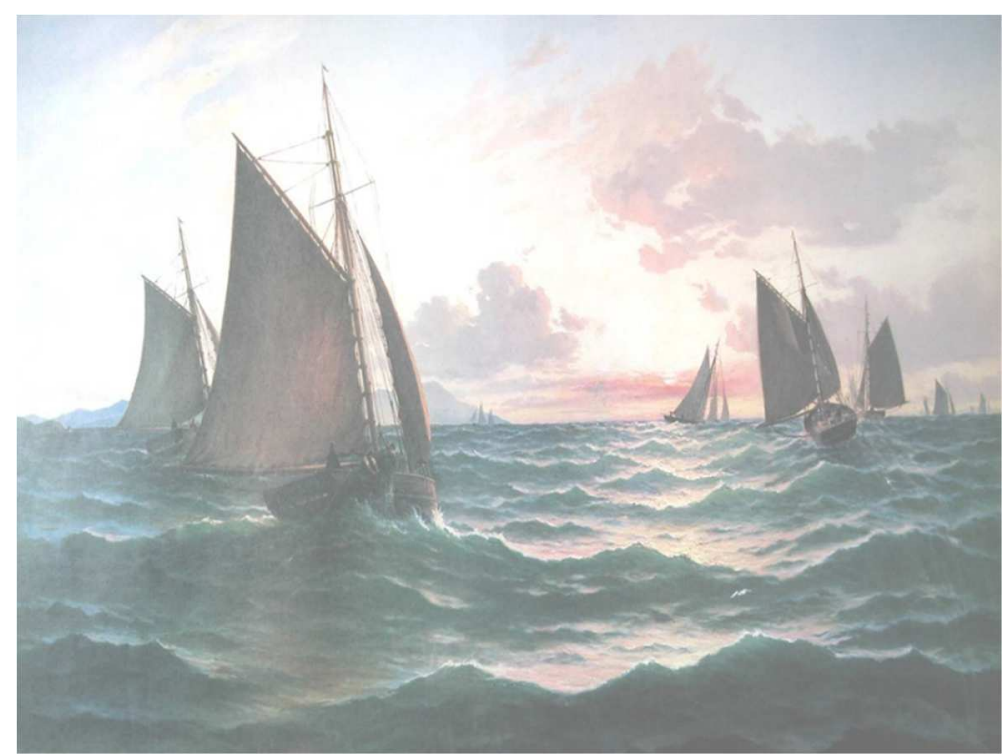

Sailing cutters dredging for oysters in Foveaux Strait c. 1880s. John Gibb (artist).

\section{BY}

Keith P. Michael

A thesis submitted to the

Victoria University of Wellington

in fulfilment of the requirements for the degree of

Doctor of Philosophy

Victoria University of Wellington

2019
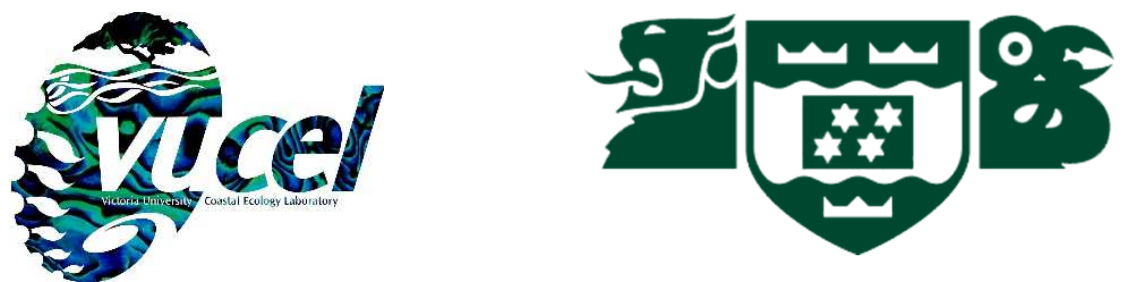
This thesis was conducted under the supervision of:

Prof. Jeffrey S. Shima (Primary Supervisor)

Victoria University of Wellington,

Wellington, New Zealand

And

Dr Stephen Hartley (Secondary Supervisor)

Victoria University of Wellington,

Wellington, New Zealand 


\begin{abstract}
This research evaluates fundamental ecological processes to facilitate an understanding of recruitment in Ostrea chilensis from Foveaux Strait, southern New Zealand. Foveaux Strait represents an extreme habitat for oysters that differs to the sheltered nearshore, muddy habitats of most other oyster populations. $O$. chilensis exhibits the extreme end of brooding strategies in Ostreinae, does not form extensive reefs, and comprises putative self-recruiting populations. The Foveaux Strait oyster fishery is nationally important. Recurrent disease mortality in these populations has put greater onus on understanding recruitment.
\end{abstract}

To evaluate the strength of a recruit-per-spawner relationship in oysters, seasonality in the settlement of larvae was determined. Most recruitment in any given year, over a 6-year period, occurred in the austral spring and summer (November to February). Fishery-wide, recruitment varied significantly between years, with most variation $(50.8 \%)$ explained by a year effect that represents the combined influences of climatic and biological conditions. Spawner densities and fishery areas explain further variation (13.8\% and $11.6 \%$, respectively), with further 2-way interactions between these factors. Recruits-per-spawner declined serially over time, despite similar or increasing densities of spawning-sized oysters. Average recruitment was lowest when spawner densities were highest; this suggests a more complex relationship between recruitment and density that has implications for management of this oyster fishery.

Recruitment to the $O$. chilensis fishery declined abruptly to low levels in 2010 and remained low until 2017. Relatively high spawning-stock sizes over this period had previously supported high recruitment. Density and oyster mortality from Bonamia exitiosa (a proxy for one or more infections) and their two-way interaction were the main determinants of recruitment. The highest recruitment occurred at times of low mortality and low density, suggesting 
reduced effects of disease on gametogenesis and reduced disease transmission. The contributions of climate factors were minor; however, a 3-way interaction between oyster density, mortality, and climate is likely to drive variation in recruitment. Pathobiomes (multiple infections in populations) may be important determinants of shellfish recruitment and population dynamics.

This research evaluates the hypothesis of self-recruitment from distributions of recruit densities around an isolated natal population, and from the relationship between recruitment and brooding-sized oyster densities. Distance from the natal population, direction along or across the tidal current, or brooders did not predict recruit densities. Recruit distributions imply greater dispersal and larval mixing than previously reported. The swift tidal currents and possibility of more variable pelagic larval durations may enhance mixing and connectivity between populations in Foveaux Strait.

Post-settlement mortality is the primary determinant of spatial structure in Foveaux Strait oysters. Productive fishery areas comprise mostly stable substrates of shells, sand, and gravel, with no or little other epifauna. Most $(66.8 \%)$ post-settlement survivors were on the heavy shells of both live and dead $O$. chilensis, which suggests an unusual recruit-adult relationship based on survival rather than settlement. Recruits and 1+ year spat grew larger and had lower mortality at eastern sites with the lowest exposure to oceanic swells and putative lowest sediment movement. Moreover, recruits on spat collectors also grew larger and had lower mortality at heights $\geq 12 \mathrm{~cm}$ than those $2 \mathrm{~cm}$ off the seabed.

This research suggests the effects of disease on brooding percentages and thereby larval supply may be the main determinant of the variation in recruitment in $O$. chilenesis, and the spatial structure of oyster populations in Foveaux Strait shaped by abiotic as well as biotic post-settlement mortality. 


\section{Acknowledgements}

First and foremost, I thank my primary supervisor Prof. Jeff Shima for his guidance, support and patience. Dr Stephen Hartley and staff at the School of Biological Sciences at Victoria University of Wellington provided encouragement and inspiration. I acknowledge the support of the Shima Lab at the Victoria Coastal Ecology Laboratory, especially Daniel McNaughtan and Becky Focht. I thank the dissertation reviewers Prof. Andrew Jeffs (UOA), Dr Alice Rogers (VUW), and Assoc. Prof. Paul Gribben (UNSW) for their contributions. Thank you to Patricia Stein, Mark Stephen and Mary Murray for their friendly assistance with admin.

Many friends and colleagues at NIWA supported me to complete this dissertation. Special thanks to Susan Jane Baird, Peter McMillan, Dr Sophie Mormede, and Dr Rosemary Hurst who always had time for a chat, critically reviewed manuscripts from this work, and their endless encouragement. I thank Dr Alison MacDiarmid for her encouragement to undertake this PhD.

I gratefully acknowledge the Bluff Oyster Management Company for their support with sampling and access to oyster industry data. The sampling programmes in Foveaux Strait would not have been possible without the assistance of Graeme Wright, David Skeggs, Victoria Pearsey, skipper Stephen Hawke and the crew of the oyster vessel F.V. Golden Quest to whom I am especially thankful.

For the many helpful discussions, assistance with accessing data, and advice on manuscripts from this thesis I thank, Dr Charles T.T. Edwards, Dr Murray Smith, Dr Ian Doonan, Dr Mark Hadfield, Dr Steve Chiswell, Dr Matt Pinkerton, Dr Brett Mullins, and Dr Jim Roberts from NIWA. My colleagues at the Ministry for Primary Industries Dr Henry Lane, Dr Anjali Pande, and Prof. Brian Jones with whom I shared many useful discussions on shellfish diseases. 
Assoc. Prof. Miles Lamare (Otago University) and three anonymous reviewers provided comments, which greatly broadened and strengthened two of the manuscripts from this thesis.

The Bluff Oyster Management Company Ltd directly funded research on recruitment and with some co-funding from Seafood Innovations Limited. The Ministry for Primary Industries levied research programmes funded surveys of oyster densities, and Bonamia exitiosa infection and mortality.

I especially thank my wife and "dissertation widow" Helen Costello, and family Madeleine, Emma, Lydia, Johanna for your encouragement and treats to keep me going, and brother George for filling in for my extended family duties. 


\section{Publications from this Thesis}

As of March 2019

Chapter 2. Michael, K. P., \& Shima, J. S. (2018). Four-year decline in Ostrea chilensis recruits per spawner in Foveaux Strait, New Zealand, suggests a diminishing stock-recruitment relationship. Marine Ecology Progress Series, 600, 85-98

Author contribution: K.P.M designed and performed the sampling, analysed the data and wrote the manuscript. J.S.S gave advice on the analysis and structure, and edited the manuscript.

Chapter 3. Michael KP (in prep). Pathogens disrupt gametogenesis and larval supply to Ostrea chilensis populations in Foveaux Strait, New Zealand

Author contribution: K.P.M designed and performed the sampling, analysed the data and wrote the manuscript. Climate data from Matt Pinkerton and Brett Mullins (NIWA). Jeff Shima and gave advice on the structure and editing. Prof. Brian Jones made comments on the manuscript

Chapter 4. Michael, K. P. (2019). Distributions of settlers suggest greater dispersal and mixing of Ostrea chilensis larvae in Foveaux Strait, New Zealand. New Zealand Journal of Marine and Freshwater Research, 53(2), 222-243

Author contribution: K.P.M designed and performed the sampling, analysed the data and wrote the manuscript. Jeff Shima suggested references to broaden scope and gave advice on the structure and editing. 


\section{Table of Contents}

\section{Contents}

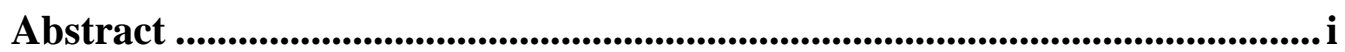

Acknowledgements ............................................................................................iii

Publications from this Thesis............................................................................... v

Table of Contents............................................................................................ vi

List of Illustrations .............................................................................................. ix

List of Tables.......................................................................................................... xvi

Chapter 1 : General Introduction ........................................................................ 1

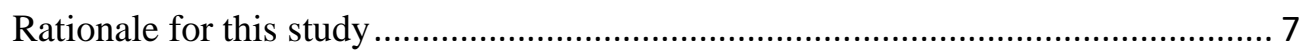

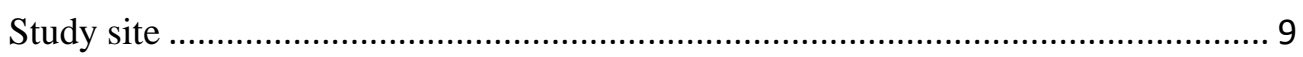

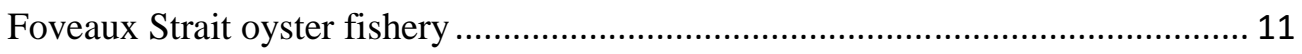

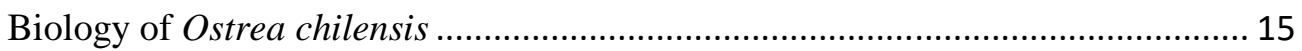

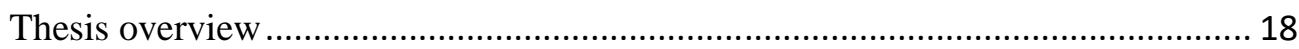

Key assumptions that underpin sampling designs and methods ......................... 20

\section{Chapter 2 : The relationship between $O$ strea chilensis spawner densities} and numbers of recruits ................................................................................... 25

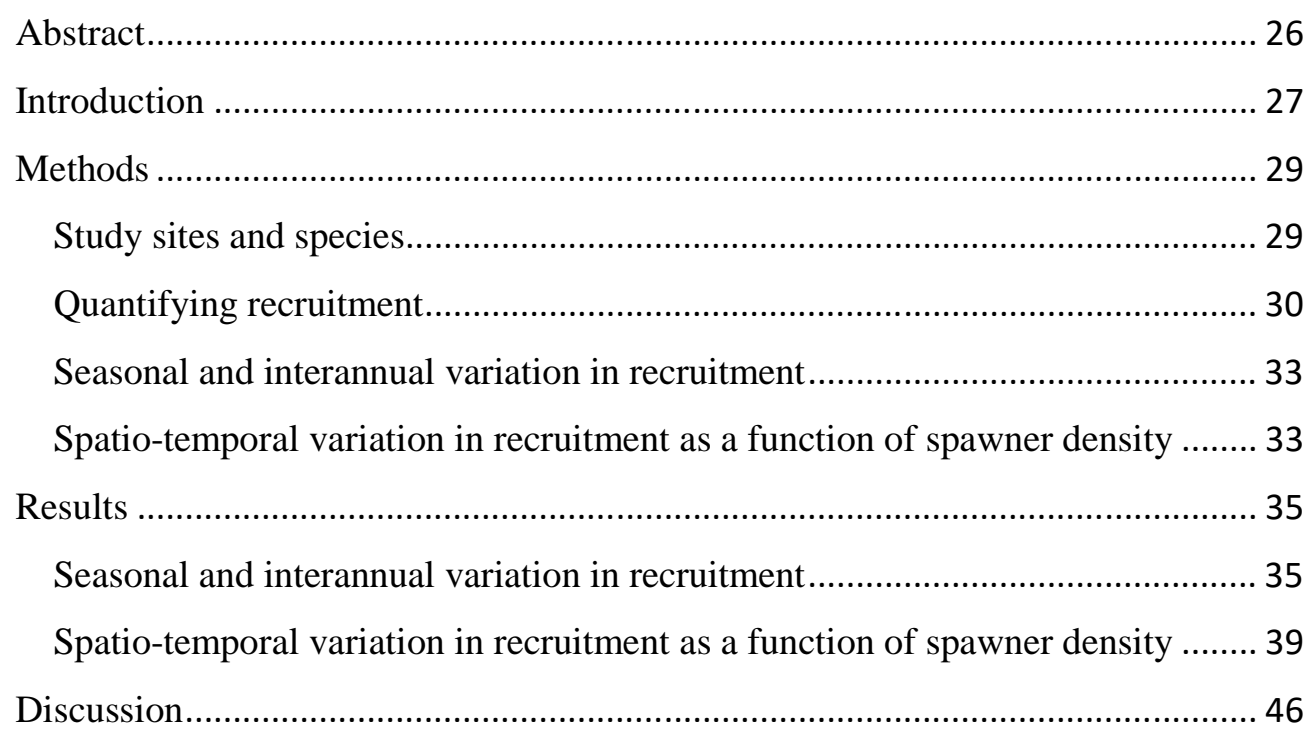


Chapter 3 : Evaluation of the effects of climatic and disease on Ostrea chilensis recruitment ................................................................................5 54

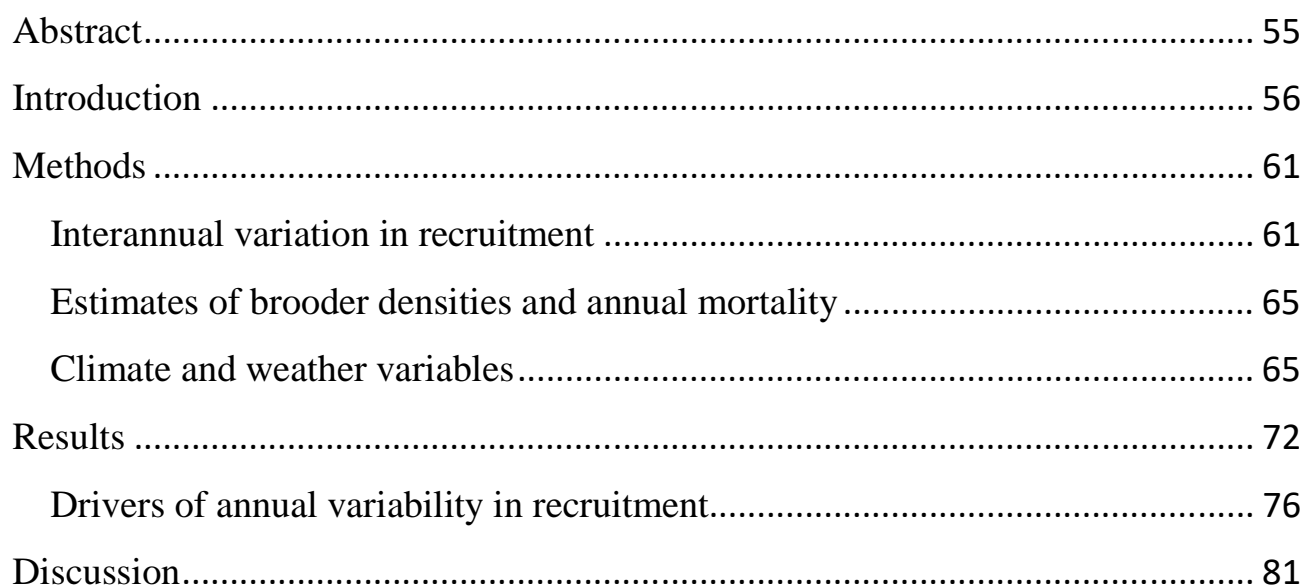

Chapter 4 : Dispersal and mixing of Ostrea chilensis larvae .....................90

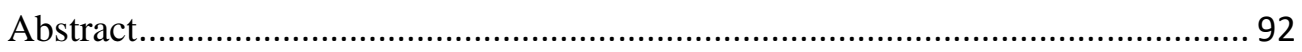

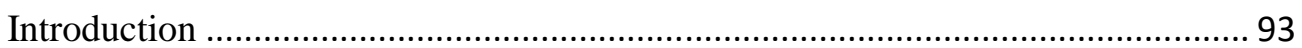

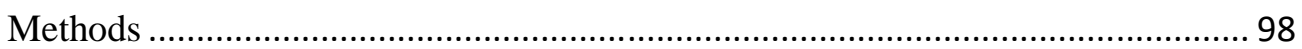

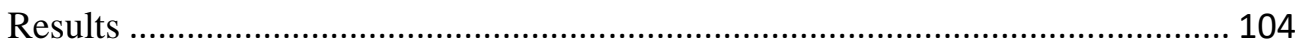

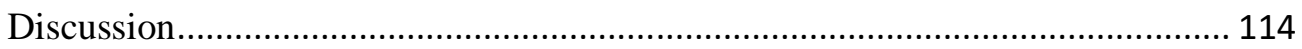

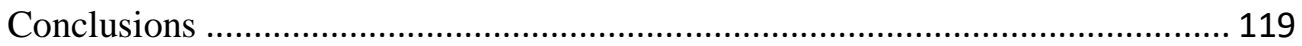

Chapter 5 : Settlement, growth, and survival of Ostrea chilensis ............ 121

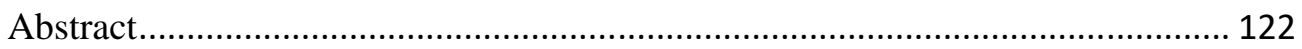

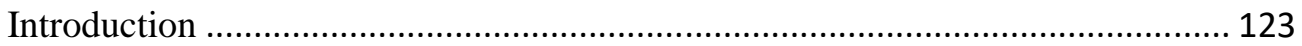

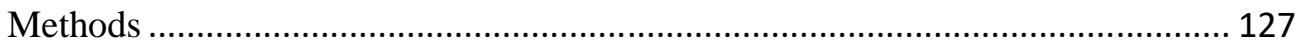

Benthic habitats and substrates targeted by commercial fishers...................... 128

Settlement substrata on which $O$. chilensis settle and survive........................... 129

Differences in growth and mortality ............................................................. 130

The survival and growth of recruits at different heights above the seabed........ 133

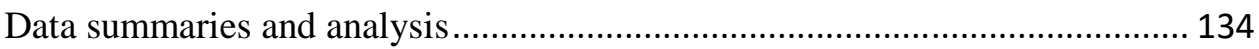


Chapter 5 : Settlement, growth, and survival of Ostrea chilensis

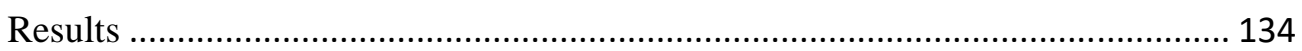

Benthic habitats targeted by commercial fishers ........................................... 134

Ostrea chilensis settlement substrata................................................................ 136

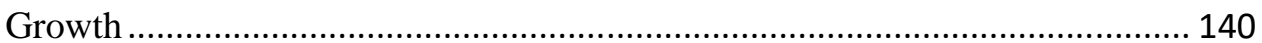

Differences in growth between western and eastern sites ................................ 141

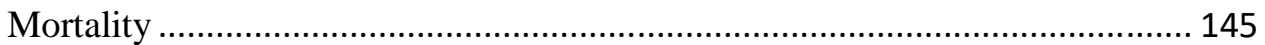

Differences in mortality between western and eastern sites ............................ 148

Differences in mortality with height above the seabed.................................... 149

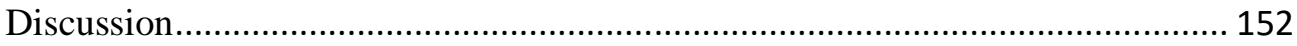

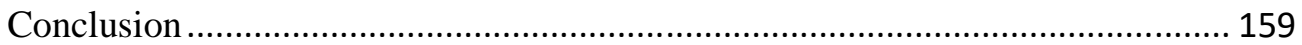

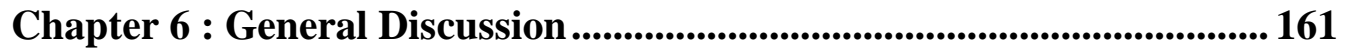

Larval supply and distribution ........................................................................ 163

Self-recruitment in $O$. chilensis ....................................................................... 166

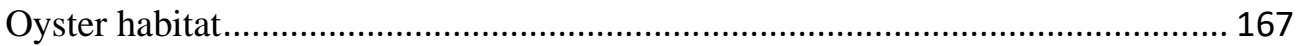

Essential habitat for Ostrea chilensis recruitment and abundance ....................... 168

Management considerations ……………………......................................... 172

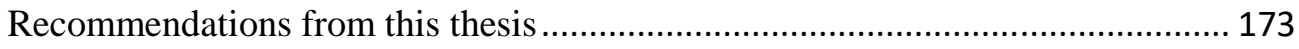

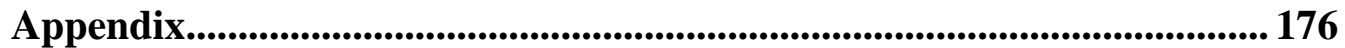

Estimates of spawner densities ........................................................................ 176

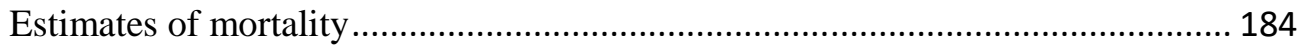

Climate variables …….................................................................................. 189

Growth and mortality $0+$ recruits and $1+$ spat .................................................. 170

Bibliography .......................................................................................................... 174 


\section{List of Illustrations}

\section{Chapter 1}

Figure 1-1. Posterior distributions of estimated recruit-sized biomass (as a percentage of $\mathrm{B}_{0}$ (the biomass before fishing began) from the OYU 5 stock assessment model (Fu et al. 2016). Horizontal dashed lines show 40\%, 20\%, and $10 \% \mathrm{~B}_{0}$. Image Kath Large, NIWA.

Figure 1-2. Foveaux Strait oyster stock (OYU 5) boundary and oyster fishery statistical reporting areas (delineated by grey lines and capitalised alpha numeric labels shown in black text), and the outer boundary of the 2007 stock assessment survey area (shaded blue) that encompasses the commercial fishery.

Figure 1-3: Three-dimensional surface plots of recruit-sized oyster densities from stock assessment surveys between 1993 and 2012.

\section{Chapter 2}

Figure 2-1. Foveaux Strait oyster stock (OYU 5) boundary (heavy black lines) and the outer boundary of the 2007 stock assessment survey area (grey lines) encompassing the commercial fishery. Seasonal and interannual variation in recruitment was sampled at a single site (light blue shading), and spatiotemporal variation in recruitment at 6 sites across the fishery (filled black circles). Inset shows the location of Foveaux Strait within New Zealand.

Figure 2-2. Passive artificial spat collectors used to estimate recruitment. Cement board plates $(220 \times 140 \mathrm{~mm}$ and $4 \mathrm{~mm}$ thick $)$ at heights of 10, 120, 240, and $360 \mathrm{~mm}$ above the seabed.

Figure 2-3. Spat plate recovered after c. 122 days showing O. chilensis recruits.

Figure 2-4. Oyster recruitment (mean \pm SE) by Season (labelled A, B, and C) from December 2005 to February 2011 at a single site (light blue shading, Fig. 1). Season A: 1 July to 31 October, Season B: 1 November to 28 or 29 February, Season C: 1 March to 30 June. Recruitment was estimated as the counts of living and dead oysters per collector (sample) settling over $122 \mathrm{~d}$. The $\mathrm{x}$-axis gives month and year of retrieval. 
Figure 2-5. Interannual and spatial variation in oyster recruitment (mean $\pm \mathrm{SE}$ ) assessed for the primary season of recruitment (November to February). Means and SE estimated from total counts of living and dead oysters from each collector (sample) which settled over $122 \mathrm{~d}$. Recruitment for sites with (A-C) putative high and (D-F) putative low spawner densities for areas East, South, and West, respectively.

Figure 2-6. Stock-recruitment relationships for oysters sampled at fixed locations across the fishery over successive years (2007-08 to 2010-11). Estimates of oyster recruitment (spat collector-1) are for the primary season (November to February). Each point represents counts from a single collector ( $n=3$ collectors deployed at each of 6 sites, each year). A few spat collectors were lost. Spawner densities estimated from dredge samples. Colours correspond to years as given in the key; fitted lines are from a negative binomial regression model, and shaded areas depict \pm SE.

\section{Chapter 3}

Figure 3-1. Foveaux Strait oyster stock (OYU 5) boundary (heavy black lines) and the outer boundary of the 2007 stock assessment survey area (grey lines) encompassing the commercial fishery. Sampling for seasonal and interannual variation in recruitment at a single site (light blue shading), spatio-temporal variation in recruitment at six sites across the fishery (filled black diamonds $\downarrow$ ), and the gradient sampling grid in blue with blue text. The lower right inset shows the location of Foveaux Strait within New Zealand.

Figure 3-2. The 2007 stock assessment area boundary shown as a heavy, black outer line, and the 26 stock assessment survey strata (light grey and blue lines). The Bonamia exitiosa survey area boundary (shown as a heavy blue line), the 14 core strata (shown as blue lines) and the single background stratum (BK) delimited by the stock assessment survey (black lines) and B. exitiosa survey (blue lines) boundaries. Strata are labelled with grey text. The site where spat collectors were deployed in 2015 (red filled circles), 2016 (blue circles), and 2017 (black circles). A polygon defining the area from which remote sensed data were extracted is shown in light blue shading.

Figure 3-3. Mean recruitment (spat per collector) $\pm 95 \%$ CI for 2006-2017 by year (A), percentage mortality of brooding-sized oyster population by year (B), mean density of brooders $\left(\mathrm{m}^{-2}\right)$ by year $(\mathrm{C})$. The light shaded region highlights the period of relatively high recruitment, while the dashed blue reference line shift to low recruitment in 2010. The darker shaded region highlights a period of low recruitment. 
Figure 3-4. The predicted mean recruitment (black line) of $O$. chilensis in the Foveaux Strait fishery area and 95\% CIs (grey lines) against mortality from time series data 2005-2017.

Figure 3-5. The predicted mean recruitment (black line) of $O$. chilensis in the Foveaux Strait fishery area and 95\% CIs (grey lines) against density from time series data 2005-2017.

\section{Chapter 4}

Figure 4-1. Foveaux Strait, southern New Zealand. Grey lines show the 2007 stock assessment survey area. The gradient design comprised four axes (North, East, South, and West), with the central cell encompassing the focal population; area boundaries shown in blue. Three, one nautical mile square cells extend along each axis (blue squares). Red filled circles scaled to brooder densities. Three randomly assigned spat collectors in each cell and nine collectors in the central cell encompassing the focal-population shown as black points.

Figure 4-2. Kernel densities of brooders ( $\geq 60 \mathrm{~mm}$ in length) within the research area (Foveaux Strait, southern New Zealand) from dredge sampling during February surveys 2009-2011 (Michael et al. 2009; Michael et al. 2011; Michael et al. 2012). Cell boundaries shown as black rectangles. Brooders scaled to density at sample locations shown as filled blue circles.

Figure 4-3. The percentage annual commercial catch of oysters (Ostrea chilensis) by reporting area, from skippers' 2011 season (1 March to 31 August, Michael 2012) logbooks. Percentage of the total annual catch shown as $5-10 \%$ (red), 3-4.9\% (orange), 1-2.9\% (yellow), and $<1 \%$ (light blue). The white background represents cells where no fishing took place. Reporting cell labels for the cells that comprise the sampling design shown in black text. The sampling grid shown as red lines.

Figure 4-4. The percentage length frequencies of live $O$. chilensis recruits. Spat collectors sampled during the summers (November to February) from 2011-12 to 2013-14.

Figure 4-5. Bar plots of mean recruit densities and 95\% confidence intervals for the three years of sampling during the summers (November to February)

from 2011-12 to 2013-14. 105 
Figure 4-6. Violin plots of $O$. chilensis recruit densities along four axes (Ax) extending west, north, east, and south from focal population for the summers (November to February) of 2011-12 to 2013-14. Violin plots show data points (dots) and probabilities for the range of recruit densities scaled to the highest recruit density. Mirrored probability distributions shown as shapes shaded by factor. Horizontal lines within distributions denote the median, 25th and 75th percentiles.

Figure 4-7. Changes in $O$. chilensis recruit densities (spat per collector) with increasing distance from the focal population over the four axes extending west, north, east, and south over the summers (November to February) of 2011-12 to 2013-14. Coloured lines and shading show fits from generalised linear model with a negative binomial distribution and a log link function (mean $\pm 1 \mathrm{SE})$.

\section{Chapter 5}

Figure 5-1. Foveaux Strait oyster logbook grid (1 nautical mile squares, grey lines) established by skippers to cover the commercial fishery area. The boundaries of the 2007 stock assessment survey area shown as a blue line. Heavy black lines in the west and east denote the OYU 5 stock boundaries. 128

Figure 5-2. The Foveaux Strait oyster fishery area delimited by the grey lines representing boundaries for stock assessment surveys and sites where settlement substrata and bycatch were sampled. Dive and dredge (2010 \&2011) sampling was within the area shaded light blue. The fishery-scale spat monitoring sites 2009-2012 are shown as black filled circles (e.g. West-low), and the 1999/2000 spat collector, growth and mortality investigation sites shown as black asterisks (W1 \&W2, E1-E4). Sites sampled for bycatch and oyster spat during the 2006 survey shown in blue diamonds and the 2007 survey in grey diamonds.

Figure 5-3. The percentage occurrences of each bycatch category from fishers' logbook data representing 100\% of the catch for years (oyster seasons, 1 March to 31 August) 2007 to 2016 combined. Kaeos (sea tulips, Pyura

pachydermatina) and mixed invertebrates mainly comprise mytilids, ascidians, and bryozoans. Boxplots show medians (solid lines) and the boxes the 25 and 75 percentiles. Whiskers shown at the 95 percentiles, with outliers shown as black circles outside of this range. 135

Figure 5-4. Percentage cover of collector plates by three categories of benthic taxa (algae, barnacles, other species) and by total cover by all taxa. Boxplots show medians (solid lines), boxes 25 and 75 percentiles, whiskers at 95 percentiles, and outliers shown as black circles above and below whiskers. . 139 
Figure 5-5. Total numbers of recruits versus percentage cover of all other benthic taxa combined by plate surface. Fitted line is a loess smoother and shaded area depicts \pm 1 SE.

Figure 5-6. Size (diameter $\mathrm{mm}$ ) of recruits (0+ oyster spat): natural-recruits (left panel) and recruits (right panel) at March 2000 (less than 140 days after settlement) by site and valve orientation. Jittered data points represent spat size coloured by valve orientation. Boxplots show medians (solid lines), mean (heavy dashed line), boxes at the 25 and 75 percentiles. Whiskers show at the 95 percentiles with outliers shown as black circles above and below whiskers. Bar widths scaled to the relevant sample sizes.

Figure 5-7. Heights ( $\mathrm{mm})$, as a proxy for diameter of recruits (0+ oyster spat) settled on passive spat collectors at six sites in Foveaux Strait between October 1999 and March 2000 (c. 140 days). There is stratification by plate height, and by plate surface. Plate heights (level) $1-4$ are at $36 \mathrm{~cm}, 24 \mathrm{~cm}, 12 \mathrm{~cm}$, and $~ 2$ $\mathrm{cm}$ (just off the seabed) respectively. There were two surfaces to each plate: the upper and lower (under side). Jittered data points represent spat size coloured by level. Boxplots show medians at each site (solid lines), mean height for all recruits at all sites (heavy dashed line), boxes 25 and 75 percentiles, whiskers at 95 percentiles, and outliers shown as black circles above and below whiskers. Bar widths scaled to sample sizes. 144

Figure 5-8. Mortality (percentage frequency of spat by valve) of recruits $(0+)$ by site, between October 1999 and March 2000.

Figure 5-9. Percentage length frequency of dead $O$. chilensis recruits (left valves) from spat collectors and oyster shells of growth experiments that died post settlement between October 1999 and March 2000.

Figure 5-10. The percentage mortality in $O$. chilensis, recruits $(0+)$ by total numbers of recruits. Fitted line is a loess smoother and shaded area depicts \pm 1 SE. Mortality of recruits from spat collectors (Collectors) by surface shown as pink dots and recruits attached to shells on cement board sticks as blue dots.

Figure 5-11. Mortality (percentage by surface) of naturally settled 0+ recruits on passive collectors by Site and Level between October 1999 and March 2000. Boxplots show medians (solid lines), mean (heavy dashed line), boxes 25 and 75 percentiles, whiskers at 95 percentiles, and outliers shown as black circles above and below whiskers. Bar widths scaled to sample sizes.

Figure 5-12. Mortality (percentage by surface) of naturally settled 0+ recruits on passive collectors by Surface and Site between October 1999 and March 2000. Boxplots show medians (solid lines), mean (heavy dashed line), boxes 25 and 75 percentiles, whiskers at 95 percentiles, and outliers shown as black circles above and below whiskers. Bar widths scaled to sample sizes. 
Figure 5-13. Ostrea chilensis recruits (shown with black arrow) on the inner surface of a right (flat) oyster valve (left) and the inner surface of an Oxyperas elongate (OEL) shell (right).

Figure 5-14. Boxplots of the weights of live oysters and oyster shell, the shells of other prominent bivalves in the bycatch, and gravel. R, Pr, and S denote recruit, pre-recruit and small size oysters respectively....

Figure 5-15. Image of the seabed (c. $4 \mathrm{~m} 2$ ) in the central Foveaux Strait fishery comprising sand and shell over gravels, with high oyster densities (2400 recruit-sized oysters per tow, $12 \mathrm{~m}^{-2}$ ).

Figure 5-16. The sediments of oyster habitat are occasionally mobile during storms and may bury oysters and recruits.

\section{Chapter 6}

Figure 6-1. Lenticular structures comprised sediment and shell, formed by hydrographic forces along the current axis south of Bluff Hill (see Cranfield et al. 2004). These structures provide the genesis for complex biogenic habitat ("reefs"). Cinctipora elegans and $O$. chilensis (black arrow) are among the early colonisers above the flat gravel seabed and beginning to be overgrown.

Figure 6-2. Cinctipora elegans overgrown and killed by a number of benthic taxa (left panel), Modiolus areolatus overgrown Dactylia varia (middle panel). Note gravel bound by byssus, and oyster spat settled on a spat collector overgrown by invertebrates, mainly bryozoans at the end of their second summer (right panel)

\section{Appendix}

Figure A-1. Spawner densities, oysters $\geq 50 \mathrm{~mm}$ in diameter) per $\mathrm{m}^{2}$ sampled from sites across the fishery in November 2007. Site codes prefixed with "Area" West (W), South (S), and East (E); and suffixed with Category of density, high density $(\mathrm{H})$, low density (L) respectively. Bars show mean densities with \pm 1 SE.

Figure A-2. Spawner densities by site from nearby, randomly allocated survey tows in strata where fishery-scale sites were located. Data from fishery independent surveys 2007-2011 (Michael et al. 2009a, 2009b, 2011, 2012, 2013). 
Figure A-3. Spawner densities sampled at each site before the spat collectors were deployed in November 2007 (Sample, red dots); and survey estimates sampled in February 2008 (Survey, blue dots). Growth in O. chilensis occurs only in the summer months (Dunn 2005) and the increase in spawner densities between November and February may more reflect recruitment of spawningsized oysters than sampling variation alone. Grey lines represent bootstrapped 95\% confidence intervals for "Sample" and "Survey" estimates and grey dots are the mean densities.

Figure A-4. The range of absolute oyster spawner densities $\left(\mathrm{m}^{-2}\right)$ sampled from random fishery surveys 2005-2011. Boxplots show medians, boxes the 25 th and 75th percentiles, and the whiskers 1.5 IQR. Outliers shown as black dots. Mean spawner densities shown as filled red circles and in black text.

Figure A-5. The percentage mortality of $O$. chilensis spat by settler densities, by Site. Fitted line is a loess smoother and shaded area depicts $\pm 1 \mathrm{SE}$.

Figure A-6. The cumulative percentage frequency of lengths of live and dead O. chilensis spat sampled 2008-2011 in season of recruitment (B: November to February).

Figure A-7. Regression of mean monthly SST $\left({ }^{\circ} \mathrm{C}\right)$ and air temperatures $\left({ }^{\circ} \mathrm{C}\right)$ recorded at the Tiwai Point weather station, Bluff $(-46.587,168.376)$, July 2002 to March 2017.

Figure A-8. Regression of mean monthly chlorophyll (Chl_a) Ocean case versus Blended case $\left(\mathrm{mg} \mathrm{m}^{-3}\right)$, July 2002 to March 2017.

Figure A-9. Wind rose for wind direction and speed at Tiwai Point, Bluff January 1980 to October 2017 (left panel) and by each of the period representing the three reproductive phases (right panel).

Figure A-10. Size (diameter mm) of oyster spat (1+) at March 2000, by site and by valve orientation. Jitter points represent spat size coloured by valve orientation. Boxplots show medians (solid lines), mean (heavy dashed line), boxes 25 and 75 percentiles, whiskers at 95 percentiles, and outliers shown as black circles above and below whiskers. Bar widths scaled to sample numbers.

Figure A-11. Percentage frequency of mortality of spat (1+) on each valve by site, between October 1999 and March 2000. 


\section{List of Tables}

\section{Chapter 2}

Table 2-1. Seasonal and interannual variation in recruitment of oysters between 2005 and 2011 at a single site in Foveaux Strait. Season B: 1 November to 28 or 29 February, Season C: 1 March to 30 June. Oyster recruitment is modelled as a function of Season and Year using zero-inflated negative binomial regression. Shown are the results of a negative binomial model for the count data (model statistics theta $=2.0943$, $\mathrm{df}=12$, and loglikelihood $=-492.4$ ) and the results of a zero-inflated model with logit coefficients for predicting excess zeros. The exponents of coefficients $\left(\mathrm{e}^{\text {coefficient }}\right)$ are shown with $95 \%$ confidence intervals (CI).

Table 2-2. Seasonal and interannual variation in recruitment of oysters at a single site in Foveaux Strait, between 2005 and 2011. Recruitment is modelled by factors Season, Year, and the interaction between Season and Year, using a negative binomial regression with a log link function. \% Dev: cumulative

percentage deviance explained, AIC: Akaike's Information Criterion. 38

Table 2-3. Spatio-temporal variation in oyster recruitment across the Foveaux Strait fishery between 2007 and 2011. Oyster recruitment is modelled as a function of Year, Spawner density, and Area, and their interactions, using data from Season B (settlement season) only. The best-fit negative binomial regression is shown. \% Dev: cumulative percentage deviance explained, AIC: Akaike's information criterion.

Table 2-4. Spatio-temporal variation in oyster recruitment across the Foveaux Strait fishery, 2007-08 to 2010-11. Oyster recruitment is modelled as a function of Year, Spawner density, and Area, and their interactions, using data from Season B (settlement period) only. Paired comparisons for the best-fit negative binomial model (model statistics theta $=10.3658$, $\mathrm{df}=43$, and loglikelihood $=-693.92$ ) are shown. Spawner densities (1)-(3) denote first- to third-order polynomials, respectively.

\section{Chapter 3}

Table 3-1. Multiple models of recruitment. Each time step and group of climate variables and their mean, 5th and 95th percentiles were run separately with density and mortality.... 
Table 3-2. Ranks of the relative variable importance for density, mortality and climate variables to predict recruitment using Cforest algorithm (Hothorn et al. 2005). Brooding-sized oyster density (Density), annual mortality from Bonamia exitiosa (Mortality), 3-monthly running means for Southern Oscillation Index (SOI3av), wind speed (WSpd), the difference in mean sealevel pressure between Hobart and the Chatham Islands (M1), mean chlorophyll a (Chl), Southern Oscillation Index (SOI), turbidity (Turb), the numbers of days of severe gales (DSGales), the difference in mean sea-level pressure between Christchurch and Campbell Island (Z2), and mean sea surface temperature (SSTav). Variable importance measure (VIM) and proxy for effect size (\%EF). Sensitivity analyses without Density (Var-1, VIM-1, and $\%$ EF-1), and without Density and Mortality (Var -2, VIM-2, and \%EF-2). Cforest run with options cforest_unbiased(ntree $=8000$, mtry $=2)$, and function varimpAUC to compute variable importance measures as the area under the curve as a proxy for effect size. VIMs represent the effects of variables in both main effects and interactions.

Table 3-3. The best-fit negative binomial regression of annual variation in oyster recruitment across the Foveaux Strait fishery between 2006 and 2017. Recruitment was estimated from recruit densities and modelled as a function of brooding-sized oyster density (Density), annual mortality from Bonamia exitiosa (Mortality), 3-monthly running means for Southern Oscillation Index (SOI3av), and the difference in mean sea-level pressure between Hobart and the Chatham Islands (M1), and their interactions. Percentage deviance (\%Dev) and cumulative percentage deviance (Cum\%Dev) explained.

Table 3-4. Annual variation in oyster recruitment across the Foveaux Strait fishery from 2006 to 2017. Oyster recruitment was modelled as a function of brooding-sized oyster density (Density), annual mortality from Bonamia exitiosa (Mortality), 3-monthly running means for Southern Oscillation Index (SOI3av), and the difference in mean sea-level pressure between Hobart and the Chatham Islands (M1), and their interactions. Density and mortality were modelled as first to third order polynomials, denoted (1)-(3) below. The best-fit negative binomial model statistics: Theta $=1.6254, \mathrm{SE}=0.0353, \mathrm{df}=3935$, $\log$-likelihood $=-43919.54$, and AIC $=43948$. NS denotes not significant..... 80 


\section{Chapter 4}

Table 4-1. Factors predicting the distributions $O$. chilensis recruits as a proxy for the dispersal of competent larval abundance from a focal population in the Foveaux Strait oyster fishery, 2011-12 to 2013-14. Recruit densities modelled as functions of year (Yr), distance (D), current axis (Cx), and their interactions (models 1-10) using negative binomial regression. Axis (Ax) was substituted for Cx for each model (models 11-13), because of the relatively small data size. Degrees of freedom (d.f.), Akaike Information Criterion (AIC), and percentage deviance explained (\% Dev) are given for each model. Selection of the best-fit model was based on AIC. Where AICs were similar between models, the percentage deviance explained (a measure of effect size, analogous to a variance component) and graphical evaluation of fits determined best-fit models (bold).

Table 4-2. Analysis of deviance for best-fit negative binomial Model 6 (glm.nb) and estimates for coefficients for factors year (Yr) and current axis (Cx). Degrees of freedom (d.f.), deviance (Dev), percentage deviance explained (\% Dev), residual degrees of freedom (Resid. d.f.), residual deviance (Resid. Dev), and $\mathrm{P}$ value ( $\operatorname{Pr}(>\mathrm{Chi}))$.

Table 4-3. Analysis of deviance for best-fit negative binomial Model 13 (glm.nb) and estimates for coefficients for factors year (Yr) and current axis $(\mathrm{Ax})$. Degrees of freedom (d.f.), deviance (Dev), percentage deviance explained (\% Dev), residual degrees of freedom (Resid. d.f.), residual deviance (Resid. Dev), and P value ( $\operatorname{Pr}(>\mathrm{Chi})$ ).

Table 4-4. Analysis of deviance for negative binomial models (glm.nb) of Recruits modelled against Ax, and Brooders. Sample sizes were too small to run interactions. Akaike Information Criterion (AIC), degrees of freedom (d.f.), deviance (Dev), percentage deviance explained (\% Dev), residual degrees of freedom (Resid. d.f.), residual deviance (Resid. Dev), and P value $(\operatorname{Pr}(>\mathrm{Chi})$ ) are given for each model. Best-fit model selected based on AIC, \% Dev, and graphical evaluation (shown in bold). 


\section{Chapter 5}

Table 5-1. Locations of the six sites used for growth and mortality investigations, where cement board sticks with $0+$ recruits and $1+$ spat on oyster shell (single valves), and spat collectors were deployed. Two sites selected in the western fishery area and four in eastern locations representing a range of habitats and exposures to oceanic swells (see Figure 5-2).

Table 5-2. Taxa and shells representing greater than $1 \%$ of the total bycatch composition by number that had $O$. chilensis recruits attached. Taxa: $O$. chilensis (OYS), the gastropod Astraea heliotropium (ASH), the Mytilid Modiolus areolatus (MOA), barnacles Balanus spp. (BAR), the mactrid Oxyperas elongate (OEL), and their shells denoted by suffix (_Shell). Numbers of each bycatch component (n), those with settlers attached (n.Recruits), the percentage of each bycatch component that had settlers attached (\%), the percentage of all bycatch components (\%TWS), and the percentage of all bycatch sampled with recruits attached (\%AWS).

Table 5-3. Estimates of the numbers of valves with and without recruits sampled from a single tow at the dive site in February 2008 (see light blue shaded area in Figure 5-2). Summary statistics of the number of each type of valve OYS, OEL, and ASH, and the numbers of live and dead oyster recruits. Percentage survival is the number of live recruits as a percentage of all recruits (live and dead).

Table 5-4. Growth in 0+ recruits and natural-recruits recovered in March 2000 (c. 140 days) at six sites in Foveaux Strait (see Figure 5-2). Median diameter mm (Median), mean diameter for comparison (Mean), $5^{\text {th }}$ and $95^{\text {th }}$ percentiles (P $0.05 \&$ P 0.95), and sample sizes (n).

Table 5-5. Growth increments in diameter $(\mathrm{mm})$ in 1+ oyster spat recovered in March 2000 after c. 140 days at 6 sites in Foveaux Strait (see Figure 5-2).

Median diameter mm (Median), mean diameter for comparison (Mean), $5^{\text {th }}$ and $95^{\text {th }}$ percentiles (P $0.05 \&$ P 0.95), and sample numbers (n).

Table 5-6. Mortality of $0+$ recruits settled on passive spat collectors between October 1999 and March 2000 (c. 140 days in Foveaux Strait) by Site, Level, and Surface. Mean (mean), standard deviation (SD), numbers of surfaces with settler (n), standard error of the mean (SE), and upper and lower 95\% confidence intervals $(95 \% \mathrm{CI})$ for lengths $(\mathrm{mm})$. 


\section{Appendix}

Table A-1: The locations of the six sites across the Foveaux Strait oyster fishery sampled for the spatio-temporal variation in recruitment.

Table A-2. Estimates of mean spawner densities (oysters $\left./ \mathrm{m}^{2}\right) \pm 1 \mathrm{SE}$ from predeployment sampling (November 2007) and annual February surveys (2007 to 2011) from strata containing the six sampling sites. Site codes prefixed with "area" west (W), south (S), and east (E) and suffixed with Category of density, high density $(\mathrm{H})$, low density $(\mathrm{L})$ respectively. For years when there was no sampling near sites, spawner density assigned as the mean value between the previous and following years estimates (year before 2007 and after 2011 not shown). Missing data shown in italics and underlined. Data from Michael et al. (2008a, 2009, 2009a, 2011, 2012). Mean distance (km) with SE, and minimum and maximum distances between dredge sample sites and collector sites also shown.

Table A-3. Oyster recruitment modelled as a function of Year, Site, and their interactions using a Negative Binomial Generalized Linear Model. Cumulative percentage deviance (\%Dev) for ranked variables and Akaike Information Criterion (AIC).

Table A-4. Estimates of pre-survey (Pre_M), post-survey (Post_M), and annual mortality (Mortality) from Bonamia exitiosa, mean population density of recruit-sized oysters (Density) with references by year for February surveys.

Table A-5. Heights of 0+ oyster spat settled on passive spat collectors between October 1999 and March 2000, c. 140 days at 6 sites in Foveaux Strait, by plate heights combined, and by plate surface. Median diameter mm (Median), mean diameter for comparison (Mean), 5th and 95th percentiles, and sample numbers (n). Plate heights 1-4: $36 \mathrm{~cm}, 24 \mathrm{~cm}, 12 \mathrm{~cm}$, and just off the seabed $(\sim 2 \mathrm{~cm})$ respectively. Surfaces represent the upper and lower (under side) of plates.. 172

Table A-6. Mortality of 1+ spat between October 1999 and March 2000 (c. 140 days in Foveaux Strait) by Site and valve-orientation. Mean (mean), standard deviation (SD), numbers of surfaces with settler (n), standard error of the mean (SE), and upper and lower $95 \%$ confidence intervals $(95 \% \mathrm{CI})$ for lengths (mm). 


\section{Chapter 1 : General Introduction}

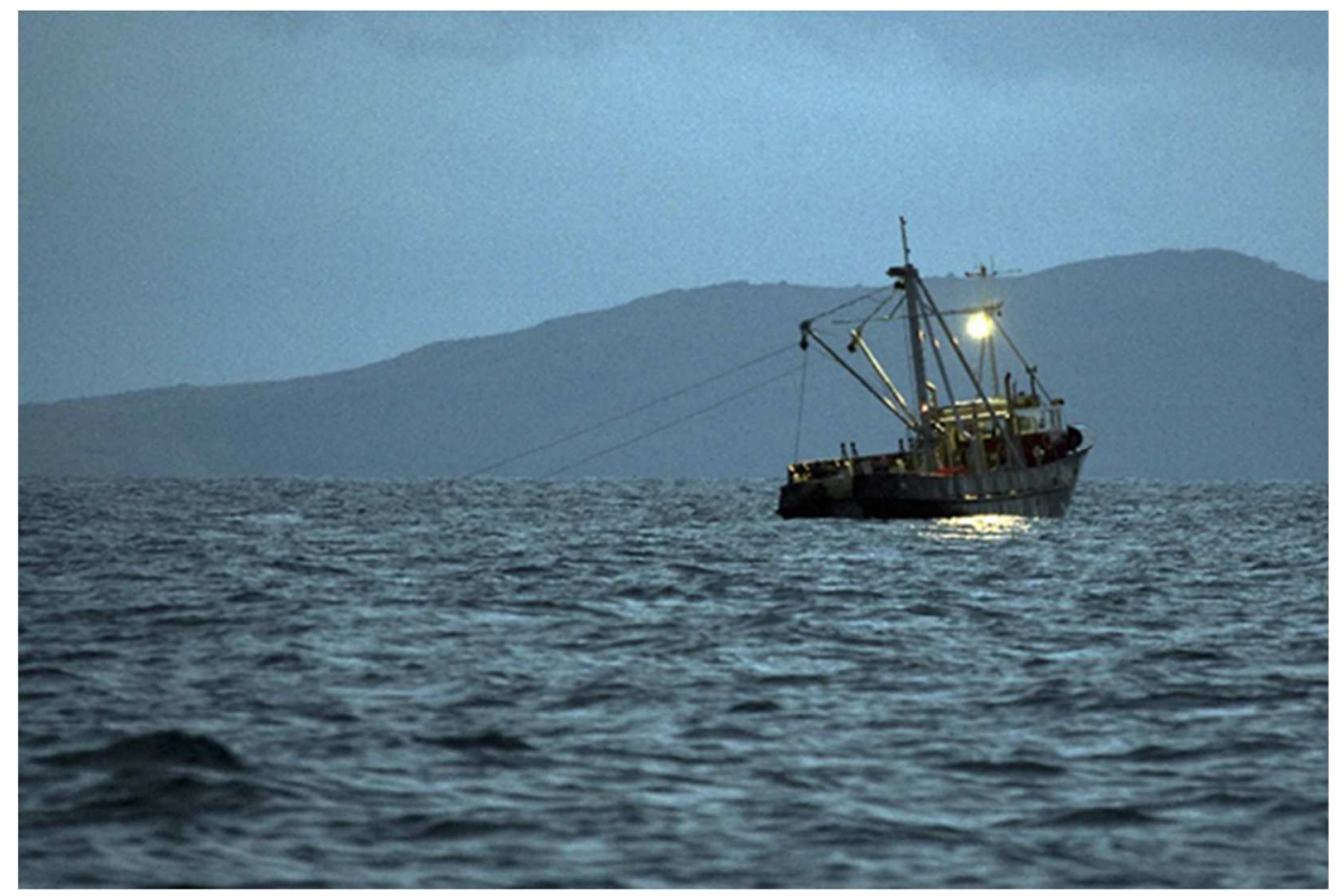

A commercial fishing vessel, the Southern Enterprise dredging for oysters (Ostrea chilensis) in Foveaux Strait, southern New Zealand (image courtesy of Tony Smith). 
Worldwide, oysters (Ostreidae Rafinesque, 1815) have been important to the ecology of benthic communities and to the wellbeing of many peoples. They inhabit a range of environments from sheltered intertidal mudflats (Powell 1979, Robjohns 1979, Wright 1990, Ruesink et al. 2005) to deep (greater than $80 \mathrm{~m}$ ) gravel substrates exposed to large oceanic swells (Buroker 1985, NABIS 2018). Historically, oysters were abundant in accessible intertidal and nearshore habitats, and were an important food source (Yonge 1966, MacKenzie et al. 1997a, MacKenzie et al. 1997b, MacKenzie et al. 1997c, Gercken \& Schmidt 2014). Many oyster stocks are now depleted (Beck et al. 2011, Schrobback et al. 2014) from over exploitation, the destruction of habitat through sedimentation (Diggles 2013), fishing practices (Rotschild et al. 1994, Jackson et al. 2001), and occasional uplift of nearshore areas by earthquakes (Aiken 1993).

These declines in wild fisheries have led to aquaculture initiatives to increase the global production of oysters. Oyster production is the highest amongst molluscs (FAO 2018) and almost all oyster production is for cupped oysters (Crassostreinae) (Wijsman et al. 2019), because of their faster growth rates and shorter production cycles. China reportedly produces by far the highest tonnages of cupped oysters globally (Wijsman et al. 2019). In contrast, Ostreinae account for a small percentage of global oyster production (FAO 2018, Wijsman et al. 2019). In many countries, mortality caused by disease has severely constrained production of endemic species as well as the non-native species introduced in an attempt to mitigate the effects of disease (Culloty \& Mulcahy 2007, Arzul \& Carnegie 2015, Pernet et al. 2016). Despite concerted efforts to reduce oyster mortality from disease, local levels of aquaculture production remain well below pre-disease production levels (Culloty \& Mulcahy 2007, Buestel et al. 2009, Arzul \& Carnegie 2015). The ecological and economic importance of oysters has prompted restoration strategies to rebuild wild populations (Schulte et al. 2009, Brown 2011) and the need to better manage them (Powell \& Klinck 2007, Powell et al. 2012, Ministry for Primary Industries 2017). 
Oysters are ecosystem engineers that structure benthic communities (Jones et al. 1994, Grabowski \& Peterson 2007), form complex habitats, and provide ecosystem services (Lenihan \& Peterson 1998, Coen et al. 1999, Coen et al. 2007, Beck et al. 2011, Grabowski et al. 2012). Habitats structured primarily by oysters and their shells are known as "oyster reefs" (Cowardin et al. 1979, Bahr \& Lanier 1981). The declines in oyster reefs and oyster fisheries have prompted efforts to conservative and restore of oyster populations (Peterson et al. 2003, Schulte et al. 2009, Beck et al. 2011, Brown 2011); however, the management of oyster fisheries has not changed greatly.

Historical management of oyster fisheries has generally been ineffective (Lenihan \& Peterson 1998, Beck et al. 2011, Ministry for Primary Industries 2017), as has the management of other sessile benthic invertebrate fisheries (MacKenzie et al. 1997a, MacKenzie et al. 1997b, MacKenzie et al. 1997c, Hobday et al. 2000, Karpov et al. 2000, Anderson et al. 2011a). Poor performance, in at least some management efforts, may be attributed to a disconnection between stock structure and management units that often leads to serial depletion (Hilborn et al. 2005). Moreover, most management efforts assume some level of a density-dependent relationship between stock size (the exploitable portion of a population) and recruitment in the form of a stock-recruit relationship (Ricker 1954, Beverton \& Holt 1957). This assumption has provided a level of convenience for managers of fisheries in that the control of spawning stock size (e.g. reference points (Mace 2012)) through harvest limits presumably ensures recruitment and thereby future yields. Management of sessile invertebrates based on stock-recruit relationships may have hastened the decline or collapse of some fisheries because the key processes that drive variability in recruitment and their interactions are not well described by stock-recruit functions used in stock assessment (King et al. 2015, Szuwalski et al. 2015).

Most sessile benthic invertebrates such as oysters have a two-stage life history: a planktonic stage where larvae or propagules are dispersed (primarily 
by currents), and a sessile post-settlement stage. In this thesis, recruits are defined as competent larvae that settle from the plankton and complete metamorphosis on substrata; consistent with the ecological definition of Stanwell-Smith \& Barnes (1997). Recruitment to the population is the number of recruits settled on substrata before post-settlement mortality occurs, and estimates of recruitment are therefore the numbers of live and dead recruits sampled on collectors or substrata on the seabed. Because Ostrea chilensis does not exhibit preferences for settlement substrata or specific settlement cues (pers. obs., and for O. edulis after Smyth et al. 2018), recruitment is assumed to reflect the numbers of competent larvae available for settlement at sampling locations. This definition of recruitment to a population differs to that of fisheryrecruitment, which is the addition of harvestable individuals from the survival and growth of recruits (Hilborn \& Walters 1992). In this thesis, I use the terms recruitment and fishery-recruitment to differentiate between recruitment to the population and to the fishery respectively.

Generally, recruitment in sessile benthic invertebrates including oysters, is a culmination of fundamental pre-and post-settlement processes that determine population demographics i.e., spatial structure and abundance (Rodriguez et al. 1993). The production of larvae, their dispersal and or retention, settlement success, and post-settlement survival and growth all play key roles. Recruitment is highly variable over space and time (Caley et al. 1996, Sale \& Kritzer 2003), and is driven by multiple processes that may differ among species, populations, locations, and with recruitment events (Thorson 1950, Shanks et al. 2003, Watson \& Barnes 2004, Broitman et al. 2008, Smale 2013). Both pre-and post-settlement processes are likely to shape recruitment (Sale \& Kritzer 2003, Shima et al. 2008, Cowen \& Sponaugle 2009, Hixon et al. 2012). Larval cohort strength, the numbers of larvae produced during a spawning event, is determined by: spawner density (Lundquist \& Botsford 2010), spawning and fertilization success (Levitan \& Sewell 1998); processes that determine larval 
growth and development (Rodriguez et al. 1993, Pineda et al. 2009), and larval survival (Rumrill 1990, Vaughn \& Allen 2010). Large larval cohorts are a prerequisite for high recruitment (Gaines \& Roughgarden 1985, Roughgarden 1988, Underwood \& Fairweather 1989, Gaines \& Bertness 1992, Caley et al. 1996, Siegel et al. 2008). However, recruitment strength is ultimately determined by physical and biological processes that determine dispersal and/or retention of larvae (Jones et al. 2009), including larval behaviour in the plankton, settlement (Coen et al. 2007, Siegel et al. 2008, Cowen \& Sponaugle 2009), and especially post-settlement survival of recruits (Hunt \& Scheibling 1997). In addition to natural variation in recruitment, human activities can severely reduce recruitment through harvests of sexually mature individuals (Levitan \& Sewell 1998), and/or negative impacts on the resources required for settlement, and post-settlement survival (Beck et al. 2001).

Recruitment processes and their interactions with one another are not well understood. The need to understand recruitment has become more urgent with increasing anthropogenic stressors (including increased exploitation of stocks) as well as climatic changes to marine systems. Improved understanding of recruitment processes can inform conservation, management and restoration efforts for sessile benthic invertebrate populations such as oysters.

Differences in reproductive strategies between subfamilies and between species within subfamilies of the family Ostreidae may in part drive variation in recruitment. Subfamily Ostreinae (Rafinesque, 1815) comprises true or flat oysters, which include Ostrea chilensis (Philippi, 1844), O. edulis (Linnaeus, 1758), O. lurida (Carpenter, 1864), O. puelchana (d'Orbigny, 1842), and $O$. stentina (Payraudeau, 1826). Members of this subfamily are larviparous (i.e. brood larvae). Brooding times vary between species, as do pelagic larval durations (PLDs). The subfamily Crassostreinae (Scarlato \& Starobogatov, 1979) comprise the cupped oysters, and includes Crassostrea virginica (Gmelin, 1791), Magallana gigas (Thunberg, 1793) formerly Crassostrea gigas (Salvi \& 
Mariottini 2017), Magallana ariakensis (Fujita, 1913), and Saccostrea glomerata (Gould, 1850). Members of this subfamily are oviparous, broadcast spawners, and typically have longer PLDs than members of subfamily Ostreinae. These differences in reproduction between Ostreinae and Crassostreinae and marked differences between the habitats and physical environments that these oyster species occupy highlights a need for species and location specific information on recruitment, i.e. the knowledge for the well-studied Crassostreinae may not be applicable to Ostreinae and vice versa.

Many of the processes that determine larval supply, settlement and survival may interact to shape patterns of recruitment (Pineda et al. 2007, Sale \& Kritzer 2003, Shima et al. 2008, Cowen \& Sponaugle 2009, Hixon et al. 2012). Successful recruitment is essential for the replenishment of local populations, and variation among subpopulations has important consequences for the larger metapopulation (Jones et al. 2009). Moreover, variation in recruitment influenced by habitat (Powell \& Klinck 2007, Soniat et al. 2012) and the effects of climate and or biological factors (Kimmel \& Newell 2007, Kimmel et al. 2014) affects the cumulative successes of these consecutive recruitment processes. These effects may greatly diminish the relationship between stock and recruits (after Szuwalski et al. 2015).

Ostrea chilensis (Ofoighil et al. 1999) was previously named O. lutaria (Hutton 1873), or Tiostrea chilensis (Chanley \& Dinamani 1980, Buroker et al. 1983). Also commonly known as the Bluff oyster, dredge oyster, or flat oyster. O. chilensis is endemic to New Zealand. O. chilensis has migrated to Chile through trans-Pacific rafting in eastward flow from northern New Zealand (Ofoighil et al. 1999), and has been introduced to Menai Strait, UK, (Walne 1974), and an unsubstantiated introduction to Tasmania, Australia in the 1920s (Dartnall 1970, Pollard \& Hutchings 1990). Jeffs \& Creese (1996), Stock (2000), Brown (2011), and Lane (2018) give overviews of the taxonomy, ecology, and biology of $O$. chilensis in New Zealand. $O$. chilensis is widely distributed at 
relatively low densities throughout New Zealand (Jeffs \& Creese 1996). Foveaux Strait is unique in that these oysters occur in high abundance and high densities (Jeffs \& Creese 1996, Ministry for Primary Industries 2017). There are four commercially exploited $O$. chilensis stocks in New Zealand (Ministry for Primary Industries 2017). Foveaux Strait (OYU 5) shows cyclic trends in abundance, driven by oyster mortality from Bonamia exitiosa (Berthe \& Hine 2003). Tasman Bay (OYS 7) has been in persistent decline and stock levels have been low since 2000. A small fishery in Cloudy and Clifford Bays (OYS 7C) was established by translocation of oysters from Foveaux Strait post 1917 (Otago Daily Times 1917). Stock levels and landings have been low, more so since 2012 (Ministry for Primary Industries 2017). Catch from the Chatham Islands (OYS 4) has been historically low. Most landings in OYS4 have been bycatch from the scallop fishery with oyster catches recorded since 2003 (Ministry for Primary Industries 2013).

\section{Rationale for this study}

A need to understand recruitment in $O$. chilensis in Foveaux Strait is the motivation for this study. Since 1985, oyster mortality resulting from disease is of particular importance: disease-related die-offs caused by Bonamia exitiosa are recurrent and substantial, with losses up to twenty times the commercial catch in some years (Doonan et al. 1994, Cranfield et al. 2005, Fu et al. 2016, Michael et al. 2018). Recruitment is critical to replenishing these losses. Harvests since 1985 have been relatively low and have had no detectable effect on future stock size, and at these levels unlikely to affect ongoing sustainability (Fu et al. 2016). During periods of low or no detectable disease mortality and long-term average recruitment, the fishery rebuilds quickly (Ministry for Primary Industries 2017). However, recruits-per-spawner declined markedly in 2010 and remained low over a long time despite spawner densities that have supported high recruitment 
in the past (Cranfield et al. 1999). A number of factors could have affected recruitment in these populations; recurrent disease mortality since 1985 may have caused a shift in fishery productivity. Credible estimates of recruit-sized biomass since 1960 (Figure 1-1) show a constantly increasing trend in abundance between 1965 and 1985 despite high levels of catch (c. 80 million oysters per year) and high fishing effort from 23 vessel operating in the fishery (Ministry for Primary Industries 2017). A B. exitiosa epizootic in 1985 (Doonan et al. 1994, Cranfield et al. 2005) caused a rapid decline in recruit-sized biomass (Figure 1-1). Recurrent B. exitiosa mortality has limited rebuilding of the fishery and caused cyclic patterns in the abundance of oysters and high density patches of oysters (Figure 1-1) that may affect recruitment. Increased climate variability and seawater temperatures may have also affected recruitment. The key focus of this research is an investigation of several potential explanations for this prolonged period of low recruitment.

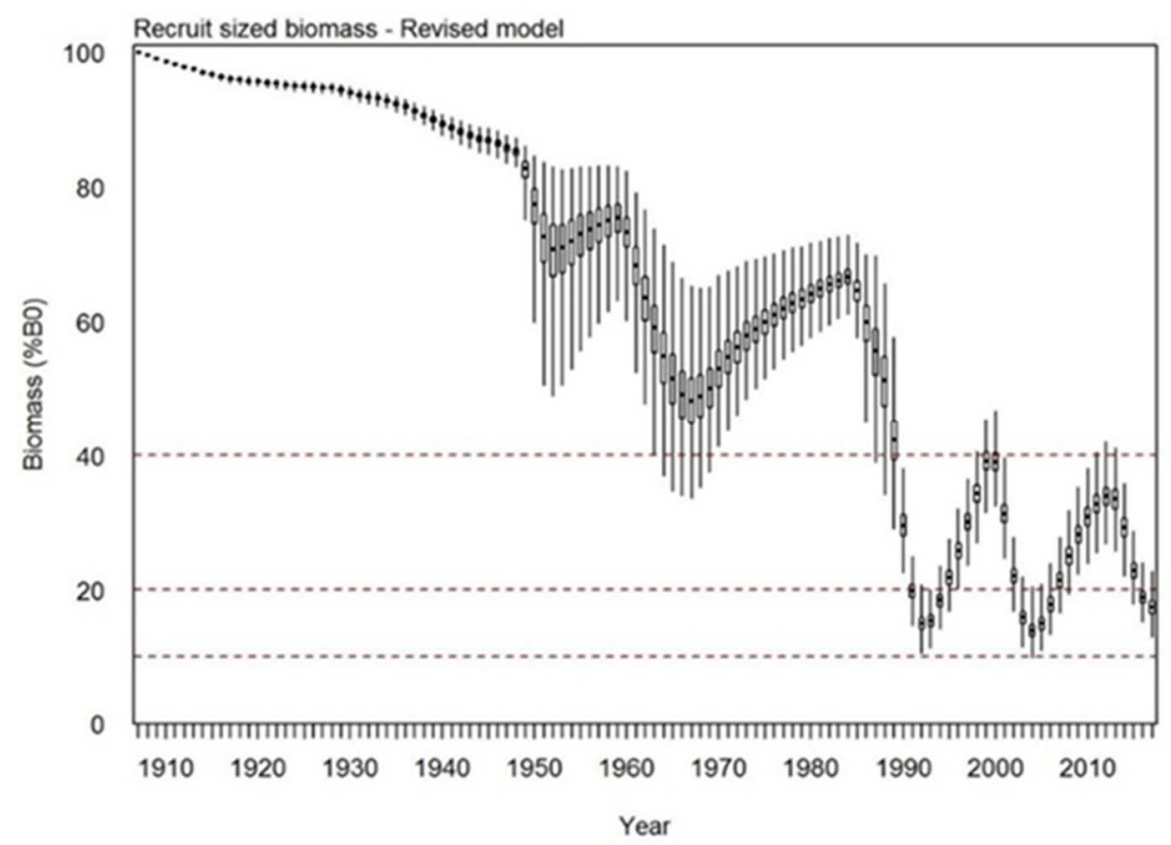

Figure 1-1. Posterior distributions of estimated recruit-sized biomass (as a percentage of $B_{0}$ (the biomass before fishing began) from the OYU 5 stock assessment model (Fu et al. 2016). Horizontal dashed lines show $40 \%, 20 \%$, and $10 \% B_{0}$. Image Kath Large, NIWA. 


\section{Study site}

Foveaux Strait is located between the South Island and Stewart Island in southern New Zealand. The western boundary of the Foveaux Strait oyster stock area (OYU 5) is defined by a line from Oraka Point (Southland) to Centre Island and on to Codfish Island and North Head (Stewart Island). The eastern boundary is a line between Slope Point (Southland) and East Cape (Stewart Island), see Figure 1-2. The commercial fishery area is well defined by the 2007 stock assessment survey area (shaded blue in Figure 1-2), as all commercial fishing occurs within this area. The seafloor rises from deep water on either side of the fishery area. On the western side of the fishery area, water depth is approximately $60 \mathrm{~m}$, and the bottom slopes gently upward to depth of $20 \mathrm{~m}$ in the east (around Ruapuke Island) before dropping in to deep water to the east. The western entrance to Foveaux Strait is the most exposed coastal area in New Zealand (Gorman et al. 2003), with large oceanic swells that produce a highenergy environment (Pickrill \& Mitchell 1979). Mean significant wave height is $2.7 \mathrm{~m}$, with waves exceeding $3 \mathrm{~m}$ more than $29 \%$ of the time and $10 \mathrm{~m}$ or more $1 \%$ of the time (Gorman et al. 2003). Tidal currents are swift and accelerate west to east (Stanton et al. 2001). This gradient in current speed is likely attributable to the increasingly shallow depth west to east, and to constrictions caused by the shoals, rocks, and islands that extend across much of the eastern entrance between Stewart Island and Slope Point. Net tidal current flow is mainly east to southeast (Houtman 1966, Gruning 1971), with this flow pattern feeding into the Southland Current along the Southland coast. On the south side of Ruapuke Island, the flow is generally to the northwest (Mark Hadfield, NIWA, personal communication). Tidal current speeds vary from 1.5 knots in the west to 4.0 knots in the east (Gruning 1971); however, wind driven currents can extend throughout the entire water column. The eastward transport increases when winds are from the west and reduces or reverses with easterly winds. Net displacement of water mass eastward is between $2.5 \mathrm{~km} \mathrm{~d}^{-1}$ (Steve Chiswell, 
NIWA, personal communication) and differs from earlier estimates of $7.0 \mathrm{~km} \mathrm{~d}^{-}$ ${ }^{1}$ in the western fishery area (Heath 1973), and $22 \mathrm{~km}$ in a NW direction each tidal cycle in south eastern areas (Cranfield 1968a). The residence time of water flowing through the fishery area is about 5 days (Cranfield \& Michael 1989), although based on net displacement this could be as long as 20 days in calm conditions with neap tides. Current flows and the topography of Foveaux Strait suggest that eddies capable of retaining larvae may form in the central strait under some conditions.

The seafloor of the fishery area is comprised of gravel substrates overlaid with sand in some areas (Cullen 1962, 1967). Current flows greatly increase during storms. Storm events can mobilise sediments that scour channels and/or form sand waves, banks, and dunes (Carter \& Lewis 1995, Hemer 2006). Benthic habitats vary with depth, substrate type, and wave exposure (Michael 2007). High primary production (Bradford et al. 1991) supports diverse and abundant benthic communities (Michael 2010), including high densities of Ostrea chilensis that comprise the Foveaux Strait oyster fishery. 


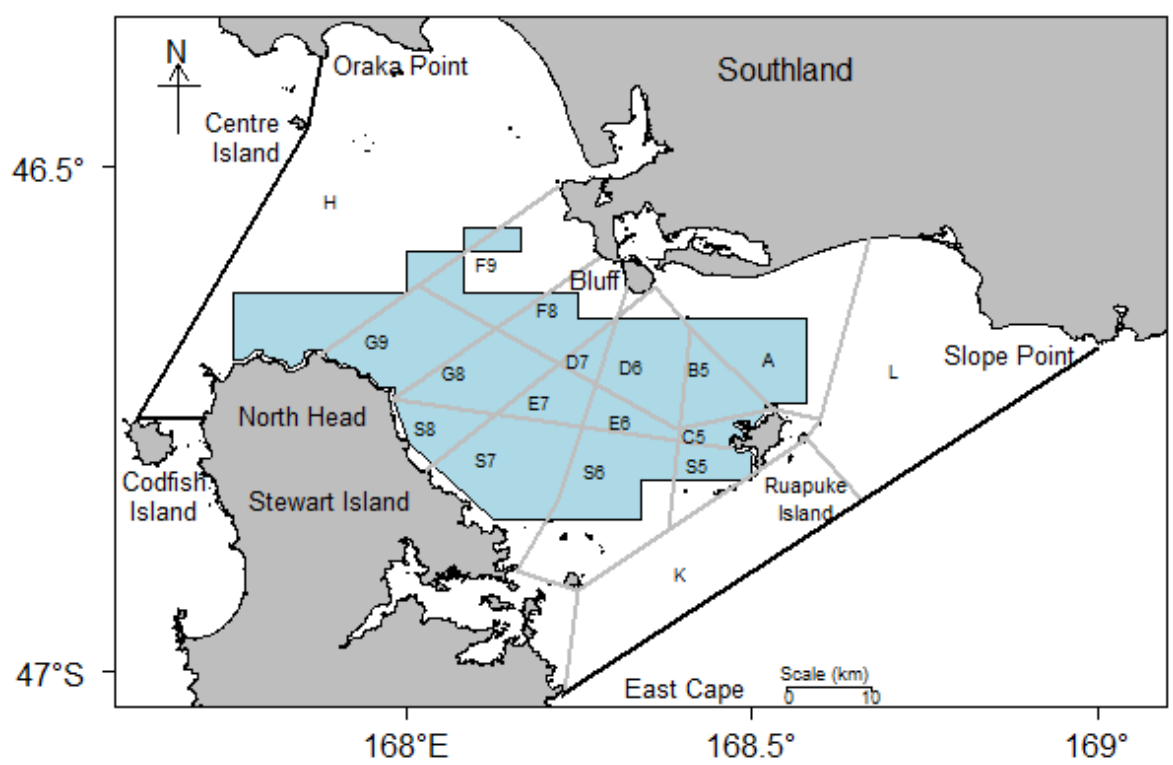

Figure 1-2. Foveaux Strait oyster stock (OYU 5) boundary and oyster fishery statistical reporting areas (delineated by grey lines and capitalised alpha numeric labels shown in black text), and the outer boundary of the 2007 stock assessment survey area (shaded blue) that encompasses the commercial fishery.

\section{Foveaux Strait oyster fishery}

The Foveaux Strait oyster (O. chilensis) fishery is commonly known as the Bluff oyster fishery, after the port town from which the fleet has been based since the 1880s. Oysters have been harvested from Foveaux Strait for over 150 years and the fishery is of high-value, and nationally significant for these reasons. Indigenous customary, recreational, and commercial fishers target oysters, which are important to the socio-economics of Southland, New Zealand (Michael et al. 2018). This is an entirely wild fishery, and is unlike many oyster fisheries elsewhere in that there has been no enhancement of stock, spat, or shell (settlement surfaces), e.g. Schulte et al. (2009). Shell enhancement trials in Foveaux Strait i.e., returning oyster shell after processing to oyster fishery areas, were largely unsuccessful (Street et al. 1973, Michael 2011).

Before the introduction of the Quota Management System in 1998, vessel numbers were limited (5-30), and at times the annual catch limited (Ministry for 
Primary Industries 2017). There is a six-month commercial fishing season for oysters extending from 1 March to 31 August. Management of the fishery assumes a single stock (OYU 5) (Ministry for Primary Industries 2017). Ostrea chilensis distribution is patchy within the $3300 \mathrm{~km}^{2}$ stock boundary, and the majority of oysters are concentrated in a smaller region of the managed area (the 2007 stock assessment survey area comprised $1072 \mathrm{~km}^{2}$, Figure. 1-2). Allen \& Cranfield (1979) and Stead (1971b) suggested the oyster fishery comprised a metapopulation of more than 50 discrete, dense localised populations generally separated by extensive areas with low $O$. chilensis densities. High densities of $O$. chilensis occur in a depth range of $20-50 \mathrm{~m}$ throughout the stock area.

Epizootics of the haplosporidian parasite Bonamia exitiosa appear to be a recurrent feature of the Foveaux Strait oyster population (Figure 1-3). B. exitiosa was first identified in samples taken during an epizootic in 1962-64 (Howell 1967, Hine \& Jones 1994) although reports of heightened mortality suggestive of disease mortality date back to 1906 (Hunter 1906). Substantial declines (c. 90\%) in recruit-sized $O$. chilensis (58 $\mathrm{mm}$ in length or larger) from B. exitiosa mortalities were recorded from 1985, 2000, 2013 (Doonan et al. 1994, Cranfield et al. 2005, Fu et al. 2016, Michael et al. 2018), reducing recruit-sized oyster population size and reducing high density patches of oysters (Figure 13). During periods of low B. exitiosa mortality and long-term average recruitment, the fishery rebuilds quickly and in the same fishery areas (Figure 1-3). 

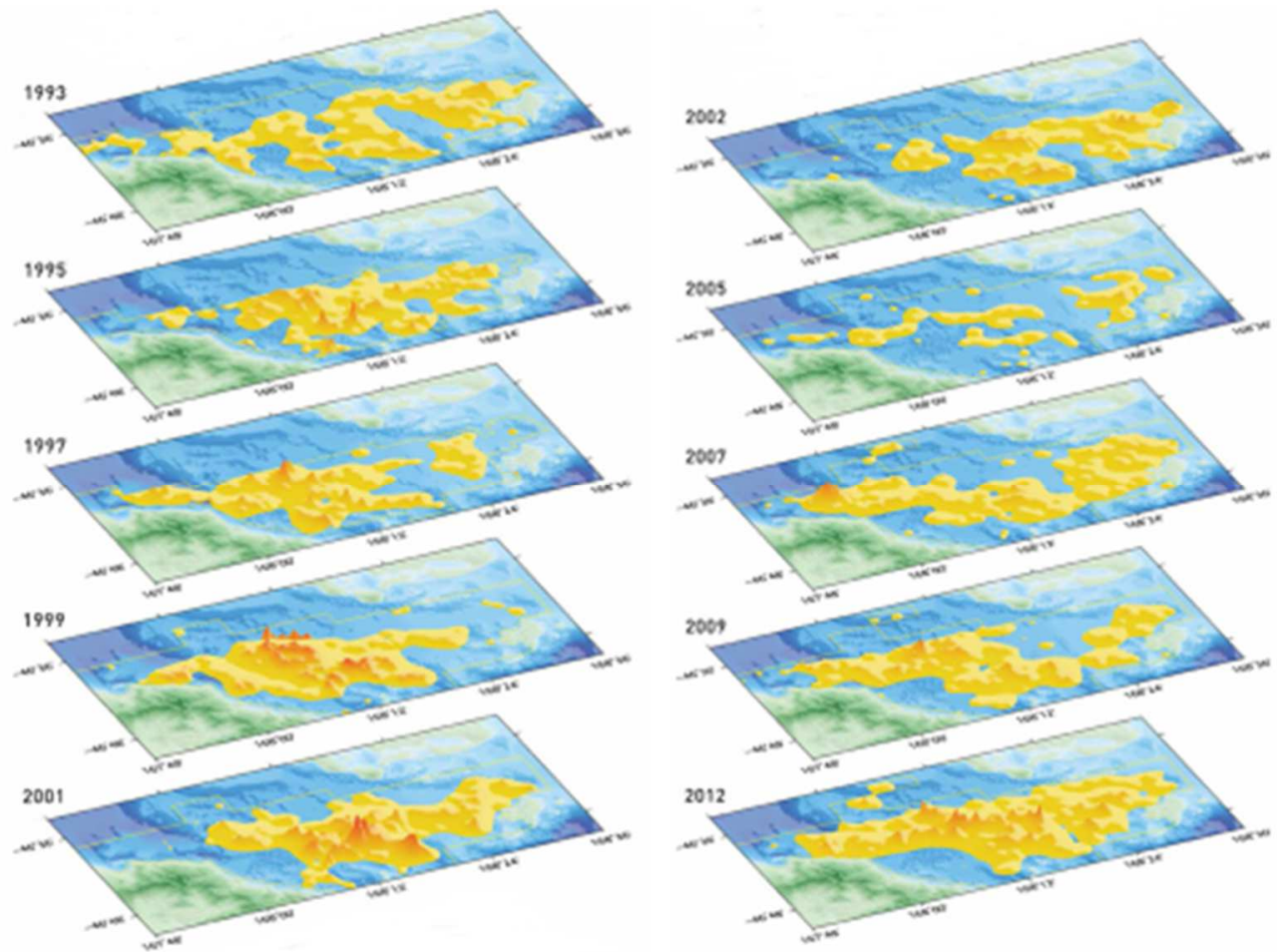

Figure 1-3: Three-dimensional surface plots of recruit-sized oyster densities from stock assessment surveys between 1993 and 2012.

Although B. exitiosa is responsible for oyster mortalities post 1985 , other pathogens such as an Apicomplexan parasite (APX) and Bucephalus longicornutus may play a significant role in oyster mortalities. B. longicornutus caused high oyster mortality ( $\geq$ 40\%) in Foveaux Strait between 1958 and 1964 (Howell 1967); however, the identification of $B$. exitiosa in oyster tissues sampled in 1964 (Hine \& Jones 1994) suggests co-infection is more likely the cause of mortality (J.B. Jones, MPI, pers. comm.). APX is not thought to cause high mortalities; however, its presence may increase the intensity of B. exitiosa infection in $O$. chilensis, increasing mortality (Hine 2002).

Recruit-sized $O$. chilensis oyster densities fell from 24 oysters $\mathrm{m}^{-2}$ in the 1960s (Allen \& Cranfield 1979) to 0.3 oysters $\mathrm{m}^{-2}$ in 1992 after the 1985 epizootic. In 1999, there was some recovery with an increase to 13 oysters $\mathrm{m}^{-2}$ (Michael et al. 2001); however, these numbers have not increased further 
because of recurrent mortality from disease. Oyster mortality appears to be density-dependent and disproportionately reduces the numbers of oysters in high-density patches. The reduction in the numbers of high-density patches has a significant effect on the fishery as these patches enable fishers to harvest economically. Before 1985, the annual commercial catch was about 80 million oysters (Dunn 2005). Since then, mortality from disease has reduced the stock size to low levels (Doonan et al. 1994, Cranfield et al. 2005). In response to the decline in oyster stock, the Ministry for Primary Industries (MPI) imposed a reduction in commercial catch from 80 to 15 million oysters annually in 1996 (Ministry for Primary Industries 2017). Disease mortality is the key determinant of oyster population decline. How it may affect recruitment is not known.

Cranfield et al. (1999) proposed a hypothesis that high densities of oysters only occur on complex biogenic habitat ("reefs") dominated by the bryozoans Cintipora elegans, and that fishing had severely reduced oyster habitat (Cranfield et al. 2004), causing a substantial decline in the oyster population. Between 1960 and 1985, the increased modification of benthic habitat by fishing and mechanical disturbance of oysters by the intense dredging may have been a major source of stress, increasing the susceptibility of oysters to this disease (Cranfield et al. 2005). Fishery data and anecdotal evidence pre and post-1985 show little support for these hypotheses. Oyster abundance increased during a period of high fishing effort and high catches (see Figure 11). The effects of fishing negatively affect benthic and cause changes to benthic habitats. However, the nature of these effects and their persistence are not known. The benthic taxa that have evolved in this high-energy environment could be well adapted to disturbance and their recolonization could be reasonably quick (Cranfield et al. 2001). The rapid decline of the oyster population was symptomatic "of newly introduced disease in an immunologically naïve population" (Cranfield et al. 2005). B. exitiosa was thought to be endemic to O. chilensis in Foveaux Strait (Cranfield et al. 2005); 
however, the extensive global distribution of B. exitiosa, that infects several oyster species (Hill et al. 2014) suggest a more generalist parasite (Arzul \& Carnegie 2015). The 1985 B. exitiosa epizootic could be a reintroduction of this species, or a co-infection of another pathogen such as an Apicomplexan parasite that substantially increased oyster mortality from B. exitiosa.

\section{Biology of Ostrea chilensis}

O. chilensis is a larviparous, protandrous hermaphrodite (Cranfield 1979). Oysters mature first as males from $19 \mathrm{~mm}$ in length, and then as simultaneous hermaphrodites with male and female gonads at $\geq 50 \mathrm{~mm}$ in length (Jeffs \& Hickman 2000). Seasonal patterns of gametogenesis are similar in populations throughout New Zealand; males tend to trickle-spawn throughout the year and females spawn predominantly in spring (September-October) (Jeffs \& Hickman 2000). Functional hermaphroditism is unlikely in the Ostreidae; however, ova and spermatozoa spawned simultaneously in a population of $O$. chilensis from northern New Zealand suggest that self-fertilisation is possible (Jeffs 1998a). The asynchronous gonadal development of males and females reduces fertilisation success within populations (Joyce et al. 2015). Broodingsized oysters are $\geq 60 \mathrm{~mm}$ in length (Jeffs \& Hickman 2000). Brooding occurs throughout the year, and peaks in November-December in southern areas including Foveaux Strait (Hollis 1962, 1963, Stead 1971a, Cranfield 1979, Westerskov 1980, Jeffs 1998a). Brooding starts earlier and finishes later (September to January) in warmer, northern areas (Jeffs et al. 1996, Brown 2011). The number of larvae released determines cohort size and predicted by the percentage of brooders in a localised population. In Foveaux Strait, only a small proportion of the spawning population brood, although 70-90\% develop male gonads (Cranfield 1979). Between $7 \%$ and $18 \%$ of individuals brooded in the 1960s, and 1970s (Hollis 1962, Stead 1971a, Cranfield 1979, Jeffs \& 
Hickman 2000) and 1-2\% in 1996-2000 (Bluff Oyster Enhancement Company, unpublished data). In New Zealand, the percentage of brooders increases with a decrease in latitude, which suggests temperature, is a primary determinant of successful spawning and fertilization, and therefore brooding. Brooding percentages increase from less than $20 \%$ in Foveaux Strait (46 S) to 55-78\% in Tasman Bay (41 S) (Brown et al. 2010), and to 78-90\% in northern New Zealand (36 S) (Jeffs 1996). Temperature along with other factors such as salinity and food availability contribute to differences in the duration of brooding in New Zealand, which typically ranges from 15 to 38 days (Westerskov 1980, Hollis 1963, Stead 1971a). Large (448 to $541 \mu \mathrm{m}$ ) larvae (Cranfield \& Michael 1989) brooded to pediveliger with eyespots (Hollis 1962, Stead 1971a) are fully competent and ready to settle immediately on release. As larval size increases with development, a small proportion of larvae may be forced out of the pallial cavity by space limitation caused by growing larvae and released early (Cranfield \& Michael 1989). In these cases, development can continue ex-parent (Hickman 2000). Larval release and almost all settlement in Foveaux Strait occur between November and February (Cranfield 1979, Michael 2011).

The larval biology of $O$. chilensis has given rise to the hypothesis that localised populations are self-recruiting (Cranfield 1968b; Cranfield 1979; Cranfield \& Michael 1989), as is hypothesised for Tasman Bay (Broekhuizen et al. 2011). Moreover, the large ova size and the absence of feeding (lecithotrophy) are associated with limited dispersal potential that should enhance selfrecruitment (Levin 2006). The mainly rapid settlement in O. chilensis underpins the expectation of a very short pelagic larval duration that suggests limited opportunity for larval transport and dispersal.

O. chilensis in Foveaux Strait grows to minimum legal size (MLS) in 4 to 5 years after settlement (Cranfield 1979), defined as oysters that are unable to pass through a $58 \mathrm{~mm}$ internal diameter ring. MLS equates to $58 \mathrm{~mm}$ in length - the maximum distance measured along the anterior-posterior axis. More than 
$60 \%$ of the oysters landed in the commercial catch are larger than $70 \mathrm{~mm}$ in length (Marsh et al. 2016), corresponding to an age $\geq 8$ years ( $\mathrm{Fu}$ et al. 2016).

The biology and ecology of $O$. chilensis differs to other species of oysters. For example, $O$. chilensis has only one main spawning event per year while multiple spawning events are common in Crassostrea virginica (Knights \& Walters 2010), O. edulis (Lapegue et al. 2006) and O. lurida (Pritchard et al. 2015). Pelagic larval durations are shorter in O. chilensis than for most other species. Durations range from 8-10 days in O. edulis (Lapegue et al. 2006), 1720 days in O. puelchana (Pascual \& Zampatti 1995), 15-25 days in C. virginica (Narváez et al. 2012, Puckett et al. 2014), 3-4 weeks in M. gigas (Robins et al. 2017), to one to eight weeks in O. lurida (Pritchard et al. 2015). Dispersal and connectivity are potentially greater in these other species.

Foveaux Strait differs markedly from the mainly low energy, shallow $(\leq 10 \mathrm{~m})$ estuarine and embayment, and intertidal habitats of other oysters: $O$. edulis (Lapegue et al. 2006), O. lurida (Pritchard et al. 2015), and C. virginica (Knights \& Walters 2010). Many oysters in these environments, especially the Crassostreinae, form reefs e.g. C. virginica (Kirby 2004) and M. gigas (Walles et al. 2015). O. chilensis may form small clusters of oysters from the successive over settlements of spat; however, they do not form "oyster reefs" (author's unpublished data). Currents aggregate $O$. chilensis shells, bound by epibenthic taxa to form lenticular structures, which are orientated along the tidal current axis. These structures are colonised by benthic taxa to become biogenic reefs (Cranfield et al. 1999, Cranfield et al. 2001). 


\section{Thesis overview}

Inferences of recruitment made from probabilistic models without descriptions of recruitment processes and empirical data may be misleading, and can bias an understanding of the processes influencing recruitment (Pineda et al. 2009). Empirical data on recruitment to O. chilensis populations is scant, and the understanding of recruitment process largely assumed from the oyster's reproductive biology. Brooding oysters release late stage, competent larvae with very short pelagic larval durations that mostly settle around the natal populations, i.e. these populations are demographically closed (self-recruit). Based on the assumption of mostly demographically closed populations, recruitment in Foveaux Strait oysters can be investigated using fishery spatialscale sampling without the need to consider spatio-temporal variations in the dispersal of larvae and connectivity among populations.

This research follows a reductionist approach where O. chilensis recruitment is partitioned into fundamental processes, and each one is investigated individually in the following chapters. The management of many fisheries including oysters a based on a stock-recruit relationship, where limiting catch to ensure the spawning stock is above reference points and thereby to ensure recruitment and future yield. Chapter 2 investigates the relationship between spawner densities and the numbers of recruits. In oysters and other invertebrates, factors other than spawner densities such as climate and/or disease may reduce spawning and brooding success, and thereby the supply of competent larvae for recruitment. These factors are investigated in Chapter 3. The assumption of self-recruitment to natal populations has implications for the spatial demographics of the oyster stock in Foveaux Strait, and the stock's resilience to fishing and disease mortality. The distributions of recruits (a proxy for competent larvae in the plankton) are described to investigate the potential for larval mixing and connectivity between populations in Chapter 4. Oyster do 
not exhibit preferences for the types of settlement substrata or require settlement cues (Ostrea appears to settle on any clean, hard substrata). Therefore, postsettlement mortality is investigated as a key determinant of the spatial structure of oyster populations in Chapter 5. A general discussion (Chapter 6) brings together the information from the proceeding chapters to provide new insights in to the recruitment of $O$. chilensis in Foveaux Strait, how recruitment may determine population dynamics, and shape their spatial structure. Chapters 2-5 are briefly summarised below and are in the format of stand-alone papers with a chapter-specific introduction and discussion to facilitate easier publication in journals. Consequently, some redundancies are inevitable.

Chapter 2 investigates the relationship between spawner densities and recruits. The numbers of recruits, i.e. numbers of competent larvae that settled on artificial substrata, were estimated from the densities of recruits on passive spat collectors. There are two concurrent sampling programmes: The first involved recruit densities sampled from a single area over 6 years to determine the seasonality of recruitment. The second sampling programme was a fisherywide study conducted over four years, whereby spat collectors were deployed at six sites; putatively high and low spawner density sites across each of three discrete fishery areas. Dredge samples were used to estimate densities of spawning-sized oysters. Recruit and spawner densities were modelled with a negative binomial regression to evaluate the stock-recruitment relationship.

Chapter 3 investigates whether other climatic and/or biological factors reduced spawning and brooding success, and thereby the supply of competent larvae for recruitment. Biological factors were limited to densities of broodingsized oysters and oyster mortality rates as indicators of fatal infections during spawning. These were estimated from surveys. Climatic factors include climate data (sea surface temperature, chlorophyll, and turbidity from remote sensing and conductivity, temperature, and depth (CTD) instrument) and climate indices (SOI, MI and Z2 indices). Climatic and biological variables were ranked in order 
of importance to the variation in recruitment using classification tree ensembles. Recruitment, oyster densities, mortality, and climate were modelled with negative binomial regression to determine key factors and their interactions.

Chapter 4 investigates the hypothesis of self-recruitment. Passive, artificial collectors were deployed in a gradient design around an isolated natal population in a 3-year study. The distributions of recruits that settled on these arrays of artificial substrata were used to infer larval mixing and connectivity between populations. Brooding-sized oyster densities were also estimated from dredge sampling, and the relationship between recruits and brooding-sized oyster densities was also investigated.

Chapter 5 investigates settlement and post-settlement survival as drivers of the spatial structure of oysters in Foveaux Strait. This chapter is mainly descriptive and establishes a foundation of empirical data for future research. Fishery and sampling data are used to: (1) identify benthic habitats on which high oyster densities occur, (2) identify surfaces on which $O$. chilensis larvae settle and survive, and (3) compare growth and mortality of recruits and juveniles between exposed and less exposed sites, and different heights above the seabed.

Chapter 6 synthesises recruitment processes from chapters 2-5 of this thesis in a general discussion of recruitment and highlights an improved understanding of oyster recruitment in Foveaux Strait. It also discusses the implications of the findings for the future management of the fishery, including roles for conservation and potential restoration efforts.

\section{Key assumptions that underpin sampling designs and methods}

Most of the literature on the biology of Ostrea chilensis dates before the 1985 Bonamia exitiosa epizootic. There is some uncertainty whether, and how, the change in fishery productivity as a result of this pathogen (Ministry for Primary Industries 2017) may have changed the reproductive success of oysters. Sampling designs and methods used in this research are based on this literature, 
and make two key assumptions: 1 . Brooder densities provide an indirect estimate of the numbers of competent oyster larvae in the plankton and thereby a proxy for larval supply, and 2. Passive, artificial spat collectors sample recruits to estimate the numbers of competent larvae in the plankton that settle and complete metamorphosis on artificial substrata, in this research on cement board plates.

This research assumes a close relationship between the numbers of brooders and the numbers of competent larvae available for settlement, and thereby larval supply at the sample locations. This assumption is based on similar percentages of brooders that release similar numbers of larvae, which settle quickly on available substrata close to their natal populations. A small proportion of the spawning population in Foveaux Strait $(<20 \%)$ brooded larvae pre-1985 (Hollis 1962, Stead 1971a, Cranfield 1979, Jeffs \& Hickman 2000). The proportion of brooders post-1985 has been consistently low (<2\% between 1996 and 2000, Bluff Oyster Enhancement Company, unpublished data). A number of factors including temperature and physiological condition affect reproductive success in O. chilensis (Westerskov 1980, Buroker et al. 1983, Joyce et al. 2015), and these factors are likely to drive interannual variation in recruitment. A little variation can also be expected at multiple spatial-scales in a given year. Data on the variation in fertility (numbers of larvae per brood) in $O$. chilensis from Foveaux Strait are scant. The estimates of mean fertility are similar: $6.5 \times 10^{4}$ (Walne 1983) and $5.7 \times 10^{4}$ (Cranfield \& Allen 1977). There are few estimates of the variability in fertility and these data are limited to ranges of fertility, $6.3 \mathrm{x}$ $10^{4}-6.7 \times 10^{4}$ (Walne 1973) and $0.7 \times 10^{4}-12.0 \times 10^{4}$ (Cranfield \& Allen 1977). Thus fertility may vary within subpopulations; however, fertility did not vary between different areas in Foveaux Strait (Cranfield \& Allen 1977).

O. chilensis broods larvae to late stage pediveliger that are fully competent and ready to settle, and have a putative, short pelagic larval duration (PLD) that suggests limited opportunity for larval transport and dispersal, 
reduced opportunities for larval mortality (Cranfield \& Allen 1977) and increased likelihood of self-recruitment. Additionally, attributes such as large, lecithotrophic larvae, such as those of $O$. chilensis in Foveaux Strait, are associated with short PLDs (Levin 2006). Moreover, the observations of Hollis (1962), Stead (1971a), Brown (2011), experiments of Cranfield (1968a), and predictive modelling of (Broekhuizen et al. (2011) all suggest short PLDs. These data suggest that large changes in larval supply (estimated indirectly as recruits per brooder) over any given year, are more likely to be driven by factors other than large variations in the percentages of brooders and their fertility.

Passive, artificial spat collectors are the main sampling method used for this research. It is assumed that $O$. chilensis larvae readily and consistently settle on these collectors to provide representative estimates of the densities of competent larvae in the plankton at sampling locations, i.e. spat collectors sample the densities of recruits as a proxy for larvae that have completed metamorphosis. Recruit densities on spat collectors do not estimate recruitment to the seabed per se, which is dependent on the availability of settlement substrata, usually shells (Smyth et al. 2018). O. chilensis appears to settle on any clean, hard substratum (mainly shell) and does not exhibit preferences for settlement substrata or requires specific settlement cues (pers. obs., and for $O$. edulis after Smyth et al. 2018). Moreover, O. chilensis readily settles on manmade substrata without conditioning and in the absence of conspecifics e.g. cement board (Cranfield 1968b, Brown et al. 2010). The settlement of larvae had previously been high on unconditioned plates deployed for similar periods of time in Foveaux Strait (1965-1967, 1999-2000; Cranfield 1968b, Cranfield et al. unpublished data). Spat collectors deployed with new cement board plates provide standard sampling units. There are a number of potential limitations of this sampling method, which are difficult to quantify.

Laboratory experiments, and observations of the release and settlement of $O$. chilensis larvae in the Hauraki Gulf (northern New Zealand, Andrew Jeffs 
per. comm.) suggest that some settlement occurs immediately after release and within meters of their maternal parent. Spat collectors are unlikely to sample this proportion of competent larvae and thereby underestimate recruitment. The proportion of larvae settling immediately and how this proportion varies spatially and temporally is not known; however, the small scale experiment of Cranfield (1968a), suggests that recruit densities on spat collectors represent recruitment within local natal populations.

O. chilensis larvae are poor swimmers (Stead 1971a), are thought to remain near the seabed (benthopelagic) in strong current conditions, and are phototaxic (Cranfield 1968b). If this is true, almost all settlement should occur on the seabed. However, it is likely that larvae are transported as passive particles by the swift currents in Foveaux Strait. Swift currents flowing over the seabed generate pulsing cyclic flows (internal seiches, see Gibbs 2001) that suspend sediments and particulates from the seabed and these particles are entrained in flows above the seabed. Larvae are likely to be transported in these flows and this vertical distribution could explain the previously high settlement and survival of recruits on cement board plates up to $360 \mathrm{~mm}$ above the seabed.

Water movement over the seabed is characterised by spatially and temporally variable flows depending on tidal currents, seabed topography, and wind direction and strength. Spat collectors could be deployed in areas that do not receive representative numbers of competent larvae in the plankton. This risk is mitigated in part by the randomly assign locations of spat collectors, and by replication. The mortality of competent larvae during settlement and metamorphosis, and early post-settlement predation could result in an underestimate of recruits on the cement board plates. The short PLD and maternal provisioning suggest greater likelihood of successful settlement (Cranfield 1979). The large prodissoconch (larval shell) and rapid growth markedly increases the detection of early settlers that have died from their left (lower) valves that remain attached to the substratum. A significant relationship between 
the planktonic larval abundance of Ruditapes decussatus (Linnaeus 1758) that has a much longer PLD (15-30 days) and recruit densities on spat collectors (Chícharo \& Chícharo 2001) suggest that on average, O. chilensis recruit densities estimated on spat collectors are likely to represent densities of competent larvae at sample locations. 


\section{Chapter 2 : The relationship between Ostrea chilensis spawner densities and numbers of recruits}

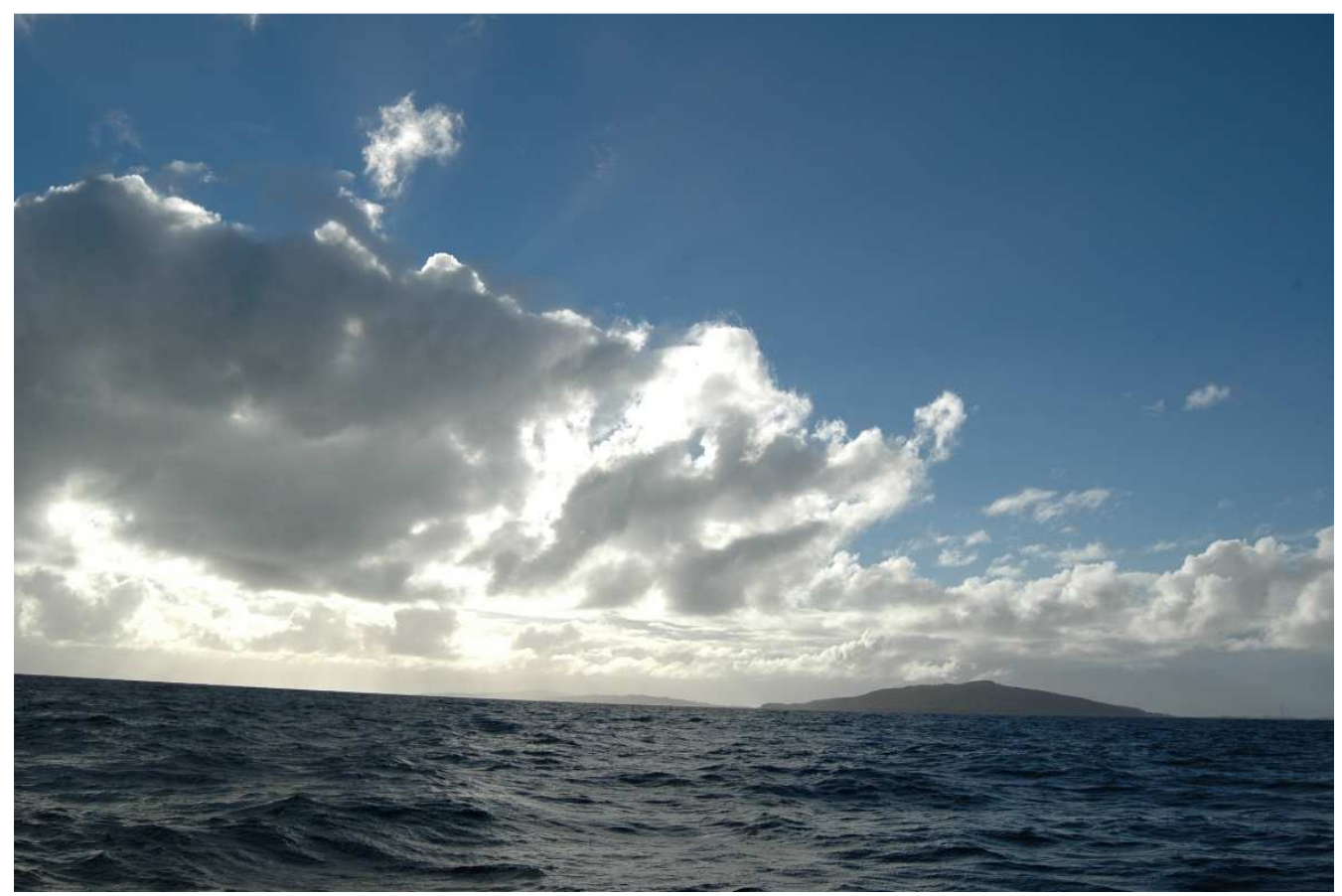

Motupohue / Bluff Hill stands as a beacon home. This landmark is visible throughout Foveaux Strait and before GPS, served as key reference for position fixing by many generations of oyster fishers. Image courtesy of Alan Blacklock. 


\begin{abstract}
Rebuilding and maintaining sufficient spawning stock to ensure recruitment is a key strategy for fisheries management and ecological restoration. This research evaluates variation in Ostrea chilensis recruitment across seasons and sites over 4-6 years in Foveaux Strait (New Zealand) to infer the relative importance of determinants of population recruitment. Recruitment varied significantly between seasons $(\mathrm{p}<0.001)$. Most recruitment in any given year $(97.8 \pm 0.9 \%$, mean $\pm \mathrm{SE})$ occurred in the austral spring and summer (November to February) with significant variation in recruitment between years ( $p<0.001)$. A separate fishery-wide study investigates the effect of spawner densities on recruitment. Spat collectors were deployed at six sites across three discrete fishery areas, and dredge samples were used to estimate densities of spawning-sized oysters. Counts of recruits and spawners were modelled with a negative binomial regression to evaluate the stock-recruitment relationship. Recruitment varied between years (50.8\% of the deviance explained), spawner densities (13.8\%), and areas (11.6\%), with further 2-way interactions between these factors. Importantly, analysis showed a continued decline in recruits per spawner, despite similar or increasing densities of spawning-sized oysters. Average recruitment for 2010-11 when spawner densities were highest was $4.6 \%$ of the level observed in 2007-08. The data suggest that factors other than densities of oysters play a major role in recruitment. Managing oyster fisheries as a single stock and maintaining oyster densities above management reference points alone may therefore not be sufficient to ensure recruitment to rebuild populations.
\end{abstract}




\section{Introduction}

Recruitment is notoriously variable (Caley et al. 1996, Sale \& Kritzer 2003) across a wide variety of taxa in marine systems: fish (Carr \& Syms 2006), algae (Vadas et al. 1992), and benthic invertebrates (Underwood \& Fairweather 1989, Rodriguez et al. 1993). The influence of climatic and biological factors on recruitment are well recognized. However, assumptions of static stockrecruitment relationships (Beverton \& Holt 1957) underpin fisheries management (Hilborn \& Walters 1992) and ecological restoration (Schulte et al. 2009). Rebuilding and maintaining sufficient spawning stock (Mace 2012) is a principal strategy to maximize larval production as a prerequisite to successful recruitment. However, stock-recruitment relationships remain poorly understood and the common assumptions of constancy in stock-recruitment relationships have important consequences for the many stocks where spawning stock size and recruitment are not positively correlated (Szuwalski et al. 2015). A mechanistic understanding of recruitment variability will better inform stock assessments and the identification of key drivers of recruitment dynamics. Here, variation in the recruitment of Ostrea chilensis in Foveaux Strait, southern New Zealand is described, and its relationship with stock size and other sources of variation evaluated.

Oysters (family Ostreidae) occur globally over a wide range of habitats. They can play key roles in benthic communities (Jones et al. 1994, Grabowski \& Peterson 2007) and provide important ecosystem services (Coen et al. 1999, Grabowski et al. 2012). Historically, oysters also provided highly valued fisheries, although many of these high-value stocks are now economically extinct (Beck et al. 2011). The $O$. chilensis fishery in Foveaux Strait is a highly valued and nationally important fishery for New Zealand (Ministry for Primary Industries 2017). O. chilensis biology and characteristics of the fishery differ markedly from other oyster species and fisheries (see Chapter 1). The short pelagic larval duration (PLD) of $O$. chilensis suggests limited opportunity for 
larval transport, and high self-recruitment to natal populations. The Foveaux Strait fishery is an entirely wild fishery with no enhancement of stock, spat, or shell. Management of this fishery assumes a single stock with a stockrecruitment relationship (Fu et al. 2016, Ministry for Primary Industries 2017). These assumptions affect projections of future stock size.

Oysters, like many marine taxa, have a pelagic larval stage and a sessile post-settlement stage. Both pre-and post-settlement processes are likely to shape their recruitment (Sale \& Kritzer 2003, Shima et al. 2008, Cowen \& Sponaugle 2009, Hixon et al. 2012). In addition, biophysical factors may affect recruitment patterns by altering larval quality and cohort size (Pineda et al. 2007), and dispersal and retention dynamics of pelagic larvae (Jones et al. 2009). A better understanding of the processes that shape recruitment will inform population models and management of the Foveaux Strait oyster fishery and have application to the management of other marine resources and communities. Evaluations of stock-recruitment relationships through time and among locations within a population are rare.

The nature and constancy of the stock-recruitment relationship that underlies management of the Foveaux Strait oyster fishery was investigated, and the significance of the combined roles of climatic and other biological factors on this relationship inferred. O. chilensis recruitment is operationally defined in Chapter 1 as the numbers of competent larvae that settle from the plankton after minutes to hours after release and complete metamorphosis on substrata; in this study on cement board plates on the spat collectors. Hence, the stockrecruitment relationship is evaluated with limited opportunity for larval dispersal and reduced opportunity for post-settlement mortality that can be highly variable in time and space (Hunt \& Scheibling 1997) and obscure stock-recruitment relationships. This study estimates oyster recruitment across a range of spatial and temporal (seasonal and interannual) scales. The relationship between 
recruits and spawner densities is evaluated and the relative importance of other determinants of population recruitment inferred.

\section{Methods}

\section{Study sites and species}

The Foveaux Strait oyster fishery (Figure $2-1$ is managed as a single stock OYU 5 (Ministry for Primary Industries 2017) and the fishery comprised a number of putative demographically closed populations (Stead 1971b, Allen \& Cranfield 1979). Fisheries-independent variation in oyster densities is mostly driven by periodic disease mortality (Doonan et al. 1994, Cranfield et al. 2005) caused by Bonamia exitiosa (previously B. exitiosus, Berthe \& Hine 2003), and variability in recruitment to the oyster population (Michael et al. 2015). This research evaluated oyster recruitment to Foveaux Strait populations, before postsettlement mortality, to understand drivers of fishery-recruitment.

Spawners (spawning-sized oysters) are defined as individuals $\geq 50 \mathrm{~mm}$ in diameter (after Dunn 2005). O. chilensis is a protandrous, larviparous hermaphrodite. Individuals mature first as males in the summer after settlement; they transition to females and initiate brooding in their fourth summer (Cranfield 1979, Jeffs \& Hickman 2000). Females typically brood larvae to late-stage pediveligers (Hollis 1962, Cranfield 1979, Chaparro et al. 2006). Cranfield \& Michael (1989) suggested that most O. chilensis larvae released into Foveaux Strait were competent and settle within minutes to hours after release (Cranfield 1979, Westerskov 1980, Chaparro et al. 2006). This putative short PLD motivates the hypothesis that most dispersal events will occur over short distances (Cranfield 1968a, Broekhuizen et al. 2011) and self-recruitment is likely to be high. Stock-recruitment relationships have therefore hypothesized to operate over relatively small spatial scales. 
The nature of stock-recruitment relationships may vary from year to year depending on biological and climatic conditions that may determine reproductive success of oysters. Here, an ecological definition of recruitment is used (i.e. the number of recently settled recruits) as per (Stanwell-Smith \& Barnes 1997) as opposed to a standard fisheries definition (i.e. the number of harvestable adults) that has been detailed in Hilborn \& Walters (1992).

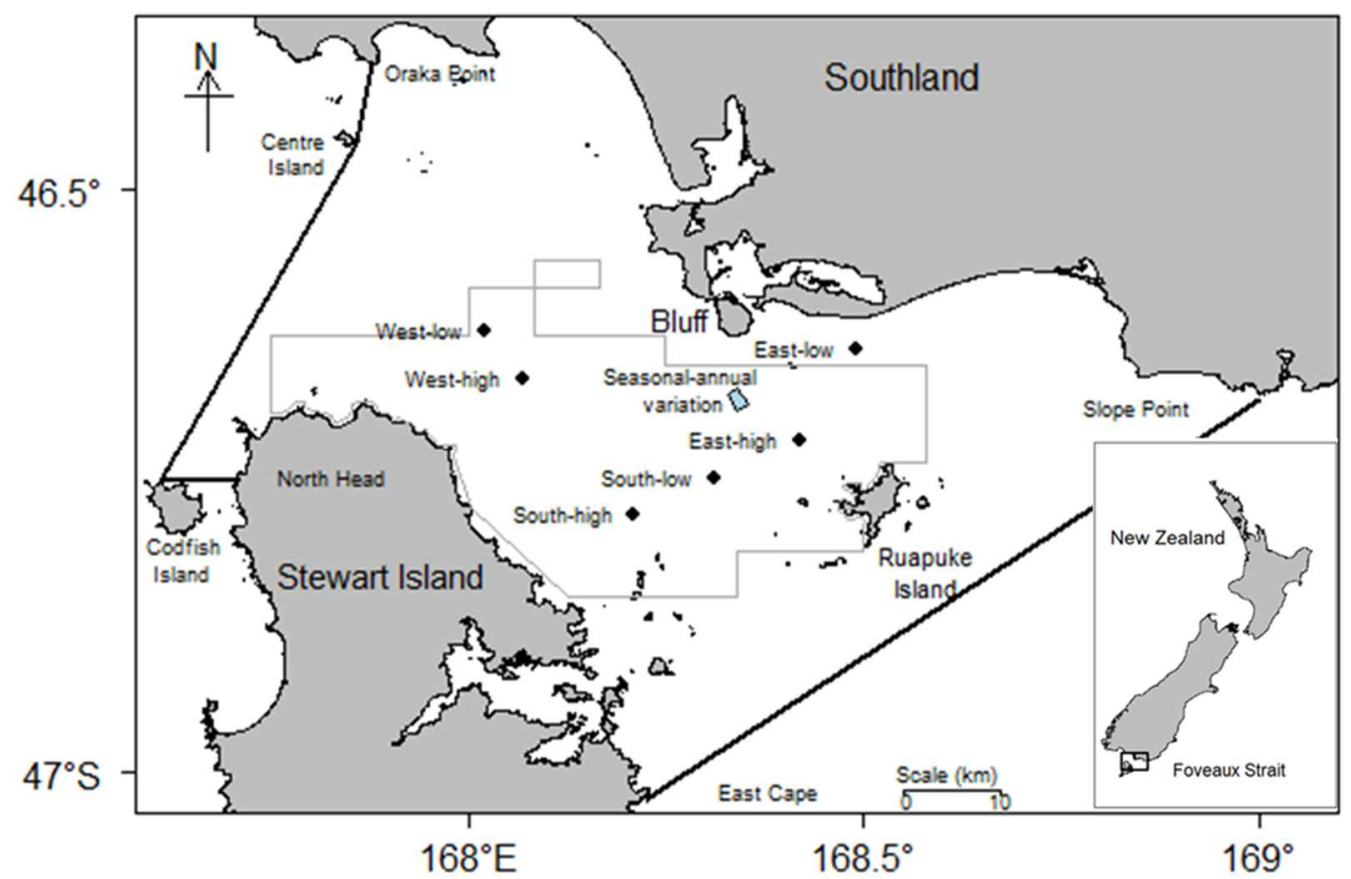

Figure 2-1. Foveaux Strait oyster stock (OYU 5) boundary (heavy black lines) and the outer boundary of the 2007 stock assessment survey area (grey lines) encompassing the commercial fishery. Seasonal and interannual variation in recruitment was sampled at a single site (light blue shading), and spatio-temporal variation in recruitment at 6 sites across the fishery (filled black circles). Inset shows the location of Foveaux Strait within New Zealand.

\section{Quantifying recruitment}

Recruitment was quantified from counts of recruits on artificial collectors (Cranfield 1968b, Brown et al. 2010). Spat collectors consisted of a reinforced concrete base with a steel frame holding 4 cement board settlement plates $(220 \times 140 \mathrm{~mm}$ and $4 \mathrm{~mm}$ thick) at heights of 10, 120, 240, and $360 \mathrm{~mm}$ above the seabed (Figure 2-2). Although conditioning of spat collectors and the 
establishment of biofilms have been shown to be important in some oyster species (e.g., C. virginia, Tamburri et al. 1992), Ostrea will settle on any clean hard substrate (Smyth et al. 2018). Because the settlement of $O$. chilensis larvae had previously been high on unconditioned plates deployed for similar periods of time in Foveaux Strait (1965-1967, 1999-2000; Cranfield 1968b, Cranfield et al. unpublished data), the settlement plates were not conditioned before deployment (Figure 2-3). Mooring lines with floats attached to each collector facilitated location and retrieval.

Oyster recruitment was sampled across years with deployment and recovery of spat collectors at approximately four-month intervals (i.e. targeting three 'seasons' per year). The sampling year (Year) began 1 July and ended the following 30 June, with year partitioned into 3 seasons. Season A (1 July to 31 October), when brooding begins, but before any significant settlement occurs. Season B (1 November to 28 or 29 February), when most settlement is thought to occur. Season C (1 March to 30 June), after the presumed period of peak settlement. Sampling began and ended in Season B as Season A was not sampled in the first year and Season C was not sampled in the last year. Each deployment of spat collectors used new cement board plates. Recruitment to each collector is the cumulative number of recruits on any plate surface (top or bottom) of any of the four plates of a given collector. Because this research focus was on recruitment before post-settlement mortality, recruitment was estimated as the total number of both living and dead recruits on plates $(>85 \%$ of oysters were alive at the time of recovery). Oyster spat that have died leave a record of their size at death, as either the whole shell (articulated valves) or only the attached left valve (once metamorphosis is complete after settlement, the shells of recruits grow quickly with the left valve continuing to attach to the substrata as it grows). Because actual deployment times varied around the target period by a small amount, estimates of recruitment were standardized to a $122 \mathrm{~d}$ sampling period for each season. 


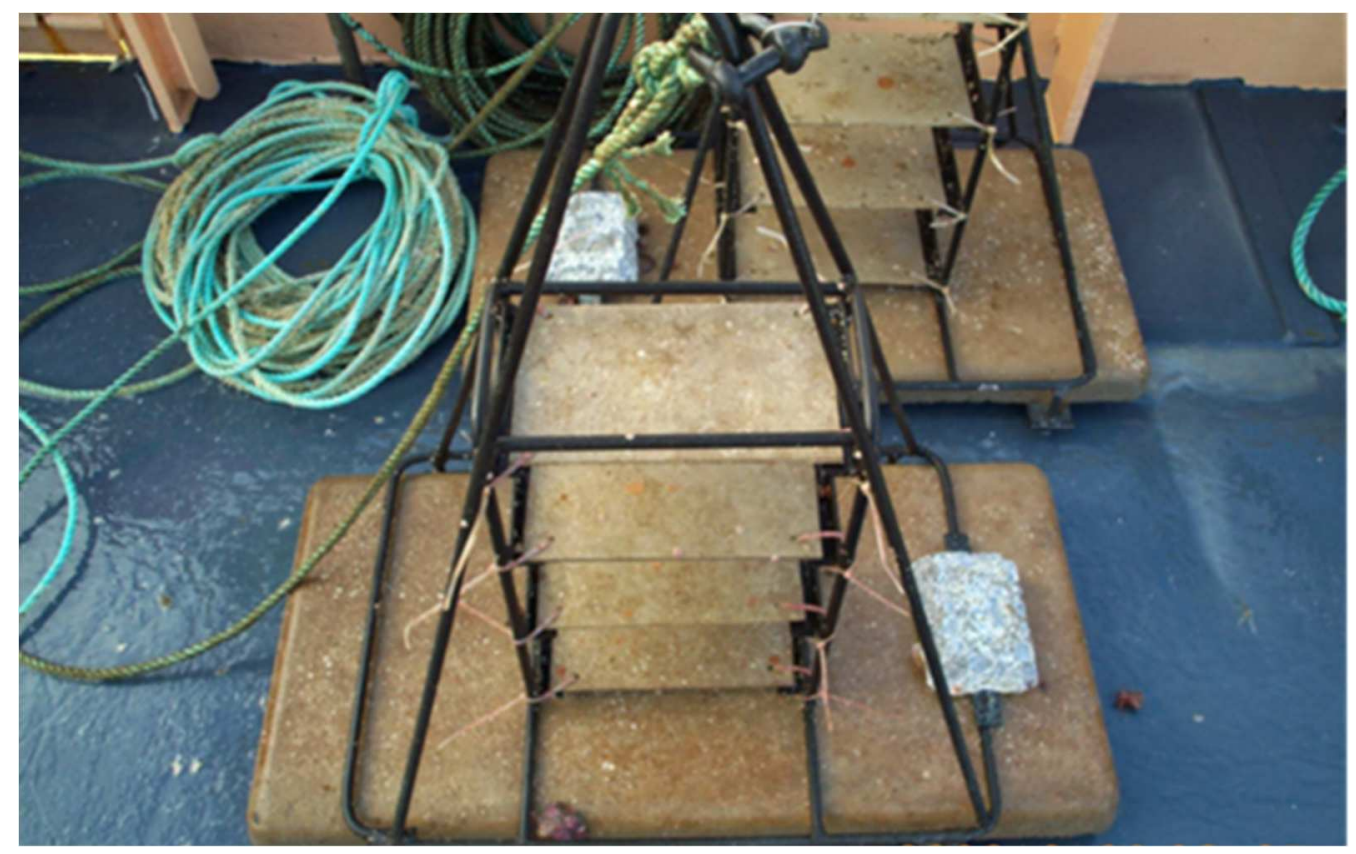

Figure 2-2. Passive artificial spat collectors used to estimate recruitment. Cement board plates $(220 \times 140 \mathrm{~mm}$ and $4 \mathrm{~mm}$ thick) at heights of 10, 120, 240, and 360 $\mathrm{mm}$ above the seabed.

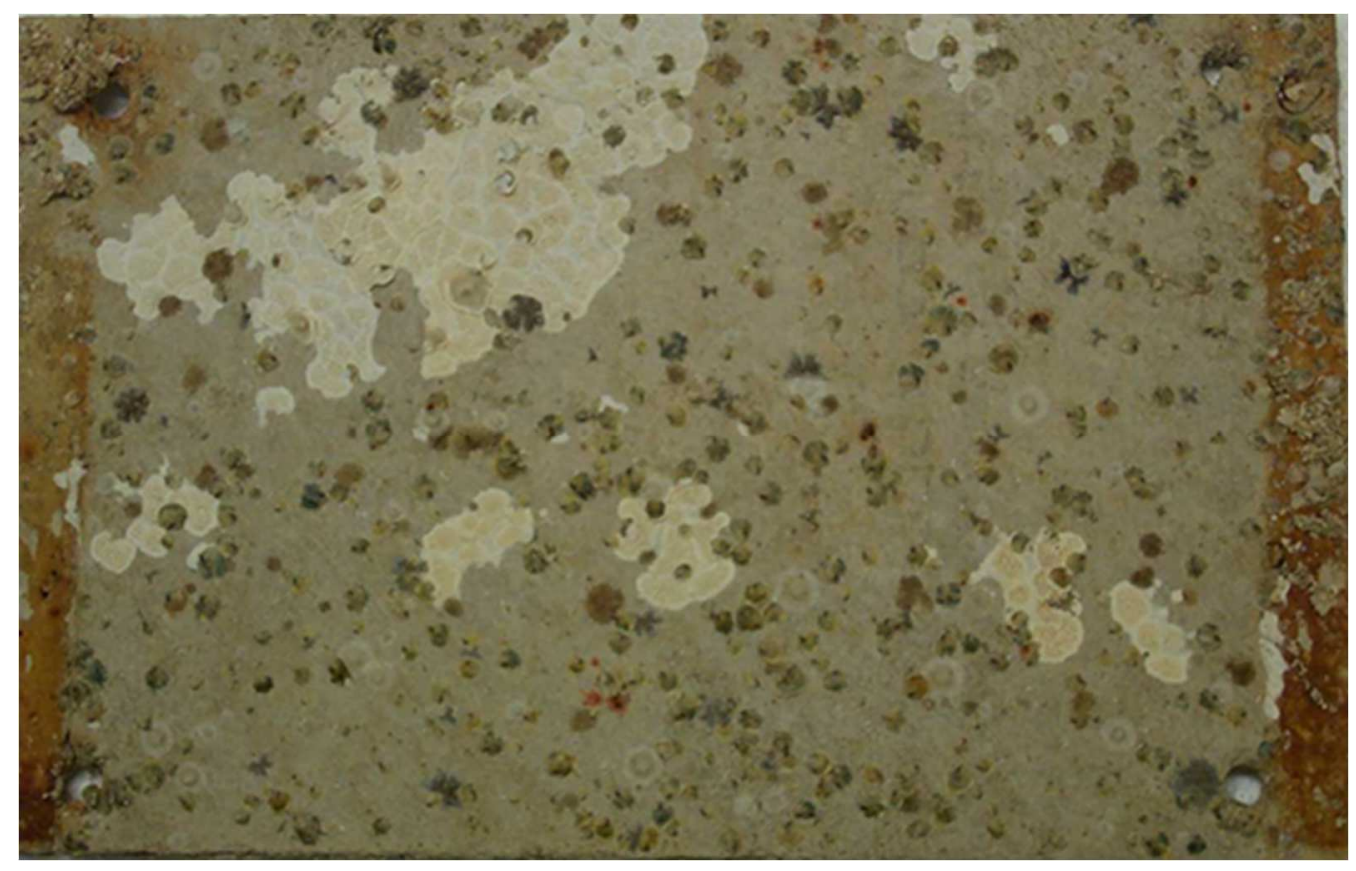

Figure 2-3. Spat plate recovered after c. 122 days showing $O$. chilensis recruits. 


\section{Seasonal and interannual variation in recruitment}

Seasonality and interannual variation in oyster recruitment were quantified with collectors deployed to a single site from December 2005 to February 2011. The site was closed to fishing. Specifically, a single collector was deployed to each of nine randomly selected locations within a $2.25 \mathrm{~km}^{2}$ area (see Figure 2-1). Collectors were sampled three times each year (Seasons A, B, and $\mathrm{C})$.

Oyster recruitment was modelled as a function of Season, Year, and the interaction between Season and Year. These count data had overdispersed distributions (chi-squared test statistic $=21323.4, \mathrm{p}<0.001$ for alpha $=0.05$ ), and contained many zeros (was zero-inflated: $W=0.24$ overall, and $W=0.85$, 0.03, and 0.12 for Seasons A, B, and C, respectively). Zeros originated from 2 sources: structural zeros because no or little settlement in Seasons A and C was expected, and sampling zeros where collectors recorded no settlement in Season B although some settlement was expected. These data were modelled with zeroinflated negative binomial mixed regression (ZINB) using the pscl package (Jackman 2008) in R (R Core Team 2016). A generalised linear model with negative binomial distribution (GLM.NB) using the pscl package was also evaluated and fits compared using the Vuong (1989) likelihood ratio tests function in the pscl package.

\section{Spatio-temporal variation in recruitment as a function of spawner density}

Spatial and interannual variation in recruitment of oysters was quantified in relation to estimates of spawner densities at different sites across the wider fishery (see Figure 2-1) to evaluate potential variation in stock-recruitment relationships operating over relatively small spatial scales. Six sampling sites were stratified across 3 discrete areas (Area) within the fishery with 2 sites in each of the West, South, and East areas (for site locations, see Figure 2-1 and also see Table A-1, estimates of spawner densities section in the Appendix). 
Minimum distances between sites ranged between 9.0 and $35.8 \mathrm{~km}$. The two sites within each area were selected non-randomly to establish contrasting densities of spawning-sized oysters ('Category': reflecting qualitatively high versus low density, see Figure A-1, estimates of spawner densities section in the Appendix). Distances between high and low paired sites ranged between 5.5 and $10.2 \mathrm{~km}$. Site selection was informed by previous surveys (Michael et al. 2005, Michael et al. 2006, Michael et al. 2008a, Michael et al. 2008b, Michael et al. 2009a), fishers' catch and effort data (Michael et al. 2012b), and interviews with oyster vessel skippers. Spawner densities were also estimated directly at each site before deployment of spat collectors (in November 2007) using standard dredge sampling procedures for Foveaux Strait oyster surveys (summarized in the estimates of spawner densities section in the Appendix, also see Michael et al. 2015). Mean spawner densities were estimated indirectly in subsequent years (2008-2011) using data from fishery-independent surveys conducted at nearby sites so as not to disturb these sites once spat collectors were deployed. These are summarized in the estimates of spawner densities section in the Appendix. Mean distances $(\mathrm{km})$ between dredge sample sites and collector sites ranged from 2.4 to $4.4 \mathrm{~km}$ (Table A2, estimates of spawner densities section in the Appendix) and are well within the potential transport of larvae in a six hour tidal cycle in normal flow (13 km, Steve Chiswell, NIWA, personal communication).

Three replicate spat collectors were deployed at each of the 6 sites (see Figure 2-1) in randomly selected locations that remained fixed during the study. Oyster recruitment was sampled between November 2007 and February 2011. Sampling was only in Season B of each year because almost all settlement occurred over this period; collectors were deployed in November and recovered in February. Foveaux Strait was closed to all oyster fishing 1 September to 28 or 29 February (Ministry for Primary Industries 2017) during the period the collectors were deployed. Between the 2007 and 2011 oyster seasons, there was no fishing within at least 1 nautical mile of 4 of the 6 sites (West-low, South- 
high, East-high, and East-low). A small amount of fishing occurred near Westhigh and South-low (between 0 and $3 \%$ of the total annual catch in any one year), and some disturbance of these collector sites may have occurred.

Interannual variation in recruitment, its coherence across the fishery, and its relationship to putative spawner density was modelled using a GLM with a negative binomial distribution and a log link function. Specifically, oyster recruitment was modelled as a function of Year, Spawner density, Area, and Category and the interactions between these factors. The effect of Spawner density was modelled as a third-order polynomial to increase the model's flexibility to better fit the data (Ver Hoef \& Boveng 2007). Model fits and compliance with statistical assumptions were evaluated graphically (after Zuur et al. 2010). The best-fit model was selected by removing non-significant factors or interactions based on Akaike's Information Criterion (AIC) (Akaike 1973).

\section{Results}

\section{Seasonal and interannual variation in recruitment}

On average in a given year, $97.8 \pm 0.9 \%$ (mean $\pm \mathrm{SE}$ ) of all recruits settled in Season B (Figure 2-4). Low levels of recruitment were observed in Season C $(2.2 \pm 0.9 \%)$ with almost none in Season A (Figure 2-4). Oyster recruitment varied significantly among Season and Year $(\mathrm{p}<0.001$, Table 2-1). Recruitment was consistently greatest in Season B, and drove among-year variation in oyster recruitment (Table 2-2, Figure 2-4). Recruitment was relatively high in 2006-07 and 2007-08 (Figure 2-4), on average 10-15\% higher than in 2005-06 (Table 2-1). Recruitment was significantly lower in 2009-10 and 2010-11 relative to 2005-06 ( $\mathrm{p}<0.001$, Table 2-1). In 2010-11, mean recruitment declined to $4 \%$ of the level in 2005-06 (Table 2-1). 
There was no significant difference between the zero-inflated negative binomial and negative binomial models (AIC-corrected Vuong $z$-statistic $=-$ $0.007, \mathrm{p}=0.497)$. Season explained $76.7 \%$ of the deviance in the best-fit model, with deviance explained to a lesser extent by interannual variation $(10.5 \%)$ and the interaction between Season and Year (3.9\%, Table 2-2). 
Table 2-1. Seasonal and interannual variation in recruitment of oysters between 2005 and 2011 at a single site in Foveaux Strait. Season B: 1 November to 28 or 29 February, Season C: 1 March to 30 June. Oyster recruitment is modelled as a function of Season and Year using zero-inflated negative binomial regression. Shown are the results of a negative binomial model for the count data (model statistics theta $=\mathbf{2 . 0 9 4 3}, \mathrm{df}=\mathbf{1 2}$, and log-likelihood $=\mathbf{4 9 2 . 4}$ ) and the results of a zero-inflated model with logit coefficients for predicting excess zeros. The exponents of coefficients ( $e^{\text {ceefficient })}$ are shown with $95 \%$ confidence intervals (CI).

\begin{tabular}{|c|c|c|c|c|c|}
\hline Source of variation & Coefficient & $\mathrm{SE}$ & $Z$ & $\mathrm{p}$ & $\mathbf{e}^{\text {coefficient }}(\mathrm{CI})$ \\
\hline \multicolumn{6}{|l|}{$\begin{array}{l}\text { Negative binomial } \\
\text { model }\end{array}$} \\
\hline Intercept & 0.758 & 0.450 & 1.684 & 0.092 & $2.135(0.883-5.161)$ \\
\hline $2006-2007$ & 0.142 & 0.246 & 0.576 & 0.565 & $1.152(0.712-1.864)$ \\
\hline 2007-2008 & 0.103 & 0.266 & 0.387 & 0.698 & $1.109(0.658-1.869)$ \\
\hline $2008-2009$ & -0.370 & 0.257 & -1.443 & 0.149 & $0.691(0.418-1.142)$ \\
\hline $2009-2010$ & -1.643 & 0.281 & -5.856 & $<0.001$ & $0.193(0.112-0.335)$ \\
\hline 2010-2011 & -3.252 & 0.321 & -10.139 & $<0.001$ & $0.039(0.021-0.073)$ \\
\hline Season B & 6.096 & 0.413 & 14.764 & $<0.001$ & $\begin{array}{r}444.081(197.697 \\
997.529)\end{array}$ \\
\hline Season C & 2.211 & 0.431 & 5.134 & $<0.001$ & $9.125(3.923-21.224)$ \\
\hline $\log ($ theta $)$ & 0.739 & 0.164 & 4.506 & $<0.001$ & \\
\hline \multicolumn{6}{|l|}{ Zero-inflated model } \\
\hline Intercept & 0.783 & 0.587 & 1.333 & 0.183 & $2.187(0.692-6.912)$ \\
\hline Season B & -21.271 & 4145.540 & -0.005 & 0.996 & 0 (0- Infinity) \\
\hline Season C & -2.976 & 0.805 & -3.696 & $<0.001$ & $0.051(0.011-0.247)$ \\
\hline
\end{tabular}


Table 2-2. Seasonal and interannual variation in recruitment of oysters at a single site in Foveaux Strait, between 2005 and 2011. Recruitment is modelled by factors Season, Year, and the interaction between Season and Year, using a negative binomial regression with a log link function. \% Dev: cumulative percentage deviance explained, AIC: Akaike's Information Criterion.

\begin{tabular}{lrrrrrrr}
\hline & df & Deviance & Residual df & Residual deviance & p & \%Dev & AIC \\
\hline & & & 126 & 1388.58 & & & \\
Season & 2 & 1108.39 & 124 & 280.18 & $<0.001$ & 0.767 & 1082.3 \\
Year & 5 & 114.37 & 119 & 165.82 & $<0.001$ & 0.872 & 1027.5 \\
Season $\times$ Year & 8 & 42.24 & 111 & 123.58 & $<0.001$ & 0.911 & 1004.7 \\
\hline
\end{tabular}




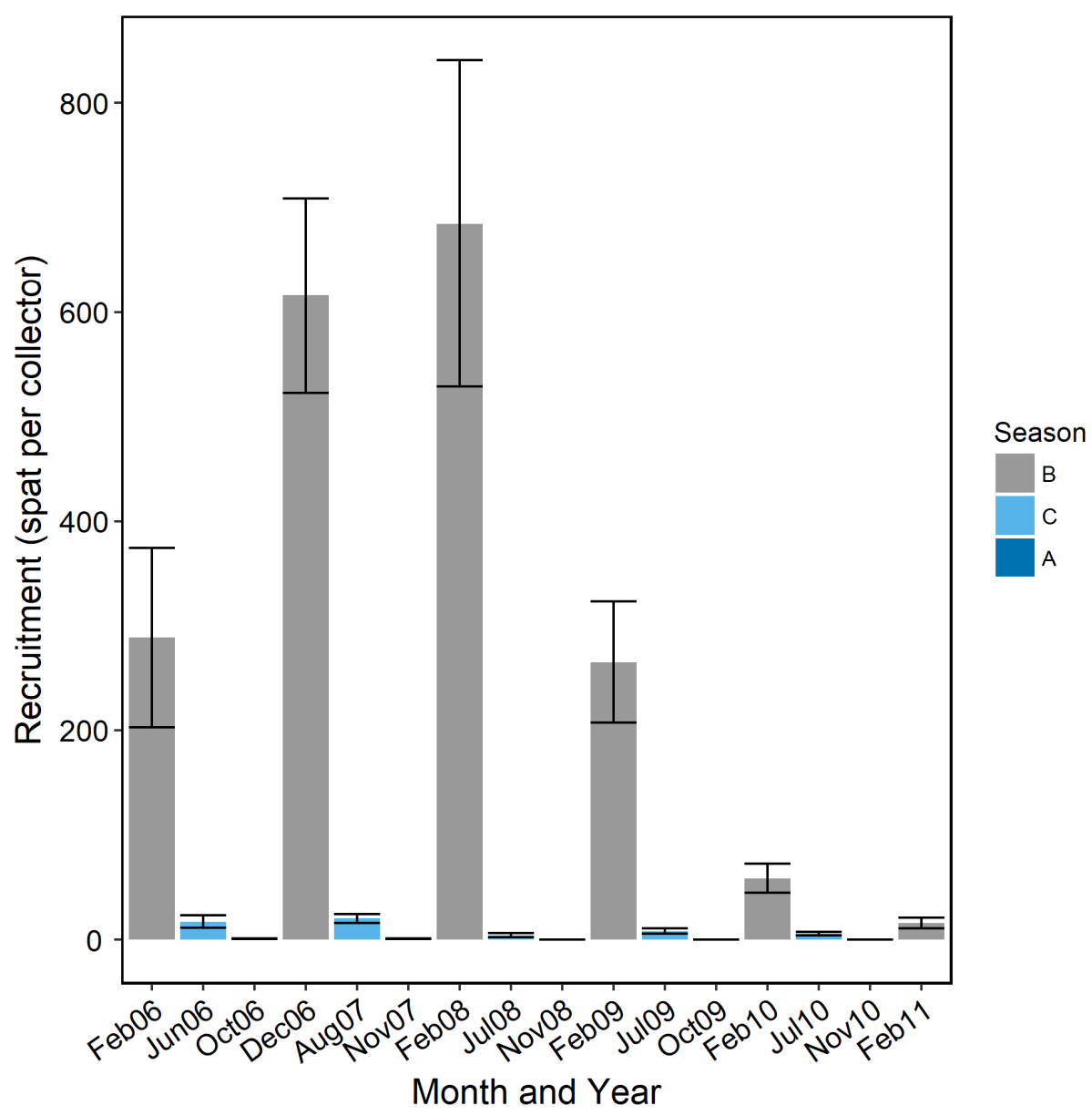

Figure 2-4. Oyster recruitment (mean $\pm \mathrm{SE}$ ) by Season (labelled $\mathrm{A}, \mathrm{B}$, and $\mathrm{C}$ ) from December 2005 to February 2011 at a single site (light blue shading, Fig. 1). Season A: 1 July to 31 October, Season B: 1 November to 28 or 29 February, Season C: 1 March to 30 June. Recruitment was estimated as the counts of living and dead oysters per collector (sample) settling over $122 \mathrm{~d}$. The $\mathrm{x}$-axis gives month and year of retrieval.

\section{Spatio-temporal variation in recruitment as a function of spawner density}

Spawner densities remained the same or increased over the study period. Spawner densities sampled directly from focal sites before deployment of the spat collectors were $0.1-1.8$ oysters $\mathrm{m}^{-2}$ (Figure A1, estimates of spawner densities section in the Appendix). For other times, spawner densities were 
estimated indirectly and were $0.3-4.6$ oysters $\mathrm{m}^{-2}$ (Figure A2 \& A3, Table A2, estimates of spawner densities section in the Appendix).

For the commercial fishery area, recruitment during Season B varied between years $(\mathrm{p}<0.001, \mathrm{df}=3$, deviance $=811.96)$, spawner density estimates $(\mathrm{p}<0.001, \mathrm{df}=2$, deviance $=189.76)$, and area $(\mathrm{p}<0.001, \mathrm{df}=2$, deviance $=$ 140.90) (Figure 2-5). There were also significant 2-way interactions between Spawner density and Area $(\mathrm{p}<0.001$, df $=6$, deviance $=114.04)$, and Spawner density and Year $(\mathrm{p}<0.001, \mathrm{df}=9$, deviance $=88.56)$. These interactions imply that recruitment patterns between years differed subtly by area and spawner densities (see Tables 2-3 \& 2-4 for the best-fit model). The factor Year explained $50.8 \%$ of the deviance, Spawner density $13.8 \%$, Area $11.6 \%$, and the 2-way interactions of Spawner density and Area and Spawner density and Year $9.9 \%$ and $8.0 \%$, respectively.

The stock-recruitment relationship for oysters in the fishery (Figure 26) varied significantly between years. Factor Area was dropped, forcing the model to use Spawner density and Year as predictors of recruitment variation. Spawner density remained significant $(\mathrm{p}<0.001, \mathrm{df}=3$, deviance $=39.778)$ when among-year variation in recruitment was taken into account $(\mathrm{p}<0.001$, df $=3$, deviance $=155.767)$. The interaction term (Year and Spawner density) also remained significant $(\mathrm{p}<0.001, \mathrm{df}=9$, deviance $=26.288)$, and accounted for a larger percentage of explained deviance (from $8.0 \%$ by the best-fit model with factor Area included, to 9.5\% without). Recruitment was greatest overall and highest with higher spawner densities in 2007-08. In all successive years, overall recruitment and the slope of the relationship between recruitment and Spawner density decreased despite fishery-wide increases in spawner densities (Figure 2$6)$. 
Table 2-3. Spatio-temporal variation in oyster recruitment across the Foveaux Strait fishery between 2007 and 2011. Oyster recruitment is modelled as a function of Year, Spawner density, and Area, and their interactions, using data from Season B (settlement season) only. The best-fit negative binomial regression is shown. \% Dev: cumulative percentage deviance explained, AIC: Akaike's information criterion.

\begin{tabular}{lrrrrrrr}
\hline & df & Deviance & Residual df & Residual deviance & p & \%Dev & AIC \\
\hline Year & & & 66 & 1429.23 & & & \\
Spawner density & 3 & 811.96 & 63 & 617.27 & $<0.001$ & 0.508 & 847.07 \\
Area & 3 & 189.76 & 60 & 427.51 & $<0.001$ & 0.646 & 828.57 \\
Spawner density $\times$ Area & 6 & 140.90 & 58 & 286.61 & $<0.001$ & 0.762 & 804.33 \\
Spawner density $\times$ Year & 9 & 114.04 & 52 & 172.57 & $<0.001$ & 0.861 & 780.00 \\
\hline
\end{tabular}


Table 2-4. Spatio-temporal variation in oyster recruitment across the Foveaux Strait fishery, 2007-08 to 2010-11. Oyster recruitment is modelled as a function of Year, Spawner density, and Area, and their interactions, using data from Season B (settlement period) only. Paired comparisons for the best-fit negative binomial model (model statistics theta $=10.3658, \mathrm{df}=43$, and log-likelihood $=-693.92$ ) are shown. Spawner densities (1)-(3) denote first- to third-order polynomials, respectively.

\begin{tabular}{|c|c|c|c|c|}
\hline Source of variation & Coefficient & SE & $\mathbf{Z}$ & $\mathbf{p}$ \\
\hline Intercept & -132.635 & 23.586 & -5.624 & $<0.001$ \\
\hline Year 2008-2009 & 152.523 & 28.681 & 5.318 & $<0.001$ \\
\hline Year 2009-2010 & 146.811 & 27.943 & 5.254 & $<0.001$ \\
\hline Year 2010-2011 & 144.964 & 27.707 & 5.232 & $<0.001$ \\
\hline Spawner density (1) & -2027.245 & 348.405 & -5.819 & $<0.001$ \\
\hline Spawner density (2) & -946.14 & 161.371 & -5.863 & $<0.001$ \\
\hline Spawner density (3) & -193.297 & 35.046 & -5.516 & $<0.001$ \\
\hline Area (South) & -8.474 & 15.205 & -0.557 & 0.577 \\
\hline Area (West) & -9.23 & 15.097 & -0.611 & 0.541 \\
\hline \multicolumn{5}{|l|}{ Spawner density $(1) \times$} \\
\hline Area (South) & -179.327 & 230.635 & -0.778 & 0.437 \\
\hline \multicolumn{5}{|l|}{ Spawner density $(2) \times$} \\
\hline Area (South) & -80.289 & 109.138 & -0.736 & 0.462 \\
\hline \multicolumn{5}{|l|}{ Spawner density $(3) \times$} \\
\hline Area (South) & -15.656 & 26.731 & -0.586 & 0.558 \\
\hline \multicolumn{5}{|l|}{ Spawner density $(1) \times$} \\
\hline Area (West) & -163.622 & 226.701 & -0.722 & 0.470 \\
\hline \multicolumn{5}{|l|}{ Spawner density $(2) \times$} \\
\hline Area (West) & -72.673 & 106.96 & -0.679 & 0.497 \\
\hline \multicolumn{5}{|l|}{ Spawner density $(3) \times$} \\
\hline Area (West) & -26.837 & 26.751 & -1.003 & 0.316 \\
\hline \multicolumn{5}{|l|}{ Year2008-2009x } \\
\hline Spawner-density (1) & 2256.905 & 422.251 & 5.345 & $<0.001$ \\
\hline
\end{tabular}


Table 2 4. Continued.

\begin{tabular}{lcrrr}
\hline Source of variation & Coefficient & SE & $\mathbf{Z}$ & p \\
Year2009-2010× & & & & \\
Spawner-density (1) & 2206.942 & 412.938 & 5.344 & $<0.001$ \\
Year2010-2011× & & & & \\
Spawner-density (1) & 2201.309 & 411.929 & 5.344 & $<0.001$ \\
Year2008-2009× & & & & \\
Spawner density (2) & 1048.731 & 197.343 & 5.314 & $<0.001$ \\
Year2009-2010× & & & & \\
Spawner density (2) & 1010.256 & 190.359 & 5.307 & $<0.001$ \\
Year2010-2011× & & & & \\
Spawner density (2) & 1012.736 & 192.724 & 5.255 & $<0.001$ \\
Year2008-2009× & & & & \\
Spawner density (3) & 232.837 & 45.889 & 5.074 & $<0.001$ \\
Year2009-2010× & & & & \\
Spawner-density (3) & 205.719 & 40.991 & 5.019 & $<0.001$ \\
Year2010-2011× & & & & \\
Spawner density (3) & 229.67 & 45.355 & 5.064 & $<0.001$ \\
\hline & & & & \\
\hline
\end{tabular}




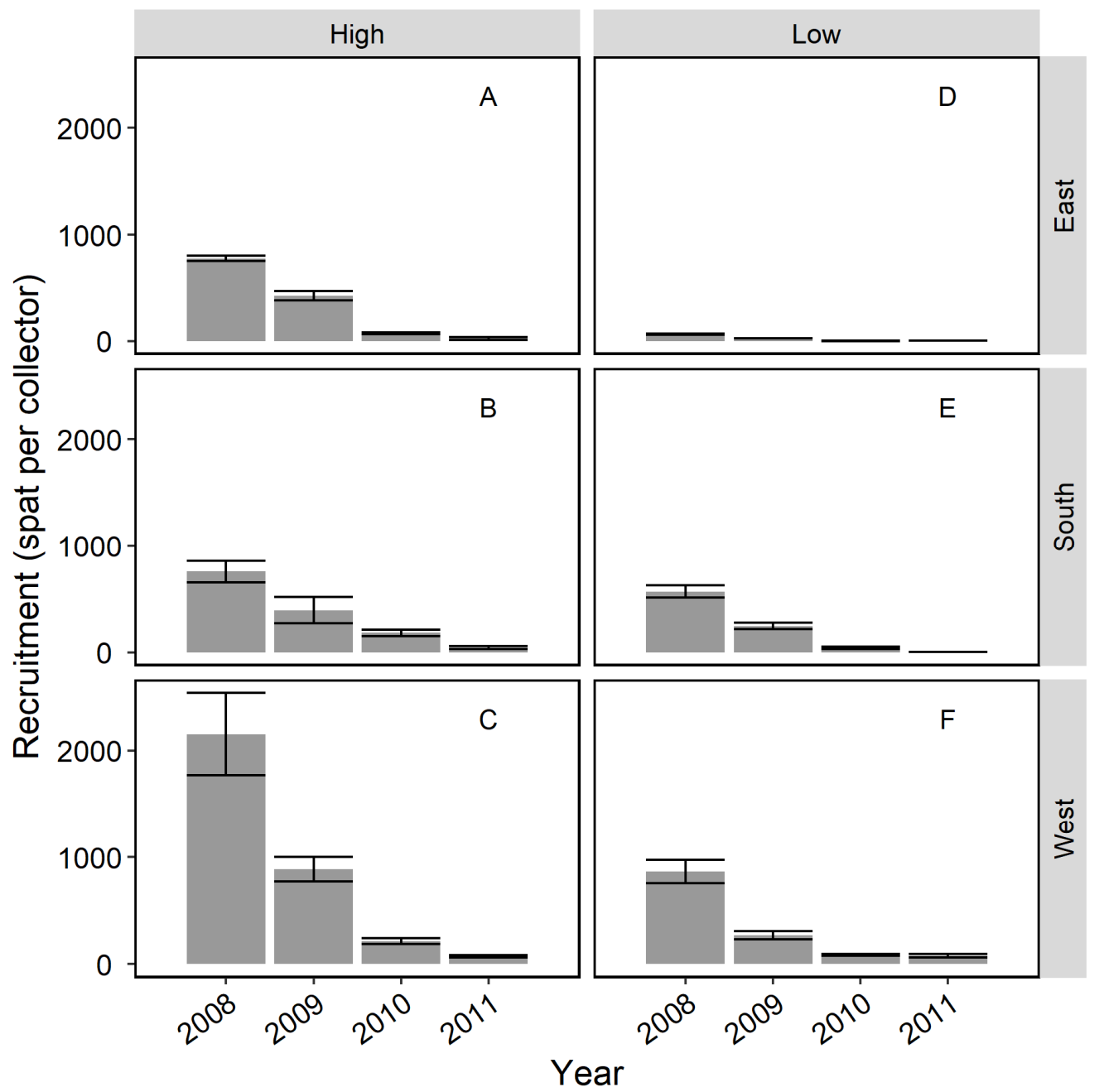

Figure 2-5. Interannual and spatial variation in oyster recruitment (mean $\pm \mathrm{SE}$ ) assessed for the primary season of recruitment (November to February). Means and SE estimated from total counts of living and dead oysters from each collector (sample) which settled over $122 \mathrm{~d}$. Recruitment for sites with (A-C) putative high and (D-F) putative low spawner densities for areas East, South, and West, respectively. 


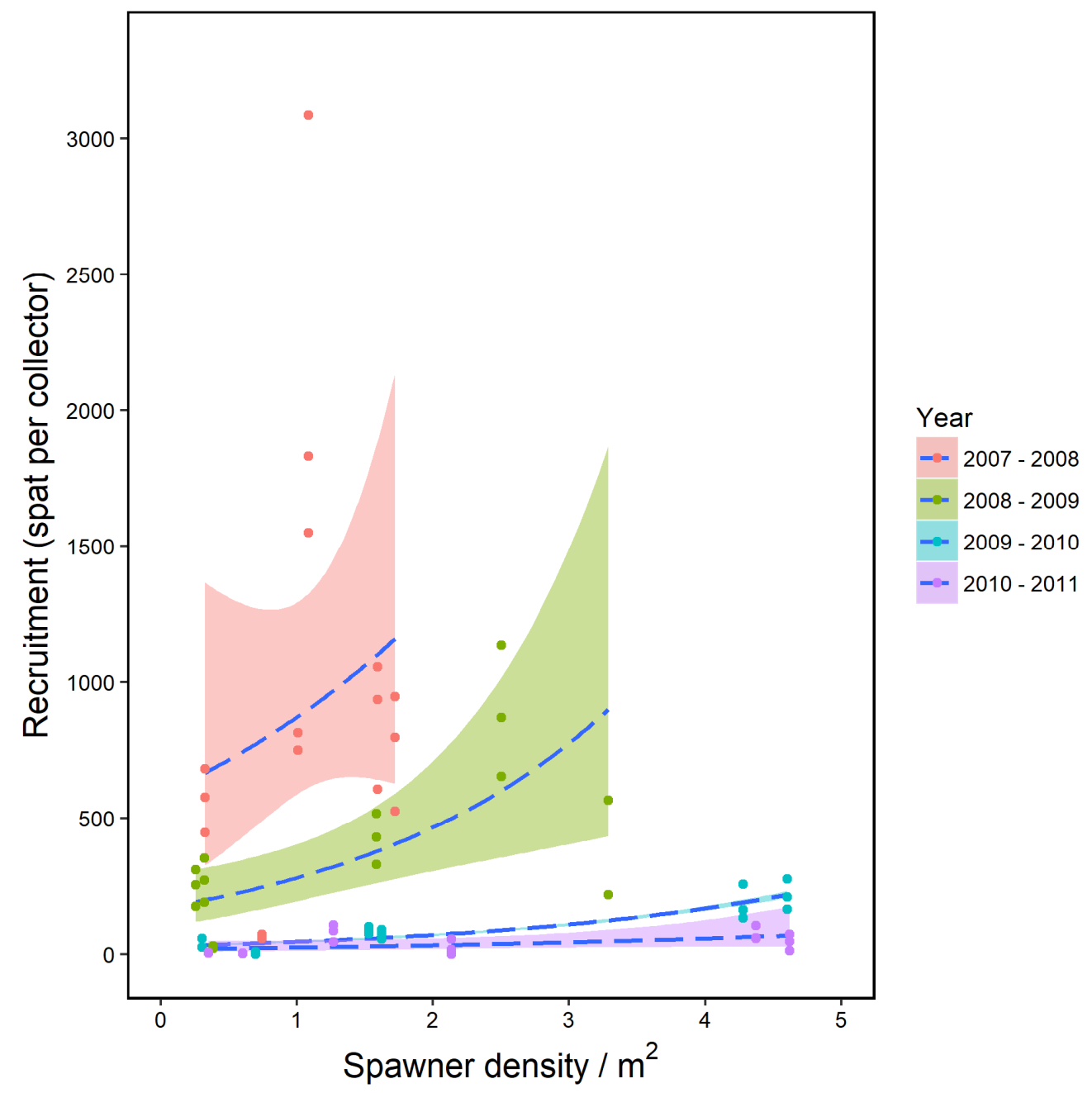

Figure 2-6. Stock-recruitment relationships for oysters sampled at fixed locations across the fishery over successive years (2007-08 to 2010-11). Estimates of oyster recruitment (spat collector-1) are for the primary season (November to February). Each point represents counts from a single collector $(n=3$ collectors deployed at each of 6 sites, each year). A few spat collectors were lost. Spawner densities estimated from dredge samples. Colours correspond to years as given in the key; fitted lines are from a negative binomial regression model, and shaded areas depict \pm SE. 


\section{Discussion}

Ostrea chilensis recruits per spawner declined over the successive 4 years of the fishery-wide study despite spawner densities that remained similar or increased over the same time. The high recruitment observed in 2007-08 and the subsequent decline in recruits per spawner was consistent with recruitment in the 6 year study at a single site (2005-06 to 2010-11, see Figures 2-4 \& 25). The oyster stock-recruitment relationships differed between years (see Figures 2-6), and by the significant interaction between Spawner density and Year in the model. The inference of a diminishing stock-recruitment relationship assumes that settler densities represent recruitment at the sites where larvae were brooded, and that our estimates of spawner densities from dredge sampling represent spawner densities at sites.

Recruitment inferred from counts of recruits on collectors assumes that O. chilensis in Foveaux Strait releases larvae that are competent and settled within minutes to hours after release (Hollis 1962, Stead 1971a, Westerskov 1980, Cranfield \& Michael 1989). This is the case in other fisheries (Chaparro et al. 2006, Broekhuizen et al. 2011). The putative short pelagic larval duration suggests that most dispersal events will occur over short distances (Cranfield 1968a, Broekhuizen et al. 2011). Moreover, O. chilensis readily settles on manmade substrates e.g. cement board (Cranfield 1968b, Brown et al. 2010), and in the absence of conspecifics. These data therefore infer that recruit densities mostly represent self-recruitment to sampling sites. During high settlement years, recruitment at sites was consistent with spawner densities (see Figure 2-5), and therefore with brooding and the release of competent larvae ready to settle. These assumptions underpin the hypothesis of a stock-recruit relationship.

Sampling in Season B represents annual recruitment. The timing of peak settlement relative to the time over which sampling occurs can affect estimates 
of recruit densities. O. chilensis broods throughout the year (Jeffs \& Hickman 2000). The levels of factors that determine peak brooding and subsequent settlement such as temperature and primary productivity are unknown. Before the Bonamia exitiosa epizootic in 1985 (Doonan et al. 1994, Cranfield et al. 2005), the highest numbers of brooders were recorded in November and December (Stead 1971a, Jeffs \& Hickman 2000) with $80-90 \%$ of settlement occurring from mid-December to mid-February (Cranfield 1979). As the timing of peak settlement may have changed, recruitment in all 3 seasons (A, B, C) was sampled in the separate 6 year study to ensure that sampling of the spatiotemporal variation in recruitment in Season B (November to February) gave reliable estimates of annual recruit densities. The seasonality of $O$. chilensis recruitment in Foveaux Strait was consistent with previous studies. In this study, $97.8 \%$ of settlement occurred in November to February (Season B), consistent with percentages of spat settling over that period during the 1960s and 1970s (Cranfield 1979).

An important assumption of this research is that recruit densities represent the densities of competent larvae ready to settle at the sampling sites, and therefore represent putative recruitment. Post-settlement mortality can affect estimates of recruit densities, especially over the four months that the spat collectors were deployed (after Knights \& Walters 2010). In Crassostrea virginica, both density-dependent and density-independent mortality determined the numbers of recruits surviving post-settlement (Knights \& Walters 2010). $C$. virginica population growth was negative after high recruitment events, when density-dependent mortality reduced oyster densities and cohort strengths. This research recorded low post-settlement mortality. Dead $O$. chilensis spat leave a record on the collector plates in the form of an attached left valve of their shells (see the estimates of mortality section in the Appendix). Overall, percent mortality was relatively low (14.6\%) and did not differ greatly between high settlement years 2007-2008 and 2008-2009 (15.1 and 13.7\%, respectively) and 
low settlement years 2009-2010 and 2010-2011 (16.6 and 7.6\%, respectively). Higher recruit densities did not incur increased mortality (Figure A-5), and there was no difference in the percentage mortality amongst sites (Figure A-5). Additionally, more than $95 \%$ of spat (live and dead) were less than $5 \mathrm{~mm}$ in length (Figure A-6). This suggests recent settlement and less opportunity for density-dependent mortality. The percentage mortality remained consistent by spat length (Figure A-6). It can be inferred from these data that the estimates of $O$. chilensis recruitment were not affected by density-dependent mortality. In contrast to the findings of Knights \& Walters (2010), O. chilensis recruit densities appeared to be determined mainly by larval supply.

Estimates of $O$. chilensis recruits per spawner from this study are sensitive to the estimates of spawner densities. The effect of spawner density averaged from dredge estimates sampled at larger spatial scales and not precisely at the locations where recruitment was evaluated. The depth, strong currents, and hard substrate limit the sampling methods available to estimate spawner densities effectively across the fishery area (see the estimates of spawner densities section in the Appendix) (Michael et al. 2008c). Stock assessments of the Foveaux Strait oyster fishery are informed by dredge sampling (Fu et al. 2016, Ministry for Primary Industries 2017). However, dredge sampling has limitations in Foveaux Strait and elsewhere. Dredge sampling gave poor estimates of market-sized $C$. virginica densities in Chesapeake Bay (United States of America (US.)). C. virginica densities in the New Jersey waters of Delaware Bay (US.) showed non-random spatial and temporal variability for market-sized oysters because of low and variable dredge efficiency (the scalar used to estimate absolute abundance) (Chai et al. 1992, Powell et al. 2007). Additionally, the patchy distribution of oysters suggests that low dredge sample numbers at each site may underestimate spawner density (Powell et al. 2017). The best available estimates of spawner densities were used and they are likely to represent differences in the spawner densities between sites. Repeat estimates 
of oyster density (Doonan et al. 1992, Michael et al. 2001) and of dredge efficiency (Fu et al. 2016) show good consistency in Foveaux Strait.

Manipulative studies to investigate the effects of spawner density on recruitment have been undertaken for O. chilensis in Tasman Bay, New Zealand (Brown 2011), and elsewhere for M. gigas and Saccostrea glomerata (Wilkie et al. 2013) and the bay scallop Argopecten irradians (Tettelbach \& Wenczel 1993, Peterson et al. 1996). The effects of increased spawner density on recruitment between these studies were mixed. Recruitment varied markedly between two sites with the same brooder densities (Brown 2011), with the complexity in the arrangement of settlement surfaces and oyster species (Wilkie et al. 2013), and recruitment increased markedly in enhanced areas receiving translocated bay scallops (Peterson et al. 1996). Manipulative studies were not considered for this study because of the depth (20-50 m), strong tides, exposure to large oceanic swells in the study area, and because handling of oysters is thought to exacerbate disease mortality from B. exitiosa (Diggles and Hine 2002). Instead, Site was modelled as a proxy for Spawner density that incorporated sites of putative high and low densities of spawners and an Area effect. Year, Site, and their interaction were significant $(\mathrm{p}<0.001$, Table A-3, estimates of spawner densities section in the Appendix). These sensitivity analyses undertaken here showed that the effect size of Year was robust to combinations of other factors representing spawner densities in alternative models. This suggests that factors other than spawner densities drove recruitment in Foveaux Strait in at least some years in the study period.

The significant interactions between Year, Area, and Spawner density suggest different patterns of recruitment through space and time with respect to putative spawner density. Recruitment scaled most strongly with spawner density in 2007-08. In this year, recruitment was relatively high at all sites even though spawner densities were less than 2 oysters $\mathrm{m}^{-2}$. By 2010-11, spawner densities were similar or had increased to over 5 oysters $\mathrm{m}^{-2}$, but average 
recruitment was only $4.6 \%$ of the levels observed in 2007-08. There were also marked spatial differences across the different sites. Recruitment to the Westhigh site was initially high (more than 2000 recruits collector $^{-1}$ ), but declined markedly in successive years (see Figure 2-5). In comparison, the East-low site was chronically low across all years of the study (see Figure 2-5). The East-low site may be an example of a localised population where spawner densities were too low to take advantage of favourable climatic and biological conditions for heightened recruitment and suggests a need to maintain local spawner densities to prevent serial depletion of stocks. Since the 1940s, spawner densities at Eastlow have been low, most likely the result of disease mortality (Cranfield et al. 2005, Dunn 2005), or possibly because of fishing effects (Cranfield et al. 1999). Both hypotheses implicate low spawner densities in low recruitment as many other commercial fishery areas in Foveaux Strait have sustained high effort and high catch and remained productive in spite of the same high $B$. exitiosa mortality (Michael 2007).

Biological reference points such as spawning stock biomass rely on a positive relationship between spawning stock sizes and recruitment (i.e. recruitment varies positively in relation to spawning stock size) and have been used to rebuild stocks towards maximum sustainable yield (see Mace 2012). Biological reference point based fisheries management has maintained or improved stocks in New Zealand (Ministry for Primary Industries 2017) and elsewhere, such as in the U.S.A (Soniat et al. 2014). However, stock-recruitment relationships are difficult to estimate for most species because there are few data for most stocks (Maunder 2012, Maunder \& Piner 2015). Moreover, estimates from models are often uncertain (Lee et al. 2012). The lack of relationship between stock size, spawner density, and recruitment is well known in oysters as many other factors determine recruitment success see Knights \& Walters (2010) and Soniat et al. (2014). The long PLD of $C$. virginica contributes to the high interannual variation in oyster numbers and biomass. C. virginica also 
forms oyster reefs, thereby creating their own habitat important to their recruitment and post-settlement survival. Shell abundance is therefore an important biological reference point, (Powell \& Klinck 2007, Soniat et al. 2012). The lack of a consistent stock-recruitment relationship in oysters and other sessile invertebrate stocks suggests that single biological reference point based management may not be appropriate for many of these stocks (after Powell et al. 2012). The diminishing stock-recruitment relationship in Foveaux Strait oysters has important implications for the management of Foveaux Strait oyster fishery and invertebrate stocks generally. This research is consistent with the findings of Szuwalski et al. (2015) in that it shows that other factors not measured in this study (most likely climatic and biological factors) more strongly influenced recruitment than spawning biomass in some years.

The Foveaux Strait oyster stock assessment model (Dunn 2005) uses a Beverton-Holt stock-recruitment relationship with steepness of 0.9 (i.e. high levels of recruitment are plausible during periods of low spawner density). High levels of recruitment were observed during a period of low spawner abundance and density between 2005-06 and 2007-08. At that time, spawning stock biomass in 2005 was $16 \%$ of $\mathrm{B}_{0}$ (the biomass before fishing began) (Fu et al. 2009). High recruitment was consistent with the stock-recruitment assumptions of Dunn (2005) based on survey data from 1992 to 2001. However, recruits per spawner decreased in times of relatively high spawner densities (2008-09 to 2010-11, see Figure 2-6). Spawning stock biomass in 2012 had increased to $34.5 \%$ of $\mathrm{B}_{0}(\mathrm{Fu} 2013)$. Our data did not show a stock-recruitment relationship consistent with the Beverton-Holt function used in the OYU 5 stock assessment model of Dunn (2005). While projections of future stock size were corroborated by subsequent surveys (the assessment model has performed well Fu 2013), our data suggest that factors other than spawner density strongly influence recruitment. Fishery indices of recruitment, catch sampling (Marsh et al. 2016) and population surveys (Michael et al. 2017b) show the low recruitment 
observed during this research continued through to 2016-2017. Collectively, these indicate a regime shift in recruitment. This regime shift suggest that the Beverton-Holt function may not predict recruitment well, and that estimates of future stock size may therefore be more uncertain for long-term projections. Maintaining spawning stock size at or above reference points alone may not ensure recruitment and rebuilding of the fishery.

Many invertebrate fisheries including $O$. chilensis in Foveaux Strait are managed by 'unit stocks' over large areas. A mismatch of the spatial scales of recruitment and fisheries management in other systems has led to overfishing, recruitment failure, serial depletion, and the eventual collapse of many invertebrate fisheries (Hilborn et al. 2005). Moreover, a persistent reduction in recruits per spawner may have flow-on effects on spawning success: consecutive years of low recruitment could reduce the density of $O$. chilensis spawning as males, potentially limiting sperm availability and fertilisation success. There is evidence of this phenomenon in both e.g. urchins (Levitan et al. 1992) and lobsters (MacDiarmid \& Butler 1999).

The diminishing stock-recruitment relationship in Foveaux Strait oysters may be due to non-mutually exclusive climatic and biological factors that can reduce cohort strength of competent larval and reduce recruitment to localised populations. Climate variability affects recruitment in fisheries (Hjort 1914), in oysters (Kimmel \& Newell 2007, Kimmel et al. 2014), and in other species (Anderson et al. 2011b, Miller et al. 2016). Models of population dynamics (Hilborn \& Walters 1992) and other models of varying complexity used in management approaches such as ecosystem-based fisheries management (EBFM), (Fulton 2010); Management Strategy Evaluation, (Fulton et al. 2014, Punt et al. 2014); and extended frameworks for fisheries assessments, (Hollowed et al. 2009) should ideally incorporate climate variability. However, these approaches are rarely implemented (Punt et al. 2014, Skern-Mauritzen et al. 2016) as discussed by Skern-Mauritzen et al. (2016, p 165): "Fisheries 
management is still predominantly single-species-oriented taking little account of ecosystem processes, implicitly ignoring that fish stock production depends on the physical and biological conditions of the ecosystem". The focus on EBFM across a range of fisheries will hasten the need to understand the effects of climate and to predict the long-term effects on recruitment (Collie et al. 2016).

Heightened recruitment can occur in oysters (Dunn 2005) as well as in other species such as scallops (Bethoney et al. 2016). In this study, prolonged (9-year) recruitment failure in oysters occurred over a time when spawner densities $\left(0.3 \mathrm{~m}^{-2}\right)$ had been previously sufficient to support high recruitment (Dunn 2005). Low recruitment continued after this study when mean spawner densities of $0.4-0.9 \mathrm{~m}^{-2}$ were above those reported by Dunn (2005). Climatic and biological factors with complex interactions may drive fishery-wide recruitment variability and may determine the persistence of their effects. However, careful consideration is required in the choice of climate data sets for analysis (Menge et al. 2011), and in the interpretation of correlations between climate and recruitment (e.g. Pacific sardine) (McClatchie et al. 2010, Lindegren et al. 2013). Long time series of recruitment data at appropriate spatial scales alongside biological and climatic data are required to explain the changes in stock-recruitment relationships observed during this study, and for the management of other marine populations and fisheries. An understanding of these effects will better inform stock assessment models to predict changes in populations, and to underpin EBFM (Hilborn \& Walters 1992, Fulton 2010, Punt et al. 2014, Collie et al. 2016, Koenigstein et al. 2016). The climatic and biological factors contributing to reduced recruits per spawner in Foveaux Strait oysters are the focus of Chapter 3. 
Chapter 3 : Evaluation of the effects of climatic and disease on Ostrea chilensis recruitment

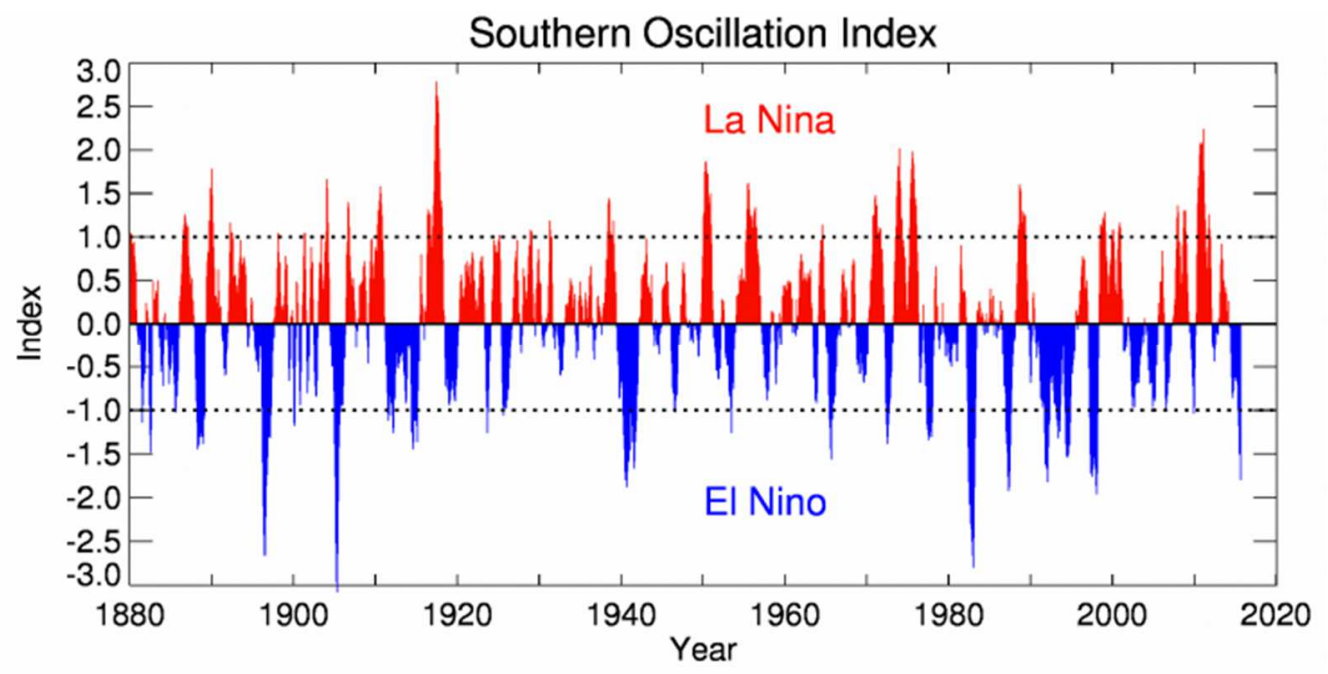

Image by NIWA 


\begin{abstract}
Recruitment to the Foveaux Strait Ostrea chilensis population declined abruptly to low levels in 2010 and remained low until 2017, in spite of a spawning-stock size over this period that had previously supported high recruitment. This research investigates the potential contributions of other factors: climate, food supply and availability, and pathogens to low recruitment.

Variable importance measures from classification tree ensembles were initially used to rank the contributions of these other factors to recruitment variation. Recruit densities were modelled as functions of oyster densities, oyster mortality, and climate variables with negative binomial regression to determine significant factors and their interactions. Oyster density and mortality, and their two-way interaction explained $68 \%$ of the deviance in the best-fit model. The highest recruitment occurred at times of low mortality indicative of low disease infection during gametogenesis and spawning and low oyster density, suggesting minimal effects of pathogens on the numbers of oysters brooding and reduced disease transmission. The contributions of climate factors were minor $(\sim 1 \%$ deviance). This research, together with fishery data and the pathology of concurrent infections in $O$. chilensis, suggests that a 3-way interaction between density, disease, and climate may drive variation in recruitment. Pathobiomes may be important determinants of shellfish recruitment and population dynamics, with important implications for stock assessment and enhancement.
\end{abstract}




\section{Introduction}

A period of historically low recruitment to the Ostrea chilensis population in Foveaux Strait between 2010 and 2017, and significant mortality from Bonamia exitiosa between 2013 and 2017, severely slowed rebuilding of the fishery between 2010 and 2013, and caused a significant decline in stock size thereafter (Ministry for Primary Industries 2017, Michael et al. 2018). B. exitiosa is an obligate parasite of oysters that can cause high mortality, primarily in the genus Ostrea (Carnegie 2017). Between 2012 and 2015, B. exitiosa reduced the recruit-sized (58 $\mathrm{mm}$ in length or larger) oyster population and brooding-sized oyster densities in Foveaux Strait to about 50\% of 2012 levels (Ministry for Primary Industries 2017). In 2015, the population size was still above levels that had previously supported high recruitment (Fu et al. 2016). Chapter 2 suggests that factors other than densities of brooding-sized oysters (hereafter referred to as brooders) operating at a fishery-wide scale more strongly influenced recruitment in some years. This chapter investigates the potential contributions of other factors: climate, food supply and availability, and pathogens to low recruitment.

Recruits are defined as competent larvae that settle from the plankton and complete metamorphosis on substrata; consistent with the ecological definition of Stanwell-Smith \& Barnes (1997). In this chapter, recruitment to the population is the number of recruits settled before post-settlement mortality occurs. Recruitment is assumed to reflect the numbers of competent larvae available for settlement and therefor settle on passive artificial collectors at sampling locations. Settlement to the seabed will be primarily dependent on the availability of clean hard substratum such as shells (Smyth et al. 2018). The magnitude of $O$. chilensis settlement and survival of juveniles (to a putative density dependent threshold Beverton \& Holt 1957, Ricker 1975) determines fishery-recruitment defined as the addition of harvestable individuals as per Hilborn \& Walters (1992), and therefore stock size and potential future harvests. 
The variation of recruitment over space and time may be explained by a series of successive recruitment processes (e.g. larval supply, dispersal, settlement and post-settlement mortality), and their flow-on effects on subsequent processes. Successful spawning and larval supply is a key prerequisite for successful recruitment. Abrupt medium to long-term shifts in recruitment are likely to reflect system changes, often driven by changes in climate (Holbrook et al. 1997, Peterson \& Schwing 2003, Perälä \& Kuparinen 2015). Knowledge of the factors driving variation in recruitment is fundamental to the management, conservation and enhancement of sessile benthic invertebrates including oysters (King et al. 2015, Levin \& Möllmann 2015, Szuwalski et al. 2015). An understanding of how biological (physical condition, physiological stress, and disease) and climatic (sea surface temperature, upwelling, and storm frequencies) factors interact is therefore essential.

Sufficient spawning stock and sufficiently high spawner densities are essential to ensure larval production in $O$. chilensis, and changes in spawner densities may drive variation in recruitment. A range of other factors and their interactions are also likely to affect recruitment. This study investigates climatic factors and the putative effects of disease. Climate is known to drive annual variation in recruitment in a number of marine species (Hjort 1914, Lehodey et al. 2006, Hollowed et al. 2011), with evidence of this in the Ostrediae family e.g. Crassostrea virginica (Kimmel \& Newell 2007, Kimmel et al. 2014).

Temperature and food rations have marked effects on gametogenesis (Westerskov 1980, Buroker et al. 1983, Joyce et al. 2015) and may play important roles in conditioning, initiating gametogenesis, and synchronising gonadal development (Joyce et al. 2015). At high temperatures $\left(\geq 20^{\circ} \mathrm{C}\right)$, the gonad cycle may advance rapidly and asynchronously to phagocytosis, thereby reduce fertilisation and brooding (Jeffs \& Hickman 2000). Temperature also affects brooding period (Chaparro 1990, Toro \& Morande 1998) and the stage of development when larvae are released (Joyce et al. 2015). Large larvae have 
greater settlement success (Cranfield \& Michael 1989, Chaparro 1990, Utting \& Millican 1997). As in other shellfish, fluctuations in food supply also play an important role in O. chilensis recruitment (Bradford et al. 1991, MacKenzie \& Rhodes 1997, MacKenzie \& Adamson 2004, Zeldis 2008, Rifi et al. 2011, Zeldis et al. 2011, Le Moullac et al. 2013). Studies conducted on O. chilensis in Chile suggest that an abundance of microalgae can increase gonad condition, enhance spawning success (Chaparro 1990), increase maternal provisioning (Wilson et al. 1996, Chaparro et al. 2006), and produce larger larvae (Chaparro 1990, Utting \& Millican 1997). Large larvae have increased rates of settlement and postsettlement survival in O. edulis (Robert et al. 2017). Foveaux Strait is a highly productive area (Bradford et al. 1991) and the strong tides there ensure the water mass (and therefore plankton) is well mixed both vertically and horizontally (Butler et al. 1992). Because of this homogeneous water mass, sea surface temperatures (SST) and primary productivity measured as Chlorophyll a (Chl) from remote sensing are used. These data are corroborated with in situ data from a conductivity, temperature, and depth (CTD) instrument incorporating a fluorometer. Climate indices can also describe broad scale trends in temperature, productivity and the sea conditions that drive then, including: the southern oscillation index (SOI), and sea level pressure indices (Z2 and M1, see methods for definition).

Reproductive processes may be further affected by storm surges that mobilise sediments (Carter \& Lewis 1995, Stanton et al. 2001, Walters et al. 2001, Hemer 2006) that bury oysters in coarse calcareous sand and gravel (Stead 1971b), and thereby reduce their ability to feed and cause physiological stress. These climatic factors and physiological stresses intensify disease (Diggles \& Hine 2002) as well as affecting recruitment. Storm surges are wind driven and the numbers of days of gales and severe gales extracted from weather station data. Suspended sediments increase turbidity, which is measured by remote sensing. 
Bonamia exitiosa is the primary cause of disease mortality in Ostrea chilensis in Foveaux Strait (Doonan et al. 1994, Cranfield et al. 2005); however, co-infections with other pathogens can intensify low intensity $B$. exitiosa infections to fatal levels. Oyster mortality from B. exitiosa (and most likely other co-infections) occurs after peak spawning and is used as a proxy for intense pathogenic infections during the reproductive period (gametogenesis and spawning). Climate factors such as high temperatures and low salinity, and low food supply or reduced access to food are known to increase disease susceptibility and intensify infections, as well as drive recruitment variability (Hine et al. 2002, Arzul et al. 2009, Engelsma et al. 2010, Rowley et al. 2014). Because all these factors determine energy budgets and physiological stress, 3way interactions between recruitment, climate and disease can be expected for this reason.

Pathogens disrupt reproduction and cause parasitic castration in many marine taxa (Sullivan et al. 1985, Oliva et al. 1999, da Silva et al. 2002, Hine \& Thorne 2002, Ngo et al. 2003, Valderrama et al. 2004, Moravec \& de Buron 2013). At high prevalence, these pathogens can affect population-scale recruitment. Several pathogens have been found in wild and farmed Ostrea chilensis populations throughout New Zealand (Dinamani et al. 1987, Hine 1997, Joyce et al. 2015). In Foveaux Strait, these pathogens include Bonamia exitiosa, Bucephalus longicornutus (Hine \& Jones 1994), and Apicomplexan spp. (APX) (Hine 2002, Lane et al. 2016, Suong et al. 2017). The effects of individual pathogens may be host specific, although concurrent infections of two or more pathogens can exacerbate the intensity of infections and mortality (Diggles 2004). For example, APX may increase the susceptibility of $O$. chilensis to B. exitiosa mortality (Hine 2002), and APX alone severely affects gametogenesis (Diggles \& Hine 2002). B. longicornutus can disrupt reproduction and cause parasitic castration, and has been responsible for high mortalities of O. chilensis in Foveaux Strait (Howell 1967). da Silva et al. (2009) 
found high to moderate intensities of $B$. ostreae infections in ripe, female $O$. edulis, as well as in partially spawned and reabsorbing females. This suggests the intensification of infection by $B$. ostreae associated with female maturation before spawning. Because B. ostreae and B. exitiosa are closely related pathogen of the genus Ostrea, bonamiosis in $O$. chilensis probably has a similar effect. Other infestations may also play critical roles in physiological stress, reduce the energy available to recruitment processes, and increase susceptibility to disease. Crassostrea virginica colonised by Cliona celata (a boring sponge, Grant, 1826) diverted significant energy from shell and somatic growth (and presumably reproductive processes) to shell maintenance and repair (Carroll et al. 2015). Cliona celata is common in the shells of $O$. chilensis in Foveaux Strait and may play a role in reducing larval supply and thereby recruitment.

This study investigates whether climate factors and disease, and any interaction between these factors reduces spawning and brooding success in $O$. chilensis and thereby recruitment to Foveaux Strait oyster populations. Because data on the prevalence and intensity of infections is not available for pathogens other than B. exitiosa, oyster mortality from annual surveys is used as a proxy for one or more high intensity infections present during gametogenesis and spawning. B. exitiosa infections intensify late in the gametogenic cycle and during spawning and O. chilensis mortality occurs after spawning (Hine 1991a). Brooder densities and oyster mortality are estimated from annual surveys. Climate data is sourced from remote-sensing satellites, CTD and weather stations. The responses of gonadal development, spawning, and brooding to variations in climate factors are likely to occur over relatively short timeframes (weeks). 


\section{Methods}

The Foveaux Strait oyster fishery (Figure $2-1$ is managed as a single stock OYU 5 (Ministry for Primary Industries 2017) and the fishery comprised a number of putative demographically closed populations (Stead 1971b, Allen \& Cranfield 1979). Fisheries-independent variation in oyster densities is mostly driven by periodic disease mortality (Doonan et al. 1994, Cranfield et al. 2005) caused by Bonamia exitiosa (previously B. exitiosus, Berthe \& Hine 2003), and variability in recruitment to the oyster population (Michael et al. 2015).

O. chilensis grows to recruit-size in four years or more after settlement (Cranfield 1979). More than 60\% of the recruited oyster population produces mature ova (Fu et al. 2016), and oysters $\geq 60 \mathrm{~mm}$ in length brood larvae (Jeffs $\&$ Hickman 2000). These larvae are fully competent and can settle on release.

\section{Interannual variation in recruitment}

Recruitment to the $O$. chilensis population is estimated from recruit densities on passive artificial collectors representing local densities of competent larvae. The collectors are similar to those used since the 1960s (Cranfield 1968b). Each spat collector held four, cement board settlement plates (220 x 140 x $4 \mathrm{~mm}$ ) at heights of 10, 120, 240, and $360 \mathrm{~mm}$ above the seabed. Although biofilms have been shown to be important in the settlement of some oyster species (e.g., C. virginia, Tamburri et al. 1992), Ostrea will settle on any clean hard substrate (Smyth et al. 2018). Because the settlement of O. chilensis larvae had previously been high on unconditioned plates deployed for similar periods in Foveaux Strait (1965-1967, 1999-2000; Cranfield 1968b, Cranfield et al. unpublished data), the settlement plates were not conditioned before deployment. Mooring lines with floats attached to each collector facilitated location and retrieval. 
Between the austral summers of 2005-06 and 2016-17, collectors were deployed in early November and recovered in late February. This period represents the time when $\sim 98 \%$ of settlement had occurred previously (see Chapter 2 and Cranfield 1968b). Each deployment of spat collectors used new cement board plates. Recruitment is defined as the numbers of recruits settled on collectors before post-settlement mortality occurs, and was calculated as the cumulative number of both living and dead recruits on any plate surface (top or bottom) of any of the four plates of a given collector. Deployment times varied by a small amount and estimates of recruitment were standardised to a 122-day sampling period each summer.

Data on recruitment comprises recruit densities from three separate sampling programmes:

1. Between 2005-06 and 2010-11, 36 collectors were deployed in each year to 6 fixed sampling sites, stratified across 3 discrete areas. See Chapter 2 for more details (see Figure 2-1).

2. Between 2011-12 and 2013-14, 45 collectors were deployed in each year to fixed sites according to a gradient design (Figure 3-1). See Chapter 4 for details.

3. Between 2014-15 and 2016-17, 45 collectors were deployed in each year to a stratified random sampling design (Figure 3-2). Passive spat collectors were deployed to the first three randomly allocated sites to be sampled for oyster densities and the status of B. exitiosa in each of the 15 strata (Figure 3-2). See Michael et al. (2018) for more details. 


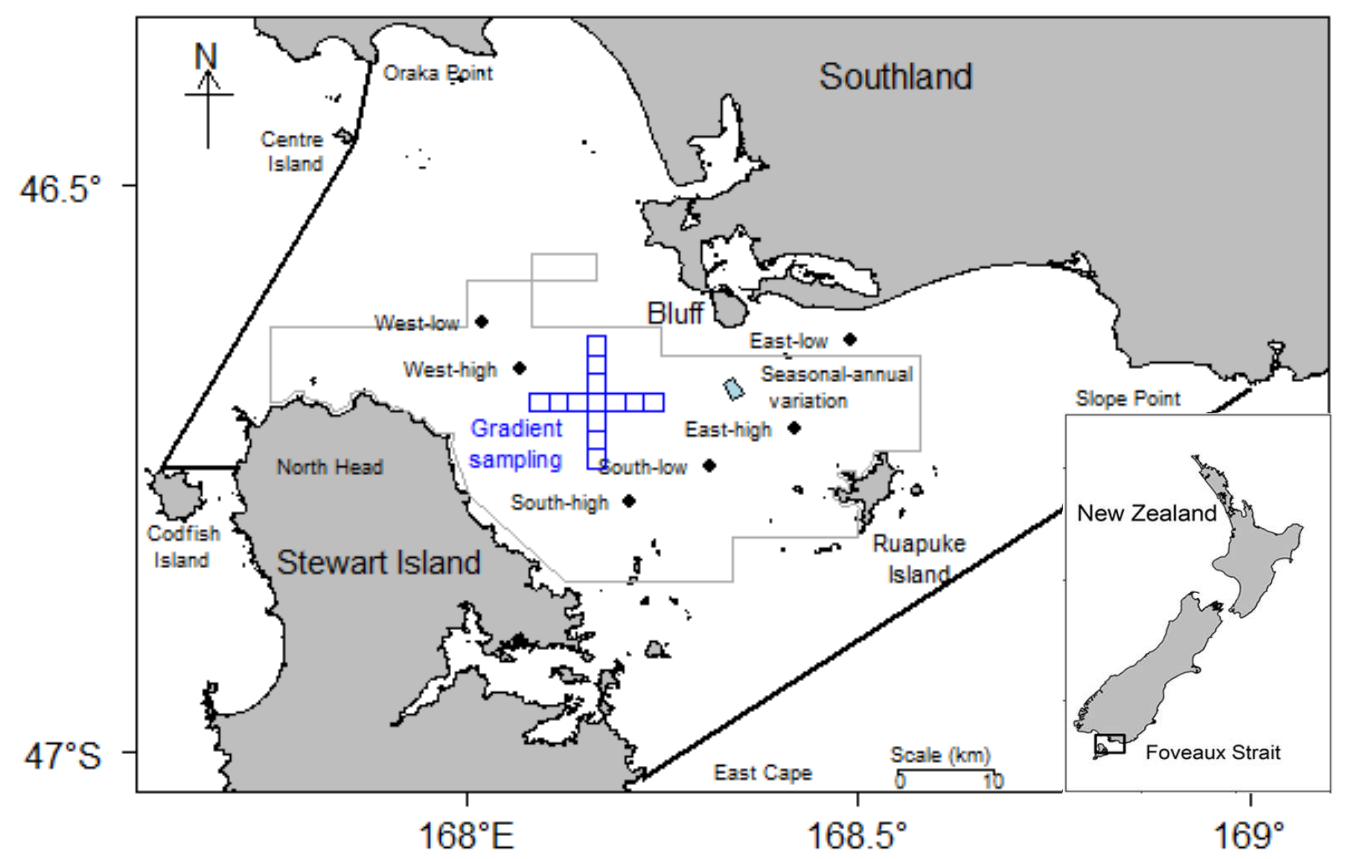

Figure 3-1. Foveaux Strait oyster stock (OYU 5) boundary (heavy black lines) and the outer boundary of the 2007 stock assessment survey area (grey lines) encompassing the commercial fishery. Sampling for seasonal and interannual variation in recruitment at a single site (light blue shading), spatio-temporal variation in recruitment at six sites across the fishery (filled black diamonds $\downarrow$ ), and the gradient sampling grid in blue with blue text. The lower right inset shows the location of Foveaux Strait within New Zealand. 


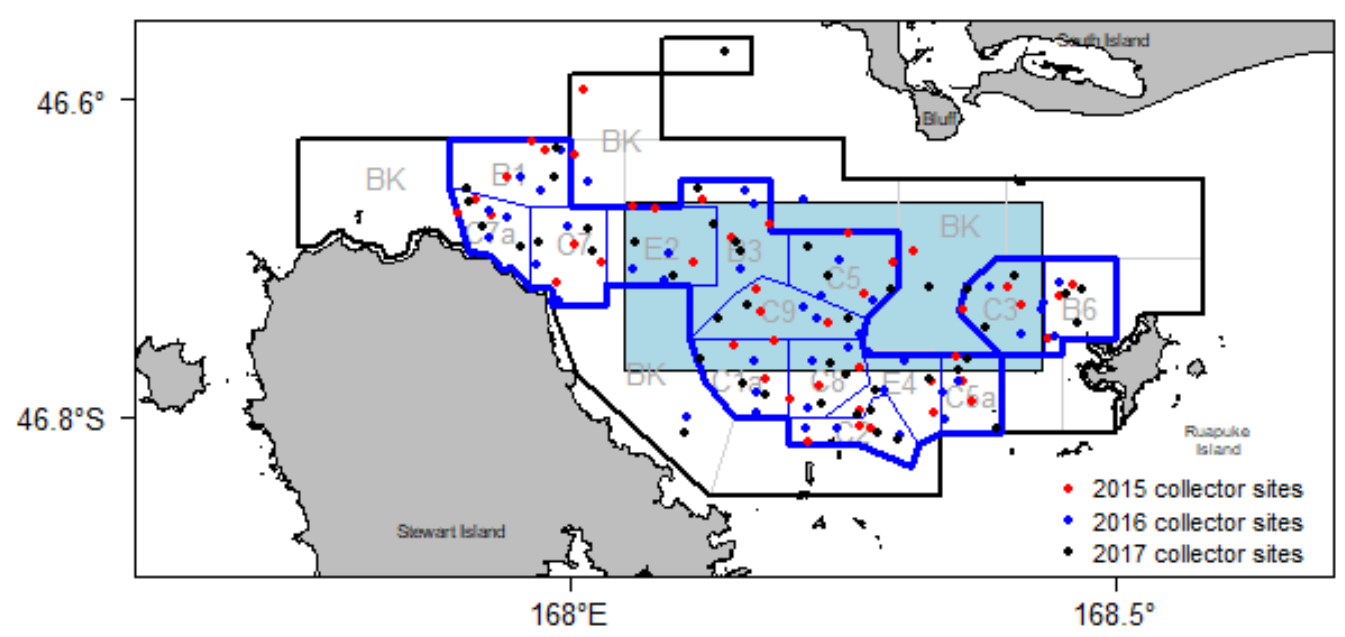

Figure 3-2. The 2007 stock assessment area boundary shown as a heavy, black outer line, and the 26 stock assessment survey strata (light grey and blue lines). The Bonamia exitiosa survey area boundary (shown as a heavy blue line), the 14 core strata (shown as blue lines) and the single background stratum (BK) delimited by the stock assessment survey (black lines) and $B$. exitiosa survey (blue lines) boundaries. Strata are labelled with grey text. The site where spat collectors were deployed in 2015 (red filled circles), 2016 (blue circles), and 2017 (black circles). A polygon defining the area from which remote sensed data were extracted is shown in light blue shading.

Annual recruitment data from collectors are corroborated using commercial catch sampling data. The numbers of $0+$ year oysters (spat from larvae produced during the previous year's spawning and settled the previous summer) attached on the shells of landed commercial-sized oysters was scaled to the size of the commercial catch over the same years (Large et al. 2018). Percentages of recruits each year between 2006 and 17, and percentages of the population size of $0+$ year oysters provide independent indices of recruitment. These are highly correlated (Pearson's correlation of $0.96, p<0.001)$. Estimates of recruitment from concurrent sampling at local scale as part of a seasonal study and from fishery-wide-scale sampling from 2007-08 to 2010-11 (see Chapter 2) provided two further estimates of recruitment. These were also highly correlated (Spearman's rank correlation rho 0.99, $\mathrm{p}<0.001$ ). The three time-series most likely reflect changes in fishery-wide scale recruitment. Because recruit densities 
represent spawning and brooding success in the previous calendar year, spat counts from catch sampling the following winter were assigned to the year gametogenesis began (i.e. commercial catch sampling year-1).

\section{Estimates of brooder densities and annual mortality}

Densities of recruit-sized oysters (58 $\mathrm{mm}$ in length or larger) from dredge samples were scaled for dredge efficiency, and scaled to population size (Michael et al. 2018, summarised in the estimates of spawner densities section in the Appendix). Variation in $O$. chilensis shell morphology and the size structure of oysters across the fishery area suggest that recruit-size is a good proxy for brooders as the difference in oysters brooding between $58 \mathrm{~mm}$ and 60 $\mathrm{mm}$ in length is likely to be negligible. Brooding-sized oyster density (hereafter density) is estimated at the beginning of the female gametogenic cycle.

Survey details and estimates of annual mortality in $O$. chilensis from $B$. exitiosa (hereafter mortality) are given in the estimates of annual mortality section and Table A-4 in the Appendix. Annual mortality estimates are scaled to population level, expressed as a percentage of the brooding population, and comprise the aggregate of two different estimates: pre-survey mortality and projections of post-survey mortality (days to weeks) from the proportion of oysters with fatal infections (see the estimates of mortality section in the Appendix). Because oyster mortality occurs in the calendar year following spawning events, mortality is assigned to the previous year (year-1) to link infection status to the year of gametogenesis.

\section{Climate and weather variables}

Climate variables and indices were divided into two groups to avoid collinearity and to facilitate the analysis of a relatively large number of variables for a relatively short time series of recruitment data. Values for group 1 variables were derived from satellite and weather stations to provide local scale conditions 
that change relatively rapidly. Data from NASA's MODIS Aqua satellite were sourced from the NOAA databases and extracted down to daily intervals from an area delimited by $46^{\circ} 39.900^{\prime}-46^{\circ} 46.200^{\prime} \mathrm{S}$ and $168^{\circ} 03.000^{\prime}-168^{\circ}$ $25.920^{\prime} \mathrm{E}$ (around 1600 pixels) at $1 \mathrm{~km}$ resolution encompassing the Foveaux Strait fishery area (shaded blue in Figure 3-2). These data were filtered to remove images with less than 100 pixels per record (Matt Pinkerton, NIWA, unpublished data). Group 2 climate indices represented regional conditions that persist for longer periods.

\section{Group 1 climate variables}

Level 3 sea surface temperature (SST, ${ }^{\circ} \mathrm{C}$ ) from MODIS Aqua are averaged temporally to daily intervals and spatially to $1 \mathrm{~km}^{2}$ (Reygondeauet al. 2011). These data were range-checked against published data from Bradford et al. (1991) and Butler et al. (1992) and unusually high and low values removed. Trends in daily air temperatures from Tiwai Point, Bluff, and two Invercargill aero stations collated from the National Institute for Water and Atmosphere's (NIWA) CliFlo database (http://cliflo.niwa. co.nz) were also compared. Mean monthly SST data showed good coherence with mean monthly air temperature data at Tiwai Point at the northern entrance to Bluff Harbour $\left(r^{2}=0.78\right.$, Figure A-7 in the climate variables section in the Appendix) and good coherence with in situ CTD data provided by Otago University. CTD casts at eight sites across the fishery area sampled on five occasions three-monthly between September 2017 and June 2018 showed temperature was vertically and horizontally consistent within a well-mixed water mass flowing through Foveaux Strait and consistent throughout the depth profile and across the commercial fishery area (Sam Hensman, Otago University, unpublished data). SST minima ranged from $7.4-9.5^{\circ} \mathrm{C}$ in July 2002 to 2017 were similar to Cranfield (1968a) and Butler et al. (1992). SST maxima in February ranged from $16.1-18.7^{\circ} \mathrm{C}$ in 2002 to 2017. 
Phytoplankton concentrations represented as chlorophyll a ( $\left.\mathrm{Chl} \mathrm{mg} \cdot \mathrm{m}^{-3}\right)$ provide a measure of food availability to oysters. MODIS-Aqua level 3 were data extracted from daily overpass data received by NIWA X-band satellite receiver using the standard blue-green band reflectance ratio algorithm that optimises estimates of chlorophyll. A resolution of $1 \mathrm{~km}$ was used as it is more appropriate for coastal regions (Pinkerton et al. 2015) Two data sets, a blended case of open ocean and coastal chlorophyll and an ocean case chlorophyll only showed good coherence $\left(r^{2}=0.78\right.$, Figure A-8 in the climate variables section in the Appendix). The ocean case was used for analysis for two reasons: the oyster fishery area in the middle of Foveaux Strait is more likely to be under the influence of oceanic water, and satellite products have higher uncertainty near the coast due to the presence of suspended sediment (Pinkerton et al. 2006). Chlorophyll levels were consistent throughout the water column, and had minima and mean values for Chl similar to published values. Some remote sensed values for Chl were abnormally high compared to published values. Maxima were truncated to below $20 \mathrm{mg} \cdot \mathrm{m}^{-3}$ for analysis.

Turbidity is an indicator of sediments suspended by storms (as well as neritic water) that may inhibit feeding in oysters. The concentration of turbidity (Turb) as Nephelometric Turbidity Units (NTU) from MODIS-Aqua data show high correlation between turbidity measured in-situ and satellite-derived turbidity (Pinkerton et al. 2014). Other measures of storms (a proxy for suspended sediments) include the numbers of days of severe gales (DSGales, > $\left.40 \mathrm{knots}, 20.8-24.4 \mathrm{~m} \cdot \mathrm{s}^{-1}\right)$ and high wind speed $\left(\mathrm{m} \cdot \mathrm{s}^{-1}\right.$, WSpd). These conditions are likely to produce large swells and strong currents that suspend and move sediments that may bury oysters. Daily DSGales and WSpd at Tiwai Point, Bluff were extracted from the NIWA CliFlo database (http://cliflo.niwa. co.nz). 


\section{Group 2 climate indices}

La Nina (the positive Southern Oscillation Index (SOI)) is characterised by more winds from the north and northeast. This leads to more settled and warmer anticyclonic weather in Foveaux Strait and less upwelling on the west coast of New Zealand's South Island. El Nino (negative index) is characterised by more winds from the west and southwest, cooler and less settled weather, and enhanced upwelling (Hurst et al. 2012). Monthly SOI were obtained from the National Center for Atmospheric Research Climate and Global Dynamics division (Trenberth 1984) and computed using the difference in the monthly mean sea level pressure anomalies between Tahiti and Darwin (Australia). The SOI is best represented as seasonal indices (3-monthly running means to annual May-April averages (SOI3av)). SOI and fisheries catch indices and seasonal upwelling have been linked to associated nutrient flux, enhanced phytoplankton, and SST (Hurst et al. 2012).

Sea conditions in the region of Foveaux Strait have been characterised using mean sea-level pressure indices (Z2 and M1) that describe monthly mean differences in average sea-level pressure between climate stations. These data were extracted by Brett Mullins (NIWA) from the NCAR database (Compo et al. 2010). $\mathrm{Z} 2$ is the monthly mean sea level pressure difference between Christchurch and Campbell Island. It approximately measures the strength of the westerly wind that may affect surface temperature (SST), primary production (Chl), and turbidity (Turb). M1 is the differences in pressure between Hobart and the Chatham Islands; a positive M1 results in more winds from the south and a negative value indicates more winds from the north. The strength of M1 may affect both SST and Chl (Hurst et al. 2012).

Climate and weather data are summarised as monthly and annual values, and in four monthly values to represent climatic conditions over the annual 
reproductive cycle of $O$. chilensis in Foveaux Strait (Jeffs \& Hickman 2000). The annual reproductive cycle is partitioned in to three phases below.

Phase 1: Post-spawning, brooding, and conditioning, January-April. Phagocytosis of unspent gametes occurs throughout the year with peaks in January-March (Jeffs \& Hickman 2000). Sea surface temperature and chlorophyll peak in this phase and are important to somatic and shell growth. Almost all growth occurs over this period (Dunn et al. 1998). Glycogen levels drop during spawning and begin to accumulate again during the gonadal resting phase (Abad et al. 1995). Any relationship between high chlorophyll, increased gonad condition, and increased recruitment may be obscured by the size of microalgae in blooms (after Dunphy et al. 2006), and the occurrence of summer storms that inhibit feeding.

Phase 2: Resting and early development, May-August. Temperatures drop to winter minima for a relatively short time in July-August. Temperatures below $12^{\circ} \mathrm{C}$ may play an important role in conditioning, stimulating gametogenesis, and synchronizing female spawning (Jeffs 1998b). However, these low temperatures may increase variability in reproductive state amongst individuals (Jeffs 1998a, b, Jeffs \& Hickman 2000, Joyce et al. 2015). Temperature minima initiate a switch in energy utilisation from somatic and shell growth to glycogen stores and maternal provisioning in O. edulis (Joyce et al. 2013).

Phase 3: Late development and spawning, September-December. A rapid increase temperature of about $2^{\circ} \mathrm{C}$ in September to October initiates spawning. Joyce (2015) suggested a spawning threshold $17-18^{\circ} \mathrm{C}$ for $O$. chilensis. Brooding occurs throughout the year and consistently peaks in November-December in Foveaux Strait (Hollis 1962, Stead 1971a, Cranfield 1979, Westerskov 1980, Jeffs \& Hickman 2000). Peak spawning should occur 
about a month or more before peak brooding, and consistent with the period of rapid rise in temperature.

Climate data were further summarised as means, 5th (minima) and 95th percentiles (maxima) within each month, phase, and year (Krebs \& Berteaux 2006) because thresholds are likely to initiate key reproductive processes. Seasonality (the timing of winter minima and summer maxima) is described using the decompose function in the tseries (V 0.10-45) package in R ( $\mathrm{R}$ Core Team 2016, Trapletti \& Hornik 2018).

\section{Analysis}

Cforest (Hothorn et al. 2005) in the Party package (version 1.3-0, Hothorn et al, http://party.R-forge.R-project.org) implemented in (R Core Team 2016) was used to rank the relative importance and contributions of climate, mortality and density variables to recruitment. Cforest provides robust variable importance measures from relatively small data sets and with large numbers of variables. Especially in cases where the predictor variables vary in their scale of measurement and there are nonlinear and complex high-order interaction effects (Strobl et al. 2007) The effects of each predictor variable are assessed individually as well as in multivariate interactions with other predictor variables with unbiased variable selection measures. The sensitivity of variable ranks and effect sizes to function selection (varimp and varimpAUC functions) was assessed using 2000, 5000, and 8000 trees for each function. The AUC-based importance of each variable is found using the area under the ROC curve (receiver operating characteristic curve). ROC is a graphical plot that illustrates the diagnostic ability of a binary classifier system as its discrimination threshold is varied). This AUC-based variable importance measure is better able to reliably rank variables in order of importance than those using varimp (Strobl et al. 2007). 
A generalised linear model with a negative binomial distribution and a log-link function was used to model recruits as a function of mortality and climate variables with two-way interactions between variables. Continuous variables (mortality, wind speed, chlorophyll, Turbidity, and sea surface temperature) were modelled as first to third order polynomials to increase model flexibility to better fit the data (Ver Hoef \& Boveng 2007). Models were constructed using the "add1" function in the R core stats package (version 3.4.1). This function computes a table of the changes in fit using all variables defined in the starting model with a single significant term added to the model at each iteration until the final model contains all significant variables. This approach allows significant variables to be added without being masked by others. Initial models were constructed using main effects only because of the relatively short time series and large numbers of variables in the available data. Significant terms were added based on the largest decrease in projected AIC.

Multiple models of annual recruitment were run as functions of annual density, annual mortality, and the two groups of climate variables by year, phase, and month. Means and percentiles were run separately (Table 3-1). Best fit models were compared, and an overall best-fit model was determined. Competing models that included two-way interactions were constructed and the overall best-fit model selected based on AIC. Model fits and compliance with statistical assumptions were evaluated graphically (after Zuur et al. 2010).

Table 3-1. Multiple models of recruitment. Each time step and group of climate variables and their mean, 5 th and 95 th percentiles were run separately with density and mortality.

\begin{tabular}{lrrrrrrrr}
\hline Time & & \multicolumn{4}{c}{ Group 1 Climate } & \multicolumn{3}{c}{ Group 2 Climate } \\
step & Density & Mortality & Mean & $\mathbf{5 \%}$ & $\mathbf{9 5 \%}$ & Mean & $\mathbf{5 \%}$ & $\mathbf{9 5 \%}$ \\
\hline Annual & $\checkmark$ & $\checkmark$ & $\checkmark$ & $\checkmark$ & $\checkmark$ & $\checkmark$ & $\checkmark$ & $\checkmark$ \\
Phase (1-3) & NA & NA & $\checkmark$ & $\checkmark$ & $\checkmark$ & $\checkmark$ & $\checkmark$ & $\checkmark$ \\
Monthly & NA & NA & $\checkmark$ & $\checkmark$ & $\checkmark$ & $\checkmark$ & $\checkmark$ & $\checkmark$ \\
\hline
\end{tabular}




\section{Results}

Recruitment declined to low levels between 2007 and 2010, and remained persistently low until 2017 (Figure 3-3, A). Mortality (Figure 3-3B) and density (Figure 3-3C) were the only two variables to show inverse trends. The climate variables did not show any such persistent trends over the sampling period.

Time series analysis of the climate data found significant departures from long-term seasonally adjusted trends (anomalies): unusually high sea surface temperatures in 2007 and low SST in 2010 corresponded to periods of high and low recruitment respectively. There is a mismatch between weather conditions attributed to climate indices and the weather recorded in Foveaux Strait, most of which was from the west or westerly quarter (Figure A-9 in the climate variables section in the Appendix). High recruitment occurred during negative M1 pressure index between 2006 and 2009 that should bring settled weather in northerly flows; however, the same conditions should occur during a positive anomaly for SOI3av in 2010 when recruitment was low. These conditions usually reduce upwelling off the west coast of the south Island; however, chlorophyll a between 2009 and 2011 was unexpectedly high.

Ranks and proxy effect sizes (defined as the individual variable percentages of all varimpAUC variable measures combined) from variable importance measures (VIMs) were robust to the numbers of trees generated and to negligible differences between the varimp and varimpAUC functions ( $\leq$ $0.01 \%)$. Density and mortality were the primary determinants of recruitment variability. These were followed (in order of rank) by: Southern Oscillation Index 3-monthly running means (SOI3av), wind speeds (WSpd), M1 sea-level pressure index, chlorophyll a (Chl), SOI, turbidity (Turb), numbers of days of severe gales (DSGales), Z2 sea-level pressure index, and sea surface temperature 
(SST) as the lowest rank (Table 3-2). Proxy effect sizes are shown in Table 32. Ranks without density, and without density and mortality did not change the importance of the top four climate variables: WSpd, M1, Chlav, and SOI3av (Table 3-2). 

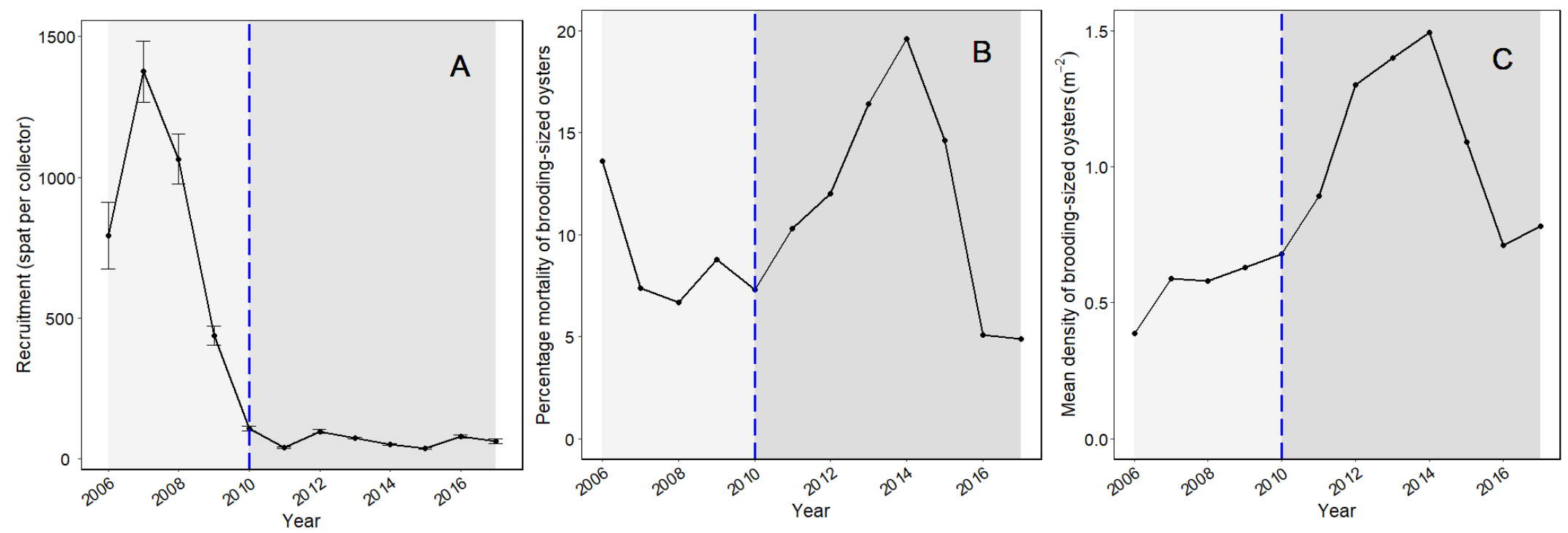

Figure 3-3. Mean recruitment (spat per collector) $\pm 95 \%$ CI for 2006-2017 by year (A), percentage mortality of brooding-sized oyster population by year $(B)$, mean density of brooders $\left(\mathrm{m}^{-2}\right)$ by year $(\mathrm{C})$. The light shaded region highlights the period of relatively high recruitment, while the dashed blue reference line shift to low recruitment in 2010 . The darker shaded region highlights a period of low recruitment. 
Table 3-2. Ranks of the relative variable importance for density, mortality and climate variables to predict recruitment using Cforest algorithm (Hothorn et al. 2005). Brooding-sized oyster density (Density), annual mortality from Bonamia exitiosa (Mortality), 3-monthly running means for Southern Oscillation Index (SOI3av), wind speed (WSpd), the difference in mean sea-level pressure between Hobart and the Chatham Islands (M1), mean chlorophyll a (Chl), Southern Oscillation Index (SOI), turbidity (Turb), the numbers of days of severe gales (DSGales), the difference in mean sea-level pressure between Christchurch and Campbell Island (Z2), and mean sea surface temperature (SSTav). Variable importance measure (VIM) and proxy for effect size (\% EF). Sensitivity analyses without Density (Var -1, VIM-1, and \%EF-1), and without Density and Mortality (Var -2, VIM-2, and \%EF-2). Cforest run with options cforest_unbiased(ntree $=\mathbf{8 0 0 0}, \mathbf{m t r y}=\mathbf{2}$ ), and function varimpAUC to compute variable importance measures as the area under the curve as a proxy for effect size. VIMs represent the effects of variables in both main effects and interactions.

\begin{tabular}{lrrrrrrrr}
\hline Variable & VIM & \%EF & Var-1 & VIM-1 & \%EF-1 & Var-2 & VIM-2 & \%EF-2 \\
\hline Density & 117299.3 & 38.1 & & & & & \\
Mortality & 65294.7 & 21.2 & Mortality & 144524.7 & 28.4 & & \\
SOI3av & 24023.4 & 7.8 & SOI3av & 65607.3 & 12.9 & WSpd & 95243.1 & 16.2 \\
WSpd & 17885.4 & 5.8 & WSpd & 53608.0 & 10.5 & M1 & 78086.9 & 13.3 \\
M1 & 15365.2 & 5.0 & M1 & 45363.3 & 8.9 & Chlav & 77478.8 & 13.2 \\
Chlav & 14630.4 & 4.8 & Chlav & 41481.1 & 8.2 & SOI3av & 72474.4 & 12.4 \\
SOI & 13298.6 & 4.3 & Turbav & 37686.0 & 7.4 & Turbav & 59210.4 & 10.1 \\
Turbav & 12295.8 & 4.0 & SOI & 37120.1 & 7.3 & DSGales & 56079.0 & 9.6 \\
DSGales & 10989.2 & 3.6 & DSGales & 30571.6 & 6.0 & SOI & 52069.8 & 8.9 \\
Z2 & 9347.5 & 3.0 & Z2 & 27936.0 & 5.5 & Z2 & 49890.5 & 8.5 \\
SSTav & 7487.8 & 2.4 & SSTav & 24858.0 & 4.9 & SSTav & 45923.0 & 7.8 \\
\hline
\end{tabular}




\section{Drivers of annual variability in recruitment}

Best-fit models of recruitment as functions of density, mortality, and climate variables showed mean, minima and maxima climate values generally differed little in their contribution to model deviance for any variable in any given phase. The best-fit model overall (Tables 3-3 \& 3-4) accounted for $68.6 \%$ of the deviance, which is analogous to an effect size in this context. The best-fit model suggests that brooder density and B. exitiosa mortality are likely to be the most significant factors contributing to variability in recruitment to the $O$. chilensis populations in Foveaux Strait. Two climatic variables were also significant in best-fit models (3-monthly running means for Southern Oscillation Index (SOI3av) and the difference in mean sea-level pressure between Hobart and the Chatham Islands (M1)); however, their effects did not contribute substantially to the variation in recruitment ( $<1 \%$ deviance). Variables were added in a stepwise iterative process in the order of their overall contribution to the model. This means that climatic variables and their interactions are unlikely to have been masked by the effects of density and mortality. On average, density $(\mathrm{p}<0.001, \mathrm{df}=3$, Deviance $=4184.7)$ and mortality $(\mathrm{p}<0.001, \mathrm{df}=3$, Deviance $=4123.1$ ) each accounted for $30 \%$ of the variation in recruitment in any given year. A significant two-way interaction between density and mortality ( $\mathrm{p}<$ 0.001, $\mathrm{df}=3$, Deviance $=1162.2$ ) accounted for a further $8 \%$ of the variation in recruitment. The climate variables SOI3av and M1 accounted for less than $1 \%$ of the best fit model deviance (Table 3-3).

The predicted response of recruitment to mortality (Figure 3-4) showed a rapid decline in recruitment above levels of $9 \%$ mortality. The increase in recruitment below this $9 \%$ threshold of mortality may reflect the 2-way interaction between mortality and density (Table 3-3) with the highest recruitment at times of low mortality and low density. Recruitment drops to low levels above a density of 0.5 oyster $\mathrm{m}^{-2}$ (Figure $3-5$ ). These results suggest 
substantial effects of density on the transmission and progression of disease and the effects of high intensity infections on reproductive success.

Recruitment modelled as functions of climate variables by reproductive phase (1-3), and with and without density and mortality showed chlorophyll a (Chl), sea surface temperature (SST), turbidity (Turb), and numbers of days of severe gales (DSGales) were significant climatic variables, although their contributions were minor, and their predictive plots showed poor fits to the data (plots not shown).

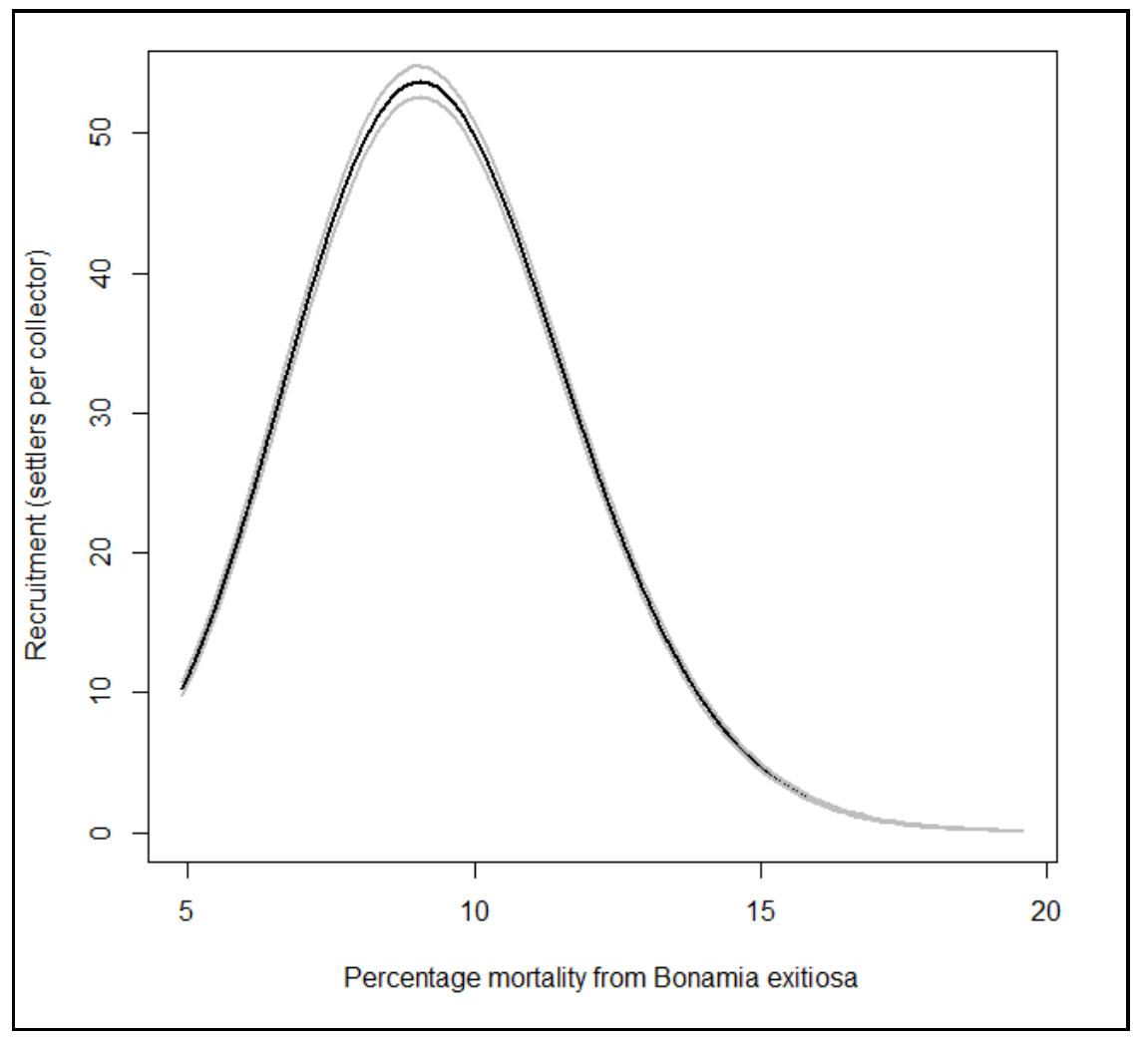

Figure 3-4. The predicted mean recruitment (black line) of $O$. chilensis in the Foveaux Strait fishery area and $95 \%$ CIs (grey lines) against mortality from time series data 2005-2017. 


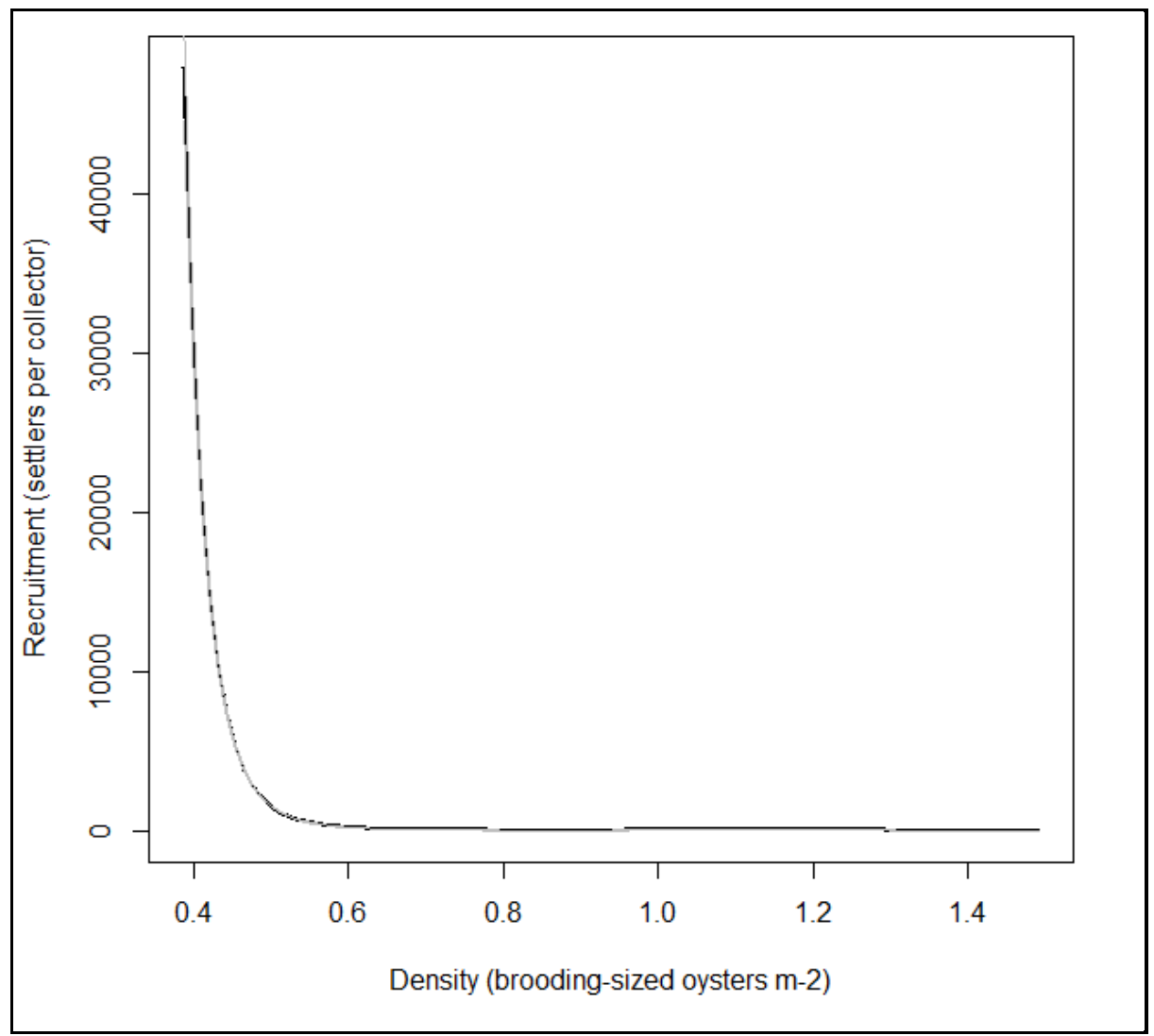

Figure 3-5. The predicted mean recruitment (black line) of $O$. chilensis in the Foveaux Strait fishery area and $95 \%$ CIs (grey lines) against density from time series data 2005-2017. 
Table 3-3. The best-fit negative binomial regression of annual variation in oyster recruitment across the Foveaux Strait fishery between 2006 and 2017. Recruitment was estimated from recruit densities and modelled as a function of brooding-sized oyster density (Density), annual mortality from Bonamia exitiosa (Mortality), 3-monthly running means for Southern Oscillation Index (SOI3av), and the difference in mean sea-level pressure between Hobart and the Chatham Islands (M1), and their interactions. Percentage deviance (\% Dev) and cumulative percentage deviance (Cum\% Dev) explained.

\begin{tabular}{|c|c|c|c|c|c|c|c|}
\hline & df & Deviance & Res. df & Res. deviance & $\mathbf{p}$ & \%Dev & Cum\%Dev \\
\hline & & & 3935 & 13932.2 & & & \\
\hline Density & 3 & 4184.7 & 3929 & 5624.4 & $<0.001$ & 30.0 & 30.0 \\
\hline Mortality & 3 & 4123.1 & 3932 & 9809.1 & $<0.001$ & 29.6 & 59.6 \\
\hline Mortality x Density & 4 & 1162.2 & 3923 & 4369.7 & $<0.001$ & 8.3 & 68.0 \\
\hline SOI3av & 1 & 71.5 & 3928 & 5552.9 & $<0.001$ & 0.5 & 68.5 \\
\hline M1 & 1 & 21 & 3927 & 5531.9 & $<0.001$ & 0.2 & 68.6 \\
\hline
\end{tabular}


Table 3-4. Annual variation in oyster recruitment across the Foveaux Strait fishery from 2006 to 2017. Oyster recruitment was modelled as a function of brooding-sized oyster density (Density), annual mortality from Bonamia exitiosa (Mortality), 3-monthly running means for Southern Oscillation Index (SOI3av), and the difference in mean sea-level pressure between Hobart and the Chatham Islands (M1), and their interactions. Density and mortality were modelled as first to third order polynomials, denoted (1)-(3) below. The best-fit negative binomial model statistics: Theta $=1.6254, \mathrm{SE}=0.0353, \mathrm{df}=3935$, log-likelihood $=$ 43919.54, and AIC = 43948. NS denotes not significant.

\begin{tabular}{lrrrr}
\hline Source of variation & Coefficient & SE & $\mathbf{Z}$ & $\mathbf{p}$ \\
\hline Intercept & 1.79 & 0.42 & 4.27 & $<0.001$ \\
Mortality (1) & -1004.00 & 117.00 & -8.58 & $<0.001$ \\
Mortality (2) & -149.60 & 24.83 & -6.03 & $<0.001$ \\
Mortality (3) & -187.70 & 17.81 & -10.54 & $<0.001$ \\
Density (1) & 616.20 & 80.33 & 7.67 & $<0.001$ \\
Density (2) & -18.87 & 17.40 & -1.09 & 0.278 \\
Density (3) & -247.20 & 38.31 & -6.45 & $<0.001$ \\
SOI3av & 0.00 & 0.03 & 0.02 & $\mathrm{NS}$ \\
M1 & 0.00 & 0.00 & 0.06 & $\mathrm{NS}$ \\
Mortality (1) x Density (1) & 13780.00 & 2064.00 & 6.67 & $<0.001$ \\
Mortality (2) x Density (1) & 41490.00 & 4982.00 & 8.33 & $<0.001$ \\
Mortality (3) x Density (1) & -2651.00 & 1051.00 & -2.52 & 0.012 \\
Mortality (1) x Density (2) & -9920.00 & 800.50 & -12.39 & $<0.001$ \\
\hline
\end{tabular}




\section{Discussion}

The highest recruitment occurred at times of low mortality and low oyster density. One explanation for this is reduced disease transmission at low density (Doonan et al. 1999), and potentially reduced effects of intense infections on recruitment processes at low oyster mortality. The best-fit negative binomial model was consistent with the variable importance measure ranks and the proxy effect sizes that included any interactions for key variables. These analyses were limited by the length and nature of time series data; they comprised a single cycle of recruitment from high to persistent low recruitment and these data met only the minimum requirement for analysis of climate time series data and drivers of recruitment variability. These limitations did not allow for key interactions between density, mortality and climate variables to be identified. Ranks and differences in proxy effect sizes (see Table 3-2) suggest interactions between climate variables and climate indices. The strength of inferences made from this research may be limited by the data; nonetheless, the analysis is highly informative and highlights particular areas that would benefit from the collection and analysis of more extensive climate, disease and recruitment data. These data show some support for the hypothesis that oyster density and mortality have an effect on oyster recruitment in Foveaux Strait.

The best-fit model suggests variation in annual recruitment to the Foveaux Strait oyster population is may be driven by oyster density and mortality (a proxy for intense infections during gametogenesis and spawning) and the interaction. Although data on the prevalence and intensity of pathogens present in co-infections and there physiological effects on the oyster host and specifically gametogenesis and spawning were not available, the interaction between oyster density and mortality suggests combined effects of Bonamia exitiosa and other pathogens on reproductive success. These findings are consistent with fishery data on changes in population size (Fu et al. 2016), oyster recruitment (Michael et al. 2001, 2018), with the pathology of B. exitiosa (Hine 
1991a, b), concurrent infections by one or more pathogens in O. chilensis (Diggles 2004) and their deleterious effects on reproductive success. High oyster densities in Foveaux Strait increase infection pressure and transmission of $B$. exitiosa (Doonan et al. 1994, Cranfield et al. 2005), which leads to higher prevalence and intensities of infection in the oyster fishery.

A mechanistic understanding of how density and mortality affect recruitment is beyond the scope of this research. However, the hypothesis informed by knowledge of diseases in O. chilensis in Foveaux Strait is proposed: namely, that recruitment to the Foveaux Strait oyster fishery since 1985 is driven by an interaction between oyster density and co-infection by one or more pathogens. This hypothesis is underpinned by fishery and disease data from Foveaux Strait. Firstly, the percentages of brooders and levels of recruitment differed markedly before and after the 1985 B. exitiosa epizootic (Doonan et al. 1994, Cranfield et al. 2005). Brooding percentages in oysters were 6\%-18\% in the 1960s and 1970s (Stead 1971a, Cranfield \& Allen 1977, Jeffs \& Hickman 2000) compared with 1-2\% in 1996-2000 (Bluff Oyster Enhancement Company data). Secondly, the effects of B. exitiosa infection or co-infections could be one explanation of these brooding differences. Thirdly, since 1985 rates of recruitment have been highest when oyster densities and mortality from $B$. exitios $a$ were lowest. There are three time periods in recently published research that support this: 1992/93 (Fu et al. 2016), 2005/06 (Michael et al. 2006), as well as in 2018 subsequent to this research (Michael et al. 2018). Furthermore, $B$. exitiosa was first detected in Foveaux Strait in 1964 (Hine \& Jones 1994) although there were no reports of disease mortality between 1964 and 1985 . Prolonged periods of low recruitment were unlikely over that time, and moderate to high levels of recruitment have been inferred by the consistently high catch rates and high and increasingly spawning-stock biomass at that time (see Figures $4 \& 7$, Fu et al. 2016). The hypothesis derived from this study assumes a link between recruitment and annual $B$. exitiosa mortality that occurs following 
gametogenesis and spawning being indicative of disruptive co-infections that disrupt gametogenesis and spawning, and reduce brooding and thereby larval supply.

One explanation for the differences in brooding pre and post the $1985 \mathrm{~B}$. exitiosa epizootic could be the disruption of gametogenesis by pathogenic coinfections. Jeffs \& Hickman (2000) found the same proportion of male and female oysters with phagocytosis of reproductive material by B. exitiosa in the 1970s, and Diggles \& Hine (2002) found higher levels in female gonads post 1985. Bonamia exitiosa mortality is used as a proxy for heightened prevalence of infection (the proportion of the population infected) and intensity of infection (parasite density in the host) by one or more pathogens during gametogenesis and spawning. An apicomplexan parasite (APX) and Bucephalus longicornutus individually or together can be co-infections with B. exitiosa. Although $B$. longicornutus generally occurs at low prevalence, and so even high intensity of infections results only in low mortalities (Hine \& Jones 1994), B. longicornutus can occur in high prevalence and cause high mortality $(\geq 40 \%)$, as it did in Foveaux Strait between 1958 and 1964 (Howell 1967). APX is widespread in this area. At high intensities of infection APX can affect reproduction in $O$. chilensis and may cause sterility (Steve Webb, Cawthron Institute, pers.com.). Oysters heavily infected with APX show disruption to reproduction; gonads have empty follicles that differ markedly from those in recently spawned oysters at a time that lacks coherence with spawning (Hine 2002). The pathology of APX infection is similar to that of Bonamiosis (disease caused by Bonamia spp.) (Hine 1997). B. exitiosa is present in the gonads of O. chilensis in Foveaux Strait all year round, albeit at low levels for most of the year (Hine 1991a). The oyster's response to infection places a high demand on its energy budget that may cause a reduction in, or complete cessation of gametogenesis (Diggles \& Hine 2002). The phagocytosis of ova by haemocytes containing B. exitiosa depletes lipid resources and so deprives the host of vital energy reserves as well as fuelling the 
rapid proliferation of B. exitiosa (Hine 1991b, a). Female and spent oysters are more likely to die from the intensifying infection than male and hermaphrodite oysters (Diggles \& Hine 2002), which suggests that the female gametogenic cycle is more likely to be disrupted. Although B. exitiosa does not directly parasitize viable gonads (Lane 2018), some studies have inferred a link between bonamiosis and disruption to the female gametogenic cycle in oysters. da Silva et al. (2009) found high to moderate intensities of B. ostreae infections in ripe, female $O$. edulis as well as in those with partially spawned and reabsorbing gonads, which suggests the intensification of infection by $B$. ostreae associated with female maturation before reabsorption of ova. Lacoste et al. (2001) described a potential mechanism for this that modulates the oyster haemocyte phagocytosis. Whether the increased energy demand to produce haemocytes to contain increasing infection also increases the levels of phagocytosis and reabsorption of ova (as a direct response to disease) is not known.

Co-infection by multiple pathogens is common in O. chilensis (Hine et al. 1986, Hine 1997, 2002, Joyce et al. 2015, Lane et al. 2016). There is, however, little information on how these pathogens interact with the host and with each other to intensify infections to fatal levels, or in the case of non-fatal infections, to reduce reproductive output. The interaction between oyster density and mortality shown by this research infer co-infections may be unidentified but significant driver of recruitment and population dynamics. Hine (2002) gives an example of co-infection by APX and B. exitiosa in O. chilensis. Although APX is not thought to cause high mortalities, its presence may increase the susceptibility of $O$. chilensis to $B$. exitiosa by denying the oyster energy to counter increasing B. exitiosa infections (Hine 2002). Additionally, $B$. longicornutus and B. exitiosa co-infection may have played a role in the 195864 mortalities of O. chilensis in Foveaux Strait (Howell 1967, Hine \& Jones 1994). B. longicornutus was initially identified as the cause of mortality although subsequent identification of $B$. exitiosa in preserved oyster tissues from that 
epizootic suggest that co-infection is more likely the cause of mortality (J.B. Jones, pers. comm.). It is not known whether APX was present in the fishery before 1985, and if it was not, whether co-infection with $B$. exitiosa could be an explanation for the recurrent oyster mortalities since 1985.

Little is known about the effects of non-fatal co-infections, how they may contribute to the intensification of disease, and their effects on reproduction. It is likely that concurrent, non-fatal infections disrupt reproduction. APX and $B$. longicornutus individually can cause gonadal castration. No confirmed mechanism of how B. exitiosa may disrupt gametogenesis has been identified. Non-fatal B. exitiosa infections that may disrupt gametogenesis and spawning increase in prevalence and intensity post-spawning, and are represented as heightened summer mortality in these data. Moreover, if the host is not killed by the intensification of infection, B. exitiosa may compete with the host and other pathogens (e.g. APX) for energy made available through the reabsorption of ova and compromise reproduction in the following cycle. In this study, the relatively high oyster mortality (> 9\%) from B. exitiosa resulted in reduced recruitment.

This research suggests that effective spread of infection and disruption to recruitment at a fishery spatial-scale may occur at 0.5 oysters $\mathrm{m}^{-2}$. Patchily distributed $O$. chilensis populations have waxed and waned in the same locations (Michael 2010). The 1985 B. exitiosa epizootic spread through the fishery in a wave of infection and mortality, as though through a naïve population (Cranfield et al. 2005). Doonan et al. (1999) estimated a threshold density of 1.26 recruitsized oysters $\mathrm{m}^{-2}$ triggered the 1985 epizootic and subsequent wave of mortality. Since then, patterns of infection and mortality have varied spatially and temporally through the fishery (Michael et al 2018). The transmission of $B$. exitiosa infection is oyster to oyster and density dependent. Oysters dying from B. exitiosa release $\sim 10^{6}$ infective particles that survive longer than 48 hours at normal summer temperatures in Foveaux Strait (Diggles \& Hine 2002). High mortality ( $20 \%$ of recruit-sized oysters $\mathrm{y}^{-1}$ ) produces high infection pressure 
caused by the release of substantial numbers of infective particles that are dispersed by rapid tidal flows. Diggles \& Hine (2002) experimentally determined the $50 \%$ lethal dose of $1.12 \times 10^{5}$. The spread of mortality in 1985 was slow $\left(\sim 5 \mathrm{~km} \cdot \mathrm{y}^{-1}\right)$ and $B$. exitiosa took $4-5$ years to spread through the relatively small Foveaux Strait fishery area (Cranfield et al. 2005). High prevalence of infection may persist in oyster patches for 2-3 years (Cranfield et al. 2005), suggesting that infections may take some time to intensify to fatal infections. Any effects of non-fatal infections on spawning and recruitment may persist at fishery spatial -scale for some years.

Climate variables affect host physiology (Engelsma et al. 2010), recruitment processes (Hjort 1914, Canning 2013, Joyce et al. 2013, Robert et al. 2017), and intensification of disease and host mortality (Hine et al. 2002, Arzul et al. 2009, Engelsma et al. 2010, Rowley et al. 2014). Because of the limitations of the data used in this study, the analysis may have underestimated the contributions of climate variables and their important interactions. Ranks of climate variables (see Table 3-2) suggests that food availability (shown be threemonthly average southern oscillation index and chlorophyll a) and the ability of $O$. chilensis to feed (inferred storms from wind speed indices) were more important to recruitment than sea surface temperature (the lowest ranked variable). Food availability (Chlorophyll a) is not likely to be limited. The climate variables: three-monthly average southern oscillation index (SOI3av), southern oscillation index (SOI), wind speed (WSpd), and numbers of days of severe gales (DSGales) from the westerly quarter and the Z2 sea surface pressure index all contribute to offshore upwelling west of Foveaux Strait. These conditions increase primary production, and the transport of plankton blooms into Foveaux Strait (Bradford et al. 1991, Butler et al. 1992, Hurst et al. 2012). Large oceanic swells and high wind-driven currents generated by storms also move sediments in Foveaux Strait (Carter \& Lewis 1995, Stanton et al. 2001, Walters et al. 2001, Hemer 2006). The burial of oysters in coarse calcareous sand 
may affect their ability to feed, thereby reduce energy available to recruitment processes, and increase physiological stress and susceptibility to disease. In this research, the complex high-level interactions between recruitment and climate, and climate effects on food supply, ability to feed, as well as estimating a threshold above which individuals cannot utilise high concentrations of food (Joyce et al. 2015) could not be resolved. Food supply (phytoplankton) can vary dramatically and can play an important role in the timing and success of spawning, larval survival and settlement in O. chilensis (Chaparro 1990), and the ability to tolerate infection.

No significant effects of sea surface temperature (SST) on recruitment were detected in this research, although other research has shown temperature to be important to spawning, brooding and settlement processes. The female gonadal cycle advances quicker in O. edulis in cooler water (Joyce 2013), and O. chilensis larvae from the cooler waters of Foveaux Strait are larger than those in Tasman Bay (central New Zealand) (Cranfield \& Michael 1989), and almost twice the size of hatchery produced larvae (Joyce et al. 2015). These studies suggests that SST may affect spawning, brooding, and settlement success and thereby recruitment; however, these effects were not detected in this study.

The same climatic and environmental factors that may stress oysters and affect recruitment may also intensify disease (Rowley et al. 2014, Adlard et al. 2015), and may thereby contribute to low recruitment. Inundation by sediments during storm events, and fishing effects (Vanbanning 1991, Cranfield et al. 1999, Cranfield et al. 2005) may play critical roles in physiological stress and disease. Increased water temperatures and mechanical disturbance in laboratory experiments increased the intensity of infection by $B$ exitiosa (Diggles \& Hine 2002). Recent outbreaks of B. exitiosa $(1985,1999$, and 2013) may be in part linked to strong El Nino events producing cooler temperatures and more gales. 
The putative effect of $B$. exitiosa and other pathogens on recruitment represent a shift in productivity of the Foveaux Strait oyster fishery. Recurrent epizootics from B. exitiosa since 1985 (Ministry for Primary Industries 2017) have caused significant losses to the recruited population and revenue to the fishery. This research suggests that these epizootics have reduced the ability of the $O$. chilensis population to rebuild. Commercial fishers rely on high-density patches of oysters to maintain economic catch rates (Hill et al. 2010). Any shift in productivity with high-density patches of oysters suffering recurrent high mortality and reduced recruitment will require new, collaborative fishing strategies to minimise the effects of disease, maintain sustainability, and maximise harvests and revenue.

Oysters play important roles in ecosystems and provide for important commercial, recreational and indigenous fisheries. This research suggests that shellfish pathogens may be an unrecognised determinant of variation in recruitment as well as mortality. Little is known about the communities of pathogens within host and host populations (pathobiomes) and whether and how they may affect population dynamics (Vayssier-Taussat et al. 2014, Stentiford et al. 2017, Sweet \& Bulling 2017). At a fishery scale, the marked reduction in recruits-per-spawner because of disease has important implications for stock assessment and management of fisheries. These fisheries mostly rely on stockrecruitment relationships. Reduced reproductive output and mortality also has important implications for the enhancement of wild invertebrate populations (such as $C$. virginica, Schulte et al. 2009) in habitats where pathogens may be present. For nearshore populations, anthropogenic effects of sedimentation and pollution together with increasing climate variability and climate change will increase the frequency and severity of disease events (Rowley et al. 2014). The integration of disease in population models in the way proposed by (Powell \& Hofmann 2015) that capture both mortality and recruitment effects of pathogens on population dynamics would greatly improve management of fisheries. 
This research suggest that disease not only causes declines in population size and spawner densities, but may also reduce recruitment through the disruption of gametogenesis and spawning, reduce brooding and thereby reduced recruitment. The high-level effects of climate on recruitment and disease are well known; however, little is known about the interactions between climate, pathobiomes and spawner density and how they may affect recruitment. Future research should include the prevalence and intensity of pathogens present in coinfections and their physiological effects on the oyster host and specifically gametogenesis and spawning. A mechanistic understanding of these interactions requires an extended time series data to inform the development of integrated recruitment models. 


\section{Chapter 4 : Dispersal and mixing of Ostrea chilensis larvae}

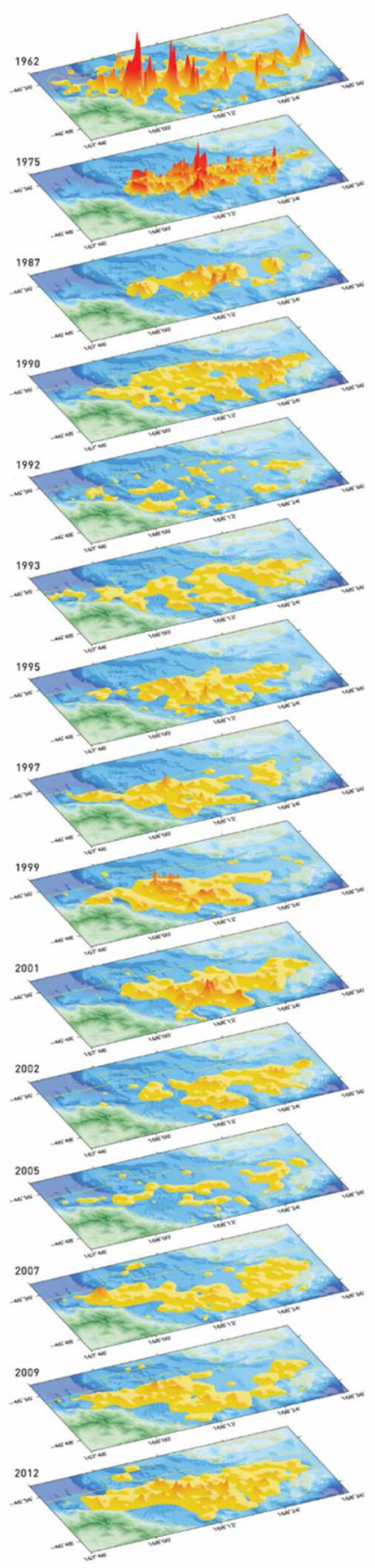

The distribution of $O$. chilensis in Foveaux Strait from dredge surveys 1962-2012. The demographics and biology of oysters suggests the fishery comprises localised, self-recruiting populations that have persisted in the same locations after high disease mortality from Bonamia exitiosa and periodic high levels of fishing. Image by Erika Mackay. 


\begin{abstract}
The Foveaux Strait oyster (Ostrea chilensis) fishery in southern New Zealand comprises many localised populations (oyster beds) that have survived 150 years of fishing and disease mortality. The reproductive biology of $O$. chilensis underlies the assumption that these populations are self-recruiting. Passive, artificial collectors deployed in a gradient design around an isolated natal population in a three-year study investigated the hypothesis of selfrecruitment. Patterns of recruits settling on collectors, a proxy for the distributions of competent larvae in the plankton, were used to describe putative dispersal. This research also investigated the relationship between recruits and brooder densities. Recruit densities were not predicted by distance from the natal-population both along and across the current, or by brooder densities. Settlement was widespread, and patterns of settlement imply greater dispersal and larval mixing than previously reported. The swift currents, and the possibility of a more variable pelagic larval duration may enhance mixing and connectivity between populations. Recruitment to mostly demographically open populations should provide some resilience to disease mortality and fishing.
\end{abstract}




\section{Introduction}

Oysters (Ostreidae, Rafinesque 1815) occur globally over a wide range of habitats. They structure benthic communities and provide ecosystem services (Coen et al. 1999, Gutierrez et al. 2003, Ruesink et al. 2005, Grabowski \& Peterson 2007, Grabowski et al. 2012). In New Zealand and internationally, oysters also comprise highly valued fisheries (Ministry for Primary Industries 2017). Worldwide, oyster reefs and fisheries are depleted (Beck et al. 2011, Alleway \& Connell 2015). Several restoration strategies have been implemented to rebuild oyster populations (Coen et al.2007, Schulte et al. 2009, Brown 2011, La Peyre et al. 2014, Zacherl et al. 2015). Knowledge of recruitment and the complex processes that regulate marine populations is fundamental the success of these restoration strategies, and to the conservation and management of oysters, and the benthic communities they are a part of. The spatial extent of dispersal and connectivity delineate population boundaries and therefore management units. This knowledge underpins models used to inform fisheries stock assessments (Hilborn et al. 2005), restoration strategies (Broekhuizen et al. 2011), and the design of marine reserve networks (Gaines et al. 2010, Puckett et al. 2014).

Recruitment - the addition of new individuals to localised populations is spatially and temporally variable. Three fundamental stages contribute to this variation: pre-settlement (spawning and brooding success, larval dispersal and survival), settlement (completion of metamorphosis on substrata), and postsettlement (recruit survival and growth). Discussion of these stages can be found in (Cowen \& Sponaugle 2009), (Shima et al. 2008), and (Hixon et al. 2012) respectively. The relative importance of these stages to recruitment success varies over space and time (Sale \& Kritzer 2003), and both between and within marine species (Jones \& Ricciardi 2014, Shima et al. 2015). There are a number of flow-on effects between these stages, which makes an understanding of presettlement, larval dispersal and connectivity fundamental to understanding 
recruitment. Sufficiently high spawning stock biomass (Beverton \& Holt 1957), spawner densities (Mendo et al. 2014), and favourable climatic and biological conditions are essential for larval production, large larval cohorts, and the potential for effective dispersal (Paris et al. 2007, Puckett et al. 2014). Biophysical factors determine larval transport, dispersal and retention of larvae. The time larvae spend in the plankton (pelagic larval duration), is often used as an indicator of the potential for dispersal. Larval traits such as large ova size and the absence of a feeding stage (lecithotrophy) suggest putative short pelagic larval durations (Levin 2006). A number of factors determine how many larvae disperse and how far they go. These include the pelagic larval duration, larval growth and survival, the initial size of larval cohorts and their fitness (Pineda et al. 2007). This fitness is likely to be dependent on maternal provisioning in lecithotropic larvae. Larval behaviour and their sensory abilities can play important roles in dispersal e.g. competent $C$. virginica larvae swam upward in highly turbulent flows (Wheeler et al. 2013), and Ostrea lurida using this vertical migration to access different flows in stratified water masses (Peteiro \& Shanks 2015), larvae altered bouyancy to facilitate settlement to suitable substrata (Hubbard \& Reidenbach 2015). These factors are especially relevant to the retention of larvae within natal populations (Sponaugle et al. 2002, Shanks et al. 2003, Levin 2006, Pineda et al. 2007, Broekhuizen et al. 2011). The direction and speed of current flows at the point where larvae are released, often influenced by wind speed and direction in coastal areas, determines larval transport (Puckett et al. 2014). How long larvae spend in the plankton may also determine how far they travel (Pineda et al. 2007).

High densities of Ostrea chilensis (Philippi, 1844) between the South Island and Stewart Island in southern New Zealand comprise the Foveaux Strait oyster fishery (Figure 4-1). O. chilensis (hereafter: oyster) in Foveaux Strait exhibits the extreme end of brooding strategies in Ostreinae; larvae develop in broods until fully competent and settle almost immediately (Cranfield 1979, 
Westerskov 1980). Moreover, Foveaux Strait represents an extreme in oyster habitat with a deep 20-50 m sand and gravel substrate, large oceanic swells and swift tidal currents. The demographics and biology of this population suggests the fishery comprises localised populations suspected to be self-recruiting (Allen 1979, Cranfield 1979). This research defines self-recruitment as the settlement of larvae to their natal population (Jones et al. 1999). That is, a demographically closed population based on the putative short pelagic larval duration and almost immediate settlement of $O$. chilensis (Cranfield 1979, Cranfield \& Michael 1989).

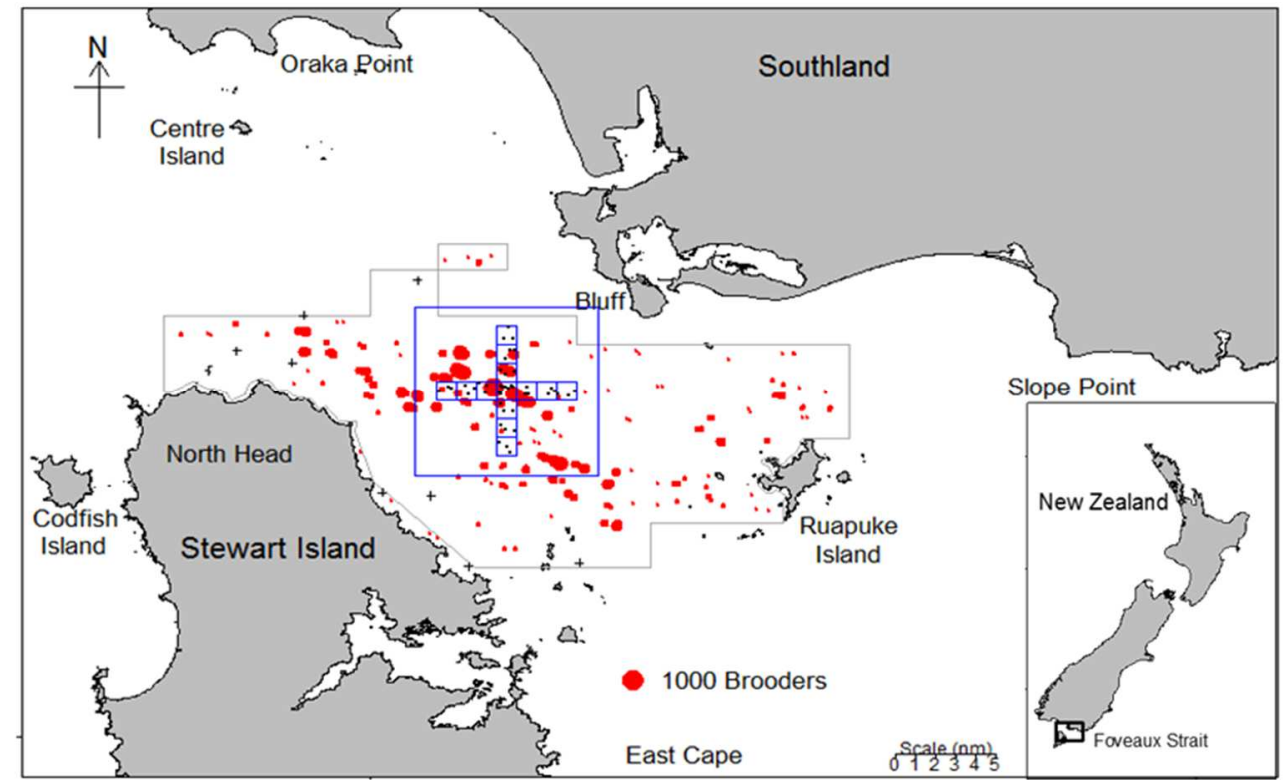

Figure 4-1. Foveaux Strait, southern New Zealand. Grey lines show the 2007 stock assessment survey area. The gradient design comprised four axes (North, East, South, and West), with the central cell encompassing the focal population; area boundaries shown in blue. Three, one nautical mile square cells extend along each axis (blue squares). Red filled circles scaled to brooder densities. Three randomly assigned spat collectors in each cell and nine collectors in the central cell encompassing the focal-population shown as black points.

Spatio-temporal variability in the availability of competent larvae contributes to local patchiness in recruitment in many marine populations. Localised populations of oysters have persisted in the same locations in Foveaux Strait after high disease mortality (Doonan et al. 1994, Cranfield et al. 2005) and 
periodic, high levels of fishing (Michael et al. 2008c). Whether the oyster populations are demographically closed (self-recruitment), demographically open (dispersal to distant populations, i.e., in Foveaux Strait, connectivity among spatially separated high density patches), or some proportion of open and closed (Jones et al. 2009) is the focus of this research. Temporal patterns in the distribution of competent larvae will help determine whether the stock comprises a metapopulation (Sale \& Kritzer 2003) or a number of self-recruiting localised populations. Self-recruitment tends to reduce resilience; given the high mortalities experienced by localised populations of oysters, an increased risk of serial depletion may therefore be expected.

Field studies of larval dispersal and connectivity are difficult. The small larvae from discrete and localised spawning events are difficult to identify and track to settlement. Moreover, the abundance of larvae from spawning events and larval mortality in the plankton are difficult to estimate. Probabilistic dispersal kernels (Siegel et al. 2003, Chiswell 2012) and deterministic models (Broekhuizen et al. 2011, Nicolle et al. 2013, Thomas et al. 2014, Smyth et al. 2016) estimate how far larvae of species with pelagic larval durations of days and weeks and with distributions over large geographical ranges disperse. Some models incorporate assumptions about larval behaviour and movement, larval mortality rates and information on physical processes. However, these models generally do not capture the complexity and variation in drivers of local transport and larval survival over relatively small spatial-scales. As a result, they may not predict dispersal and recruitment well (Wasson et al. 2016). These models are also unable to predict whether larvae survive settlement. Few models incorporate observed measures of dispersal to validate model predictions (Gawarkiewicz et al. 2007, Puckett et al. 2014). Arnold et al. (2017) showed some inconsistencies between modelled and sampled recruitment of Crassostrea virginica, model outcomes were not validated by field sampling. Reliable predictions of dispersal and connectivity in $O$. chilensis larvae would require information of the 
demographics of the localised-populations and data on the location, timing and duration of larval release relative to hydrographical features - these data were not available for $O$. chilensis in Foveaux Strait for this study. For further discussion on larval dispersal, see reviews by Levin (2006), Pineda et al. (2007), and Kool et al. (2013).

The relatively small area of the Foveaux Strait fishery and the uncertainty about the spatial-temporal variation in pelagic larval duration (Hollis 1962, 1963, Cranfield \& Michael 1989) have led to this study. Data on factors that influence dispersal in Foveaux Strait oysters are scant. This three-year field study evaluates the potential for larval dispersal and connectivity amongst localised populations of oysters in Foveaux Strait in order to test the hypothesis of self-recruitment. This research has two objectives. The first objective is to describe the distribution of oyster recruits on passive artificial collectors around a putative, localised natal population (focal-population). Recruit densities represent the availability of competent oyster larvae in the plankton that settle within minutes to hours after release (Cranfield 1979, Westerskov 1980). This knowledge underpins the hypothesis that most dispersal events will occur over short distances and self-recruitment is likely to be high i.e., recruit densities distributed tightly around the focal-population. Alternatively, widespread distribution of recruits implies larval mixing, and therefore some connectivity amongst distant populations, and be evidence against mostly self-recruiting populations.

Previous studies used the relationship between recruits and brooder density to infer Ostrea dispersal was limited and populations demographically closed (Cranfield 1968a, Brown 2011, Pritchard et al. 2015). The second objective evaluates this relationship between brooder densities and recruit densities as evidence for self-recruitment. The hypothesis of self-recruitment has an expectation of almost immediate settlement of competent larvae around the focal-population. A high correlation between brooders and recruit densities may 
imply self-recruitment, while no correlation could imply dispersal beyond the natal populations. This research also describes the consistency in the interannual distributions of recruit densities as many factors can influence larval dispersal. Evidence for mostly demographically open populations with larval mixing in Foveaux Strait has implications for resilience in localised oyster populations to the high disease mortality and fishing, and therefore their management.

\section{Methods}

Oyster distribution in Foveaux Strait is patchy with oysters concentrated in a smaller region of the managed area, the 2007 stock assessment area (see Figure 4-1). Management of the fishery assumes a single stock for convenience (OYU 5, Ministry for Primary Industries 2017) even though, Allen \& Cranfield (1979) suggest that this fishery is instead comprised of approximately 50 discrete, dense localised populations ( $>4$ nautical miles apart) that separated by extensive areas with low oyster densities. Stead (1971b) has suggested a higher number of populations within this area.

The larval biology of $O$. chilensis has given rise to the hypothesis that these localised populations self-recruit in Foveaux Strait (Cranfield 1968a, Cranfield 1979, Cranfield \& Michael 1989) and in Tasman Bay, New Zealand (Broekhuizen et al. 2011). O. chilensis is larviparous (Cranfield 1979) and in Foveaux Strait, up to $12 \%$ of the oyster population (c. $60 \mathrm{~mm}$ in length), brood larvae to pediveliger that are fully competent and can settle immediately on release (Hollis 1962, 1963, Stead 1971a, Jeffs \& Hickman 2000). These large, lecithotropic larvae have limited dispersal potential that should enhance selfrecruitment. A presumption of a very short pelagic larval duration underpins an expectation of mostly rapid settlement in O. chilensis, and thereby limited opportunity for larval transport and dispersal. Laboratory experiments suggest that most settlement occurs within hours (Stead 1971a, Brown 2011), while field 
experiments suggest that settlement occurs immediately around natal populations (Cranfield 1968a). O. chilensis larvae are poor swimmers (Stead 1971a), remain near the seabed (benthopelagic) in strong current conditions, and are phototaxic (Cranfield 1968b). Almost all settlement in Foveaux Strait oysters occurs between November and February (see Chapter 2 and Cranfield 1979).

The swift currents in Foveaux Strait could enable greater dispersal of $O$. chilensis larvae than predicted by Cranfield (1968a), Broekhuizen et al. (2011) and Brown (2011). Current speeds of 1.0-2.2 knots measured close to the sampling site in 1993 and 1998 flowed along an east-southeast west-northwest axis. Currents in Foveaux Strait may flow north for a time in strong southerly winds and vice versa (Mark Hadfield, NIWA, pers. comm.). The displacement of water mass in a single direction in normal flow is c. $13 \mathrm{~km}$. Net displacement of water mass is $2.5 \mathrm{~km} \mathrm{~d}^{-1}$ to the east (Steve Chiswell, NIWA, pers. comm.). The residence time of a water mass in the 2007 stock assessment area is 5 to 20 days (Cranfield \& Michael 1989).

A localised, focal-population was identified from research surveys 20092011 (Michael et al. 2009b, Michael et al. 2011, Michael et al. 2012a) (Figure 4-2), supplemented with annual catch data from fishers' logbooks (Figure 4-3) and oyster skipper interviews. The putative high brooder density in the focal population was spatially isolated from neighbouring populations by a surrounding area of low brooder density (Figures 4-2 \& 4-3), and by about 5 $\mathrm{km}$ between populations. 


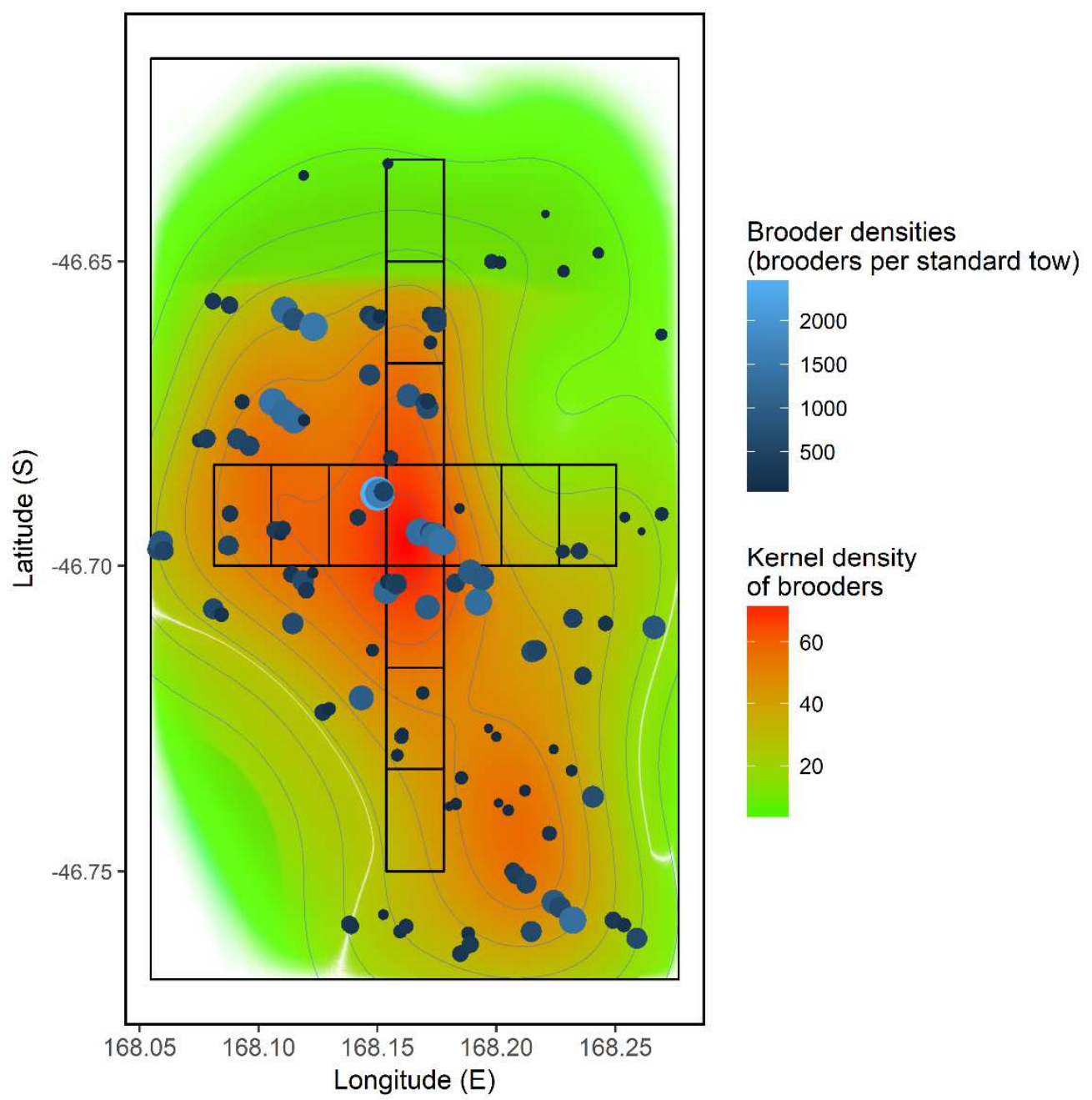

Figure 4-2. Kernel densities of brooders ( $\geq 60 \mathrm{~mm}$ in length) within the research area (Foveaux Strait, southern New Zealand) from dredge sampling during February surveys 2009-2011 (Michael et al. 2009; Michael et al. 2011; Michael et al. 2012). Cell boundaries shown as black rectangles. Brooders scaled to density at sample locations shown as filled blue circles. 


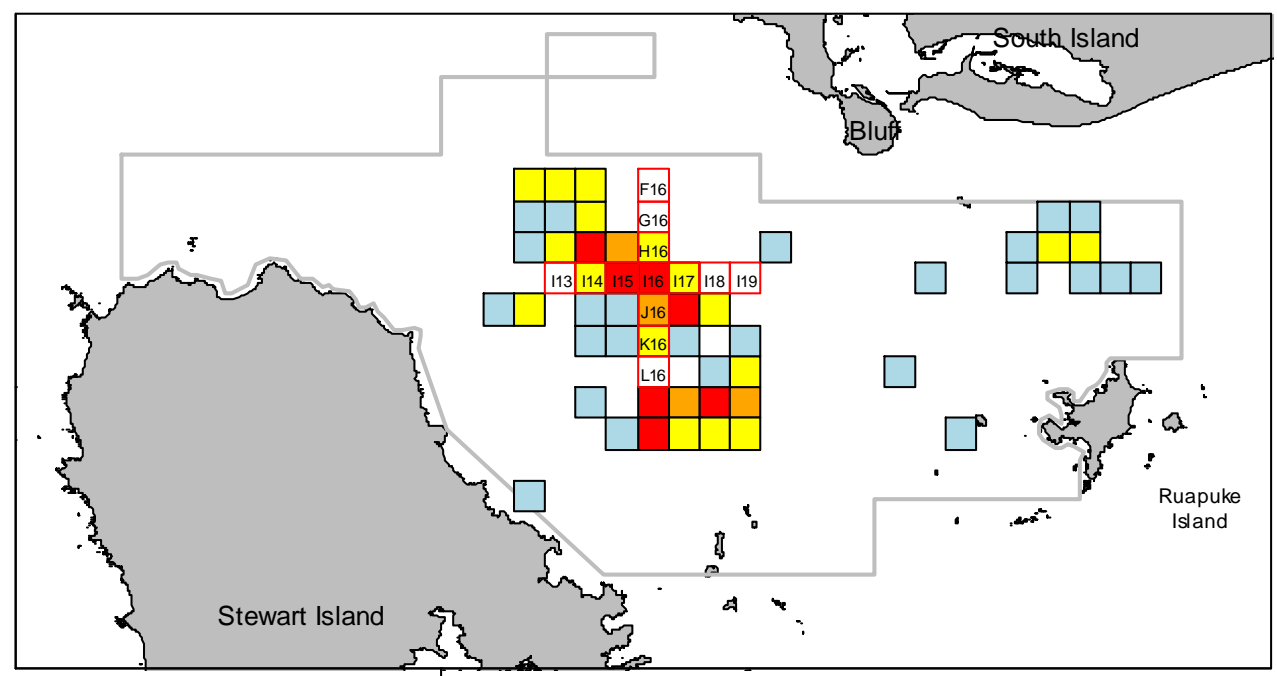

Figure 4-3. The percentage annual commercial catch of oysters (Ostrea chilensis) by reporting area, from skippers' 2011 season (1 March to 31 August, Michael 2012) logbooks. Percentage of the total annual catch shown as 5-10\% (red), 34.9\% (orange), 1-2.9\% (yellow), and $<1 \%$ (light blue). The white background represents cells where no fishing took place. Reporting cell labels for the cells that comprise the sampling design shown in black text. The sampling grid shown as red lines.

Sampling followed a gradient design because it was likely to be more sensitive in detecting dispersal from a point source (Ellis \& Schneider 1997). The gradient design is similar to the Helix design used by Sammarco \& Andrews (1989) to investigate differential localised dispersal and recruitment patterns in Great Barrier Reef corals. The Foveaux Strait oyster logbook reporting cells (one nautical mile squares) formed the basis for the sampling design (see Michael et al. 2012b). A central cell encompassed the focal-population (see Figure 4-2). Four axes orientated north, east, south, and west each extended three cells from the central cell (see Figure 4-2). Nine collector sites were randomly allocated to the central cell, and three sites to each of the three cells extending in each direction ( $\mathrm{n}=45$ per year). Collector locations remained fixed for the three years of sampling. Outside the sampling area, relatively high densities of brooders were present some distance across tide and to the north of the western axis (see Figure 4-3). 
O. chilensis competent larvae readily settle on manmade substrates without conditioning and in the absence of conspecifics (see Chapter 2). Sampling of recruits and estimates of recruitment used the same methods and passive spat collectors with cement board plates as detailed in Chapter 2. The collectors were deployed over three years (2011-12 to 2013-14) during the austral spring and summer (November to February). Recruitment to each collector is the cumulative number of recruits on any plate surface (top or bottom) of any of the four plates of a given collector. Because this research focus was on recruitment before post-settlement mortality, recruitment was estimated as the total number of both living and dead recruits on plates $(>92 \%$ of oysters were alive at the time of recovery; dead oysters leave a record of their size at death). At the end of the study (February 2014), brooder densities at each collector location were estimated using standard dredge sampling procedures for Foveaux Strait oyster surveys (see the estimates of spawner densities section in the Appendix for details, also Michael et al. 2017b). Estimates of recruitment were standardized to a $122 \mathrm{~d}$ sampling period for each season.

The timing of settlement peaks may vary from year to year. Comparison of recruit percentage length frequency distributions of live $O$. chilensis ensured sampling reliably captured peak settlement in each year. Oyster shell lengths (the greatest distance along the anterior-posterior axis), were measured to the lower whole millimetre.

Recruit densities are shown as points independent of distance along the four axes and within the focal-population, and with mirrored probabilities for the range of recruit densities observed (shaded areas) using violin plots in the ggplot2 package (Wickham 2009) in R Core Team (2016). Violin plots scale the probabilities for a given density by the highest recruit density observed along each respective axis. Interannual differences, reported as differences in the mean numbers of recruits, are used evaluate larval cohort sizes. 
The distribution of recruit densities around the focal-population may reflect the potential for mixing of larvae with neighbouring populations. Recruit densities (Recruits) modelled as a function of factors that represent distances and directions from the boundaries of the focal-population as indicators of the dispersal of competent larvae, both along and across current. Axis (Ax) represents the direction of settlement (West, East, North, and South) from the focal-population. Current Axis $(\mathrm{Cx})$ denotes either an along or across tidal current orientation, combining data from West and East (along current), and North and South axes (across current). Distance (D) is a measure from the boundary of the focal population (central cell) to the fixed spat collector locations. Year (Yr) is also a factor as interannual larval abundance can vary considerably at a fishery-wide scale independent to brooder density in some years (see Chapters 2 and 3). The 45 collectors deployed each year represent a balanced sampling design of nine collectors per $A x$ and nine in the central cell encompassing the focal-population. The sample size for analysis $(n=134$, as one collector was lost) is small. Negative binomial regression has preferable performance with relatively small sample sizes and for over-dispersed count data such as these recruit data (Gardner et al. 1995, Robinson \& Smyth 2008). The glm.nb function of the MASS package (Venables \& Ripley 2002) in R, with a log link function described the relationship between recruit densities and predictor variables. Multiple models used subsets of predictor variables and their interactions rather than a single model of all predictor variables because of the relatively small sample size. With non-significant factors and interactions removed, Akaike Information Criterion (AIC) (Akaike 1973) used to select the best-fit models (Table 4-1). Where AICs were similar between models, the percentage deviance explained (a measure of effect size, analogous to a variance component) decided the best-fit model. The graphical methods of Zuur et al. (2010) used to evaluate the best-fit models and their compliance with statistical assumptions. Recruits were also modelled as a function of brooders and Ax using 
glm.nb, modelling brooders as first to third order polynomials that provided increased flexibility to better fit to the data (Ver Hoef \& Boveng 2007).

\section{Results}

Sampling extended over peak settlement periods in each of the three years. The percentage length frequencies of recruits comprised unimodal, normal distributions with similar modes. Importantly, diminishing percentages of small recruits show that settlement declined by the end of each sampling period (Figure 4-4). Two of these years (2012-13 and 2013-14) show a small percentage of recruits were of large size (Figure 4-4). Allowing for some variability in growth, these larvae most likely settled early before the main settlement period.

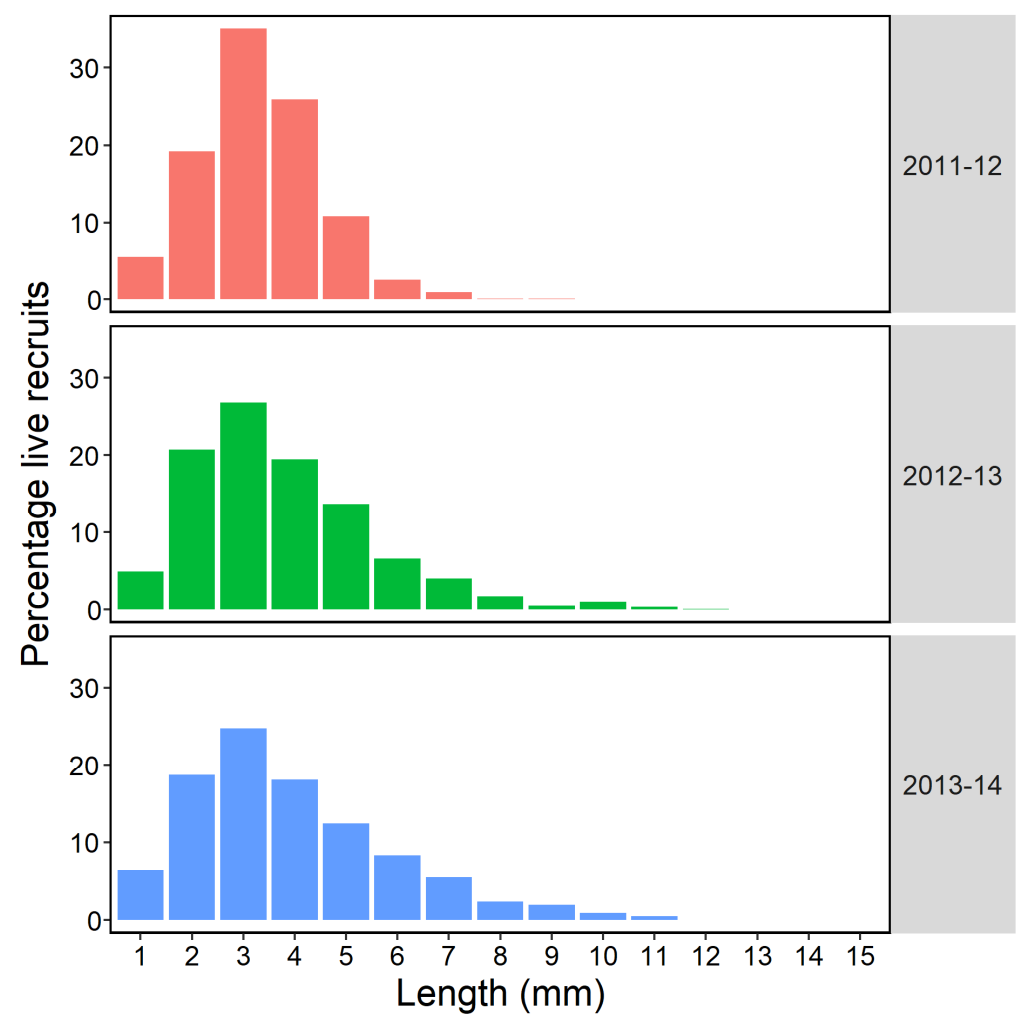

Figure 4-4. The percentage length frequencies of live $O$. chilensis recruits. Spat collectors sampled during the summers (November to February) from 2011-12 to 2013-14. 
Recruit densities declined significantly between 2011-12 and 2013-14 $(50.3 \%, \mathrm{P}=<0.003$, d.f. $=2$, Deviance $=11.358$ and see Table $4-2$ and Figure 4-5). There were increasingly fewer numbers of high recruit densities over the study period (Figure 4-6). Most sample sites received between 50 and 100 recruits per collector $\left(203-406 \mathrm{~m}^{-2}\right)$, irrespective of the distance or direction from the focal-population. For a given year, violin plots show similar probability distributions for the numbers of recruits (independent of distance), between the focal-population and the four axes (Figure 4-5). The range and median densities of recruits were also similar, regardless of current orientation or axis (Figure 4 6). Recruit densities were generally similar or lower within the focal-population relative to the four axes, which suggests widespread availability of competent larvae. High recruit densities decreased over subsequent years (Figures 4-5 \& 4-6).

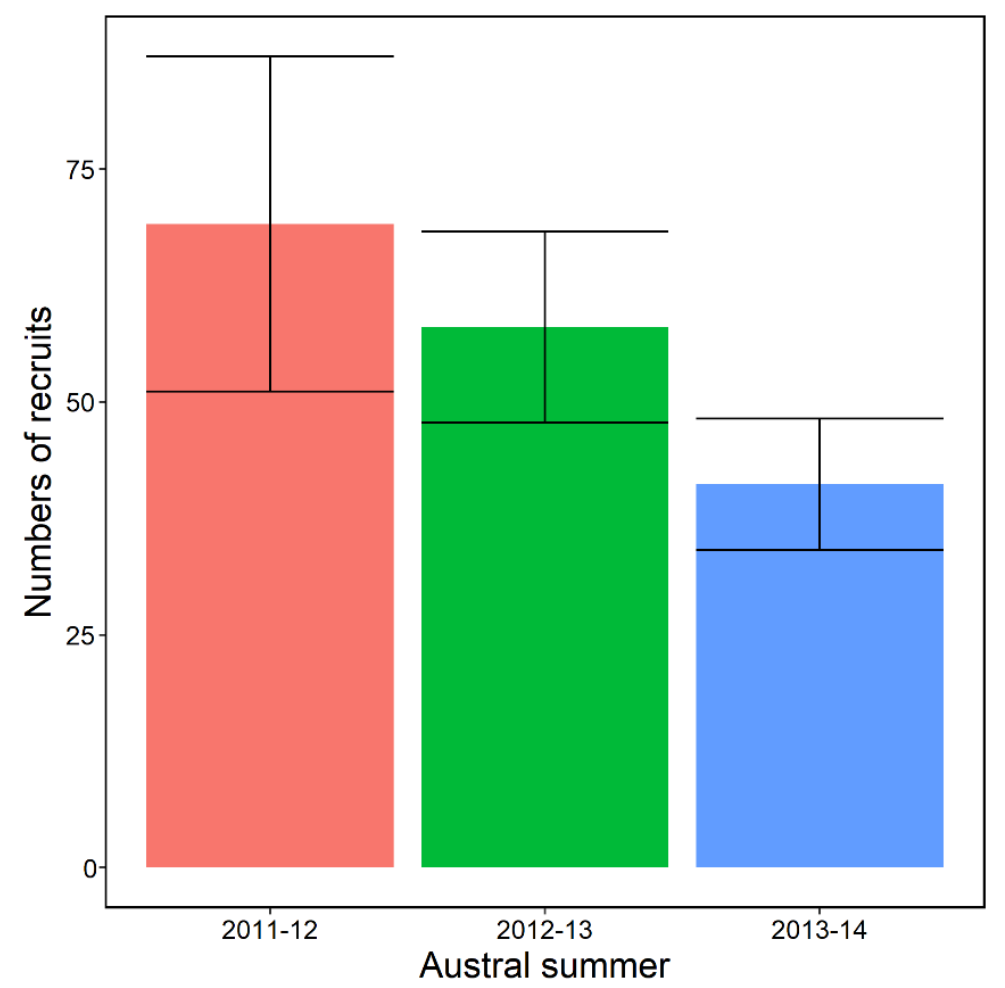

Figure 4-5. Bar plots of mean recruit densities and $95 \%$ confidence intervals for the three years of sampling during the summers (November to February) from 2011-12 to 2013-14. 
Models 1-10 were run with factors year (Yr), distance (D), current axis $(\mathrm{Cx})$, and their two-way and three-way interactions to determine a best-fit model (Table 4-1). AICs and the percentages of deviance explained did not vary greatly for the best-fit models (5-8), presumably because of the lack of pattern in the distribution of recruits (Figure 4-5). Model $6(\mathrm{Yr}+\mathrm{Cx})$ was chosen as the bestfit based on AICs, percentage of deviance explained, and slightly improved plots of residuals and QQ-plots. Models 11-13 (Table 4-1) substituted Cx for Ax, and all interactions that did not improve the model fits subsequently dropped. Model $13(\mathrm{Yr}+\mathrm{Ax})$ was the best-fit model of the three, and the best-fit overall based on the same criteria as above. Yr was the only significant variable with $\mathrm{D}, \mathrm{Cx}$, and $\mathrm{Ax}$ and their interactions accounting for distance and direction from the focal-population were not significant at alpha $=0.05$. The full model (Model 1, Table 4-1) accounted for $18.2 \%$ of the deviance while the best-fit Models 6 and 13 (Table $4-1$ ) accounted for $9.1 \%$ and $13.5 \%$ of the deviance respectively.

Recruitment is assumed to reflect the numbers of competent larvae available for settlement and therefor settle on passive artificial collectors at sampling locations. Settlement to the seabed will be primarily dependent on the availability of clean hard substratum (Smyth et al. 2018). Trends in recruit densities with increasing distance from the focal population boundary varied with axis direction (Figure 4-7, Table 4-3). Along current axes, settlement densities increased with increasing distance to the west and decreased to the east. Across current axes showed a similar pattern that increased to the north and decreased to the south. Increases in recruit densities were in directions towards neighbouring areas of relatively high brooder densities (Figures 4-1 \& 4-2). These trends were consistent among years. Trends in recruit densities by distance from the focal-population imply flat distributions of competent larvae, and therefore suggest putative flat dispersal kernels.

Putative brooder densities sampled in 2014 varied between axes, but had little effect on local recruit densities settled in 2013-2014. Recruits modelled as 
a function of brooders and Ax explained $47.0 \%$ of the deviance, however, brooders alone were not a good predictor of nearby settlement (Table 4-4). Moreover, trends in recruit densities varied with axis. Axis was the most significant factor $(\mathrm{P}<0.001$, d.f. $=4$, Deviance $=34.27)$ accounting for $45.5 \%$ of the deviance in model 3 (Table 4-4). 
Table 4-1. Factors predicting the distributions $O$. chilensis recruits as a proxy for the dispersal of competent larval abundance from a focal population in the Foveaux Strait oyster fishery, 2011-12 to 2013-14. Recruit densities modelled as functions of year (Yr), distance (D), current axis $(\mathrm{Cx})$, and their interactions (models 1-10) using negative binomial regression. Axis (Ax) was substituted for Cx for each model (models 11-13), because of the relatively small data size. Degrees of freedom (d.f.), Akaike Information Criterion (AIC), and percentage deviance explained (\% Dev) are given for each model. Selection of the best-fit model was based on AIC. Where AICs were similar between models, the percentage deviance explained (a measure of effect size, analogous to a variance component) and graphical evaluation of fits determined best-fit models (bold).

\begin{tabular}{|c|c|c|c|c|}
\hline Model & Factors and interactions & d.f. & AIC & $\%$ Dev \\
\hline 1 & $\mathrm{Yr}+\mathrm{D}+\mathrm{Cx}+\mathrm{Yr} * \mathrm{D}+\mathrm{Yr} \mathrm{r}^{*} \mathrm{Cx}+\mathrm{Yr} \mathrm{r}^{*} \mathrm{Cx}$ & 19 & 1338.731 & 18.2 \\
\hline 2 & $\mathrm{Yr}+\mathrm{D}+\mathrm{Cx}+\mathrm{Yr} * \mathrm{D}+\mathrm{Yr} * \mathrm{Cx}$ & 13 & 1337.134 & 12.4 \\
\hline 3 & $\mathrm{Yr}+\mathrm{D}+\mathrm{Cx}+\mathrm{Yr} \mathrm{r}^{*} \mathrm{D}$ & 9 & 1333.698 & 9.7 \\
\hline 4 & $\mathrm{Yr}+\mathrm{D}+\mathrm{Cx}+\mathrm{Yr} * \mathrm{Cx}$ & 11 & 1333.503 & 12.2 \\
\hline 5 & $\mathrm{Yr}+\mathrm{D}+\mathrm{Cx}$ & 7 & 1330.214 & 9.4 \\
\hline 6 & $\mathbf{Y r}+\mathbf{C x}$ & 6 & 1328.617 & 9.1 \\
\hline 7 & $\mathrm{Yr}+\mathrm{D}$ & 5 & 1329.377 & 7.5 \\
\hline 8 & $\mathrm{Yr}$ & 4 & 1328.686 & 6.7 \\
\hline 9 & $\mathrm{D}$ & 3 & 1336.171 & 0.7 \\
\hline 10 & $\mathrm{Cx}$ & 4 & 1334.912 & 2.8 \\
\hline 11 & $\mathrm{Ax}$ & 6 & 1333.548 & 6.1 \\
\hline 12 & $Y r+A x+D$ & 9 & 1326.787 & 6.7 \\
\hline 13 & $\mathbf{Y r}+\mathbf{A x}$ & $\underline{8}$ & $\underline{1325.189}$ & $\underline{\underline{13.5}}$ \\
\hline
\end{tabular}


Table 4-2. Analysis of deviance for best-fit negative binomial Model 6 (glm.nb) and estimates for coefficients for factors year (Yr) and current axis $(\mathrm{Cx})$. Degrees of freedom (d.f.), deviance (Dev), percentage deviance explained (\% Dev), residual degrees of freedom (Resid. d.f.), residual deviance (Resid. Dev), and P value (Pr (>Chi)).

\begin{tabular}{lrrrrrrr}
\hline & & & & & $\begin{array}{r}\text { Resid. } \\
\text { d.f. }\end{array}$ & $\begin{array}{r}\text { Resid. } \\
\text { Dev }\end{array}$ & $\begin{array}{r}\text { Pr } \\
(>\text { Chi) }\end{array}$ \\
\hline Factor & d.f. & Dev & \% Dev & & & \\
& & & & & 133 & 169.34 & \\
Yr & 2 & 11.358 & 6.7 & 131 & 157.98 & 0.003 \\
Cx & 2 & 4.131 & 2.4 & 129 & 153.85 & 0.127 \\
\hline
\end{tabular}

\begin{tabular}{lrrrr} 
Coefficients: & Estimate & $\begin{array}{r}\text { Std. } \\
\text { Error }\end{array}$ & z value & $\operatorname{Pr}(>\mid \mathbf{z})$ \\
\hline Intercept & 4.124 & 0.133 & 30.969 & $<0.001$ \\
Yr 2012-13 & -0.155 & 0.154 & -1.006 & 0.315 \\
Yr 2013-14 & -0.503 & 0.154 & -3.265 & 0.001 \\
Cx (Along) & 0.247 & 0.140 & 1.757 & 0.079 \\
Cx (Focal-popn) & -0.037 & 0.175 & -0.211 & 0.833 \\
\hline
\end{tabular}




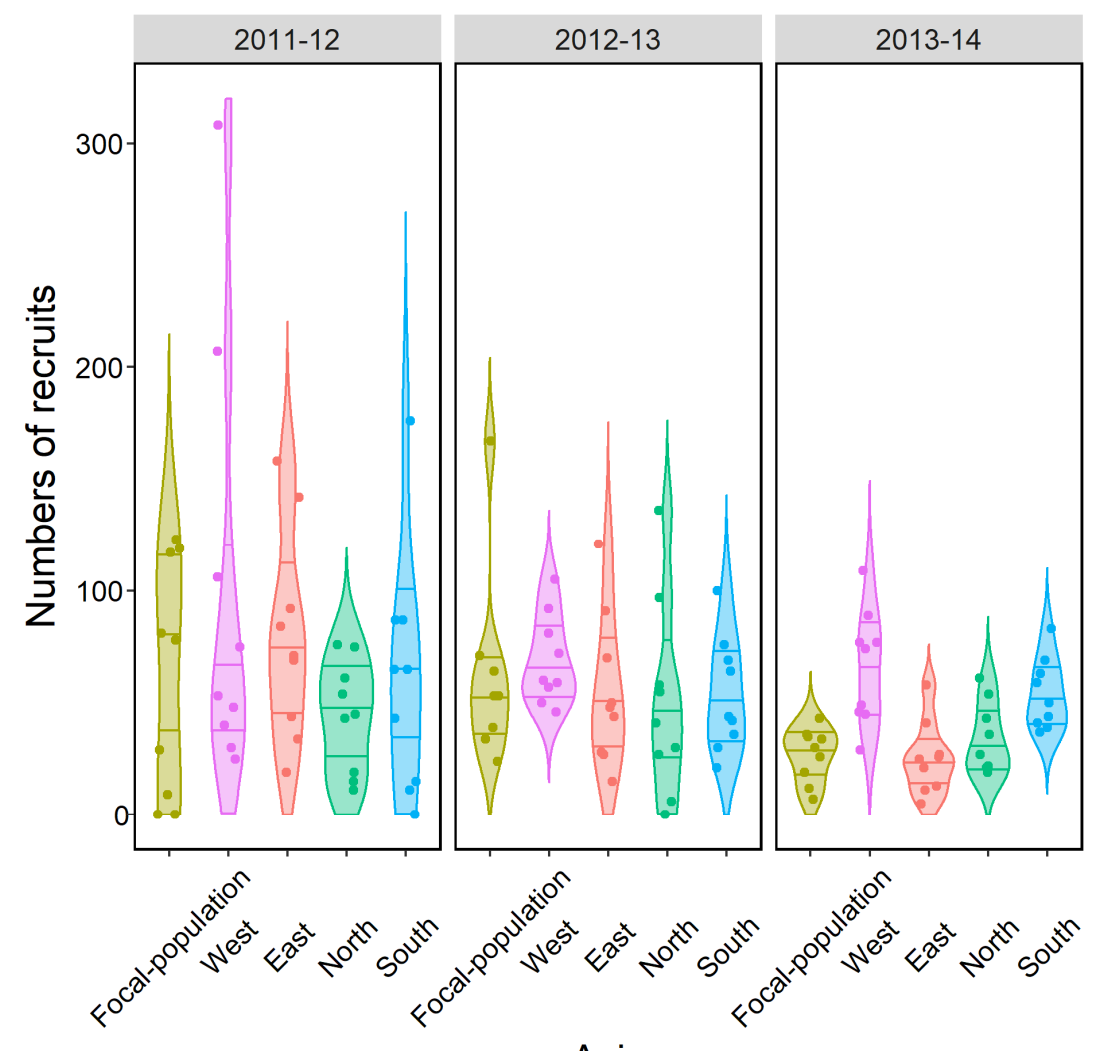

Axis

Figure 4-6. Violin plots of $O$. chilensis recruit densities along four axes (Ax) extending west, north, east, and south from focal population for the summers (November to February) of 2011-12 to 2013-14. Violin plots show data points (dots) and probabilities for the range of recruit densities scaled to the highest recruit density. Mirrored probability distributions shown as shapes shaded by factor. Horizontal lines within distributions denote the median, 25th and 75th percentiles. 


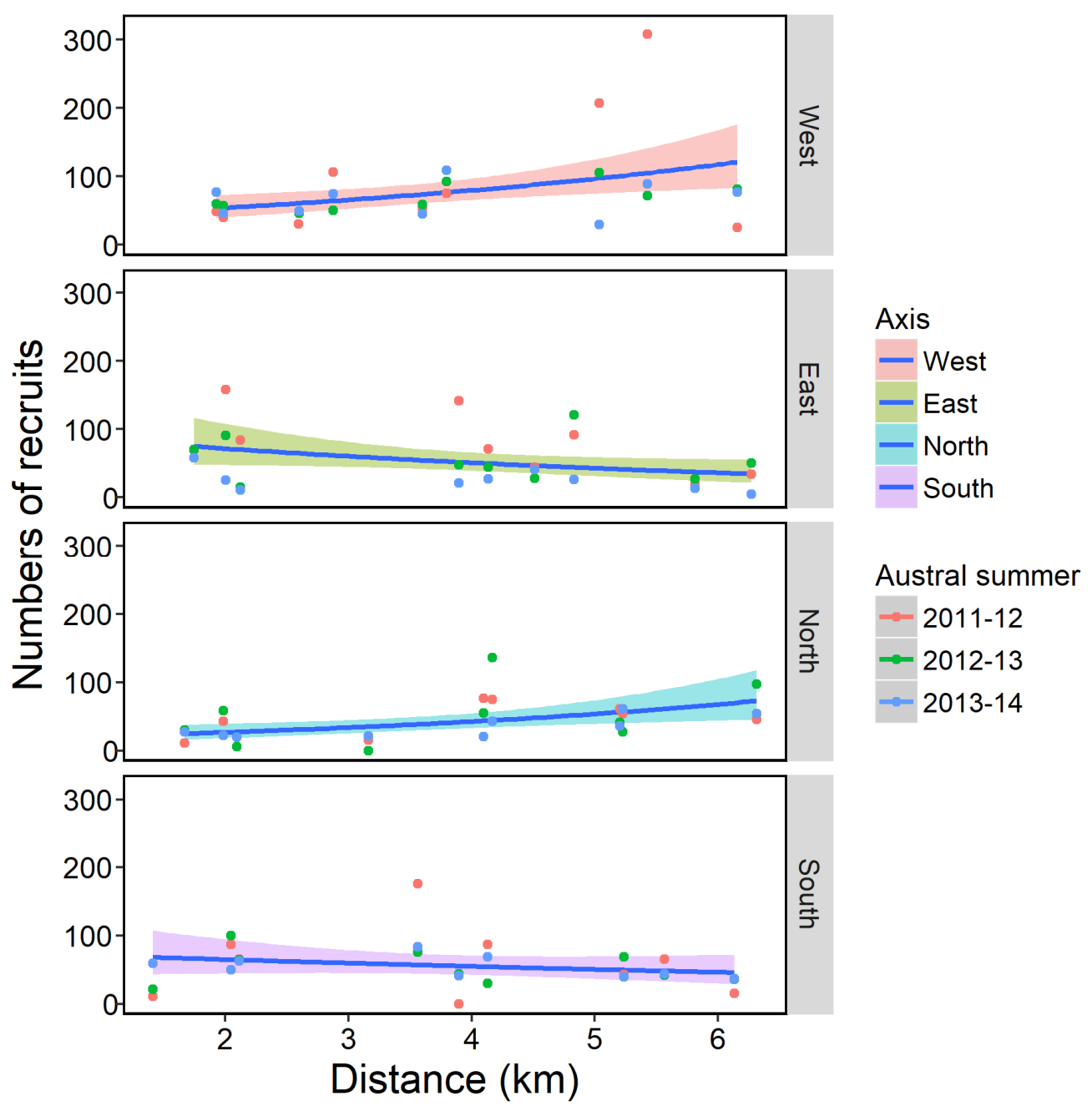

Figure 4-7. Changes in $O$. chilensis recruit densities (spat per collector) with increasing distance from the focal population over the four axes extending west, north, east, and south over the summers (November to February) of 2011-12 to 2013-14. Coloured lines and shading show fits from generalised linear model with a negative binomial distribution and a log link function (mean $\pm 1 \mathrm{SE}$ ). 
Table 4-3. Analysis of deviance for best-fit negative binomial Model 13 (glm.nb) and estimates for coefficients for factors year (Yr) and current axis (Ax). Degrees of freedom (d.f.), deviance (Dev), percentage deviance explained (\% Dev), residual degrees of freedom (Resid. d.f.), residual deviance (Resid. Dev), and P value (Pr (>Chi)).

\begin{tabular}{|c|c|c|c|c|c|c|}
\hline Factor & d.f. & Dev & \% Dev & Resid. d.f. & Resid. Dev & $\operatorname{Pr}(>$ Chi $)$ \\
\hline & & & & 133 & 177.93 & \\
\hline$Y r$ & 2 & 11.991 & 6.7 & 131 & 165.94 & 0.002 \\
\hline$A x$ & 4 & 11.994 & 6.7 & 127 & 153.94 & 0.017 \\
\hline Coefficients: & & & Estimate & Std. Error & $\mathrm{z}$ value & $\operatorname{Pr}(>|z|)$ \\
\hline Intercept & & & 4.131 & 0.162 & 25.553 & $<0.001$ \\
\hline $\operatorname{Yr} 2012-13$ & & & -0.151 & 0.150 & -1.002 & 0.317 \\
\hline Yr 2013-14 & & & -0.539 & 0.150 & -3.595 & 0.000 \\
\hline$A x$ (North) & & & -0.154 & 0.194 & -0.794 & 0.427 \\
\hline$A x$ (Focal-population) & & & -0.036 & 0.196 & -0.186 & 0.853 \\
\hline$A x$ (South) & & & 0.143 & 0.193 & 0.737 & 0.461 \\
\hline$A x$ (West) & & & 0.450 & 0.193 & 2.239 & 0.020 \\
\hline
\end{tabular}


Table 4-4. Analysis of deviance for negative binomial models (glm.nb) of Recruits modelled against Ax, and Brooders. Sample sizes were too small to run interactions. Akaike Information Criterion (AIC), degrees of freedom (d.f.), deviance (Dev), percentage deviance explained (\% Dev), residual degrees of freedom (Resid. d.f.), residual deviance (Resid. Dev), and $P$ value $(\operatorname{Pr}(>C$ Chi) ) are given for each model. Best-fit model selected based on AIC, \% Dev, and graphical evaluation (shown in bold).

\begin{tabular}{|c|c|c|c|c|c|c|c|c|}
\hline Model & AIC & Factor & d.f. & Dev & \% Dev & Resid. d.f. & Resid. Dev & $\operatorname{Pr}(>\mathrm{Chi})$ \\
\hline \multirow[t]{3}{*}{1} & 340.55 & & & & & 38 & 77.815 & \\
\hline & & Brooders & 1 & 8.195 & 10.5 & 37 & 69.620 & 0.004 \\
\hline & & $A x$ & 4 & 28.385 & 36.5 & 33 & 41.235 & $<0.001$ \\
\hline \multirow[t]{2}{*}{2} & 353.77 & & & & & 38 & 45.655 & \\
\hline & & Brooders & 1 & 4.689 & 10.3 & 37 & 40.967 & 0.030 \\
\hline \multirow[t]{2}{*}{3} & 339.66 & & & & & 38 & 75.298 & \\
\hline & & $A x$ & 4 & 34.27 & 45.5 & 34 & 41.029 & $<0.001$ \\
\hline
\end{tabular}




\section{Discussion}

There was no pattern detected in the distributions of recruit densities (thereby numbers of competent larvae) around the focal population over the three summers of sampling. None of the predictor variables investigated: directions either-way along or across the current, distance from the focal population, and density of putative brooders predicted recruit densities. The distributions of recruits suggest that competent $O$ strea chilensis larvae were widespread over the sample sites extending three nautical miles along the four axes from the focal population. Additionally, brooder densities sampled at spat collector locations did not predict recruit densities; this suggests that larvae either settled differentially at these sites, or more likely dispersed beyond the brooders. Pelagic larval duration, $O$. chilensis population demographics, and the small scale study of Cranfield (1968a) where high densities of recruits settled over the highest concentration of oysters have underpinned the hypothesis of demographically mostly closed populations (self-recruitment). Under the hypothesis of selfrecruitment, there was an expectation of Gaussian distributions (after Chiswell 2012) of recruit densities (indicative of dispersal kernels), with the highest numbers of recruits centred immediately on the focal population. The numbers of recruits should have decreased rapidly with an increase in distance down current. There was also an expectation of highly truncated Gaussian distributions of recruits along axes across current. The flat recruit distributions observed in this research, however, show similar numbers of competent larvae consistently along and across current in all directions from the focal population. These data suggest competent oyster larvae may be dispersed much greater distances by the swift currents in Foveaux Strait than predicted by Cranfield (1968b), and by Broekhuizen et al. (2011) in Tasman Bay $(<1 \mathrm{~km})$. Regardless whether these larvae have come from one or more localised populations, the distribution of recruits shows a potential for larval mixing that implies these populations are likely to be mostly demographically open rather than mostly demographically 
closed. Findings of this research do not support the hypothesis of mostly selfrecruitment. Moreover, previous studies in Foveaux Strait (Cranfield 1968a), in Tasman Bay central New Zealand (Brown 2011), and for a related oyster on the west coast of the US., Ostrea lurida (Pritchard et al. 2015) suggest that recruit densities were closely related to brooder density, and therefore dispersal was limited and those populations mostly demographically closed. This research found no relationship between $O$. chilensis brooder and recruit densities in Foveaux Strait. This lack of relationship is consistent with the findings of the fishery-wide study detailed in Chapters 2 and 3 during the low recruitment years between $2008-09$ and $2010-11$.

Recruit numbers and their peak densities decreased each year (see Figure 4-6). The declining trend is consistent with a continuing trend of declining recruitment in the Foveaux Strait oyster fishery since 2007-08 (Michael et al. 2017b). Mortality in O. chilensis caused by the oyster parasite Bonamia exitiosa (Doonan et al. 1994, Berthe \& Hine 2003, Cranfield et al. 2005) is a recurrent feature of the Foveaux Strait oyster population (Michael et al. 2017b). Fisherywide mortality from B. exitiosa over the summers of 2010-11 to 2012-13 reduced recruit-sized oyster densities and brooder densities by 10.3\%, 12.0\%, and $16.4 \%$, respectively (Michael et al. 2017b). Over the same period, recruit densities decreased to $50.3 \%$. Declining numbers of recruit-sized oysters and the potential effects of disease on reproduction (see Chapter 3, and Hine \& Jones 1994, Hine 2002) may have decreased the proportions of oysters brooding, with flow-on effects to the numbers of competent larvae and recruit densities. Overall, recruit densities were historically low (50-100 recruits per collector). These were much lower than recorded during 2007-08 (c. 2000 recruits per collector) at a nearby location West-high (see Chapter 2).

Larval cohort size can strongly influence the range of dispersal. Some oysters can vary reproductive output over space and time, e.g. Crassostrea 
virginica (Mroch et al. 2012). Any variation in the numbers of $O$. chilensis broods can strongly influence larval cohort size, with flow-on-effects on dispersal and connectivity, and therefore recruit densities. The percentages of brooders in Foveaux Strait may have decreased markedly since the 1960s and have been relatively low since the 1990s. Lower spawner densities and higher percentages of brooders in northern oyster populations (Jeffs \& Creese 1996, Brown et al. 2010) than in Foveaux Strait populations suggest that temperature may be a key factor in brooding percentages; however, Chapter 3 shows pathogens may have a larger effect the percentage of brooders within a population.

A key assumption of this research is that competent $O$. chilensis larvae in Foveaux Strait readily settle on manmade substrates without conditioning and in the absence of conspecifics. O. chilensis in Foveaux Strait readily settles on unconditioned cement board plates (Cranfield 1968b, Brown et al. 2010) and in areas with no or low oyster densities (see Chapter 2 for further discussion). This research found a strong positive correlation (Pearson's correlation, 0.96, $\mathrm{P}<$ 0.001) between the densities of recruits on spat collectors and the numbers of oyster spat (0+ year class) attached to commercial-sized oysters landed during the following winter fishing season over a twelve year period that included high and low settlement years (see Chapter 3). This research suggests that factors that induce settlement in other oysters and other marine invertebrates (reviewed by Rodriguez et al. (1993) do not appear to be important to the settlement of $O$. chilensis. In $C$. virginia these include conspecifics and biofilms (Tamburri et al. 1992), conspecific shell (Vasquez et al. 2014) and underwater sounds (Lillis et al. 2013). Manmade substrates and adult oysters of other species are also important factors in C. ariakensis settlement (Tamburri et al. 2008). This study is consistent with Smyth et al. (2018), Ostrea will settle on any clean, hard substratum. 
Longer pelagic larval durations may be one explanation for the flat settlement kernels observed in this study. The release of some early stage larvae in New Zealand (Cranfield \& Michael 1989) and in Chile (Chaparro 1990) suggests that pelagic larval duration may be more variable in $O$. chilensis than appreciated. In this study, the release of some $O$. chilensis larvae at an early stage of development, with longer pelagic larval durations and a greater opportunity to disperse further before settlement may have occurred (Jeffs \& Hickman 2000). Westerskov (1980) found smaller numbers of late-stage larvae compared to the numbers of early-stage larvae brooded by oysters of the same size, which suggests losses of larvae during development. In laboratory trials, larvae released early as veligers survived ex-parent and continued to develop to full competency (Hickman 2000). The reproductive biology of $O$. chilensis may not be a good predictor of pelagic larval duration, and its variability underestimated. If the proportion of larvae released early in Foveaux Strait (and elsewhere) is at times substantial, the swift currents in Foveaux Strait could increase dispersal and connectivity. Intraspecific variation is common in the development of larvae (Kamel et al. 2010), and may provide a bet hedge strategy (Crean \& Marshall 2009) in response to changing environments, usually temperature (Burgess \& Marshall 2011). Ostrea chilensis in Foveaux Strait may also employ this bet hedge strategy in response to changing conditions.

Simulations of larval dispersal in $C$. virginica and other marine taxa suggest that natal location, gamete or larval release date, and current flows (Edwards et al. 2007, Puckett et al. 2014), and variation in pelagic larval duration (Treml et al. 2012) account for the largest sources of variation in larval dispersal distance. In Foveaux Strait, site-specific differences may affect the numbers of brooders, brooding periods and synchrony in the release of broods. Wind can strongly influenced the speed and direction of tidal currents, and therefore determines larval transport. Moreover, Chiswell (2012) showed swift currents produce flat non-Gaussian dispersal kernels; therefore the swift currents in 
Foveaux Strait could result in flat recruit distributions along the current axis as observed in this study. A single flood or ebb tide may transport larvae up to 13 $\mathrm{km}$ in normal flows and considerably further in high flows. Wind generated cross-shelf flows are common at depths of 20-50 m (Lentz \& Fewings 2012), and are evident in Foveaux Strait and elsewhere (Puckett et al. 2014). These flows could in part explain the higher than expected levels of settlement across the current axes in this study. Regardless of normal flushing times (Gaines \& Bertness 1992), the bathymetry of Foveaux Strait may facilitate the development of gyres under some wind conditions that entrain and retain $O$. chilensis larvae over the fishery area. These conditions may be another explanation for the lack of pattern in the distribution of recruit densities.

The potential for larval transport in Foveaux Strait is higher than reported in Tasman Bay (c. $1 \mathrm{~km} \mathrm{~d}^{-1}$, Broekhuizen et al. 2011), and for other Ostreidae with longer pelagic larval durations (e.g. C. virginica with pelagic larval duration of 21 days and dispersal ranged $0.1-1.9 \mathrm{~km} \mathrm{~d}^{-1}$, Puckett et al. 2014). Despite the potential for long-range dispersal in larvae with long pelagic larval durations, some of these larvae exhibit substantial self-recruitment (Swearer et al. 2002, Swearer \& Shima 2010). Larval behaviour and their sensory abilities may play important roles in dispersal and especially in retention of larvae within natal populations. Deterministic models of dispersal show the effects of larval behaviour are mixed; these ranged from being of high importance in Corell et al. (2012) to having only a small effect elsewhere (Edwards et al. 2007, Puckett et al. 2014, Daigle et al. 2016). Swimming speeds for oysters are low (Hidu \& Haskin 1978, Dekshenieks et al. 1996) and high current speeds such as those in Foveaux Strait reduce swimming ability and vertical migration (see Peteiro \& Shanks 2015 for a discussion of this in Ostrea lurida). O. chilensis are poor and sporadic swimmers (Stead 1971a), remain near the seabed (are benthopelagic) and avoid light (are negatively phototaxic) (Cranfield 1968b). O. chilensis larvae could therefore be considered as passive particles carried by swift currents in 
Foveaux Strait and dispersal determined by pelagic larval duration and current flows. Additionally, the vertically mixed water mass in Foveaux Strait (Bradford et al. 1991, Butler et al. 1992) does not provide the advantages of different current flows, access to better food supplies, and of more favourable physical environments found in stratified water masses (Pineda et al. 2007, North et al. 2008).

\section{Conclusions}

The widespread and consistent distribution of recruits over the study area and the lack of relationship between brooders and recruits at paired sites imply greater dispersal and larval mixing of $O$. chilensis larvae than previously reported. The low recruit densities recorded in this research reflect relatively low larval cohort sizes that should result in more localised settlement than observed and by a truncated Gaussian distribution of recruits. The swift currents in Foveaux Strait, and the possibility that pelagic larval duration for some larvae may be longer than initially thought, suggest that dispersal may be further and connectivity may be higher than previously presumed for $O$. chilensis in Foveaux Strait. Although the O. chilensis fishery in Foveaux Strait is well studied, data on spatial and temporal variability in brooding, variation in the pelagic larval duration of oyster larvae, and the drivers of the variability in these stages have been scant. Moreover, the recurrent Bonamia exitiosa epizootics since 1985 discussed in Chapter 3 may have changed the reproductive output in oysters and reduced larval cohort size and possibly brooding periods. The lack of evidence for predominantly self-recruitment in $O$. chilensis from Foveaux Strait in this research and the uncertainty around pelagic larval duration emphasises the need for site-specific and species-specific information on recruitment for the management of oyster resources.

Many sessile benthic taxa including $O$. chilensis in Foveaux Strait have patchy distributions. Empirical studies of dispersal between subpopulations in 
the marine environment are rare (Gawarkiewicz et al. 2007, Pineda et al. 2007). Studies of the patterns in recruit densities at appropriate spatio-temporal scales provide estimates of the densities of competent larvae available for settlement, putative dispersal and the potential for larval mixing. These types of studies can inform the development of models and validate their predictions. Additionally, models of dispersal provide powerful tools to simulate the importance of factors driving dispersal (Puckett et al. 2014). A combination of modelling and empirical approaches will greatly increase our knowledge of dispersal, recruitment, and population structure.

This research found little evidence for mainly self-recruitment in $O$. chilensis from Foveaux Strait. Recruitment between mostly demographically open populations of $O$. chilensis should provide for greater resilience to oyster mortality from disease and fishing. The likelihood of a fishery-wide distribution of competent larvae and an abundance of settlement surfaces on the seabed (see Chapter 5) strongly suggests that post-settlement and density-dependent processes (Knights \& Walters 2010) probably drive the patchy spatial structure of oysters in Foveaux Strait. 


\section{Chapter 5 : Settlement, growth, and survival of Ostrea chilensis}

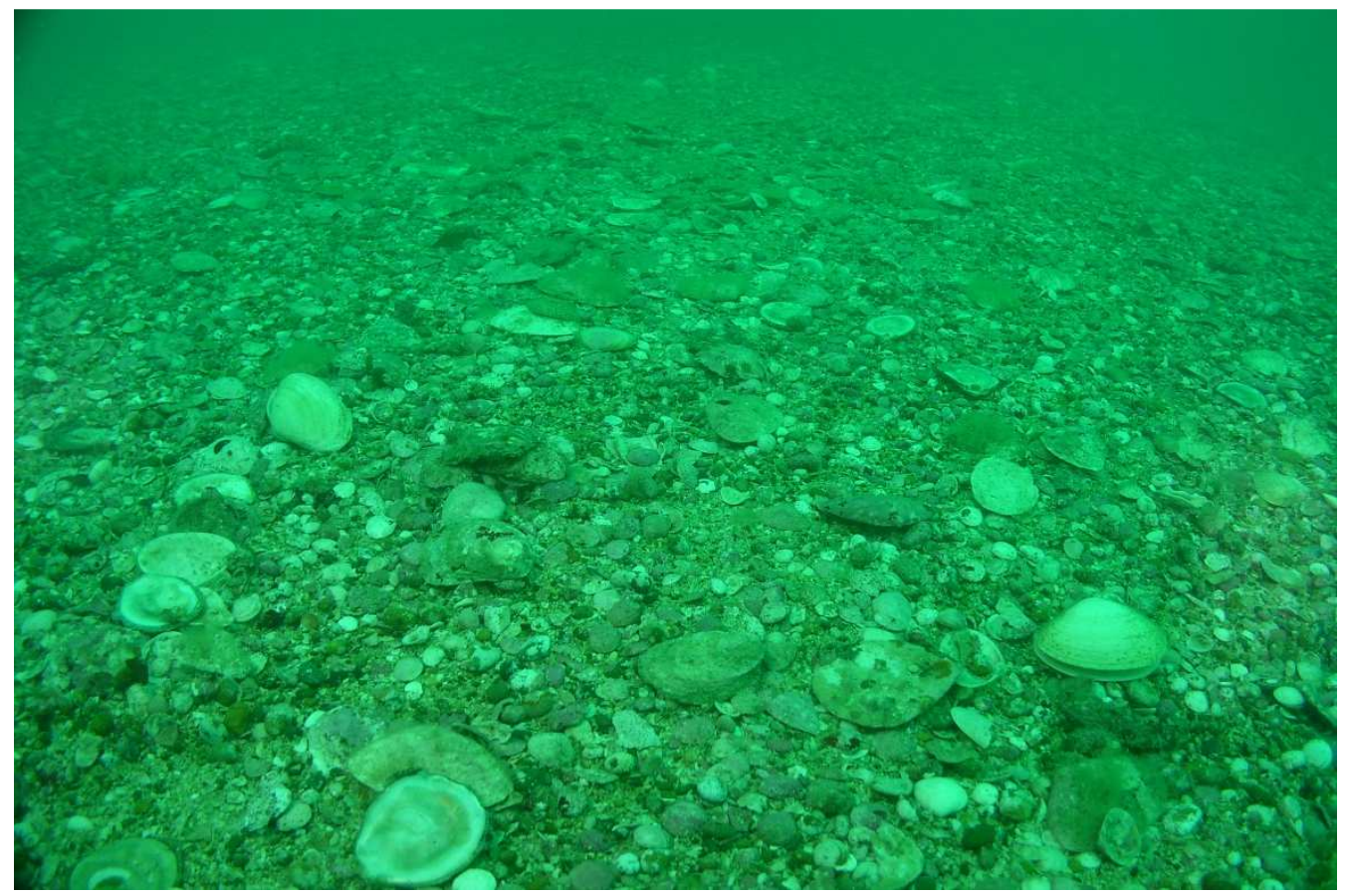

Shells for the settlement of $O$. chilensis larvae are abundant in Foveaux Strait. Image Mike Page, 


\begin{abstract}
Worldwide, many oyster populations have declined, and some are the focus of conservation and restoration efforts. Wild oyster fisheries without enhancement such as the Ostrea chilensis fishery in Foveaux Strait, southern New Zealand are rare. The spatial structure of this oyster population is typical of sessile benthic invertebrates and comprises of high-density populations separated by areas of low oyster density. Settlement and post-settlement mortality are investigated as key determinants of this spatial structure. In this research, fishery and bycatch sampling data, and growth and survival trials are used to: (1) identify benthic habitats on which high oyster densities occur, (2) identify substrata on which $O$. chilensis larvae settle and survive, and (3) compare growth and mortality of recruits $(0+)$ and spat $(1+)$ between exposed and less exposed sites, and at heights above the seabed. Shells for settlement of $O$. chilensis are abundant on the seabed. Most (66.8\%) post-settlement survivors were on the heavy shells of live and dead O. chilensis. Shells of Oxyperas elongate and Astraea heliotropium were also important. Productive fishery areas comprise mostly stable substrates of shells, sand, and gravels with little other epifauna. Sediment stability and height above the seabed are important to increased $O$. chilensis growth and reduce mortality. Findings from this research are not consistent with the need for complex biogenic habitat as essential habitat for the recruitment and abundance of $O$. chilensis in Foveaux Strait, and suggest an unusual stock-recruit relationship. Post-settlement mortality is the primary determinant of spatial structure.
\end{abstract}




\section{Introduction}

Distributions of sessile benthic invertebrates are typically patchy. Oysters (Ostreidae), like many sessile taxa, require suitable habitat as a critical prerequisite for settlement (Schulte et al. 2009), which is patchily distributed at multiple spatial-scales. Spatio-temporal variation in larval supply further adds to patchiness in settlement (see Cowen and Sponaugle 2009). Variable settlement and post-settlement mortality are also important determinants of the distributions of juveniles, and thereby patchiness in sessile adults (Hunt \& Scheibling 1997). The interaction of these stages of recruitment shape the demographics of sessile benthic invertebrate populations (David et al. 1997)

Intertidal and shallow estuarine habitats sheltered from oceanic swell typically have muddy substrates. Recruitment of oysters in these habitats is dependent on suitable substrata for settlement. Biogenic and shell reefs provide structural complexity that enhances larval settlement of oysters. Habitat complexity alters the turbulent boundary layer of the seabed (Eckman 1987, Jonsson et al. 1991, Hendriks et al. 2006, Wheeler et al. 2015). Water-borne biochemicals produced within these communities (Hidu 1969, Veitch \& Hidu 1971, Turner et al. 1994) and settlement substrata provided by conspecific and other shells (Tamburri et al. 2008, Vasquez et al. 2014) enhance settlement. There is a positive relationship between more settlement substrata and the increased probability of settlement (Powell \& Klinck 2007, Schulte et al. 2009, Smyth \& Roberts 2010, Soniat et al. 2012, Waldbusser et al. 2013). Complex habitats can stabilise sediments (Lenihan 1999), and reduce abiotic mortality of recruits (Thomsen \& McGlathery 2006, Brown 2011). The habitat complexity of oyster reefs provides refuge for juvenile oysters from predation (Grabowski 2004). However, mortality is dependent on predator oyster interactions (O'Connor et al. 2008), and high habitat complexity may increase predation of juveniles (Grabowski \& Powers 2004). Habitat complexity alters boundary flows that 
enhance feeding conditions for oysters and other filtering invertebrates (Lenihan et al., 1999).

The Ostrea chilensis fishery in Foveaux Strait, southern New Zealand is one of the last wild oyster fisheries without habitat or stock enhancement. $O$. chilensis distribution is patchy and comprises discrete, high-density subpopulations separated by areas of low oyster density (Allen \& Cranfield 1979, Michael 2010). Since 1998, levels of catch have been relatively low (7.510.0 million oysters per year with Total Allowable Catch of 15.0 million oysters, Ministry for Primary Industries 2017), less than $2 \%$ of the recruit-sized population. Between 2007 and 2012, oyster mortality from Bonamia exitiosa killed $8-12 \%$ of recruit-sized (legal-sized) oysters per year and up to $20 \%$ per year between 2013 and 2017. The trend in the abundance of oysters in the Foveaux Strait fishery is driven by disease mortality from B. exitiosa and the levels of recruitment (Ministry for Primary Industries 2017). The recurrent, high mortality of mainly recruit and pre-recruits (50-57 $\mathrm{mm}$ in length) oysters introduces high levels of oyster shell to the seabed that provides refugia and settlement substrata for a wide range of taxa, and is aggregated with sediments into physical structures by storms.

Competent $O$. chilensis larvae are likely to be ubiquitous in the fishery area and independent of the distributions of oysters (see Chapter 4). The $O$. chilensis habitat in Foveaux Strait differs markedly to those of other oysters, as does its reproductive biology (see Chapter 1). Settlement and post-settlement mortality in this species may therefore also differ markedly to that for other oysters. Cranfield et al. (1999) proposed a hypothesis: recruitment is dependent on complex biogenic habitat dominated by the bryozoans Cintipora elegans. High densities of oysters only occur on these biogenic reefs (Cranfield et al. 1999). This hypothesis is based an assumption that biogenic reefs may provide better conditions for settlement and post-settlement survival (Cranfield et al. 
$1999,2003,2004)$ as is the case in other complex habitats, such as the maerl grounds in Scotland (Hall-Spencer \& Moore 2000) and oyster reefs (Schulte et al. 2009). Cranfield et al. (2004) presented a theoretical model for succession in sessile benthic invertebrate species and benthic habitat regeneration believed to be important to oyster recruitment.

Anecdotal evidence suggests an alternative hypothesis: that oyster density in complex habitats is low and oyster condition poor (author's data; Stead 1971b) and oysters thrive on substrates with little epifauna (Fleming 1952, Cullen 1962, Stead 1971b, Robjohns 1979, Hill et al. 2010). Post settlement mortality is high in sessile invertebrates (Stoner 1990, Hunt \& Scheibling 1997, Pineda et al. 2006) and in Foveaux Strait oysters (Cranfield 1979). Mortality caused by both biotic processes (predation, over-colonisation, and disease) and abiotic disturbance that may include abrasion and or burial by sediments mobilised during storms, and incidental mortality from dredging (Cranfield et al. 1997). Of the relatively small numbers of $0+$ year class oysters (the previous summers spat) encountered by a dredge, up to $80 \%$ are killed; however, the mortality of recruit and pre-recruits oysters is substantially lower (Cranfield et al. 1997). Substrata suitable for settlement of $O$. chilensis in complex biogenic habitats are likely to be scarce as they are readily colonised by other epibenthic taxa. Moreover, oyster spat themselves provide settlement substrata and overcolonised by other taxa (author's unpublished data). Complex habitats may increase the abundance and variety of oyster predators: polychaete worms, gastropods, crabs, octopuses, and brittle stars (Cranfield 1975) and thereby increase predation pressure, only in part mediated by refuges provided by complex biogenic habitat (Talman et al. 2004). These contrasting hypotheses have prompted this research of settlement and survival of $O$. chilensis in Foveaux Strait.

Large swells and high tidal currents create a high-energy environment in Foveaux Strait that determines the distribution and stability of sediments and the 
composition and distribution of benthic communities, as in the UK (Bricheno et al. 2015, Joshi et al. 2017). Storms maintain a dynamic process of habitat destruction (through scouring and sediment inundation) and regeneration (Roff et al. 2015). The western entrance to Foveaux Strait is the most exposed coastal area in New Zealand (Gorman et al. 2003), and subjected to greater sediment mobility during storms than in the eastern area. Storms also increase tidal current flows, which are higher in the shallow, eastern strait. The effects of this changeable, high-energy environment on the spatio-temporal distribution of benthic communities are poorly known. Differences in benthic communities in Foveaux Strait, and the contributions of infauna and epifauna are most likely determined by the gradient of exposure to oceanic swells and the mobility of sediments (Michael 2007). The frequency and magnitude of disturbance determines resilience in these communities (DeAlteris et al. 1999). In Foveaux Strait, changes in benthic biogenic communities (Cranfield et al. 1999), release and transport of sediments (Cranfield et al. 2003), and spatio-temporal patterns of regeneration (Cranfield et al. 2001, 2004) are all attributed to dredging for oysters, with no consideration of the effects of the frequent storms. In this chapter, available data, some dating back to 1998, is used to explore the effects of exposure to oceanic swells and sediment movement on $O$. chilensis recruitment. Despite the limitations and age of these data, the aim is to summarise these in a way that will enable new hypotheses and future research to be undertaken.

The aims of this study are to: (1) identify benthic habitats on which commercial fishers target high densities of oysters, i.e. habitats important to fishers (2) identify the range of settlement substrata on which $O$. chilensis settle and survive, and (3) estimate differences in growth and mortality of 0+ recruits and $1+$ spat between western and eastern areas. As the normal flows in Foveaux Strait are swift and likely to transport sediment and shell, (4) this study also investigated how the survival and growth of recruits on artificial collectors may 
vary with height above the seabed. These data aim to provide insights into oyster recruitment and the important habitat attributes for successful settlement and post-settlement survival. Discussion of these research finding includes the roles of complex biogenic habitats to oyster production in Foveaux Strait specifically, which represents a different oyster habitat from those studied elsewhere.

\section{Methods}

The depth, strong currents, and hard substrate of Foveaux Strait limit the methods available to sample recruits and settlement substrata (Michael et al. 2008c). Photographic, video and grab sampling methods have severe limitations in Foveaux Strait. Most of the area is too deep for effective sampling by divers. Data to inform this study were collated from a number of programmes, these used three sampling methods: (1) dredge sampling, conducted over relatively broad geographic areas; (2) sampling by divers conducted in a localised, shallow eastern area; and (3) sampling by passive, artificial spat collectors at sites in western and eastern fishery areas. Dredge sampling can be an effective method for sampling recruits as they remain attached to large settlement substrata for $3+$ years and to a size greater than $30 \mathrm{~mm}$ in length. Moreover, the left cupped valves of dead recruits attached to the settlement substrata represent oyster mortality and their sizes at death (Cranfield 1968b). The portion of the area on cement board plates (comprising the spat collectors) settled by other organisms was also summarised; this competition for space may affect the space available to $O$. chilensis larvae and ultimately oyster recruitment. 


\section{Benthic habitats and substrates targeted by commercial fishers}

The Foveaux Strait oyster fishers' logbooks record fine spatial-scale catch and effort data from the fishery (Michael et al. 2012b). Daily data are recorded to a spatial resolution of one nautical mile squares based on a grid that covers the main oyster fishery area (Figure 5-1). Bycatch data provide qualitative and semi-quantitative information on the seabed composition (substrate) and the fauna encountered by the dredge to identify important habitats to oyster production. Eight categories are recorded in $10 \%$ increments: (A) empty dredge indicating fine sands only, (B) red algae, (C) kaeos (sea tulips, Pyura pachydermatina), (D) shell, (E) sand, (F) gravel, (G) sponges, and (H) mixed invertebrates (mainly comprising mytilids, ascidians, and bryozoans). Bycatch from fishers' logbook data are summarised graphically for years 2007 to 2016 combined.

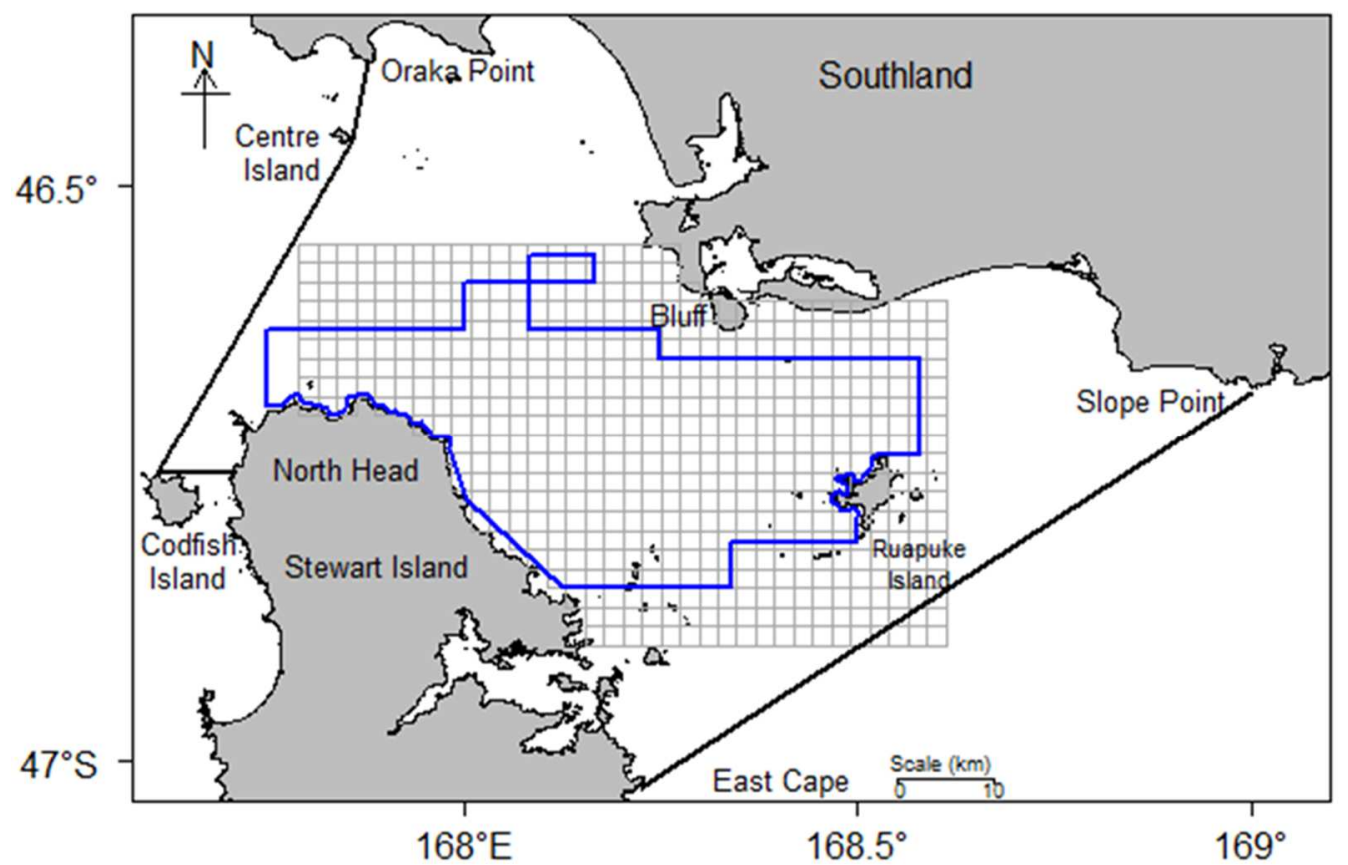

Figure 5-1. Foveaux Strait oyster logbook grid (1 nautical mile squares, grey lines) established by skippers to cover the commercial fishery area. The boundaries of the 2007 stock assessment survey area shown as a blue line. Heavy black lines in the west and east denote the OYU 5 stock boundaries. 


\section{Settlement substrata on which $O$. chilensis settle and survive}

Bycatch to investigate substrata for $O$. chilensis settlement was sampled during fishery surveys in February 2006, 2007, 2010, and 2011 (Figure 5-2), using standard Foveaux Strait oyster dredge sampling methods (see the estimates of spawner densities section in the Appendix). Dredges were landed unwashed to minimise the loss of small shells and other taxa. Dredge size selectivity and dredge efficiency (the scalar used to estimate absolute abundance from dredge samples) most likely vary between different sized and shaped taxa for the initial part of the dredge tow. However, filtration of dredge contents rapidly ceases, which allows sediments and small shells down to a size of c. $10 \mathrm{~mm}$ in diameter to be retained (author's unpublished data). No data on the dredge selectivity of different taxa are available, and the analysis of bycatch assumes similar dredge selectivity and efficiency among bycatch components. The numbers of taxa and their shells with and without recruits $(0+$ year class oysters that settled within months before February surveys) are summarised.

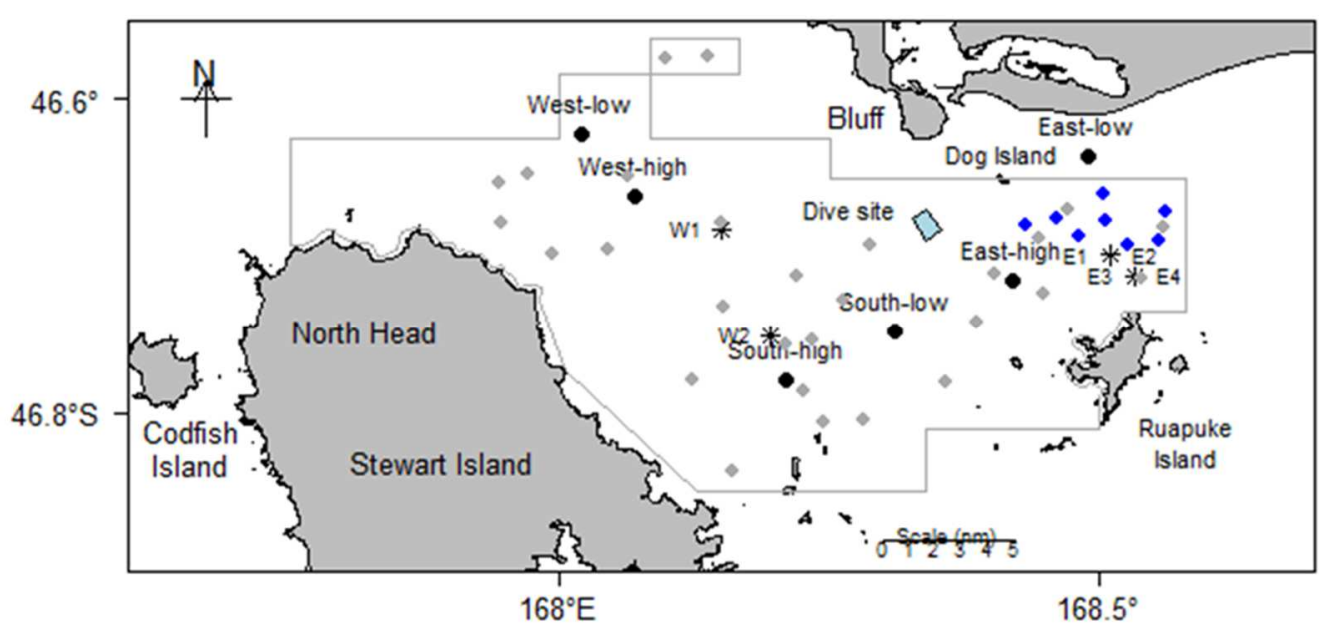

Figure 5-2. The Foveaux Strait oyster fishery area delimited by the grey lines representing boundaries for stock assessment surveys and sites where settlement substrata and bycatch were sampled. Dive and dredge ( 2010 \&2011) sampling was within the area shaded light blue. The fishery-scale spat monitoring sites 2009-2012 are shown as black filled circles (e.g. West-low), and the 1999/2000 spat collector, growth and mortality investigation sites shown as black asterisks (W1 \&W2, E1-E4). Sites sampled for bycatch and oyster spat during the 2006 survey shown in blue diamonds and the 2007 survey in grey diamonds. 
Divers sampled $27 \times 1 \mathrm{~m}^{2}$ quadrats from six shallow ( 20 m) sites in an eastern fishery area in December 2007 (indicated by "Dive site" in Figure 5-2). Data comprised counts of the numbers of shells (valves) of each species, with and without $O$. chilensis recruits. In February 2008, an opportunistic sample from the dive site was taken from a single dredge tow after a high recruitment event (see Chapter 2). Dredge contents were randomly subsampled and counts of valves and shells with and without recruits were scaled to the whole catch (x16 for O. chilensis (OYS), x8 for the mactrid Oxyperas elongata (OEL, Quoy \& Gaimard, 1835), and x1 for the gastropod Astraea heliotropium (ASH; Martyn, 1784). These counts are adjusted for dredge efficiency (0.17) and the area swept by the dredge $\left(1221 \mathrm{~m}^{2}\right)$. Summary statistics of the number of each valve of OYS, OEL, and ASH shells, and the numbers of live and dead oyster recruits are calculated.

\section{Differences in growth and mortality}

Sites selected for growth and mortality studies from historical sampling represent a range of habitats and exposures to oceanic swells (see Figure 5-2, Table 5-1). Of these, only two were available from the western fishery area and four in eastern locations. Sites are described in detail (Cranfield et al. 2004).Western sites (c. $40 \mathrm{~m}$ ) were predominantly sand and shell habitats and subjected to sediment movement during storms (Michael et al. 2008c). Eastern areas were in depths of 18-25 m. These sites habitats were predominantly gravel and shell with higher current flows, and variable sediment stability and benthic structure among sites. Eastern sites were mostly sheltered from oceanic swells although occasionally subjected to mobile sediments (Michael et al. 2008c).

Ostrea chilensis growth is strongly seasonal and only occurs over the summer (Dunn et al. 1998). A recruit and spat growth and mortality study was undertaken between October 1999 and March 2000, over the growing period. Spring storms are also frequent over this time, and some mortality was expected 
over this period. The Bluff Oyster Management Company Limited (BOMC) provided two year classes of settlers for this study, oyster recruits and spat. The 0+ year class recruits (hereafter recruits) comprised late stage larvae collected from oysters harvested from Foveaux Strait before the 1999 oyster season and settled on oyster valves held in mesh bags. The 1+ year old oyster spat (hereafter spat) were settled by the same method as the recruits in 1998, and in October 1998 transferred to wharfs in Bluff Harbour and held in suspended culture until October 1999 when mean diameter of recruits was c. $0.5 \mathrm{~mm}$ and mean diameter of spat was $8.6 \mathrm{~mm} \pm 0.1 \mathrm{~mm}($ mean $\pm \mathrm{SE})$.

Table 5-1. Locations of the six sites used for growth and mortality investigations, where cement board sticks with $0+$ recruits and 1+ spat on oyster shell (single valves), and spat collectors were deployed. Two sites selected in the western fishery area and four in eastern locations representing a range of habitats and exposures to oceanic swells (see Figure 5-2).

\begin{tabular}{lrrrr}
\hline Site & $\begin{array}{r}\text { Latitude } \\
\text { Deg }\end{array}$ & Min & $\begin{array}{r}\text { Longitude } \\
\text { Deg }\end{array}$ & Min \\
\hline W1 & 46 & 40.9640 & 168 & 9.0449 \\
W2 & 46 & 45.0164 & 168 & 11.7619 \\
E1 & 46 & 41.9453 & 168 & 30.6194 \\
E2 & 46 & 41.9453 & 168 & 30.6194 \\
E3 & 46 & 42.7541 & 168 & 31.9956 \\
E4 & 46 & 42.7541 & 168 & 31.9956 \\
\hline
\end{tabular}

Estimates of mean densities of recruits and spat were made from thirty randomly selected valves of each year class. Each oyster valve contained at least twenty recruits or spat. At the end of the study in March 2000, counts of live and dead recruits or spat per valve were recorded. Numbered cement board sticks (900 mm long, $120 \mathrm{~mm}$ wide and $9 \mathrm{~mm}$ thick) had ten oyster valves with either recruits or spat attached with cable ties. Hand drawn maps recorded the orientation of each oyster valve on the sticks and the location of each numbered recruit or spat on the valves. The orientation of each oyster valve recorded as cupped valve up (CU), cupped valve down (CD), flat valve up (FU), and flat 
valve down (FD). Only spat were measured for height (greatest distance dorsal ventral axis) and length (anterior posterior axis) to the nearest millimetre down in situ before deployment. Only oyster valve orientation was recorded from cement board sticks with recruits. The sticks were held in slotted boxes to protect valves from mechanical damage and held in flowing seawater until they were set out on the seabed in Foveaux Strait.

At each site (see Figure 5-2), five sticks with recruits, five sticks with spat, and five passive spat collectors were pegged to the seabed by divers in October 1999. Spat collectors consisted of a reinforced concrete base with a steel frame holding 4 cement board settlement plates. The settlement plates were not conditioned before deployment (see Chapter 2). Differential Global Positioning Systems (DGPS) with less than $1 \mathrm{~m}$ positioning accuracy was used to record the site locations where sticks and collectors were haphazardly distributed on the seabed.

Divers recovered the cement board sticks in March 2000 after deployments of between 130 and 138 days. Data on the height and length of recruits and spat, along with their status as alive or dead were recorded. Height and length data of spat at recovery were recorded against their initial measurements determined from their unique identifier comprising: stick, valve, and spat numbers and their location on the shell maps. The data for recruits were similarly recorded; however, because recruits were deployed to the seabed shortly after settlement, growth increments (length and height) were therefore the sizes of live recruits in March 2000. For live spat, growth increments were the differences in size between October 1999 and March 2000.

Once $O$. chilensis larvae settle, the juvenile shell grows quickly, extending away from initial larval shell (prodissoconch). During this time of rapid growth, the left valve remains attached to the settlement substratum for two to three years. Oyster spat that have died leave a record of their size at death, 
as either the whole shell (articulated valves) or only the attached left valve. The percentage size frequencies of dead spat provide information on when postsettlement mortality occurs. Estimates of mortality calculated as the proportion of dead to all spat (dead and alive) at March 2000. In addition to those recruits deployed on sticks, some larvae settled from the plankton and completed metamorphosis on the cement board sticks after they were deployed to the seabed. These $0+$ year recruits are distinguished in the data as "natural-recruits". Growth and mortality in recruits, natural-recruits and spat, are estimated separately. To avoid any confusion, no records were made of natural-recruits from shells on sticks with recruits. These data allow comparisons between sites, and the performance of recruits and natural-recruits.

The shapes of fast-growing juvenile oyster shells are determined by the available space around them, and their shapes may vary. Dunn et al. (1998) estimated growth as change in diameter ((length + height $) / 2)$. This research records growth as diameter, except for settler data from spat collectors recorded as heights only. Height and diameter are highly correlated $(\mathrm{R}=0.96)$, and for the small size range of recruits and spat, differences were negligible (less than 0.5 $\mathrm{mm})$.

\section{The survival and growth of recruits at different heights above the seabed}

Divers also recovered passive artificial spat collectors in March 2000, at the same time cement board sticks were recovered (after deployments of between 130 and 138 days). Data from recruits that settled on spat collectors were recorded by site, collector, height off the seabed (levels 1-4: $36 \mathrm{~cm}, 24 \mathrm{~cm}, 12$ $\mathrm{cm}$, and $\sim 2 \mathrm{~cm}$ respectively), and surface (upper and lower). Their heights only, and status as live or dead recorded as for recruits and spat from the cement board sticks. 


\section{Data summaries and analysis}

A Poisson distribution best represented the overdispersed settler count and size data. Samples contained different numbers and these data often contained missing values and were therefore analysed using non-parametric methods. Tests for overall significant differences among groups used the Wilcoxon rank sum (also known as Mann-Whitney test) and Kruskal-Wallis tests for pairwise comparison using the stats v3.5.1 package in $\mathrm{R}$ ( $\mathrm{R}$ Core Team 2016). Summary statistics are given as means with $95 \%$ CI or medians, $5^{\text {th }}$ and $95^{\text {th }}$ percentiles as appropriate.

\section{Results}

\section{Benthic habitats targeted by commercial fishers}

Benthic habitats and substrates targeted by commercial fishers are determined from fishers' logbook data. The oyster season in Foveaux Strait is 1 March to 31 August. Logbook data (2006-2017, 9241 records) represent 100\% of the catch from commercial fishing and prospecting (exploratory fishing) over that time. Almost all fishing occurred in areas of shell, sand and gravel dominated substrates (Figure 5-3), and these areas are likely to represent the most productive areas in the fishery. Mostly small volumes of epifaunal bycatch were present in the 8250 commercial dredge tows (Figure 5-3): sponges were present in $20.1 \%$ of tows and mixed invertebrates (comprised mytilids, ascidians, and bryozoans) in $24.9 \%$ of tows. Because of the greatly overdispersed percentages of these bycatch categories (Figure 5-3), median percentages and percentiles are given. Very few tows contained high percentages of biogenic bycatch. Of the tows that contained sponges or and mixed invertebrates, sponges accounted for a median of 5\% (5th \& 95th percentiles: $1 \% \& 30 \%$ ) and mixed invertebrates $5 \%$ (5th \& 95th percentiles: $1 \%$ \& 50\%) of 
the bycatch volume excluding oysters. This composition suggests some regeneration of epibenthic fauna as proposed by Cranfield et al. (2001).

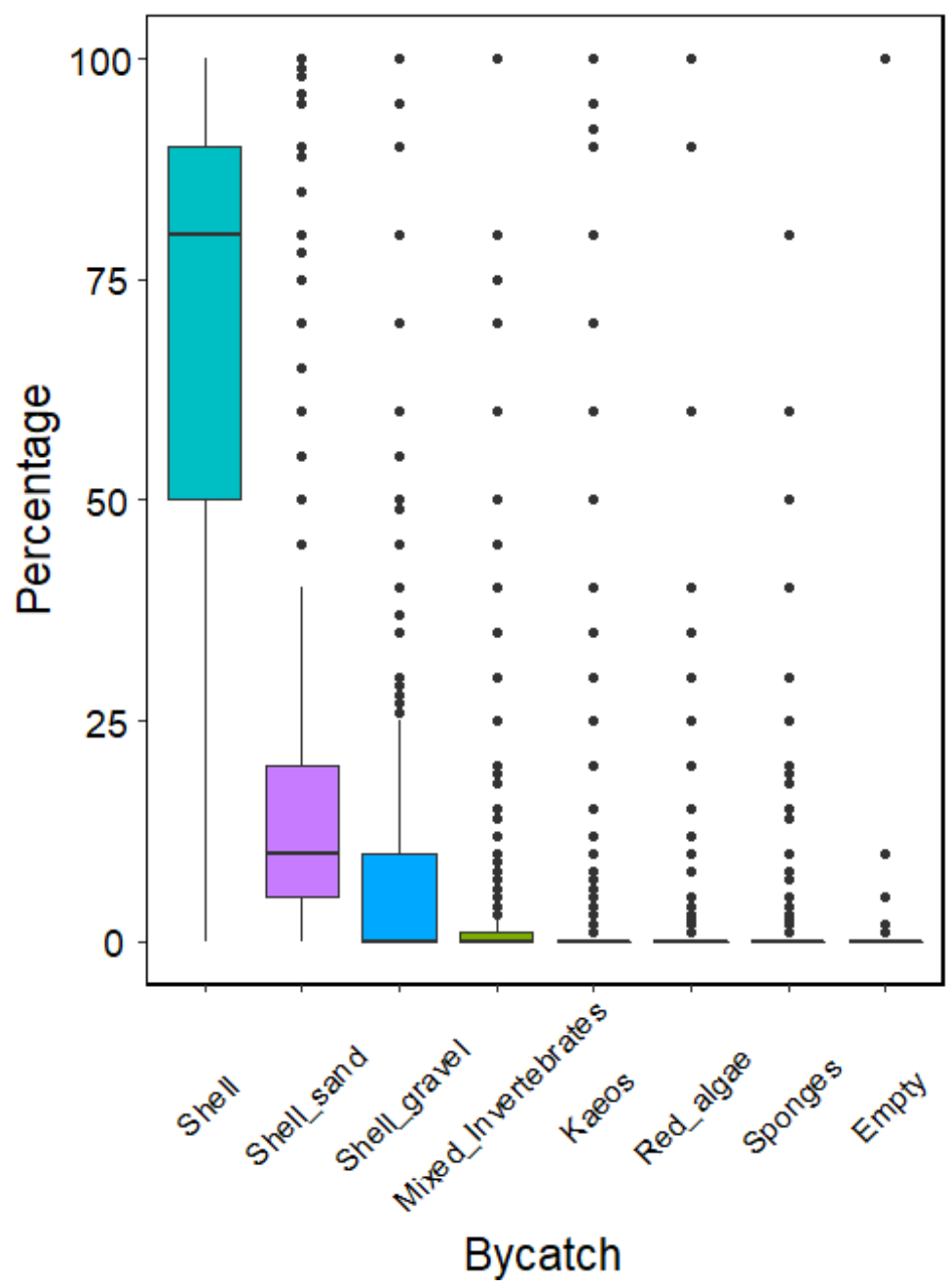

Figure 5-3. The percentage occurrences of each bycatch category from fishers' logbook data representing $100 \%$ of the catch for years (oyster seasons, 1 March to 31 August) 2007 to 2016 combined. Kaeos (sea tulips, Pyura pachydermatina) and mixed invertebrates mainly comprise mytilids, ascidians, and bryozoans. Boxplots show medians (solid lines) and the boxes the 25 and 75 percentiles. Whiskers shown at the 95 percentiles, with outliers shown as black circles outside of this range. 


\section{Ostrea chilensis settlement substrata}

Settlement substrata on which $O$. chilensis settle and survive were determined from the combined bycatch data from dredge sampling in 2006, 2007, 2010, and 2011. Although all benthic habitats were not sampled in the fishery area, fishers target high densities of oysters where ever they occur. Anecdotal evidence and Fleming (1952), Cullen (1962), Stead (1971b), Robjohns (1979), and Hill et al. (2010) suggest oyster densities are low in biogenic habitat; however, high densities of oysters can occur on the edges of "biogenic reefs" after Cranfield et al. (1999). Catches comprised the shells and live animals of 64 taxa $(n=13650)$. Recruits readily settled on the shells of live and dead $O$. chilensis (OYS) and the gastropod Astraea heliotropium (ASH). Together, the two substrata accounted for $90.8 \%$ of all post-settlement survivors (larvae that has settled and completed metamorphosis) (Table 5-2). Shells of the mytilid Modiolus areolatus (MOA, Gould, 1850), barnacles (Balanus spp.), and the mactrid Oxyperas elongate (OEL) accounted for a substantial portion of the remainder (Table 5-2). The percentages of live OYS, OYS_shell, and live ASH with settlers over all taxa was similar between 2006 and 2007: live OYS 42.6\% and $40.2 \%$, OYS shell $24.5 \%$ and $23.6 \%$, and ASH $18.9 \%$ and $20.7 \%$ respectively. Data from this research show live OYS and their shells are the most important substrata for settlement and survival. 
Table 5-2. Taxa and shells representing greater than $1 \%$ of the total bycatch composition by number that had $O$. chilensis recruits attached. Taxa: $O$. chilensis (OYS), the gastropod Astraea heliotropium (ASH), the Mytilid Modiolus areolatus (MOA), barnacles Balanus spp. (BAR), the mactrid Oxyperas elongate (OEL), and their shells denoted by suffix (_Shell). Numbers of each bycatch component (n), those with settlers attached (n.Recruits), the percentage of each bycatch component that had settlers attached (\%), the percentage of all bycatch components (\% TWS), and the percentage of all bycatch sampled with recruits attached (\% AWS).

\begin{tabular}{lrrrrr}
\hline Taxa & n & n.Recruits & \% & \% TWS & \%AWS \\
\hline OYS & 7817 & 390 & 5.0 & 48.6 & 3.1 \\
OYS_Shell & 2370 & 146 & 6.2 & 18.2 & 1.1 \\
ASH & 211 & 112 & 53.1 & 14.0 & 0.9 \\
ASH_shell & 675 & 80 & 11.9 & 10.0 & 0.6 \\
MOA_shell & 803 & 42 & 5.2 & 5.2 & 0.3 \\
BAR_shell & 219 & 16 & 7.3 & 2.0 & 0.1 \\
OEL_Shell & 489 & 8 & 1.6 & 1.0 & 0.1 \\
& & & & & \\
Totals & 12545 & 794 & & & \\
\hline
\end{tabular}

Samples collected by divers in December 2007 comprised mostly OYS $(\mathrm{n}=408)$ and OEL $(\mathrm{n}=145)$ shells. Samples did not contain any live recruitsized oysters. A mean of $87.5 \%$ (95\% CI 75.2 - 99.7\%) of all O. chilensis recruits were on OYS shell. The mean number of OYS valves with one or more recruits was $13.9 \%$ (95\% CI $6.3-21.4 \%$ ) and the mean of OEL valves with one or more recruits was $1.4 \%$ (95\% CI $0-3.1 \%)$. Dredge sampling 3 months later found most $O$. chilensis recruits were OYS shell (77.8\%), with some OEL (22.2\%) and only a few ASH shells (Table 5-3). The numbers of recruits per valve were similar between bycatch components (Table 5-3). 
Table 5-3. Estimates of the numbers of valves with and without recruits sampled from a single tow at the dive site in February 2008 (see light blue shaded area in Figure 5-2). Summary statistics of the number of each type of valve OYS, OEL, and ASH, and the numbers of live and dead oyster recruits. Percentage survival is the number of live recruits as a percentage of all recruits (live and dead).

\begin{tabular}{lrrrr}
\hline & OYS & OEL & ASH & All valves \\
\hline Total all valves & 7,248 & 2,064 & 4 & 9,316 \\
Number valves with spat & 4,960 & 1,336 & 4 & 6,300 \\
Percent of all valve types & 77.8 & 22.2 & 0 & 100 \\
Percent with spat & 68.4 & 64.7 & 100 & - \\
Percent of all valves, all & 53.2 & 14.3 & 0 & - \\
types with spat & & & & \\
& & & & 27,496 \\
Total number of spat (live & 21,056 & 6,424 & 16 & \\
and dead) & & & & \\
Spat per valve & 2.9 & 3.1 & 4 & \\
Number of live spat & 16,480 & 5,616 & 4 & \\
Percentage survival & 78.3 & 87.4 & 25 & \\
\hline
\end{tabular}

The effects of collector plate coverage by benthic taxa on Ostrea chilensis settler densities

Spat collector surfaces settled by benthic taxa combined covered a median surface area of $30 \%$, ranging from $0 \%$ to $100 \%$ (Figure 5-4). Primarily filamentous algae accounted for a median of 3\% (range: $0 \%$ to $90 \%$ ), barnacles (mostly Balanus decorus, Darwin, 1854) a median of 5\% (range: 0\% to 95\%), and other species combined a median of 3\% (range: $0 \%$ to $41 \%$ ). No inhibition of $O$. chilensis settlement or competition for settlement space was detected (Figure 5-5). An upward trend in settler densities with increasing cover may reflect local-scale current flows and the numbers of all larvae encountering the spat collectors. 


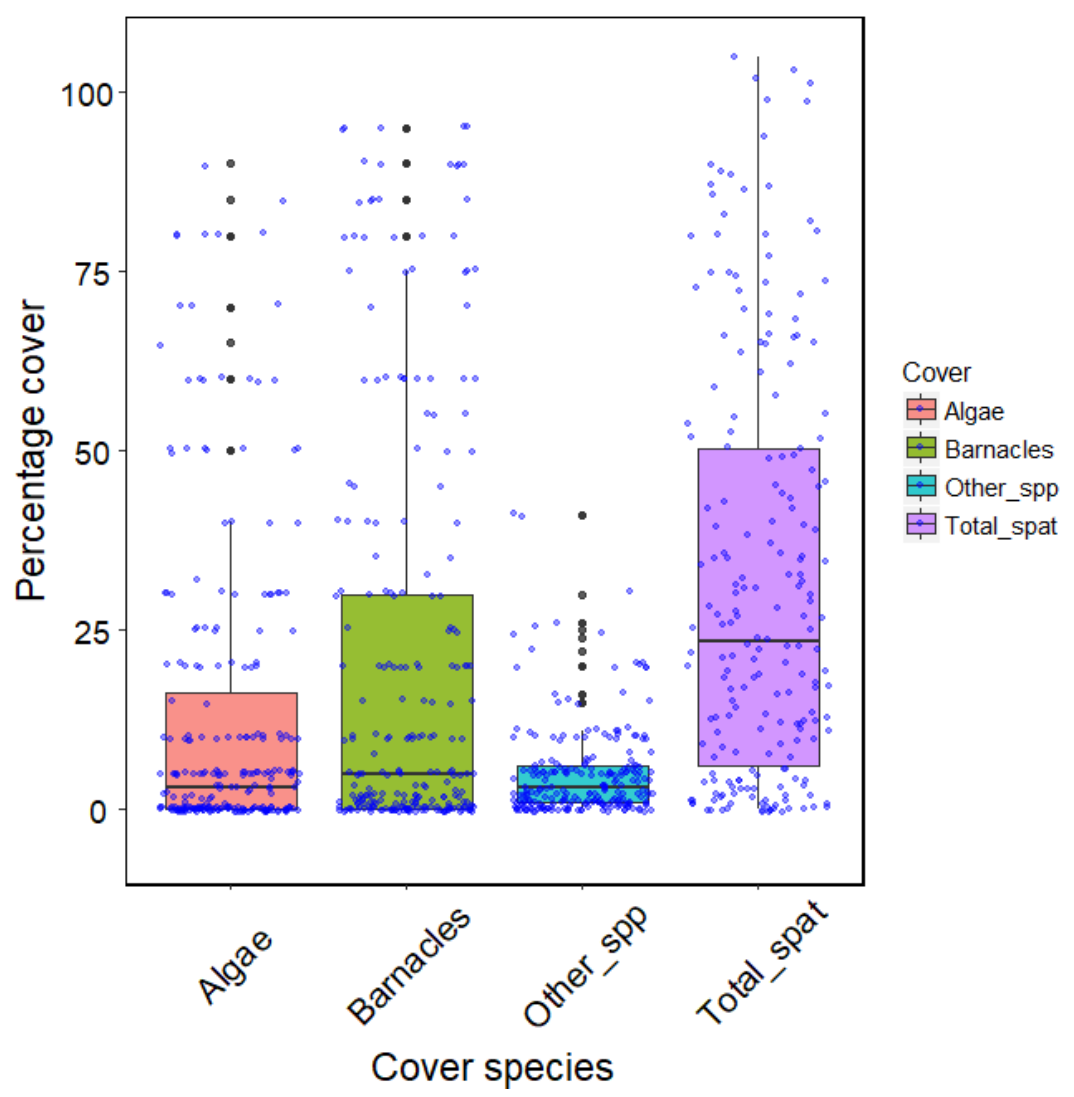

Figure 5-4. Percentage cover of collector plates by three categories of benthic taxa (algae, barnacles, other species) and by total cover by all taxa. Boxplots show medians (solid lines), boxes 25 and 75 percentiles, whiskers at 95 percentiles, and outliers shown as black circles above and below whiskers. 


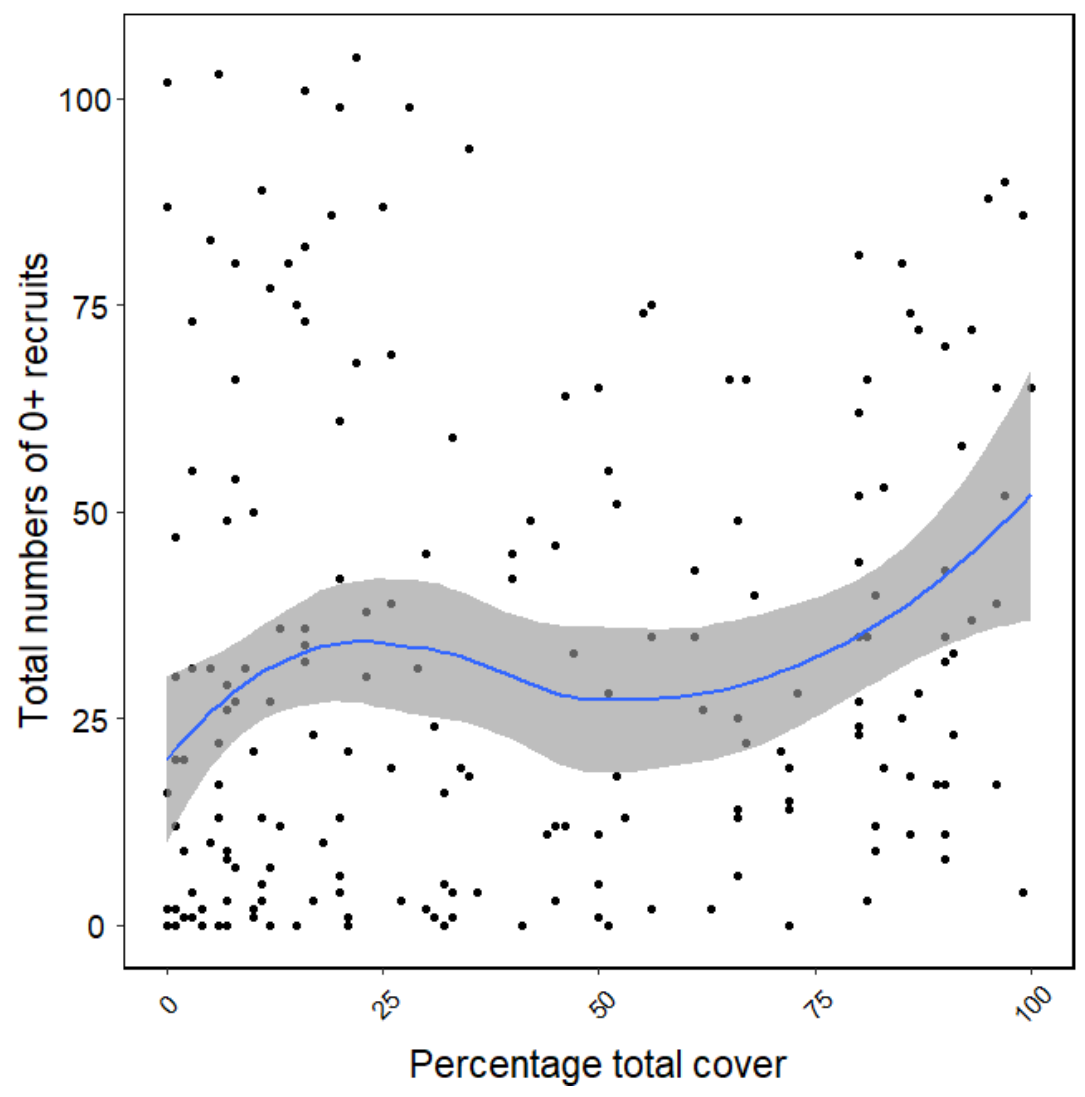

Figure 5-5. Total numbers of recruits versus percentage cover of all other benthic taxa combined by plate surface. Fitted line is a loess smoother and shaded area depicts \pm 1SE.

\section{Growth}

Recruits across all sites $(\mathrm{n}=1232)$ grew to a mean diameter of $4.5 \mathrm{~mm}$ $\left(5^{\text {th }} \& 95^{\text {th }}\right.$ percentiles: $\left.2.0 \& 8.5 \mathrm{~mm}\right)$, and natural-recruits $(\mathrm{N}=138)$ grew to a median diameter of $4.5 \mathrm{~mm}$ ( 5 th $\neg 95$ th percentiles $2.0-9.5 \mathrm{~mm})$. Natural-recruit sizes may represent several settlement events (larval cohorts). Growth in recruits and natural-recruits was not significantly different across all sites $(\mathrm{p}=0.659)$. Recruits on passive collectors $(n=10918)$ across all sites and all levels (heights above the seabed) grew to a median height of $5.0 \mathrm{~mm}$ (5th \& 95th percentiles 2 \& $10 \mathrm{~mm})$. Spat recovered in March $2000(\mathrm{n}=714)$ had a median diameter of 
$17.0 \mathrm{~mm}(5$ th $\&$ 95th percentiles $8.5 \& 27.0 \mathrm{~mm})$. Mean increment in diameter after c. 140 days grow out was $8.0 \mathrm{~mm}$ (95\% CI: 1.5-15.5).

\section{Differences in growth between western and eastern sites}

Growth in $0+$ recruits on cement board sticks differed significantly between western and eastern areas $(\mathrm{p} \leq 0.001)$, which had median diameters of $2.5 \mathrm{~mm}$ and $4.5 \mathrm{~mm}$ respectively. Growth also differed significantly between sites, recruits grew significantly less at western sites (W1 \& W2) $(\mathrm{p} \leq 0.001)$ (see Figure 5-6 and Table 5-4).

The numbers of live natural-recruits on shells that settled from the plankton and survived after metamorphosis were low. Recruit growth differed significantly $(\mathrm{p} \leq 0.001)$ between western and eastern areas, with median diameters of $2.7 \mathrm{~mm}$ in the west and $4.5 \mathrm{~mm}$ in the east. Growth also differed significantly between sites $(\mathrm{p} \leq 0.001)$, and recruits grew less at W2 $(\mathrm{p}<0.023)$ than the other five sites including W1, (see Figure 5-6 and Table 5-4).

Growth of all recruits on artificial spat collectors was not significantly different between western and eastern areas $(\mathrm{p}=0.29)$. A key difference between recruits on collectors and recruits attached to shells on cement board sticks is that recruits on collectors are mostly growing above the seabed and recruits attached to shells are on the seabed. Growth of recruits on all plates and levels was significantly different between sites ( $\mathrm{p} \leq 0.001$, Figure 5-7 and Table A-5 in the growth and mortality $0+$ recruits and $1+$ spat section in the Appendix), pairwise Wilcox test showed growth at only three sites were not significantly different (E1 \& E2, E1 \& W1, and E4 \& W2). Recruit sizes were significantly different both between heights (levels), and between upper and lower plate surfaces ( $\mathrm{p} \leq 0.001$, respectively). All combinations of levels, top to bottom (360 $\mathrm{mm}, 240 \mathrm{~mm}, 120 \mathrm{~mm}$, and $20 \mathrm{~mm}$ off the seabed) except for the middle two plates (Level $2 \&$ Level 3) were significantly different $(p \leq 0.001)$ to each other. 
The largest recruits were on the highest plates (Level 1) above the seabed and recruits closest to the seabed (Level 4) were smaller than for levels 1-3. Recruit size at level 4 was not significantly different between sites ( $\mathrm{p}=0.857)$, Figure 57 and Table A-5 in the growth and mortality $0+$ recruits and 1+ spat section in the Appendix. Recruits on the upper surfaces of plates were significantly larger than those on the under/lower surfaces $(\mathrm{p} \leq 0.001)$.

Spat (1+) growth increments (diameter) were not significantly different $(\mathrm{p}=0.086)$ between eastern and western areas; however, these increments were significantly different $(\mathrm{p} \leq 0.001)$ between sites (Figure A-10 in the growth and mortality 0+ recruits and 1+ spat section in the Appendix and Table 5-5). Spat grew less than the mean for all sites at W2 and more than all sites at E4 (Figure A-10 in the growth and mortality $0+$ recruits and $1+$ spat section in the Appendix). 


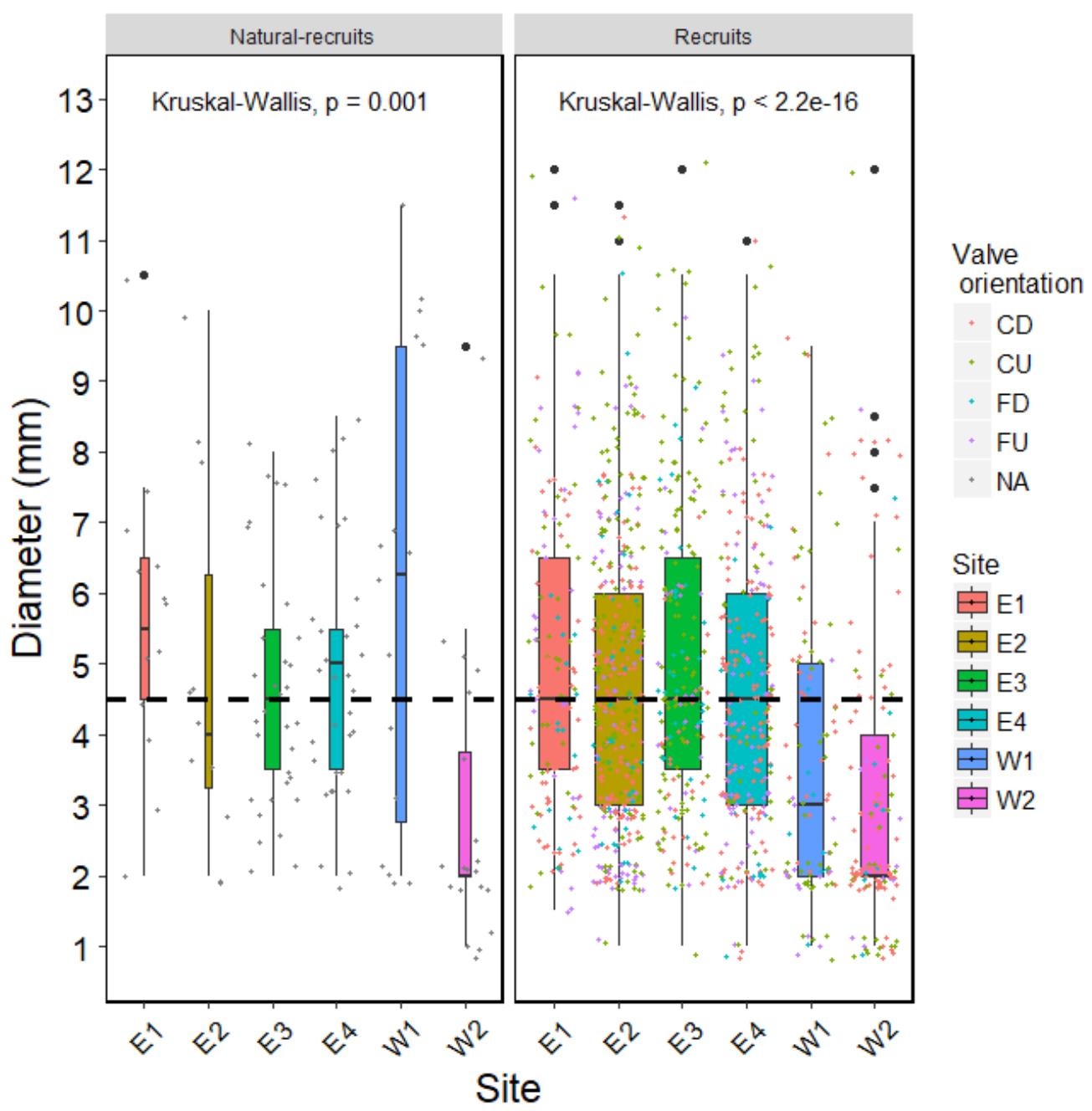

Figure 5-6. Size (diameter $\mathrm{mm})$ of recruits $(0+$ oyster spat): natural-recruits (left panel) and recruits (right panel) at March 2000 (less than 140 days after settlement) by site and valve orientation. Jittered data points represent spat size coloured by valve orientation. Boxplots show medians (solid lines), mean (heavy dashed line), boxes at the 25 and 75 percentiles. Whiskers show at the 95 percentiles with outliers shown as black circles above and below whiskers. Bar widths scaled to the relevant sample sizes. 


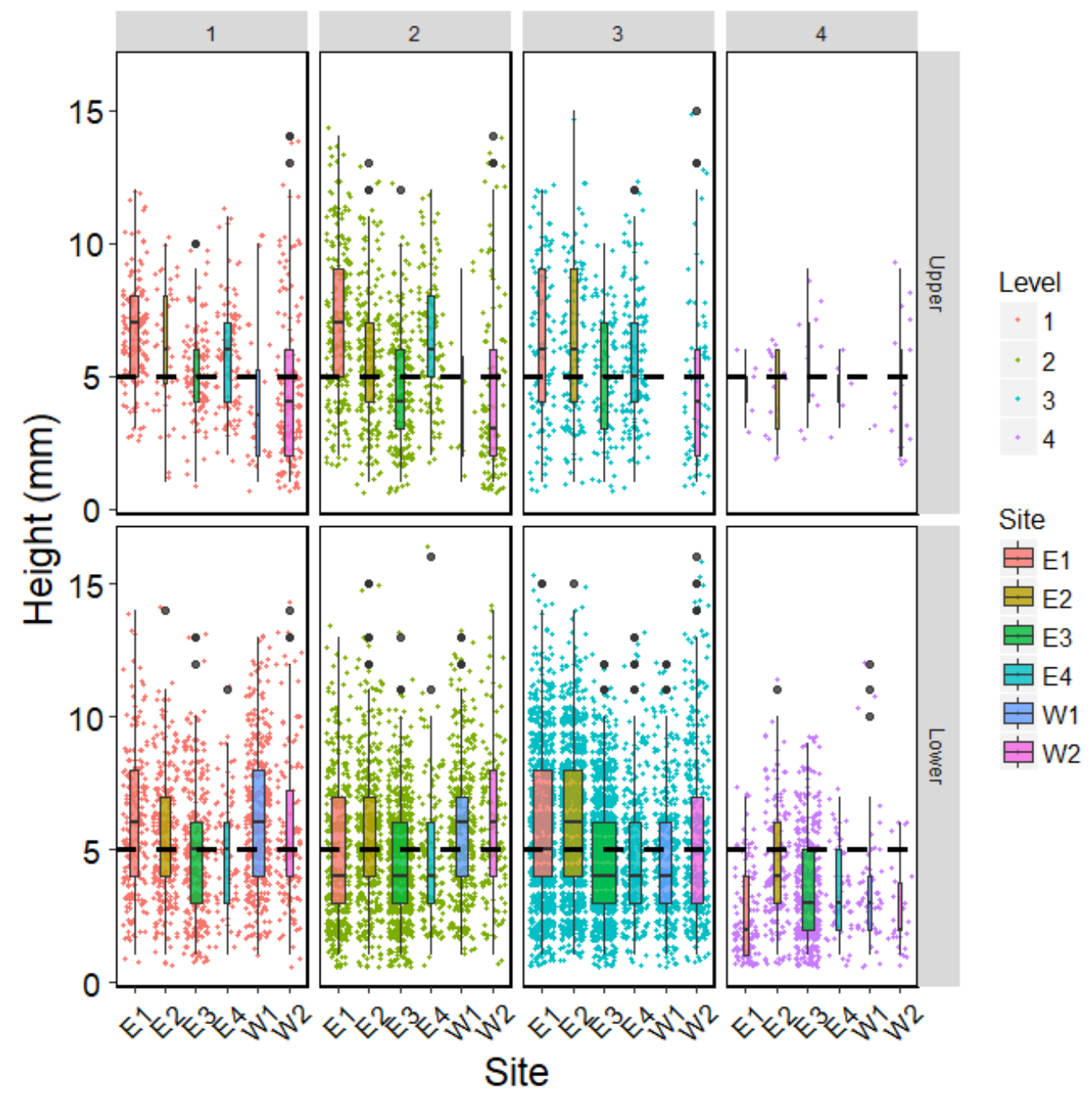

Figure 5-7. Heights ( $\mathrm{mm})$, as a proxy for diameter of recruits (0+ oyster spat) settled on passive spat collectors at six sites in Foveaux Strait between October 1999 and March 2000 (c. 140 days). There is stratification by plate height, and by plate surface. Plate heights (level) $1-4$ are at $36 \mathrm{~cm}, 24 \mathrm{~cm}, 12 \mathrm{~cm}$, and $\sim 2 \mathrm{~cm}$ (just off the seabed) respectively. There were two surfaces to each plate: the upper and lower (under side). Jittered data points represent spat size coloured by level.

Boxplots show medians at each site (solid lines), mean height for all recruits at all sites (heavy dashed line), boxes 25 and 75 percentiles, whiskers at 95 percentiles, and outliers shown as black circles above and below whiskers. Bar widths scaled to sample sizes. 
Table 5-4. Growth in 0+ recruits and natural-recruits recovered in March 2000 (c. 140 days) at six sites in Foveaux Strait (see Figure 5-2). Median diameter $\mathrm{mm}$ (Median), mean diameter for comparison (Mean), $5^{\text {th }}$ and $95^{\text {th }}$ percentiles (P 0.05 \& P 0.95), and sample sizes (n).

\begin{tabular}{lrrrrr}
\hline Site & Median & Mean & P 0.05 & P 0.95 & n \\
\hline Recruits & & & & & \\
E1 & 4.5 & 5.0 & 2.0 & 8.6 & 157 \\
E2 & 4.5 & 4.7 & 2.0 & 8.5 & 373 \\
E3 & 4.5 & 5.1 & 2.0 & 9.0 & 198 \\
E4 & 4.5 & 4.7 & 2.0 & 8.5 & 283 \\
W1 & 3.0 & 3.7 & 1.0 & 8.1 & 98 \\
W2 & 2.0 & 3.1 & 1.0 & 8.0 & 123 \\
& & & & & \\
Natural-recruits & & & & & \\
E1 & 5.5 & 5.6 & 2.7 & 8.6 & 14 \\
E2 & 4.0 & 4.8 & 2.0 & 9.0 & 11 \\
E3 & 4.5 & 4.6 & 2.3 & 7.5 & 33 \\
E4 & 5.0 & 4.8 & 2.0 & 8.0 & 33 \\
W1 & 6.3 & 6.0 & 2.0 & 10.4 & 16 \\
W2 & 2.0 & 2.9 & 1.0 & 5.7 & 20 \\
\hline
\end{tabular}

Table 5-5. Growth increments in diameter $(\mathrm{mm})$ in 1+ oyster spat recovered in March 2000 after c. 140 days at 6 sites in Foveaux Strait (see Figure 5-2). Median diameter $\mathbf{m m}$ (Median), mean diameter for comparison (Mean), $5^{\text {th }}$ and $95^{\text {th }}$ percentiles $(P 0.05 \& P(0.95)$, and sample numbers $(n)$.

\begin{tabular}{lrrrrr}
\hline Site & Median & Mean & P 0.05 & P 0.95 & n \\
\hline E1 & 8.0 & 7.9 & 2.5 & 13.5 & 152 \\
E2 & 7.8 & 7.9 & 2.5 & 13.5 & 124 \\
E3 & 9.0 & 9.4 & 2.6 & 17.9 & 85 \\
E4 & 9.5 & 9.9 & 3.5 & 15.4 & 63 \\
W1 & 9.0 & 8.8 & 2.6 & 15.5 & 124 \\
W2 & 6.5 & 7.3 & 1.0 & 16.5 & 166 \\
\hline
\end{tabular}

Mortality

The loss of $0+$ recruits from oyster shell (valves) on cement board sticks pegged to the seabed was high and only a small percentage (up to 25\%) of the estimated 200 recruits per valve initially attached to shells were found at the time of recovery. Of the recruits that remained, the distributions of their mortalities 
by valve ( $\mathrm{n}=289$ valves) was bimodal (Figure 5-8); generally, there was either no mortality (on between $52.5 \%$ and $72.5 \%$ of individual valves), or all spat died (100\% mortality on between $2.5 \%$ and $40.0 \%$ of valves).

Mortality of recruits on passive spat collectors from all sites, collectors, levels and surfaces combined $(\mathrm{n}=224)$ was $17.1 \%(95 \%$ CI $14.0 \%-20.3 \%)$. Mortality was similar to that estimated for $0+$ recruits that had naturally settled on Ostrea chilensis (OYS) and Oxyperas elongata (OEL) shells (21.7-22.6\%) sampled by divers in December 2007 (see Table 5-2). Most O. chilensis recruits (65.7\%) died between $2 \mathrm{~mm}$ and $5 \mathrm{~mm}$ in diameter (Figure 5-9). Mean size of all dead recruits from all collectors and growth studies $(n=570)$ in 1999/2000 was $5.7 \mathrm{~mm}(95 \%$ CI $5.3-6.0 \mathrm{~mm})$. Settler mortality does not appear to be density dependent (Figure 5-10).

Mortality of spat (1+) by valve varied within sites. Mean percent mortality per valve $(n=257$ valves) was $59.3 \%$ (95\% CI $55.5-63.1 \%)$. 


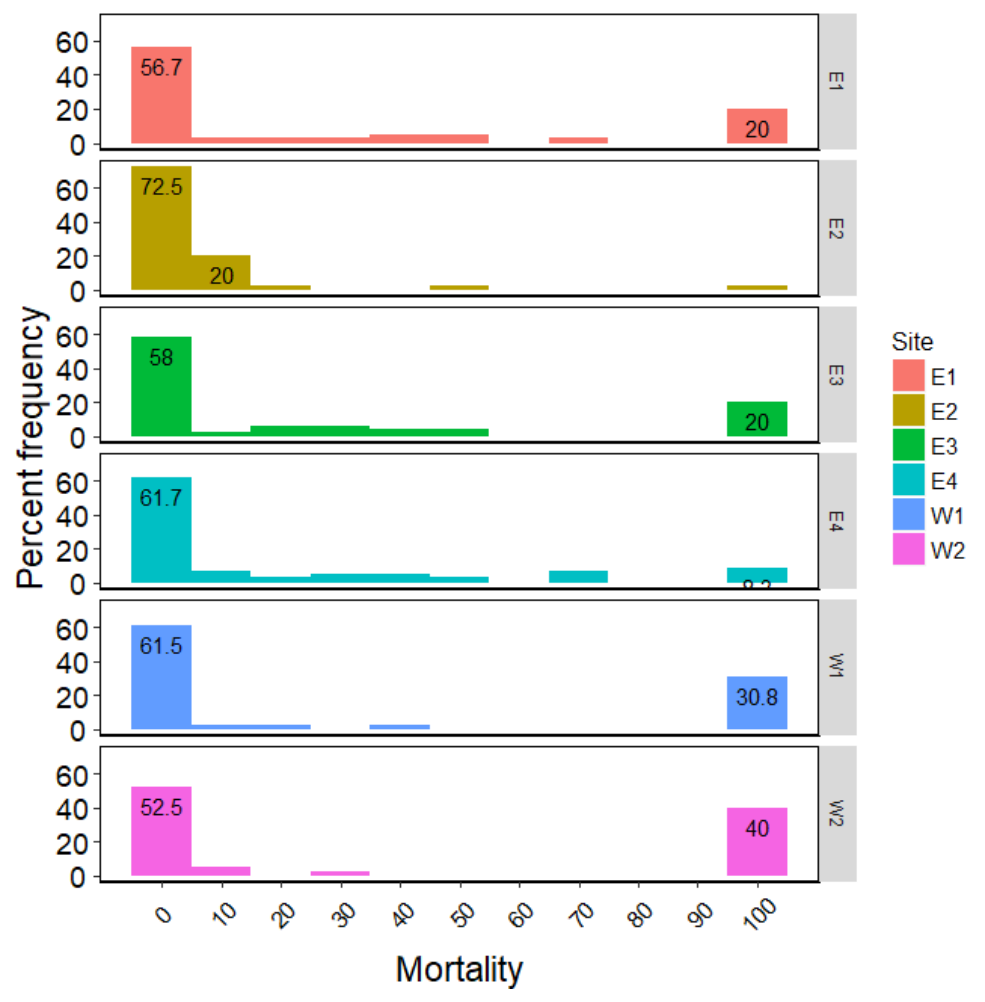

Figure 5-8. Mortality (percentage frequency of spat by valve) of recruits $(0+)$ by site, between October 1999 and March 2000.

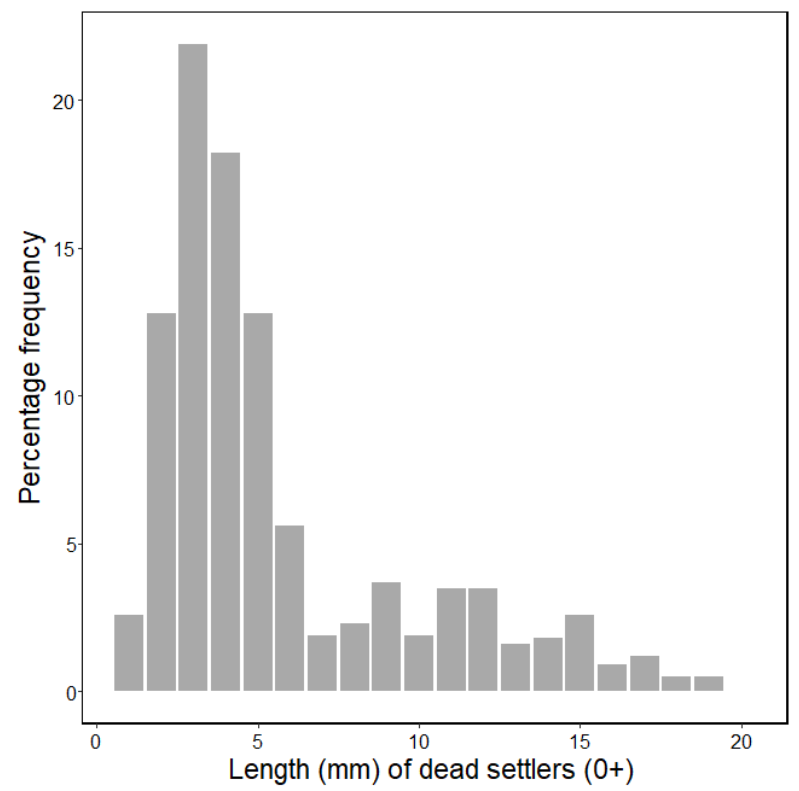

Figure 5-9. Percentage length frequency of dead $O$. chilensis recruits (left valves) from spat collectors and oyster shells of growth experiments that died post settlement between October 1999 and March 2000. 


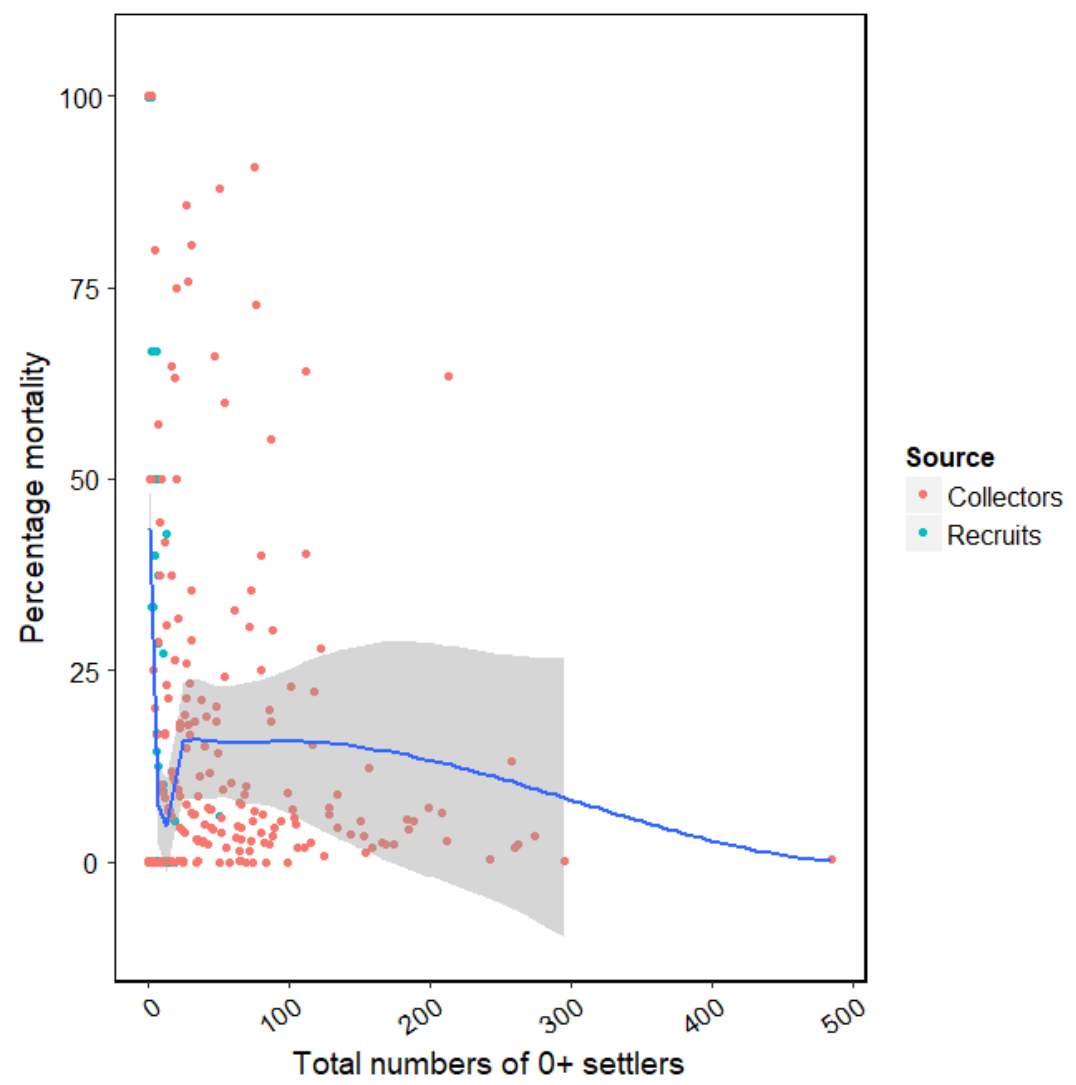

Figure 5-10. The percentage mortality in $O$. chilensis, recruits $(0+)$ by total numbers of recruits. Fitted line is a loess smoother and shaded area depicts \pm 1 SE. Mortality of recruits from spat collectors (Collectors) by surface shown as pink dots and recruits attached to shells on cement board sticks as blue dots.

\section{Differences in mortality between western and eastern sites}

Mortality of $0+$ recruits attached to shells on cement board sticks was not significantly different between western and eastern areas $(\mathrm{p}=0.079)$ and between sites $(\mathrm{p}=0.078)$. Mortality was significantly different between valve orientation $(\mathrm{p}=0.006)$; it was lower on cupped valve up (CU) than on flat valve down (FD) $(\mathrm{p}<0.001)$, and on cupped valve down $(\mathrm{CD})$ than on flat valve down (FD) $(\mathrm{p}=0.022)$. The loss of recruits from oyster shell (valves) held on the seabed at the different sites was greater than $18.9 \%$ at E1, 38.5\% at E2, $22.1 \%$ at E3, 32.6\% at $\mathrm{E} 4,11.3 \%$ at $\mathrm{W} 1$; and $14.3 \%$ at $\mathrm{W} 2$. The instantaneous mortality of all recruits 
could not be estimated because losses from individual valves could not be quantified; however, if the estimate of 200 recently settled spat per valve in October 1999 is correct, mortality may be $>90 \%$ if the recruits assumed to be missing between October 1999 and March 2000 are included as dead.

Mortality of spat $(1+)$ per valve was significantly different $(\mathrm{p} \leq 0.001)$ between sites, in pairwise comparisons (Figure A-11, in the growth and mortality $0+$ recruits and $1+$ spat section in the Appendix). However, was not significantly different between western and eastern area $(\mathrm{p}=0.253)$, and was not significantly different between valve orientations $(\mathrm{p}=0.13)$ (Table A-6 in the growth and mortality $0+$ recruits and $1+$ spat section in the Appendix).

\section{Differences in mortality with height above the seabed}

Mortality of $0+$ recruits on spat collectors was significantly different between sites ( $\mathrm{p} \leq 0.001)$ (Figure 5-11), between levels $(\mathrm{p} \leq 0.007)$, and between surfaces $(\mathrm{p}=0.049)$ (Figure 5-12 and Table 5-6). On average, mortality on lower plates was significantly different to plates higher on collectors, and the mortality on the upper surfaces of plates significantly higher than on the lower surfaces (Table 5-6). 
Table 5-6. Mortality of $0+$ recruits settled on passive spat collectors between October 1999 and March 2000 (c. 140 days in Foveaux Strait) by Site, Level, and Surface. Mean (mean), standard deviation (SD), numbers of surfaces with settler (n), standard error of the mean (SE), and upper and lower $95 \%$ confidence intervals $(95 \% \mathrm{CI})$ for lengths $(\mathrm{mm})$.

\begin{tabular}{lrrrrrr}
\hline & Mean & SD & n & SE & $\begin{array}{r}\text { Lower } \\
\text { CI }\end{array}$ & $\begin{array}{r}\text { Upper } \\
\text { CI }\end{array}$ \\
\hline Site & & & & & & \\
E1 & 22.0 & 29.1 & 39 & 4.7 & 12.6 & 31.4 \\
E2 & 20.3 & 26.2 & 39 & 4.2 & 11.8 & 28.8 \\
E3 & 8.4 & 10.7 & 39 & 1.7 & 5.0 & 11.9 \\
E4 & 5.0 & 7.3 & 37 & 1.2 & 2.5 & 7.4 \\
W1 & 28.5 & 31.6 & 33 & 5.5 & 17.3 & 39.7 \\
W2 & 20.0 & 22.3 & 37 & 3.7 & 12.5 & 27.4 \\
& & & & & & \\
Level & & & & & & \\
$1(36 \mathrm{~cm})$ & 13.4 & 17.3 & 59 & 2.3 & 8.9 & 17.9 \\
$2(24 \mathrm{~cm})$ & 11.7 & 20.0 & 60 & 2.6 & 6.5 & 16.9 \\
$3(12 \mathrm{~cm})$ & 11.8 & 17.2 & 57 & 2.3 & 7.3 & 16.4 \\
$4 \quad(2 \mathrm{~cm})$ & 34.9 & 33.1 & 48 & 4.8 & 25.3 & 44.5 \\
& & & & & & \\
Surface & & & & & & \\
Lower & 14.1 & 21.1 & 118 & 1.9 & 10.3 & 18.0 \\
Upper & 20.5 & 26.6 & 106 & 2.6 & 15.4 & 25.6 \\
\hline
\end{tabular}




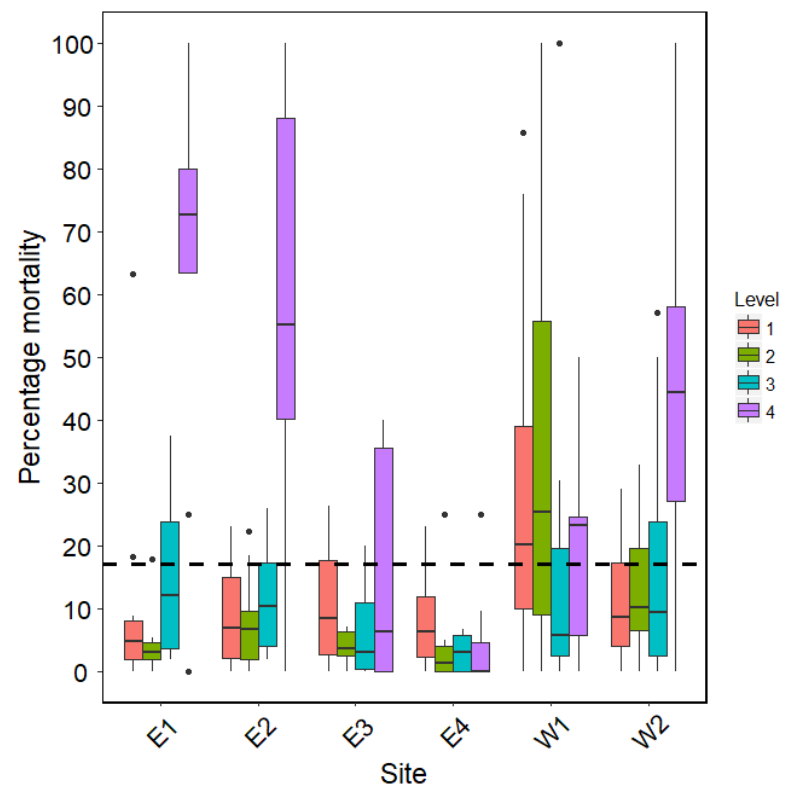

Figure 5-11. Mortality (percentage by surface) of naturally settled $0+$ recruits on passive collectors by Site and Level between October 1999 and March 2000.

Boxplots show medians (solid lines), mean (heavy dashed line), boxes 25 and 75 percentiles, whiskers at 95 percentiles, and outliers shown as black circles above and below whiskers. Bar widths scaled to sample sizes.

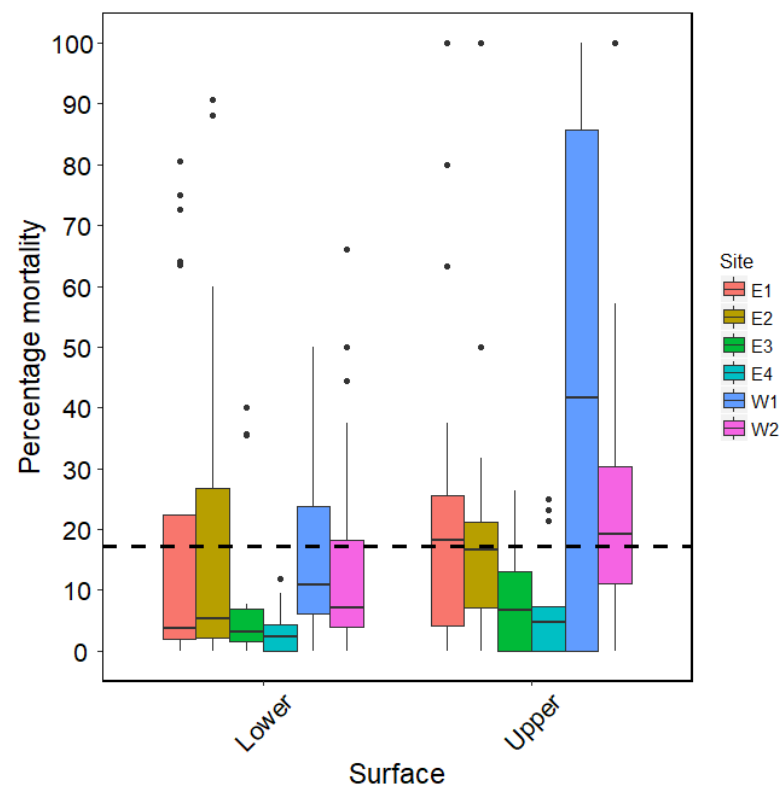

Figure 5-12. Mortality (percentage by surface) of naturally settled $0+$ recruits on passive collectors by Surface and Site between October 1999 and March 2000. Boxplots show medians (solid lines), mean (heavy dashed line), boxes 25 and 75 percentiles, whiskers at 95 percentiles, and outliers shown as black circles above and below whiskers. Bar widths scaled to sample sizes. 


\section{Discussion}

Data from fishery and bycatch sampling, and growth and survival trials suggest settlement of Ostrea chilensis 0+ recruits is greatest on clean shell, survival greatest on heavy or cupped shells such as those of $O$. chilensis, Oxyperas elongate and Astraea heliotropiumon and habitats with little other epifauna. Fishery bycatch data showed commercial fishers repeatedly target high densities of oysters on low complexity habitats, and benthic communities quickly recolonise fished areas. The sediments in these habitats are occasionally mobilised by storms. Live $O$. chilensis and their shells represented the most important substrata for settlement and post-settlement survival, possibly offering greater protection from the effects of mobile sediments. Growth and survival are higher $2 \mathrm{~cm}$ off the seabed and greater, away from moving sediments that may cause mortality through abrasion or burial of recently settled $O$. chilensis recruits. These findings suggest high levels of biotic and abiotic mortality in $O$. chilensis $0+$ recruits that influence oyster population dynamics. Spat (1+ year) have lower mortality. Findings from this research suggest an alternative hypothesis for essential habitat for settlement and post-settlement survival of $O$. chilensis in Foveaux Strait, and suggest an unusual stock-recruit relationship in Foveaux Strait oysters.

Fishers target high-density patches of oysters to maintain high catch rates (Hill et al. 2010). These patches rebuild in the same locations (Michael 2010), and are repeatedly fished (Hill et al. 2010). Bycatch data show these high-density patches occur on shell, sand and gravel dominated substrates (see Figure 5-3). These data suggest that habitat on which high densities of oysters occur may not have changed greatly from the 1960s (Fleming 1952, Cullen 1962, 1967, Stead 1971b). The essential oyster habitat described by this research differs to that suggested by Cranfield et al. (1999), commercial densities of oysters only occur on epifaunal reefs dominated by the bryozoans Cintipora elegans and that regeneration of biogenic habitat is important to oyster recruitment (Cranfield et 
al. 2004). In an extensive survey of the oyster population in Foveaux Strait 196064, Stead (1971) found oyster density was low and oyster condition poor on complex biogenic habitat. Hill et al. (2010) interviewed skippers, some with 50 years of experience about oysters, fishing and oyster habitat. Most skippers reported oysters being more abundant and of better quality on shell, sand and gravel dominated substrates with little other bycatch, as well as on the edge of underwater topographical features including biogenic areas. This research shows that competent $O$. chilensis larvae in Foveaux Strait are likely to settle on the shells of a range of benthic taxa although post-settlement survival is greatest on live oysters and oyster shell rather than in complex biogenic habitat as hypothesised by Cranfield et al. (1999). Given the abundance of suitable settlement substrata and ubiquitous distributions of larvae in Foveaux Strait, recruit survival is a key determinant of the spatial patterns of recruitment in $O$. chilensis.

The larvae of sessile benthic organisms including oysters generally settle on any "clean" stable surface (Wahl 1989), including shells of oysters and gastropod species (Heasman et al. 2004, Lok \& Acarli 2006, Trimble et al. 2009, Smyth \& Roberts 2010, Romero et al. 2013, Waldbusser et al. 2013, Smyth et al. 2018). Moreover, the importance of persistent, heavy shells to the settlement of oyster larvae in Ostreinae is well recognised: O. chilensis (Brown 2011), O. edulis (Smyth \& Roberts 2010, Smyth et al. 2018), O. lurida (Trimble et al. 2009), O. puelchana (Pascual \& Zampatti 1995), and O. angasi (Heasman et al. 2004), and the Crassostreinae, e.g. C. virginica (Waldbusser et al. 2013). Settlement substrata for $O$. chilensis were abundant in bycatch throughout Foveaux Strait and mostly comprised live oysters, oyster shell and the shells of bivalves and gastropods, and recruits found on the shells of a wide range of bivalves (Figure 5-13). O. chilensis recruits were most abundant on large shells in this study. Although large shells provide a larger substratum and therefore greater chance of settlement, greater post-settlement survival than greater 
settlement is more likely. Small bivalve shells such as Glycymeris modesta and Tawera spissa are abundant in Foveaux Strait (author's unpublished data), and were represented in samples the selectivity of dredge sampling most likely underestimated their numbers. Small shells did not have settlers attached. This research shows that recruitment in $O$. chilensis is not limited by available settlement substrata as it is in other oyster populations (Schulte et al. 2009, Trimble et al. 2009, Knights \& Walters 2010, Brown 2011).

Live $O$. chilensis and A. heliotropium and their shells were the heaviest components of the catch (Figure 5-14) and are less likely to be moved by the swift currents than lighter components under normal sea conditions and tidal flow. Cullen (1967) found the tidal currents in Foveaux Strait could move gravel and shell, and eventually erode large flat heavy shells to calcareous grit. Lighter shells can be tumbled over the seabed by normal current speeds (Cullen 1967), and small spat on these shells are likely to be abraded off or buried (Figures 515 \& 16). Stead (1971) found live oysters with live and dead spat attached buried under $125 \mathrm{~mm}$ of pea gravel in eastern fishery areas. Sediment volume, sediment size and transport increases markedly during storms, as illustrated by the large waves of heavy cobbles in depths of $60 \mathrm{~m}$ at the western entrance to Foveaux Strait (see Station 51 on page 8 of Michael et al. 2008c). The disappearance of recruits $(0.5 \mathrm{~mm}$ diameter) from shells held on the seabed was high $(67.4 \%-$ $88.7 \%$ ), which suggests that abrasion by mobile sediments as well as the likelihood of predation.

Growth in $O$. chilensis is strongly seasonal and all growth occurs over the summer months (Dunn et al. 1998). Mean growth was similar across all sites for all recruits and natural-recruits $(4.5 \mathrm{~mm}-5.0 \mathrm{~mm}$ diameter), and slightly more than for data recorded in subsequent studies between 2006 and 2017 (n = $34107)$ median of $4.3 \mathrm{~mm}\left(5^{\text {th }} \& 95^{\text {th }}\right.$ percentiles $1.2 \& 7.2 \mathrm{~mm}$ (authors unpublished data). During this period, median settler diameters differed significantly between years ( $\mathrm{p}<0.001)$, smallest median diameters in 2009 (2.4 
mm diameter) and largest in 2014, 2016, and 2017 (4.8 mm). These larger sizes are consistent with sizes from this study. The median annual size is probably more likely determined by the timing of peak settlement (a single but protracted settlement is assumed) than growth rates.

In this research, the growth of recruits attached to shells on cement board sticks at western sites was significantly less than at eastern sites, which suggests that western sites were more vulnerable to the effects of mobile sediments. Sticks holding the shells with recruits $(0+)$ and spat $(1+)$ at the W2 site were buried under 20-30 mm of coarse shelly sand. Recruits (0+) that settled higher on the passive spat collectors $(12-36 \mathrm{~cm}$ off the seabed) and clear of the seafloor grew significantly larger than those settle on the lowest plate $\sim 2 \mathrm{~cm}$ off the seabed (Table A-5). This suggests longer and better feeding conditions, which is consistent with growth in C. virginica on oyster reefs (Lenihan 1999). Spat (1+) had a mean diameter of $8.6 \mathrm{~mm}$ in October 1999, compared with the $4.5 \mathrm{~mm}-$ $5.0 \mathrm{~mm}$ diameter of recruits (0+) in March 2000. The differences in size between recruits at the end of the growing season and spat at the beginning of their grow out period may more reflect differences between feeding condition in suspended culture in Bluff Harbour than interannual difference in growth. Increased growth in suspended culture is similar to the effects of height and flow on $C$. virginica reefs (Lenihan 1999). 


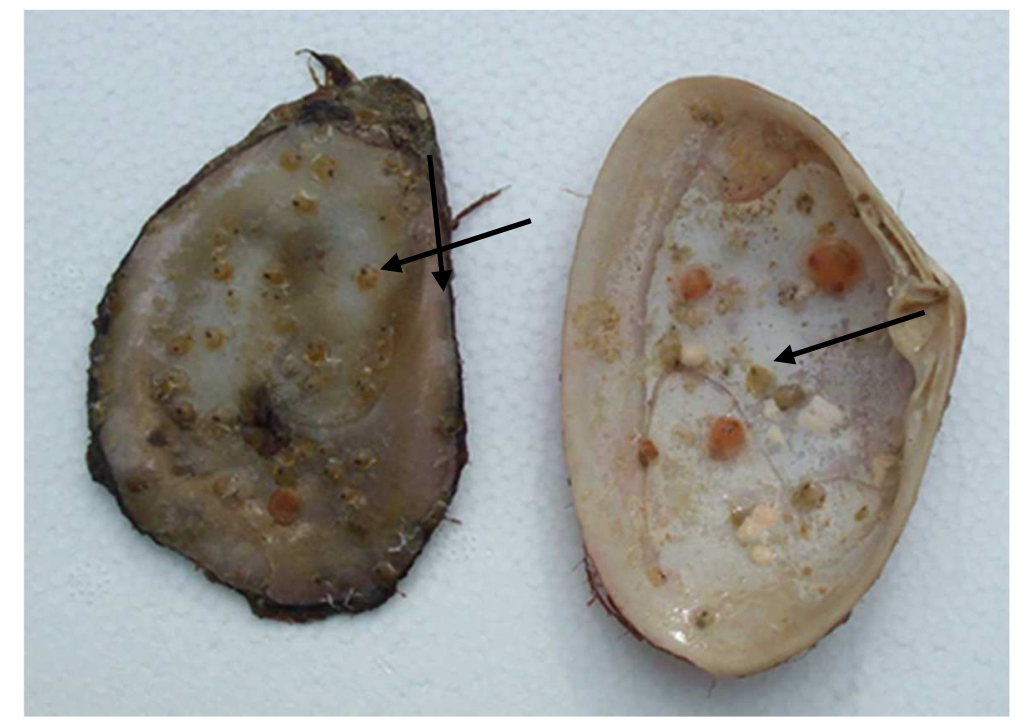

Figure 5-13. Ostrea chilensis recruits (shown with black arrow) on the inner surface of a right (flat) oyster valve (left) and the inner surface of an Oxyperas elongate (OEL) shell (right).

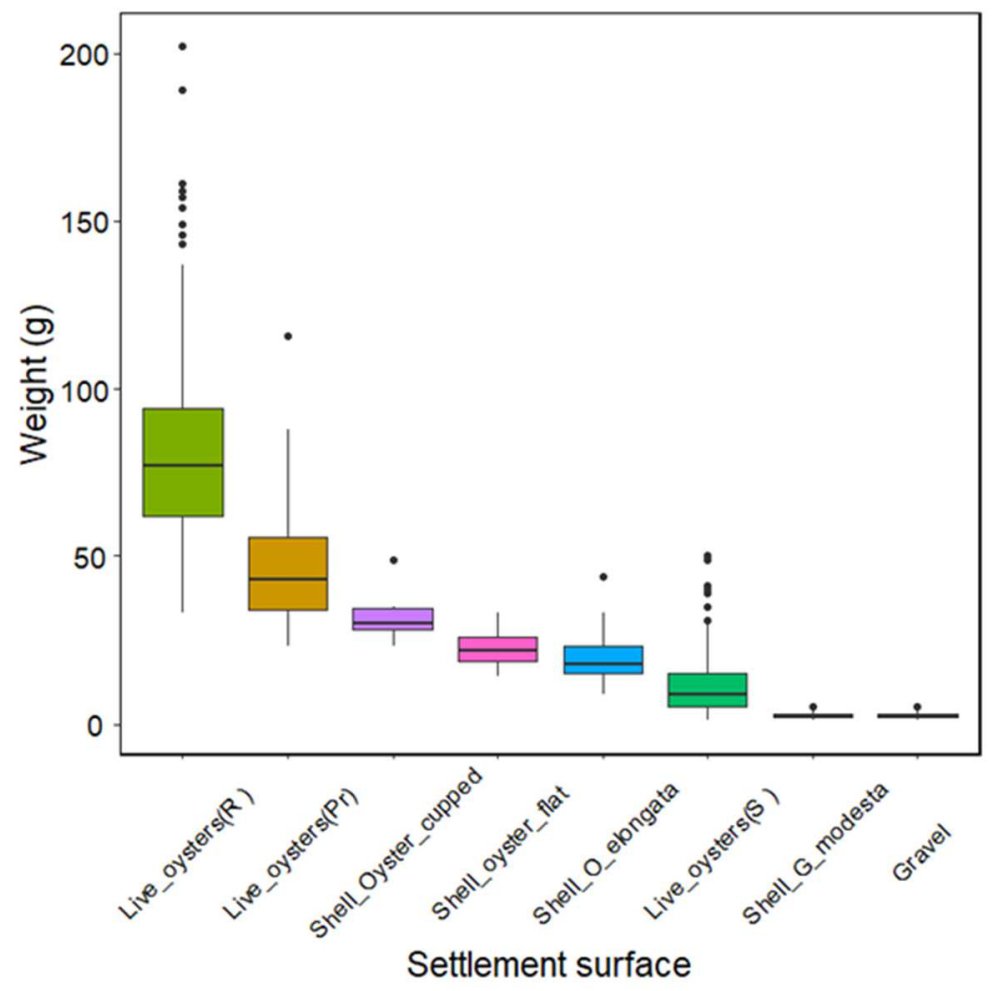

Figure 5-14. Boxplots of the weights of live oysters and oyster shell, the shells of other prominent bivalves in the bycatch, and gravel. $\mathrm{R}, \mathrm{Pr}$, and $\mathrm{S}$ denote recruit, pre-recruit and small size oysters respectively. 


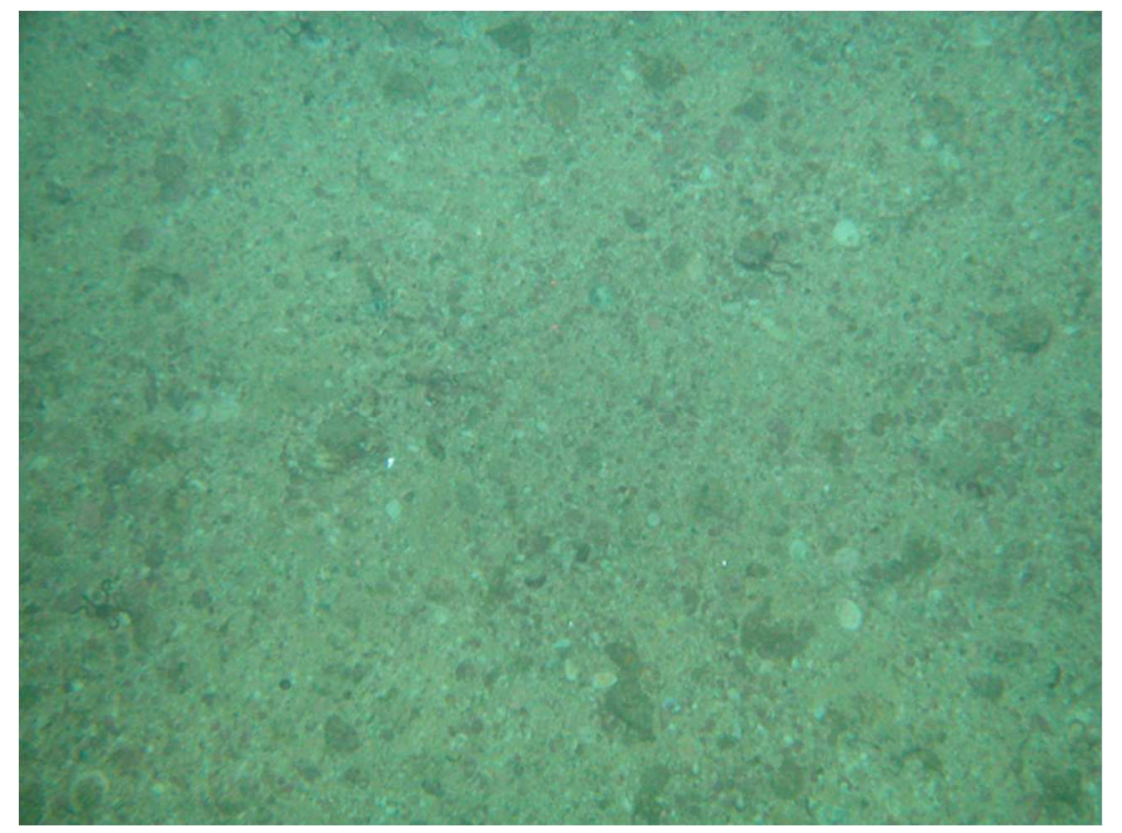

Figure 5-15. Image of the seabed (c. $4 \mathrm{~m} 2)$ in the central Foveaux Strait fishery comprising sand and shell over gravels, with high oyster densities (2400 recruitsized oysters per tow, $12 \mathrm{~m}^{-2}$ ).

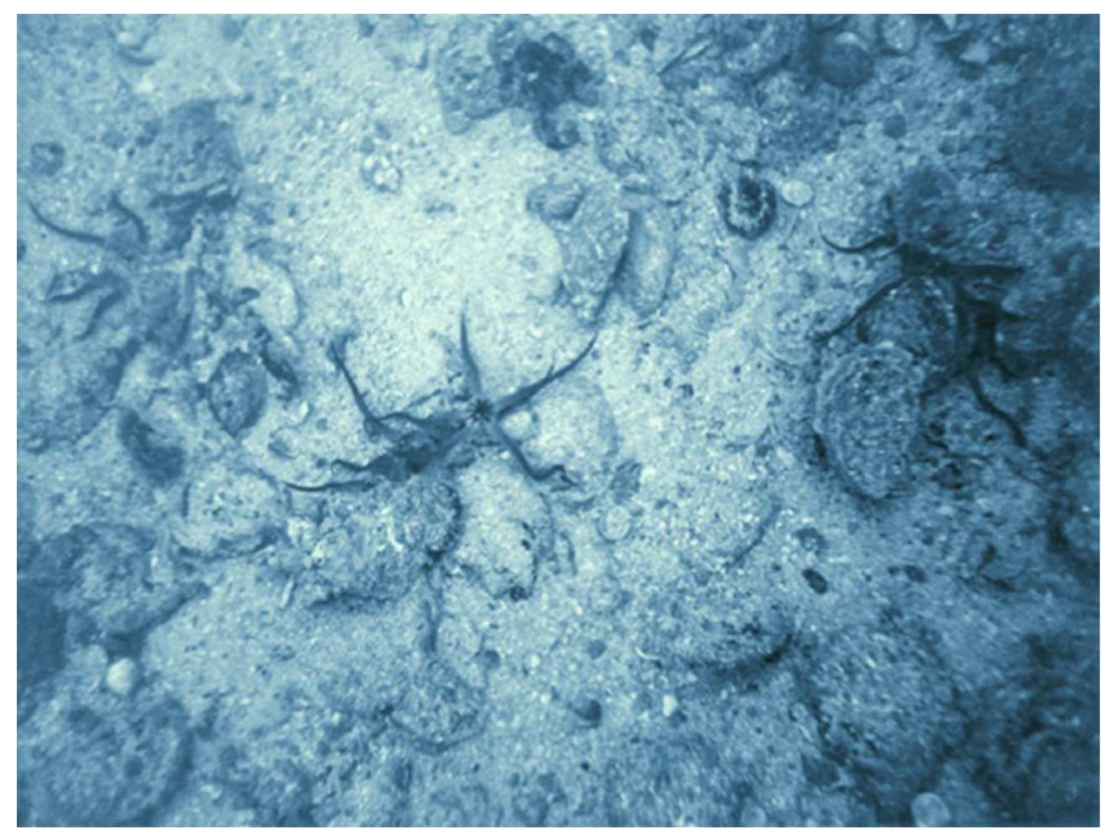

Figure 5-16. The sediments of oyster habitat are occasionally mobile during storms and may bury oysters and recruits. 
Settler densities of sessile invertebrates can influence levels of mortality, primarily through predation (Talman et al. 2004). Knights \& Walters (2010) found both density-dependent and density-independent mortality in C. virginica. In this research, no density dependent mortality was apparent (see Figure 5-8) over the c. 140 days recruits on shells and on collectors were held on the seabed. Reported mortality of recruits varies greatly from $3 \%$ of spat on collectors (Cranfield 1968b) to high predation (>90\%) of recruits (Cranfield 1979). Predation is assumed as the cause of death, from the drill holes in the upper (right) valves from boring gastropods, probably Calliostoma spp. that are abundant in Foveaux Strait. Mortality of recruits on shells was bimodal (see Figure 5-6), which is likely indicative of differential effects of mobile sediments on valves and substrata. A larger percentage of valves suffered $100 \%$ mortality of recruits at the more exposed western sites than at eastern sites. The shell of $O$. chilensis is inequivalve; the right valve is flat and relatively smooth with scaly laminations whereas the left valve is convex with short irregular corrugations (Powell 1979). Mortality of recruits was higher on flat valves than the curved valves that may offer some protection from mobile sediments and abrasion when shells are tumbled by the swift tidal flows. Overall, median mortality of recruits on collectors $(6.7 \%)$ was lower than the median mortality $(8.4 \%)$ between 2006 and 2017 ( $n=1369$ ) (author's unpublished data). However, mortality on the bottom plates more exposed to mobile sediments was significantly higher (34.9\%). Cranfield (1968b) found most spat mortality occurred immediately after settlement whereas in this study $65.7 \%$ died at a size range of $2 \mathrm{~mm}-5 \mathrm{~mm}$ in diameter, sometime after settlement suggesting a wide spread abiotic mortality. Area of settlement, shell weight (see Figure 5-14) and shell shape are shown to be important factors that influence post-settlement survival. 
Recruits (0+) and spat (1+) at W2 survived burial under sand, which is reportedly a regular occurrence in the observations of Stead (1971) and Cullen (1962), who suggested that oysters may be regularly covered in sand and gravel throughout the fishery area. Further evidence for the burial of oysters by moving sediments comes from fishers' observations, oysters in high-density patches disappear after storms and reappear some time later. The regular deposition of coarse calcareous sediments overlaying gravel substrates (Cullen 1967) during rough weather and the clearance of these sediments by tidal currents could explain these observations. Moreover, moving sediments could possibly offer oysters a level of protection from predation and over colonisation by benthic taxa (live oysters generally do not have epifauna attached). Storms may also move oysters as sedimentary particles. Moving sediments appear to play a key role in the demographics of oysters in Foveaux Strait.

\section{Conclusion}

Recruitment to the Foveaux Strait Ostrea chilensis population is not settlement surface limited and shells suitable for settlement are abundant. This includes a substantial quantity of oyster shells from the recurrent mortality of oysters from Bonamia exitiosa (Doonan et al. 1994, Cranfield et al. 2005, Fu et al. 2016). Competent $O$. chilensis larvae readily settle on the shells of a range of species. Post-settlement mortality can be high depending on sediment stability and settlement height above the seabed, and most likely independent of settler densities. Abiotic mortality caused by moving sediments, together with over-colonisation and predation may be the primary determinant in the spatial patterns of recruitment in Foveaux Strait. Post-settlement survival is highest on heavy, live $O$. chilensis and their shells. The importance of heavy, live oysters in the high-energy environment of Foveaux Strait suggests an unusual recruit-adult relationship. The most productive fishery areas are those with mostly stable substrates of shell sand and gravel. This research provides evidence in support of an alternative hypothesis for recruitment of $O$. chilensis 
in Foveaux Strait that shows oyster recruitment is highest on low complexity habitats, where sediments are less mobile, and that recruitment increases with height above the seabed. Finding from this research are not consistent with the need for complex biogenic habitat as essential habitat for the recruitment and abundance of Ostrea chilensis in Foveaux Strait. 


\section{Chapter 6 : General Discussion}
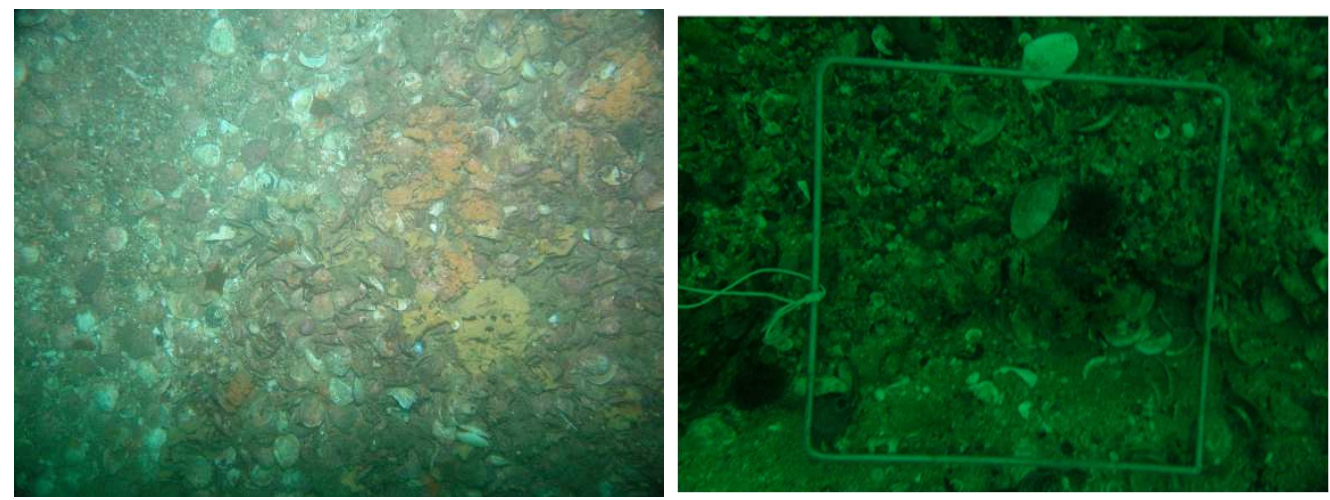

Storms can mobilise sediments and cause recruit mortality and inundate epibenthic communities. Regenerating habitat before (left) and after a December storm (right). 
This $\mathrm{PhD}$ thesis provides new information on fundamental stages of recruitment in Ostrea chilensis from Foveaux Strait. This research differs to that published for this oyster in New Zealand. Findings of this research provides new insights into the effects of disease on recruitment as well as mortality. The findings of this study emphasise the importance of species-specific, locationspecific information to understand population dynamics and inform the management of sessile benthic invertebrates. This research investigated prerequisites for successful recruitment: larval supply (Chapters 2, 3 and 4), and critical habitat, settlement and post-settlement survival (Chapter 5 with discussion in Chapter 6), . This is also the first study into recruitment since 1985, when recurrent epizootics of Bonamia exitiosa began and may have started to affect recruitment. A fishery wide, empirical study such as this one is rare. The extreme differences of oyster habitat in Foveaux Strait compared to other populations made a location specific study essential. This study used dredge sampling and vessel deployed equipment due to the difficulty in undertaking manipulative experiments in Foveaux Strait. The sampling scope and spatiotemporal scale provided a new fishery-wide perspective on recruitment. This scope comprised the nature of a stock-recruit relationship, larval supply and the distribution of competent larvae inferred from the distributions of settler densities, and requirements for settlement and post settlement survival of recruits.

Prior to this thesis, our understanding of recruitment in $O$ chilensis from Foveaux Strait was largely derived from both laboratory and field studies conducted during the 1960s and 1970s (Hollis 1963, Cranfield 1968b, Cranfield 1968a, Stead 1971a, Allen \& Cranfield 1979, Cranfield 1979, Westerskov 1980), or from samples collected around that time (Jeffs \& Hickman 2000). This thesis documents an unusually long period of low recruitment between 2010 and 2017 in a post 1985 period where disease has changed fishery productivity (Ministry for Primary Industries 2017). Spawner biomass based upon inferences derived 
from earlier studies ought to have been sufficient to replenish the population, but this had not occurred. This discrepancy highlighted the need to evaluate recruitment dynamics in the context of more recent disease regimes and/or changing environmental conditions.

This research found that the stock-recruit relationship in O. chilensis is weak in some years, and that disease may play a significant role in recruitment and population dynamics. Infections by one or more pathogens may reduce brooding levels in the populations and based on the reproductive biology of $O$. chilensis, severely reduce larval cohort strength and settler densities, and thereby recruitment. However, the distributions of recruits suggest that competent larvae were ubiquitous in Foveaux Strait. This suggests some larval mixing and exchange, and at least low levels of demographically open populations. This mixing provides some resilience against serial depletion from reduced numbers of high-density patches. Shells for settlement are also abundant. Post-settlement mortality is generally high but spatially variable, most likely determined by environmental conditions. Post-settlement mortality may determine the demographics of oyster populations. This thesis provides new information on essential oyster habitat and drivers of fisheries production.

\section{Larval supply and distribution}

Recurrent epizootics and warming seas have not changed the timing of peak settlement in $O$. chilensis from the 1960s and 1970s despite the potential of these factors to change the timing of spawning, brooding and settlement. Long data time series that capture multiple cycles of high and low recruitment are critical to understand variation in recruitment, key drivers of this variation, and to provide data for modelling. Sampling settler densities between November and February provides an effective index of annual recruitment. The high correlation with $0+$ year recruits sampled from the commercial catch corroborates trends in 
recruitment. The close relationship between $0+$ year recruits sampled on passive spat collectors at the end of summer and these same recruits sampled again from the commercial catch during the autumn and winter oyster season can also highlight high post-settlement mortality events that can inform stock assessments.

Spawner densities are important to larval supply, which is the first of a number of critical stages of recruitment. Localised populations with high spawner densities had high recruitment in high recruitment years although populations with comparably low densities showed little recruitment in any given year, which suggests a threshold density below which larval production fails (Chapter 2). Conditions other than spawner densities were key determinants of larval production (in this oyster, are assumed to be closely linked to densities of $0+$ recruits) that persisted for several years with prolonged low recruitment (Chapters 1 and 2). Even with relatively high spawning stock biomass. A disconnect between recruits and spawners could be at least partly explained by the reproductive biology of true oysters (subfamily Ostreinae). The stock-recruit relationship assumes most brooding-size individuals will contribute to larval supply in any given year. Within a given population, there may be high spatial, temporal, and annual variation in brooding. Asynchronous gonadal development in oysters (Joyce et al. 2015) and low proportions of oysters successfully brooding larvae reduce larval supply. Moreover, spatio-temporal variations in larval release (Puckett et al. 2014) affect the size of larval cohorts and patterns of larval dispersal.

In Chapter 3, high recruitment only occurred at a time when both spawner density and disease mortality were low. These data together with our understanding of the effects of shellfish pathogens and historical fishery data suggest that climate, oyster density, the effects of pathogens and their three-way interactions probably determine brooding success and therefore $O$. chilensis 
larval supply in Foveaux Strait. Chapter 3 suggest that disease and disease mortality from $B$. exitiosa affect brooding success and together with oyster density were key contributors to variation in recruitment. B. exitiosa mortality implies pathogenic infections during gametogenesis. At least three pathogens occur in the Foveaux Strait $O$. chilensis populations: Bonamia exitiosa, Bucephalus longicornutus, and an Apicomplexan (APX). Each of these pathogens can occur singularly or as co-infections; and affect gametogenesis and cause gonadal castration, although a mechanism by which this this occurs for Bonamiosis is yet to be determined. Both the effects and mechanisms by which pathogens affect brooding success in $O$. chilensis need to be tested.

This research is the first to show a counter intuitive process whereby in some years, low spawner densities resulted in high recruitment while high spawner densities resulted in low recruitment. Based on fishery data and information on pathogens of $O$. chilensis in Foveaux Strait, one explanation for this is fishery wide-scale disruption of recruitment by pathogens and that disease mortality that reduces spawner densities actually increases rather than decreases recruitment. Co-infections were likely to have been a significant contributor to the 1985 epizootic in Foveaux Strait (Hine 2002). However, there is little information on the prevalence and intensity of pathogens and co-infections in $O$. chilensis before 1985. Both B. exitiosa and B. longicornutus were present in 1958 to 1964 during a period of heightened mortality. Although B. exitiosa was identified in oyster tissues sampled in 1964, no further mortality was recorded until 1985, and therefore it is unlikely that B. exitiosa alone was responsible for the 1985 epizootic. Hine (2002) identified APX as a co-infection post 1985 . The spread of infection, as through a naïve population, suggest that APX may have been a newly introduced pathogen some time before 1985. Another explanation for the 1985 epizootic proposes the effects of fishing; however, this is unlikely as levels of disturbance were high for twenty years prior to the epizootic. Other potential explanations include genetic changes in the host susceptibility and/or 
disease pathogenicity (Henry Lane, MPI pers. comm.), and the extraordinary El Nino event in 1983 that may have increased the susceptibility of $O$. chilensis to B. exitiosa (Brian Jones, Murdoch University, Perth, pers. comm.). While it is likely that these factors may have contributed to the 1985 epizootic, the putative effects of co-infection are most likely. B. exitiosa together with other pathogens compete with the host for available energy, especially during the reabsorption phase of the female reproductive cycle. This competition may have legacy effects on energy available future reproduction and maternal provisioning. This research found the highest recruitment occurred at a time of low disease mortality. The possibility of $B$. exitiosa affecting gametogenesis is worthy of further investigation.

\section{Self-recruitment in $O$. chilensis}

The evidence for self-recruitment to natal populations in $O$. chilensis is based on laboratory observations (Hollis 1962, Stead 1971a, Brown 2011), relatively small spatial-scale experiments (Cranfield 1968a), predictive modelling (Broekhuizen et al. 2011), and the patchy spatial structure of the Foveaux Strait populations (Allen \& Cranfield 1979). The spatial scale of sampling in this study was large enough to identify predominantly selfrecruitment to the focal-population over the three years of sampling if it had occurred, i.e. localised settlement around the focal population should have been greater than some distance away from it. Moreover, historically low settler densities in 2012-14, suggest small larval cohorts that are likely to have reduced larval mixing and dispersal between localised populations. However, settler densities were widespread that suggests greater larval mixing than previously reported. In years of average to high larval cohorts, greater mixing and dispersal than indicated by this research is likely.

Finding of this research suggest that pelagic larval duration in $O$. chilensis may be more variable than thought and at times larvae may be carried 
further by the strong tidal currents in Foveaux Strait. This variation may arise from larvae released at earlier stages of development because of space limitations in the pallial cavity (see biology of $O$. chilensis in Chapter 1 ) or in response to environmental disturbance (Joyce et al. 2015). Moreover, the strong tidal currents may reduce the opportunity for settlement and limit the effectiveness of larval behaviour, conspecific settlement and settlement cues. These findings differ to previous studies and the predictions of $O$. chilensis dispersal (Broekhuizen et al. 2011). Pineda et al. (2009) warned that inferences made from probabilistic models may be misleading without an understanding of recruitment processes and data. This research provides a better understanding of recruitment and settler data that could be useful for validating future models.

\section{Oyster habitat}

This research provides information on settlement and post-settlement survival of $O$. chilensis in Foveaux Strait that provides a different perspective on oyster habitat. Findings from this research suggest that usually stable sediments, an abundance of shell, and sparse to low benthic epifauna are the key elements for oyster habitat in Foveaux Strait. Small encrusting bryozoans are abundant throughout Foveaux Strait (Cranfield et al. 2004) and play key roles in structuring benthic communities. They bind and stabilise mollusc shells and sedimentary particles (Dennis Gordon, NIWA, pers. comm.); as well as facilitating the settlement and survival of benthic taxa. These opportunistic species are likely to play a significant role as primary colonisers and were occasionally abundant on spat collectors deployed in this study. At a fishery spatial-scale, red algae and Pyura pachydermatina also provide a stabilising role on gravels. This is particularly true in the shallower eastern areas where tidal current flows are strongest and water depth is shallowest, which allows for good light penetration for algal growth. The mytilids, mainly Modiolus areolatus and Modiolarca impacta, also bind and stabilise sedimentary particles and shells (Cranfield et al. 2001). This study showed low settlement of $O$. chilensis on 
mytilids. In high densities, mytilids are more likely to be colonised by sponges and ascidians.

Bycatch data from this research showed abundant and diverse bivalve communities comprised of $O$. chilensis, Oxyperas elongate, Tucetona laticostata, Panopea smithae, Glycymeris modesta, and Tawera spissa in Foveaux Strait. The shells of dead bivalves are exposed by orbital velocities of swell and tidal currents, and provide an abundance of settlement substrata for oysters and other benthic taxa. Of these six species, oysters were the most abundant and most important. The recurrent $B$. exitiosa epizootics maintain high levels of oyster shell and their large, heavy shells persist longer in this environment. $O$. chilensis readily settle on any clean substratum; however, abiotic mortality of recruits on small or light shells (probably from abrasion and burial) is higher than for heavy shells. Oysters and oyster shell are key determinants of settlement and post-settlement survival in $O$. chilensis.

\section{Essential habitat for Ostrea chilensis recruitment and abundance}

This thesis adds new information to the discussion on complex biogenic reefs as essential habitats for Ostrea chilensis recruitment and abundance (Cranfield et al. 1999, Cranfield et al. 2001, Cranfield et al. 2003, Cranfield et al. 2004, Cranfield et al. 2005). The differences in habitat and the reproductive biology between Ostreinae and Crassostreinae highlighted by this and other studies suggest caution is needed when information from other settings and from other species are used to describe essential habitats.

Chapter 5 shows recruitment and abundance of $O$. chilensis is higher on stable habitats with low complexity. This provides evidence for an alternative hypothesis to that proposed by Cranfield et al. (1999): that climax biogenic habitats dominated by the bryozoans Cinctipora elegans (Stage 5, Figure 4 in Cranfield et al. 2004) are thought to be critical to oyster recruitment (Cranfield 
et al. 1999, Cranfield et al. 2003, Cranfield et al. 2004). Cinctipora elegans is regarded as a structuring species (Batson \& Probert 2000, Cranfield et al. 2003); however, it is less resistant to abrasion than the more calcified encrusting species found in Foveaux Strait. C. elegans is one of the first colonisers on elevated structures, which grows quickly (Michael 2011), and readily over-settled by many other taxa (Figure 6-2, author's unpublished data). The growth of colonisers can be rapid, such as the colonial ascidian Botryloides leachi that can quickly over-colonise epibenthic fauna.

Climax benthic communities in Foveaux Strait are much more likely to be dominated by erect sponge complexes (Figure 2 (e) in Cranfield et al. 2003 and see Roberts et al. 2006). Sponges readily overgrow C. elegans colonies, as is the case in the tropical systems (Lopez-Victoria et al. 2006). Allelo-chemicals released on the surfaces of sponges for defence prevent other larvae from settling, e.g. ascidian larvae do not settle on Crella incrustans (Carter, 1885) (Davis et al. 1991), and some sponge species deter grazing by urchins (Wright et al. 1997). C. incrustans, Chondropsis spp. (Cranfield et al. 2004) are abundant in Foveaux Strait and together with Dactylia varia (Gray, 1843) dominate some climax communities (author's unpublished data).Although complex habitats may provide substrate stability and structural height above the seabed, both found to be important in this study, settlement substrata are likely to be scarce. Moreover, mortality from predation and over settlement is also likely to be high on these structures (author's unpublished data).

Oyster shells contribute substantially to good oyster habitat. Lenticular structures comprising shells, sand and gravel accumulated by hydrological forces provide stability and height (see Cranfield et al. 2004 for further detail on this hypothesis). These structures are often the foundations for settlement and succession of sessile benthic invertebrates and are the genesis of biogenic "reefs" (Figure 6-1) (Smyth \& Roberts 2010, Romero et al. 2013, Waldbusser et al. 2013). The colonisation of the structures depends on sources of reproductive 
propagules and delivery mechanisms (Caddy \& Defeo 2003). Colonising propagules could be transported considerable distances in the swift currents of Foveaux Strait and spatial and temporal patterns of colonisation are likely to vary depending on the species of larvae or propagules available for settlement. Benthic taxa other than oysters that settled on spat collectors during the study suggest the composition of the communities will differ between areas.

Chapter 5 suggests that if oysters settle early during the settlement period, and above the seabed (Figure 6-1), they are likely to benefit from higher growth and lower mortality through better conditions for feeding and survival. However, findings from this research suggest that succession toward a climax benthic community is likely to decrease oyster settlement and increase feeding inhibition and mortality. These inferences are consistent with studies of oyster reefs in the US. (Grabowski \& Powers 2004, O'Connor et al. 2008). Complex biogenic habitat may provide refuges to mitigate predation (Talman et al. 2004); however, increased habitat complexity and biodiversity may increase numbers of predators and therefore reduce the ability of habitat to mediate predation (Grabowski \& Powers 2004). Moreover, mortality will vary dependent on whether increased species complexity actually provides effective refuges from predator prey interactions (Grabowski 2004), i.e. mortality will be dependent on predator identity (O'Connor et al. 2008). 


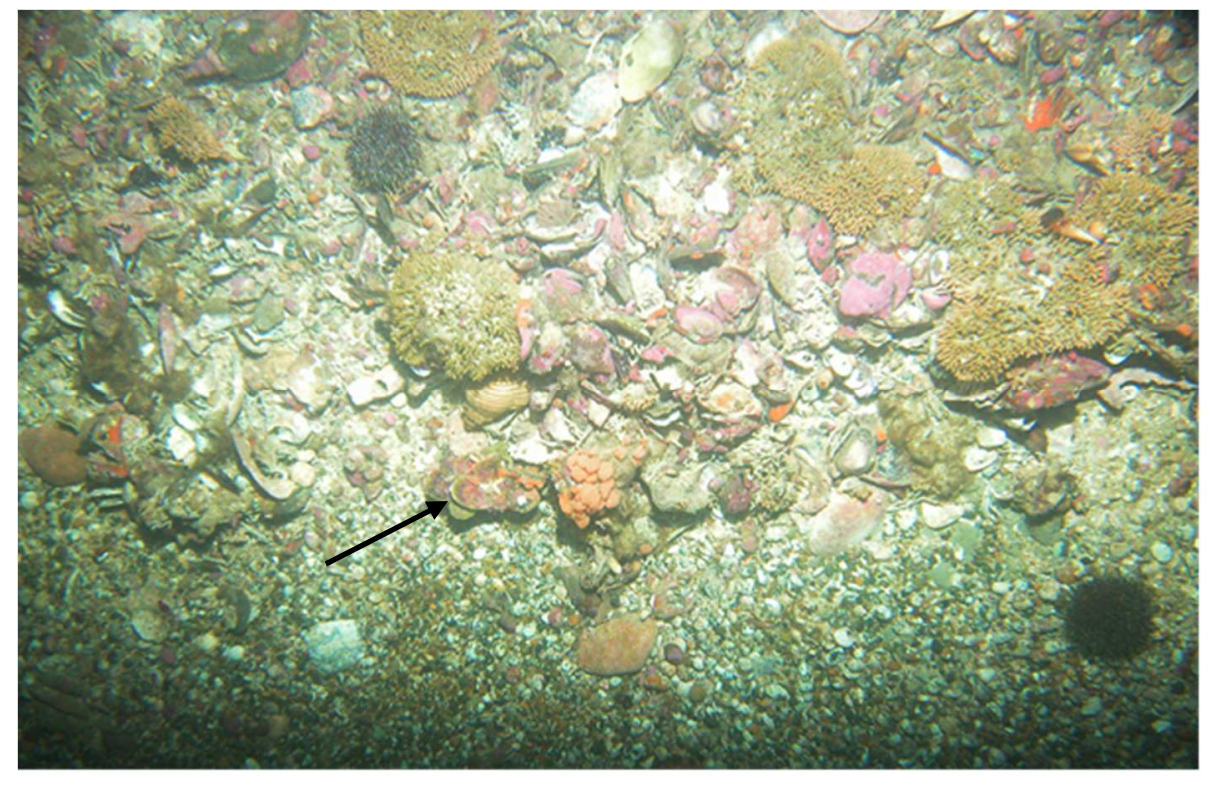

Figure 6-1. Lenticular structures comprised sediment and shell, formed by hydrographic forces along the current axis south of Bluff Hill (see Cranfield et al. 2004). These structures provide the genesis for complex biogenic habitat ("reefs"). Cinctipora elegans and $\boldsymbol{O}$. chilensis (black arrow) are among the early colonisers above the flat gravel seabed and beginning to be overgrown.
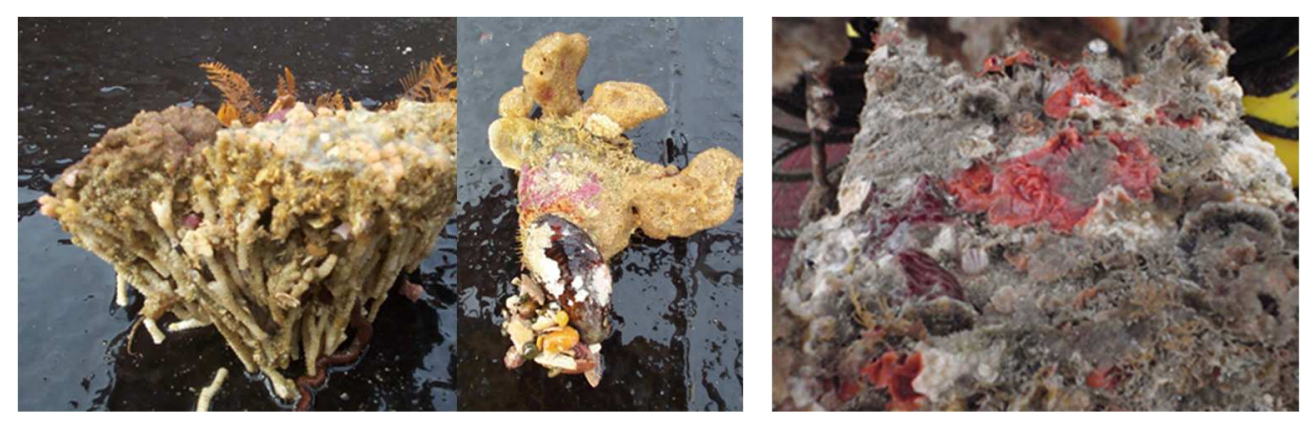

Figure 6-2. Cinctipora elegans overgrown and killed by a number of benthic taxa (left panel), Modiolus areolatus overgrown Dactylia varia (middle panel). Note gravel bound by byssus, and oyster spat settled on a spat collector overgrown by invertebrates, mainly bryozoans at the end of their second summer (right panel). 


\section{Management considerations}

Oysters are typically managed using tools and approaches developed for finfish stocks although their inability to readily move from unfavourable environmental conditions and biotic challenges makes them more vulnerable to recruitment failure and serial depletion than mobile species. The fisheries management systems failure to incorporate such significant differences in stock structure and recruitment has potentially contributed to population declines (King et al. 2015, Szuwalski et al. 2015).

The management of most fisheries and benthic invertebrate populations assumes a fundamental relationship between spawning stock biomass (SSB) and recruitment. By simply managing SSB through harvest controls, recruitment is expected to progress toward maximum yield. Adequate SSB and spawner densities are critical for reproduction; however, stock-recruit relationships (Ricker 1954, Beverton \& Holt 1957) in sessile benthic invertebrates are often weak because factors other than stock size and spawner densities substantially contribute to variation in recruitment. Fisheries management, especially for sessile benthic invertebrates, has been slow to formally recognise the poor relationship between SSB and recruitment alone and to integrate key drivers of the variation in recruitment. Therefore, management of these fisheries has generally been ineffective and fisheries have declined or collapsed as a result (MacKenzie et al. 1997a, MacKenzie et al. 1997b, MacKenzie et al. 1997c, Lenihan \& Peterson 1998, Hobday et al. 2000, Karpov et al. 2000, Anderson et al. 2011a, Beck et al. 2011, King et al. 2015, Szuwalski et al. 2015, Ministry for Primary Industries 2017). The lack of a consistent stock-recruitment relationship suggests that single biological reference point based management may not be appropriate for many of these stocks (after Powell et al. 2012). Models of population dynamics (Hollowed et al. 2009, Fulton 2010, Fulton et al. 2014, Punt et al. 2014) can incorporate key drivers of variation in recruitment although these complexities have rarely been incorporated in any capacity until recently (Punt 
et al. 2014, Skern-Mauritzen et al. 2016). This is presumably due to a lack of knowledge and data on recruitment. This research highlights the need for information on the recruitment in sessile benthic invertebrate populations.

Sessile benthic invertebrates, especially those nearshore, face increasing challenges from climate variability and change, environmental and habitat degradation, and disease. A better mechanistic understanding of recruitment processes and long-time series of recruitment, biological (including disease) and climatic data at appropriate spatial scales are needed to inform stock assessment models. This information will also be critical for Ecosystem-Based Approaches to Fisheries Management (Hilborn \& Walters 1992, Fulton 2010, Punt et al. 2014, Collie et al. 2016, Koenigstein et al. 2016), which are currently being advocated in New Zealand's Sustainable Seas National Science Challenge.

This thesis suggests that disease could limit population-scale recruitment, and that the effects of multiple pathogens may be an unappreciated and hidden driver of wild shellfish population dynamics. Many important wild shellfish stocks are in decline in New Zealand (Ministry for Primary Industries 2017), and elsewhere (Caddy \& Defeo 2003, Beck et al. 2011). The effects of disease mortality on wild shellfish populations are well known (Arzul \& Carnegie 2015). Diseases also affect meat condition, growth and recruitment. Recruitment failure is a feature of declining populations and Chapter 3 suggests that co-infections may play substantial roles in these failures.

\section{Recommendations from this thesis}

1. The low contribution of spawner densities to $O$. chilensis recruitment in some years and the inferred effects of disease and oyster density on larval supply have implications for stock assessment. A better understanding of the processes driving larval abundance, and time series of settler data will better inform further development of stock assessment models and improve the fiveyear projections of future stock size required for this fishery (Ministry for 
Primary Industries 2017). Since 1985, recurrent cycles of 'boom and bust' within oyster density thresholds suggest a shift in production. Fishers rely on highdensity patches for economic catch rates. New spatial fishing strategies may be required to minimise losses and disruption, and to maximise recruitment and the numbers of high-density patches available to fishers.

2. There is a need for a better understanding of the extent of larval dispersal amongst subpopulations to understand recruitment at fishery scale. Thomas (2015) sampled five sites in Foveaux Strait as part of a larger study of the genetic structure of $O$. chilensis populations around New Zealand. He found oysters from two sites in Foveaux Strait and a site in the Awarua Estuary (Bluff Harbour) were from the same genetic stock. These findings may provide some evidence for longer dispersal and connectivity between populations. However, the two other nearby sites in southern Foveaux Strait aligned more closely with distant populations raising some uncertainty about these results. High-resolution studies of $O$. edulis population genetics successfully used single-nucleotide polymorphisms (SNPs) (Gutierrez et al. 2017, Hollenbeck \& Johnston 2018). Genetic studies may help to resolve patterns of recruitment at finer scales and undertaken in conjunction with sampling of settler densities should provide a more detailed description of mixing and dispersal.

This thesis has provided a better understanding of recruitment in Ostrea chilensis from Foveaux Strait and in doing so highlighted several crucial knowledge gaps in understanding recruitment in $O$. chilensis generally. The effects of co-infections on gametogenesis, synchrony in spawning, brooding percentages in populations, larval development at release, and variation in pelagic larval durations are poorly understood. Knowledge of diseases in shellfish populations that are important to fisheries and to ecosystems is scant. Increasing climate variability, environmental stresses, and new pathogens introduced to naïve populations are likely to increase the frequency and severity 
of disease. As shellfish provide the high socio-economic and ecological benefits, information to better understand and assess the effects of disease on recruitment and population dynamics is critical. Baseline studies of pathobiomes, the prevalence and intensity of pathogen infections are an important first step. These data are critical to determine whether future epizootics are new introductions to naïve populations or the result of changes in climatic and environmental factors, and or co-infections. Time series data for key stocks are critical to explore how multiple pathogens and their interactions affect recruitment and population dynamics. These data should include climatic, environmental, hosts' physiological status and the interactions between pathogens in host populations. This thesis has shown that these processes are especially applicable to $O$. chilensis in Foveaux Strait. 


\section{Appendix}

Table A-1: The locations of the six sites across the Foveaux Strait oyster fishery sampled for the spatio-temporal variation in recruitment.

\begin{tabular}{lllllll}
\hline Site & \multicolumn{2}{l}{ Latitude } & \multicolumn{3}{l}{ Longitude } \\
\hline East-high & 46 & 42.9000 & $\mathrm{~S}$ & 168 & 25.1760 & $\mathrm{E}$ \\
West-high & 46 & 39.7020 & $\mathrm{~S}$ & 168 & 4.1520 & $\mathrm{E}$ \\
South-high & 46 & 44.8560 & $\mathrm{~S}$ & 168 & 18.6300 & $\mathrm{E}$ \\
West-low & 46 & 37.3020 & $\mathrm{~S}$ & 168 & 1.2480 & $\mathrm{E}$ \\
East-low & 46 & 38.1720 & $\mathrm{~S}$ & 168 & 29.3940 & $\mathrm{E}$ \\
South-low & 46 & 46.7340 & $\mathrm{~S}$ & 168 & 12.6240 & $\mathrm{E}$ \\
\hline
\end{tabular}

\section{Estimates of spawner densities}

Because of the depth, strong currents, and hard substrate of Foveaux Strait, dredge sampling is the only method available to estimate oyster densities. Photographic, video and grab sampling methods have severe limitations in Foveaux Strait. Repeat estimates of oyster density (Doonan \& Cranfield 1992, Michael et al. 2001) show good consistency. Dredge efficiency, the proportion of recruit-sized oysters encountered by the dredge actually retained (0.17), is the scalar used to adjust oyster densities from dredge sampling to absolute abundance (Fu et al. 2016).

Many of the six sites sampled across the fishery were deeper than $40 \mathrm{~m}$ meaning they were too deep for divers to sample. Before spat collectors were deployed in November 2007, standard dredge sampling methods (Michael et al. 2015) were used to estimate Ostrea chilensis spawner densities (Table A-2). After 2007, mean estimates of recruits to the fishery ( $\geq 58 \mathrm{~mm}$ in length) and prerecruit-(50-57 $\mathrm{mm}$ in length) sized oysters were used as putative estimates of local spawner densities ( $\geq 50 \mathrm{~mm}$ in length) from nearby survey sites (Michael et al. 2013), to avoid disturbing the spat collector sites (Table A-2). These surveys sampled different combinations of subareas (survey strata) each year (Table A-3). For years when there was no sampling near the sites, interpolated 
means of spawner density were estimated from the previous and following year's estimates (Table A-3). Spawner densities were estimated after spawning and settlement occurred, but before significant disease mortality and any fishing.

Sampling used a $3.3 \mathrm{~m}$ wide commercial oyster dredge towed in a straight-line, down tide. The standard tow length was 0.2 nautical miles $(371 \mathrm{~m})$, and target speed of $2.5-3.0$ knots. Estimated sampling efficiency of the dredge was 0.17 (95\% confidence intervals 0.13 - 0.22, Dunn 2005). Estimates of absolute $O$. chilensis density were calculated using this scalar.

Spawner densities (oysters $/ \mathrm{m}^{2}$ ) were calculated by adjusting catches to a standard tow distance $(371 \mathrm{~m})$, scaling for dredge efficiency $(0.17)$, and dividing by the area swept $\left(1224.3 \mathrm{~m}^{2}\right)$. Because of the low sample numbers $(3-4$ tows at each site), 95\% CIs were estimated using nonparametric bootstrapping $(B=1000)$. Figure $A-1$ shows spawner densities for the six sites (Table $A-1)$ in November 2007. 
Table A-2. Estimates of mean spawner densities (oysters $\left./ \mathbf{m}^{2}\right) \pm 1 \mathrm{SE}$ from pre-deployment sampling (November 2007) and annual February surveys (2007 to 2011) from strata containing the six sampling sites. Site codes prefixed with "area" west (W), south (S), and east $(E)$ and suffixed with Category of density, high density $(H)$, low density $(L)$ respectively. For years when there was no sampling near sites, spawner density assigned as the mean value between the previous and following years estimates (year before 2007 and after 2011 not shown). Missing data shown in italics and underlined. Data from Michael et al. (2008a, 2009, 2009a, 2011, 2012). Mean distance $(\mathbf{k m})$ with $\mathrm{SE}$, and minimum and maximum distances between dredge sample sites and collector sites also shown.

\begin{tabular}{|c|c|c|c|c|c|c|c|c|c|c|c|c|}
\hline \multicolumn{13}{|c|}{ Pre-deployment } \\
\hline \multirow[t]{3}{*}{ Site } & \multicolumn{2}{|l|}{$\mathbf{E H}$} & \multicolumn{2}{|l|}{$\mathbf{E L}$} & \multicolumn{2}{|l|}{ SH } & \multicolumn{2}{|l|}{ SL } & \multicolumn{2}{|l|}{ WH } & \multicolumn{2}{|l|}{ WL } \\
\hline & Mean & SE & Mean & SE & Mean & SE & Mean & SE & Mean & SE & Mean & SE \\
\hline & 1.26 & 0.11 & 0.16 & 0.10 & 1.53 & 0.47 & 0.11 & 0.06 & 1.83 & 0.59 & 0.11 & 0.08 \\
\hline \multicolumn{13}{|c|}{ Survey estimates } \\
\hline Stratum & $\mathbf{C 3}$ & & C6a & & C8 & & B7 & & E2 & & B2 & \\
\hline Year & Mean & SE & Mean & SE & Mean & SE & Mean & SE & Mean & SE & Mean & SE \\
\hline 2007 & 1.05 & 0.05 & 0.77 & 0.34 & 1.69 & 0.54 & 0.32 & - & 0.99 & 0.25 & 1.18 & 0.25 \\
\hline 2008 & 1.01 & 0.40 & 0.74 & 0.22 & 1.72 & 0.18 & $\overline{0.32}$ & 0.08 & 1.08 & 0.25 & 1.59 & 0.60 \\
\hline 2009 & 1.58 & 0.64 & 0.32 & 0.15 & 3.27 & 0.82 & 0.25 & 0.06 & 2.65 & 0.73 & 0.32 & 0.22 \\
\hline 2010 & 1.62 & 0.36 & 0.70 & 0.67 & 4.28 & 1.62 & $\underline{0.32}$ & - & 4.61 & 0.85 & 1.53 & - \\
\hline 2011 & 2.13 & 0.79 & 0.60 & - & 4.62 & 1.63 & $\overline{0.35}$ & 0.10 & 4.37 & 0.76 & 1.30 & - \\
\hline
\end{tabular}


Table A-2. Continued.

\begin{tabular}{lllllll}
\hline Site & EH & EL & SH & SL & WH & WL \\
Stratum & C3 & C6a & C8 & B7 & E2 & B2 \\
\hline Survey tow distances & $(\mathbf{k m})$ from collector sites & & & & \\
Mean & 2.6 & 4.4 & 2.4 & 3.4 & 4.0 & 4.0 \\
SE & 1.4 & 1.3 & 0.9 & 0.6 & 1.0 & 1.5 \\
Minimum & 0.4 & 2.6 & 1.3 & 3.0 & 1.7 & 1.5 \\
Maximum & 5.3 & 5.9 & 3.5 & 4.3 & 5.5 & 5.8 \\
\hline
\end{tabular}




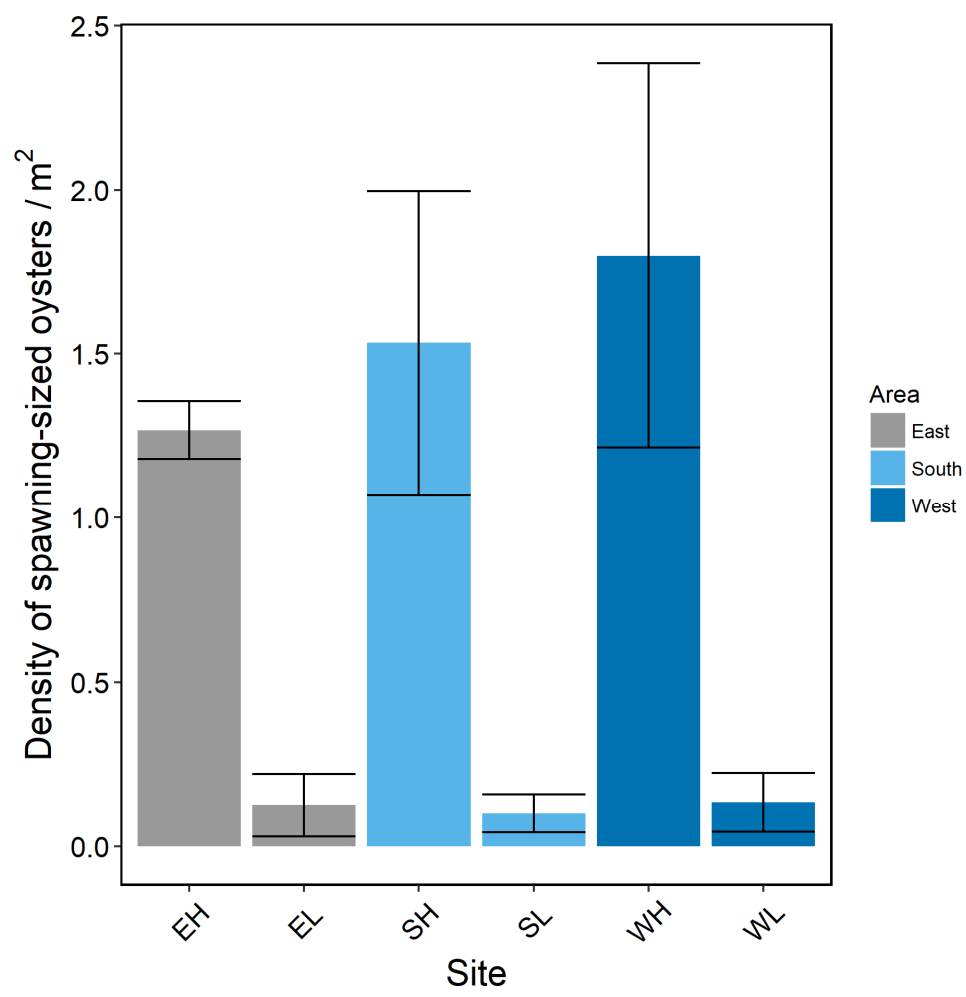

Figure A-1. Spawner densities, oysters $\geq 50 \mathrm{~mm}$ in diameter) per $\mathrm{m}^{2}$ sampled from sites across the fishery in November 2007. Site codes prefixed with "Area" West (W), South (S), and East (E); and suffixed with Category of density, high density $(\mathrm{H})$, low density $(\mathrm{L})$ respectively. Bars show mean densities with $\pm 1 \mathrm{SE}$.

Putative annual estimates of spawner densities are derived from stratum level estimates from fishery independent surveys 2008-2011 (Michael et al. 2009a, Michael et al. 2009b, Michael et al. 2011, Michael et al. 2012a), and only from those samples that were randomly allocated (Figure A-2). Spawner densities at collector sites assumed: dredge tows before sampling began were representative of localised densities, and these local densities remained the same or increased over the sampling period consistent with the estimates from fishery independent surveys. 


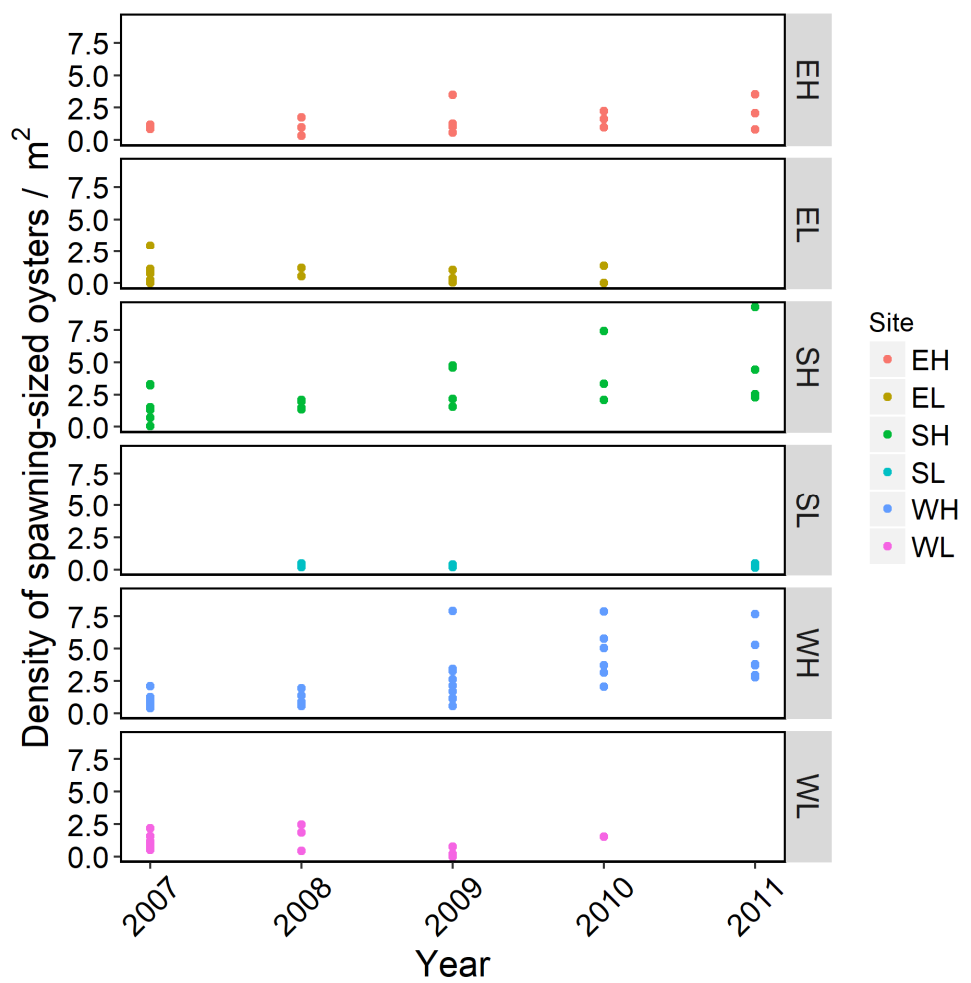

Figure A-2. Spawner densities by site from nearby, randomly allocated survey tows in strata where fishery-scale sites were located. Data from fishery independent surveys 2007-2011 (Michael et al. 2009a, 2009b, 2011, 2012, 2013).

Spawner densities sampled (Sample) in November 2007 and putative estimates from surveys in February 2008-11 (Survey) were similar at four of the six sites except the West-Low and East-Low sites (Figure A-3). Growth in $O$. chilensis occurs only in the summer months (Dunn et al. 1998), and the increase in spawner densities between November 2007 and February 2008 may be more indicative of recruitment of spawning-sized oysters than sampling variation alone. Moreover, survey strata define fishery areas of relatively high spawner density and the random locations of the survey samples likely to be closer to our spat collector sites. Spawner densities at West-Low and East-Low sites were similar over the study period, February 2008 to February 2011 (see Figure A2). 


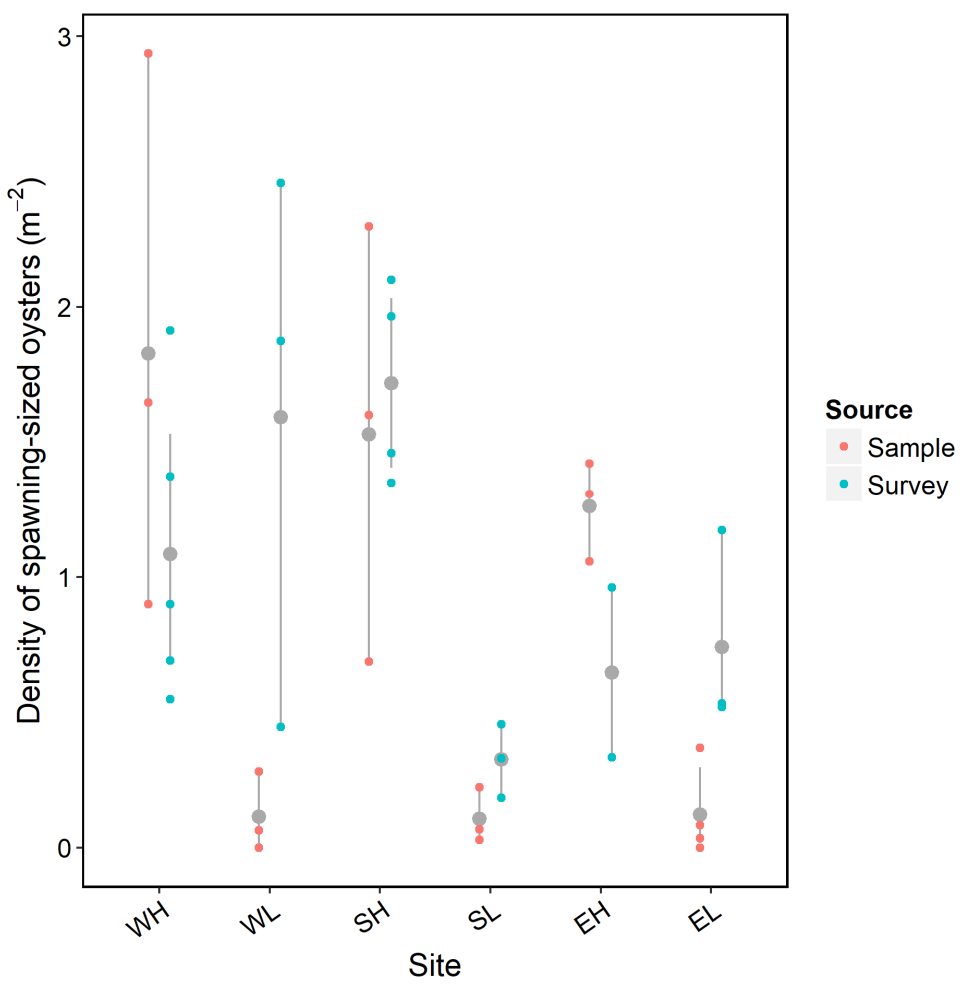

Figure A-3. Spawner densities sampled at each site before the spat collectors were deployed in November 2007 (Sample, red dots); and survey estimates sampled in February 2008 (Survey, blue dots). Growth in $O$. chilensis occurs only in the summer months (Dunn 2005) and the increase in spawner densities between November and February may more reflect recruitment of spawningsized oysters than sampling variation alone. Grey lines represent bootstrapped 95\% confidence intervals for "Sample" and "Survey" estimates and grey dots are the mean densities.

Assessments of the Foveaux Strait O. chilensis stock (Fu 2013) shows the population size of oysters recruiting to the fishery increased $47 \%$ between 2007 and 2012, and catch per unit effort (CPUE), indicative of oyster densities in commercial fishery areas, increased $70 \%$ over the same period. Small annual surveys between stock assessments (Michael et al. 2015) show similar or increasing spawner densities 2006-2008 when recruitment was high, but higher densities in 2009-2011 when recruitment was low. A slight decline in density occurred in 2011, due to summer mortality from B. exitiosa, but after the time of spawning and brooding. Estimates of spawner densities used in the study 0.1- 
1.8 in 2007 and $0.3-4.6$ in 2011 (see Table A-2) are similar to the 75 percentiles of spawner densities in the fishery (Figure A-4).

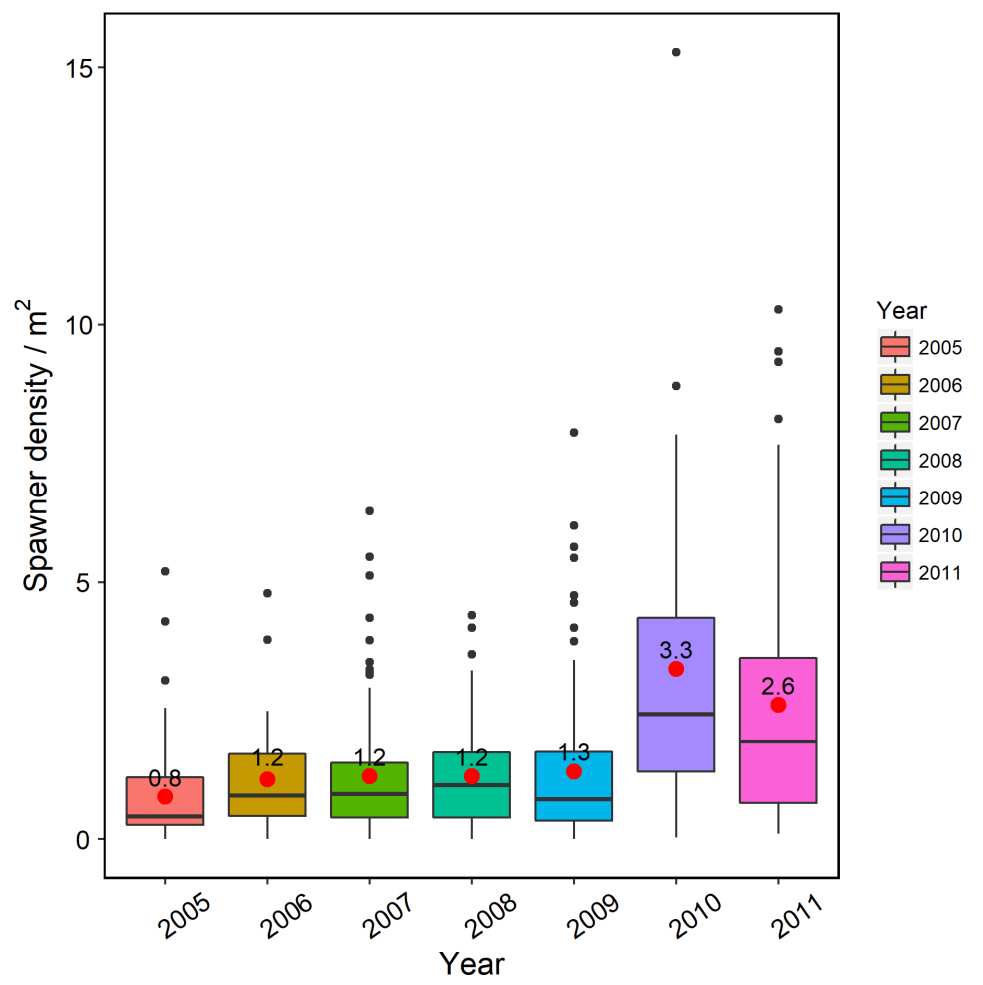

Figure A-4. The range of absolute oyster spawner densities $\left(\mathrm{m}^{-2}\right)$ sampled from random fishery surveys 2005-2011. Boxplots show medians, boxes the 25th and 75th percentiles, and the whiskers 1.5 IQR. Outliers shown as black dots. Mean spawner densities shown as filled red circles and in black text.

Site is a location specific factor comprising area and category and is a proxy for local spawner density. To test the sensitivity of the effect of factor year in the generalized linear model to spawner density, factor spawner density was substituted for area. Year and site were significant, as was their interaction. The year effect remained the same at $50.8 \%$ of deviance. 
Table A-3. Oyster recruitment modelled as a function of Year, Site, and their interactions using a Negative Binomial Generalized Linear Model. Cumulative percentage deviance (\% Dev) for ranked variables and Akaike Information Criterion (AIC).

\begin{tabular}{|c|c|c|c|c|c|c|c|}
\hline & $\mathrm{df}$ & Deviance & $\begin{array}{r}\text { Residual } \\
\text { df }\end{array}$ & $\begin{array}{l}\text { Residual } \\
\text { deviance }\end{array}$ & $\mathrm{p}$ & $\%$ Dev & AIC \\
\hline & & & 66 & 1429.23 & & & 897.57 \\
\hline Year & 3 & 811.96 & 63 & 617.27 & $<0.001$ & 0.508 & 847.07 \\
\hline Site & 5 & 472.56 & 58 & 144.71 & $<0.001$ & 0.883 & 756.76 \\
\hline Year*Site & 15 & 60.7 & 43 & 84.01 & $<0.001$ & 0.941 & 743.92 \\
\hline
\end{tabular}

\section{Estimates of mortality}

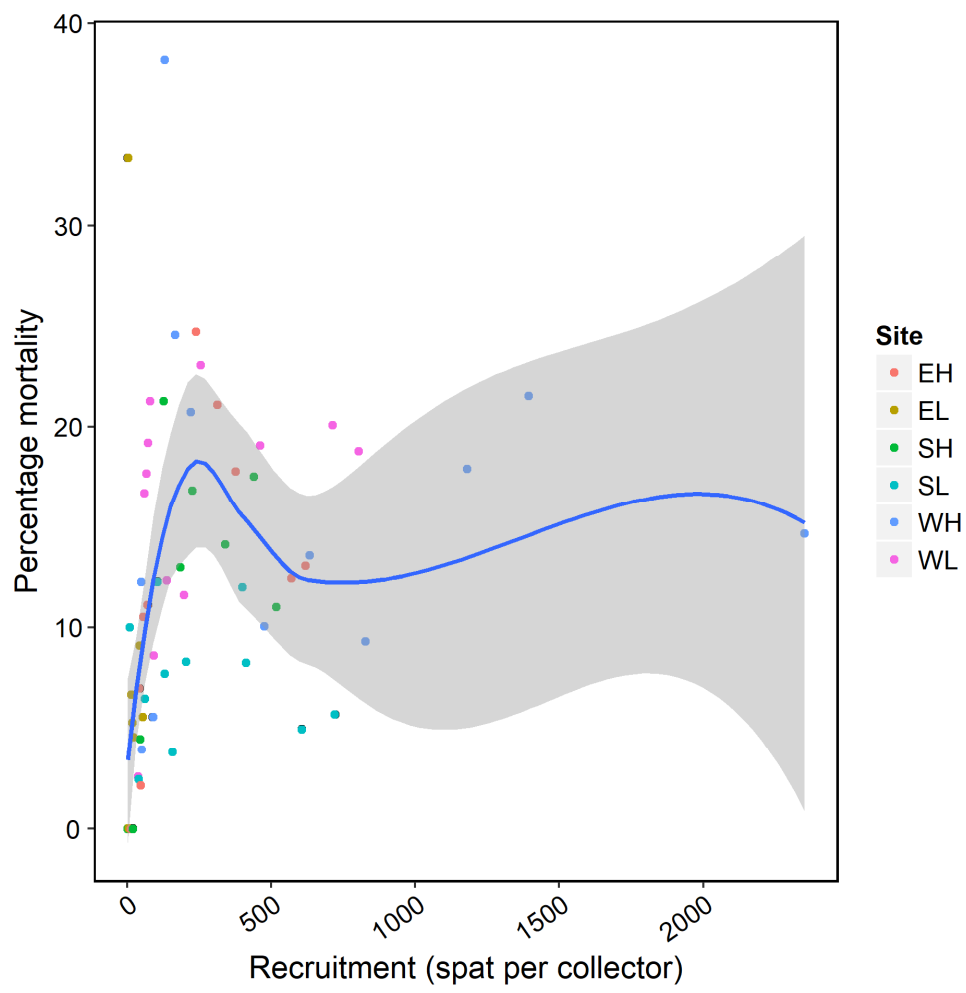

Figure A-5. The percentage mortality of $O$. chilensis spat by settler densities, by Site. Fitted line is a loess smoother and shaded area depicts $\pm 1 \mathrm{SE}$. 


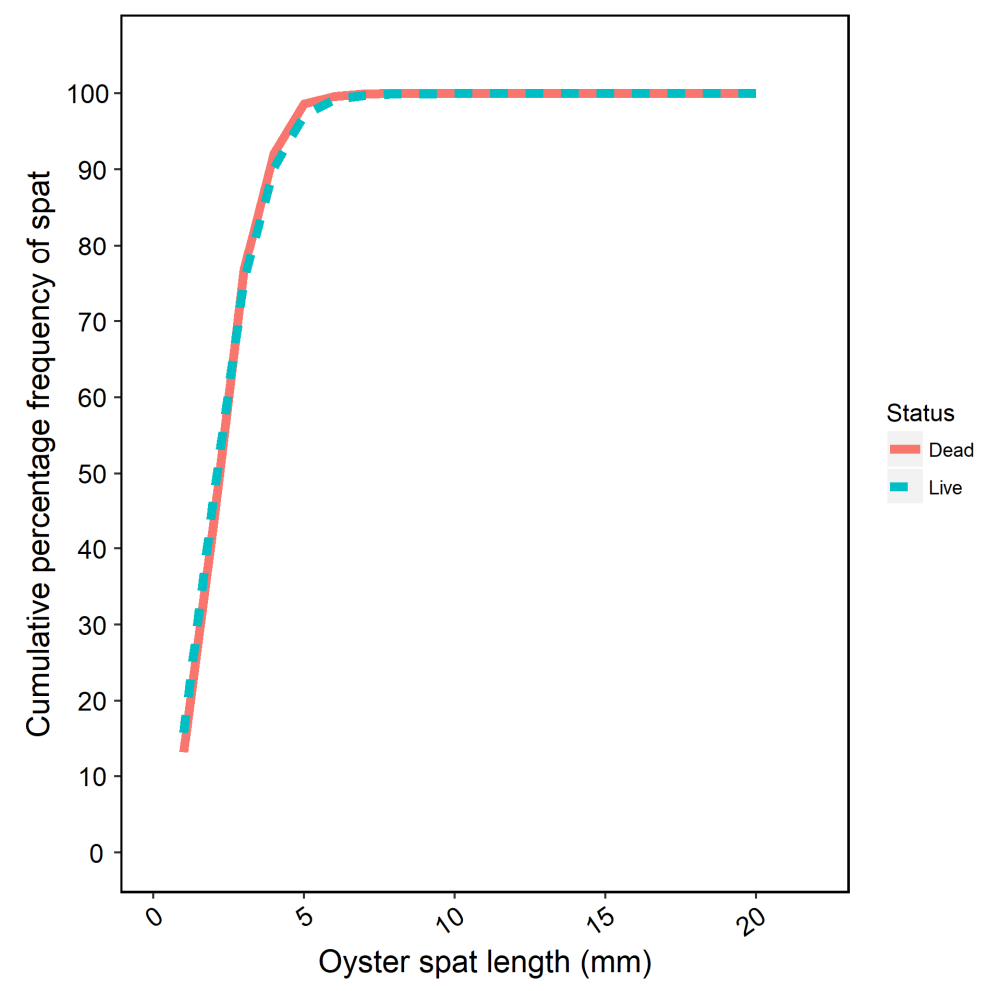

Figure A-6. The cumulative percentage frequency of lengths of live and dead $O$. chilensis spat sampled 2008-2011 in season of recruitment (B: November to February).

\section{Estimates of annual mortality}

Almost all mortality of Ostrea chilensis from Bonamia exitiosa since 2000 occurs between January and March. February (austral summer) surveys estimate annual mortality when it is at its peak. Estimates of recruit-sized (i.e., brooding-size) oyster mortality between 2006 and 2017 are given in Table A-4 (see Michael et al. 2018 for details). Annual mortality comprises the aggregate of two different estimates, both scaled to population level and expressed as a percentage of the recruited population:

1. Pre-survey mortality estimated from the absolute population size of articulated shells of oysters that had died over the summer, just before and 
during the survey and moribund oysters (i.e. recruit-sized new clocks and gapers - see Michael et al. (2018) for definitions and details), and

2. Projections of post-survey mortality that occur in days to weeks, from the proportion of oysters with fatal infections (categories 3+ infections based on the classification of Diggles et al. (2003). Bonamia exitiosa infections were scaled-up to the size of the recruited oyster population.

Estimates of recruit-sized ${ }^{1}$ oysters, gapers ${ }^{2}$ and new clocks ${ }^{3}$ are from standard dredge sampling (see above). All 15 strata were sampled by spat collectors and by dredging (see Figure 3-2). Estimates of abundance for each stratum were calculated using 0.17 as a scalar for dredge efficiency to calculate absolute density (oysters $\mathrm{m}^{-2}$ ) see Fu et al. 2016, and density scaled by the size of the stratum area $\left(\mathrm{km}^{2}\right)$ (see Michael et al. 2018 for details). Aggregated stratum estimates give absolute population estimates. Pre-survey mortality is percentage of dead recruit-sized gapers and new clocks over recruit-sized live oysters, gapers and new clocks.

Up to 25 recruit-sized, oysters were sampled from each site for DNA testing and heart imprints (heart ventricles that are dissected from oysters and dabbed on to a glass slides, to extract samples of haemolymph and haemocytes containing Bonamia exitiosa cells) and to estimate B. exitiosa infection (see Michael et al. 2018 for details) and post-survey mortality (fatal infections). The numbers of infected oysters (prevalence ${ }^{4}$ ) were estimated using quantitative polymerase chain reaction (qPCR) and droplet digital polymerase chain reaction (ddPCR). Estimates of ntensity ${ }^{5}$ of infection made from a subsample of heart imprints for oysters that tested positive by qPCR or ddPCR at each site. Scores of intensity of infection used the categorical scale of Diggles et al (2003), and the numbers of non-fatal (categories $1 \& 2$ ) and fatal (categories 3 - 5) scaled-up to the size of the recruit-sized oyster population by strata, and for the survey area.

${ }^{1}$ Recruit-sized, unable to pass through a $58 \mathrm{~mm}$ internal diameter ring. 
${ }^{2}$ Gapers, live, but moribund oysters containing the whole oyster and valves (the two shells of a bivalve shellfish) remaining apart after the adductor muscle has lost its ability to contract.

${ }^{3}$ New clocks. Clocks are the articulated shells of recently dead oysters with the ligament attaching the two valves intact. New clocks defined as those that had clean inner valves that had retained their lustre but may have had some minor speckling of fouling organisms.

${ }^{4}$ Prevalence is as the proportion of oysters in the sample or population with $B$. exitiosa infection, usually estimated using qPCR or ddPCR.

${ }^{5}$ Mean intensity is defined from histology samples (heart imprints) only as the mean frequency of stages 1-5 oysters (i.e. the mean stage of all oysters examined that had at least one B. exitiosa cell observed). 
Table A-4. Estimates of pre-survey (Pre_M), post-survey (Post_M), and annual mortality (Mortality) from Bonamia exitiosa, mean population density of recruit-sized oysters (Density) with references by year for February surveys.

\begin{tabular}{lrrrrr}
\hline Year & Pre_M & Post_M & Mortality & Density & Reference \\
\hline 2006 & 0.062 & 0.074 & 0.136 & 0.39 & (Michael et al. 2008a) \\
2007 & 0.016 & 0.058 & 0.074 & 0.59 & (Michael et al. 2008b) \\
2008 & 0.019 & 0.048 & 0.067 & 0.58 & (Michael et al. 2009a) \\
2009 & 0.023 & 0.065 & 0.088 & 0.63 & (Michael et al. 2009b) \\
2010 & 0.008 & 0.066 & 0.073 & 0.68 & (Michael et al. 2011) \\
2011 & 0.036 & 0.066 & 0.103 & 0.89 & (Michael et al. 2012a) \\
2012 & 0.032 & 0.088 & 0.120 & 1.30 & (Michael et al. 2013) \\
2013 & 0.043 & 0.121 & 0.164 & 1.40 & (Michael et al. 2014b) \\
2014 & 0.076 & 0.120 & 0.196 & 1.49 & (Michael et al. 2014a) \\
2015 & 0.045 & 0.101 & 0.146 & 1.09 & (Michael et al. 2015) \\
2016 & 0.006 & 0.044 & 0.051 & 0.71 & (Michael et al. 2017b) \\
2017 & 0.015 & 0.035 & 0.049 & 0.78 & (Michael et al. 2017a) \\
\hline
\end{tabular}




\section{Climate variables}

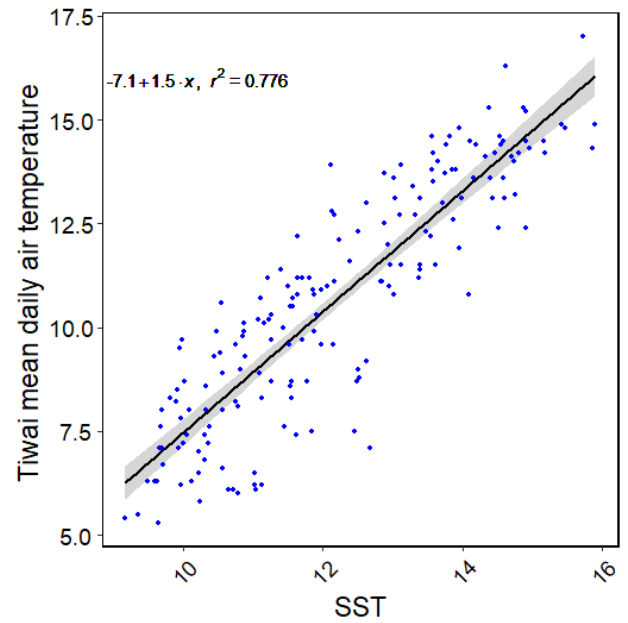

Figure A-7. Regression of mean monthly SST $\left({ }^{\circ} \mathrm{C}\right)$ and air temperatures $\left({ }^{\circ} \mathrm{C}\right)$ recorded at the Tiwai Point weather station, Bluff (-46.587, 168.376), July 2002 to March 2017.

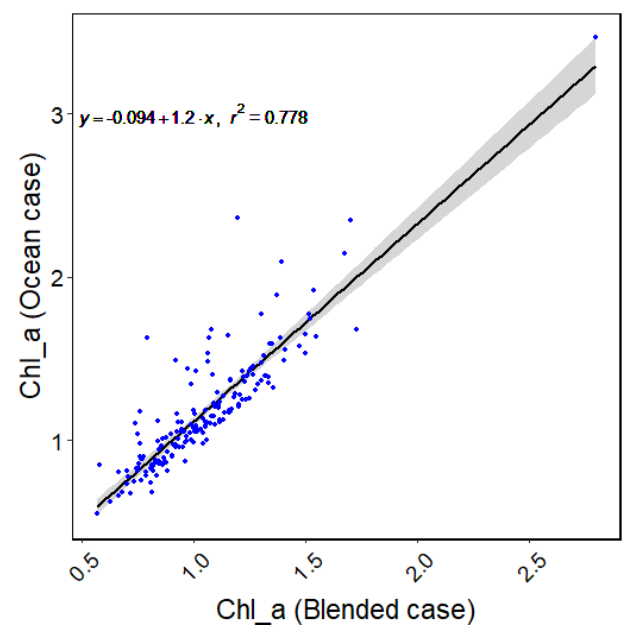

Figure A-8. Regression of mean monthly chlorophyll (Chl_a) Ocean case versus Blended case $\left(\mathrm{mg} \mathrm{m}^{-3}\right)$, July 2002 to March 2017. 


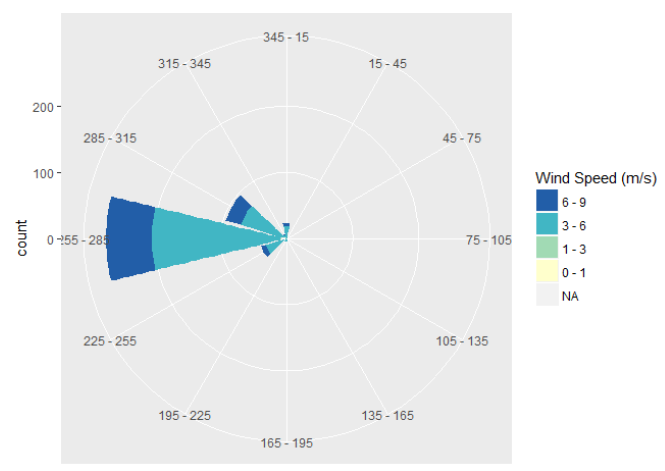

Figure A-9. Wind rose for wind direction and speed at Tiwai Point, Bluff January 1980 to October 2017 (left panel) and by each of the period representing the three reproductive phases (right panel).
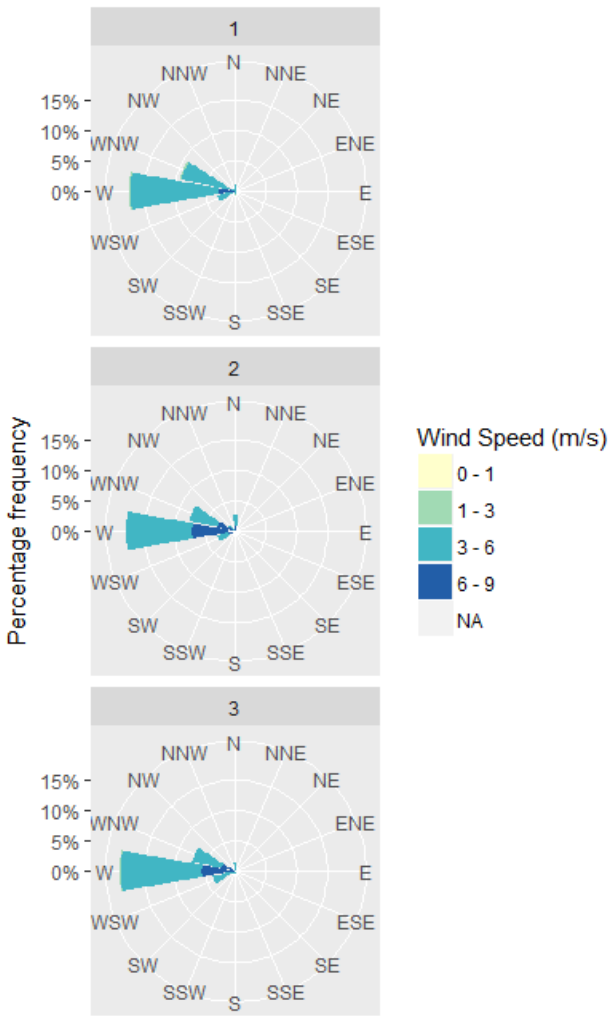


\section{Growth and mortality $0+$ recruits and $1+$ spat}

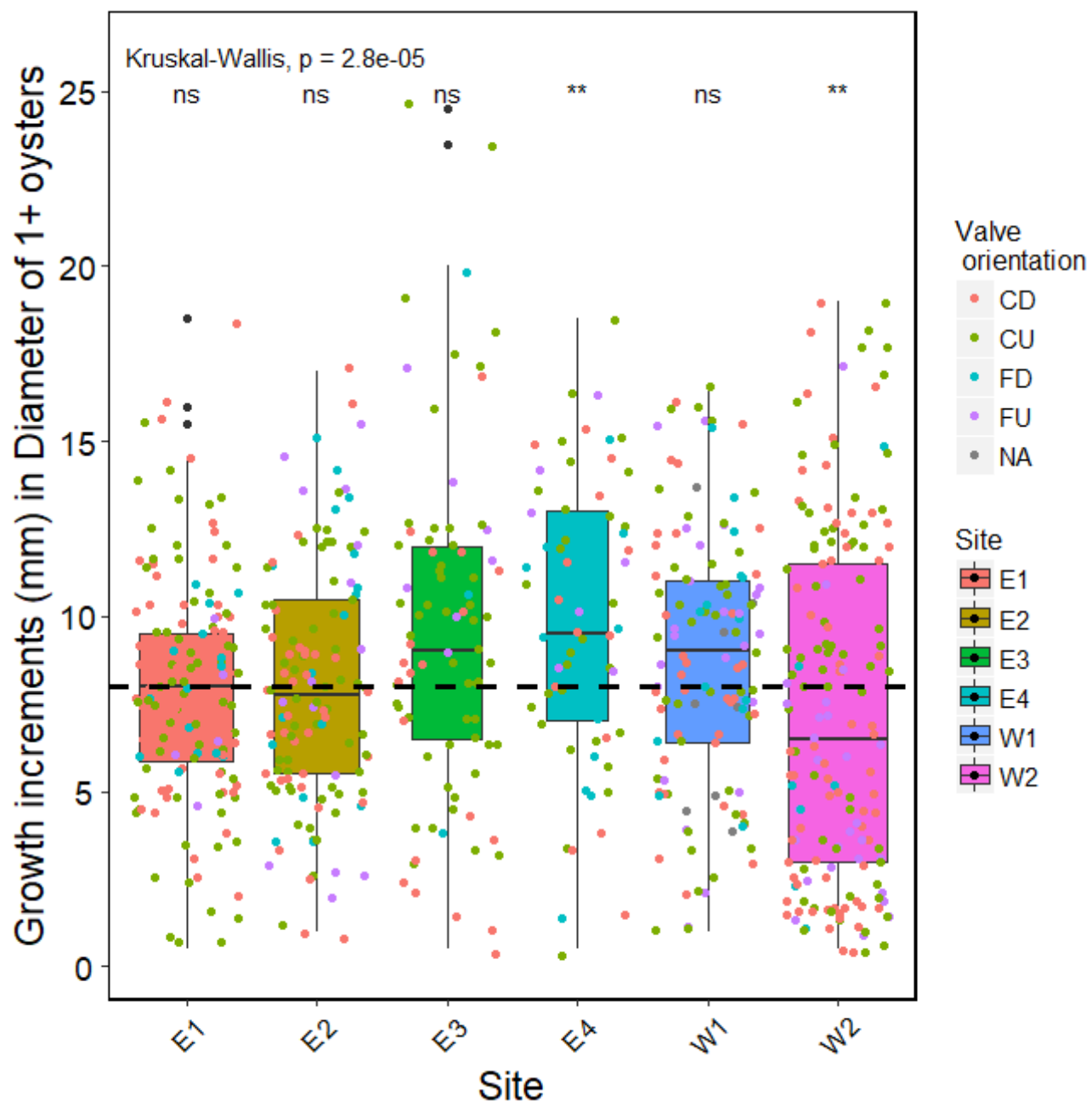

Figure A-10. Size (diameter mm) of oyster spat (1+) at March 2000, by site and by valve orientation. Jitter points represent spat size coloured by valve orientation. Boxplots show medians (solid lines), mean (heavy dashed line), boxes 25 and 75 percentiles, whiskers at 95 percentiles, and outliers shown as black circles above and below whiskers. Bar widths scaled to sample numbers. 


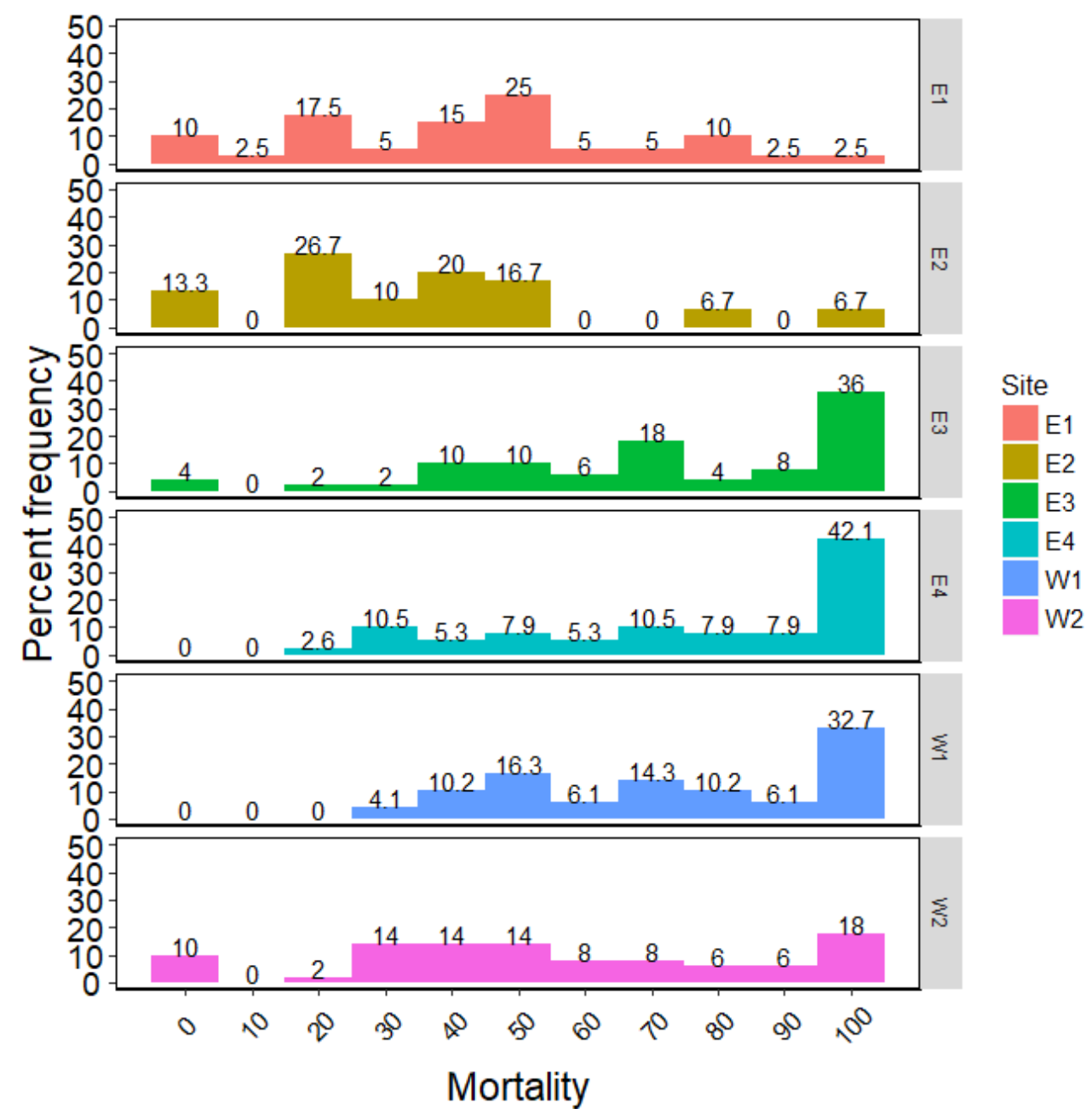

Figure A-11. Percentage frequency of mortality of spat (1+) on each valve by site, between October 1999 and March 2000. 
Table A-5. Heights of $0+$ oyster spat settled on passive spat collectors between October 1999 and March 2000, c. 140 days at 6 sites in Foveaux Strait, by plate heights combined, and by plate surface. Median diameter mm (Median), mean diameter for comparison (Mean), 5th and 95th percentiles, and sample numbers (n). Plate heights 1-4: $36 \mathrm{~cm}, 24 \mathrm{~cm}, 12$ $\mathrm{cm}$, and just off the seabed $(\sim 2 \mathrm{~cm})$ respectively. Surfaces represent the upper and lower (under side) of plates.

\begin{tabular}{lrrrrr}
\hline & Median & Mean & P 0.05 & P 0.95 & n \\
\hline Site & & & & & \\
E1 & 5.0 & 5.2 & 1.0 & 10.0 & 2641 \\
E2 & 5.0 & 5.2 & 1.0 & 10.0 & 2570 \\
E3 & 4.0 & 4.6 & 1.0 & 8.0 & 3467 \\
E4 & 5.0 & 5.1 & 2.0 & 10.0 & 988 \\
W1 & 5.0 & 5.4 & 2.0 & 10.0 & 1467 \\
W2 & 4.0 & 5.0 & 1.0 & 11.0 & 1274 \\
& & & & & \\
Height & & & & & \\
1 & 5.0 & 5.5 & 2.0 & 10.0 & 2217 \\
2 & 5.0 & 5.2 & 2.0 & 10.0 & 3348 \\
3 & 5.0 & 5.3 & 2.0 & 10.0 & 5323 \\
4 & 2.0 & 2.9 & 1.0 & 7.0 & 1519 \\
Surface & & & & & \\
Lower & 5.0 & 4.9 & 1.0 & 10.0 & 9920 \\
Upper & 5.0 & 5.5 & 2.0 & 10.0 & 2487 \\
\hline
\end{tabular}


Table A-6. Mortality of 1+ spat between October 1999 and March 2000 (c. 140 days in Foveaux Strait) by Site and valve-orientation. Mean (mean), standard deviation (SD), numbers of surfaces with settler (n), standard error of the mean (SE), and upper and lower $95 \%$ confidence intervals (95\% CI) for lengths ( $\mathrm{mm})$.

\begin{tabular}{lrrrrrr}
\hline & Mean & SD & n & SE & Lower CI & Upper CI \\
\hline Site & & & & & & \\
E1 & 40.2 & 25.1 & 40 & 3.96 & 32.2 & 48.2 \\
E2 & 35.5 & 26.8 & 30 & 4.90 & 25.5 & 45.5 \\
E3 & 71.0 & 28.7 & 50 & 4.06 & 62.9 & 79.2 \\
E4 & 74.7 & 28.3 & 40 & 4.47 & 65.6 & 83.7 \\
W1 & 70.7 & 25.0 & 49 & 3.57 & 63.5 & 77.9 \\
W2 & 53.7 & 31.0 & 50 & 4.39 & 44.9 & 62.5
\end{tabular}

Valve-

orientation

\begin{tabular}{lllrlll} 
CD & 57.2 & 30.8 & 83 & 3.38 & 50.5 & 63.9 \\
CU & 58.1 & 31.2 & 107 & 3.01 & 52.2 & 64.1 \\
FD & 53.8 & 30.5 & 23 & 6.36 & 40.6 & 66.9 \\
FU & 68.7 & 31.0 & 46 & 4.57 & 59.5 & 77.9 \\
\hline
\end{tabular}




\section{Bibliography}

Abad M, Ruiz C, Martinez D, Mosquera G, Sánchez J (1995) Seasonal variations of lipid classes and fatty acids in flat oyster, Ostrea edulis, from San Cibran (Galicia, Spain). Comparative Biochemistry and Physiology Part C: Pharmacology, Toxicology and Endocrinology 110:109-118

Adlard RD, Miller TL, Smit NJ (2015) The butterfly effect: parasite diversity, environment, and emerging disease in aquatic wildlife. Trends in Parasitology 31:160-166

Aiken D (1993) Bivalve culture in Chile: Seaweed and salmon still dominate the Chilean aquaculture production statistics, but bivalve culture is attracting a lot of attention. Journal of the World Aquaculture Society 24:6

Akaike H (1973) Maximum likelihood identification of Gaussian autoregressive moving average models. Biometrika 60:255-265

Allen RL (1979) A yield model for the Foveaux Strait oyster (Ostrea lutaria) fishery. Rapports et Procès-verbaux des réunions Conseil Permanent International pour l'Exploration de la Mer 175:70-79

Allen RL, Cranfield HJ (1979) A dredge survey of the oyster population in Foveaux Strait. Rapports et Procès-verbaux des réunions Conseil Permanent International pour l'Exploration de la Mer 175:50-62

Alleway HK, Connell SD (2015) Loss of an ecological baseline through the eradication of oyster reefs from coastal ecosystems and human memory. Conservation Biology 29:795-804

Anderson SC, Flemming JM, Watson R, Lotze HK (2011a) Serial exploitation of global sea cucumber fisheries. Fish and Fisheries 12:317-339

Anderson SC, Mills Flemming J, Watson R, Lotze HK (2011b) Rapid Global Expansion of invertebrate fisheries: trends, drivers, and ecosystem effects. PLoS One 6:e14735

Arnold WS, Meyers SD, Geiger SP, Luther ME, Narváez D, Frischer ME, Hofmann E (2017) Applying a coupled biophysical model to predict larval dispersal and source/sink relationships in a depleted metapopulation of the eastern oyster Crassostrea virginica. Journal of Shellfish Research 36:101-118 
Arzul I, Carnegie RB (2015) New perspective on the haplosporidian parasites of molluscs. Journal of Invertebrate Pathology 131:32-42

Arzul I, Gagnaire B, Bond C, Chollet B, Morga B, Ferrand S, Robert M, Renault T (2009) Effects of temperature and salinity on the survival of Bonamia ostreae, a parasite infecting flat oysters Ostrea edulis. Diseases of Aquatic Organisms 85:67-75

Bahr LM, Lanier WP (1981) The ecology of intertidal oyster reefs of the South Atlantic Coast: A community profile. (No. 81/15). US Fish and Wildlife Service. FWS/OBS

Batson PB, Probert PK (2000) Bryozoan thickets off Otago Peninsula. New Zealand Fisheries Assessment Report. 2000/46. 31 p

Beck MW, Brumbaugh RD, Airoldi L, Carranza A, Coen LD, Crawford C, Defeo O, Edgar GJ, Hancock B, Kay MC, Lenihan HS, Luckenbach MW, Toropova CL, Zhang G, Guo X (2011) Oyster reefs at risk and recommendations for conservation, restoration, and management. BioScience 61:107-116

Berthe FCJ, Hine PM (2003) Bonamia exitiosa Hine et al. 2001 is proposed instead of Bonamia exitiosus as the valid name of Bonamia sp. infecting flat oysters Ostrea chilensis in New Zealand. Diseases of Aquatic Organisms 57:181

Bethoney ND, Asci S, Stokesbury KDE (2016) Implications of extremely high recruitment events into the US sea scallop fishery. Marine Ecology Progress Series 547:137-147

Beverton RJH, Holt SJ (1957) On the Dynamics of Exploited Fish Populations. Her Majesty's Stationery Office, London. 553 p.

Bradford JM, Cranfield HJ, Michael KP (1991) Phytoplankton biomass in relation to the surface hydrography of southern New Zealand and possible effects on the food chain. New Zealand Journal of Marine and Freshwater Research 25:133-144

Bricheno LM, Wolf J, Aldridge J (2015) Distribution of natural disturbance due to wave and tidal bed currents around the UK. Continental Shelf Research 109:67-77 
Broekhuizen N, Lundquist CJ, Hadfield MG, Brown SN (2011) Dispersal of oyster (Ostrea chilensis) larvae in Tasman Bay inferred using a verified particle tracking model that incorporates larval behavior. Journal of Shellfish Research 30:643-658

Brown SN (2011) Ecology and Enhancement of the flat oyster Ostrea chilensis (Philippi, 1845) in central New Zealand. Doctor of Philosophy in Zoology, University of Canterbury, Canterbury, New Zealand.

Brown SN, Handley S, Michael K, Schiel D (2010) Annual pattern of brooding and settlement in a population of the flat oyster Ostrea chilensis from central New Zealand. New Zealand Journal of Marine and Freshwater Research 44:217-227

Buestel D, Ropert M, Prou J, Goulletquer P (2009) History, status, and future of oyster culture in France. Journal of Shellfish Research 28:813-820

Burgess SC, Marshall DJ (2011) Temperature-induced maternal effects and environmental predictability. The Journal of Experimental Biology 214:2329-2336

Buroker N, Chanley P, Cranfield H, Dinamani P (1983) Systematic status of two oyster populations of the genus Tiostrea from New Zealand and Chile. Marine Biology 77:191-200

Buroker NE (1985) Evolutionary patterns in the family Ostreidae: Larviparity vs. oviparity. Journal of Experimental Marine Biology and Ecology 90:233-247

Butler E, Butt J, Lindstrom E, Teldesley P, Pickmere S, Vincent W (1992) Oceanography of the subtropical convergence zone around southern New Zealand. New Zealand Journal of Marine and Freshwater Research 26:131-154

Caddy JF, Defeo O (2003) Enhancing or restoring the productivity of natural populations of shellfish and other marine invertebrate resources FAO Fisheries Technical Paper Rome.159p.

Caley MJ, Carr MH, Hixon MA, Hughes TP, Jones GP, Menge BA (1996) Recruitment and the local dynamics of open marine populations. Annual Review of Ecology and Systematics 27:477-500 
Canning A (2013) The Settlement and Survival of the Chilean Oyster (Ostrea chilensis) in Relation to Climate Warming during the Summer of 2013, within the Menai Strait, North Wales. MSc, University of Wales, Bangor, Menai Bridge, Anglesey

Carnegie RB (2017) Bonamiosis of oysters caused by Bonamia exitiosa. ICES Identification Leaflets for Diseases and Parasites of Fish and Shellfish. 6 $\mathrm{p}$

Carr M, Syms C (2006) Recruitment. In: The Ecology of Marine Fishes: California and Adjacent Waters. L.G. Allen, D.J. Pondella, and M. H. Horn (eds.), p 411-427. University of California Press, Berkeley 670 p.

Carroll JM, Shaughnessy KA, Diedrich GA, Finelli CM (2015) Are oysters being bored to death? Influence of Cliona celata on Crassostrea virginica condition, growth and survival. Diseases of Aquatic Organisms117:31-44

Carter L, Lewis K (1995) Variability of the modern sand cover on a tide and storm driven inner shelf, south Wellington, New Zealand. New Zealand Journal of Geology and Geophysics 38:451-470

Chai A-L, Homer M, Tsai C-F, Goulletquer P (1992) Evaluation of oyster sampling efficiency of patent tongs and an oyster dredge. North American Journal of Fisheries Management 12:825-832

Chanley P, Dinamani P (1980) Comparative descriptions of some oyster larvae from New Zealand and Chile, and a description of a new genus of oyster, Tiostrea. New Zealand Journal of Marine and Freshwater Research 14:103-120

Chaparro OR (1990) Effect of temperature and feeding on conditioning of Ostrea chilensis Philippi, 1845 reproductors. Aquaculture Research 21:399-405

Chaparro OR, Navarrete LR, Thompson RJ (2006) The physiology of the larva of the Chilean oyster Ostrea chilensis and the utilisation of biochemical energy reserves during development: An extreme case of the brooding habit. Journal of Sea Research 55:292-300

Chícharo L, Chícharo MA. 2001. Effects of environmental conditions on planktonic abundances, benthic recruitment and growth rates of the bivalve mollusc Ruditapes decussatus in a Portuguese coastal lagoon. Fisheries Research. 53(3):235-250 
Chiswell SM (2012) Non-Gaussian larval dispersal kernels in Gaussian ocean flows. Aquatic Biology 16:203-208

Coen LD, Brumbaugh RD, Bushek D, Grizzle R, Luckenbach MW, Posey MH, Powers SP, Tolley SG (2007) Ecosystem services related to oyster restoration. Marine Ecology Progress Series 341:303-307

Coen LD, Luckenbach MW, Breitburg DL (1999) The role of oyster reefs as essential fish habitat: a review of current knowledge and some new perspectives. American Fisheries Society Symposium 22:438-454

Collie JS, Botsford LW, Hastings A, Kaplan IC, Largier JL, Livingston PA, Plagányi É, Rose KA, Wells BK, Werner FE (2016) Ecosystem models for fisheries management: finding the sweet spot. Fish and Fisheries $17: 101-125$

Compo GP, Whitaker JS, Sardeshmukh PD, Matsui N, Allan, R. J., , Yin X, Gleason BE, Vose RS, Rutledge G, Bessemoulin P, Bronnimann S, Brunet M, Crouthamel RI, Grant AN, Groisman PY, Jones PD, Kruk, M. C., , Kruger AC, Marshall GJ, Maugeri M, Mok HY, Nordli O, Ross TF, Trigo RM, Wang XL, Woodruff SD, Worley SJ (2010) International Surface Pressure Databank (ISPDv2). In: Research Data Archive at the National Center for Atmospheric Research CaISL (ed) Dataset

Corell H, Moksnes P-O, Engqvist A, Döös K, Jonsson PR (2012) Depth distribution of larvae critically affects their dispersal and the efficiency of marine protected areas. Marine Ecology Progress Series 467:29-46

Cowardin LM, Carter V, Golet FC, LaRoe ET (1979) Classification of wetlands and deepwater habitats of the United States. US Department of the Interior, US Fish and Wildlife Service

Cowen RK, Sponaugle S (2009) Larval dispersal and marine population connectivity. Annual Review of Marine Science 1:443-466

Cranfield HJ (1968a) An unexploited population of oysters Ostrea lutaria Hutton, from Foveaux Strait. Part 1. Adult stocks and spatfall distribution. New Zealand Journal of Marine and Freshwater Research $2: 3-22$ 
Cranfield HJ (1968b) An unexploited population of oysters Ostrea lutaria Hutton, from Foveaux Strait. Part II. Larval settlement patterns and spat mortality. New Zealand Journal of Marine and Freshwater Research 2:183-203

Cranfield HJ. 1975. Molluscs: Bluff oysters. 1. New Zealand's nature heritage. 5(71)):1965-1970.

Cranfield HJ (1979) The biology of the oyster, Ostrea lutaria, and the oyster fishery of Foveaux Strait. Rapports et Procès-verbaux des réunions Conseil Permanent International pour l'Exploration de la Mer 175:44-49

Cranfield HJ, Allen RL (1977) Fertility and larval production in an unexploited population of oysters, Ostrea lutaria Hutton, from Foveaux Strait. New Zealand Journal of Marine and Freshwater Research 11:239-253

Cranfield HJ, Carbine G, Michael KP, Dunn A, Stotter DR, Smith DJ (2001) Promising signs of regeneration of blue cod and oyster habitat changed by dredging in Foveaux Strait, southern New Zealand. New Zealand Journal of Marine and Freshwater Research 35:897-908

Cranfield HJ, Doonan IJ, Michael KP. 1997. Incidental mortality of Foveaux Strait Dredge oysters during dredging. Final Research Report Project SOOY002 (Unpublished report held by NIWA, Wellington.). Wellington: NIWA. Final Research Report Project SOOY002.

Cranfield HJ, Dunn A, Doonan IJ, Michael KP (2005) Bonamia exitiosa epizootic in Ostrea chilensis from Foveaux Strait, southern New Zealand between 1986 and 1992. ICES Journal of Marine Science 62:3-13

Cranfield HJ, Manigetti B, Michael KP, Hill A (2003) Effects of oyster dredging on the distribution of bryozoan biogenic reefs and associated sediments in Foveaux Strait, southern New Zealand. Continental Shelf Research 23:1337-1357

Cranfield HJ, Michael KP (1989) Larvae of the incubatory oyster Tiostrea chilensis (Bivalvia: Ostreidae) in the plankton of central and southern New Zealand. New Zealand Journal of Marine and Freshwater Research 23:51-60 
Cranfield HJ, Michael KP, Doonan IJ (1999) Changes in the distribution of epifaunal reefs and oysters during 130 years of dredging for oysters in Foveaux Strait, southern New Zealand. Aquatic Conservation: Marine and Freshwater Ecosystems [Aquat Conserv: Mar Freshwat Ecosyst] 9:461-483

Cranfield HJ, Rowden AA, Smith DA, Gordon DP, Michael KP (2004) Macrofaunal assemblages of benthic habitat of different complexity: the relative importance of fishing disturbance and source of propagules to habitat regeneration in Foveaux Strait, New Zealand. Journal of Sea Research 52:109-125

Crean AJ, Marshall DJ (2009) Coping with environmental uncertainty: dynamic bet hedging as a maternal effect. Philosophical Transactions of the Royal Society B: Biological Sciences 364:1087-1096

Cullen DJ (1962) The influence of bottom sediments upon the distribution of oysters in Foveaux Strait, New Zealand. New Zealand Journal of Geology \& Geophysics 5:271-275

Cullen DJ (1967) The Submarine geology of Foveaux Strait. New Zealand Oceanographic Institute Memoir, New Zealand Department of Scientific and Industrial Research Memoir 3367 p

Culloty SC, Mulcahy MF (2007) Bonamia ostreae in the native oyster Ostrea edulis: a review. Marine Environment and Health Series (Dublin) 29:136

da Silva PcM, Magalhães AR, Barracco MA (2002) Effects of Bucephalus sp.(Trematoda: Bucephalidae) on Perna perna mussels from a culture station in Ratones Grande Island, Brazil. Journal of Invertebrate Pathology 79:154-162

Daigle RM, Chassé J, Metaxas A (2016) The relative effect of behaviour in larval dispersal in a low energy embayment. Progress in Oceanography 144:93117

Dartnall A (1970) The asterinid sea stars of Tasmania. Papers and Proceedings of the Royal Society of Tasmania 104:73-80

David P, Berthou P, Noel P, Jarne P (1997) Patchy recruitment patterns in marine invertebrates: a spatial test of the density-dependent hypothesis in the bivalve Spisula ovalis. Oecologia 111:331-340 
Davis AR, Butler AJ, van Altena I (1991) Settlement behaviour in ascidian larvae: preliminary evidence for inhibition by sponge allelochemicals. Marine Ecology Progress Series 72:117-123

DeAlteris J, Skrobe L, Lipsky C. 1999. Thesignificance of seabed disturbance by mobile fishing gear relative to natural processes: A case study in Narraganset Bay, RI. American Fisheries Society Symposium,. (Fish Habitat: Essential Fish Habitat and Rehabilitation

Dekshenieks M, Hofmann EE, Klinck JM, Powell EN (1996) Modeling the vertical distribution of oyster larvae in response to environmental conditions. Marine Ecology Progress Series 136:97-110

Diggles BK (2004) Survey of dredge oysters (Ostrea chilensis) from Foveaux Strait for Bonamiosis, oyster condition, and other concurrent infections. DigsFish Pathology Services Report.15 p

Diggles BK (2013) Historical epidemiology indicates water quality decline drives loss of oyster (Saccostrea glomerata) reefs in Moreton Bay, Australia. New Zealand Journal of Marine and Freshwater Research 47:561-581

Diggles BK, Cochennec-Laureau N, Hine PM (2003) Comparison of diagnostic techniques for Bonamia exitiosus from flat oysters Ostrea chilensis in New Zealand. Aquaculture 220:145-156

Diggles BK, Hine PM (2002) Bonamia exitiosus epidemiology in Foveaux Strait oysters. NIWA Final Research Report to the Ministry of Fisheries. Project No. OYS1999/01A/other services. (Unpublished report held by the Ministry of Fisheries, Wellington). $52 \mathrm{p}$

Dinamani P, Hickman RW, Hine PM, Jones JB, Cranfield HJ, MAF Fisheries Fisheries Research Centre. Wellington (1987) Report on investigations into the disease outbreak in Foveaux Strait oysters, Tiostrea lutaria, 1986-87. $30 \mathrm{p}$

Doonan IJ, Cranfield HJ (1992) Foveaux Strait oyster (Tiostrea chilensis) assessment, 1992. New Zealand Fisheries Assessment Research Document 92/11 (Unpublished report held in NIWA library, Wellington). MAF Fisheries, Wellington 
Doonan IJ, Cranfield HJ, Michael KP (1994) Catastrophic reduction of the oyster, Tiostrea chilensis (Bivalvia: Ostreidae), in Foveaux Strait, New Zealand, due to infestation by the protistan Bonamia sp. New Zealand Journal of Marine and Freshwater Research 28:335-344

Doonan IJ, Cranfield HJ, Michael KP (1999) Analysis and modelling of Bonamia sp. epizootic data 1986-1992 and estimation of critical density of infection. Unpublished Final Research Report to the Ministry of Fisheries held by the NIWA library, Wellington

Dunn A (2005) Stock assessment of Foveaux Strait dredge oysters (Ostrea chilensis) for the 2003-04 fishing year. New Zealand Fisheries Assessment Report 2005/25:63 p

Dunn A, Doonan IJ, Cranfield HJ, Michael KP, Stotter DR (1998) Modelling growth of the Foveaux Strait Oyster (Tiostrea chilensis). Final Research Report to the Ministry of Fisheries (Project OYS9801). Unpublished report held in the NIWA Library, Wellington.16 p

Dunphy BJ, Hall JA, Jeffs AG, Wells RMG (2006) Selective particle feeding by the Chilean oyster, Ostrea chilensis; implications for nursery culture and broodstock conditioning. Aquaculture 261:594-602

Eckman JE (1987) The role of hydrodynamics in recruitment, growth, and survival of Argopecten irradians (L) and Anomia simplex (Dorbigny) within eelgrass meadows. Journal of Experimental Marine Biology and Ecology 106:165-191

Edwards K, Hare J, Werner F, Seim H (2007) Using 2-dimensional dispersal kernels to identify the dominant influences on larval dispersal on continental shelves. Marine Ecology Progress Series 352:77-87

Ellis JI, Schneider DC (1997) Evaluation of a gradient sampling design for environmental impact assessment. Environmental Monitoring and Assessment 48:157-172

Engelsma MY, Kerkhoff S, Roozenburg I, Haenen OLM, van Gool A, Sistermans W, Wijnhoven S, Hummel H (2010) Epidemiology of Bonamia ostreae infecting European flat oysters Ostrea edulis from Lake Grevelingen, The Netherlands. Marine Ecology Progress Series 409:131142 
FAO (2018) The state of world fisheries and aquaculture 2018. Meeting the sustainable development goals. Aquaculture Department, Food and Agriculture Organization of the United Nations, Rome

Fleming CA (1952) A Foveaux Strait oyster bed. New Zealand Journal of Science and Technology 34:73-85

Fu D (2013) An updated stock assessment for Foveaux Strait dredge oysters (Ostrea chilensis) for the 2012 fishing year. Unpublished report held by the Ministry for Primary Industries, Wellington. Final Research Report for OYS2009-01C, Objective 1.56 p

Fu D, Dunn A, Michael KP (2009) Estimates of the length frequency from commercial catch sampling of Foveaux Strait dredge oysters (Ostrea chilensis) in 2008. Final Research Report for Ministry of Fisheries research project OYS2007-01, objective 3 (Unpublished report held by the Ministry of Fisheries Wellington):16 p.

Fu D, Dunn A, Michael KP, Hills J (2016) The development and performance of a length-based stock assessment of Foveaux Strait oysters (Ostrea chilensis, OYU 5) in southern New Zealand, and application to management. Fisheries Research 183:506-517

Fulton EA (2010) Approaches to end-to-end ecosystem models. Journal of Marine Systems 81:171-183

Fulton EA, Smith AD, Smith DC, Johnson P (2014) An integrated approach is needed for ecosystem based fisheries management: insights from ecosystem-level management strategy evaluation. PLoS One 9:e84242

Gaines SD, Bertness MD (1992) Dispersal of juveniles and variable recruitment in sessile marine species. Nature 360:579-580

Gaines SD, Roughgarden J (1985) Larval settlement rate: A leading determinant of structure in an ecological community of the marine intertidal zone. Proceedings of the National Academy of Sciences 82:3707-3711

Gaines SD, White C, Carr MH, Palumbi SR (2010) Designing marine reserve networks for both conservation and fisheries management. Proceedings of the National Academy of Sciences 107:18286-18293 
Gardner W, Mulvey EP, Shaw EC (1995) Regression analyses of counts and rates: Poisson, overdispersed Poisson, and negative binomial models. Psychological Bulletin 118:392

Gawarkiewicz GG, Monismith SG, Largier J (2007) Observing larval transport processes affecting population connectivity: progress and challenges. Oceanography 20:40-53

Gercken J, Schmidt A (2014) Current status of the European Oyster (Ostrea edulis) and possibilities for restoration in the German North Sea. Neu Broderstorf. 2014. BFN report

Gibbs MM (2001) Sedimentation, suspension, and resuspension in Tasman Bay and Beatrix Bay, New Zealand, two contrasting coastal environments which thermally stratify in summer. New Zealand Journal of Marine and Freshwater Research. 35(5): 951-970

Grabowski JH (2004) Habitat complexity disrupts predator-prey interactions but not the trophic cascade on oyster reefs. Ecology 85:995-1004

Grabowski JH, Brumbaugh RD, Conrad RF, Keeler AG, Opaluch JJ, Peterson $\mathrm{CH}$, Piehler MF, Powers SP, Smyth AR (2012) Economic valuation of ecosystem services provided by oyster reefs. American Institute of Biological Sciences 62:900-909

Grabowski JH, Peterson CH (2007) Restoring oyster reefs to recover ecosystem services. In: Kim Cuddington JEBWGW, Alan H (eds) Theoretical Ecology Series, Book Volume 4. Academic Press

Grabowski JH, Powers SP (2004) Habitat complexity mitigates trophic transfer on oyster reefs. Marine Ecology Progress Series 277:291-295

Gruning JF (1971) New Zealand Pilot: The coasts of North and South Islands of New Zealand, Stewart Island and adjacent islands, Kermadec, Chatham, Bounty, Antipodes, Auckland and Campbell Islands. Hydrographic Department, Great Britain. 504 p

Gutierrez AP, Turner F, Gharbi K, Talbot R, Lowe NR, Peñaloza C, McCullough M, Prodöhl PA, Bean TP, Houston RD (2017) Development of a medium density combined-species SNP array for Pacific and European oysters (Crassostrea gigas and Ostrea edulis). G3: Genes, Genomes, Genetics:g3-117 
Gutierrez JI, Jones CG, Strayer DL, Iribarne OO (2003) Mollusks as ecostsem engineers: the role of shell production in aquatic habitats. Oikos 101:7990

Hall-Spencer JM, Moore PG (2000) Scallop dredging has profound, long-term impacts on maerl habitats. ICES Journal of Marine Science 57:14071415

Heasman M, Diggles BK, Hurwood D, Mather P, Pirozzi I, Dworjanyn S (2004) Paving the way for continued rapid development of the flat (angasi) oyster (Ostrea angasi) farming industry in New South Wales. Final Report to the Department of Transport \& Regional Services. Project No. NT002/0195. June 2004. New South Wales Fisheries Final Report Series No. 66

Heath R (1973) Direct measurements of coastal currents around southern New Zealand. New Zealand Journal of Marine and Freshwater Research $7: 331-367$

Hemer MA (2006) The magnitude and frequency of combined flow bed shear stress as a measure of exposure on the Australian continental shelf. Continental Shelf Research 26:1258-1280

Hendriks IE, van Duren LA, Herman PM (2006) Turbulence levels in a flume compared to the field: implications for larval settlement studies. Journal of Sea Research 55:15-29

Hickman RW (2000) Use of premature New Zealand dredge oyster Tiostrea lutaria Hutton larvae for spat production. Aquaculture Research 31:529536

Hidu H (1969) Gregarious setting in the American oyster Crassostrea virginica Gmelin. Chesapeake Science 10:85-92

Hidu H, Haskin HH (1978) Swimming speeds of oyster larvae Crassostrea virginica in different salinities and temperatures. Estuaries 1:252-255

Hilborn R, Orensanz JM, Parma AM (2005) Institutions, incentives and the future of fisheries. Philosophical Transactions of the Royal Society B: Biological Sciences 360:47-57

Hilborn R, Walters CJ (1992) Quantitative fisheries stock assessment. Choice, dynamics and uncertainty. Chapman and Hall, New York 
Hill NAO, Michael KP, Frazer A, Leslie S (2010) The utility and risk of local ecological knowledge in developing stakeholder driven fisheries management: The Foveaux Strait dredge oyster fishery, New Zealand. Ocean \& Coastal Management 53:659-668

Hill KM, Stokes NA, Webb SC, Hine PM, Kroeck MA, Moore JD, Morley MS, Reece KS, Burreson EM, Carnegie RB. 2014. Phylogenetics of Bonamia parasites based on small subunit and internal transcribed spacer region ribosomal DNA sequence data. Dis Aquat Org. 110(1-2):33-54.

Hine P, Diggles B, Parsons M, Pringle A, Bull B (2002) The effects of stressors on the dynamics of Bonamia exitiosus Hine, Cochennec-Laureau \& Berthe, infections in flat oysters Ostrea chilensis (Philippi). Journal of Fish Diseases 25:545-554

Hine P, Thorne T (2002) Haplosporidium sp. (Alveolata: Haplosporidia) associated with mortalities among rock oysters Saccostrea cuccullata in north Western Australia. Diseases of Aquatic Organisms51:123-133

Hine PM (1991a) The annual pattern of infection by Bonamia sp in New Zealand flat oysters, Tiostrea-chilensis. Aquaculture 93:241-251

Hine PM (1991b) Ultrastructural observations on the annual infection pattern of Bonamia sp. in flat oysters Tiostrea chilensis. Diseases of Aquatic Organisms 11:163-171

Hine PM (1997) Health status of commercially important molluscs in New Zealand. Surveillance: MAF Biosecurity, MAF Authority reporting New Zealand's Animal Health Status 24:25-30

Hine PM (2002) Severe apicomplexan infection in the oyster Ostrea chilensis: a possible predisposing factor in bonamiosis. Diseases of Aquatic Organisms 51:49-60

Hine PM, Dinamani P, Jones JB (1986) Results of a survey of parasites and diseases of oysters (Tiostrea lutaria) around New Zealand, JulyNovember 1986. Unpublished report held by the NIWA library, Wellington. $11 \mathrm{p}$

Hine PM, Jones JB (1994) Bonamia and other aquatic parasites of importance to New Zealand. New Zealand Journal of Zoology 21:49-56 
Hixon MA, Anderson TW, Buch KL, Johnson DW, McLeod JB, Stallings CD (2012) Density dependence and population regulation in marine fish: a large-scale, long-term field manipulation. Ecological Monographs 82:467-489

Hjort $\mathbf{J}$ (1914) Fluctuations in the great fisheries of northern Europe viewed in the light of biological research. ICES Journal of Marine Science

Hobday AJ, Tegner MJ, Haaker PL (2000) Over-exploitation of a broadcast spawning marine invertebrate: Decline of the white abalone. Reviews in Fish Biology and Fisheries 10:493-514

Holbrook SJ, Schmitt RJ, Stephens JS (1997) Changes in an assemblage of temperate reef fishes associated with a climate shift. Ecological Applications 7:1299-1310

Hollenbeck CM, Johnston IA (2018) Genomic Tools and Selective Breeding in Molluscs. Frontiers in Genetics 9:253

Hollis PJ (1962) Studies on the New Zealand mud-oyster, Ostrea lutaria, Hutton, 1873. MSc, Victoria University, Wellington, New Zealand

Hollis PJ (1963) Some studies on the New Zealand oysters. Zoological Publications Victoria University, Wellington:1-28

Hollowed AB, Aydin KY, Essington TE, Ianelli JN, Megrey BA, Punt AE, Smith ADM (2011) Experience with quantitative ecosystem assessment tools in the northeast Pacific. Fish and Fisheries 12:189-208

Hollowed AB, Bond NA, Wilderbuer TK, Stockhausen WT, A'mar ZT, Beamish RJ, Overland JE, Schirripa MJ (2009) A framework for modelling fish and shellfish responses to future climate change. ICES Journal of Marine Science: Journal du Conseil 66:1584-1594

Hothorn T, Bühlmann P, Dudoit S, Molinaro A, Van Der Laan MJ (2005) Survival ensembles. Biostatistics 7:355-373

Houtman TJ (1966) A note on the hydrological regime in Foveaux Strait. New Zealand Journal of Science 9:472-483

Howell M (1967) The trematode, Bucephalus longicornutus (Manter, 1954) in the New Zealand mud-oyster, Ostrea lutaria. Transactions of the Royal Society of New Zealand (Zoology) 8:221-237 
Hubbard AB, Reidenbach MA (2015) Effects of larval swimming behavior on the dispersal and settlement of the eastern oyster Crassostrea virginica. Marine Ecology Progress Series 535:161-176

Hunt HL, Scheibling RE (1997) Role of early post-settlement mortality in recruitment of benthic marine invertebrates. Marine Ecology Progress Series 155:269-301

Hunter RC (1906) Report on oyster beds in Foveaux Strait. Report on New Zealand Fisheries 1905.16-17

Hurst R, Renwick J, Sutton P, Uddstrom M, Kennan S, Law C, Rickard G (2012) Climate and ocean trends of potential relevance to fisheries in the New Zealand region. New Zealand Aquatic Environment and Biodiversity Report No 90. Ministry of Fisheries, Wellington

Jackman S (2008) The pscl Package. In: Simon Jackman with contributions from Alex Tahk AZ, Christina Maimone and Jim Fearon (ed) Political Science Computational Laboratory, Stanford University

Jackson JB, Kirby MX, Berger WH, Bjorndal KA, Botsford LW, Bourque BJ, Bradbury RH, Cooke R, Erlandson J, Estes JA (2001) Historical overfishing and the recent collapse of coastal ecosystems. Science 293:629-637

Jeffs AG (1998a) Gametogenic cycle of the Chilean oyster, Tiostrea chilensis (Philippi, 1845), in north-eastern New Zealand. Invertebrate Reproduction \& Development 34:109-116

Jeffs AG (1998b) Reproductive biology and early life history of the Chilean oyster, with special reference to populations in northern New Zealand. PhD, University of Auckland, Auckland

Jeffs AG, Creese RG (1996) Overview and bibliography of research on the Chilean oyster Tiostrea chilensis (Philippi, 1845) from New Zealand waters. Journal of Shellfish Research 15:305-311

Jeffs AG, Creese RG, Hooker SH (1996) Annual pattern of brooding in populations of Chilean oysters, Tiostrea chilensis, (Philippi, 1845) from northern New Zealand. Journal of Shellfish Research 15:617-622 
Jeffs AG, Hickman RW (2000) Reproductive activity in a pre-epizootic wild population of the Chilean oyster, Ostrea chilensis, from southern New Zealand. Aquaculture 183:241-253

Jones CG, Lawton JH, Shachak M (1994) Organisms as ecosystem engineers. Oikos 69:373-386

Jones G, Milicich M, Emslie M, Lunow C (1999) Self-recruitment in a coral reef fish population. Nature 402:802

Jones GP, Almany GR, Russ GR, Sale PF, Steneck RS, van Oppen MJH, Willis BL (2009) Larval retention and connectivity among populations of corals and reef fishes: history, advances and challenges. Coral Reefs 28:307325

Jones LA, Ricciardi A (2014) The influence of pre-settlement and early postsettlement processes on the adult distribution and relative dominance of two invasive mussel species. Freshwater Biology 59:1086-1100

Jonsson PR, Andre C, Lindegarth M (1991) Swimming behavior of marine bivalve larvae in a flume boundary-layer flow - evidence for near-bottom confinement. Marine Ecology Progress Series 79:67-76

Joshi S, Duffy GP, Brown C (2017) Mobility of maerl-siliciclastic mixtures: Impact of waves, currents and storm events. Estuarine Coastal and Shelf Science 189:173-188

Joyce A, Holthuis TD, Charrier G, Lindegarth S (2013) Experimental effects of temperature and photoperiod on synchrony of gametogenesis and sex ratio in the European oyster Ostrea edulis (Linnaeus). Journal of Shellfish Research 32:447-458

Joyce A, Webb S, Mussely H, Heasman K, Elliot A, King N (2015) Toward selective breeding of a hermaphroditic oyster Ostrea chilensis : Roles of nutrition and temperature in improving fecundity and synchrony of gamete release. Journal of Shellfish Research 34:831-840

Kamel SJ, Oyarzun FX, Grosberg RK (2010) Reproductive biology, family conflict, and size of offspring in marine invertebrates. Integrative and Comparative Biology 50:619-629 
Karpov K, Haaker P, Taniguchi I, Rogers-Bennett L (2000) Serial depletion and the collapse of the California abalone (Haliotis spp.) fishery. Canadian Special Publication of Fisheries and Aquatic Sciences:11-24

Kimmel DG, Newell RIE (2007) The influence of climate variation on eastern oyster (Crassostrea virginica) juvenile abundance in Chesapeake Bay. Limnology and Oceanography 52:959-965

Kimmel DG, Tarnowski M, Newell RIE (2014) The relationship between interannual climate variability and juvenile eastern oyster abundance at a regional scale in Chesapeake Bay. North American Journal of Fisheries Management 34:1-15

King JR, McFarlane GA, Punt AE (2015) Shifts in fisheries management: adapting to regime shifts. Philosophical Transactions of the Royal Society of London B: Biological Sciences 370:20130277

Kirby MX (2004) Fishing down the coast: Historical expansion and collapse of oyster fisheries along continental margins. Proceedings of the National Academy of Sciences of the United States of America 101:13096-13099

Knights AM, Walters K (2010) Recruit-recruit interactions, density-dependent processes and population persistence in the eastern oyster Crassostrea virginica. Marine Ecology Progress Series 404:79-90

Koenigstein S, Mark FC, Gößling-Reisemann S, Reuter H, Poertner H-O (2016) Modelling climate change impacts on marine fish populations: processbased integration of ocean warming, acidification and other environmental drivers. Fish and Fisheries 17 (4): 972-1004

Kool JT, Moilanen A, Treml EA (2013) Population connectivity: recent advances and new perspectives. Landscape Ecology 28:165-185

Krebs CJ, Berteaux D (2006) Problems and pitfalls in relating climate variability to population dynamics. Climate Research 32:143-149

La Peyre M, Furlong J, Brown LA, Piazza BP, Brown K (2014) Oyster reef restoration in the northern Gulf of Mexico: Extent, methods and outcomes. Ocean \& Coastal Management 89:20-28

Lacoste A, Malham SK, Cueff A, Poulet SA (2001) Noradrenaline modulates oyster hemocyte phagocytosis via a $\beta$-adrenergic receptor-cAMP signaling pathway. General and Comparative Endocrinology 122:252259 
Lane HS (2018) Studies on Bonamia parasites (Haplosporidia) in the New Zealand flat oyster Ostrea chilensis. PhD, University of Otago, Otago

Lane HS, Webb SC, Duncan J (2016) Bonamia ostreae in the New Zealand oyster Ostrea chilensis: a new host and geographic record for this haplosporidian parasite. Diseases of Aquatic Organisms118:55-63

Lapegue S, Beaumont A, Boudry P, Goulletquer P European flat oyster-Ostrea edulis. Proc GENINPACT-Evaluation of genetic impact of aquaculture activies on native population A European network, WP1 workshop Genetics of domestication, breeding and enhancement of performance of fish and shellfish. GENINPACT Final Scientific Report 70-75

Large K, Doonan IJ, Michael KP. (2018). Foveaux Strait oyster (OYU 5) stock assessment. An updated stock assessment for Foveaux Strait dredge oysters (Ostrea chilensis) for the 2017 fishing year. Prepared for Bluff Oyster Management Company Ltd. NIWA Client Report: 201819WN (Project BOM17302). 117 p

Le Moullac G, Soyez C, Sham-Koua M, Levy P, Moriceau J, Vonau V, Maihota M, Cochard JC (2013) Feeding the pearl oyster Pinctada margaritifera during reproductive conditioning. Aquaculture Research 44:404-411

Lee H-H, Maunder MN, Piner KR, Methot RD (2012) Can steepness of the stock-recruitment relationship be estimated in fishery stock assessment models? Fisheries Research 125:254-261

Lehodey P, Alheit J, Barange M, Baumgartner T, Beaugrand G, Drinkwater K, Fromentin J-M, Hare S, Ottersen G, Perry R (2006) Climate variability, fish, and fisheries. Journal of Climate 19:5009-5030

Lenihan HS (1999) Physical-biological coupling on oyster reefs: How habitat structure influences individual performance. Ecological Monographs 69:251-275

Lenihan HS, Peterson CH (1998) How habitat degradation through fishery disturbance enhances impacts of hypoxia on oyster reefs. Ecological Applications 8:128-140

Lentz SJ, Fewings MR (2012) The wind and wave-driven inner-shelf circulation. Annual Review of Marine Science 4:317-343 
Levin LA (2006) Recent progress in understanding larval dispersal: new directions and digressions. Integrative and Comparative Biology 46:282297

Levin PS, Möllmann C (2015) Marine ecosystem regime shifts: challenges and opportunities for ecosystem-based management. Philosophical Transactions of the Royal Society B: Biological Sciences 370

Levitan DR, Sewell MA, Chia F-S (1992) How distribution and abundance influence fertilization success in the sea urchin Strongylocentotus franciscanus. Ecology 73:248-254

Lillis A, Eggleston DB, Bohnenstiehl DR (2013) Oyster larvae settle in response to habitat-associated underwater sounds. PLoS One 8:e79337

Lindegren M, Checkley Jr DM, Quinn T (2013) Temperature dependence of Pacific sardine (Sardinops sagax) recruitment in the California Current Ecosystem revisited and revised. Canadian Journal of Fisheries and Aquatic Sciences 70:245-252

Lok A, Acarli S (2006) Preliminary study of settlement of flat oyster spat (Ostrea edulis L.) on oyster and mussel shell collectors. The Israeli Journal of Aquaculture-Bamidgeh:105-115

Lundquist CJ, Botsford LW. 2010. Estimating larval production of a broadcast spawner: the influence of density, aggregation, and the fertilization Allee effect. Canadian Journal of Fisheries and Aquatic Sciences. 68(1):30-42

Lopez-Victoria M, Zea S, Wei E (2006) Competition for space between encrusting excavating Caribbean sponges and other coral reef organisms. Marine Ecology Progress Series 312:113-121

MacDiarmid AB, Butler MJ (1999) Sperm economy and limitation in spiny lobsters. Behavioral Ecology and Sociobiology 46:14-24

Mace PM (2012) Evolution of New Zealand's fisheries management frameworks to prevent overfishing. ICES Document CM 50:09

MacKenzie JR, Clyde L, Burrell JR, Rosenfield A, Hobart WL (1997a) The history, present condition, and future of the molluscan fisheries of north and central America and Europe: Volume 2, Pacific Coast and Supplemental Topics. NOAA/National Marine Fisheries Service, (NOAA Technical Report NMFS, 128) 
MacKenzie JR, Clyde L, Burrell VG, HOBART WL (1997b) The History, Present Condition, and Future of the Molluscan Fisheries of North and Central American and Europe: Volume 1, Atlantic and Gulf Coasts. NOAA/National Marine Fisheries Service, (NOAA Technical Report NMFS, 127)

MacKenzie JR, Clyde L, Burrell VG, Rosenfield A, Hobart WL (1997c) The History, Present Condition, and Future of the Molluscan Fisheries of North and Central America and Europe: Volume 3, Europe. NOAA/National Marine Fisheries Service, (NOAA Technical Report NMFS, 129)

MacKenzie L, Adamson J (2004) Water column stratification and the spatial and temporal distribution of phytoplankton biomass in Tasman Bay, New Zealand: implications for aquaculture. New Zealand Journal of Marine and Freshwater Research 38:705-728

MacKenzie L, Rhodes L (1997) Tasman Bay Scallops; Feast or Famine? Seafood New Zealand 5:38-39

Marsh C, Michael KP, Wright G, Fu D (2016) Estimates of the length frequency from commercial catch sampling of Foveaux Strait dredge oysters (Ostrea chilensis) in 2015. Final Research Report for Ministry of Fisheries research project OYS2013-01, objective 9 (Unpublished report held by the Ministry for Primary Industries, Wellington):25 p.

Maunder MN (2012) Evaluating the stock-recruitment relationship and management reference points: application to summer flounder (Paralichthys dentatus) in the US mid-Atlantic. Fisheries Research 125:20-26

Maunder MN, Piner KR (2015) Contemporary fisheries stock assessment: many issues still remain. ICES Journal of Marine Science: Journal du Conseil 72:7-18

McClatchie S, Goericke R, Auad G, Hill K (2010) Re-assessment of the stockrecruit and temperature-recruit relationships for Pacific sardine (Sardinops sagax). Canadian Journal of Fisheries and Aquatic Sciences 67:1782-1790 
Mendo T, Moltschaniwskyj N, Lyle J, Tracey S, Semmens J (2014) Role of density in aggregation patterns and synchronization of spawning in the hermaphroditic scallop Pecten fumatus. Marine Biology 161:2857-2868

Menge BA, Gouhier TC, Freidenburg T, Lubchenco J (2011) Linking long-term, large-scale climatic and environmental variability to patterns of marine invertebrate recruitment: Toward explaining "unexplained" variation. Journal of Experimental Marine Biology and Ecology 400:236-249

Michael KP (2007) Summary of information in support of the Foveaux Strait Oyster Fishery Plan: The Foveaux Strait ecosystem and effects of oyster dredging. Final Research Report for the Ministry of Fisheries for project ZBD200504 (Unpublished manuscript held by the Ministry of Fisheries, Wellington): $120 \mathrm{p}$.

Michael KP (2010) A summary of information from Foveaux Strait oyster (Ostrea chilensis, OYU 5) strategic research 2000-2009: A context for the 2010 strategic research plan. New Zealand Fisheries Assessment Report 2010/20:37 p

Michael KP (2011) Increasing production and revenue of Foveaux Strait oysters through the development of management strategies, technology, and industry capability. To develop and evaluate strategies to increase oyster production and minimise the effects of disease. 1 April 2006 to 31 March 2011. NIWA Client Report: WLG2011-46 (Project SIL07301) Available from the Bluff Oyster Management Company Limited, Invercargill:56 p.

Michael KP, Bilewitch J, Forman J, Hulston D, Sutherland J, Moss G, Large K (2018) A survey of the Foveaux Strait oyster (Ostrea chilensis) population (OYU 5) in commercial fishery areas and the status of Bonamia (Bonamia exitiosa) in February 2018. New Zealand Fisheries Assessment Report 2018/XX.64 p

Michael KP, Dunn A, Andrew. N. L., Breen PA (2001) Foveaux Strait dredge oyster (Tiostrea chilensis) stock assessment, 1999. New Zealand Fisheries Assessment Report 2001/38:42 p.

Michael KP, Dunn A, Forman J (2005) A survey of Bonamia exitiosa infection in Foveaux Strait dredge oysters (Ostrea chilensis), oyster density and recruitment, January 2004. Unpublished report held by the Ministry of Fisheries, Wellington. $31 \mathrm{p}$ 
Michael KP, Dunn A, Forman J (2006) A survey of Bonamia exitiosa infection, and oyster density and recruitment in Foveaux Strait dredge oyster (Ostrea chilensis), January 2005. New Zealand Fisheries Assessment Report 2006/40:31 p

Michael KP, Dunn A, Forman J (2008a) A survey of Bonamia exitiosa infection, and oyster density and recruitment in Foveaux Strait dredge oysters (Ostrea chilensis), February 2006. New Zealand Fisheries Assessment Report 200/47:35 p

Michael KP, Dunn A, Forman J (2009a) The status of infection by Bonamia exitiosa in Foveaux Strait oysters (Ostrea chilensis), changes in the distributions and densities of recruit, pre-recruit, and small oysters, and projections of disease mortality in February 2008. New Zealand Fisheries Assessment Report 2009/32 (Unpublished Report held by the Ministruy of Fisheries, Wellington):50 p

Michael KP, Dunn A, Forman J, Arlidge A (2008b) A survey of the distribution and absolute abundance of pre-recruit and recruited dredge oysters (Ostrea chilensis) in both non-commercial and designated commercial areas of Foveaux Strait, and estimates of the prevalence and intensity of infection by Bonamia exitiosa, February 2007. New Zealand Fisheries Assessment Report 2008/61:50 p

Michael KP, Forman J, Fu D, Hulston D (2012a) The status of infection by Bonamia (Bonamia exitiosa) in Foveaux Strait oysters (Ostrea chilensis) in February 2011, estimates of pre-survey and projections of post-survey disease mortality, and implications for the projections of future stock status made in the 2009 stock assessment for OYU 5. New Zealand Fisheries Assessment Report 2012/37:55 p

Michael KP, Forman J, Hulston D (2015) A survey of the Foveaux Strait oyster (Ostrea chilensis) population (OYU5) in commercial fishery areas and the status of bonamia (Bonamia exitiosa) in February 2015. New Zealand Fisheries Assessment Report 2015/73:86 p

Michael KP, Forman J, Hulston D, Bilewitch J, Moss G (2017a) The Foveaux Strait oyster and Bonamia surveys, February 2017. NIWA Client Report (2017374WN) prepared for the Bluff Oyster Management Company Ltd for project BOM17302. 
Michael KP, Forman J, Hulston D, Fu D (2011) The status of infection by Bonamia (Bonamia exitiosa) in Foveaux Strait oysters (Ostrea chilensis), changes in the distributions and densities of recruit, pre-recruit, and small oysters in February 2010, and projections of disease mortality . New Zealand Fisheries Assessment Report 2011/5:51 p

Michael KP, Forman J, Hulston D, Maas E, Fu D (2014a) A survey of the Foveaux Strait oyster (Ostrea chilensis) population (OYU5) in commercial fishery areas and the status of bonamia (Bonamia exitiosa) in February 2014. Unpublished report held by the Ministry for Primary Industries, Wellington. $98 \mathrm{p}$

Michael KP, Forman J, Hulston D, Sutherland J (2017b) A survey of the Foveaux Strait oyster (Ostrea chilensis) population (OYU 5) in commercial fishery areas and the status of bonamia (Bonamia exitiosa) in February 2016. New Zealand Fisheries Assessment Report 2017/42.

Michael KP, Forman J, Maas E, Hulston D, Fu D (2014b) The status of infection by bonamia (Bonamia exitiosa) in Foveaux Strait oysters (Ostrea chilensis) in February 2013, estimates of summer disease mortality, and implications for the projections of future stock status made in the 2012 stock assessment for OYU 5. New Zealand Fisheries Assessment Report 2014/49:63 p

Michael KP, Fu D, Forman J (2009b) Foveaux Strait oyster (Ostrea chilensis) 2009 stock assessment: estimates of oyster population size, the distribution of oyster densities, the status of bonamia infection in oysters, and status of the fishery. New Zealand Fisheries Assessment Report 2009/45:56 p

Michael KP, Fu D, Forman J, Hulston D (2013) The Foveaux Strait oyster (Ostrea chilensis, OYU5) stock assessment survey and status of Bonamia infection and mortality, February 2012. New Zealand Fisheries Assessment Report 2013/09:64 p

Michael KP, Fu D, Wright G (2012b) Increasing production and revenue of Foveaux Strait oysters through the development of management strategies, technology, and industry capability. To develop the capability of the Bluff oyster industry to develop, evaluate, and manage harvest and fishery management strategies. 1 April 2009-30 June 2011. NIWA Client Report: WLG2012-44 (Project SIL07301, Objective 4), held by the Bluff Oyster Masngement Company Limited, Invercargill, NZ:119 p. 
Michael KP, Gorman R, Hadfield M, Richardson K (2008c) Summary of information in support of the Foveaux Strait Oyster Fisheries Plan: The Foveaux Strait ecosystem and effects of oyster dredging. NIWA Information Series No 68:18 p

Miller MJ, Feunteun E, Tsukamoto K (2016) Did a "perfect storm" of oceanic changes and continental anthropogenic impacts cause northern hemisphere anguillid recruitment reductions? ICES Journal of Marine Science: Journal du Conseil 73:43-56

Ministry for Primary Industries (2013) Review of sustainability and other management controls for Chatham Island dredge oyster (OYS 4). MPI Discussion Paper No: 2013/19.

Ministry for Primary Industries (2017) Fisheries Assessment Plenary, November 2017: stock assessments and stock status. Compiled by the Fisheries Science Group, Ministry for Primary Industries, Wellington, New Zealand.

Moravec F, de Buron I (2013) A synthesis of our current knowledge of philometrid nematodes, a group of increasingly important fish parasites. Folia Parasitologica 60 (2): 81-101

Mroch RM, Eggleston DB, Puckett BJ (2012) Spatiotemporal variation in oyster fecundity and reproductive output in a network of no-take reserves. Journal of Shellfish Research 31:1091-1101

NABIS (2018) The National Aquatic and Biodiversity Information System. Ministry for Primary Industries. Wellington, New Zealand. (https://catalogue.data.govt.nz/dataset/national-aquatic-biodiversityinformation-system-nabis-fish-layers)

Narváez DA, Klinck JM, Powell EN, Hofmann EE, Wilkin J, Haidvogel DB (2012) Modeling the dispersal of eastern oyster (Crassostrea virginica) larvae in Delaware Bay. Journal of Marine Research 70:381-409

Ngo T, Berthe FC, Choi K-S (2003) Prevalence and infection intensity of the ovarian parasite Marteilioides chungmuensis during an annual reproductive cycle of the oyster Crassostrea gigas. Diseases of Aquatic Organisms 56:259 
Nicolle A, Dumas F, Foveau A, Foucher E, Thiebaut E (2013) Modelling larval dispersal of the king scallop (Pecten maximus) in the English Channel: examples from the Bay of Saint-Brieuc and the bay of Seine. Ocean Dynamics 63:661-678

North EW, Schlag Z, Hood R, Li M, Zhong L, Gross T, Kennedy VS (2008) Vertical swimming behavior influences the dispersal of simulated oyster larvae in a coupled particle-tracking and hydrodynamic model of Chesapeake Bay. Marine Ecology Progress Series 359:99-115

O'Connor NE, Grabowski JH, Ladwig LM, Bruno JF (2008) Simulated predator extinctions: Predator identity affects survival and recruitment of oysters. Ecology 89:428-438

Ofoighil D, Marshall BA, Hilbish TJ, Pino MA (1999) Trans-Pacific range extension by rafting is inferred for the flat oyster Ostrea chilensis. Biological Bulletin 196:122-126

Oliva ME, Olivares AN, Diaz CD, Pasten MV (1999) Parasitic castration in Concholepas concholepas (Gastropoda: Muricidae) due to a larval digenean in northern Chile. Diseases of Aquatic Organisms 36:61-65

Otago Daily Times (1917) Oysters in Cook Strait. Otago Daily Times, Dunedin 19 July 1917, Dunedin

Paris CB, Chérubin LM, Cowen RK (2007) Surfing, spinning, or diving from reef to reef: effects on population connectivity. Marine Ecology Progress Series 347:285-300

Pascual MS, Zampatti EA (1995) Evidence of a chemically mediated adultlarval interaction triggering settlement in Ostrea puelchana: applications in hatchery production. Aquaculture 133:33-44

Perälä T, Kuparinen A (2015) Detecting regime shifts in fish stock dynamics. Canadian Journal of Fisheries and Aquatic Sciences 72:1619-1628

Pernet F, Lupo C, Bacher C, Whittington RJ (2016) Infectious diseases in oyster aquaculture require a new integrated approach. Philosophical Transactions of the Royal Society B: Biological Sciences 371:20150213

Peterson CH, Grabowski JH, Powers SP (2003) Estimated enhancement of fish production resulting from restoring oyster reef habitat: quantitative valuation. Marine Ecology Progress Series 264:249-264 
Peterson CH, Summerson HC, Luettich RA (1996) Response of bay scallops to spawner transplants: A test of recruitment limitation. Marine Ecology Progress Series 132:93-107

Peterson WT, Schwing FB (2003) A new climate regime in northeast Pacific ecosystems. Geophysical Research Letters 30 (17)

Pickrill RA, Mitchell JS (1979) Ocean wave characteristics around New Zealand. New Zealand Journal of Marine and Freshwater Research 13:501-520

Pineda J, Hare JA, Sponaugle S (2007) Larval transport and dispersal in the coastal ocean and consequences for population connectivity. Oceanography 20:22-39

Pineda J, Reyns NB, Starczak VR (2009) Complexity and simplification in understanding recruitment in benthic populations. Population Ecology $51: 17-32$

Pineda J, Starczak V, Stueckle TA (2006) Timing of successful settlement: demonstration of a recruitment window in the barnacle Semibalanus balanoides. Marine Ecology Progress Series 320:233-237

Pinkerton M, Gall M, Wood S (2014) Remote sensing of suspended solids in Lyttelton Harbour/Whakaraupō water using satellite images. Environment Canterbury Technical Report R14/55. Christchurch.

Pinkerton MH, Bell R, Chiswell SM, Currie K, Mullan AB, Rickard G, Stevens C, Sutton P (2015) Reporting on the state of the New Zealand marine environment: recommendations for ocean indicators as part of the Atmospheric and Ocean Climate Change Tier 1 Statistic. New Zealand Aquatic Environment and Biodiversity Report: 151. Ministry for Primary Industries, Wellington

Pinkerton MH, Moore GF, Lavender SJ, Gall MP, Oubelkheir K, Richardson KM, Boyd PW, Aiken J (2006) A method for estimating inherent optical properties of New Zealand continental shelf waters from satellite ocean colour measurements. New Zealand Journal of Marine and Freshwater Research 40:227-247 
Pollard D, Hutchings P (1990) A review of exotic marine organisms introduced to the Australian region. 2. Invertebrates and algae. Asian Fisheries Science 3:223-250

Powell A, W, B. (1979) New Zealand Mollusca: Marine Land and Freshwater Shells. Willian Collins Publishers Ltd, Auckland

Powell EN, Ashton-Alcox KA, Kraeuter JN (2007) Reevaluation of eastern oyster dredge efficiency in survey mode: Application in stock assessment. North American Journal of Fisheries Management 27:492511

Powell EN, Hofmann EE (2015) Models of marine molluscan diseases: trends and challenges. Journal of Invertebrate Pathology 131:212-225

Powell EN, Klinck JM (2007) Is oyster shell a sustainable estuarine resource? Journal of Shellfish Research 26:181-194

Powell EN, Klinck JM, Ashton-Alcox K, Hofmann EE, Morson J (2012) The rise and fall of Crassostrea virginica oyster reefs: The role of disease and fishing in their demise and a vignette on their management. Journal of Marine Research 70:505-558

Powell EN, Mann R, Ashton-Alcox KA, Kuykendall KM, Long MC (2017) Can we estimate molluscan abundance and biomass on the continental shelf? Estuarine, Coastal and Shelf Science 198:213-224

Pritchard C, Shanks A, Rimler R, Oates M, Rumrill S (2015) The Olympia oyster Ostrea lurida: Recent advances in natural history, ecology, and restoration. Journal of Shellfish Research 34:259-271

Puckett BJ, Eggleston DB, Kerr PC, Luettich RA (2014) Larval dispersal and population connectivity among a network of marine reserves. Fisheries Oceanography 23:342-361

Punt AE, A'mar T, Bond NA, Butterworth DS, de Moor CL, De Oliveira JA, Haltuch MA, Hollowed AB, Szuwalski C (2014) Fisheries management under climate and environmental uncertainty: control rules and performance simulation. ICES Journal of Marine Science: 71:2208-2220

R Core Team (2016) R: A Language and Environment for Statistical Computing. R Foundation for Statistical Computing, Vienna. 
Reygondeau G, Demarcq H, Bonhommeau S, Chassot E, Nieto K, Polovina JJ, Huret M, Dulvy NK. 2011. Satellite remote sensing for an ecosystem approach to fisheries management. ICES J Mar Sci. 68(4):651-666.

Ricker WE (1954) Stock and recruitment. Journal of the Fisheries Board of Canada 11:559-623

Ricker WE (1975) Computation and interpretation of biological statistics of fish populations. Bulletin of the Fisheries Research Board of Canada 191:2973

Rifi M, Le Pennec G, Salem MB, Souissi JB (2011) Reproductive strategy of the invasive cockle Fulvia fragilis in the Bay of Tunis (Tunisia). Journal of the Marine Biological Association UK 91:1465-1475

Robert R, Vignier J, Petton B (2017) Influence of feeding regime and temperature on development and settlement of oyster Ostrea edulis (Linnaeus, 1758) larvae. Aquaculture Research 48:4756-4773

Roberts DE, Cummins SP, Davis AR, Chapman MG (2006) Structure and dynamics of sponge-dominated assemblages on exposed and sheltered temperate reefs. Marine Ecology Progress Series 321:19-30

Robins PE, Tita A, King JW, Jenkins SR (2017) Predicting the dispersal of wild Pacific oysters Crassostrea gigas (Thunberg, 1793) from an existing frontier population - a numerical study. Aquatic Invasions 12:117-131

Robinson MD, Smyth GK (2008) Small-sample estimation of negative binomial dispersion, with applications to SAGE data. Biostatistics 9:321-332

Robjohns HC (1979) Bluff oyster industry. Bluff Oyster Boat Owners [Association], Invercargill

Rodriguez SR, Ojeda FP, Inestrosa NC (1993) Settlement of benthic marineinvertebrates. Marine Ecology Progress Series 97:193-207

Roff G, Chollett I, Doropoulos C, Golbuu Y, Steneck RS, Isechal AL, van Woesik R, Mumby PJ (2015) Exposure-driven macroalgal phase shift following catastrophic disturbance on coral reefs. Coral Reefs 34:715725 
Romero MV, Brezina SS, Hernandez D, Casadio S, Bremec C (2013) Differential settlement of associated species on Ostrea puelchana d'Orbigny, 1842 (Ostreidae) in Patagonia (Argentina). American Malacological Bulletin 31:311-321

Rotschild B, Ault J, Goulletquer P, Heral M (1994) Decline of the Chesapeake Bay oyster population: a century of habitat destruction and overfishing. Marine Ecology Progress Series 111:29-39

Roughgarden J, Gaines S, Possingham H (1988) Recruitment dynamics in complex life cycles. Science 241:1460

Rowley AF, Cross ME, Culloty SC, Lynch SA, Mackenzie CL, Morgan E, O'Riordan RM, Robins PE, Smith AL, Thrupp TJ, Vogan CL, Wootton EC, Malham SK (2014) The potential impact of climate change on the infectious diseases of commercially important shellfish populations in the Irish Sea-a review. ICES Journal of Marine Science 71:741-759

Ruesink JL, Lenihan HS, Trimble AC, Heiman KW, Micheli F, Byers JE, Kay MC (2005) Introduction of non-native oysters: Ecosystem effects and restoration implications. Annual Review of Ecology Evolution and Systematics 36:643-689

Sale PF, Kritzer JP (2003) Determining the extent and spatial scale of population connectivity: decapods and coral reef fishes compared. Fisheries Research 65:153-172

Salvi D, Mariottini P (2017) Molecular taxonomy in 2D: a novel ITS2 rRNA sequence-structure approach guides the description of the oysters' subfamily Saccostreinae and the genus Magallana (Bivalvia: Ostreidae). Zoological Journal of the Linnean Society 179:263-276

Sammarco PW, Andrews JC (1989) The Helix experiment: Differential localized dispersal and recruitment patterns in Great Barrier Reef corals. Limnology and Oceanography 34:896-912

Schrobback P, Pascoe S, Coglan L (2014) History, status and future of Australia's native Sydney rock oyster industry. Aquatic Living Resources 27:153-165

Schulte DM, Burke RP, Lipcius RN (2009) Unprecedented restoration of a native oyster metapopulation. Science 325:1124-1127 
Shanks AL, Grantham BA, Carr MH (2003) Propagule dispersal distance and the size and spacing of marine reserves. Ecological Applications 13:159169

Shima JS, Noonburg EG, Swearer SE (2015) Consequences of variable larval dispersal pathways and resulting phenotypic mixtures to the dynamics of marine metapopulations. Biology Letters 11:20140778

Shima JS, Osenberg CW, St Mary CM (2008) Quantifying site quality in a heterogeneous landscape: recruitment of a reef fish. Ecology 89:86-94

Siegel DA, Kinlan BP, Gaylord B, Gaines SD (2003) Lagrangian descriptions of marine larval dispersion. Marine Ecology Progress Series 260:83-96

Skern-Mauritzen M, Ottersen G, Handegard NO, Huse G, Dingsør GE, Stenseth NC, Kjesbu OS (2016) Ecosystem processes are rarely included in tactical fisheries management. Fish and Fisheries 17:165-175

Smyth D, Kregting L, Elsasser B, Kennedy R, Roberts D (2016) Using particle dispersal models to assist in the conservation and recovery of the overexploited native oyster (Ostrea edulis) in an enclosed sea lough. Journal of Sea Research 108:50-59

Smyth D, Mahon AM, Roberts D, Kregting L. 2018. Settlement of Ostrea edulis is determined by the availability of hard substrata rather than by its nature: Implications for stock recovery and restoration of the European oyster. Aquatic Conservation-Marine and Freshwater Ecosystems. 28(3):662-671

Smyth D, Roberts D (2010) The European oyster (Ostrea edulis) and its epibiotic succession. Hydrobiologia 655:25-36

Soniat TM, Cooper N, Powell EN, Klinck JM, Abdelguerfi M, Tu S, Mann R, Banks PD (2014) Estimating sustainable harvests of eastern oysters, Crassostrea virginica. Journal of Shellfish Research 33:381-394

Soniat TM, Klinck JM, Powell EN, Cooper N, Abdelguerfi M, Hofmann EE, Dahal J, Tu S, Finigan J, Eberline BS (2012) A shell-neutral modeling approach yields sustainable oyster harvest estimates: a retrospective analysis of the Louisiana state primary seed grounds. Journal of Shellfish Research 31:1103-1112 
Sponaugle S, Cowen RK, Shanks A, Morgan SG, Leis JM, Pineda J, Boehlert GW, Kingsford MJ, Lindeman KC, Grimes C (2002) Predicting selfrecruitment in marine populations: Biophysical correlates and mechanisms. Bulletin of Marine Science 70:341-375

Stanton BR, Goring DG, Bell RG (2001) Observed and modelled tidal currents in the New Zealand region. New Zealand Journal of Marine and Freshwater Research 35:397-415

Stanwell-Smith D, Barnes DKA (1997) Benthic community development in Antarctica: recruitment and growth on settlement panels at Signy Island. Journal of Experimental Marine Biology and Ecology 212:61-79

Stead DH (1971a) Observations on the biology and ecology of the Foveaux Strait dredge oyster (Ostrea lutaria, Hutton). N.Z. Fisheries Technical Report No.68. New Zealand Marine Department, Wellington. 49 p.

Stead DH (1971b) Survey of Foveaux Strait oyster beds 1960-64. New Zealand Fisheries Technical Report No. 16. Published by the New Zealand Marine Department. 29 p

Stentiford GD, Sritunyalucksana K, Flegel TW, Williams BAP, Withyachumnarnkul B, Itsathitphaisarn O, Bass D (2017) New paradigms to help solve the global aquaculture disease crisis. PLOS Pathogens 13:e1006160

Stock R (2000) Brooding and larval biology of the flat oyster, Tiostrea chilensis. MSc, University of Otago, Dunedin, New Zealand.

Stoner DS (1990) Recruitment of a Tropical colonial ascidian: Relative importance of pre-settlement vs. post-settlement processes. Ecology $71: 1682-1690$

Street RJ, Crowther GS, Kirkman JS. 1973. Oyster shell return experiment: Foveaux Strait 1970-1971. Wellington: Fisheries Division, Ministry of Agriculture and Fisheries. N.Z. Fisheries Technical Report No.10. 15 p.

Strobl C, Boulesteix A-L, Zeileis A, Hothorn T (2007) Bias in random forest variable importance measures: Illustrations, sources and a solution. BMC Bioinformatics 8:25 
Sullivan JT, Cheng TC, Howland KH (1985) Studies on parasitic castration: castration of Ilyanassa obsoleta (Mollusca: Gastropoda) by several marine trematodes. Transactions of the American Microscopical Society:154-171

Suong NT, Webb S, Banks J, Wakeman KC, Lane H, Jeffs A, Brosnahan C, Jones B, Fidler A (2017) Partial 18S rRNA sequences of apicomplexan parasite ' $\mathrm{X}$ '(APX), associated with flat oysters Ostrea chilensis in New Zealand. Diseases of Aquatic Organisms127:1-9

Swearer SE, Shima JS (2010) Regional variation in larval retention and dispersal drives recruitment patterns in a temperate reef fish. Marine Ecology Progress Series 417:229-236

Swearer SE, Shima JS, Hellberg ME, Thorrold SR, Jones GP, Robertson DR, Morgan SG, Selkoe KA, Ruiz GM, Warner RR (2002) Evidence of selfrecruitment in demersal marine populations. Bulletin of Marine Science $70: 251-271$

Sweet MJ, Bulling MT (2017) On the Importance of the Microbiome and Pathobiome in Coral Health and Disease. Frontiers in Marine Science 4: 9

Szuwalski CS, Vert-Pre KA, Punt AE, Branch TA, Hilborn R (2015) Examining common assumptions about recruitment: a meta-analysis of recruitment dynamics for worldwide marine fisheries. Fish and Fisheries 16:633-648

Talman SG, Norkko A, Thrush SF, Hewitt JE (2004) Habitat structure and the survival of juvenile scallops Pecten novaezelandiae: comparing predation in habitats with varying complexity. Marine Ecology Progress Series 269:197-207

Tamburri MN, Luckenbach MW, Breitburg DL, Bonniwell SM (2008) Settlement of Crassostrea ariakensis larvae: effects of substrate, biofilms, sediment and adult chemical cues. Journal of Shellfish Research 27:601-608

Tamburri MN, Zimmer-Faust RK, Tamplin ML (1992) Natural sources and properties of chemical inducers mediating settlement of oyster larvae: A re-examination. The Biological Bulletin 183:327-338 
Tettelbach S, Wenczel P (1993) Reseeding efforts and the status of bay scallop Argopecten irradians (Lamarck, 1819) populations in New York following the occurrence of" brown tide" algal blooms. Journal of Shellfish Research 12:423-431

Thomas LJ (2015) A molecular and population genetics study of the Bluff Oyster (Ostrea chilensis). PhD, Victoria University of Wellington,

Thomas Y, Dumas F, Andrefouet S (2014) Larval dispersal modeling of pearl oyster Pinctada margaritifera following realistic environmental and biological forcing in Ahe Atoll Lagoon. PLoS one 9(4), e95050

Thomsen MS, McGlathery K (2006) Effects of accumulations of sediments and drift algae on recruitment of sessile organisms associated with oyster reefs. Journal of Experimental Marine Biology and Ecology 328:22-34

Toro JE, Morande PR (1998) Effect of food ration and temperature on length of brooding period, larval development and size of pediveligers released in the Chilean oyster Ostrea chilensis. Journal of the World Aquaculture Society 29:267-270

Trapletti A, Hornik K (2018) tseries: Time Series Analysis and Computational Finance.

Treml EA, Roberts JJ, Chao Y, Halpin PN, Possingham HP, Riginos C (2012) Reproductive output and duration of the pelagic larval stage determine seascape-wide connectivity of marine populations. Integrative and Comparative Biology 52:525-537

Trenberth KE (1984) Signal versus noise in the Southern Oscillation. Monthly Weather Review 112:326-332

Trimble AC, Ruesink JL, Dumbauld BR (2009) Factors preventing the recovery of a historically overexploited shellfish species, Ostrea lurida Carpenter 1864. Journal of Shellfish Research 28:97-106

Turner E, Zimmer-Faust R, Palmer M, Luckenbach M, Pentchef N (1994) Settlement of oyster (Crassostrea virginica) larvae: Effects of water flow and a water-soluble chemical cue. Limnology and Oceanography 39:1579-1593

Underwood AJ, Fairweather PG (1989) Supply-side ecology and benthic marine assemblages. Trends in Ecology \& Evolution 4:16-20 
Wijsman JWM, Troost K, Fang J, Roncarati A (2019) Global production of marine bivalves. Trends and challenges. In: Smaal AC, Ferreira JG, Grant J, Petersen JK, Strand $\varnothing$ (eds) Goods and Services of Marine Bivalves. Springer International Publishing, Cham

Utting SD, Millican PF (1997) Techniques for the hatchery conditioning of bivalve broodstocks and the subsequent effect on egg quality and larval viability. Aquaculture 155:45-54

Vadas RL, Johnson S, Norton TA (1992) Recruitment and mortality of early post-settlement stages of benthic algae. British Phycological Journal 27:331-351

Valderrama K, Oliva M, Campos B, Brown D (2004) Parasitic castration of Eurhomalea lenticularis (Bivalvia: Veneridae) by a digenetic trematode: quantitative histological analysis. Diseases of Aquatic Organisms 59:151-158

Vanbanning P (1991) Observations on Bonamiasis in the stock of the European flat oyster, Ostrea edulis, in the Netherlands, with special reference to the recent developments in Lake Grevelingen. Aquaculture 93:205-211

Vasquez HE, Hashimoto K, Kitamura H, Satuito CG (2014) Wheat germ agglutinin-binding glycoprotein extract from shells of conspecifics induces settlement of larvae of the Pacific oyster Crassostrea gigas (Thunberg). Journal of Shellfish Research 33:415-423

Vayssier-Taussat M, Albina E, Citti C, Cosson JF, Jacques M-A, LEBRUN MH, Le Loir Y, Ogliastro M, Petit M-A, Roumagnac P, Candresse T (2014) Shifting the paradigm from pathogens to pathobiome: new concepts in the light of meta-omics. Frontiers in Cellular and Infection Microbiology 4,29

Veitch F, Hidu H (1971) Gregarious setting in the American oyster Crassostrea virginica Gmelin: I. Properties of a partially purified "Setting factor". Chesapeake Science 12:173-178

Venables WN, Ripley BD (2002) Modern Applied Statistics with S. Fourth Edition. Springer, New York. ISBN 0-387-95457-0 
Ver Hoef JM, Boveng PL (2007) Quasi-Poisson vs. negative binomial regression: how should we model overdispersed count data? Ecology $88: 2766-2772$

Vuong QH (1989) Likelihood ratio tests for model selection and non-nested hypotheses. Econometrica: Journal of the Econometric Society: 307-333

Wahl M (1989) Marine epibiosis. I. Fouling and antifouling: some basic aspects. Marine Ecology Progress Series 58:175-189

Waldbusser GG, Powell EN, Mann R (2013) Ecosystem effects of shell aggregations and cycling in coastal waters: an example of Chesapeake Bay oyster reefs. Ecology 94:895-903

Walles B, Mann R, Ysebaert T, Troost K, Herman PMJ, Smaal AC (2015) Demography of the ecosystem engineer Crassostrea gigas, related to vertical reef accretion and reef persistence. Estuarine, Coastal and Shelf Science 154:224-233

Walne PR (1963) Breeding of the Chilean oyster (Ostrea chilensis Philippi) in the laboratory. Nature. 197: 676.

Walne PR (1974) Culture of Bivalve Molluscs: Fifty Years Experience at Conwy. Fishing News Book Ltd. Famham, Surrey, England.189

Walters RA, Goring DK, Bell RG (2001) Ocean tides around New Zealand. New Zealand Journal of Marine and Freshwater Research 35(3):567-579

Wasson K, Hughes BB, Berriman JS, Chang AL, Deck AK, Dinnel PA, Endris C, Espinoza M, Dudas S, Ferner MC (2016) Coast-wide recruitment dynamics of Olympia oysters reveal limited synchrony and multiple predictors of failure. Ecology 97:3503-3516

Westerskov K (1980) Aspects of the biology of the dredge oyster Ostrea lutaria Hutton, 1873. PhD Thesis, University of Otago, Dunedin

Wheeler JD, Helfrich KR, Anderson EJ, McGann B, Staats P, Wargula AE, Wilt K, Mullineaux LS (2013) Upward swimming of competent oyster larvae Crassostrea virginica persists in highly turbulent flow as detected by PIV flow subtraction. Marine Ecology Progress Series 488:171-185 
Wheeler JD, Helfrich KR, Anderson EJ, Mullineaux LS (2015) Isolating the hydrodynamic triggers of the dive response in eastern oyster larvae. Limnology and Oceanography 60:1332-1343

Wilkie EM, Bishop MJ, O'Connor WA (2013) The density and spatial arrangement of the invasive oyster Crassostrea gigas determines its impact on settlement of native oyster larvae. Ecology and Evolution $3: 4851-4860$

Wilson JA, Chaparro OR, Thompson RJ (1996) The importance of broodstock nutrition on the viability of larvae and spat in the Chilean oyster Ostrea chilensis. Aquaculture 139:63-75

Wright JT, Benkendorff K, Davis A (1997) Habitat associated differences in temperate sponge assemblages: the importance of chemical defence. Journal of Experimental Marine Biology and Ecology 213:199-213

Wright K (1990) Nelson and Marlborough Oyster History. Book 2. Nelson Historical Society (Inc.), Nelson

Yonge CM (1966) Oysters. Collins Clear-Type Press, London and Glasgow

Zacherl DC, Moreno A, Crossen S (2015) Exploring restoration methods for the Olympia oyster Ostrea lurida Carpenter, 1864: Effects of shell bed thickness and shell deployment methods on shell cover, oyster recruitment, and oyster density. Journal of Shellfish Research 34:819830

Zeldis J (2008) Origin and processing of nutrients in Golden and Tasman Bays. NIWA client report, NIWA Project ELF08205 TSDC35, May 2008, Book CHC2008-052

Zeldis J, Hadfield M, Morrisey D, Broekhuizen N, Stenton-Dozsey J (2011) Tasman Aquaculture: guidance on farming additive species - Stage 1. NIWA client report, NIWA Project PRM201022, February 2011 CHC2011-005

Zuur AF, Ieno EN, Elphick CS (2010) A protocol for data exploration to avoid common statistical problems. Methods in Ecology and Evolution 1:3-14 